SPECIES HEPATICARUM 


\section{SPECIES IIEPATICARII}

Eine Darstellung ihrer Morphologie und Beschreibung ihrer Gattungen wie aller bekannten Arten in Monographien unter Berücksichtigung ihrer gegenseitigen Verwandtschaft und geographischen Verbreitung

Franz STEPHANI

VOL. I

\section{A NACROG YNAE}

Separ.-Abdr. aus dem Bulletin et Mémoires de l'Herbier Boissier.

GENÈVE ET BALE

GEORG \& $\mathrm{C}^{\mathrm{ie}}$, LIBRAIRES-ÉDITEURS

MÊME MAISON A LYON

1900 
SPECIES HEPATICARUM 


\section{SPECIES IIEPATICARIII}

Eine Darstellung ihrer Morphologie und Beschreibung ihrer Gattungen wie aller bekannten Arten in Monographien unter Berücksichtigung ihrer gegenseitigen Verwandtschaft und geographischen Verbreitung

von

Franz STEPHANI

VOL. I

\section{ANACROGYNAE}

Separ.-Abdr. aus dem Bulletin et Mémoires de l'Herbier Boissier.

GENÈVE ET BALE

GEORG \& Cie, LIBRAIRES-ÉDITEURS

MÊME MAISON A LYON

1900 
Extrait du Bulletin de l'Herbier Boissier.

Tome VI. No 4. Avril 1898.

\title{
SPECIES HEPATICARUM
}

\author{
AUCTORE
}

Franz STEPHANI

Der Unterzeichnete hat sich die Aufgabe gestellt, die gesammten bisher bekannten Hepaticæ in der Form von einzelnen Aufsätzen successive in diesen Heften zu beschreiben; es ist ihm dazu die Hülfe seiner botanischen Freunde und vieler öffentlichen Institute bereitwilligst gewährt worden und sie wird mit dem Fortschreiten der Arbeit auch noch häufig in Anspruch genommen werden müssen, um die gewünschte Vollständigkeit zu erreichen.

Hinsichtlich der Priorität der Gattungsnamen bin ich der Ansicht gefolgt, dass eine Diagnose, welche die Pflanze erkennen lässt, zweifellos gefordert werden muss; ist die älteste Diagnose schlecht oder ist die Gattung eine zusammengesetzte, so muss diejenige jüngere Diagnose, welche zuerst die Gattung genügend und rein dargestellt hat, benutzt und deren Name gewählt werden; eine Verbesserung der alten Beschreibung ist nicht zulässig. Damit fallen manche Namen Dumortier's und fast alle Gattungen Gray's, mit Ausnahme von Pallavicinius; ich belasse hier die männliche Endung, da wir ja viele andere Gattungen mit einer solchen besitzen.

Was die Synonyme angeht, so werde ich alte, längst abgethane Namen nicht wieder aufnehmen; ebensowenig manche auf Grund neuer Anschauungen entstandene Namen. Jch will dem dringenden Bedürfniss einer Beschreibung aller bekannten Lebermoose abhelfen und in übersichtlicher und gedrängter Form das Wissenswerthe bieten; hierzu brauche ich nur diejenigen Synonyme, welche volle Klarheit schaffen für den Namen der Pflanzen und das Citat; was manche neuere Nomen- 
clatoren, die gar keine Kenntnisse auf dem Gebiete der hier behandelten Pflanzen besitzen, noch zu besitzen vorgeben und daher gar nicht im Stande sind, zu beurtheilen, ob eine Diagnose für den Fachmann noch annehmbar ist oder nicht, was diese Herren uns an Namen aufdrängen wollen, kann in vielen Fällen übergangen werden, denn es ist ein nutzloser Ballast, eine bibliographische Studie aber keine botanische.

Leipzig, den 6. Februar 1898.

\section{F. STEPHANI.}

Riccia Mich. nov. gen. p. 107.

Plantæ thallosæ, parvæ, terrestres, raro natantes, carnosæ, repentes, dichotome-ramosæ, interdum ramulos adventivos e ventre proferentes. Frons e facie postica radicans, antice lamellis suberectis chlorophylliferis ædificata, postice costam e cellulis parenchymaticis formatam gerens; inter costam et stratum anticum adest fasciculum hyalinum cellularum prosenchymaticarum. Epidermis antica stomatibus normalibus (Ricciella) vel rudimentariis (Riccia) instructa; ad latera frondis, sub margines pro more occultæ, squamæ oriuntur, oblique insertæ, integerrimæ vel ciliatæ, in Ricciellis fere semper deficientes, e basi radiculas punctatim incrassatas proferentes. Antheridia et Archegonia (monoice vel dioice distributa) primum nuda, dein strato chlorophyllifero increscente immersa. Involucra nulla. Ostiola mascula epidermide insidentia, sæpe longe prominentia; pistilla fere semper purpurea, parum exserta. Capsulæ immersæ, in costa sessiles, pariete tenera demum evanida; calyptra longe persistens sporasque includens. Sporæ magnæ, tetraëdræ, cuticulam validam lamellatam sæpeque papilliferam gerentes.

Die Frons der Riccien hat einen Vegetationspunkt, welcher bei den fleischigen Formen an der tiefsten Stelle der Scheitelfurche liegt; die Seiten dieser Furche sind fast senkrecht und die jungen Zellen schon durch diese Lage geschützt; bei den flachen dünnen Formen liegt der Scheitel am Grunde einer tiefen Einkerbung des Laubes und dieses erscheint daher an der Spitze zweilappig, im Gegensatz zu den dickeren Arten, die ein rundlich gestutztes Laubende besitzen; die Ventralschuppen verhüllen ausserdem die Spitze der Frons und haben, ähnlich 
wie die Amphigastrien der höheren Lebermoose, keinen anderen Zweck als den des Schutzes; die zapfenförmig verdickten Rhizoiden, welche aus den Basalzellen der Schuppen entspringen, habe ich in einer früheren Arbeit schon dahin gedeutet, dass sie zur Wasserleitung besonders befähigt sind, insofern die capillare Anziehung der vorspringenden Zapfen im Lumen der Zelle das Aufsteigen der Wassersäule beschleunigt.

Zweifellos haben die meisten Riccien eine von Anfang an doppelte Reihe Ventralschuppen; an den grösseren Arten ist das sehr leicht zu constatieren; sie sind am Vegetationspunkte abwechselnd von rechts und links übereinandergelagert; eine Stelle, an welcher eine Zerreissung der einst terminalen Schuppe in $\mathbf{2}$ laterale Theile stattgefunden haben sollte, ist nicht nachweisbar.

Die Verzweigung der Frons ist bei ungehindertem Wachsthum stets eine Dichotomie unter rechtem Winkel; bei mechanischen Hindernissen oder bei reicherer Verzweigung, wo sich die Aeste gegenseitig behindern, ändert sich dieser Winkel; wenn ich trotzdem ihn in den Diagnosen erwähne, so geschieht es, weil er den Pflanzen schliesslich doch einen äusseren feststehenden Character verleiht und ihren Habitus wesentlich beeinflusst; in Rosettenform wächst eine einzelne Frons niemals; eine einfache Ueberlegung besagt schon, dass das nicht möglich ist; wo also eine vollkommene Rosettenform vorhanden ist, sind es mehrere Pflanzen, die sich aus zusammengelagerten Sporen gleichzeitig entwickelt haben und die Rosette vervollständigten; aus diesem Grunde habe ich sie in den Diagnosen, als eine Erscheinung, die bei jeder Art vorkommen kann, nicht erwähnt; sie als diagnostisches Merkmal zu benutzen, wie das bisher geschah, ist nach dem Gesagten unmöglich.

Viele Ricciellen haben $\mathbf{2}$ oder 4 Vegetationspunkte, das heisst sie besitzen Gabeläste, die längere Zeit verbunden bleiben und vorhanden sind, lange ehe sie äusserlich in die Erscheinung treten; das Laub hat dann einen keilförmigen Zuschnitl; wenn ich von der Breite der Frons spreche, bezieht sie sich natürlich stels auf den einzelnen, selbständig entwickelten Gabelast; je nach dem Alter, in welchem die Pflanze angetroffen wird, werden solche Arten einen ganz verschiedenen Habitus zeigen und es ist daher nicht unnöthig darauf hinzuweisen, dass zu einer sicheren Bestimmung verticale Querschnitte des Astes auf keinen Fall entbehrt werden können; ebenso sind die Sporen, wegen der grossen Aehnlichkeit des Laubes mancher Arten, in den meisten Fällen unerlässlich.

Die chlorophyllführende dorsale Laubschicht wird, wie bekannt, bei 
der Gattung Riccia aus langen aufrechten, säulenförmigen Lamellen gebildet, die aus Zellreihen bestehen und unter sich der Länge nach verwachsen sind; von ihnen schliessen immer je vier einen engen Kanal ein. Ricciella unterscheidet sich hiervon durch flächenförmige Lamellen, die weile Lufträume begrenzen. Ricciella vesiculosa C. et P. steht in der Mitte zwischen beiden Gattungen und ist daher von hervorragendem Interesse. Die vier Lamellen sind hier auch säulenförmig normal ausgebildet, zwischen je 2 derselben ist aber eine dritte Säule eingeschoben, so dass die dadurch wesentlich erweiterten Luftkanäle von 8 Zelleschnüren begrenzt werden (die Zahl variirt zwischen 7 bis 9). Denken wir uns die eingeschobenen Zellreihen fort, so haben wir den normalen Typus von Riccia; eine solche Uebergangsform, welche den Werdegang anzeigt, macht die Scheidung der Gruppe in zwei Gattungen, Riccia und Ricciella, hinfällig; die Trennung habe ich daher nur aus praktischen Rücksichten in der Form von Unterabtheilungen durchgeführt.

Die chlorophyllführende Schicht des Laubes hat eine sehr verschiedene Höhe bei den verschiedenen Arten; bei breiten flachen Formen ist sie niedrig, bei den schmalen fleischigeren Formen wesentlich höher und bis zu $1 / 3$ der Dicke des Laubes einnehmend; es ist, danach zu urtheilen, der Assimilations-Apparat dem Bedürfniss der Pflanze genau angepasst; wie schon in früheren Arbeiten öfters erwähnt, repräsentiren diese Lamellen in ihrer Anordnung eine bedeutende, vor Austrocknung geschützte, assimilirende Oberfläche; ist das Laub schmal, so werden die Lamellen länger, bei den breiten Formen kürzer, deren in die Breite angeordnete grosse Anzahl dasselbe Assimilations-Resultat erreichen, welches die langen Lamellen im schmalen Laube leisten.

Die chlorophyllführende Schicht erfährt mit der zunehmenden Ausbildung ein starkes Wachsthum der dorsalen Oberhaut und zwar nicht nur in der Richtung der Längs-Axe des Laubes, sondern auch in transversaler Richtung zu derselben; demgemäss sind die Lamellen nicht nur in der Richtung der Längs-Axe geneigt, sondern sie neigen auch nach rechts und links und liegen in den verdünnten Rändern fast horizontal : es ist auch leicht an Schnitten zu bemerken, besonders an Pflanzen mit wenigen grossen Lufthöhlen, dass diese nach der costa zu enger werden; sie divergiren von der kleineren Oberfläche der costa zur grösseren der oberen Epidermis; auch bei Riccia findet dasselbe statt; die nach oben zunehmende Erweiterung der Kanäle ist hier aber nur wenig bemerkbar, weil die Gesammtverbreiterung auf eine sehr grosse Anzahl kleiner Räume vertheilt ist. 
Zum Verständniss einiger in der Diagnose gebrauchter Bezeichnungen füge ich an Hand der beigesetzten Abbildungen von Querschnitten Folgendes hinzu: das parenchymatische Grundgewebe habe ich costa genannt (Fig. 1. g), denn sie enspricht funktionell wie habituell der costa bei Marchantia; die Seitentheile derselben (h) steigen bei manchen Arten steil empor und laufen ohne jede Einbuchtung direct dem Rande der dorsalen Epidermis zu (a), ich nenne das latera stricte excurrentia. Die dorsale Furche (c) nenne ich sulcus im Gegensalze zu Lindberg und Anderen, die sie carina nennen. $d$ habe ich mit alæ bezeichnet, weil diese Theile die costa häuflg flügelartig überragen, wie in fig. 2; von e sage ich latera costæ sinuatim in alas excurrentia; ich gebrauche sinus also für den einspringenden Bogen, arcuatus für den ausspringenden; im klassischen Latein wird sinus für beides gebraucht. Canaliculatus nenne ich f und nicht sulcatus oder carinatus, wie es die alten Autoren häufig gethan haben; von i sage ich lateribus sulci alte adscendentibus extrosum curvatis. Alles Andere ergiebt sich von selbst. Die von mir angegebenen
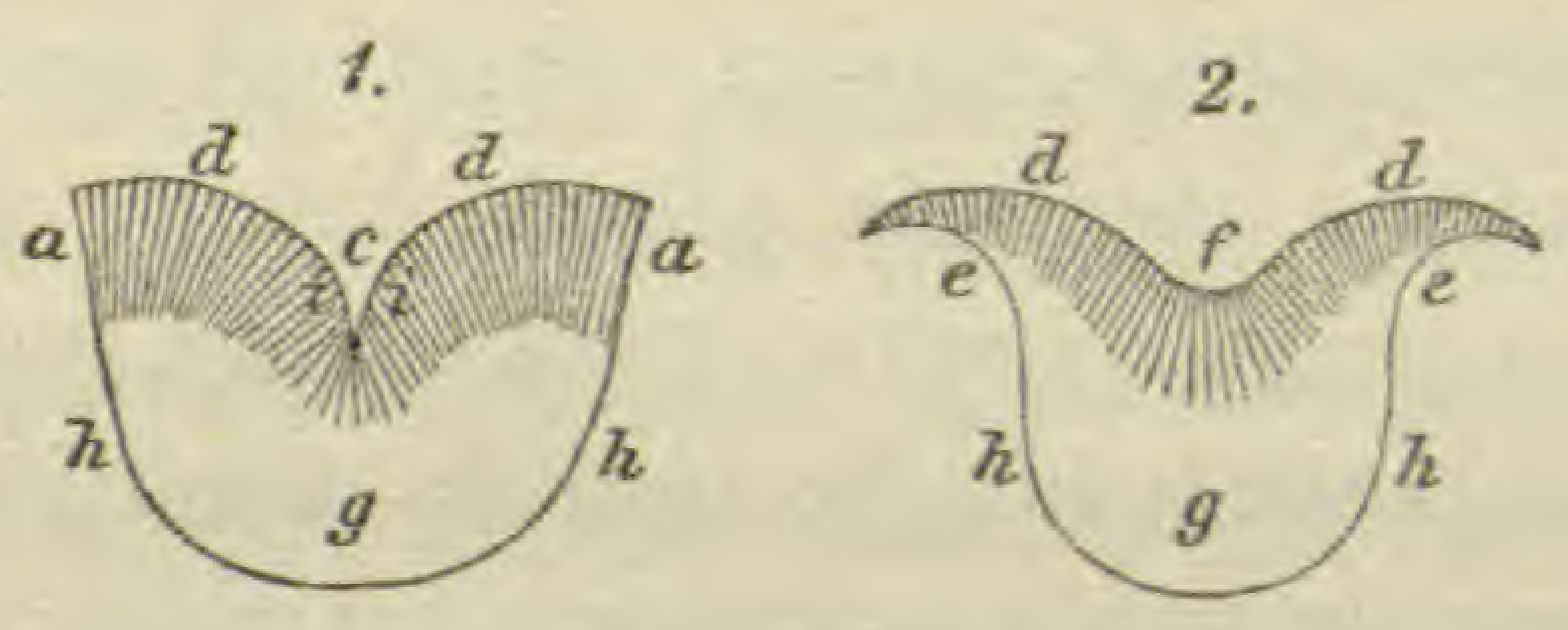

Maasse der Frons beziehen sich stets auf den vollständig entwickelten Theil des Laubes, je nach der Grösse der Art also 1 bis $3 \mathrm{~mm}$. hinter der Spitze, an Schnitten gemessen. Die Sporen variiren innerhalb einer Kapsel ein wenig; es wird aber leicht sein, unter den vielen Sporen einer Kapsel die normale mittlere Grösse, wie ich sie angegeben habe, zu ermitteln. Die convexe Seite der Sporen, welche in der Sporenmutterzelle ihre äussere freie Oberfläche darstellt, zeigt nicht selten eine ganz andere Sculptur als die flachen Seiten derselben; in den Diagnosen ist nur jene berücksichtigt. Die Wimpern (ciliæ), welche bei einer Anzahl von Arten gefunden werden, sind sehr variabel innerhalb des Formenkreises einer Species und Anzahl und Länge derselben können daher nur mit Vorsicht beim Bestimmen einer Riccia benutzt werden.

Zur Behandlung alter Riccienpflanzen (Ricciella ist viel leichter zu handhaben) empfehle ich, sie in heissem Wasser aufzuweichen, das Erdreich zu entfernen und nun die Schnitte auszuführen; legt man diese in Milchsäure und erwärmt sie, so kehren sie meist von selbst in ihre natür- 
liche Form zurück oder sind durch leichten Druck dahinzubringen; sind die Pflanzen allerdings schon einmal angefeuchtet und dann wieder getrocknet worden, so giebt es kein Mittel, sie wieder zur Turgescenz zu bringen; sie werden völlig werthlos.

\section{A. RICGIA}

\section{a. Ciliatæ}

\section{Frons tenuis, multo latior quam crassa.}

1. R. japonica St. Bull. Herb. Boiss. 1897, p. 106.

Monoica minor, cœrulescens. Frons tenuis usque ad $10 \mathrm{~mm}$. longa, repetilo-fureata, furcis divergentibus, brevibus, late linearibus, apice rotundatis. breviter bilobis; antice plano-convexa, solum sub apice leniter canaliculata, marginibus parum attenuatis, obtusis, ciliatis, ciliæ breves patula. Costa medio postico parum convexa, utroque latere levi sinu in margines excurrens. Squamæ posticæ minutæ, hyalinæ, tenerrimæ, facile evanidæ. Sporæ 75 $\mu$, subatræ, laxissime reticulatim lamellatæ, lamellis gracilibus, angulis papilla erecta ornatis; ala latissima, exciso interrupta, foveola $20 \mu$.

Hab. Japonia, Tosa, Sakawa (Inouë).

Sequenti simillima, sporis laxe reticulatis distincta.

\section{R. subinermis Lindb. Rev. bryol. 1882, p. 82.}

Monoica, mediocris, viridis. Frons usque ad $4 \mathrm{~mm}$. longa, obcuneata, apice quadriloba i. e. bis dichotoma, fureis brevibus, latis, ubique xquicrassa, sextuplo latior quam alta, antice plana, marginibus decurvis, acuminatis acutis; costa lata subplana, spinæ marginales sparsæ, brevissimæ; squamæ posticæ minutissimæ, hyalinæ vel purpureo maculatæ. Capsulæ valde numerosæ denseque aggregatæ. Sporæ $68 \mu$, late alatæ, reticulatim lamellatæ, papillatæ, foveolis $10 \mu$.

Hab. Fennia (Lindberg) Gallia, Angers (abbé Hy). Germania Nen Ruppin (Warnstorf).

Diese Standorte lassen vermuthen, dass die Pflanze auch in dem dazwischen liegenden Gebiete zu finden sein wird. 
3. R. californica Austin. Torrey Bull. VI, p. 46.

Monoica, minor, viridis. Frons 5ั-7 mm. longa, linearis, subplana, tenuis, breviter furcata, furcis parum divergentibus, apice distincte breviterque bilobis, marginibus attenuatis, costa parum incrassata, planoconvexa; sectio transversa frondis itaque anguste fusiformis. Squama posticæ parvæ, hyalinæ. Sporæ parvæ, $51 \mu$, anguste alatæ, minute reticulatim-lamellatæ, foveolis $4 \mu$ tantum.

Hab. America septentr. California (Boländer).

Cilien besitzt die von mir untersuchte Originalpflanze nicht; nach der Originalbeschreibung sollen sie zuweilen fehlen; die Pflanze ist an den ausserordentlich klein gefelderten Sporen sehr leicht kenntlich; das Exemplar war nicht gut erhalten und die Form der Frons, die nicht mehr in genügender Weise zum Aufquellen zu bringen war, kann ich für die frische Pflanze nicht verbürgen. Die Sporen werden es aber ermöglichen, sie wiederzuerkennen.

\section{R. ligula St. n. sp.}

Monoica, exigua, viridis. Frons usque ad $3 \mathrm{~mm}$. longa, longe furcata, furcis divergentibus, angustis, optime ligulatis, crassis, 4 plo latioribus quam altis antice posticeque æqualiter plano-convexis, apice rotundatis. marginibus obtusis, sparsim ciliatis; ciliæ strictæ, porrectæ (haud recte patulæ). Squamæ posticæ in apice frondis tantum visibiles, hyalinæ. minutæ, integerrimæ. Sporæ fusco-brunneæ $68 \mu$, late alatæ, ala integerrima, reticulatim-lamellatæ, breviter papillatæ, foveolis $8 \mu$.

Hab. Italia. Lago Maggiore (Al. Levier).

\section{Frons crassa, abrupte alata.}

5. R. Bischoffii Hüben. Ann. Pharm. 1833, VII, p. 68.

Syn. : Riccia ciliifera Link in Ldbg. Syn. hep. europ., p. 119.

Dioica, magna, pallide viridis. Frons usque ad $15 \mathrm{~mm}$. longa, obconicooblonga, furcata, furcis late divergentibus, apice obtusis, antice sparsim ciliiferis, sub apice sæpe profunde sulcatis, alis curvatim adscendentibus vel plus minus explanatis, marginibus semper longius attenuatis, plus minus crebre ciliatis; costa multo angustior valdeque producta, alte radicellosa; frondis adultæ sectio transversa dein duplo solum latior quam alta, antice convexula, leniter emarginata, postice rotundata, lateribus adscendentibus et abrupte in angulos horizontales longeque acuminatos exeuntibus. Squamæ posticæ magnæ, hyalinæ, dense imbricatæ, plus 
minus crebre irregulariterque ciliatx, sub margine frondis desinentes. Ostiola mascula longe prominentia. Sporæ $\mathbf{I 0 0} \mu$. alte reticulatim cristatæ papillatæ.

Hab. Europa, Italia, Sardinia, Gallia (Angers), Tyrol (Meran), Germania (Schriesheim, Wittekind), Africa, Algeria, Teneriffa.

forma montana.

Syn. : Riccia pedemontana Steph. Hedw. 1883, no 4, minor, simplex, alis semper erectis, antice itaque profunde canaliculata; costa maxime producta, alis duplo altiore; antice crebre ciliatu, frondis et squamarum marginibus maxime armatis.

Hab. Hungaria, Nadays. Piemont, Val Lontay. Helvetia, Biel.

6. R. Gougetiana Mont. Ann. sc. nat., ser. 3, vol. XI, p. 3æ̃.

Dioica, magna, in sicco flavicans. Frons $150-20 \mathrm{~mm}$. longa, obcuneata, apice breviter emarginato biloba, lobis late rotundatis, 3-plo latior quam crassa, antice anguste canaliculata, canali parum profundo, plano, alis convexo-explanatis, tenuibus margine attenuato dense breviterque spinosis; costa valde et abrupte producta, si alas excipis planta parum latior quam alta, postice rotundata, lateribus rotundatis, adscendentibus, abrupte in alas attenuatas abeuntibus. Squamæ hyalinæ maximæ, imbricatæ, margine valide spinosæ, spinis irregularibus. Ostiola mascula magna, robusta, longe prominentia. Sporæ nigræ, maximæ, $\mathbf{1 3 6} \mu$ in diametro, late alatæ, ala erosa, aspera; reticulatim lamellatæ, lamellis humilibus asperis, haud papilliferis; foveolis $17 \mu$.

Hab. Algeria (Gouget, Trabut).

Facile cum R. Bischoffii Hüb. commutanda; sporis giganteis sine ullo dubio diversa.

\section{Frons crassa, marginibus acutis vel obtusis, nusquam abrupte alata.}

7. R. asprella Carr. et P. Linn. Soc. N. S. Wales. 1887, p. 1059.

Dioica? minor, dilute virens. Frons 4-ว̆ mm. longa, crassa, obcuneata, breviter furcata, furcis divergentibus, late rotundato-truncatis breviterque emarginato-bilobis, sub apice canaliculatis, ceterum subplanis, marginibus vallatim angusteqae incrassatis, dense setosis, costa humilis, plana, latissima, lateribus abrupte adscendentibus; frondis sectio transversa sextuplo latior quam alta. Squamæ posticæ magnæ, hyalinæ, integerrimæ. Sporæ a magnæ, $100 \mu$ in diametro, fusco-brunneæ, minute verruculosæ s secundum diagn. auctorum. 
Hab. Australia, Sydney (Whitelegge).

Die Sporen habe ich nicht gesehen; sie sind von den Autoren bei nur schwacher Vergrösserung gezeichnet und der Bau des Exosporiums ist daher nicht erkennbar gewesen; aus dem Bilde ist aber zu vermuthen, dass die Sporen, wie die fast aller Arten, ein Leisten-Netz tragen, dessen Ecken papillär emporgezogen sind; eine mehrreihige Anordnung der marginalen Cilien, welche die Autoren hervorheben, habe ich nicht finden können.

\section{R. lusitanica Levier n. sp.}

Monoica, glauco-virens, major. Frons usque ad $12 \mathrm{~mm}$. longa, furcata, crassa, plus triplo latior quam alta, anguste linearis, sub apice profunde sulcata, in fronde adulta plana, alis crassis, attenuatis, obtusis, margine remote valideque spinosis, spinis anguste triangulatis. Costa strato antico multo angustior $(4: 6)$ postice convexa, lateribus sensim in alas excurrentibus. Squamæ magnæ, marginem superantes, interdum hic illic spina longa instructæ. Ostiola mascula parum prominentia. Sporæ magnæ, $90 \mu$, late alatæ, ala repando multilobulata, reticulatim lamellosæ, foveolis $12 \mu$, alte papillatis.

Hab. Portugal, Cintra (Welwitsch 1842).

9. R. crinita Taylor. J. of Bot. 1846, p. 415.

Dioica? minor, glauco-virens. Frons usque ad fै $\mathrm{mm}$. longa, furcata, ungusta, linearis, antice snbplana, marginibus rotundatis; costa crassa, valde convexa ; ciliæ marginales creberrimæ, longissimæ, frondis diametro multo longiores; reliqua desunt; specimen originale pauperculum, haud emolliturum!

Hab. Australia, Swan River (Drummond).

Ciliis longissimis primo visu distinguenda.

10. R. hirta Und. Bol. Gaz. XIX, p. 274.

Syn. R. arvensis var. hirta Austin. Ac. Phil. 1869, p. 232.

Monoica, minor, glauco-viridis; frons usque ad $10 \mathrm{~mm}$. longa, linearis, bi-trifurcata, furcis divergentibus, apice obtusa, antice ample sulcata, sulco obtuso, alis leniter adscendentibus, plano-convexis, crassis, margine acutis, dense breviterque ciliatis; costa valde producta, angusta, postice rotundata, lateribus alte adscendentibus levi sinu in margines excurrentibus; frondis sectio transversa vix duplo latior quam alta, subtriangularis ob costam postice angustatam. Squamæ posticæ hyalinæ, facile eva- 
nidæ. Sporæ ferrugineæ $8 \check{\mu} \mu$ anguste alatæ, reticulatim lamellatæ, vix papillatæ, foveolis $14 \mu$.

Hab. America septentr., New Jersey (Austin). Louisiana (Langlois).

\section{R. Breidleri Juratzka. Steph. in Hedwigia 1885.}

Monoica, parva, viridis. Frons 3-4 mm. longa, simplex vel divaricatim furcata, furcis ex angusta basi ligulatis, apice acuminatis, obtusis breviterque spinosis; antice convexa, distincte sulcata, sulcus amplus, parum profundus; costa valde producta; sectio frondis adultæ parum latior quam alta, postice semicircularis, angulis aculis, parum prominentibus. Squama posticæ parvæ, remotiusculæ, hyalinæ et purpureo-maculatæ. 0stiola mascula pro planta maxima. Sporæ maturæ ignotæ.

Hab. Alpes Austriæ, Schladming (Breidler). Grossglockner (Kern).

$R$. sorocarpa Bisch. toto cœelo differt configuratione frondis.

12. R. Warnstorfii Limp. Verh. Bot. Ver. Brdbg. 188כ, p. 58.

Monoica, parva, flavo-virens. Frons $3 \mathrm{~mm}$. longa, crassa, duplo latior quam alta, bifureata, furcis divergentibus, linearibus, apice obtusis, antice sulcatu, sulco angusto, obtuso, sat profundo, alæ tumidæ margine obtusæ, hic illic spina brevissima armatæ; costa valde producta, postice planoconvexa, lateribus parum convexis alte adscendentibus, sinuatim in margines excurrens. Squamæ purpureæ, parvæ, sub margines desinentes. Sporæ $60 \mu$, fusco-brunneæ anguste alatæ reticulatim-lamellatæ, foveolis $8 \mu$, papillatæ.

Hab. Germania, Neu Ruppin (Warnstorf).

\section{R. Beyrichiana Hampe. Syn. Hep. p. 601.}

Monoica, mediocris, glauco-virens. Frons usque ad $10 \mathrm{~mm}$. longa, angusta, crassa, furcis linearibus parum divergentibus, antice ubique distincte canaliculatis, marginibus rotundatis hic illic breviter ciliatis; costa lata crassaque, lateribus rotundatis, alte adscendentibus; frondis sectio transversa duplo latior quam alta. Squamæ posticæ parvæ, purpureæ, margine sparsim breviterque ciliatæ. Sporæ nigræ, maximæ, $120 \mu$, læves i. e. humiliter reticulatæ, nusquam papillatæ, foveolis $18 \mu$.

Hab. America septentr., Jefferson (Beyrich).

Underwood (Bot. Gaz. XIX, p. 276) stellt diese Pflanze als fraglich für Nord-America hin. Die mir zu Gebote stehende Pflanze ist aber von Beyrich bei Jefferson gesammelt und zweifellos eine gute Art. 
14. R. ciliata Hoffm. Fl. germ. crypt., t. II, p. 9气̃.

Monoica, mediocris, fusco-viridis, in vivo nitida. Frons 6-8 mm. longa, repetito-furcata, furcis minus divergentibus, apice subtruncatis, antice late plano-canaliculatis, ciliæ ad latera descendentes, quasi pluriseriatim dispositæ, hamatæ; costa late convexa, crassa, lateribus rotundatis cum frondis margine obtuso confluentibus. Frondis adultæ sectio transversalis triplo latior quam alta, ubique æquicrassa, facie antica posticæ subparallela i, e. æqualiter curvata. Squamæ posticæ parvæ, evanidæ, interdum purpureo maculatæ, integerrimæ. Ostiola mascula et fem. breviter prominentia; sporæ nigræ, anguste marginatæ, $88 \mu$, reticulatim lamellatæ, creberrime papillatæ, papillis subclavatis, foveolæ $8 \mu$.

Hab. Europa, Fennia, Germania, Britannia, Gallia, Italia (Firenze).

\section{4อ.. R. spinosissima St. Hedwigia, 1885 .}

Dioica? minor, flavo-virens. Frons $5 \mathrm{~mm}$. longa, apice furcata, fureis latissime divergentibus, crassa, anguste linearis, apice angustata obtusa, antice profunde obtuseque canaliculata, alis maxime vallatim ampliatis, erectis (costam haud lateraliter superantibus) densissime spinosis. Costa valde producta, postice subcarinata, lateribus alte adscendentibus, sinuatim in alas erectas excurrens; frondis adultæ sectio transversalis circumscriptione fere trigona, antice rima profundissima bipartita, fundo rimæ concavo lateribusque arcuatim adscendentibus. Squamæ magnæ; hyalinæ, margine longe valideque spinosæ. Reliqua desunt.

Hab. Algeria (Trabut).

16. R. Michelii Raddi. Opusc, scient. Bologna, p. 392.

Syn. : R. ciliata Radd. 1818, 1. c.

R. tumida Ldbg. 1899. Syr. Hepat. europ., p. 120.

R. palmata Ldbg. 1836. Mon. Ricc., p. 457.

R. paradoxa Denot. 1839. Prim. Hep. Hal., p. 69.

R. subalpina Limpricht. ms.

Dioica, mediocris, pallide-virens. Frons usque ad $10 \mathrm{~mm}$. longa, pauciramosa, fureis obeuneato-oblongis, apice parum angustatis, obtusis, erassis, sulco antico amplo in fundo convexo, marginibus vallatim ampliatis basi et apice contiguis, in medio magis remotis, breviter spinosis, costa crassa, convexa, lateribus sensim in margines obtusos excurrens. Sectio transversa frondis adultæ plus duplo latior quam alta, postice lunatim convexa, antice duobus incisuris brevibns quasi tripartita, partibus aqualibus convexis; squamæ posticæ hyalinæ, margine incisæe et plus minus 
longe ciliatæ. Sporæ $102 \mu$, reticulatim lamellatæ, foveolis $17 \mu$, in angulis alte papillatæ.

Hab. Europa et Africa mediterranea, Gallia, Montpellier (Philibert, Montagne). Cantal (Gasilien). Cannes (Metzler) Algeria (Trabut).

Dieser Pflanze wieder zu ihrem richtigen Namen verholfen zu haben ist das Verdienst Levier's. Siehe Bull. Herb. Boiss. II, 1894.

17. R. Lindmanii St. in K. Svenska Vet.-Akad, 1897, vol. 23.

Dioica, minor, viridis. Frons $10-13 \mathrm{~mm}$. longa, $2 \mathrm{~mm}$. lata, repetito furcata, in medio subplana, marginibus crassis, vallatim intumescentibus, extus creberrime spinosis, spinis longis recte patentibus, granulatis. Squamæ magnæ, hyalinæ, occultæ, marginibus spinosis. Costa latissima, postice late convexa, in margines incrassatos excurrens. Frondis sectio transversa circumscriptione fere elliptica, triplo latior quam alta, antice sulco lato in fundo plano interrupta. Sporæ $8 a ̈ \mu$, rufo-brunneæ, anguste limbatæ, reticulatæ, areolis $\mathbf{1 5}-\mathbf{1 8}$ in diametro, ex angulis humiliter papillatis. Androecia ignota.

R. Michelii Raddi differt fronde squamisque minus dense spinosis, sporis minoribus, multo arctius reticulatis.

Hab. Paraguay, Asuncion (Lindman).

18. R. canescens St. n. sp.

Monoica, minor. Frons 10-12 mm. longa, longe furcata, furcis divergentibus, linearibus, crassis (vix duplo latioribus quam altis) antice profunde canaliculatis, canali in fundo suo plano-convexo, marginibus vallatim incrassatis erectis, rotundatis, spinisque longissimis validissimis armatis; costa valde producta convexa, lateribus rotundato-erectis in margines sensim excurrrentibus. Squamæ parvæ, purpureæ, similiter spinosæ. Planta itaque hispidissima, in sicco spinis incurvis omnino obvelata et vix pro Ricciam habenda. Ostiola mascula brevissima. Spora $85 \mu$, reticulatim-lamellatæ, foveolis $8 \mu$, haud papillatis.

Hab. Africa, Oran (Balansa).

$R$. Henriquesii et $R$. spinosissimæ similis; setis numerosis et longissimis facile distinguenda.

19. R. atromarginata Levier n. sp.

Dioica? parva, ramosa, fuseo-viridis, margine atro-purpurea, valde carnosa. Frons 3-4 mm. longa, simplex vel furcata, furcis oblongis divergentibus ovatis, apice acuminatis obtusis, antice leniter canaliculatis 
sparsimque ciliiferis, marginibus parum elevatis, breviter attenuatis, creberrime breviterque ciliatis; costa strato antico æquilata, crassa, postice plano-convexa, lateribus abrupte adscendentibus et abrupte in margines breves excurrentibus. Sectio frondis triplo latior quam alta. Squamæ posticæ breves, atropurpureæ. Sporæ ignotæ.

Hab. Sicilia, Palermo (Ross.).

20. R. Henriquesii Levier. Bull. Soc. bot. ital. 1894.

Syn. : R. bicarinata Lindb. Rev. bryol. 1877, p. 34.

Dioica, major, viridis. Frons usque ad $12 \mathrm{~mm}$. longa, furcata, furcis late divergentibus, angustis, margine obtusis ciliatis; ciliis sæpe ad basin geminatim vel ternatim coalitis; apice rotundata, antice ob margines vallatim incrassatos sulcata; sulcus sub apice angustus, profundus, in medio frondis amplificatus, fundo convexo quasi duplicatus (unde nomen ceterum falsum Lindbergii) postice rotundata, lateribus subrecte adscendentibus, sæpe purpureo maculatis; frondis adultæ sectio transversa duplo latior quam alta. Squamæ hyalinæ vel purpureæ. Sporæ magnæ, $120 \mu$, reticulatim lamellatæ, papillis humilibus, foveolis magnis $17 \mu$, ala angusta aspera.

Hab. Portugal, Coimbra ; Corsica, Gallia, Bretagne prope Lorient(Herb. Montagne).

Lindberg's Name beruht auf einer nicht seltenen Verwechslung von carina und sulcus; in gleicher Weise wird sinus häufig verschieden gebraucht, bald im Sinne einer einspringenden Landbucht bald als vorgewölbte Form; da Lindberg's Bezeichnung gradezu falsch ist, lasse ich Levier's Namen bestehen.

Uebrigens trägt Lindberg's Original nicht die langen Cilien die er beschreibt, sondern ganz die der Art eigenthümlichen Wimpern, die aber nicht immer so kurz sind, wie sie Levier abgebildet hat.

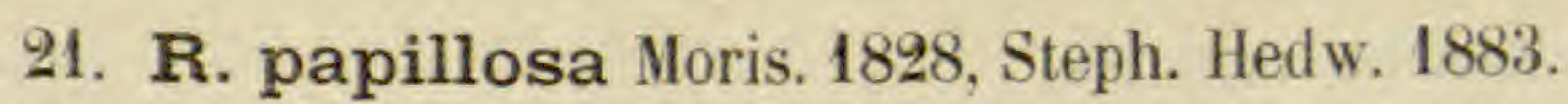

Syn. R. setosa Müller ms. in Herb. Sard.

R. minima Ldbg ex parte. Ac. Leop. XVHI, p. 427.

Dioica, minor, pallide glauco-virens. Frons usque ad $8 \mathrm{~mm}$. longa, gracilis, bi-trifurcata, furcis parum divergentibus, pro planta longissimis. anguste linearibus, apice obtusis, crassis; antice late canaliculata, alis oblique adscendentibus, ciliis brevibus obtusis hirta, marginibus crassis. acutis, suberectis, ciliis similibus dense seriatis armatis. Costa valde producta, postice plano-convexa, lateribus parum rotundatis, alte adscenden- 
tibus. Sectio transversa frondis adultæ parum latior quam alta, si paginam anticam excisam excipis, rotundato-quadrata. Squamæ posticæ minute, hyalinæ, Sporæ ignotæ.

Hab. Italia, Sardinia (Müller, Iter Unio). Napoli (Gasparini sub : R. trichophylla ms.). Firenze (Levier).

\section{R. pseudopapillosa Levier. n. sp.}

Monoica, parva. Frons irregulariter bis dichotoma, fureis longe coalitis sæpe obconico-oblongis, apice obtusis, crassis (vix latioribus quam altis) antice subplana, rima angusta percursa, ciliis brevibus sæpe hamatim incurvis hirta, marginibus obtusis æqualiter hirtis; costa valde producta, strato antico æquilata, postice rotundata, parietibus alte adscendentibus. Sporæ maturæ ignotæ.

Hab. Austria, Stein prope Wien (Baumgartner).

Configuratione frondis a R. papillosa Moris, cui simillima, facile distinguenda.

\section{b. Inermes}

IV. Frons minus crassa, subtenuis, antice plana vel late concava, marginibus longe attenuatis (in una tantum obtusatis.)

23. R. plano-biconvexa St.in K. Svensk Vet. Akad. 1897. Yol. 23. Sterilis, major, late expansa, viridis, robusta, tenax. Frons usque ad $20 \mathrm{~mm}$. longa, repetito-furcata, furcis brevibus, parum divergentibus, apice emarginatis, antice plano-convexis, sub apice parum sulcatis, marginibus attenuatis acutis planis. Squamæ hyalinæ, parvæ, occultæ; costa postice plano-convexa, paginæ anticæ compar; frondis sectio transversa itaque symmetrice plano-biconvexa vel fusiformis, angulis attenuatis acutis, ceterum sextıplo latior quam alta. Stratum aëriferum humillimum, costie triplo humilius, canalibus angustis.

Hab. Brasilia (Lindman).

R. glauca L. primo visu differt statura minore frondeque longe suleata.

24. R. amboinensis Sehiff. Forsch. Gazelle IV, 44.

Dioica, magna, pallide virens, margine sæpe purpurea. Frons usque ad $2 . \mathrm{mm}$. longa, tenuis, furcata, ob fureas longe coalitas basi obconica, furcis apice distincte bilobis angusteque sulcatis, ceterum planis, mar- 
ginibus longe attenuatis costam late superantibus; costa postice planoconvexa, sensim in alas attenuata; frondis sectio itaque sextuplo latior quam alta, antice plana, postice plano-convexa; stratum anticum humillimum (fere quadruplo minor quam costa in sectione). Squamæ posticæ breves, hyalinæ, remotæ. Sporæ magnæ, $119 \mu$, late alatæ, ala tenuis varie profundeque emarginata, sublobata, laxe reticulatim lamellatæ, lamellis altis, acutis; foveola $17 \mu$ vel majores, valde irregulares, papillis nullis.

Hab. Amboina (Exped. Gazelle).

\section{R. Treubiana St. n. sp.}

Monoica, major, pallide virens, margine purpurea. Frons $20 \mathrm{~mm}$. longa, tenuis, profunde furcata, furcis $\breve{~ m m}$. latis, apice truncato rotundatis, brevissime bilobis, antice subplana, sulco tenui percursa, alis vix adscendentibus, planis, marginibus longius altenuatis, acutis. Costa aquilata, parum convexa, lateribus convexis oblique adscendentibus. Squamæ parvæ hyalinæ, marginem haud superantes. Sporæ magnæ $93 \mu$ intense rufæ vel subpurpureæ, laxe reticulatim lamellatæ, lamellis crassis, in angulis haud papillatis, foveolis sub $20 \mu$; ala angusta erosa.

Hab. Java. Builenzorg (Treub).

26. R. hortorum Bory Syn. Hep. p. 607.

Dioica, major, virens, alis postice purpureis. Frons parum furcata, furcis oblongis, crassis, כૅ-plo tamen latioribus quam altis, antice sub apice parum breviterque sulcatis, ceterum subplanis vel parum canaliculatis, alis convexo-planis, leviter acuminatis margine aculis; costa duplo angustiore quam stratum anticum, postice plano-convexa, sensim in alas attenuata; frondis sectio transversa itaque fere symmetrice fusiformis, antice tantum leniter emarginata. Squamæ posticæ parvæ, purpurea. Sporæ magnæ $102 \mu$, late alatæ, ala irregulariter repando-vel inciso cristæformi, laxissime reticulatim-lamellatæe, lamellis angustis, altis, repandis, haud papillatis; foveolis $17 \mu$.

Hab. : Insula Bourbon (Bory Sit Vincent).

\section{R. angolensis St. n. sp.}

Dioica, ㅇ ignota, minor, glauco-virens. Frons angusta obcordata vel obconico-oblonga, breviter furcata, furcis divergenlibus, breviter ligulatis, apice late rotundatis breviterque bilobis, ubique fere plana, sub apice solum brevi rima instrueta, postice parum incrassata; costa convexa in alas longe sensimque attenuata, marginibus tenui- 
bus. Frondis sectio transversa sextuplo latior quam crassa, antice plana, postice late lunata, angulis longe acuminatis, acutis. Squamæ posticæ magnæ, oblique ovatæ, remotæ, purpure0-maculatæ, integerrimæ, longe productæ.

Hab. Africa, Angola (Welwitsch, iter angol. 2气̄a).

28. R. Lesquereuxii Austin. Acad. Phila. 1869, p. 232. false R. Lescuriana Austin.

Monoica, mediocris, glauco-virens, expansa. Frons usque ad $7 \mathrm{~mm}$. longa, repetito-furcata, fureis brevibus, ultimis ovatis, acutiusculis, planis. marginibus parum attenuatis, crassis, oblusis; costa convexa, sensim in margines attenuata; sectio transversa frondis adultæ quadruplo fere latior quam alta. Squamæ posticæ parvæ, hyalinæ. Sporæ $8 \check{\mu} \mu$, rufæ, alte reticulatim-lamellatæ, foveolis $10 \mu$, lamellis crassis, vix papilliferis.

Hab. America septentr. haud rara, New-Jersey, Illinois, Florida (teste Underwood).

\section{S. Elliottii St, n. sp.}

Monoica, mediocris, dilute viridis. Frons $8 \mathrm{~mm}$. longa, profunde bi- vel trifurcata, furcis parum divergentibus, obconico-oblongis, apice rotundatis, profunde bilobis, antice sulco amplo percursis, alis convexo-explanatis, marginibus attenuatis acutis, costa humilis, lata, sinuatim in alas excurrens; sectio transversa frondis 3 plo latior quam alta. Squamæ posticæ hyalinæ, basi pupureæ, marginem parum superantes, integerrimæ. Sporæ subnigræ, $85 \mu$, ala angusta circumdatæ, grosse reticulatæ, haud papillatæ, maculis $14 \mu$, convexis.

Hab. Insula Dominica (Elliott).

\section{R. flavispora St. n. sp.}

Monoica, dilute viridis, mediocris, expansa. Frons $10 \mathrm{~mm}$. longa, profunde bi- vel trifurcata, furcis obconico-linearibus, apice rotundatis, brevissime bilobis, antice subplanis, sub apice solum parum lateque concavis, alis plano-convexis, marginibus attenuatis; costa latissima, parum convexa, sensim in alas excurrens; frondis sectio transversa sextuplo latior quam alta. Squamæ postieæ parvæ, hyalinæ, marginem haud excedentes. Sporæ (maturæ!) dilute flavescentes, alte reticulatim lamellatæ, foveolis $8 \mu$. lamellis apice emarginatis haud papillatis, ala lata integerrima, lævis.

Hab. Brasilia subtropiea (Ule no 219). 
31. R. grandis Nees in Martius Fl. bras. I, p. 300.

Dioica? major, viridis. Frons usque ad $150 \mathrm{~mm}$. Ionga, tenuis, late linearis, apice breviter biloba, antice late concava, alis leniter adscendentibus longe attenuatis, marginibus tenerrimis; costa humilis latissima, convexa, sensim in alas excurrens; squamæ posticæ magnæ hyalinæ vel purpureæ, marginem frondis parum excedentes. Reliqua desunt.

Hab. Brasilia (St. Hilaire), Rio Janeiro (Martius).

\section{R. Breutelii Hampe ms.}

Dioica, minor, flavo-virens. Frons usque ad $10 \mathrm{~mm}$. longa, tenuis et angusta, longe furcata, furcis late divergentibus, ligulatis, apice rotundatis, breviter bilobis, antice in medio leniter concava, alis plano-convexis, marginibus attenuatis, acutis; costa latissima, parum convexa, in margines sensim attenuata; sectio transversa frondis dein lunatim subfusiformis. Squamæ posticæ minime hyalinæ, evanidæ et solum in apice asservatæ. Sporæ pro planta magnæ $93 \mu$, late alatæ, arete reticulatim lamellatæ (foveolæ $8 \mu$ ) lamellis altis, emarginatis, ad angulos papillatis.

Hab. India occid. Insulæ S'Kitts et S. Juan.

33. R. grandisquama St. in K. Svenska, Vet. Akad. 1897. Vol. 23.

Dioica? Major, in sicco flavo-virens. Frons usque ad $10 \mathrm{~mm}$. Ionga, $3 \mathrm{~mm}$. lata, tenax, simplex vel furcata, furcis divergentibus, apice late rotundatis, breviter bilobis, sub apice parum sulcatis, ceterum leviter concavis, ad margines attenuatos planis. Squamæ magnæ, dense imbricatæ, usque ad marginem frondis accretæ, apice angustatæ obtusæ, illum longe superantes, hyalinæ, integerrimæ. Costa latissima, postice late convexa. levi sinu in alas late attenuata. Sectio frondis transversa quintuplo latior quam alta, anguste lunata, angulis horizontalibus longe attenuatis. Reliqua desunt.

R. squamata Nees, differt statura minore, fronde multo erassiore squamisque fusco purpureis subviolaceis.

Hab. Brasilia, Rio Grande, Cachoeira (Lindmann).

\section{R. concava Bisch. Syn. Hep. p. 604 .}

Major, glauca, bis dichotoma, tenuis, canaliculata, furcis ovatis, obtusis vel emarginatis, in sicco concavis, conchæformibus, marginibus adscendentibus, squamis posticis albidis magnis (ipse haud vidi).

Hab. Caput bonæ spei (1) Krauss). 
" Ricciæ albomarginatæ $\beta$ majori et $R$. lamellosæ similis; lobis ovatis concavis ab utraque diversa, "Syn. Hep.

Ob die Art hierher gehört, ist ganz zweifelhaft; schon die Vergleichung der Pflanze seitens des Autors mit $R$. albomarginata, die ein ganz dünnes Laub hat, und mit $R$. lamellosa, die sehr fleischig ist, deuten darauf hin, dass sie ungenügend untersucht und beschrieben wurde.

V. Frons minus crassa (pro more quintuplo latior quam crassa) antice sulcata, marginibus plus minus attenuatis.

\section{R. Weinionis St. n. sp.}

Monoica, magna, fusco-viridis. Frons usque ad $25 \mathrm{~mm}$. longa, 3-4 mm. lata, simplex vel furcata, tenax, apice angustata, obtusa, antice sulcata, alis sub apice frondis adscendentibus, ceterum horizontalibus, convexis. Squamæ hyalinæ, parvæ, sub margine oceultæ vel parum prominentes. Costa lata, in medio postico magis prominente, convexa, sensim in alas attenuata. Sectio transversa quintuplo latior quam alta, ad latera longe attenuata. Sporæ $102 \mu$, subnigræ, humiliter reliculatim-lamellatæ, foveolis $12 \mu$.

Hab. Brasilia, Rio Janeiro (Weinio).

36. R. limbata Bisch. Syn. Hep. p. 606.

Dioica? major, obscure viridis. Frons usque ad $13 \mathrm{~mm}$. longa, bifureata, furcis parum divergentibus, linearibus. apice rotundatis, erassis, in pagina antica sub apice profunde sulcatis, in furcis adultis late canaliculatis, alis plano-convexis, haud incurvis, attenuatis, margine acutis, costa lata, convexa, lateribus oblique adscendentibus, sinuatim in margines attenuata; sectio frondis fere quadruplo latior quam alta, postice late lunata, angulis longe attenuatis, antice (in planta adulta) late lunata, Squamæ posticæ maximæ, dense imbricatæ, purpureæ, frondis marginem superantes. Reliqua desunt.

Hab. Africa australis, Prom. bonæ spei. (Krauss).

\section{R. Billardieri M. et N. Syn. Hep. 602.}

Monoica? major, expansa, flavicans, purpureo marginata. Frons solitaria 10-12 mm. Ionga, $2-3 \mathrm{~mm}$. lata, inferne longe simplex, superne furcata, subplana vel medio leniter canaliculata, apice acute sulcata profundeque biloba, tenuis, versus basin sensim incrassata; marginibus attenualis acutis, leniter decurvis. Squamæ magnæ, dense imbricatæ, pur- 
pureæ, marginem frondis longe superantes, integerrimæ. Costa adulta postice late convexa, in margines sensim excurrens. Sectio transversa frondis quadruplo latior quam alta, postice late lunata, angulis late acuminatis, antice subplana vel sinu amplo emarginata. Sporæ maximæ, $102 \mu$, rufo-brunneæ, reticulatim lamellatæ, lamellis altis, foliaceis, apice truncatis emarginatis, alveolos magnos (10 in faciei diametro) includentibus.

Hab. Java (La Billardière, Solms-Laubach). Tonkin (Bon).

38. R. discolor L. et L. Pugill. IV.

Dioica? parva, glauco-viridis, subtus atropurpurea. Frons כ̆ mm. Ionga, breviter furcata, linearis, angusta, antice subplana, rima angusta obtusa percursa, costa subtriplo angustior, convexa, sensim in alas attenuatas sinuatim excurrens, marginibus tenerrimis; sectio frondis sextuplo latior quam alta. Squamæ posticæ atropurpureæ, imbricatæ, parvæ. Reliqua desunt.

Hab. Nepal (Wallich). Himalaya, Dehra Dun (Duthie).

39. R. Ridleyi Gepp. Linn. Soc. 1890.

Dioica? pusilla, fusco-viridis. Frons usque ad $5 \mathrm{~mm}$. longa, parum furcata, furcis oblongis, ultimis acuminatis acutis, sulco sub apice valde profundo, acuto, alis arcuatim adscendentibus, convexo patulis, in planta adulta minus profundo alisque subhorizontalibus; margines longius attenuati, acuti; costa postice plano-convexa, lateribus oblique adscendentibus, in margines sensim attenuatis; sectio transversa frondis adultæe fere quadruplo latior quam alta, postice late lunata, antice plano convexa, recto angulo mediano interrupta, angulis lateralibus attenuatis acutis. Squamæ posticæ parvæ, purpureæ, marginem haud superantes. Sporæ $100 \mu$ (teste (Gepp.).

Hab. Insula Fernando Noronha (Ridley).

Ricciæ Mauryanæ St. simillima; sporæ maturæ desunt.

\section{R. Mauryana St. n. sp.}

Dioica, major. Frons 10-12 mm. longa, $2 \mathrm{~mm}$. lata, bis terque furcata, furcis recto angulo divergentibus, brevibus, profunde acuteque sulcatis, alis alte adscendentibus, convexis, marginem versus sensim altenualis, ipso margine acutis. Squamæ hyalinæ, tenerrimæ, valde fugaceæ, magnæ, sub frondis margine occultæ, in apice plantæ solum prominentes, integerrimæ. Costa valde incrassata, strato aërifero triplo altior, e pagina 
ventrali hemisphærica dense longeque radicans; frondis sectio transversa dein subquadruplo latior quam alta, postice rotundata, lateribus rotundato-adscendentibus et extrorsum nutantibus, ad angulos attenuatos acuta, antice acute plus minus profunde (versus apicem maxime) sulcata. Ostiola $\sigma^{\gamma}$ ignota. Flores of sparsi. Sporæ $85 \ddot{\mu} \mu$, subnigræ, dense minuteque papillatæ.

Hab. Mexico, Cerro de Guadalupe (P. Maury).

\section{R. congoana St. n. sp.}

Dioica, magna, fusco-viridis, expansa. Frons usque ad $15 \mathrm{~mm}$. longa, tri-quadrifurcata, furcis late linearibus longe coalitis, parum divergentibus, frons itaque optime obcuneata, furcis crassis, 4 plo latioribus quam altis, apice rotundatis, sub apice profunde acuteque sulcatis. lateribus sulci convexis oblique adscendentibus, marginibus longius attenuatis, crassis, acutis. Costa postice rotundata, lateribus alte adscendentibus sinuatim in margines attenuata. Squamæ maximæ, imbricatæ, purpureæ, marginem haud excedentes. Sporæ $7 \ddot{\circ} \mu$, rufo-brunneæ, reticulatim lamellatæ, lamellis altis longe papillatis, papillis acuminatis, foveolis $7 \mu$.

Hab. Africa. Territorium congoanum gallicum (Voz).

42. R. glauca L. Spec. plant. p. 1605 .

Syn. R. Lindenbergii Sauter, ex parte. Syn. hep. p. 611.

Monoica, minor, glauco-viridis, expansa. Frons ä mm. longa, fere 4 plo latior quam crassa, breviter furcata, furcis ligulatis, apice acutis, antice sulco amplo percursis, alis sub apice oblique adscendentibus, ceterum explanatis, plano convexis, marginibus acutis. Costa latissima, plano convexa, sensim in margines attenuata. Squamæ hyalinæ, tenerrimæ, facile evanidæ, integræ, marginem haud excedentes. Sporæ subatræ, $68 \mu$, late marginatæ, margine crebre denticulato, reticulatim-lamellatæ, papillatæ, foveolis $7 \mu$.

Hab. Europa, Asia et America septentr. Norvegia et Sibiria usque ad $61^{\circ}$ lat. sept. Gallia, Montpellier. Japonia. Alpes Austrix (Semmering $800 \mathrm{~m}$.$) .$

\section{R. macrospora St. n. sp.}

Monoica, magna, expansa, fusco-virens. Frons solitaria 14-16 mm. longa, $4 \mathrm{~mm}$. lata, bis terque furcata, furcis brevibus el apicibus tantum solutis; frons itaque circumscriptione late obcuneata, apice quadri-vel pluries lobata, ibidemque $8-10 \mathrm{~mm}$. lata, interdum ramis brevioribus 
mixtis valde irregularis, celerum subplana, margine acuta, sulco parum profundo lateque aperto percursa, alis planis, solum sub apice frondis leniter ascendentibus ibidemque margine late incurvo. Squamæ magnæ, imbricatæ, integerrimæ, nigro-purpureæ, frondis marginem longe superantes. Costa latissima, sat crassa, postice plano-convexa, lateribus brevibus sensim excurrens. Sectio plantæ transversa itaque quadruplo latior quam alta, angulis late acuminatis, postice late lunata, antice angulo late aperto incisa. Flores masculi femineis approximati. Sporæ maximæ, $150 \mu$, crebre et regulariter lamellatæ; anguli lamellarum papilla alta truncata instructi, exosporium dein maxime hirtum.

Hab. Australia centralis. Arco eillinna well. Elder Explor. Exped. (Helms).

44. R. albomarginata Bisch. Syn. Hep. p. 604.

Monoica, minor, viridis, ob squamas hyalinas prominentes quasi marginata, unde nomen. Frons usque ad $10 \mathrm{~mm}$. longa, 2-3 mm. lata, furcata, furcis obovato-ligulatis, obtusis, sub apice solum profunde canaliculatis, sulco angusto, lateribus alte curvatimque adscendentibus, in parte adulta frondis sensim sensimque explanatis atque ad planum demittentibus, ceterum haud crassa, plus quadruplo latior quam alta; sectio transversa dein valde variabilis, sub apice pagina antica late profundeque incisa, postica hemisphærica, in medio frondis tamen antice vix emarginata, postice plano-convexa; marginibus ubique acutis, haud attenuatis. Squamæ posticæ magnæ, confertæ, oblique ligulatæ, rotundatæ, integerrimæ, marginem frondis longe superantes. Sporæ $76 \mu$, lamellis radiatim dispositis, crebre anostomosantibus dense obtectæ.

Hab. Promont. bonæ spei (Zeyher, Krauss). Plantam Kraussei haud vidi.

\section{5.. R. inflexa Taylor. J. of Bot. 1846, p. 417.}

Dioica? minor, pallide-virens. Frons usque ad है mm. longa, simplex vel breviler furcata, crassa sub quadruplo latior quam alta, furcis angustis, linearibus, apice acuto, squamis atropurpureis obvelato, antice profunde canaliculata, canalis lateribus prærupte adscendentibus, in parte adulta frondis magis apertis, marginibus breviter attenuatis acutissimis; costa crassa, strato antico aquilata, postice plano-convexa, lateribus rotundatis, sinuatim in margines excurrens. Squamæ posticæ atropurpureæ, magnæ, imbricatæ, duræ fragilesque, marginem frondis superantes. Sporæ " magnæ " teste Taylori; mihi ignotæ.

Hab. Australia, Swan River (Drummond). 


\section{Frons crassa (pro more triplo latior quam crassa) abrupte alata.}

46. R. Fruchartii St. n. sp.

Monoica, magna, glauco-virens. Frons $20 \mathrm{~mm}$. longa, bifurcata, furcis $4 \mathrm{~mm}$. latis, brevibus, ante bifurcationem longe coalitis, parum divaricatis, ultimis ligulatis, apice truncatis breviter bilobis, antice subplanis: costa multo magis angusta (plus 2 plo) crassa, postice plano-convexa, lateribus brevibus, adscendentibus, abrupte in alas latissimas tenerrimas abeunte. Sectio transversa frondis 6 plo latior quam alta, vel (alæ tenues neglectæ) triplo latior solum. Stratum aëriferum humillimum; squama postice parvæ, hyalinæ vel purpureo maculatæ. Sporæ magnæ, $102 \mu$. rufo-brunneæ, anguste marginatæ, reticulatim lamellatæ, lamellis humilibus, vix papillatis, foveolis $12 \mu$.

Hab. Montevideo (Fruchart).

\section{R. runssorensis St. n. sp.}

Dioica, minor. Frons $\breve{-7 ~ m m . ~ I o n g a, ~} 1 \mathrm{~mm}$. lata, simplex vel apice furcata, furcis recto angulo divergentibus, profunde acuteque sulcatis (magis versus apicem, minus profunde versus basin plantæ) ob margines adscendentes valde concavis, margine abrupte breviterque attenuatis foliaceis purpureis, apice marginibus erecto-incurvis quasi acuminatis. Squamæ purpureæ, dense imbricatæ, integerrimæ, frondis marginem haud excedentes. Costa valde incrassata, strato aerifero æquilata duplo tamen altior, e pagina ventrali lata et plana dense breviterque radicans. Frondis sectio transversa dein duplo latior quam alta, postice plano-convexa, lateribus rotundato-adscendentibus, angulis superis in acumen breviusculum suberectum attenuatis, antice plano-convexa, sulco acuto plus minus profunde interrupla. Ostiola $\sigma^{\top}$ ignota. Flores $o$ numerosi, geminati vel solitarii. Sporæ fusco-brunneæ, $93 \mu$, papillis longiusculis ligulatis recteque truncatis densissime hirtæ.

Hab. Africa tropica; in monte Runssoro (Scott Elliott.).

Die Sporen dieser Pflanze stehen hinsichtlich ihrer papillaren Bekleidung einzig unter den Verwandten da.

\section{R. Wichuræ St. n. sp.}

Monoica, mediocris, parum ramosa. Frons usque ad $7 \mathrm{~mm}$. longa, furcis parum divergentibus, crassis, triplo fere latioribus quam altis, antice 
late subprofundeque canaliculatis, alis plano convexis, marginibus breviter acuminatis, acutis, costam parum superantibus. Costa valde producta, strato antico parum angustior, postice plano-convexa, lateribus rotundatis abrupte in alas excurrentibus. Squamæ posticæ parvæ, sæpe purpureo maculatæ. Ostiola mascula angusta, parum prominentia. Sporæ $68 \mu$, late alatæ, ala aspera, in facie convexa reticulatim lamellatæ, lamellis angustis, altis alteque papillatis, foveolæ $12 \mu$; in faciebus planis minute et creberrime lamellatæ.

Hab. Japonia (Wichura).

Es ist zweifelhaft, ob die Pflanze nicht aus einem anderen Theile Asiens stammt; wenigstens wurden mir andere Hepatica dieses Sammlers in dieser Hinsicht als fragwürdig bezeichnet; jedenfalls ist aber die Pflanze neu.

49. R. tenuilimbata St. in K. Svensk. Vet. Akad. 1897. Vol. 23.

Dioica, major, dense ramosa, dilute viridis, carnosa. Frons usque ad $15 \mathrm{~mm}$. longa, repetito-fureata, furcis brevibus parum divergentibus, antice rima profunda percursis, alis convexo-adscendentibus, marginibus horizontalibus, tenerrimis, hyalinis, in fronde juvenili incurvis. Squamæ imbricatæ, purpurex, integerrimæ, occultæ. Costa crassa, postice valde convexa, lateribus rotundatis alte adscendentibus abrupte in margines, attenuatos excurrens; frondis sectio itaque vix duplo latior quam alta, postice semicircularis, angulis longius productis longeque attenuatis, antice sulco plus minus profundo dimidiata, dimidiis convexis leniter adscendentibus. Antheridia in medio frondis seriata, ubique geminata, ostiolis longis hyalinis longeque prominentibus. ㅇ ignota.

Hab. Paraguay. Colonia Pres. Gonzales (Lindman).

รั0. R. lata Taylor. J. of Bot. 1846, p. 416.

Dioica, magna, valde robusta, viridis. Frons 12-14 mm. longa, furcata, furcis oblongis apice obtusis, late divergentibus, maxime crassa vix duplo latior quam crassa, antice profunde canaliculata, canali sub apice frondis profundissimo acuto, in parte magis adulta antice plano-convexa, alis abrupte adscendentibus subinde extrorsum curvatis, marginibus attenuatis decurvis; costa valde producta, postice maxime convexa, lateribus rotundatis alte adscendentibus alteque radicellosis (i. e. fronde substrato suo profundissime immersa) abrupte sinuatim in margines excurrentibus. Squamæ posticæ magnæ, imbricatæ, hyalinæ vel purpureæ, marginem frondis haud superantes. 
Ostiola of longe prominentia, magna. Sporæ (perfecte maturas haud vidi) $119 \mu$, fuscescentes teste Taylori, reticulatim lamellatæ; foveolis $12 \mu$, breviter papillatis.

Hab. Australia, Swan River (Drummond).

sı. R. rubrispora St. n. sp.

Dioica, major. Frons 10-15̆ mm. longa, $2 \mathrm{~mm}$. lata, simplex vel furcata, furcis recto angulo divergentibus, canaliculatis, sulcus nullus, nisi ad ipsam apicem plantæ. Alæ versus marginem attenuatæ, ipso margine acutæ atropurpureæ. Squamæ remotiusculæ, subatræ, breves et marginem frondis haud attingentes, integerrimæ. Costa valde incrassata, strato aërifero triplo altior, in apice frondis in alas abrupte transiens, in medio plantæ latior, postice late plano-convexula, lateribus oblique adscendentibus sensimque in alas excurrentibus. Sectio transversa plantæ itaque triplo latior quam alta, postice leniter concava, lateribus oblique adscendentibus, angulis in acumen cuspidatum oblique patulum protraclis, antice late lunata. Androcia ignota. Flores $q$ numerosi, dispersi, pistilla longissime exserta. Sporæ $70 \mu$, purpuræ, vel subviolaceæ, laxe reticulatim lamellatæ, lamellis valde regularibus, æquialtis, e basi latiore attenuatis, alveolos concavos includentibus, papillis angularibus subnullis.

Hab. Australia centralis. Askariaga. Elder Explor. Exped, (Helms.).

52. R. marginata Carr. el P. Linn. Soc. N. S. Wales. 1887, p. 10 อั6.

Dioica, major, fusco-viridis, intra margines purpureo-maculata ; frons usque ad $15 \mathrm{~mm}$. longa, plus 2 plo latior quam crassa profunde fureata, furcis minus divergentibus, late ligulatis, profunde bilobis, lobis connivente-tectis, antice planis (in furcis junioribus parum concavis); costa duplo angustiore, valde producta, postice plano-convexa, lateribus alte adscendentibus abrupte in margines attenuatos abeuntibus; squamæ posticæ magnæ, hyalinæ vel purpureo-notatæ, marginem frondis haud superantes. Sporæ $110 \mu$, anguste alatæ, reticulatim lamellatæ.

Hab. Australia. New-South Wales, Paramatta (Whitelegge).

\section{R. bulbifera St. n. sp.}

Monoica? major, flavo-virens. Frons usque ad $2.5 \mathrm{~mm}$. longa, angusta, repetito furcata, furcis longis, ligulatis, versus apicem ample canaliculatis, ceterum planis, marginibus tenuibus; costa sat producta; frondis sectio transversa itaque 3 plo latior quam alta, antice plana, postice late lunata 
abrupte in angulos acuminatos excurrens. Squamæ posticæ parvæ remotiusculæ, purpureæ, marginem parum excedentes. Sporæ magnæ, $102 \mu$. grosse reticulatim-lamellatæ (solum quinque foveolæ in diametro) lamellis grosse angulatim repandis, subdentatis.

In apice furcarum inveniuntur bulbi solitarii, pyriformes, frondis diametro æquilati, haud in terram descendentes sed horizontaliter protracti, radicellis hyalinis ubique vestiti, haud squamuliferi, e cellulis parenchymaticis valde oleiferis ædificati.

Hab. India orient. Bengal. (Sulp. Kurz. Sept. 1868).

Die Knollen entspringen aus dem Vegetationspunkte mit kurzer, stielförmiger Basis und sind dem lockeren Boden horizontal eingelagert; ein ruhender Vegetationspunkt mit kleinzelligem Gewebe ist an der birnförmig verbreiterten Spize nicht bemerkbar; die Oberfläche ist allseitig dicht mit Rhizoiden bekleidet und eine Trennung von Ober- und Unterseite nicht vorhanden. Der (nach 30 Jahren) noch erhaltene starke Oelgehalt des gleichmässig parenchymatischen Gewebes deutet auf einen Reservestoffbehälter, wie Anthoceros ihn zuweilen fast in gleicher Weise besitzt.

\section{ั̆4. R. crispatula Mitten. Linn. Soc. V, p. 127.}

Dioica, maxima, in sicco obscure flavo-virens, subcrspitans. Frons usque ad $20 \mathrm{~mm}$. longa, angusta, linearis, longe furcata, furcis apice rotundatis, antice subplanis, marginibus explanatis, attenuatis, costam late superantibus; costa valde producta, postice plano convexa lateribus abrupte recteque adscendentibus, abrupte in margines attenuatos excurrens; frons dein plus duplo latior quam crassa vel-alas attenuatas exceptas-diametro crassitudini subæquali. Squamæ posticæ intense purpureæ, imbricatæ, apice rotundatæ, marginem frondis parum superantes, haud plano appressæ sed concavæ patulæque; margo frondis dein quasi crispatus, re vera perfecto planus el integerrimus.

Sporæ $8 \check{\mu} \mu$ rufescentes, laxissime reticulatæ; foveolis paucis sub $2 \partial ّ \mu$; lamellæ altæ, crassæ, ala lata tenui.

Hab. Ceylon, Matale (Gardner).

\section{อิว. R. cartilaginosa Steph. Hedwigia 1889, p. 44.}

Monoica, minor, obscure viridis. Frons usque ad $8 \mathrm{~mm}$. longa, crassa. tenax et cartilaginea, furcala, furcis brevibns lateque divergentibus, versus apicem profunde lateque canaliculatis, versus basin sensim planioribus, marginibus crassis, attenuatis, acutis, costam superantibus; costa 
duplo angustior valde producta alte radicellosa; frondis adultæ sectio transversa triplo latior quam alta, antice leniter convexa, sinu brevi lunato interrupta, postice plano-convexa, lateribus oblique adscendentibus, angulis acutis. Squamæ posticæ hyalinæ, cellulis prominulis subdentatæ. Ostiola mascula magna, longe producta. Sporæ maturæ ignotæ.

Hab, Australia, Queensland (Bailey).

\section{R. papillispora St. n. sp.}

Dioica, major (in sicco flavicans). Frons usque ad $7 \mathrm{~mm}$. longa, furcata, furcis parum divergentibus, ovatis, acuminatis, obtusis, breviter bilobis, antice subplanis ubique æquicrassis, costa itaque latissima, crassa, subplana, lateribus brevibus verticalibus, in margines abrupte attenuatos desinentibus; margines ceterum tenues, costam breviter superantes, acuti. Squamæ posticæ magnæ, purpureæ, dense imbricatæ, margines longe superantes, versus apicem frondis hamatim incurvæ, marginem apicemque plantæ tegentes. Sporæ $7 \check{\mu} \mu$, reticulatim lamellatæ foveolis $6 \mu$, papillatæ, papillis magnis validis acuminatis.

Hab. Abyssinia ad ripas flum. Insaba prope Keren (Beccari).

\section{Frons crassa (pro more triplo latior quam crassa) marginibus crassis acutis vel obtusis.}

\section{R. nigrella DC. Flore franc. V, p. 193.}

Syn. $R$. minima Raddi. Opusc. scient. Bologna II, $3 \Xi 3$.

R. minima L. ex parte. Spec. plant. p. 1605.

Monoica, exigua, tenax, viridis, marginibus purpureis in sicco brunneolis. Frons $3 \mathrm{~mm}$. longa, subtriplo latior quam crassa furcata, furcis divergentibus ultimis ovatis, acuminatis acutis, profunde acuteque sulcatis, alis oblique adscendentibus, parum convexis, in planta adulta magis apertis, marginibus crassis acutis, in sicco haud mutatis; costa postice late convexa, lateribus rotundatis, oblique adscendentibus, Squama posticæ atropurpureæ, imbricatæ, integerrimæ. Sporæ $59 \mu$, subnigræ, anguste marginatæ, minute reticulatim-lamellate. alte papillatæ, foveolis $\therefore \mu$.

Hab. Gallia, Montpellier (De Candolle), Ille et Vilaine (Dubuysson), Côte du nord (Morin). Italia. Firenze (Levier).

Das Original De Candolles ist länger und stärker verzweigt, im Bau des Laubes aber sonst ganz wie die italienische Pflanze, von weleher ich aber auch längere und stärker verzweigte Exemplare gesehen habe. 
Riccia.

Sporen habe ich an dem Original nicht gefunden, obwohl die Exemplare gut ausgebildete sind! Ueber die englische unter dicsem Namen ausgegebene Pflanze siehe R. Pearsoni St.

:8. R. sorocarpa Bisch. Nova Acta Ac. Cæs. Leop. 1835̈, XVII, p. $10 \Xi 3$. Syn. : R. minima L. ex parte. Spec. plant. p. 460 s.

R. epicarpa Wallroth. Syn. Hep. p, 600.

R. Lindenbergii Sauter ex parte. Syn. p. 611.

Monoica, parva, glauco-virens. Frons usque ad $4 \mathrm{~mm}$. longa, crassa, triplo latior quam alta, furcata, furcis brevibus ultimis ovatis acutis vel acuminatis, sulco profundo acutoque percursis, alis plano-convexis alte adscendentibus, in fronde adulta magis apertis, costa postice convexa, lateribus alte adscendentibus, marginibus crassis, acutis, costam haud superantibus. Squamæ parvæ hyalinæ integerrimæ rarius dilute violaceæ. Capsulæ in medio frondis dense seriatæ, sulco itayue fere semper sporis maturis repleto. Sporæ $76 \mu$, subnigræ, late marginatæ, margine aspero, reticulatim-lamellatæ, alte papillatæ, foveolis sub $10 \mu$.

Hab. Europa. Germania, haud rara. Italia Firenze (Levier). America septentr. Closter. (Austin).

\section{R. insularis Levier n. sp.}

Dioica, mediocris, glauco-viridis. Frons usque ad $8 \mathrm{~mm}$. longa, divaricatim furcata, 3 plo latior quam crassa furcis ligulatis, apice rotundatis, distincte bilobis, sulco acuto percursis, alis convexo-decurvis, crassis, acutis, costa strato antico multo angustior, humilis, postice plano convexa, lateribus parum adscendentibus, sinuatim in alas attenuatis. Squamæ posticæ parvæ, hyalinæ, vel purpureæ integerrimæ. Sporæ $76 \mu$, reticulatim lamellatæ, lamellis humilibus, in angulis truncato papillatis, margine angusto aspero, foveolis $8 \mu$.

Hab. Sicilia, Palermo (Dr Noss).

\section{R. Pearsoni St. n. sp.}

Syn. R. nigrella Pearson (non DC.). Hep. exsicc. Brit.

Dioica, fusco viridis, marginibus purpureis. Frons usque ad $10 \mathrm{~mm}$. longa, bi-trifurcata, furcis longis angustis, linearibus, late divaricatis. apice rotundatis, crassis, profunde acuteque sulcata, sulci parietibus alte adscendentibus subinde extrorsum curvatis, marginibus acuminatis, acutis, in sicco involutis; costa valde producta, postice plano-convexa, lateribus abrupte alteque adscendentibus, sinuatim in margines excurrentibus. 
Sectio transversa frondis duplo latior quam alta. Squamæ posticæ magnæ, integerrimæ, dense imbricatæ. atropurpureæ, marginem haud superantes. Sporæ $75 \mu$ (teste Pearson).

Hab. Britannia, Wales, Barmouth (Pearson).

\section{R. Raddiana Jack et Levier n. sp.}

Monoica, major, glauco-virens. Frons usque ad 12 mm. longa, crassa. bifurcata, furcis divergentibus, brevibus, ultimis late ligulatis, apice rotundatis, sulco sub apice profundo acuto percursis, in planta adulta leniter canaliculatis, alis plano-convexis, marginibus crassis acutis; costa valde producta, alte convexa, lateribus rotundatis alte adscendentibus; sectio frondis adultæ duplo latior quam alta; squamæ posticæ parvæ, hyalina. Sporæ fusco-brunneæ, alte truncato papillate, foveolatæ, foveolis 8 p..

Hab. Italia, Firenze.

62. R. acuminata Taylor J. of Bot. 1846, p. 444.

Monoica, minor, expansa, pallide virens. Frons usque ad $2 \mathrm{~cm}$. longa, furcis divergentibus, apice obtusis, ob margines in sicco inflexos quasi acuminatis (unde nomen) ceterum crassa, antice leniter canaliculata, in ætate subplana marginibus crassis acutis; costa postice plano-convexa, duplo angustior quam pagina antica; frondis sectio transversa subtriplo latior quam alta, late triangularis, lateribus oblique atque substricte adscendentibus, antice convexa medioque parum emarginata, angulis late acuminatis, acutis postice subtruncata. Squamæ posticæ parvæ, occultæ hyalinæ. Sporas haud vidi.

Hab. Australia, Swan River (Drummond).

63. R. Austini St. n. sp.

Syn. : R. lamellosa Austin (non Raddi).

Monoica, mediocris, dilute virens. Frons 10-12 mm. longa, furcata, furcis oblongis, apice angustatis, obtusis, in parte juniore profunde acuteque sulcatis, parietibus sulci curvatim adscendentibus, marginibus acutis; costa latissima, postice subplana; frondis sectio duplo solum latior quam alta, antice angulo subrecto excisa, postice subplana, lateribus alte adscendentibus. Squamæ posticæ magnæ, subimbricatæ, oblique ovatæ, obtusæ, hyalinæ, marginem longe superantes. Sporæ 82 p., scaberulæ, reticulatim lamellatæ, foveolis $14 \mu$, papillatæ.

Hab. America septentr. Closter (Austin).

R. lamellosa Raddi differt fronde crassiore (fere magis alta quam lata) 
sulco obtuso, totam frondem percurrente, marginibus atlenuatis, irregulariter dentatis, squamarum marginibus papuloso-crenulatis vel subdentatis, sporis majoribus $(9 \Xi ّ)$ ) laxius reticulatis.

\section{R. corcovadensis St. n. sp.}

Monoica, major, fusco-viridis. Frons usque ad $15 \mathrm{~mm}$. longa, vix duplo latior quam crassa profunde bifurcata, furcis brevibus, late oblongis, acutis, antice profunde acuteque sulcata, alis adscendentibus extrorsum curvatis, marginibus acutis; costa æquilata, postice rotundata, lateribus alte adscendentibus. Squamæ posticæ purpureæ, magnæ, dense imbricatæ, integerrimæ, frondis marginem haud superantes. Sporæ magnæ, $\mathbf{1 1 0} \mu$, haud reticulatim-lamellatæ, sublæves.

Hab. Brasilia, Rio Janeiro in M. Corcovado (Guillemin, Ule).

6ว. R. australis St. n. sp.

Dioica, major, pallide virens, expansa. Frons usque ad $10 \mathrm{~mm}$. longa, $2 \mathrm{~mm}$. lata, 1-2 furcata, furcis linearibus, apice angustatis, divergentibus; crassa, triplo latior quam alta, antice convexa, sulcata, sulco sub apice acuto, haud profundo, versus basin frondis nullo; margines crassi, obtusi, costa leniter convexa in margines sensim attenuata; sectio transversa frondis optime elliptica, medio sulco incisa. Squamæ parvæ, hyalinæ vel purpurascentes. Sporæ magnæ $102 \mu$, anguste alatæ, reticulatim lamellatæ, foveolis $14 \mu$, papillis altis, subspiniformibus.

Hab. Montevideo (Fruchart).

\section{R. porosa Taylor. J. of Bot. $1846,416$.}

Dioica? mediocris. Frons $8 \mathrm{~mm}$. longa, repetito furcata, furcis parum divergentibus, sæpe contiguis, inferne longe coalitis, apice solum liberis, linearibus, apice obtusis, crassis, plus duplo latioribus quam altis, antice sulco tenui profundeque percursis, ceterum subplanis, marginibus obtusis; costa postice subplana, strato supero frondis æquilata, lateribus abrupte erectis; sectio frondis adultæ itaque optime parallelogramma. Squamæ posticæ, majusculæ, hyalinæ vel purpurascentes, marginem vix attingentes. Spor $72 \mu$ (haud perfecte maturæ) anguste marginatæ, minute reticulatæ foveolis sub $8 \mu$, ex angulis breviter papillatis.

Hab. Australia, Swan River (Drummond).

Die Taylor'schen Riccia-Namen, wie auch der obige, sollten zum Theil eingezogen werden, da sie häufig in Folge völliger Verkennung der specifischen Merkmale gewählt worden sind; die Beschreibungen sind 
meist unbrauchbar und niemand ist im Stande die Pflanzen zu erkennen.

67. R. Junghuhniana N. et Ldbg. Syn. Hep. p. 609.

Monoica, mediocris, viridis, expansa. Frons usque ad $10 \mathrm{~mm}$. longa, multifurcata, furcis late linearibus, ultimis acuminatis, obtusis; antice distincte acuteque sulcata, alis plano-convexis, attenuatis, crassis, obtusis; costa in medio frondis parum producta, late convexa, utroque latere sub alis sensim adscendens; sectio transversa frondis adultæ sub triplo latior quam alta. Squamæ posticæ magnæ, hyalinæ, sub alis occultæ. Sporæ dilute rufæ, pro planta parvæ, $68 \mu$, minute reticulatim lamellatæ, foveolis solum $\tilde{\Xi} \mu$, lamellis crassis parum elevatis, angulis truncatopapillatis.

Hab. Java (Junghuhn).

In der Syn. Hep., p. 609, ist diese Art als " cavernosa " beschrieben und zu Ricciella gestellt; die Originalpflanze im Herb. Nees ist aber eine Riccia.

\section{R. minutissima St. n. sp.}

Monoica, exigua, pallide glauco-virens, expansa. Frons 3-4 mm. longa, subtriplo latior quam crassa bifurcata, furcis divergentibus, angustis, linearibus (Ricciæ fluitanti in adspectu similibus), apice profunde bilobis. sulco antico ad rimam brevem apicalem angustissimam reducto, in fronde aduito nullo; margines crassi obtusi, ultra costam parum prominentes; costa in medio postico plano convexa, lateribus brevibus oblique adscendentibus, sinuatim in margines breves excurrente. Squamæ posticæ hyalinæ, magnæ, marginem attingentes. Sporæ $76 \mu$ late marginatæ, alte reticulatim lamellatæ, longe papillatæ, foveolis $8 \mu$.

Hab. Madeira (Fritze), Coimbra (Moller).

69. R. bifurca Hoffm. Fl, crypt. germ. p. 9 s.

Syn. : R, glaucescens Carr. Hep. Exsicc. brit.

R. marginata Lindberg.

Monoica, mediocris, expansa, glauco-virens. Frons usque ad $5 \mathrm{~mm}$. longa, sæpe bi-trifurcata, furcis plus minus divergentibus, apice rotundatis, antice late leniterque canaliculatis, marginibus parum elevatis, obtusis, costa lata crassaque, postice plano-convexa, lateribus leniter adscendentibus, rotuudatis; sectio frondis transversa ubique æquicrassa fere triplo latior quam alta. Squamæ posticæ parvæ, remotæ, hyalinæ vel 
violaceo-maculatæ, integerrimæ. Sporæ $68 \mu$, late marginatæ, reticulatim lamellatæ, angulis_alte papillatis, foveolis $8 \mu$.

Hab. Europa et America septentr. Sibiria Jenisei (Arnell).

R. glaucescens Carr. bietet gar keine Unterschiede; es scheint aber mehr als eine Art unter diesem Namen ausgegeben worden zu sein, z. B. R. glauca.

In Europa übersteigt diese Art die Alpen nicht und in Nord-Amerika scheint sie auch den südlichen Staaten zu fehlen.

70. R. commutata Jack n. sp.

Monoica, minor, glauco-viridis. Frons usque ad $6 \mathrm{~mm}$. longa, crassa, bi-trifurcata, furcis brevibus, late divergentibus, linearibus, antice planoconvexis, apice distincte emarginato-bilobis, profunde angusteque sulcatis; sulcus in fundo subplanus, marginibus crassis obtusis; costa planoconvexa; sectio transversa frondis adultæ itaque æqualiter biconvexa, in fronde juniore antice exciso canaliculata (sulco quasi immerso in superficie subplano), ceterum triplo latior quam alta; squamis posticis minutis, hyalinis. Sporæ fusco-brunneæ, $68 \mu$, reticulatim lamellatæ, lamellis tenuibus, in angulis alte papillatis, foveolis $8 \mu$.

Hab. Italia, Firenze (Levier).

VIII. Frons maxime crassa, pro more diametro parum humilior.

«. Frons antice plana vel canaliculata (haud sulcata).

\section{R. Schweinfurthii St. n. sp.}

Dioica, minor, fuscoviridis. Frons linearis, usque ad $12 \mathrm{~mm}$. longa, $1 \mathrm{~mm}$. lata, repelito furcata, furcis longis late divergentibus, antice plana, sub apice solum anguste canaliculata, marginibus costam minime et abrupte superantibus, acutis. Squamæ minutæ, violaceo maculatæ, sub margine occultæ, integerrimæ. Costa omnium maxima, profunde in lerram descendens, frondis sectio transversalis itaque minus lata quam alta, antice plana, marginibus alarum minime productis, postice sacculatim ampliata; stratum aëriferum sat altum, strato solido duplo humilius. Androcia ignota. Sporæ nondum evolutæ, pistilla maxime exserta.

Hab. Africa centralis (Schweinfurth, $\mathrm{a}^{\circ}$ 1823).

72. R. arvensis Austin. Acad. Phila. 1869, p. 232.

Monoico, parva, glauco-virens, marginibus purpureis. Frons $3-4 \mathrm{~mm}$. longa, repetito furcata, furcis angustis late divergentibus, acuminatis, 
acutis, ob margines vallatim incrassatos late humileque canaliculatis; costa valde producta, strato antico multo angustior marginibus crassis acutis. Frondis sectio transversa itaque vix duplo latior quam alta, antice convexa medioque late lunatim excisa, angulis late acuminatis acutis, postice semicircularis, lateribus alte adscendentibus sinuatim in angulos excurrentibus. Squamæ posticæ parvæ, purpureæ. Sporæ pro planta maximæ, $102 \mu$, ala lata cristatim incisa circumdatæ, reticulatim-lamellatæ, foveolis magnis ex angulis breviter papillatis.

Hab. America septentr. Closter (Austin).

Die Beschreibung ist nach Austins Originalpflanze gefertigt, welche keine Cilien hat; Austins var. hirta hat nichts damit zu thun, da sie eine eigene Art darstellt (R. hirta Austin).

\section{R. antarctica St. n. sp.}

Monoica, minor, glauco-virens. Frons usque ad $15 \mathrm{~mm}$. longa, profunde bifurcata, furcis obtusis, antice late canaliculatis, obtuse marginatis, postice fere duplo angustioribus valdeque incrassatis. Frondis sectio transversa duplo latior quam alta, postice late plano-convexa, lateribus adscendentibus, sub alis abrupte sinuatim abeuntibus, antice convexa, late et parum profunde excisa, angulis obtusis. Squamæ posticæ valde evanidæ, magnæ, occultæ, integerrimæ, hyalinæ. Sporæ $90 \mu$, arcte reticulatim lamellatæ, ala angusta aspera, foveolis $8 \mu$, ex angulis papillatis.

Hab. Chile (Herb. Nees sub R. glauca var. $\beta$. major).

74. R. Trabutiana St. Revue bryolog. 1889, p. 6 5.

Dioica, minor, fusco-viridis margine purpurea. Frons $8 \mathrm{~mm}$. longa, tenax, crassa, parum latior quam alta, furcata, furcis longis, parum divaricatis, obovato-oblongis, apice rotundatis, breviter bilobis, antice late canaliculatis, marginibus acutis. Costa valde producta, postice rotundata, Jateribus convexis verticaliter adscendentibus; sectio transversa frondis circumscriptione semicirculari, antice exciso truncata, angulis suberectis acutis. Squamæ posticæ magnæ, purpureæ, marginem attingentes. Sporæ 78 p, vix marginatæ, minute reticulatim lamellatæ, lamellis humilibus vix papillatis, foveolis $7 \mu$.

Hab. Algeria (Trabut).

75. R. lamellosa Raddi. 0pusc. scient. Bologna II, p. 35 I. Syn. ; R. Dufourii Nees. Hep. Eur. IV, 390. 
Dioica, minor, pallide glaueo-viridis. Frons $6 \mathrm{~mm}$. longa, simplex vel furcata, furcis sæpe inæquales, ovatis vel oblongis, apice angustato obtusis, antice profunde canaliculatis. marginibus abrupte attenuatis, acutis, sæpe denticulatis; costa haud angustior, crassa, postice rotundata, lateribus alte adscendentibus, sectio transversa frondis adultæ vix latior quam alta. Squamæ posticæ maximæ, validæ, marginem frondis excedentes, dense imbricatæ, hyalinæ, margine papuloso-crenulatæ vel subdentalæ. Sporæ fusco-rubaæ, $75 \mu$, laxe reticulatim lamellatæ, lamellis gracilibus, ad angulos breviter papillatis, foveolis $10 \mu$, ala angusta minute crenulata.

Hab. Europa et Africa mediterranea; Abyssinia, Anseba (Penzig), Gallia Montpellier (Schimper).

\section{R. chilensis St. n. sp.}

Monoica, minor, fusco-viridis; frons usque ad $10 \mathrm{~mm}$. longa, $1 \mathrm{~mm}$. lata, furcata, furcis late divaricatis, $\check{\check{m m}}$. longis, acuminatis, antice profunde angusteque canaliculatis, alis horizontalibus, convexis, marginibus breviter attenuatis, acutis, decurvulis. Squamæ posticæ hyalinæ, ephemeræ minutæque, sub margine occultæ. Costa valde incrassata, sub margines constricta, abrupte in alas attenuata, postice late plano-convexa; frondis sectio transversa vix duplo latior quam alta, angulis late acuminatis breviter protractis subdecurvis, postice subplana, lateribus alte adscendentibus, superne sinu profundo abeuntibus, antice canali profundo angustoque dimidiata, dimidiis convexis; ostiola o parva, vix prominentia. Sporæ $62 \mu$, fusco brunneæ, papillis parvis humilibus obtusisque asperæ.

Hab. Chile, Valparaiso (Dusén).

77. R. squamata Nees. in Mart. Fl. bras. I, p. 301.

Monoica, mediocris, fusco-viridis, margine atropurpurea, expansa. Frons $8 \mathrm{~mm}$. longa, crassa, angusta, linearis, longe bi vel trifurcata, furcis parum divergentibus, antice rima profundissima obtusa percursa, alis erectis attenuatis, crassis, margine acutis. Costa postice convexa, lateribus verticaliter adscendentibus; frondis sectio transversa parum altior quam lata, postice late rotundata, lateribus strictis erectis, antice ad $2 / 3$ bifida, laciniis anguste conicis acutis, erectis. Squamæ posticæ pro plantæ magnitudine maximæ, atropurpureæ, marginem frondis superantes. Sporæ parvæ, $68 \mu$, subnigræ, vix marginatæ, lamellis crassis vermicularibus multoties irregulariterque anastomosantibus; papillis omnino nullis.

Hab. Chile (Gay) nuperius a Dusenio prope Valparaiso reperta. 


\section{ß. Frons antice sulcata.}

78. R. punctata Taylor. J. of Bot. 1846, p. 416.

Dioica? minor, glauco-viridis. Frons $4-5 ٌ \mathrm{~mm}$. longa bifurcata, crassa, duplo latior quam alta, furcis late divergentibus, brevibus, apice breviter rotundato-acuminatis, antice sulco acuto percursis, alis oblique adscendentibus vel subhorizontalibus, marginibus obtusiusculis; costa lata,crassa, leniter convexa, lateribus prærupte stricteque adscendentibus. Squamæ posticæ magnæ, imbricatæ, atropurpureæ, margines haud excedentes. Sporæ " magnæ, angulo-rotundatæ, saturate fuscæ, læves " teste Taylor.

Hab. Australia, Swan River (Drummond).

\section{R. aggregata Und. Bol. Gaz. XIX, p. $27 \%$.}

Dioica, minor, fusco-viridis, marginibus atropurpureis. Frons usque ad $7 \mathrm{~mm}$. longa, crassa, vix duplo latior quam alta, repetito furcata, furcis ultimis oblongis acuminatis, acutis, antice acute angusteque sulcatis, alis plano-convexis, marginibus acutis; costa valde producta, postice plano convexa, lateribus alte stricteque adscendentibus. Squamæ posticæ parvæ. purpureæ. Sporæ (75̈ $\mu$, subnigræ, reticulatæ teste Underwood).

Hab. America septentr. California (Mc Clatchie).

Quoad frondis configurationem R. punctatæ Taylor simillima.

\section{R. mamillata St. Rev. bryol, 1889 , p. 6 . .}

Dioica, minor, triste viridis; frons usque ad $40 \mathrm{~mm}$. longa, crassa, parum latior quam alta, bi vel trifurcata, furcis late divergentibus, longis, linearibus, ultimis acuminatis acutis, antice sulco acuto percursis. alis subplanis oblique adscendentibus, marginibus acutis, costam haud superantibus; cellulæ superficiales anticæ globosæ, vertice mamillatim angustatæ, mamilla valde incrassata; costa valde producta, postice planoconvexa, lateribus alte-subverticaliter-adscendentibus. Squamæ parvæ, hyalinæ, apice serratæ veI crenulatæ. Sporæ desunt.

Hab. Algeria (Trabut).

\section{R. lanceolata St. n. sp.}

Doica, mediocris, flavo-virens. Frons usque ad $10 \mathrm{~mm}$. longa, profunde bifurcata, furcis late divergentibus, anguste lanceolatis, acutis, crassis, antice sulcatis sulco acuto (sub apice magis profundo) alis tamen subplanis, marginibus acutis, in apice frondis attenuatis. Costa crassa, postice 
convexa, lateribus rotundatis alte adscendentibus, sectio transversa frondis adultæ plus duplo latior quam alta, antice subplano, parvo angulo acuto in medio interrupta, postice subsemicircularis. Squamæ posticæ minutæ, facile evanidæ, hyalinæ. Reliqua desunt.

Hab. Africa, Dahomey. Canné, Ajuda (Francis Newton).

\section{R. numeensis St. n. sp.}

Dioica? minor, pallide flavo-virens. Frons usque ad $10 \mathrm{~mm}$. longa, multifurcata, furcis pro planta longissimis, parum divergentibus, ligulatis, crassis, ultimis apice late rotundatis, sulco antico subapicali profundo acuto, alis oblique adscendentibus, in planta adulta magis apertis, late canaliculatis, denique horizontalibus (sulco nullo), margines parum attenuati, acuti; costa valde producta, postice convexa, lateribus alte subverticaliter adscendentibus, stricte in margines excurrentibus. Squamæ posticæ parvæ, hyalinæ, facile evanidæ. Reliqua desunt.

Hab. Nova Caledonia, Numea (Saves).

83. R. macrocarpa Levier et Jack n. sp.

Dioica, mediocris, viridis. Frons usque ad $6 \mathrm{~mm}$. longa, crassa, parum latior quam alta, furcata, furcis longis, divergentibus, e basi obcuneata oblongis, apice parum angustatis, breviter emarginatis, antice profunde acuteque sulcata, alis e fundo arcuatim adscentibus subplane explanatis, marginibus acutis ultra costam parum exstantibus. Costa valde producta ventre alte convexa, lateribus alte adscendentibus sinuatim in marginem excurrens. Squamæ posticæ magnæ, hyalinæ, integerrimæ, marginem haud superantes. Sporæ $93 \mu$, subnigræ, reticulatim lamellatæ, foveolis $12 \mu$, alte papillatæ.

Hab. Italia Firenze (Levier), Sardinia (Fr. Müller), Napoli (Gasparini), Algeria (Trabut). 

Extrait du Bulletin de l'Herbier Boissier.

Tome VI. No כ̃. Mai 1898.

\section{SPECIES HEPATICARUM}

AUCTORE

Franz STEPUANI

\section{B. RICGIELLA}

IX. Frons tenerrima, membranacea.

84. Riccia membranacea G. et L. Syn. Hep., p. 608.

R. tenuis Austin. Acad. Phila. 1869, p. 233.

R. lanigera Spruce. Bot. Soc. Edinb. 188\%, p. 570.

Dioica, major, viridissima, nitida, pro more subcaspitosa; frons usque ad $10 \mathrm{~mm}$. longa, late obcuneata, apice breviter furcata, furcis late truncato-rotundatis, tenerrima, in sicco chartacea, fragillima, lamellis anostomosantibus optime reticulata; costa $\mathbf{2}$ cellulas crassa, stratum aëriferum humillimum, poris magnis sparsis, marginibus unam cellulam crassis. Sporæ dilute rufescentes $42 \mu$, haud reticulatæ, ubique dense breviterque setosæ.

Hab. Brasilia (Spruce, Ule), Mexico (Liebmann), America sept. (Austin).

\section{8อ. R. Welwitschii St. n. sp.}

Dioica, major, flavo-virens, expansa vel substratificata. Frons usque ad $6 \mathrm{~mm}$. longa, oblongo-obcuneata, apice breviter furcata, furcis brevibus divergentibus, profunde bilobis; tenuis, ob lamellas perlucentes anguste reticulata; costa minima, paucas cellulas alta, fronde subtriplo angustior, alis itaque costam latissime superantibus, marginibus tenerrimis; stratum 
cavernosum humillimum. Sporæ $42 \mu$, haud reticulatim lamellatæ, ubique spinis brevibus creberrime hirtæ.

Hab. Africa Angola. Lifune (Welwitsch).

Præcedenti simillima, fronde anguste reticulata sporisque longius spinosis distincta.

86. R. paraguayensis Spruce. Bull. Soc. bot. franc. 1889, p. 190. Syn. : R. macropora St. in K. Svenska Akad. 1897, XXIII.

Monoica, major, viridis, expansa. Frons $10 \mathrm{~mm}$. longa trifurcata, furcis divergentibus, late linearibus, apice truncato rotundatis, tenerrima, plana, antice poris maximis instructa; cavernæ $\breve{5}-6$ in diametro frondis; costa tres cellulas alta, strato antico æquilata, marginibus tenerrimis, chartaceis; sporæ $60 \mu$, anguste alatæ, ala crenulata, reticulatim lamellatæ, foveolis $10 \mu$, papillatæ.

Hab. Paraguay, Asuncion (Balansa, Lindman).

87. R. ochrospora M. et N. in Ldbg. Mon. Ricc. (Ac. Cæs. Leop. XVIII, p. 5004 b.

Monoica, parva, dilute viridis. Frons $4 \mathrm{~mm}$. longa, late obcuneata, furcata, furcis longe coalitis, brevibus, apice divergentibus, late truncato rotundatis, ubique æquicrassis, haud chartaceis, antice posticeque planis, marginibus haud attenuatis rotundatis; costa latissima, tres cellulas alta, stratum anticum multoties altius, laxe cavernosum. Sporæ maturæ non adsunt.

Hab. Chile (Bertero).

Der Name ist unzutreffend, da die gelben Sporen zweifellos nicht reif waren; Lindenberg nennt sie nebenbei auch ziegelroth (Monogr. Ricc. p. 504c), was auf einen reiferen Zustand hinweist.

88. R. amazonica Spruce, Bot. Soc. Ed. 1885, p. 571.

Dioica, mediocris, in sicco flavo-virens. Frons usque ad $6 \mathrm{~mm}$. longa, furcata, furcis late divergentibus, brevibus, late linearibus $2 \mathrm{~mm}$. latis, tenerrimis, apice profunde bilobis, antice posticeque subplana, ob lamellas perlucentes laxe reticulata; costa humillima. Sporæ parvæ $34 \mu$, maturæ pallide flavidæ ubique creberrime papillatæ, papillis humilibus, hyalinis, obtusis.

Hab. Brasilia ad flumen Ramos, Tarapoto (Spruce).

89. R. Spruceana St. n. sp.

Monoica, major, viridis, expansa. Frons usque ad $10 \mathrm{~mm}$. longa, tenuis, 
multiramosa, sæpe uno latere magis furcata, furcis longis simplicibus mixta, ramificatio dein valde irregularis; ceterum anguste linearis, apice breviter biloba, antice posticeque plana, marginibus longe attenuatis. tenerrimis; costa humillima 2-3 cellulas alta, duplo angustiore quam stratum anticum i. e. marginibus ultra costam late exstantibus; caverna amplæ 8 in diametro frondis, lamellis subhorizontalibus. Sporæ öl p., rufo brunneæ, late alatæ, ala eroso-dentata, reticulatim lamellatæ, foveolis $5 \mu$, ex angulis papillatæ.

Hab. Brasilia ad flum. Ramos (Spruce).

X. Frons magis costata, alis attenuatis costam late superantibus.

90. R. muscicola St. Hedwigia 1885 .

Dioica, mediocris, muscicola vel terricola, subcæspitosa, rosulas $40 \mathrm{~mm}$. latas formans; frons $8 \mathrm{~mm}$. longa, bi-trifureata, furcis sublinearibus, apice truncato-rotundatis, breviter bilobis, sub apice leniter canaliculatis, ceterum subplanis, alis tenerrimis, ultra costam late exstantibus, ob lamellas perlucentes pulchre reticulatis. Costa angusta, postice plana. lateribus brevibus abrupte adscendentibus. Sporæ $60 \mu$, late alatæ, dense lamellatæ, lamellis regulariter ramosis, ad retem, sæpe interruptum confluentibus.

Hab. Australia, Trinity Bay (Karsten) Ord River (Nyasly).

91. R. purpurascens L. et L. Pugill. pl. IV (1832), p. 23.

Dioica, major, stolonifera, tenerrima, hyalina vel rosea, irregulariter furcata, furcis sæpe brevibus, aliis elongatis attenuatis in stolones abeuntibus, normaliter apice profunde biloba, antice plana, costa angusta, abrupte producta postice plana alis tenerrimis costam late superantibus; stratum anticum humile, cavernis amplis formatum; squamæ nullæ. Stolones longi, hyalini, e medio postico costæ orti, distincte bilaterali, i. e. postice tantum radicelliferi, convexi, antice profunde canaliculati, marginibus conniventibus, strato lamellifero nullo, ubique cellulis parenchymaticis, haud chlorophylliferis, ædificati. Sporæ juveniles solum adsunt - planta mascula ignota.

Hab. Caput Bonæ Spei, in monte Tabulari (Ecklon).

Die Stolonen entwickeln hier also keine knollenförmigen ReservestoffbehäIter, sondern stellen nur reducirte Laubsprosse dar, welche unter der Mutterpflanze am Boden wurzelnd hinkriechen und sobald sie an die freie Erdoberfläche gelangen, zum Thallus auswachsen. 
92. R. crassifrons Spruce H. A. A, p. 571 in Bot. Soc. Ed. 1885.

Dioica, gracilis, major, pallide virens, expansa. Frons usque ad $12 \mathrm{~mm}$. longa, repetito furcata, $R$. fluitanti simillima, magis tenuis tamen, marginibus latis attenuatis, antice subplana, ventre convexa, sextuplo latior quam crassa, cavernis sub 10 in diametro frondis; costa majuscula, 4-气̆ cellulas crassa, multo angustior quam facies antica frondis, sensim in alas attenuata. Sporæ $51 \mu$, rufescentes haud alatæ, reticulatim lamellatæ, lamellæ altæ, ad angulos longe papillatæ, papillis sæpe recte truncatis; foveolis sub $12 \mu .0$ stiola mascula parum prominentia.

Hab. Brasilia, ad flumen Negro (Spruce).

\section{R. Donnellii Austin. Torrey Bull. VI, 15 7.}

Dioica, magna, gracilis, dilute viridis, expansa. Frons usque ad $25 \mathrm{~mm}$. longa, profunde 3-4 furcata, furcis divergentibus, linearibus, $2 \mathrm{~mm}$. latis, crassis ( 2 plo latioribus quam altis) antice leniter canaliculata vel subplana, alis tenuibus longissime attenuatis, costam late superantibus; costa frondis superficie antica triplo angustior, valde producta, postice rotundata, lateribus verticaliter adscendentibus. Sporæ maximæ, $136 \mu$, subnigræ, alte lamellatæ, lamellis subradiatim dispositis, strictis vel vermiculariter curvatis, irregulariter anostomosantibus, ceterum grossis altisque; ala integra angusta.

Hab. America sept. Florida (J. Donnel Smith).

\section{R. subtilis St. K. Svenska Akad. 1897, p, 31.}

Dioica? mediocris, in sicco flavo-viridis, sæpe subcæspitosa. Frons usque ad $12 \mathrm{~mm}$. longa, bi-trifurcata, furcis $2 \mathrm{~mm}$. latis, divergentibus, brevibus, apice distincte biloba, sulco aculo parum profundo percursa; alæ valde convexæ, marginibus decurvis, acuminatis, acutis, critssa, quadruplo latior quam alta, medio postico valde prominente, costa tamen angustissima, $3-5$ cellulas alta, 4 plo angustiore quam stratum anticum; frons itaque omnino fere cavernosa; cavernæ minimæ sub 20 in diametro frondis, valde obliquæ, ad basin haud angustatæ, stomata minima, ore $5 ّ \mu$ solum. Reliqua desunt.

Hab. Paraguay (Lindman).

Optime distineta frondis configuratione, in sectione transversa quasi avem volantem simulante.

93. R. abnormis St. Hedw. 1891, p. 213.

Monoica, pallide virens, in sicco albicans, postice hic illic purpureo 
maculata, dense stratificata! Frons usque ad $10 \mathrm{~mm}$. longa, gracilis, angusta, linearis, apice truncato-rotundata, profunde biloba, sub apice sulcata, sulco brevi, acuto profundo, fronde tumescente mox evanido, ideoque subplana; costa crassa plano-convexa in margines attenuatos sensim excurrente, in medio frondis sporogoniis tumescentibus valde producta. Stratum æriferum humile, cavernis angustis. - 0stiola mascula longissime prominentia. Sporæ rufo-fuscæ, parvæ, 50 p, late marginatæ, reticulatim lamellatæ, foveolis $8 \mu$, papillis omnino nullis.

Hab. Kamerun (Dusén, Jungner), Angola Welwitsch.

Auch bei dieser Pflanze sind die Lufthöhlen vielfach so eng, dass sie denen von Riccia ähnlich werden; im basalen Theile des chlorophyllführenden Gewebes sind es nur 4-こ̌ Zellreihen, die einen Luftkanal einschliessen; nach der dorsalen Oberfläche zu erweitern sie sich jedoch beträchtlich. Siehe die Anmerkung zu R. vesiculosa C. et P.

XI. Frons angusta, magis incrassata, antice plana.

96. R. Brandegei Und, Bot. Gaz. XIX, p. 275.

Monoica, major, pallide virens. Frons usque ad $10 \mathrm{~mm}$. longa, linearis, furcis parum divergentibus, crassis, duplo solum latioribus quam altis, in fronde adulta ob capsulas magnas numerosas multo crassioribus, antice plana marginibus obtusis; costa lata, postice plano-convexa, humilis (4-5̆ cellulas alta), frondis lateribus alte adscendentibus, convexis, sectio transversa frondis itaque fere parallelogramma; cavernæ angustæx, sub 16 in diametro frondis. Sporæ 85 $\mu$ anguste alatæ, ala aspera, in faciebus planis lamellis brevibus vermicularibus notatæ, in facie convexa lamellis radialibus, repetito dichotomis obsitæ, i. e. furcis centralibus simplicibus, versus marginem sensim ramosioribus brevioribusque.

Hab. America septentr. California (Brandegee).

R. Sullivanti Austin similis, quæ differt fronde minus crassa sperisque multo minoribus regulariter reticulatis.

\section{R. multifida St. Hedwigia 1889, p. 45.}

Dioica? minor, viridis, expansa. Frons usque ad $10 \mathrm{~mm}$. longa, triquadrifurcata, furcis valde divaricatis, anguste linearibus, sub apice acute humiliterque sulcata, ceterum plana, crassa, duplo latior quam alta, postice valde convexa, angulis obtusis; costa duplo humilior quam stratum anticum, laxe cavernosum; cavernis sub 8 in diametro frondis, ad basin multo angustioribus; poris anticis magnis; reliqua desunt. 
Hab. Australia, Bellender Ker Range (Karsten).

A $R$. burnettiensi, cui simillima, differt nostra fronde multo crassiore et inflorescentia dioica.

98. R. fluitans L. Spec. plant. p. 1606.

Syn. : R. canaliculata Hoffm. Fl. germ.

R. centrifuga Arnell. Rev. bryol. IV, p. 34.

R. nodosa Bouch. Fl. d'Abbeville 88.

R. stenophylla Spruce. Bull. Soc. bot. fr. 1889, p. 195.

R. Oerstediana? Ldbg, et Hpe. Linnæa 18ฉ1. XXIV.

Dioica, minor, viridis. Frons usque ad $4 \mathrm{~mm}$. longa, anguste linearis, crassa, duplo latior quam alta, furcata, furcis late divergentibus, sub apice leniter canaliculata, antice ceterum plana, alis attenuatis, obtusis, costam late superantibus; costa convexa, angusta, strato antico æquialta, duplo tamen angustiore; cavernæ valde obliquæ, 8 in diametro frondis, ex angusta basi sensim ampliata. Sporæ $68 \mu$, late alatæ, regulariter reticulatim lamellatæ, foveolis in pagina convexa sub 12 in diametro, magnis, $17 \mu$, haud papillatis.

Forma fluitans differt ramificatione maxima, fronde minus crassa et absentia radicellarum.

Hab. per orbem terrarum : Sibiria, Amur, Japonia, Himalaya, Samoa, Nova Zelandia, Natal, Kamerun, Argentinia, Brasilia, Chimborazo, etc. etc.

Der Name R. fluitans hat die Priorität - ; da er seit Linné's Zeiten in Gebrauch ist, gehört wirklich ein Fanatismus dazu, ihn durch $\boldsymbol{R}$. canaliculata zu ersetzen, weil letztere die fruchtende und normal gebaute Pflanze ist; dann müsste auch Ricciocarpus natans der Landform wegen einen anderen Namen erhalten, während die alten Benennungen fluitans und natans doch zutreffender gar nicht gewählt werden könnten, da die Landformen sehr selten sind.

99. R. cancellata Taylor. J, of Bot. 1846, p. 444.

Syn. : R. vesicata Taylor J. of Bol. 1846, p. 414.

Dioica? Gracilis spectabilis, pallide virens, expansa. Frons usque ad $15 \mathrm{~mm}$. longa, bis furcata, furcis anguste linearibus, crassis (plus duplo latioribus quam altis, in sectione ellipsoideis, i. e. antice posticeque æqualiter plano convexis, marginibus late obtusis. Stratum æriferum laxissime lamellatum, cavernis paucis (sub 6) in diametro frondis, magnis, valde divergentibus basique valde angustatis. Costa humillima, strato antico subduplo angustior, Reliqua desunt. 
Hab. Australia, Swan River (Drummond).

R. fluitans, cui simillima, differt fronde fertili multo crassiore, costa mutto magis evoluta et dimidium crassitudinis frondis tenente.

\section{R. Frostii Austin. Torrey Bull. VI, p. 17.}

Syn. : $R$. Watsoni Austin I. c.

Dioica, minor, fusco-viridis, ventre interdum purpureo tincta, expansa. Frons usque ad $5 \mathrm{~mm}$. longa, profunde multifurcata, furcis angustis linearibus, apice truncato-rolundatis, breviter bilobis, crassis, quadruplo latioribus quam altis, antice leniter concavis, ventre convexis, faciebus itaque subparallelis frondeque ubique æquicrassa, marginibus rotundatis; costa humiiis, latissima, stratum cavernosum triplo altius quam costa, lamellis subverticalibus, cavernis angustis, sub 20 in diametro frondis.

Sporæ parvæ, $42 \mu$, rufo-brunneæ, creberrime lamellatæ, lamellis radialiter dispositis, vermicularibus, multoties /urcalis, ala angusta.

Hab. America sept. Colorado, Nevada, Ohio, Illinois.

Die Sporen von R. Frostii und R. Watsoni sind völlig gleich; ich folge daber Underwoods Angaben, denen zufolge er beide Arten vereinigt, obwohl die Ex. von $R$. Frostii eine genügende Untersuchung nicht gestatteten und mir den Eindruck hinterliessen, dass die beiden Pflanzen nicht identisch seien.

\section{R. subsimilis St. K. Svenska Akad. 1897, p. 31.}

Dioica, major, dilute viridis, expansa, vel subcæspitosa. Frons usque ad $8 \mathrm{~mm}$. longa, bi-trifurcata, furcis late divergentibus, late linearibus, sub $2 \mathrm{~mm}$. latis, subcrassis, 4 plo latioribus quam altis, apice truncatorotundatis, antice posticeque planis, marginibus late rotundatis; costa paucas cellulas alta, cavernæ amplæ 6 in diam. frondis. 0stiola mascula longe prominentia. Sporæ $60 \mu$ reticulatim lamellatæ, papillis longissimis retem obvelantibus hirtæ.

Hab. Paraguay (Lindman), Brasilia, Serra Itatiaia (Ule).

\section{R. Delavayi St. n. sp.}

Monoica, major, in sicco pallide flavicans, expansa. Frons usque ad $10 \mathrm{~mm}$. longa, multifurcata, fureis longe coalitis, apice tantum divisis, oblongis obtusis, crassis (triplo fere latioribus quam altis) antice subplanis; costa humillima, strato cavernoso æquilata, tres cellulas alta, stratum cavernosum multo altius, lateribus suberectis; frondis sectio transversa fere parallelogramma cavernis angustis maxime præruptis et facile 
cum iis Ricciarum commutandis. Sporæ $76 \mu$, anguste alata, ala minute crenulata haud papillatæ, irregulariter furcatm lamellatæ, lamellis remotis, crassis vermiculariter flexuosis.

Hab. China, Yuennan. Tapintze (Delavay).

\section{R. microspora St. n. sp.}

Dioica, parva, glauco-virens, expansa. Frons $4 \mathrm{~mm}$. longa, trifurcata, furcis parum divergentibus, anguste linearibus, crassis, quadruplo latioribus quam altis, antice posticeque plano-convexa, marginibus haud attenuatis, crassis rotundatis; stratum cavernosum lamellis crassis valde obliquis formatum; costa humilis, strato antico quadruplo humilior. Sporæ minimæ $34 \mu$, anguste alatæ, haud reticulatim lamellatæ, lamellis creberrimis radialiter percurrentibus, maxime furcatis, furcis vermicularibus.

Hab. India orientalis, ad ripas flum. Ganges (Sulp. Kurz).

104. R. plana Taylor. J. of Bot. 1846, p. 414.

Dioica, minor, in sicco flavescens. Frons usque ad $8 \mathrm{~mm}$. longa, furcis longe coalitis obconica, apice inciso-biloba crassa, 4 plo latior quam alta, antice plana, marginem versus parum sed distincte attenuata, margine ipso obtuso. Costa parum angustior quam facies antica, plano-convexa, humillima et paucas cellulas crassa. Stratum aëriferum lamellis vix nutantibus subverticalibus ædificatum, eavernis sub 16 in diametro frondis. Sporæ $72 \mu$, marginatæ, margine angusto distincte irregulariterque denticulato, reticulatim lamellati, foveolis $8 \mu$ alte angusteque papillatis.

Hab. Australia, Swan River (Drummond).

Underwood (Bull. Illinois State Labor. II, p. 27) stellt diese Pflanze zu $R$. crystallina, mit der sie allerdings grosse Aehnlichkeit hat; sie unterscheidet sich aber durch ihre Grösse, durch die steil aufgerichteten, enggestellten Lamellen und durch die Sporen, die wesentlich grösser sind und ein viel weiteres Lamellennetz zeigen.

108. R. crystallina L. Spec. plant. p. 1605.

Dioica, mediocris, glauco-viridis. Frons usque ad $6 \mathrm{~mm}$. longa, pro more optime obcuneata, margine supero ramis parvis nascentibus $4-6$ lobata, vel magis furcata, furcis late linearibus obtusis; antice posticeque subplana, marginibus obtusis; cavernæ amplæ, humiles. Sporæ 70 p. reticulatim lamellatæ, foveolis 8 p, alte papillatæ, papilis apice sæpe bifidis; ala angusta, margine crebre geminatim papillata. 
Hab. Germania, Italia, Pisa, Napoli, Corfu. Portugal. Coimbra, nusquam communis; plantæ germanæ in Herbario Neesii pro parte ad R.fluitantem pertinent.

\section{R. Montagnei St. n. sp.}

Syn. : $R$. crystallina var. $\propto$. Syn. Hep. p. 608.

Dioica, ma'or, fusco-virens. Frons usque ad $7 \mathrm{~mm}$. longa, 2-3 furcata, furcis profundius divisis, parum divergentibus, brevibus, late linearibus, antice posticeque planis, apice truncato-rotundatis, ubique requicrassis, quadruplo latior quam altis, marginibus obtusis vel rotundatis; costa 3-4 cellulas crassa, strato supero zequilata; stratum superum laxe cavernosum, lamellis præruptis. Sporæ $68 \mu$, anguste alatæ, ala minute crenulata, reticulatim lamellatæ, lamellis laxe dispositis, irregularibus, varie anostomosantibus, papillatis, papillis truncatis.

Hab. Chile.

Sporis haud regulariter reticulatis a $R$. crystallina optime diversa.

\section{R. Curtisii Jameson, ms.}

Syn.? Thallocarpus Curtisii Lindb. Acta Soc. sc. fenn. X, つૅ4.

Cryptocarpus Curtisii Austin. Proc. Phil. Ac. 1869, p. 231.

Monoica, minor, pallide flavo-virens, subcæspitans, Frons $50-6 \mathrm{~mm}$. longa, ubique rquicrassa, furcala, ob furcas longe coalitas obcuneata apiceque quasi 2-4 lobata, lobis apice profunde bilobis, antice leniter convexis, postice planis, marginibus crassis obtusis; costa minima, 16 cellulas lata, medio 4 cellulas alta; squamæ nullæ, radicellis punctatim incrassatis nullis. Ostiola mascula brevissime prominentia, hyalina, pistilla purpurea, Iongius exserta, antheridiis in medio frondis, sporogoniis geminatim oppositis. Capsula pro planta maximæ; sporæ 60 p. sub lente rufo-brunneæ, reticulatim lamellatæ foveolis $4 \mu$, papillatæ, papillis hyalinis obtusis, ala angusta minute serrulata.

Hab. America sept. South Carolina (Curtis) Florida.

Die Beschreibung ist nach der Originalpflanze angefertigt, welche Pastor Curtis in seinem Garten gesammelt hat; wäre die Pflanze nicht monoecisch und die Sporen abweichend, so könnte man sie von $R$. crystallina nicht unterscheiden. Pearson besitzt das Original-Exemplar (aus Austins Herbarium), welches mit meiner Diagnose völlig |übereinstimmt.

Die Diagnose Austins ist mir nicht zugänglich gewesen und ich kann nicht beurtheilen, ob zwei verschiedene Pflanzen unter Cryplocarpus ausgegeben worden sind oder ob diese Gattung überhaupt nicht existirt. 
108. R. Balansæ St. n. sp.

Dioica, parva, in sicco fusco flava. Frons $4 \mathrm{~mm}$. longa, furcata vel bifurcata, furcis late divergentibus, ovato-oblongis, apice acuminatis obtusis, crassis, plus duplo latioribus quam altis, antice convexis, marginibus crassis, obtusis, costam superantibus, postice subplana, lateribus abrupte adscendentibus, costa humillima, 4 cellulas alta, stratum cavernosum quintuplo altius, cavernis amplis, antice facile ruptis. Sporæ $60 \mu$, castanex, lamellis irregulariter furcatis, laxe dispositis, fere ad retem confluentibus, ala angusta minute crenulata.

Hab. Tonkin (Balansa).

109. R. victoriensis St. n. sp.

Dioica? Magna, robusta, glauco-virens. Frons usque ad 15 mm. longa, crassa, 8 plo latior tamen quam alta, furcata, furcis divergentibus ligulatis, antice planis, marginem versus leniter atlenuatis, ipso margine obtusis, costa strato antico parum angustior, plano convexa, humilis (4-כ̆ cellulas crassa). Cavernæ numerosæ (sub 26) in diametro frondis, angustæ. Squamæ posticæ parvæ, purpureo maculatæ, frondis marginem haud excedentes. Reliqua desunt.

Hab. Australia, Victoria, Melbourne (Herb. Kew, sub nomine «R. plana? Taylor " leg. F. M. A. 48sั4. No 306).

Species spectabilis et distinctissima.

110. R. Gatalinæ Und. Bot. Gaz. XIX, p. 27У,

Monoica, major, pallide virens. Frons usque ad $12 \mathrm{~mm}$. longa, repetito furcata, furcis divergentibus, linearibus, ultimis acuminatis, obtusis, antice sub apice parum sulcatis, ceterum planis, ubique æquicrassis, sextuplo latioribus quam altis, margine obtusis. Costa humillima, 3-4 cellulas alta, fronde duplo angustior; stratum anticum laxe cavernosum, cavernis sub 12 in diametro frondis. Ostiola mascula longe prominentia. Sporæ $85 \mu$, anguste alatæ, ala minute acuteque aspera, reticulatim lamellatæ foveolis $12 \mu$, lamellis crassis, papillatis, papillis erassis truncatis, ceterum, ob exosporium crassum nigræ et solum sub acido sulph. maceratæ perlucentes.

Hab, America septentr. California (Mc Clatchie).

XII. Frons magis incrassata, antice sulcata vel canaliculata.

111. R. burnettensis St. n. sp.

Monoica, major, viridis, expansa; frons $4-5$ furcata, $8 \mathrm{~mm}$. longa, fur- 
cis valde divergentibus, angustis, linearibus, antice sulco humili angustoque percursis apice breviter bilobis, crassis, quintuplo latior quam alta, in sectione elliptica, antice posticeque plano convexa marginibus parum attenuatis obtusis. Costa 6 cellulas crassa, duplo altior quam stratum anticum, cavernis valde obliquis, sub $\mathbf{1 0}$ in frondis diametro. 0stiola mascula Iongissime prominentia. Sporæ parvæ, sิ1 $\mu$, late alatæ, minute reticulatim lamellatæ, foveolis $5 \mu$, haud papillatis.

Hab. Australia, Burnett River (Keys) Herb. Melbourne.

A $R$. fluitante differt nostra sporis multo minoribus, anguste alatis atque exosporio minute reticulato.

112. R. linearis Schiff. Forsch. Gazelle IV, p. 43.

Monoica, gracilis, exigua, dilute viridis. Frons usque ad $ّ \mathrm{~mm}$. longa, bi-trifurcata, furcis valde divergentibus, linearibus, obtusatis, crassis, triplo latioribus quam altis, antice acute sulcata, alis late divergentibus, convexo-explanatis, marginibus obtusis; costa in medio postico carinatim prominente, lateribus strictis, oblique adscendentibus; sectio frondis dein fere late triangularis; stratum anticum ample cavernosum, cavernis sub 10 in diametro. Sporæ $51 \mu$, rufæ, anguste alatæ, reticulatim lamellatæ. Foveolæ $7 \mu$, papillis nullis.

Hab. Insulæe vitienses (Exped. Gazelle).

R. fluitanti simillima, sporis bene distineta.

413. R. novohannoverana Schiff. Forsch. Gazelle IV, p. 44.

Monoica, major, dilute-virens, tenera. Frons usque ad $15 \mathrm{~mm}$. longa, repetito-furcata, furcis longis, linearibus, apice distincte bilobis, antice ample canaliculatis. alis plano-convexis leniter adscendentibus, longe attenuatis, margine acutis; stratum anticum lamellis dense dispositis anguste cavernosum, cavernis sub 30 in frondis diametro. Costa bene evoluta, strato antico æquicrassa, multo tamen angustior, lateribus alte rhiziferis sensimque in alas excurrentibus. Frons adulta minus canaliculata, fere plana, quintuplo latior quam crassa. Ostiola mascula parum prominentia. Sporæ $7 \stackrel{5}{\mu}$, late alatæ, reticulatim lamellatæ, foveolis $8 \mu$, papillis nullis.

Hab. Insula Neu Hanover (Expedil. Gazelle).

114. R. laxisquamata St. Engler. Bot. Jahrb. 1895, p. 299.

Dioica, parva, pallide-virens. Frons usque ad $15 \mathrm{~mm}$. longa, crassa, duplo latior quam alta, furcata, furcis parum divergentibus, ovatis, acuminatis, breviter bilobis, antice plano-canaliculatis, marginibus longe atte- 
nualis, tenerrimis, versus apicem arcte incurvis, versus basin planopatulis, ultra costam late exstantibus; costa valde producta, postice planoconvexa, lateribus alte adscendentibus, abrupte in alas attenuata; stratum anticum lamellis densissime aggregatis formatum, vix frondis dimidium altitudinis occupans, antice facile ruptum ; ostiola mascula parva, parum prominentia. Sporæ $8 \Xi$, anguste alatæ, reticulatim lamellatæ, foveolis $7 \mu$, ex angulis alte papillatæ. Squamæ posticæ atropurpureæ, magnæ, marginem parum superantes, dense imbricatæ.

Hab. Abyssinia. Tigre (Schimper).

115ั. R. perennis St. n. sp.

Minor, pallide virens tuberifera. Frons usque ad $8 \mathrm{~mm}$. longa, furcata, crassa, triplo latior quam alta, antice plano-convexa (sub apice solum profunde sulcata, alisque leniter adscendentibus) marginem versus parum attenuata, ipso margine obtuso ; costa humilis, strato antico triplo angustior, distincte producta, abrupte in alas excurrens (præcipue in frondis parte juniore). Stratum anticum laxe cavernosum, cavernis sub 42 in frondis diametro. Reliqua desunt.

Hab. Algeria prope urbem Algers. (Trabut).

Die Pflanze trägt an der Basis eine Knolle von der halben Breite der Frons; ihre flache Oberseite ist nicht bewurzelt, der Umriss eiförmig, die ventrale sehr gewölbte Seite dicht mit Wurzelhaaren besetzl; aus ihrem apicalen Ende entspringt der Spross, der sofort die chlorophyllführenden dorsalen Lamellen zeigt, welche der Oberseite der Knolle, die von der Erde bedeckt ist, fehlt; sie ist aus völlig homogenen parenchymatischen Zellen aufgebaut und zeigt eine kleinzellige Epidermis verdickter Zellen; alle Zellen waren leer und die Reservestoffe, die sie voraussichtlich enthalten haben, zum Aufbau der schon weit entwickelten und verzweigten Pflanze verbraucht. Vielleicht ist die Erseheinung verbreiteter als man annimmt und nur bisher wenig gefunden worden; denn es ist nicht unwahrscheinlich, dass diöcische Pflanzen auf diese Weise die trockne Jahreszeit überstehen und die Pflanze für die nächste Vegetationsperiode erhalten.

116. R. Mœnkemeyeri St. Engler. Bot. Jahrb. VIII, p. 9 . .

Monoica, magna, gracilis, pallide-virens, expansa, sæpe dense stratificata. Frons usque ad $20 \mathrm{~mm}$. longa, tri-quadrifurcata, furcis longis, linearibus, apice truncato-rotundatis, breviter bilobis, crassis, subtriplo latioribus quam altis, antice late canaliculata, alis convexis, marginibus 
decurvis, crassis, attenuatis, obtusis, ultra costam late exstantibus; stratum anticum laxe cavernosum, costæ subæquialtum, lamellis valde obliquis, cavernis basi haud angustioribus, antice facile ruptis. Cosla crassa, in medio postico prominente, plano-convexa, lateribus oblique adscendentibus sinuatim in margines abeuntibus. Squamæ ventrales magnæ, rosex, laxissime reticulate, sub margine occultæ. Ostiola $\delta$ longe prominentia. Sporæ fusco-brunneæ $8 \%$ $\mu$, late alatæ, reticulatim lamellatæ, foveolis valde inæqualibus 7-12 $\mu$, haud papillatis.

Hab. Africa. Niger, Old Calabar (Mönkemeyer) Kamerun (Jungner).

117. R. multilamellata St. Hedwigia 1889, p. 44.

Monoica, mediocris, viridis, expansa. Frons crassa, 3 plo latior quam alta, usque ad $10 \mathrm{~mm}$. longa, trifurcata, usque ad margines radicellifera, furcis parum divergentibus fere conliguis, late linearibus, apice truncato rotundatis, antice subplanis, cavernis, angustis; costa latissima, late convexa, duplo humilior quam stratum anticum, lateribus substrictis, in margines obtusos excurrens. Sporæ $60 \mu$ anguste alatæ, lamellis irregulariter ramosis, hic illic ad reticulum confluentibus notatæ.

Hab. Australia, Finke River (W. F. Schwarz).

\section{R. deserticola St. n. sp.}

Monoica, magna, dilute viridis. Frons usque ad $14 \mathrm{~mm}$. longa, furcata, furcis late linearibus parum divergentibus, crassis, 4-plo latioribus quam altis, apice rotundato truncatis, ubique late canaliculatis, alis convexis leniter adscendentibus, marginibus crassis obtusis; costa postice subplana, lateribus abrupte et oblique adscendentibus, strictis. Sporæ parvæ 55 $\mu$, anguste alatæ, reticulatim-lamellatæ, foveolis 6 p., ex angulis spinosopapillatis.

Hab. Australia centralis, Arco Eillinna Well. (Helms, Elder Exploring Exped.).

119. R. albida Sull. ms. in Austin, Proc. Phil. Ac. 1869, p. 231.

Dioica? mediocris, albicans, gregaria. Frons usque ad $4 \mathrm{~mm}$. longa, crassa, plus duplo latior quam alta, multiramosa, ramis aggregatis, subfasciculatim furcata, furcis linearibus ultimis late acuminatis, antice canale angusto profundo planoque percursis, alis valde convexis e fundo arcuatim adscendentibus et convexo-explanatis, marginibus crassis subacutis; costa postice plana, convexa, lateribus rotundatis in margines abeunte. Reliqua desunt.

Hab. America septentr. Texas (Wright). 
120. R. Hasskarliana St. n. sp.

Dioica, minor, gracilis, pallide virens. Frons usque ad こ̆ mm. longa, multiramosa, ramis ultimis contiguis porrectis, linearibus, angustis, crassis (3-plo latioribus quam altis) antice sulco amplo acuto percursis (in planta adulta subplanis); alæ plano-convexæ, leniter adscendentes, margine acutæ; stratum anticum laxe cavernosum, lamellis sub 12 in diametro frondis, postice valde convexa, costa humillima, paucas cellulas crassa, parum angustior tamen quam stratum anticum. Ostiola mascula parum prominentia. Sporæ $72 \mu$, late alatæ, ala integra, reticulatim lamellatæ, foveolis $8 \mu$, humiliter papillatis.

Hab. Java (Hasskarl).

XIII. Frons valde incrassata, pro more duplo latior quam alta.

121. R. Hübeneriana Ldbg. in Monogr. Ricc. p. こ̌04d (Acad. Cæs. Leop. XVIII).

Monoica, exigua, expansa, purpurea, raro cœerulescens. Frons usque ad $4 \mathrm{~mm}$. longa, bi-trifurcata, furcis divergentibus, crassis, duplo latioribus quam altis, apice rotundatis, antice subplanis, versus apicem solum sulco obtuso humili instructis; cavernæ amplæ, sub 8 in diametro frondis, costa convexa, lateribus alte adscendentibus, marginibus haud exstantibus, obtusis; ostiola mascula brevissima crassa; sporæ parvæ 5̈I $\mu$, anguste alatæ reticulatim lamellatæ, foveolis $8 \mu$, ex angulis papillatis.

Hab. Germania, Gallia, Italia, Portugal, Norvegia, Japonia.

122. R. Sullivantii Austin. Ac. Phila 1869, p. 233.

Monoica, parva, flavo-virens, subcespitosa. Frons 2-3 mm. longa, bi-trifurcata, furcis divergentibus, linearibus, apice angustatis, crassa, duplo latior quam alta, antice anguste humiliterque canaliculata, alis plano convexis, marginibus haud exstantibus, obtusis, subtus valde convexa, lateribus rotundatis, ad margines alte adscendentibus; costa quadruplo humilior quam stratum anticum; cavernæ angustæ, sub $\mathbf{1 4}$ in diametro frondis, valde obliquæ. Sporæ $60 \mu$, late alatæ, regulariter reticulatim lamellatæ, lamellis humilibus, haud papillatis, foveolis $10 \mu$.

Hab. America septentr. Closter (Austin), Ohio (Lesquereux).

R. Huibeneriana differt sporis valde diversis.

R. fluitans toto coelo diversa est.

123. R. Beckeriana St. n. sp.

Dioica, minor, gracilis, viridis. Frons usque ad $7 \mathrm{~mm}$. longa, multifur- 
cata, furcis ultimis contiguis, angustissimis, crassis (duplo latioribus quam altis, antice anguste canaliculata, canale haud profundo, alis planoconvexis, margine rotundatis. Costa humilis (3-plo humilior quam stratum anticum) eoque rquilatum, lateribus frondis subverticaliter alteque adscendentibus; frondis sectio transversa itaque fere parallelogramma, angulis obtusatis, medio antico breviter emarginato. Ostiola $\delta$ ignota. Sporæ $42 \mu$, dilute rufo-brunneæ, anguste alatæ, ala integerrima, irregulariter lamellatæ, lamellis ramosis vermicularibus.

Hab. Russia, Sarepta (Becker).

Die wurmförmige Sculptur des Exosporiums bei dieser, wie bei anderen Arten entsteht durch Abortiren einzelner Theile des Lamellen-Netzes, die oft in langen Zügen fehlen, so dass eine geschlängelte, radial gerichtete Lamelle entsteht; diese sind verzweigt und die Aeste mannigfach verbogen, oft isolirt dazwischen stehend, kurz je nach dem Ausfall einzelner Maschen ist das Bild verschieden und wechselnd, dazwischen liegen oft kleine Gruppen vollkommener Maschen. Heeg (Bot. Not. 1898, stellt diese Pflanze zu R. Frostii, der sie zweifellos sehr ähnlich ist; die Sporen beider bieten keinen Unterschied; ich habe fruchtende Pflanzen beider Arten untersucht, die bei gleicher Höhe der Frons wesentlich in der Breite differiren, denn R. Frostii ist mehr als doppelt so breit wie R. Beckeriana; das geht aber über die Variabilität hinaus, die man bei einer Riccia erwarten kann.

\section{R. bahiensis St. n. sp.}

Syn. : R. crystallina var. . Syn, Hep. p. 608.

Monoica, mediocris, dilute viridis, gracilis. Frons usque ad $6 \mathrm{~mm}$. longa, crassa (duplo latior quam alta) profunde bifurcata, furcis parum divergentibus, linearibus, $1 \mathrm{~mm}$. latis, apice obtusis, antice profunde canaliculata, canale amplo, in fundo plano, alis abrupte curvatim adscendentibus, convexo-explanatis ultra costam parum exstantibus, marginibus obtusis; costa lata planaque, humillima, 3-4 cellulas crassa, stratum cavernosum lamellis laxe dispositis formatum. Sporæ $68 \mu$, late alatæ, irregulariter subreticulatim lamellatæ, lamellis crassis, paucas papillas gerentibus, foveolis $12 \mu$.

Hab. Brasilia, Bahia (Martius).

Ramificatione aliisque notis plane diversa.

125. R. vesiculosa Carr, et P. Linn. Soc. N. S. Wales. 1887. p. 1058. 
Syn. : R. bullosa var, vesiculosa Carr. et P.

Monoica, major, pallide virens, subcrespitosa. Frons usque ad $10 \mathrm{~mm}$. longa, bi-trifurcata, ob furcas longe coalitas obcuneata, furcis e margine supero emergentibus, late ligulatis, $1 \mathrm{~mm}$. latis, apice rotundatis, crassa, parum latior quam alta, antice ob cavernas inflatas papulosa, sulco acuto profundoque percursa, lateribus sulci curvatim adscendentibus, in ætate magis explanatis valdeque convexis, margine oblusalo; costa valde producta, strato antico æquialta, basi sua convexa, duplo fere angustiore, lateribus costæ oblique stricteque adscendentibus. Cavernæ valde angustæ, subverticales, lamellarum diametro 3 -plo tantum ampliores. Sporæ ignotæ.

Hab. Australia, Paramatta (Whitelegge) Burnett River (J. Keys).

Diese Pflanze nähert sich in ihrem Bau der Gattung Riccia mehr als irgend eine andere Ricciella; die Lamellen umschliessen enge Luftcanäle; auf einem horizontalen Schnitt sind es meist 8 Zellen, welche den Canal begrenzen; von diesen sind 4 grösser, quasi Pfeilerzellen, denn an diese schliessen sich die Wänder der nächsten Canäle an; zwischen diesen 4 grossen liegen 4 wesentlich kleinere; denken wir uns letztere entfernt, so haben wir genau das Luftkammer-Gewebe von Riccia; es ist denkbar, dass, wie diese Form eine Anpassung an das trockne Klima Australiens darstellt, sich die Ricciellen aus der Gattung Riccia entwickelt haben und dass mit dem Flächenwachsthum der Lamellen die grösseren Lufträume, die Verbreiterung der dorsalen Deckhaut und damit eine Bloslegung des apicalen Porus entstand, den ja jede Riccia hat. Es ist kaum berechtigt, die Gattung in 2 zu spalten, wo, wie diese Pflanze zeigt, Uebergänge vorhanden sind.

\section{R. crassa St. n. sp.}

Monoica, parva, in sicco flavescens. Frons $10 \mathrm{~mm}$. longa, obcuneata, crassa, breviter furcata, duplo latior quam alta, apice acuta, antice breviter acuteque sulcata, alis convexim explanatis, costam parum superantibus, marginibus crassis acutis; costa valde producta, postice convexa, lateribus rotundatis adscendentibus profunde sinuatim excurrentibus. Stratum æriferum altum ( $1 / 3$ frondis altitudinis) cavernis angustissimis. Sporæ $70 \mu$, anguste marginatæ, reticulatim lamellatæ, lamellis humilibus, haud papillatis foveolis $6 \mu$.

Hab. Australia centralis. Ackariaga (Helms. Elder Exploring Exped.). 
127. R. papulosa St. Hedwigia 1889, p. 45े.

Dioica. magna, dilute viridis. Frons simplex, usque ad $10 \mathrm{~mm}$. longa, $4 \mathrm{~mm}$. lata, late oblonga, apice rotundata, sub apice breviter sulcata sulco profundisssimo, lateribus sulci compresso-contiguis, ceterum in æatate anguste canaliculata, alis convexo explanatis, marginibus attenuatis acutis, crassa, duplo latior quam alta; costa valde producta valdeque convexa, duplo fere angustiore duploque humiliore quam stratum anticum, lateribus rotundatis, abrupte sub alis desinentibus; stratum anticum anguste cavernosum, cavernis sub 30 in diametro frondis, basi vix angustatis; squamæ parvæ, sub alis occultæ, hyalinæ vel purpureo-maculatæ, laxe reticulatæ (cellulis $50 \mu$ ). Sporæ ignotæ.

Hab. Australia, Victoria, Silverton (Bastow).

128. R. bullosa Link. in Ldbg. Syn. Hep., p. 119.

Dioica maxima, in sicco flavo-rubescens. Frons usque ad $20 \mathrm{~mm}$. longa, furcata, furcis $4 \mathrm{~mm}$. latis, late divergentibus, apice breviter biloba, profunde sulcata, antice convexa, marginibus decurvis, cavernis bullatim prominentibus rugulosa; cavernæ e basi angustissima sensim ampliatæ, antice multoties ampliores, in vertice porosæ, poris a sex cellulis concentricis anguste conicis formatis, in ætate fissis et conniventi-apertis. Costa crassa pro planta angusta, postice convexa maximeque radiculosa, lateribus rotundatis abrupte in alas exstantes abeunte. Sporæ $76 \mu$, nigræ, facie convexa minute reticulatim lamellatæ foveolis vix $5 \mu$, brevissime creberrimeque papillatis; faciebus planis angustissime radiatim lamellatæ.

Hab. Africa australis (Ecklon).

Die portugiesische Pflanze, welche Welwitsch 1847 bei Vendas am Tajo wiedergefunden hat und die der Cappflanze im Habitus täuschend ähnlich zieht, ist keine Riccia sondern eine Marchantiacee; sie hat im Grunde der Lufthöhlen eine dem Grundgewebe aufsitzende niedrige Lage chlorophyllführenden Zellfäden, die dreizellig sind und deren Endzelle keulenförmig verdickt ist; ausserdem trägt die frons grosse, schief halbmondförmige, Ventralschuppen mit langem fädigen Spitzenanhängsel; aus der Spitze treibt sie keulenförmige, ringsum bewurzelte, schief nach unten in das Erdreich eindringende Knollen, welehe fast so lang sind als die frons selbst; sie brechen sehr leicht ab und sind vielleicht desshalb übersehen worden. Levier versichert mir, dass diese Pflanze die authentische portugiesische R. bullosa sei. Zu welchem Genus sie zu stellen ist, bleibt eine offene Frage. Ich erwähne hier auch, dass Riccia lutescens wahrscheinlich eine Marchantiacee ist; schon die grossen Schuppen mit abgesetztem BULL. HERB. BOISS., mai 1898. 
Spitzenanhängsel deuten darauf hin; die Pflanze ist nur steril in den Herbarien zu finden.

\section{R. Rautanenii St. Bull. Herb. Boiss. 1890 .}

Monoica, major, viridis, expansa. Frons $15 \mathrm{~mm}$. longa, bi-trifurcata, furcis parum divergentibus, linearibus, $1 \mathrm{~mm}$. latis, crassis, duplo latioribus quam altis, antice plana, marginibus parum attenuatis, ultra costam parum prominentibus; stratum anticum altissimum, laxe cavernosum, cavernis sub 14 in diametro, lateribus concavis, in sectione transversa sub margines itaque constrictis; costa humilis $ّ$-6 cellulas alta, plano convexa, lateribus rotundatis. Sporæ $8 \check{\rho} \mu$, angusle alatæ, ala minute crenulata, laxe lamellatæ, lamellis altis, vermicularibus, subreticulatim confluentibus.

Hab. Africa australis. Hereroland (Rautanen, Dr Fleck). Angola ad flum. Bero (Welwitsch).

\section{R. concava Bisch.}

Dioica, major, glauco-virens. Frons usque ad $12 \mathrm{~mm}$. longa, ad medium divergenti-dichotoma, furcis late ovatis, obtusis breviter bilobis, antice concavis, intra marginem vallatim incrassatis, ipso margine acutis, ceterum crassis, plus triplo tamen latioribus quam altis, ventre late convexis, ubique æquicrassis. Squamæ posticæ magnæ, hyalinæ, marginem longe excedentes, integerrimæ. Pistilla hyalina. Reliqua desunt.

Hab. Caput bonæ spei (Dr Krauss).

Riccia albomarginata (planta capensis) differt frondis configuratione valde aberrante, nostræ ceterum simillima.

Nachdem es mir nachträglich gelungen ist, das Original dieser Pflanze zu erhalten, füge ich deren Diagnose hier am Schlusse bei; dem Bau des Laubes nach gehört diese Art in meine Abtheilung VII, hinter Riccia porosa; sie ist in Abtheilung IV, wohin ich sie früher als zweifelhaft gestellt hatte, zu streichen.

An Synonymen etc. habe ich folgende noch zu verzeichnen, als nicht zu Riccia gehörend :

Riccia cochleata H. et T. ist eine Aneura.

$\begin{array}{lll}\text { fimbriata Nees } & \text { " } & \text { Exormotheca. } \\ \text { natans } \mathrm{L} \text {. } & \text { Ricciocarpus. } \\ \text { nigrescens } \text { Mont. } & \text { Anthoceros (sp.?). } \\ \text { paradoxa Wils. Hook. } & \text { " } & \text { Cronisia. } \\ \text { reticulata } \text { Swartz. } & \text { Protonema. } \\ \text { spuria } \text { Dickson } & \text { " } & \text { Cyathodium (?). } \\ \text { tuberosa } \text { Taylor } & \text { Anthoceros. } \\ \text { velutina } \text { Wils. } & \text { Ricciocarpus. }\end{array}$


Extrait du Bulletin de l'Herbier Boissier.

Tome VI. No 10. Octobre 1898.

\title{
SPECIES HEPATICARUM
}

AUCTORE

Franz STEPHANI

(Suite.)

\section{RICCIOCARPUS Corda}

\author{
in 0piz. Beiträge, p. $6 \breve{1}$.
}

Plantæ thallosæ, parvæ, terricolæ vel natantes, carnosæ, antice rima nuda (strato lamellifero recedente) percursæ, dichotome ramosæ, cavernosæ, cavernis pluristratis. Stomata composita, costa humillima, angustissima, squamæ posticæ longissimæ interdum nullæ. Antheridia et Archegonia medio antico costæ immersa, involucrata, antheris in soris vallatis longissimis bene definitis aggregatis, a vagina communi circumdatis, Archegonia seriata, singula parvo involucro cupuliformi styloque pertuso tecta. Capsula et Sporæ ut in Ricciis.

1. R. natans (L) Corda, l. c.

Syn. Riccia natans L. Syst. veget. p. 956 .

Dioica, mediocris, læte viridis, marginibus sæpe purpureis, pro more natans, rarius terricola. Forma terricola usque ad $10 \mathrm{~mm}$. longa, bitrifurcata, furcis late linearibus, $2 \mathrm{~mm}$. latis, apice truncato-rotundata, breviter biloba, profunde sulcata, sulco acuto, ob latera compresso-conniventia in adspectu minus distincta, alis convexis, prærupte maximeque ad margines attenuatis, in parte adulta plantæ tenuis, antice subplana, BULL. HERB. BOISS., octobre 1898. 54 
marginibus attenuatis obtusis; stomata minima, composita i. e. cellulis 6-8 conico conniventibus formata, epidermidi perforatæ insidentibus et parvum cavum includentibus; postice subplana, medio postico abrupte incrassata ibidemque costam humillimam radicelliferam gerens. Cavernæ sub 30 in diametro frondis, angustæ, valde obliquæ, basi majores, superficies antica cavernis perlucentibus minute reticulata. Squamæ posticæ vel nullæ vel oblique insertæ utroque latere costæ triseriatæ, plus minus longe ligulatæ, margine remote dentatæ. Sporæ parvæ こั1 $\mu$, anguste alatæ, reticulatim lamellatæ, lamellis transversis evanidis interdum radiatim lamellatæ.

Forma natans maxime differt fronde late obconica, furcis longe coalitis, sulco antico magis aperto, absentia radicellarum et squamis longissimis pendulis.

Hab. Europa. Tonkin (Bon) Japonia (Dickins, Dönitz) Brasilia (Ule, Lindman) Australia (Keys) Nova Zelandia (Kirk) Mexico (Schaffner) China (Delavay); ex Africa adhuc non relata.

\section{R. velutinus (Wilson) Steph.}

Syn. Riccia velutina Wilson in Hooker, Ic. pl. V, t. 249.

Dioica? major, robusta, in sicco flavo-rubescens, expansa, terricola. Frons usque ad $12 \mathrm{~mm}$. longa, bis dichotoma, furcis ligulatis, apice profundissime inciso-bilobis, lobis crassis, arcte connivente-appressis, rima profunda in sectione frondis tantum visibili; sulcus in frondis parte adulta acutus, alæ convexo-explanatæ, crassæ, tumescentes, ob cavernas numerosas bullatim inflatas papulosæ, versus marginem sensim attenuatæ, margine ipso obtuso. Costa humillima, frondis medium solum tenente fronde ideoque subarhiza. Squamæ omnino nullæ. Sporas haud vidi.

Hab. Texas (Drummond) Mobile (Mohr) Cuba.

Im Herbar in Kew ist dem Exemplar eine gedruckte Abbildung beigelegt (wohl aus Hooker Icones plant.) welche den Habitus der Pflanze recht gut darstellt; der abgebildete verticale Querschnitt des Laubes zeigt die Kapseln in mehreren Etagen über einander; das kommt bei keiner Riccia vor; dabei ist die dabei liegende originale Pflanze völlig steril; in der Synopsis (deren Autoren schreiben "nobis non visa ") werden die Sporen aterrimi genannt; dann sind sie jedenfalls von einer anderen Pflanze genommen; woher aber stammt die wunderbare Stellung der Capseln?

Im Uebrigen ist die Pflanze zweifellos ein Ricciocarpus, und gleicht der Landform der $R$. natans sehr. 


\section{RUPINIA Corda}

in Opiz, Beiträge, 1829 , p. 650 .

Syn. Riccia Raddi, 0p. scient. Bologna, II, p. 350.

Tessellina Dum. Comment. bot. p. 78 (nomen nudum).

Oxymitra Bisch. in Ldbg. Synops. Hep. Eur. (Acad. Leop. 1829, p. 124).

Plantæ thallosæ, terricolæ, dichotome ramosæ vel ramulis posticis lateralibus innovatæ, antice cavernosæ, lamellis unistratis, medio anticostrato antico recedente-sulcatæ; stomata simplicia, minima. Squamæ posticæ magnæ, utroque latere frondis seriatæ, e basi radiculas incrassatas proferentes. Androcia costæ inserta, antheridiis in soro vallatim ampliato lineari et bene definito seriatis, vagina communi squamulisque circumdata; cavernis monandris. Archegonia seriata, singula involucro spongioso, conico-cylindrico, apice aperto circumvallata; calyptra basi involucri coalita. Capsula sphærica, parietibus bistratis, subinde evanidis. Sporæ tetrædræ, lamellatæ. Elateres nulli.

\section{R. pyramidata Corda, 1. c.}

Syn. Riccia pyramidata Raddi, l, c.

Tessellina pyramidata Dum. 1. c.

Oxymitra pyramidata Hüb. Hepaticologia germ. p. 24.

Dioica, minor, viridis, marginibus purpureis, tenax. Frons usque ad $2 \mathrm{~cm}$. longa, furcata vel ramulis posticis innovata, fureis divergentibus, late linearibus, apice rotundatis, antice subplanis, marginibus attenuatis, adscendentibus, plus triplo latioribus quam altis; costa valida strato lamellifero æquialta, duplo fere angustiore, postice plano convexa, dense radicellifera, lateribus adscendentibus sensim in alas excurrentibus; antice rima nuda percusa; squamæ posticæ oblique triangulares, magnæ, basi purpureæ denseque imbricatæ, apice liberæ, hyalinæ, longe cuspidatæ, marginem frondis longe superantes, in apice frondis hamatim incurvæ; stratum anticum lamellis approximatis anguste cavernosum; stomata 6 cellulis conicis superficialibus formata, parietibus radialibus maxime incrassatis. Bracteæ vaginæ masculæ lineares, purpureæ, erectæ. Ostiola mascula longe producta. Involucra feminea cavernosa, porifera, 
hic illic bractea parva basali instructa. Sporæ $120 \mu$, brunneæ, reticulatim lamellatæ.

Hab. Italia, Gallia, Alpes Austriæ, Germania, Portugal, Algeria, Corfu, Brasilia, Paraguay.

\section{CORSINIA Raddi}

\section{Op. sc. Bologna, II, p. 354 .}

Plantæ thallosæ, terricolæ, dichotome ramosæ, sulco antico nullo, cavernosæ, cavernis unistratis, basi filiferis. Stomata simplicia. Squamæ posticæ parvæ, irregulariter distributæ, e basi radiculas incrassatas proferentes. Andrœeia linearia, utroque latere strato lamellifero proximo cristatim involucrata. Antheridia costæ immersa, aggregata, numerosa, cavernis monandris. Archegonia singularia vel in soros aggregata, strato antico recedente costæ inserta, filis septatis circumdata; involucrum e toro pistillorum ortum, erectum, squamiforme vel magis evolutum et fructum semi-amplectens, pluristratum haud poriferum, interdum e centro sori ortum apiceque umbelliforme dilatatum. Calyptra magna, crassa, medio supero papillis elongatis hispidissima. Capsula sphærica, magno bulbo inserta, parietibus unistratis sine fibris spiralibus. Pseudoelateres $50 \mu$ longi, late fusiformes, fibra spirali nulla. Sporæ tetrædræ in facie convexa reticulatim sulcatæ.

1. C. marchantioides Raddi, I, c.

Dioica, interdum monoica, pallide viridis, spongiosa, fragilis, arcte repens. Frons usque ad $2 \mathrm{~cm}$. longa, furcata, furcis divergentibus, late oblongis, apice breviter emarginatis et squamarum appendiculis protectis, antice subplana, stomata parva, poro a 6 cellulis concentricis circumdato; costa strato antico duplo humiliore duploque angustiore, postice planoconvexa, sensim in alas attenuata, medio dense radiculosa. Squamæ posticæ hyalinæ, conicæ, appendiculo apicali longissimo, filiformi. Stratum anticum laxe cavernosum, filis chlorophylliferis e fundo cavernarum ortis. Ostiola mascula parum prominentia. Involucrum pro more parvum, irregulariter laceratum, fructum a tergo tegens. Sporæ $120 \mu$, anguste alatæ, ala aspera, cuticula e laminis magnis hexagonis formata, cuticula interlaminari angusta minusque crassa retiformi. 
Hab. Europa mediterranea, Tenerifa, Louisiana (Langlois), Japonia (Makino).

Ich nenne die sterilen Zellen auch hier schon Pseudo-Elateren, da sie ihrer Anlage und Bedeutung nach diesen gleichwertig sind. Gœebel, in seiner vortrefflichen Abhandlung über "Funktion und Anlegung der Lebermoos Elateren " ( Flora " 1895) betont ihren Charakter als Reservestoffbehälten; ich möchte sie eher als Leitungsbahnen für die Reservestoffe ansprechen, welche jedes Lebermoos im basalen Gewebe des Fruchtstandes speichert; andere haben die Calyptra zu Reservestoffbehältern ausgebildet oder wie bei den beuteltragenden Lebermoosen stellt die Beutelwand einen Behälter für gespeicherte Stoffe dar; in allen Fällen führt deren Weg durch den Fuss des Sporogons vermittelst der Elateren in die Sporenmasse.

Wir treten mit dieser Gattung in die lange Reihe der Marchantiaceen ein; wenn ich hier, wie in der Folge, mich lediglich darauf beschränke, die Gattungen in ihrer natürlichen Verwandtschaft aneinander zu reihen und mir vorbehalte, am Schluss der Arbeit eine Uebersicht der Familien zu geben, so geschieht das nur, weil ich manche der alten Originalexemplare nicht kenne und sie meist nur mit grosser Mühe und grossem Zeitverlust allmählig zu beschaffen vermag; in diesen Originalpflanzen slecken aber oft, wie ich aus Erfahrung weiss, sehr überraschende, ganz. abweichende Dinge, die eine vorzeitig gegebene Familien-Uebersicht unsicher, ja hinfällig machen können; ich bin daher gezwungen, mich zunächst auf das allmählige Aufarbeiten der Gattungen zu beschränken, um später das Fehlende nachzuholen.

Ich konnte und wollte aber den Beginn der Arbeit nicht länger hinausschieben und nicht warten, bis Alles niedergeschrieben ist, weil der zur Bewältigung der Arbeit zurückzulegende Weg ein langer ist, von dem ich hoffe, dass ich ihn zu machen im Stande sein werde.

\title{
CRONISIA Berkeley
}

\author{
Intr. Crypt. Bot. p. 434.
}

Syn. Riccia Wilson et Hook. J. of Bot., 1844, p. 166.

Plantæ thallosæ, terricolæ, cavernosæ, sulco antico nullo; cavernis unistratis, e latere lamellarum, epidermide approximata, fila chlorophyl- 
lifera horizontalia gerentes; stomata simplicia; squamæ posticæ frondis alis insertæ, e basi radiculas incrassatas proferentes. Andrœcia in soros aggregata, involucro nullo. Antheridia tumescenti costæ immersa; Archegonia in alveolis costæ inserta. Involucrum tenue erectum, monophyllum, cucullatum, fructum a tergo semi-amplectens. Calyptra tenuis, unistrata, lævis. Capsula magna, magno bulbo inserta, parietibus unistratis, cellulis semiannulatim incrassatis. Elateres? Sporæ tetrædræ, magnæ, grosse papulosæ.

Nach ${ }_{s}$ dem Gesagten steht diese Gattung der Corsinia sehr nahe; leider verbot das sehr geringfügige überreife und vielfach zerstörte Material, tiefer in den Bau und die Entwicklung dieser interessanten und bisher fast unbekannten Gattung einzudringen.

1. C. paradoxa (Wils. et Hook), Berkeley, l. c.

Syn. Riccia paradoxa Wils. et Hook. 1. c.

Monoica, frons 5 - $6 \mathrm{~mm}$. longa, simplex, (semper?) viridis, apice breviter biloba, rima apicali appendiculis squamarum repleta, antice plana, marginibus latis tenerrimis plicatulis, oblique adscendentibus; stratum lamelliferum humile, cavernis magnis formatum; stomata minima; costa crassa, duplo altior quam stratum anticum, postice carinatim angustata sensimque in alas attenuata. Squamæ posticæ seriatæ, atropurpureæ vel violaceæ, oblique triangulatæ, appendiculo æquilongo filiformi hyalino. Antheridia numerosa, ostiolis hyalinis longissimis. Involucra magna, circumscriptione ovata, tergo valde convexa, altero latere (versus apicem plantæ spectante) conniventi-aperta, marginibus lobulatis vel repandis. Capsula irregulariter dehiscens. Sporæ $70 \mu$, rufo brunneæ sub lente, in sicco nigræ.

Hab. Brasilia Prov. Piauhy prope Oeiras (Gardner).

\section{FUNICULARIA Trevisan}

\section{Mem. R. Istit. Lomb. 1877, vol. IV, p. 443.}

Plantæ thallosæ, terricolæ, antice cavernosæ, sulco antico nullo, cavernis unistratis, e fundo cavernarum filiferis; stomata simplicia; squamæ posticæ alis frondis insertæ, basi radiculas incrassatas gerentes. Androecia solitaria. Antheridia remota, seriata, costæ immersa, involucro 
nullo. Archegonia ad 3 vel 4 alveolo costæ inserta, paraphyllis circumdata. Involucrum tenue, erectum, monophyllum, cucullatum. Calyptra tenuis, lævis; capsula magna, globosa, parvo bulbo inserta, parietibus unistratis, cellulis semiannulatim incrassatis. Elateres parvi, fusiformes, spiraliter incrassati. Sporæ tetrædræ magnæ, grosse papulosæ,

\section{F. Weddellii (Mont) Trev. l, c.}

Syn. Boschia Weddellii Mont. Ann. sc. nat. 1850.

Dioica; Frons usque ad $25 \mathrm{~mm}$. longa, anguste linearis, simplex, radiculis villosa, arcte repens, apice parum angustata, breviter incisa, rima appendiculis squamarum repleta, antice plana, marginibus adscendentibus, ipso margine acuta, integerrima, costa valde convexa, sensim in alas excurrens, ad latera squamis obtecta, squamæ fusco-purpureæ, imbricatæ, late lunatæ, margine irregulariter longeque fimbriatæ. Stomata simplicia, poro magno, 气̄-6 cellulis angustis circumdato. Stratum lamelliferum duplo humilius quam costa; cavernæ amplæ, sub 14 in diametro frondis, filis chlorophylliferis, 3-4 cellulas longis dense repletæ. Antheridia ostiolis longis angustis. Archegonia in fundo foveolæ, strato Iamellifero vallatim ampliato circumdatæ; paraphyllis filiformibus 3-4 cellulas longis. Involucrum juvenile squamæforme, pistilla a tergo tegens, post fecundationem valde evolutum, fructum obvelantem, basi pluristratum, superne tenuis, dorso cellulis poriformibus parvis oleiferis punctatum. Calyptra basi 3-4 cellulas crassa, superne tenuis. Sporæ $60 \mathrm{u}$.

Hab. Brasilia (Weddel, Burchell.)

\section{TARGIONIA L.}

$$
\text { Sp. pl. p. } 1604 .
$$

Plantæ thallosæ, terricolæ, repentes. Frons simplex, ex apice vel e latere costæ innovata, rare dichotome ramosa, cavernosa, cavernis humillimis, filiferis; stomata magna, simplicia; squamæ posticæe basi laminaque radiculas incrassatas proferentes. Inflorescentia monoica vel dioica. Andrœcia in ramulis parvis, e latere costæ ortis, ostiolis papilliformibus. Archegonia in soro aggregata, e sulco apicali orta, post fecundationem fronde antice increscente a dorso tecta, - postice marginibus sulci ampliatis - immersa denique involucro bivalvi occulta. Calyptra pluristrata. 
Capsula magno bulbo inserta, breviter pedicellata, parietibus unistratis, fibris spiralibus vel annularibus instructis; Elateres bispiri, sæpe ramosi. Sporæ tetrædræ, facie convexa reticulatim alato-cristatæ.

1. T. hypophylla. L. Spec. plant. p. 1604.

Syn. T. Michelii Corda in Opitz, Beitr. I, p. 649.

T. bifurca Mont. Ann. sc. nat. IX, p. 143.

T. capensis Hüb. Hep. germ. p. 17.

T. convoluta L. et G. Syn. Hepat. p. 576.

T. mexicana L. et L. Pugill. IV, p. 27.

Monoica vel dioica. Frons usque ad $15 \mathrm{~mm}$. longa, antice plana viridis, postice nigro-purpurea, linearis subtenuis, apice inciso-biloba; costa duplo crassiore duploque angustiore quam stratum anticum, plano-convexa, sensim in alas attenuata; stratum anticum humile, cavernæ filis ramosis dense repletæ; cellulæ epidermidis trigone incrassatæ; stomata magna, tabulata i. e. tres cellularum circulis superpositis formata. Squamæ posticæ purpureæ, remotæ, oblique triangulares, longe cuspidatæ, marginibus integerrimis vel varie dentatis, sub involucro multo majores magisque armatæ. Ramuli masculi e basi tereti in laminam parvam discoideam ampliati, ostiolis numerosis aggregatis hirti, postice dense squamosi. Involucrum compresso ovatum, conchæforme, atropurpureum, ad maturitatem capsulæ rima semicirculari dehiscens. Archegonia pro more 3-4 in soro aggregata. Capsula sphærica. Elateres $220 \mu$ longi, atlenuati, fibris laxe spiralibus vel multo breviores et ramosi. Sporæ $76 \mu \mathrm{vel}$ - alis minus evolutis vel omnino deficientibus - multo minores

Hah. Europa mediterranea, Tenerifa, Madeira, Insulæ canarienses, Gallia, Belgium, Britannia, Germanin, Helvetia, Austria, Madagascar, Caput b. spei, Abyssinia, Mexico, Peru, Ecuador, Chile, Nova Zelandia, Australia, Tasmania.

\section{T. elongata. Bisch. Syn. Hep. p. כ̃76.}

Dioica, præcedenti simillima, major tamen, tenuis. Frons usque ad $30 \mathrm{~mm}$. longa, profunde furcata, apice profondius incisa, costa triplo angustior quam stratum anticum, abrupte producta, postice plano convexa. Squamæ posticæ magnæ, imbricatæ, purpureæ, appendiculo magno oblongo, obtuso, repando-dentato. Involucrum inflatum, compresso-globosum, a dorso haud visibile. Sporæ maturæ flavidæ, $42 \mu$, late alatæ, laxe reticulatim lamellatæ, lamellis angulatis vel repando-dentatis. Elateres $220 \mu$, duplo angustiores quam in T. hypophylla; planta mascula ignota. 
Hab. Abyssinia (Schimper).

Die kleinen porenartigen hyalinen Zellen der Ventralschuppen bezeichnen diejenigen Stellen, aus welchen punktförmig verdickte Wurzelhaare entspringen; letztere reissen beim Reinigen der Pflanze ab und hinterlassen in ihrer Basalzelle (in der Ventralschuppe) ein Loch, das durch seine hellere Farbe auffällt; diese punktierten Wurzelhaare vereinigen sich an der Basis der Schuppe zu einem Bündel und laufen den übrigen unwerdickten Wurzelhaaren unter der Costa zu. Jch habe schon vor vielen Jahren darauf aufmerksam gemacht, dass die verdickten Rhizoiden meist aus den Schuppen stammen und nur vereinzelt aus den Ventralzellen der frons dicht an der Basis der Schuppen. Trotzdem werden selbst in neuerem Arbeiten gegentheilige Ansichten ausgesprochen, weil man nur mit Herbar Material arbeitet; an cultivirten Marchantiaceen kann man den wahren Sachverhalt bei einiger Vorsicht sehr leicht beobachten.

\section{CYATHODIUM Kunze}

in Lehm. Pug. VI, p. 17.

Syn. Synhymenium Griff. Notulæ, p. 344.

Monosolenium Griff. Notulæ, p. 341.

Riccia Dickson, Pl. cr. IV, p. 20.

Plantæ thallosæ, parvæ, tenerrimæ, terricolæ vel rupicolæ, radicellis normalibus vel punctatim incrassatis instructæ, depresso cæspitosæ, furcatæ, cavernosæ, cavernis unistratis, humillimis; costa lata, unam cellulam crassa, cellulis in lumen cavernarum convexo-prominulis. Stomata magna, simplicia, poro magno, cellularum angustarum cireulis sexseriatis circumdato. Squamæ posticæ minutæ vel omnino deficientes. Inflorescentia monoica. Andrœecia in ramulis posticis, sub apice frondis ortis, flori femineo sæpe approximatis, parvis subglobosis, basi paleaceis; Antheridia numerosa, ostiolis verruciformibus. Archegonia ad 3 vel 4 in soro aggregata, primo nuda, subinde, fronde furcatim increscente a dorso tecta, postice involucrata. Involucrum pendulum, plus minus saccatum, basi postica paleaceum, apice valvatim hiante. Capsula globosa, sessilis, parvo bulbo inserta, parietibus unistratis, medio supero abrupte validioribus annulatimque incrassatis, operculo bene definito clausa subinde 8 laciniis 
æquimagnis profunde dehiscens. Calyptra tenuis, unistrata. Elateres fusiformes, trispiri. Sporæ sphæricæ, plus minus hirtæ.

\section{C. cavernarum Kunze. 1. c.}

Dilute viridis, minor. Frons usque ad $10 \mathrm{~mm}$. longa furcis brevibus, apice inciso-bilobis, antice plana, epidermide tenera cellulisque hand incrassatis, postice plana, costa in medio plantæ solum 2 cellulas crassa, paucas squamas minutas, e 3 cellulis superpositis formatas gerens. Ramuli masculi e cellulis unistratis cylindricis erectis conflati, postice paucis paleis filiformibus obtecti. Involucrum breviter inflato saccatum, bivalvatum, valvulæ haud carinatim hiantes sed late emarginato-apertæ et frondis furcis floralibus brevissimis rotundatis parum occultæ, ceterum tenue, versus apicem magis coloratum cellulisque magnis magis magisque incrassatis durum, ceterum integerrimum et postice paucis paleis filiformibus obtectum. Sporæ fuscobrunneæ 33 -ə๊0 $\mu$, papillis longis echinatæ. Elateres $500 \mu$, longi, fibris confertim spiralibus.

Hab. Cuba.

\section{C. aureo-nitens (Griff.) Schiffn.}

Syn. Synhymenium aureo-nitens Griff. 1. c. Monosolenium tenerum? Griff. I. c.

Magis robusta, fusco-viridis, præcedenti ceterum simillima, differt frondis furcis involucralibus anguste ligulatis, involucro magis elongato circumscriptione obovato-oblongo, tertio supero solum breviter bivalvi, postice subcarinato valvulis itaque angulo acuto hiantibus; paleæ involucrales majores, interdum laceratæ. Ramuli masculi hypogyni, pistillis maxime approximatis. Sporæ magnæ, usque ad $68 \mu$ in diametro, muriculatx.

Hab. Tonkin (Balansa), Africa, Kamerun (Staudt), Togo (Büttner), Fernando-Po (Mönkemeyer), Loango (Welwitsch), Kulongo, Africæ centr. (Schweinfurth), India orientalis, Calcutta (Sulp. Kurz), Bombay (Schiffner), Maharadjapore (Sulp. Kurz), Dehra-Dun (Gamble), Assam (Sulp. Kurz), Sikkim (Hooker), Birma (Sulp. Kurz), Java (Solms, Schiffner).

Diese Pflanze producirt neben normalen Inflorescenzen auch zahlreiche anormale, deren Involucrum ganz fehlt; an seiner Stelle ist ein kleiner normaler Art entwickelt, der auf seiner vorderen breiteren Hilfte die Capsel trägt, die ganz nackt auf ihm inserirt, völlig normal ausgebildet ist; hiernach zu urtheilen ist die Hülle von Cyathodium und Targionia 
ein metamorphosirter Ventralast, dessen tiefeingeschnittenes zweilappiges Ende die zweiklappige 0effnung des Involucrums darstellt.

\section{- 3. G. foetidissimum Schffn. Iter ind. Exsicc.}

Robusta, sæpe usque ad $20 \mathrm{~mm}$. longa, $3 \mathrm{~mm}$. lata, radicellis punctatim incrassatis valde numerosis. Involucra minima, omnino postica, a dorso haud videnda, furcis involucralibus frondis longis, porrectis, contiguis (haud divergentibus, lateque rotundatis, ceterum obovatum, breviter valvatum, valvulis angulo acuto hiantibus. Squamæ ventrales majores, foliaceæ, longe setaceæ. Ramuli masculi magni, pistillis contigui, tempori fecundationis illis incumbentibus, magni oblongi, margine papulosi. Sporæ $34 \mu$, grosse papulosæ, fusco-purpureæ ut elateres.

Hab. Tahiti (Nadeaud), Nukahiwa (Jardin), Java (Schiffner).

Ich gebe die Beschreibung nach der Tahiti-Pflanze, da die javanischen Exemplare, aus der Regenzone des Gebirges, vegetativ schwach entwickelt sind; die auffallende Form der Sporen lässt diese Art leicht erkennen.

Riccia spuria. Dickson in Schottland gesammelt gehört, nach Lindberg, vermutlich zu dieser Gattung; die Pflanze ist aber fertil nicht bekannt. Ich habe sie nicht gesehen.

\section{SAUTERIA Nees}

\section{Nat. eur. Leb. IV, p. 139.}

Plantæ thallosæ, minores, virides. Frons crassa, dichotome ramosa vel e latere costæ innovata, ramis ligulatis, fertilibus late obcordatis; antice subplaana; costa valde producta; stratum anticum anguste cavernosum, cavernis unistratis. Stomata parva, simplicia, poro parvo a cellulis radiatim conniventibus formato, parietibus radialibus trigone incrassatis stellatimque attenuatis. Squamæ posticæ bi-vel quadriseriatæ, minores, teneræ, vix imbricatæ.

Inflorescentia monoica. Andræcia in medio frondis nuda (haud paleis cincta) minus definita, antheridiis haud pulvinatim aggregatis, irregulariter approximatis, ostiolis angustis hyalinis. Carpocephala terminalia 
in fronde sub flore haud innovante, e fundo nudo alveoli apicalis orta. Pedunculus basi nudus, apice interdum paleaceus, leniter rimosus, sulco profundo percursus. Receptaculi discus centralis parvus, parum prominens, stomatis nullis ; lobi 3-气̆ profunde discreti, sæpe inæquales, decurvi, contigui, obovati ; Involucra tubulosa, apice recte truncata, late aperta, haud inciso-bilabiata-hiantia, ceterum monogyna. Calyptra tenerrima. Capsulæ pedicellus brevis vel nullus, parvo bulbo insertus; capsula globosa, vix exserta, irregulariter disrumpens, parietum incrassatio semiannulata bene evoluta. Elateres fusiformes, curvati, 2 vel 3 spiri obtusi. Sporæ plus minus papulosæ.

\section{S. alpina. Nees. 1. c. pag. 143.}

Monoica, parva, tenerrima, glauco-virens; Frons usque ad $12 \mathrm{~mm}$. longa, in medio sæpe viridis, marginibus hyalinis; duplo latior quam crassa, postice subangulatim convexa, in sectione itaque late-trigona; costa strato antico multo angustior, duploque humilior; alæ sensim attenuatæ tenerrimæ; epidermis antica cellulis haud incrassatis formata. Squamæ posticæ imbricatæ, quadriseriatæ, hyalinæ, e lata basi oblique trigonæ, magnis cellulis irregularibus formatæ, apice sensim acuminatæ, medio supero cellulis clavatis irregulariter grosseque dentata vel sublaciniata. Carpocephala longe pedunculata, pedunculo usque ad $20 \mathrm{~mm}$., hyalino, sulco profundo labiisque obtusis conniventibus integerrimis. Paleæ receptaculi magnæ, oblongæ, obtusæ, paucis cellulis clavatis ornatæ. Capsula distincte pedunculata, pariete rufo-fusco. Elateres usque ad $200 \mu$, flavescentes, bispiri, spiris laxe tortis. Sporæ $59 \mu$, fusco-brunneæ, dense papulosæ.

Hab. Alpes Europæ, Tatra (Limpricht) Norvegia (Sahlberg) Sibiria (Sahlberg) Kaschmir, Liddar Valley 13000' (Duthie.)

\section{S. Berteroana. Mont.}

Syn. Grimaldia debilis Bisch.

Monoica, parva, robusta tamen et tenax, crassa, antice viridis, postice purpurea. Frons anguste linearis, usque ad $10 \mathrm{~mm}$. longa, antice plana, subtus maxime incrassata; costa in planta juvenili semicylindrica, abrupte in alas attenuatas excurrens, strato antico æquialta, in planta adulta humilior et minus producta. Cavernæ valde angustæ, epidermide antica haud incrassata; stomata numerosissima. Squamæ posticæ parvæ, purpureæ, e basi oblique ovata abrupte appendiculatæ, appendiculo æquilongo, 2 cellulas lato, apice longe filiformi, papillis clavatis nubnullis. 
Pedunculus receptaculi longus, minus tamen quam in S. alpina, apice haud paleaceus, acute angulatus, canali profunde inciso labiisque acutis. Receptacula quadriloba iis Saut. hyalinæ simillima. Capsula pedicello carens, in ipso bulbo sessilis, pariete microcellulari maximeque annulatim incrassato. Elateres breves flavo-brunnei, bi-vel trispiri. Sporæ $60 \mu$, papulosæ, marginibus cristato-alatis.

Hab. Chile (Bertero).

3. S. crassipes. Aust. Ac. Phila. 1869.

Frons obcordata vel subcuneata, bifida, fuscescente-purpurea vel viridis, antice subpapuloso-reticulata, minutissime porosa; squamæ ventrales purpureæ, marginem frondis haud superantes nisi in apice frondis; pedunculus breviusculus, basi parum paleaceus, apice breviter barbatus. Receptacula 4-7 loba. Capsula pedicellata. Elateres trispiri.

Der Autor fügte in einer Anmerkung hinzu : « it resembles Preissia very much, also Duvalia. Involucre rather large aud flattish.

Hab. Japonia (Rodgers.)

Diese Pflanze liegt in keinem öffentlichen Herbar Americas oder Europas und scheint ganz verloren gegangen zu sein; nach der nichtssagenden Diagnose des Autors, die ich oben übersetzt habe, dürfte sie kaum wieder zu erkennen sein.

\section{CLEVEA Lindb.}

Not. Soc. F. Fl. fenn. IX, p. 291.

Plantæ thallosæ, minores, spongiosæ et teneræ, virides vel purpurascentes. Frons regulariter dichotoma vel ex apice innovata, interdum ramulum posticum e latere costæ ortum proferens, apice inciso biloba, antice plana vel marginibus adscendentibus leniter concava. Costa humilis. Stratum lamelliferum altum, cavernis angustis unistratis. Stomata parva, simplicia, poro minuto, a cellulis 5̃ vel 6 radiatim conniventibus atque in lumen pori convexo prominentibus formato; pori itaque quasi stellæformes, parietibus radialibus maxime incrassatis. Squamæ posticæ magnæ, longe appendiculatæ, radicellis incrassatis e basi tantum (haud ex ipsa pagina postica squamarum) ortis. Inflorescentia monoica vel dioica. Androecia oblonga, pulvinata, bene definita, haud disciformia, nuda. 
Antheridia aggregata, irregulariter biseriata. Pedunculus receptaculi plus minus longus, interdum brevissimus, e costæ pagina antica - strato hypoporo recedente - ortus, haud sulcatus, basi nudus, apice pro more paleaceus vel non. Discus centralis carpocephali minimus, laxe cavernosus, stomatis parvis haud incrassatis, lobi 3 vel 4, profunde discreti, monogyni, leniter decurvi ; involucra conico-cylindrica, antice leniter carinata, apice bilabiata, labiis tenerrimis, verticalibus in ætate late hiantibus. Calyptra tenuis. Capsula sphærica, matura haud exserta, irregulariter valvatim dehiscens, pariete unistrata, fibris annulatis vel semiannulatis instructa, vertice cellulis majoribus suboperculata et utriculos breves annuliferos in lumen capsulæ pendulos gerens. Elateres breves, vix attenuati 3-4 spiri. Sporæ dense grosseque papulosæ.

1. C. hyalina (Somm.) Lindb. 1. c. p. 291.

Syn. Marchantia hyalina Somm. Magaz. Nat. 1833, I, p. 284. Plagiochasma erythrospermum Sull. Acad. Philad. 1869.

Fimbriaria nana Ldbg. Hep. Eur. p. 110.

Clevea suecica Lindb. Musci scand. p. 1.

Dioica, parva, glauco-virens vel purpurascens et limbo hyalino circumdata. Frons ligulata vel oblonga, regulariter dichotoma, rarius ex apice innovata, usque ad $12 \mathrm{~mm}$. longa, tenera, tenuis vel magis robusta et costa abrupte prominente. Stomata valde prominentia, parietibus radialibus normaliter valde incrassatis, incrassatione stellatim attenuata (unde Leitgebii nomen " Astroporæ n). Squamæ posticæ magnæ, frondis marginem longe superantes, hyalinæ, oblique lunatæ, in acumen longissimum arcuatum, integerrimum apiceque filiforme attenuatæ. Pedunculus receptaculi quoad longitudinem variabilis, usque ad $1 \mathrm{~cm}$. longus, compressus vel subteres, apice paleaceus, paleæ pallidæ, integerrimæ, lanceolatæ longeque cuspidatæ, margine basali paucis laciniis filiformibus pinnatæ. Receptacula pro more quadriloba, lobis antice ad ${ }^{1 / 3}$ fissis, labiis itaque profunde discretis, apice rotundatis, integerrimis. Sporæ̉ ferrugineæ, $51 \mu$. Elateres concolores, $98 \mu$, fibris laxe tortis. Antheridia irregulariter biseriata.

Hab. Alpes Europæ, Italia Appenini Montes (Gasparini), Fennia (Brotherus), Grøenlandia (Vahl), Germania, Harz (Wallroth, Vocke) Norvegia, Spitzbergen (Berggren), Caucasus (Brotherus), Lapponia (Lindberg), Rocky Mountains (Macoun), ubique in solo calcareo. 
2. G. Rousseliana (Mont) Leitg. Unters. üb. Leb. 1881, Heft. VI. Syn. Plagiochasma Rousselianum Mont. Ann. sc. nat. 1838,vol. X, p. 334.

Sauteria Rousseliana G. in G. et R. Hep. exsic. 542.

Dumortiera Spathysii Nees. Nat. Leb. IV, p. 158 teste Solms.

Monoica, parva, intense viridis, postice purpurea, valde carnosa et tenera. Frons usque ad $\breve{~} \mathrm{~mm}$. longa, late oblonga, apice profunde inciso biloba, ramis nascentibus sæpe latior et pluries lobata, marginibus crispatulis; costa crassa, postice valde convexa, abrupte in alas attenuatas abeunte; lamellæ minus anguste dispositæ; cellulæ epidermidis anticæ trigone incrassatæ; stomata alte conica, pori majores, cellulis haud radialiter incrassatis. Squamæ postice valde fugaceæ, purpureæ, e parva basi triangulata varieque lobato spinosa abrupte in acumen longissimum anguste ligulatum apiceque filiforme attenuatæ; cellulæ disci irregulariter hexagonæ, in acumine elongatæ angulatim prominulæ. Pedunculus receptaculi usque ad $6 \mathrm{~mm}$. longus, subteres, apice paleaceus; paleæ hyalinæ, longe attenuatæ, basi paucis laciniis lateralibus armatæ; receptacula disco centrali nullo, tri-quadriloba; involucra profunde soluta, magna, horizontaliter patula, ovato-rotundata, inflata, labiis profunde solutis rotundatis. Capsula haud exserta, brevissime pedunculata, parvo bulbo inserta, pariete annulatim incrassato, irregulariter disrumpens. Operculum haud distincte definitum, intus cellulis elateriformibus pendulis auctum. Elateres trispiri, flavescentes $180 \mu$. Sporæ $51 \mu$, rufo brunneæ, alte creberrimeque papulosæ. Andrœcia irregulariter pulvinata, basi pedunculi approximata. Antheridiis plus minus numerosis, interdum solitariis.

Hab. Algeria (Roussel. Paris. Trabut.) Corfu (Spathys) Sicilia teste Massalongo.

\section{C. andina Spruce.}

Monoica, viridis, marginibus purpureis. Frons usque ad $12 \mathrm{~mm}$. longa, ob ramulos nascentes late obcordata, tenera, subplana, apice profunde inciso-biloba; costa lata, humilis, abrupte in alas excurrens; alæ tenerrimæ lamellis perlucentibus striolatæ et plicatulæ; stratum anticum humile, laxe cavernosum; stomata itaque minus conferta, ceterum parum convexa, parietibus radialibus haud incrassatis. Cellulæ epidermidis trigonis parvis incrassatæ. Squamæ posticæ purpureæ, margines haud superantes, oblique ovatæ, longe acuminatæ, integerrimæ, interdum profunde bifidæ. Carpocephala seriata, pedunculo usque ad $10 \mathrm{~mm}$. longo, hyalino, tereti, apice barbato, paleis brevibus, linearibus, hyalinis. Receptacula parva, 
biloba, lobis oppositis, recte patentibus, ore bilabiato integerrimo. Capsula sphærica, in pedicello longiore, matura haud exserta, pariete annulis confertissimis incrassata. Elateres flavescentes $250 \mu$, anguste fusiformes, trispiri, fibris laxe tortis. Sporæ $42 \mu$, rufescentes, papulis confertis elongatis subechinatæ. Andrœcia parva, bene definita, ostiolis purpureis.

Hab. Andes quitenses (Spruce).

Wie wenig Werth auf die radiale Verdickung der Porenzellen zu geben ist, die bekanntlich Leitgeb zum Merkmal einer Familie (der Astroporæ) erhob, zeigt unsere Pflanze, die diese Verdickungen gar nicht besitzt; ausserdem haben eine Anzahl ächter Plagiochasma Arten genau die Poren der Cleveiden, wie Graf Solms diese Gruppe lieber nennen möchte.

\section{C. pulcherrima St. Engl. Bot. Jahrb. XX, p. 303.}

Dioica, major, tenax, robusta, dense 'crspitosa. Frons simplex, ex apice innovata, oblonga, apice profunde obcordata, usque ad $12 \mathrm{~mm}$. lata, medio viridis, alis late hyalinis. Costa valde producta, in alas abrupte attenuata. Stratum lamelliferum costæ æquialtum, cavernis angustissimis. Stomata itaque numerosissima, parva, minus convexa, parietibus radialibus maxime æqualiterque incrassatis, i. e. haud stellatim attenuatis; reliquæ cellulæ epidermidis validæ, trigonis nullis. Squamæ posticæ robustæ, dense imbricatæ, maximæ, frondis margines longe superantes, hyalinæ, oblongæ, obtusæ vel abrupte longeque acuminatæ, cellulis magnis (apice $68 \times 102 \mu$ basi $35 \times 170 \mu$ ) formatæ. Carpocephala seriata; pedunculus receptaculi crassus, subteres, hyalinus, brevissimus apice haud barbatus. Receptaculi lobi bini oppositi, basi tantum coaliti, ore bilabiato labiis crassis. Capsula (haud matura) magna, calyptra crassa, hyalina, pistillo brevissimo coronata. Antheridia numerosa in medio frondis aggregata, ostiolis maximis hyalinis.

Hab. Abyssinia (Schimper, Beccari).

\section{C. robusta St. n. sp.}

Dioica, robusta, viridis. Frons usque ad $20 \mathrm{~mm}$. longa, regulariter furcata vel bis dichotoma ramis $4 \mathrm{~mm}$. latis, crassis duplo latioribus quam altis, marginibus haud attenuatis, antice plana; costa strato antico duplo angustior, postice subplana, lateribus oblique adscendentibus stricteque in frondis margines obtusos abeuntibus. Stomata parva, parum convexa, normaliter stellatim incrassata. Stratum anticum cavernis angustis ædificatum. Squamæ posticæ oblique rotundatæ, integerrimæ, plus minus abrupte appendiculatæ, appendiculo 4-plo breviore, cuspidato acuto. An- 
droecia bene definita, linearia, furcatim in ramis continuata, ostiolis atropurpureis, paleis nullis. Reliqua desunt.

Hab. Chile. Valparaiso in humo (lez P. Dusén).

$\mathrm{Ob}$ die Pflanze nicht etwa zu Sauteria gehört kann natürlich ohne Untersuchung reifer Capseln nicht gesagt werden; der scharf begrenzte männliche Blüthenstand bringt sie jedenfalls eher zu Clevea.

\section{C. limbata (Austin) Solms. ms.}

Syn. Sauteria limbata Austin, Acad. Phila. 1869, p. 229.

Frons obovato-oblonga, subdichotoma, concava, reticulato-papulosa, læte viridis, latissime marginata, subtus atropurpurea valdeque incrassata; margine nigro-purpurea, membranacea subplicata, undulato-crenata et involuto-incurva. Squamæ arete imbricatæ, sanguineo-purpureæ, basi ampliatæ obliquæ apice bicornutæ, nodoso- dentatæ; Pedunculo subunciali pallido nudo. Receptacula 1-3 carpa, subtus dense breviterque paleacea.

Pedicel sulcate, Receptacle very obtuse, one fruited in our meagre specimen.

Hab. California, under wet rocks.

Zu vorstehender Diagnose, die ein Excerpt Austins ist, schreibt mir Graf Solms, dass das von ihm untersuchte Original-Exemplar aus 2 Arten besteht, es enthält :

1) Eine sterile, tief purpurfarbene Cleveide, die eher zu Clevea als zu Sauteria gehört; sie hat ein rinnenartig vertieftes Laub, von einem breiten, radial gefältelten Rande gesäumt, beiderseits tief purpurfarben, fast schwarz. Die Schuppen haben die gleiche Färbung, ihr breitgezogener basaler Teil, mit regellos buchtigem Rande läuft oben in $1-3$, meist zwei schmale Fortsätze aus, die an der Basis 2 Zellen breit sind und als einfacher Zellfaden endigen. Der Bau des Assimilationsgewebes, sowie die Spaltöffnungen schliesst sich in jeder Hinsicht an Clevea hyalina an.

2) Die andere Pflanze hat flachere, dünnere, vorn herzförmig verbreitete Sprosse, von rein grüner Farbe; die Luftkammern sind ganz wie bei Clevea hyalina, entbehren also ein fädiges Assimilationsgewebe. Die Spaltöffnungen sind aber ganz die der Operculatæ; sie haben eine weite, rundlich ovale Oeffnung, von einem hyalinen Membramvorsprung gesäumt und von einem Kranz ganz unverdickter Zellen umgeben. Die Ventralschuppen ähneln denen von Cl. hyalina, sind aber weniger plötzlich verschmälert. Der Stiel des Receptaculums ist ziemlich lang, wie 
bei Sauteria alpina durchsichtig, von kreisrundem Querschnitt, ohne Wurzelrinne und entspringt aus einer dorsalen Grube, ohne Schuppen. Das fünfstrahlige Carpocephalum hat gleichfalls Cleveïden-Charakter, nur eine grössere Hülle ist fertil; an der Basis des Köpfchens ist ein dichtes Büschel lanzettlicher, gespitzter Spreuschupppen, welche herabhängen; der Bulbus der Kapsel ist nicht erhalten, die Seta kurz, dick, glashell; die mehr lappig eingerissene Wand der Theca gleicht vollkommen der von Cl. hyalina, nur ist sie mehr gelbbraun. Die Sporen fehlen, ebenso die männliche Pflanze.

Das unvollständige Material gestattet nicht, diese ausgezeichnete Art und wahrscheinlich neue Gattung zu benennen, deshalb soll hier für die wieder aufzusuchende Pflanze der Befund der spärlichen Reste nur niedergelegt werden. Austin hat in seiner Beschreibung die fertilen Organe nach der zweiten Art, die vegetativen nach der ersten Art geschildert.

7. G. pedicellata (Griff) Lindb. Acta Soc. F. Fl. fenn.

Syn. Plagiochasma pedicellatum Griff. Nolulæ, II, p. 331.

Dioica, cæspitosa. Frons oblonga, prolifera, apice, dilatata, margine denticulata; squamis posticis dense imbricatis, marginem superantibus. Frons mascula, femineæ similis, medio papillis elevatis instructa. Carpocephala longe pedunculata, pedunculo striato, e frondis parte inferiori (i. e. haud ex apice sed in medio frondis) orto, paleaceo, apice barbato. Involucra viridi-carnosa, antice sulcata (i. e. bilabiata). Capsula exserta.

Hab. Assam (Griffith).

Obwohl die Pflanze, deren mangelhafte Originalbeschreibung ich in ihren massgebenden Teilen hier reproduziert habe, nicht genügend charakterisirt ist, wollte ich doch nicht unterlassen, sie aufzuführen, da sie wahrscheinlich zu den Cleveïden gehört und es doch möglich sein wird, sie unter den wenigen Arten dieser Gattung wiederzuerkennen.

\section{PELTOLEPIS Lindb.}

Soc. F. F. fenn. 1876.

Plantæ thallosæ, majores, robustæ, virides vel purpurascentes. Frons late linearis, dichotome ramosa, apice profunde inciso biloba, antice 
plana; stratum lamelliferum laxe cavernosum, cavernis unistratis costæ æquialtis. Costa latissima, plano-convexa, haud abrupte producta, in frondis margines sensim attenuata. Stomata parum convexa, parva, ut in Clevea cellulis in lumen pori convexo-prominentibus substellata, parietibus radialibus valde breviterque incrassatis, reliquis cellulis epidermidis vix incrassatis. Squamæ posticæ magnæ, hyalinæ vel basi purpureæ, e basi semilunata abrupte appendiculatæ, appendiculo (rarius 2 vel 3 ) lanceolato, acuminato, apice margineque cellulis clavatis armato. Inflorescentia paroica vel monoica vel heteroica, Carpocephala terminalia, pedunculo e rima apicalis orto, ob frondem uno latere increscentem quasi e sinu laterali adscendente, usque ad $45 \mathrm{~mm}$. longo, valido bisulcato, carinis humilibus longe decurrentibus obtecto, basi nudo, apice breviter paleaceo, paleis roseis occultis, ex angusta basi lanceolatis, cellulis clavatis numerosis subpinnatæ. Receptacula rufescentia, interdum purpurea vel subnigra, disco centrali bene definito, convexo-prominulo, lobis normaliter 6, profunde discretis, contiguis, decurvis, antice obtuse carinatis, crassis; involucra apice breviter bilabiata, labiis postice hiantibus i. e. fissura haud in dorsum involucri adscendente (ut in Clevea). Stomata receptaculi antica nulla. Involucra monogyna; Calyptra tenuis. Capsula sphærica, irregulariter valvatim rumpens, matura vix exserta, pariete unistrata, fibris annulatis instructa. Elateres sulphurei, trispiri $20 \Xi \mu$. Sporæ fusco brunneæ, dense papulosæ $50 \mu$. Andrœcia bene definita, disciformia, rotunda vel oblonga vel semilunata, purpurea, paleis brevibus cincta, ostiolis breviter conicis.

1. $\mathbf{P}$ grandis. Lindb. 1. c. 1882. II, p. 4.

Syn. Preissia quadrata (Scop.) Nees Nat. d. Leb. IV, p. 135 pro parte. Peltolepis sibirica Lindb. 1. c.

Hab. Alpes Europæ. Tatra (Limpricht), Norvegia, Fennia (Brotherus), Sibiria (Arnell. Sahlberg), Groenland (Vanhöffen).

\title{
PLAGIOCHASMA L. et L.
}

\author{
in Lehm. Pug. Pl. IV, p. 13.
}

Plantæ thallosæ, fragiles, majusculæ vel magnæ, gregariæ vel cæspitosæ, ob ramificationem multifariam sæpe maxime intricatæ, terricolæ 
vel rupiculæ, arete repentes, radiculis longissimis, antice sæpe subplanæ, virides, subtus pro more purpureæ. Frons normaliter furcata, sæpe tamen ex apice - haud raro iteratim - innovata vel e latere costæ ramosa, medio crassa, alis sæpe valde attenuatis, lamellis perlucentibus striolatis et plicatulo-crispatis, margine crenulatis ; costa humilis, postice planoconvexa, nusquam abrupte producta. Stratum anticum humile, costæ æquialtum, cavernis pluristratis angustis. Stomata sæpe minima, 4-气̆ cellulis parvis conicis formata, poro exiguo vel magna, poro multo ampliore, a 6-9 cellulis conicis et pluriseriatis circumdato; parietes radiales stomatum interdum maxime incrassatæ, stellæformes; epidermis antica fere semper trigone incrassata.

Squamæ posticæ sæpe imbricatæ, semilunatæ, rare marginem frondis superantes, appendiculis (forsan in omnibus speciebus) nunc solitariis nunc geminatis.

Inflorescentia monoica et dioica. Andrœcia sessilia, disciformia, paleis minutis circumdata rotundata vel bifurcata, ostiolis brevibus rubris.

Carpocephala parva, bi-tri-quadriloba; discus centralis minimus lobis brevissimis convexo-decurvis vel plus minus alte adscendentibus, vertice mamillatim productis vel in cornua attenuatis, subtus involucratis. Involucra monogyna, e margine loborum orta, magna, inflata, conchæformia, basi longe coalita, pedunduli apicem obvelantia, extus bilabiata, labiis primo clausis subinde rima verticali dehiscentibus, valvulis late hiantibus. Pedunculus medio frondis impositus, haud sulcatus, sæpe brevissimus, basi paleis parvis lanceolatis purpureis circumdatus, apice semper barbatus, paleis longis, lanceolatis, sæpe coloratis. Calyptra tenera. Capsula sphærica, magno bulbo inserta, operculo indistincto irregulariter dehiscens, pariete tenera, valida, unistrata, apice (operculo) bistrata, cellulis æqualiter (haud annulatim) incrassatis. Sporæ magnæ flavescentes, tetrædræ, in facie convexa laxe alteque reticulatim lamellatæ, lamellis asperis. Elateres subbreves, bi-vel trispiri, flavescentes, interdum furcati.

Es gibt kaum eine zweite Gattung unter den Lebermoosen, welche ein so gleichmässiges Gepräge besitzt, wie Plagiochasma; in der Grösse differieren die meisten nur wenig von einander, in der Farbe fast gar nicht, wenigstens nicht an Herbar-Material, die Chlorophyll führende Schicht hat bei allen ungefähr dieselbe Höhe und die Luftkammern sind bei einigen kaum etwas weiter; die Stärke der costa variirt schon innerhalb einer Art bedeutend, je nach dem Standort und ist kein brauchbares diagnostisches Merkmal; die Sporen und Elateren sind von ausserordentlicher Uebereinstimmung und da ihre Grösse innerhalb einer 
Kapsel bereits ziemlich variabel ist, so versagt hier auch dieses sonst so werthvolle Unterscheidungsmittel; hierzu kommt, dass die Fruchlköpfe häufig nicht normal ausgebildet sind, dass sie oft nur ein Involucrum tragen; sie sind dann sehr abweichend ausgebildet; der Scheitel ist ganz auf die Seite gedrängt und die charakteristische Ausbildung der Scheitellappen entweder zu einer glattgewölbten Fläche oder ihre hörnerartige Zuspitzung ist unterblieben. Auffallend ist bei dieser Gattung die geringe Fruchtbarkeit der zahlreichen weiblichen Blüten, auch bei monøecischen Arten.

Der männliche Blütenstand tritt ausserordentlich variabel auf, sobald er nicht rein dioecisch ist; ich habe 1 Exemplar einer monœcischen Art gesehen, das aus 5 In in einer Reihe innovirten Gliedern besteht; die zwei untersten waren männlich, dann folgte ein weiblicher Spross, dann abwechselnd $\sigma^{7}$ und o; alle diese Glieder hatlen aber wieder ventrale verzweigte Seitenprosse und zwar bald weibliche Glieder mit männlichen Zweigen, bald umgekehrt; es waren auch rein parœcische Sprosse darunter und ein ventraler gegabelter Spross, dessen eine Lacinie o , die andere o war. Diese Mannigfaltigkeit ist in ähnlicher Weise bei vielen monœeischen Arten vorhanden, bei manchen wegen des spärlichen Materials aber nicht zu konstatieren; stirbt von dergleichen gemischten Sprosssytemen ein Teil ab, so kann sehr leicht der Eindruck eines rein diøecischen Blütenstandes gewonnen werden; auch diese Verhältnisse erhöhen die Schwierigkeiten, eine Art sicher wieder zu erkennen; es bleiben als sicherste Merkmale der Bau des Carpocephalums, der Spaltöffnungen und die Form der Ventralschuppen, so dass, entgegen manchen anderen Gattungen, nur fertile Exemplare sicher bestimmt werden können.

\section{a. Carpocephala plus minus convexa.}

\section{a. Macropora.}

\section{P. japonicum St. Bull. Herb. Boiss. 1897, p. 84 .}

Monoica vel dioica, minor, fusco-viridis, ventre purpurascens. Frons ligulata, dichotome ramosa, pro more ex apice vel e latere costæ innovata, tenuis, antice plana, alis adscendentibus purpureis crispatulis. Stomata magna, valde convexa, poro magno, parietibus radialibus valde incrassatis, 6-8 cellulis $3-4$ seriatis circumdato; reliquæ cellulæ epidermales angulis 
trigone incrassatæ. Costa angusta, parum producta. Squamæ posticæ sub fronde occultæ, confertæ et imbricatæ, purpureæ, appendiculo parvo, interdum geminato, ovato oblongo vel elliptico integerrimo. Pedunculus crassus, attenuatus, apice dense breviterque barbatus, paleis linearibus vel lanceolatis. Capitula vertice plano-convexa, 2-3 loba, lobis antice convexis subsphæricis. Sporæ $50 \mu$, late alato-reticulatæ. Elateres $187 \mu$, parum flexusi, solidi i. e. Iumen ob parietum incrassationem fere nullum, ad rimam angustam reductum, fibra spirali nulla. Androcia parva, paleis brevibus cincta vel in planta propria vel in ramulo postico frondis o vel in planta $\sigma^{\top}$ apice femineo-innovata.

Hab. Japonia, Tosa (Inouë).

2. P. fissisquamum St. Soc. sc. nat. Cherbourg, vol. XXIX, p. 209.

Syn. Aitonia fissisquama St. 1. c.

Monoica, pallide virens subtus purpurea. Frons usque ad $2 \mathrm{~cm}$. longa, subplana, crassa i. e. costa magis evoluta sensim in alas attenuata, ex apice repetito innovata, innovationibus breviter lateque obcordatis, dense consecutivis, Stomata magna, cellulis 7-8 circumdata. Cellulæ epidermidis validæ, angulis (etiam in ipso ore stomatum) trigone incrassatis. Squamæ ventrales parvæ, purpureæ, imbricatæ, oblique semilunatæ, longe appendiculatæ, appendiculis geminatis, anguste lanceolatis, margine paucispinosis. Pedunculus brevissimus, apice dense barbatus, paleis purpureis linearibus acuminatis. Receptacula itaque subsessilia, 3-4 lobata, vertice plano-convexo sensimque in lobulos convexos abeunte, lobis profunde solutis, ex angusta basi inflato bivalvatis. Sporæ et Elateres desunt. Andrœcia rotunda vel furcata, flori femineo approximata, ostiolis brevibus purpureis.

Hab. China, Yuennan (Delavay).

Squamis grosse paucispinosis primo visu distinguenda.

\section{ß. Micropora.}

\section{P. dschallanum St. n. sp.}

Monoica, minor, glauco-virens, margine et postice purpurea. Frons usque ad $2 \mathrm{~cm}$. longa, $3 \mathrm{~mm}$. lata, anguste lignlata, antice plana, alis adscendentibus, attenuatis plicatulo-crispatis; costa angusta, parum producta. Stomata parva, poro minimo, 4 cellulis parvis obconicis circumdato; cellulæ epidermidis trigone incrassatæ. Squamæ purpureæ late 
lunatæ, sensim in appendiculum angustata, appendiculis hyalinis solitariis, e lata basi acuminatis breviusculis, acutis, haud constrictis.

Carpocephala breviter pedunculata, pedunculo-fusco-brunneo, attenuato, apice breviter barbato; capitula vertice breviter umbonata, rugulosa. Sporæ $76 \mu$. Elateres breves $200 \mu$, bispiri, spiris anguste tortis. Andrœcia furcata, in ramulis posticis obcordatis.

Hab. Africa orient. Kilimandscharo, ad lacum Dschalla (Holst).

\section{P. tenue St. n. sp.}

Dioica, major, viridis vel pallide virens. Frons usque ad $2 \mathrm{~cm}$. longa, 3-4 mm. lata, ex apice innovata, antice subplana, postice purpurea, costa angusta, vix producta, alis tenerrimis, crispatulis. Stomata minima, poro parvo, 4 solum cellulis conicis circumdato, sæpe ad rimam angustam reducta. Cellulæ epidermidis trigonis magnis incrassatæ. Squamæ posticæ magnæ, marginem frondis superantes, e lata basi subtrigonæ, apice ad $2 / 3$ bifidæ, lobis geminatim approximatis, arcte parallelis anguste triangulatis sensim acuminatis, acutis, nullibi constrictis. Pedunculus brevis (7 mm. longus), apice longe barbatus. Receptacula valde convexa, biloba, lobi antice convexi; sporæ reticulatim anguste alatæ $60 \mu$, flavescentes. Elateres concolores, $220 \mu$ trispiri, spiris laxe tortis. Androcia ignota.

Hab. Africa australis. Transvaal (Mac Lea, Wilms.), Usambara (Holst), Angola (Welwitsch).

Squamis triangulatis profunde bifidis facile distinguenda.

ร. P. limbatum (Taylor) Nees. Syn. Hep. p. 516.

Syn. Fegatella limbata Taylor, J. of Bot. 1845, p. 950 .

Dioica, minor, viridis, subtus purpurea. Frons usque ad $18 \mathrm{~mm}$. longa, §̋ mm. lata, dichotome ramosa, crassa, costa lata, convexa. Stomata parva, poro minuto, cellulis ら obconicis circumdato, parietibus radialibus maxime æqualiterque incrassatis. Cellulæ epidermidis trigonis magnis incrassatæ. Squamæ posticæ parvæ, oblique lunatæ, longe (sæpe geminatim) appendiculatæ, appendiculis haud constrictis, e lata basi longe acuminatis, acutis, margine papulosis. Carpocephala plus minus longe pedunculata (ipse haud vidi) pedunculo longe barbato; capituli discus centralis rugosus, involucra plerumque 2. Sporæ? Elateres breves. Andræcia rotunda sæpe seriata.

Hab. Insula Ascension. (Hooker). 
6. P. crenulatum G. Hep. Mex. p. 266.

Monoica. Minor, viridis, subtus purpurea. Frons usque ad 10 $\mathrm{mm}$. longa, $8 \mathrm{~mm}$. lata, semper ex apice innovata, interdum ramulos masculos e latere costæ proferens. Stomata magna, 8-9 cellulis conicis 6 seriatis circumdata, parietibus radialibus maxime trabeculatim incrassatis; cellulæ epidermidis trigone incrassatæ. Squamæ posticæ late semilunatæ, appendiculis sæpe geminatis ovato-oblongis vel late linearibus, breviter acuminatis. Carpocephala subsessilia, vertice plano-convexa, longius barbata. Sporæ el Elateres? Andrœcia semper in ramulo proprio, e latere costæ orto vel basi apiceque consecutivo.

Hab. Mexico (F. Müller, Liebmann).

\section{P. algericum St. n. sp.}

Dioica, pusilla, fusco-viridis, subtus subatra. Frons sterilis obovato-oblonga, dichotome ramosa vel ex apice innovata, ramis fertilibus late obcordatis, carnosa, alis attenuatis nullis, postice valde convexa. Stomata parva, ore amplo, cellulis 6 obconicis circumdato; cellulæ epidermidis haud incrassatæ. Squamæ posticæ parvæ, late semilunatæ, appendiculo acquilongo haud constricto, lanceolato acuto. Carpocephala subsessilia, pedunculo brevissimo, apice longe barbato, trilobata, vertice plano-convexa; involucra a dorso visa ovato-trigona, longitudinaliter carinata, ad medium connata, horizontaliter patula, duplo longiora quam alta, ore angustato bilabiata, subtruncata. Sporæ 85 u. Elateres $300 \mu$. bispiri. Androecia ignota.

Hab. Algeria (Trabut).

\section{b. Carpocephala vertice plus minus excavata.}

\section{«. Macroporæ.}

\section{P. cordatum L. L. Pug. IV, p. 13.}

Monoica, major, viridis, subtus haud colorata. Frons usque ad $20 \mathrm{~mm}$. longa, $10 \mathrm{~mm}$. lata, antice plana, postice parum convexa, costa lata, alis adscendentibus attenuatis, plicatulo-erispatis, crenulatis. Stomata magna, ore amplo, cellulis 6-7, obconicis, quadriseriatis circumdato. Squamæ posticæ roseæ, magnæ, imbricatæ oblique semilunatæ, geminatim appendiculatæ, appendiculis longis, approximatis, parallelis, linearibus, acutis, margine grosse eroso-dentatis. Carpocephala pedunculata, pedunculo 
Plagiochasma. Franz STEPHANI. SPEGIES hePATICARUM.

$7 \mathrm{~mm}$. longo, tenui, apice breviter barbato; capitula vertice concava, lævia, involucra 2. Sporæ $68 \mu$. Elateres $290 \mu$. bi-vel trispiri, spiris anguste tortis. Andrœcia in ramulis propriis ex apice vel e latere costæ ortis.

Hab. Nepal (Wallich), Himalaya (Hooker, Duthie).

9. P. microcephalum St. in Engler. Bot. Jahrb. 1895, p. 301.

Monoica, parva, tenuis, viridis, margine et postice purpurascens. Frons 2-3 cm. longa, furcata, subplana, marginibus attenuatis plicatulis; costa angusta parum prominente; stomata parva, poro amplo, cellulis 8 obconicis et parvis circumdato. Squamæ ventrales haud imbricatæ, roseæ vel purpureæ, late semilunatæ, appendiculo magno ovato, breviter acuminato. Carpocephala numerosa, pedunculo filiformi, nigro, usque ad $15 \mathrm{~mm}$. Iongo, apice longe barbato. Capitula minuta, vix $1 \mathrm{~mm}$. lata, vertice truncata vel leniter emarginata, lobi pro more 2 oppositi, apice haud mamillati. Andrœcia minuta, pedunculo approximata, ostiolis paucis, purpureis mamillatis. Sporæ $50 \mu$, Elateres $220 \mu$, bispiri.

Hab. Africa orient. Usambara.

10. P. eximium (Schffn.) St. Engl. Bot. Jahrb. 1893. XX. p. 300. Aitonia eximia Schiff. 1. c.

Dioica, longe lateque cæspitans, major, fusco-olivacea, margine posticeque purpurea. Frons $3-4 \mathrm{~cm}$. longa, 6-7 mm. lata, tenuis, ex apice repetito innovata, rare dichotome ramosa. Costa angusta, parum producta marginibus tenuibus adscendentibus, crispato plicatulis. Squamæ ventrales magnæ, purpureæ, oblique semilunatæ vel subovatæ, longe appendiculatæ, appendiculis ad 2 vel 3, ligulatis vel abrupte lanceolatis, acutis, quintuplo longioribus quam latis, sæpe crispatis, marginem superantibus. Stomata convexa, magna, cellulis obconicis $6-7$, et 4 vel 5 seriatis circumdata. Pedunculus $1 \mathrm{~cm}$. Iongus, alte piuricarinatus, apice parum breviterque barbatus. Capitula parva, vertice profunde lateque excisa, 2-4 lobata, lobis erecto-subcornutis. Sporæ $68 \mu$ late reticulatim alatæ, rufescentes. Elateres $250 \mu$, bispiri, spiris laxe tortis flavescentes. Androcia ignota.

Hab. Kamerun, Buea (Preuss) in caverna humida, $2500 \mathrm{~m}$.

\section{P. Beccarianum St. n. sp.}

Monoica, mediocris, pallide virens, subtus atropurpurea. Frons usque ad $2 \mathrm{~cm}$. longa, $4 \mathrm{~mm}$. lata, ex apice innovata, raro furcata, antice plana, postice plano-convexa, alis attenuatis. Stomata magna, poro amplo, cel- 
Iulis 8-9 obconicis, sexseriatis circumdato; cellulæ epidermidis trigonis magnis incrassatæ. Squamæ posticæ roseæ, tenerrimæ, oblique lunatæ, ad $1 / 2$ acute bifidæ laciniis lanceolatis, margine repando-angulatæ vel breviter lobulatæ, anguli cellulis clavatis, facile deciduis, hyalinis coronati. Carpocephala subsessilia, pedunculo brevissimo, apice dense breviterque barbato; paleæ lanceolatæ cellulis clavatis ornatæ; discus centralis capituli concavus, 3-4 lobatus, lobis divergentibus curvatim adscendentibus, in acumen breve erectum et obtusum abeuntibus. Sporæ et Elateres? (capsulæ haud maturæ.) Andræcia rotunda, flori fem. approximata.

Hab. Abyssinia, Keren, in monte Deban. (Beccari).

\section{P. appendiculatum L. et L. Pug. IV. p. 14.}

Monoica, maxima, pallide virens, subtus purpurea. Frons $4 \mathrm{~cm}$. longa, $12 \mathrm{~mm}$. lata, sæpe dichotome ramosa, tenuis, antice plana, alis attenuatis adscendentibus, crispato-plicatulis, crenatis. Stomata magna, poro amplo, cellulis 6 obconicis quinque seriatis circumdato. Cellulæ epidermidis maxime (trigone vel trabeculatim) incrassatæ. Squamæ posticæ magnæ, marginem frondis superantes, basi purpureæ, late semilunatæ, appendiculis (sæpe geminatis) hyalinis, magnis, basi maxime constrictis, cordatis vel late ovatis, obtusis, integerrimis. Carpocephala brevipedunculata vel sessilia, maxime barbata, paleis hyalinis, anguste lanceolatis, hic illic dentatis, disco centrali capituli emarginato, bi- vel trilobato, lobis curvatim erectis cornutis. Sporæ $51 \mu$. Elateres $250 \mu$, bispiri spiris laxe tortis. Andrcecia rotunda, flori femineo approximata.

Hab. Himalaya, Nepal (Wallich), Tisa (Duthie), Saharanpor (Gamble), Sine loco (Stolitzka), Manila (Wallis).

Appendiculis giganteis rotundis primo visu distinguenda.

\section{P. intermedium Ldbg et G. Syn. Hep., p. 513.}

Dioica, dense cæspitosa, antice pallide virens, postice purpurea. Frons usque ad $2 \mathrm{~cm}$. longa, $5 \mathrm{~mm}$. lata, ligulata, ex apice innovata, rare dichotoma. Costa angusta, humilis. Stomata magna, convexa, poro 8 cellulis obeonicis triseriatis circumdato; epidermidis cellulæ parietibus validis, haud trigone incrassatis. Squamæ posticæ magnæ, imbricatæ, purpureæ, geminatim appendiculatæ, appendiculis basi valde constrictis, ovato-oblongis, acuminatis acutis integerrimis. Pedunculus brevis, atro-purpureus, 10-12 mm. longus, apice barbatus, paleis linearibus, brevibus hyalinis. Capitula parva, quadriloba, vertice concava, lobis cornutis cornubus erecto-recurvis conniventibus. Sporæ $60 \mu$ late alato-reticulatæ. Elateres 
$220 \mu$, flavescentes, omnino solidi lumine nullo fibraque spirali nulla. Androcia rotunda vel bifurca, vel in planta propria vel in ejus ramis brevibus posticis.

Hab. Mexico (Liebman, Maury, Fr. Müller, Berendt).

14. P. Wrightii Sull. Muse. Am. t. VI.

Syn. Aitonia Wrightii Und. Hep. Am. in III. St. Lab. II, p. 43.

Dioica, mediocris glanco viridis, postice purpurea. Frons usque ad $2 \mathrm{~cm}$. longa, ex apice innovata, late ligulata, antice subplana; costa lata, humilis, alis attenuatis. Stomata magna, parum convexa, poro amplo, cellulis 6 obconicis, 2-3 seriatis circumdata. Squamæ posticæ purpureæ parvæ, late semilunatæ, appendiculo basi constricto, ovato, acuto, integerrimo. Carpocephala breviter pedunculata, pedunculo 3-4 mm. longo, crasso, apice breviter paleaceo, capitula vertice profunde biloba, lobis sinu amplo acuto divergentibus, apice mamillatis. Sporæ $72 \mu$. Elateres $136 \mu$. Andrœecia ignota.

Hab. Texas (Wright).

\section{ß. Micropora.}

15. P. rupestre (Forster) St.

Syn. Aitonia rupestris Forster, Comm. Soc. Gott. IX, p. 73.

Plagiochasma Aitonia Nees, Naturg. Eur. Leb. IV, p. 41.

Dioica, mediocris, viridis, subtus purpurea, valida. Frons usque ad $2 \mathrm{~cm}$. longa, $6 \mathrm{~mm}$. lata, rarissime dichotoma, pro more ramulis posticis e latere costæ ortis innovata, antice plana, postice plano convexa, costa lata haud prominente. Stomata parva, poro minimo, cellulis 50, parvis obconicis circumdato. Cell. epidermidis valde incrassatæ, trigonis magnis sæpe trabeculatim confluentibus. Squamæ posticæ imbricatæ, purpureæ, late semilunatæ, abrupte appendiculatæ, appendiculo anguste lanceolato, acuto, integerrimo. Carpocephala subsessilia, longe barbata, paleis anguste lanceolatis apice longe flliformibus, normaliter quadriloba, vertice lobis adscendentibus anguste foveolata. Sporæ $72 \mu$. Elateres $200 \mu$, trispiri, spiris anguste tortis. Andræcia in ramulis posticis rotunda vel oblonga, sæpe 2 vel 3 dense consecutiva.

Hab. Europa mediterranea, præcipue Græcia (Heldreich), Madeira (Holl et Exped. Novara), Tenerifa (Krause), Abyssinia (Beccari, Penzig.), Cap (Breutel). 
16. P. nepalense (Ldbg et Bisch.) St.

Syn. Anthrocephalus nepalensis L. et B. Nova Acta XVIII, p. 682.

Plag. Colsmannianum L. et G. Syn. Hep. p. כั18.

Dioica, mediocris, viridis, postice purpurascens. Frons usque ad $2 \mathrm{~cm}$. longa, $6 \mathrm{~mm}$. lata, e latere costæ innovata, plana, costa crassa, magis producta, alis attenuatis venoso-striatis, plicatulo-crispatis, adscendentibus. Stomata parva, poro minuto, cellulis $\breve{~ o b c o n i c i s ~ c i r c u m d a t o ; ~ c e l l u l æ ~}$ epidermidis trigone incrassatæ. Squamæ parvæ imbricatæ, purpureæ, apice sensim attenuatæ, in appendiculum hyalinum anguste trigonum subobtusum abeuntes, appendicula interdum geminata, basi nunquam constricta. Carpocephala (ipse haud vidi) pedunculata, pedunculo longiore barbato, paleis numerosis, rubris. Involucra solitaria vel 2 opposita, capituli discus emarginatus, bene evolutus, crassitudine ab involucris distinctus. Sporæ? Elateres? Andrœecia furcata.

Hab. Nepal (Wallich).

17. P. chlorocarpum. Mont in Orbigny. Voy. Am. mér. Bot. p. อ̆9.

Dioica, major, pallide viridis, postice purpurea. Frons usque ad $2 \frac{1}{2} \mathrm{~cm}$. longa, $8 \mathrm{~mm}$. lata, costa angusta, alis latis adscendentibus, attenuatis, plicatulo-crenulatis. Stomata parva, poro minimo, cellulis 4 , obconicis circumdato, parietibus radialibus valde incrassatis, stellatim attenuatis; cellulæ epidermidis trigone incrassatæ. Squamæ posticæ magnæ, oblique ovatæ, purpureæ, appendiculis duplo brevioribus, ligulatis, breviter acuminatis, acutis, interdum geminatis vel ternis. Carpocephala longe pedunculata, pedunculo usque ad $2 \mathrm{~cm}$. longo, tenui, apice longe barbato, verlice anguste breviterque emarginata, angulis mamillatim productis, haud cornutis. Sporæ $68 \mu$. Elateres $270 \mu$, trispiri sæpe ramosi. Capsula tenerrima. Androecia ignota.

Hab. Chile (Bertero. Gay).

\section{P. validum Bisch. Term. II, p. ฮั6.}

Dioica, major, robusta. Frons usque ad $3 \frac{1}{2} \mathrm{~cm}$. longa, $6 \mathrm{~mm}$. lata, simplex vel furcata vel ex apice prolifera, plana, alis latis adscendentibus, postice purpurascens, costa angusta, parum producta, longissime radicellosa. Stomata parva, poro minimo, cellulis 4 -5, obconicis circumdato, parietibus radialibus valde incrassatis, stellatim attenuatis. Squamæx imbricatæ, late semilunatæ, abrupte (interdum geminatim) appendiculatæ, appendiculis anguste ligulatis apice acutis. Carpocephala longius pedunculata, pedunculo basi maxime crasso et longitudinaliter rimoso, superne 
valde attenuato, ipso apice 6-plo angustiore longeque barbato. Capitula biloba, vertice leniter emarginata, mammoso verrucosa, involucris validis. Reliqua desunt ( ut in reliquis » Syn. Hep., p. 521).

Hab. Chile (Bertero), Bolivia, Sorata (Mandon).

19. P. australe (Taylor), Nees. Syn. Hep., p. 515.

Syn. Fegatella australis Taylor, J. of Bot. 1844, p. 572.

Monoica, minor, viridis postice atropurpurea. Frons usque ad $2 \mathrm{~cm}$. longa, $3 \mathrm{~mm}$. lata, furcata, antice plana, postice convexa, costa humilis angusta, alis parum attenuatis. Stomata parva, poro exiguo, cellulis ら obconicis circumdato. Cellulæ epidermidis haud incrassatæ. Squamæ posticæ parvæ, late semilunatæ, geminatim appendiculatæ, appendicula abrupte ligulata, breviter acuminata, acuta, squamæ æquilonga. Carpocephala pedunculata, pedunculo $8 \mathrm{~mm}$. longo, tenui, apice longe barbato. Capitula biloba, vertice anguste lunatim excisa, angulis mamillatim prominentibus. Sporæ $60 \mu$, Elateres $250 \mu$. Andrœcia rotunda, flori femineo approximata.

Hab. Nova Zelandia (Hooker), Australia (Ferd. v. Müller, teste Gottsche).

Die Beschreibung ist nach dem australischen Exemplare gefertigt, da das Hooker'sche Original (in Kèw) fertile Sprosse nicht enthält.

20. P. elongatum Ldbg et G. Syn. Hep., p. 5̈19.

Monoica, dense cæspitosa, viridis subtus purpurea. Frons anguste ligulata, usque ad $35 \mathrm{~mm}$. longa, $4 \mathrm{~mm}$. lata, dichotome ramosa vel ex apice innovata, medio antico plana, marginibus attenuatis, adscendentibus. Stomata minima, cellulis 2 vel 3 circumdata; cellulæ epidermidis trigone incrassatæ. Squamæ magnæ, imbricatæ, purpureæ, apice roseæ, semilunatæ, abrupte in appendiculum longum raro geminatum anguste lanceolatum attenuatæ. Carpocephala parva, brevi pedunculata vel sessilia, paleis rubris, lanceolatis vel filiformibus barbata vertice breviter emarginata, biloba. Sporæ $86 \mu$. Elateres bispiri vel trispiri $300 \mu$. Androcia rotunda, pedunculo approximato.

Hab. Mexico (Liebman, Deppe et Schiede, Stahl).

\section{P. cœrulescens Nadeaud.}

Dioica, mediocris, tenuis, glauco-virens, fere cœrulescens, postice haud colorata. Frons simplex vel ex apice innovata, anguste linearis, usque ad $3 \mathrm{~cm}$. longa, $4 \mathrm{~mm}$. lata costa angusta, alis tenerrimis. Stomata parva, poro minimo 4-ă cellulis obconicis circumdato; cell. epidermidis trigone 
incrassatæ. Squamæ magnæ, oblique triangulares, longe cuspidatæ vel profunde bifidæ, laciniis anguste ligulatis, apice semper obtusis vel rotundatis, mucronatis basi purpureis, apice hyalinis. Carpocephala breviter pedunculata breviterque 3-4 cornuta subtus longe barbata, paleis angustè lanceolatis hyalinis. Sporæ $76 \mu$, Elateres $280 \mu$, trispiri. Andræcia subrotunda breviter paleacea.

Tahiti (Nadaud, Vesco, Vieillard et Panchet, Lépine, Jardin), N. Caledonia (Deplanche).

\section{P. brasiliense St. n. sp.}

Dioica, magna, sæpe longe bifurcata, furcis subparallelis, antice glaucoviridis, postice purpurascens. Frons usque ad $\breve{5} \mathrm{~cm}$. longa, $7 \mathrm{~mm}$. lata, valida; costa lata, alæ attenuatæ angustæ, margine distincte crenulatæ. Stomata parva, poro minimo. cellulis 4 vel 5 parvis obconicis circumdato; cellulæ epidermidis trigonis parvis incrassatæ. Squamæ maximæ, purpureæ, late semilunatæ, appendiculis geminatis vel solitariis, squamæ æquilongis, basi constrictis, lanceolatis, acutis, hic illic grosse spinosis. Carpocephala breviter pedunculata, subsessilia, trilobata, vertice alveolata; involucra magna, vertice breviter cornuta; barba maxima, paleis longissimis confertissimisque, anguste lanceolatis longe acuminatis. Sporeæ $51 \mu$. Elateres $300 \mu$, bi vel trispiri. Andrœcia ignota.

Hab. Brasilia, Apiahy (Puiggari).

\section{P. peruvianum N. et M. Nat. Eur. Leb. IV, p. 40.}

Monoica, minor, pallide virens, subtus atrosanguinea. Frons $2 \mathrm{~cm}$. longa, $6 \mathrm{~mm}$. lata, ex apice innovata; costa lata, valida, alis angustis. Stomata parva, poro minuto, cellulis $4-5$ obconicis circumdato, parietibus radialibus valde æqualiterque incrassatis; reliquæ cellulæ epidermidis trigonis magnis incrassatæ. Squamæ posticæ oblique ovatæ, appendiculo integerrimo, æquilongo, lanceolato, acuto (haud attenuato) interdum geminato. Carpocephala longius pedunculata, pedunculo tenui, apice breviter sparsimque barbato. Involucra solitaria (perfecta non adsunt) apice breviter cornuta. Sporæ $72 \mu$. Elateres ignotæ. Andrcecia bifurca, pedunculo approximata.

Hab. Peru (d’Orbigny).

24. P. Fischeri St. Engler. Bot. Jahrb. 1895, p. 301.

Syn. Aitonia Fischeriana., l. c.

Dioica, majuscula, glauco-virens. Frons $3-4 \mathrm{~cm}$. longa, $ّ \mathrm{~mm}$. lata, 
apice furcata vel ex apice innovata, antice plana, marginibus attenuatis crenulatis plicatulis, ventre purpurea, costa parum prominente. Squamæ ventrales magnæ, purpureæ, imbricatæ, appendiculo subcirculari, hyalino, integerrimo. Stomata parva, poro 6 cellulis circumdato, reliquæ cellulæ epidermales valde æqualiterque incrassatæ, trigonis magnis. Pedunculus capituli brevissimus, apice longe barbatus, paleis ligulatis, hyalinis, acutis. Capitula vertice profunde excavata, trilobata, lobis vertice cornutis, cornua brevia obtusa erecta. Sporæ et Elateres desunt. Andrœcia ignota.

Hab. Africa orient. Ligaijo (F. Fischer.)

20.. P. italicum (Sassi.) De Not. Ac. Tor. 18599, p. 476.

Syn. Anthrocephalus italicus Sassi. Att. se. it. 1840, p. 160.

Aitonia italica Lindb. F. FI. fenn. IX, p. 291.

Monoica, minor, gregarie crescens viridis, subtus purpurea. Frons usque ad $1 \mathrm{~cm}$. longa, $5 \mathrm{~mm}$. lata, ex apice innovata vel et latere costæ ramosa, crassa, antice plana, postice plano-convexa, costa parum producta. Stomata parva, poro exiguo, cellulis 4 obconicis circumdato; cellulæ epidermidis trigone incrassatæ. Squamæ posticæ sanguineæ, magnæ, oblique ovatæ apice sensim acuminatæ, acutæ i. e. appendiculo basi haud constricto, e lata basi anguste trigono, ceterum hyalino, interdum geminato vel terno. Carpocephala subsessilia, pedunculo brevissimo apice longe paleaceo, vertice anguste lunatim exciso-subcornuta. Sporæ $76 \mu$, Elateres $200 \mu$, bi-trispiri, spiris arctissime tortis. Andræcia rotunda vel oblonga vel furcata, in ramulis femineis flori approximata vel in ramulis posticis omnino masculis, e fronde feminea ortis.

Hab. Italia Voltri (Baglietto) Mentone (Moggridge).

26. P. mexicanum Ldbg. et G. Syn. Hep., p. כ̈19.

Monoica, major, tenera, viridis, postice purpuracens. Frons usque ad $3 \mathrm{~cm}$. longa, $7 \mathrm{~mm}$. lata, ex apice innovata. Stomata parva, 506 cellulis obconicis circumdata, parietibus radialibus valde incrassatis, incrassatione stellatim attenuata; cellulæ epidermidis trigone incrassatæ. Squamæ posticæ late semilunatæ, abrupte appendiculatæ, appendiculo simplici, anguste lanceolato, longe attenuato, duplo fere longiore quam squama. Carpocephala subsessilia, pedunculo apice longissime barbato, bi-vel trilobata, vertice profunde exciso-cornuta, cornubus obtusis recurvoconiventibus. Elateres trispiri, maximi, $450 \mu$. Sporæ 800 .. Andrœcia in ramulis parvis posticis, lateralibus.

Hab. Mexico (Liebmann). 
27. P. lanigerum (Spruce) St.

Syn. Aitonia lanigera Spruce. Bot. Soc. Edimb. XV, p. 568.

Monoica vel dioica, minor, in latas plagas expansa, tenuis, pallide viridis, margine et postice purpurascens. Frons usque ad $15 \mathrm{~mm}$. longa, $7 \mathrm{~mm}$. lata subplana, alis attenuatis plicatulo-crispatis, crenulatis, costa angusta. Stomata parva, poro minimo, cellulis 5 obconicis circumdato; cellulæ epidermidis trigone incrassatæ; squamæ posticæ roseæ oblique ovatæ, longe appendiculatæ, appendicula basi haud constricta, squamæ æquilonga, lanceolata, acuta. Carpocephala pedunculata, pedunculo tenui, $8 \mathrm{~mm}$. longo, apice barbato, paleis filiformibus. Capitula biloba, vertice ad 1/3 exciso-bicornuta, cornubus recurvo-conniventibus. Sporæ $68 \mu$, Elateres $205 \mu$ bi-quadrispiri. Andrœcia bifurcata, flori femineo approximata vel in fronde propria.

Hab. Andes quitenses (Spruce).

\section{c. Incertæ sedis.}

\section{«. Macropora.}

\section{P. Schimperi St. n. sp.}

Dioica, magna, pallide-virens, tenuis. Frons usque ad $2 \mathrm{~cm}$. longa, late obcordata, $15 \mathrm{~mm}$. lata, ex apice innovata vel dichotome ramosa, ramis late obconicis, plana, costa lata, marginibus minus attenuatis. Stomata magna parum convexa, poro cellulis 5-6 obconicis, 3-4 seriatis circumdato. Squamæ magnæ, sanguineæ, late semilunatæ, longe appendiculatæ, appendiculis anguste ligulatis, basi constrictis, apice breviter acuminatis, acutis. Androcia in disco magno, paleis brevibus lanceolatis purpureis cincta. Reliqua desunt.

Hab. Abyssinia, in monte Semen (Schimper).

Facile distinguenda fronde latissima.

\section{$\beta$. Micropora.}

29. P. extensum St. nsp.

Dioica, glauco-virens, subtus purpurea, valida, carnosa, in latas plagas expansa. Frons $3-4 \mathrm{~cm}$. longa, 5 $\mathrm{mm}$. lata, simplex vel furcata, late linearis, costa crassa bene producta, alis attenuatis, antice plana. Stomata parva, poro minimo, cellulis 4-5̆ obconicis circumdato; cellulæ epider- 
midis trigone incrassatæ. Squamæ posticæ maximæ, atro-purpureæ, latissime semilunatæ, ad 3/4 trifidæ, laciniis magnis, attenuatis, Flores feminei paleis numerosis parvis lanceolatis purpureis circumdati; pistilla magna e disco sessili longe producta.

Hab. Australia occident. (Elder Exploring Exp. Camp. 10 (Helms).

Crassitudine frondis et squamis giganteis longeque trifidis bene distincta.

\section{P. subplanum (Spruce) St.}

Syn. Aitonia subplana Spruce, Bot. Soc. Edimb. XV, p. こ̋7.

Dioica, major glauco-viridis, postice marginibusque purpurascens. Frons usque ad $3 \mathrm{~cm}$. longa, $10 \mathrm{~mm}$. lata, ex apice innovata vel e latere costæ ramosa, antice plana, costa angusta, parum producta, alis adscendentibus tenerrimis, venoso-strialis, plicatulo-crispatis. Stomata parva, poro minimo cellulis 4-כ̈ obconicis circumdato; cellulæ epidermidis haud incrassatis. Squamæ parvæ, roseæ, imbricatæ, late semilunatæ, abrupte appendiculatæ, appendiculis anguste ligulatis, 4 cellulas latis, apice breviter acuminatis. Carpocephala (ipse haud vidi) breviter pedunculata, pedunculo apice Ionge barbato, paleis pallidis, angustis longe subulatis. Involucra 1 vel 2; sporæ $50 \mu$. Elateres $300 \mu$ tetraspiri, obtusi. Andrcecia magna. raro rotunda, pro more inæqualiter lobatim-furcata.

Hab. Andes quitenses, Canelos (Spruce).

$\mathrm{Zu}$ dieser Gattung gehören ferner die folgenden Arten, welche in keinem europäischen Herbar existieren und wahrscheinlich ganz verloren gegangen sind; da ihre Beschreibungen sich lediglich auf generische Mierkmale beziehen, ist es nicht möglich, die Diagnosen wiederzugeben; nach den Abbildungen wird vielleicht Plagiochasma polycarum Griff. und Plagiochasma pingue (sub Athalamia Falconer wiederzuerkennen sein.

Es sind:

P. megacarpum Griff. Notulæ, p. 337.

P. paradoxum Griff. ibidem, p. 330.

P. polycarpum Griff, ibidem, p. 337 .

P. pingue (Falc.) Steph. Linn. Soc. XX., p. 397.

31. P. pterospermum Mass. Acad. Verona, Vol. 73, p. 46.

Frons frucata vel ex apice innovans, oblonga, margine crenulata, antice sordide viridis, postice atrosanguinea; squamæ ventrales subovatæ, bi-vel trifidæ, laciniis sæpe sparsim ciliato-dentatis. Carpocephala 1-3 carpa, BULL. HERB. BOISS, octobre 1898.86 
subtus barbata, pedunculo 2-3 $\mathrm{mm}$. longo, fusco, striato, basi paleaceo. Sporæ 60-80 $\mu$, hemisphærico-subpyramidales, reticulato-rugosæ et alatocristatæ, cristis sinuosis 9-12 $\mu$ latis, episporio punctato-scabro. Elateres elongati, bispiri, medio $12 \mu$ crassi. Disci masculi subcordato-lunulati.

Hab. China in Mte Lunsanhuo (Giraldi).

Aus der Abbildung ist an wichtigen Merkmalen noch zu ersehen, dass die Pflanze monoecisch ist, dass die Stomata gross sind und aus 8 Zellen bestehen, die in $\check{5}$ concentrischen Reihen den grossen Porus umranden. Die Zellwände der Epidermis und des Porus sind ohne alle Eckenverdickungen gezeichnet (?). Das wichtigste Art-Merkmal, die Bildung des Fruchtkopfes ist aus dem Bilde nicht zu erkennen, da er in Fig. 1 einen abgerundeten, in Fig. 2 einen kegelförmig emporragenden Scheitel trägt; wahrscheinlich ist die Pflanze identisch mit meinem P. fissisquamum aus der gleichen Gegend.

\title{
REBOULIA Raddi.
}

\author{
Opusc. sc. Bol. II, p. 357.
}

Plantæ frondosæ, majusculæ, terrestres, rupicolæ vel muscicolæ, in latas plagas expansæ, radiculis brevibus arcte repentes, virides vel plus minus flavescentes, postice purpureæ. Frons usque ad $4 \mathrm{~cm}$. longa, $15 \mathrm{~mm}$. lata, furcata, sub apice vel e latere costæ innovata, linearis vel oblonga vel obcordata, subplana, margine crenulata, apice florifero profunde biloba. Costa crassa, postice sæpe subcarinata, sensim in alas attenuata; stratum anticum costæ æquialtum, cavernosum, cavernæ amplæ, inæquales, pro parte poriferæ, lamellis accessoriis numerosis, apice sæpe liberis, erectis vel pendulis auctæ. Cellulæ epidermidis valde incrassatæ; stomata simplicia, magna, valde convexa, poro parvo 6 cellulis sexseriatis circumdato.

Squamæ posticæ purpureæ, oblique lunatæ, appendiculis parvis geminatis anguste linearibus, basi constrictis, apice acutis. Inflorescentia monoica vel dioica. Andrecia in pagina antica frondis, parva disciformia, paleis parvis circumdata; antheridia numerosa, ostiolis verruciformibus.

Carpocephala longe vel longissime pedunculata; pedunculus, e fundo nudo alveoli terminalis ortus, basi apiceque longe paleaceus, paleis apicalibus filiformibus, hyalinis, basalibus brevioribus anguste lanceolatis 
purpureis, unisulcatus, superficie varie profundeque carinatus. Capitula 4-6 lobata, lobis ad medium solutis obtusis, junioribus decurvis, in ætate patulis, subtus valvatim involucratis. Stomata composita, poro interno parvo, cellulis conico-oblongis, radialiter et convexo-conniventibus circumdato; involucra e margine loborum orta, sub lobis evoluta (haud interlobulares) monogyna, inflata, marginibus conniventibus, primo clausa, subinde rima dehiscentia, valvulis late apertis. Perianthia nulla. Capsula magna brevipedicellata, magno bulbo inserta, apice operculo bene definito dehiscens, dein irregulariter fissa, pariete unistrata viridi, cellulis apicalibus (operculi) brevioribus magisque robustis, annulo 2-3 cellulas lato. Sporæ flavescentes, magnæ, $35 \mu$ late alatæ, ala aspera, in facie convexa reticulatim lamellatæ, lamellis angulatim repandis. Elateres longiusculi, usque ad $260 \mu$, fusiformes, flavescentes, bi-vel trispiri.

\section{R. hemisphærica (L.) Raddi.}

Syn. Marchantia hemisphærica L. Sp. Pl., p. 1604.

R. javanica Nees. Syn. Hep., p. 549 .

R. longipes Sande in Miquel Fl. japon., p. 373.

R. microcephala (Taylor) Nees. Syn., p. 790.

R. Sullivanti Lehm. Pag. X, p. 28.

Diese sehr polymorphe, auf der ganzen Erde verbreitete Art variirt sehr in der Grösse des Laubes; in allen wesentlichen Theilen stimmen aber die Pflanzen aller Länder überein, so auch die sehr abweichende, als $R$. longipes beschriebens Pflanze, welche eine schlecht entwickelte, über Moosen wachsende Form ist, mit sehr langen, dünnen pedunculis und kleinen Fruchtköpfchen; sie zeichnet sich auch durch eine sehr reiche ventrale Astbildung aus.

Hab. Europa, haud rara, præcipue in terris mediterraneis, Asia minor, Himalaya (Gamble), Japonia (Miyoshi, Faurie, Tokubuschi, Makino, Inouë), Java (Junghuhn, Schiffner), Caucasus (Kärnbach, Radde, Levier), Amer. septentr. haud rara. Mexico (Stahl), Brasilia (Lindman), Africa Transvaal (Mac Lea), Abyssinia (Schweinfurth), Australia Queensland (Bailey), New Zealand (Kirk). 


\title{
GRIMALDIA Raddi.
}

\author{
Opusc. sc. Bol. II, p. 3 əั6.
}

Plantæ frondosæ, minores, gregarie crescentes, terrestres vel rupicolæ, radiculis brevibus arcte repentes, virides, subtus interdum purpureæ. Frons furcata, sæpe e latere costæ innovata vel ex apice innovata, linearis, antice canaliculata; costa crassa, fere semper acute carinata. Stratum anticum alte cavernosum, cavernæ pro parte solum poriferæ sub epidermide filis erectis liberis dense repletæ. Stomata simplicia, valde convexa. Cellulæ epidermidis magis altæ quam latæ. Squamæ posticæ magnæ vel maximæ, biseriatæ, pro more appendiculis geminatis magnis, lanceolatis instructæ. Inflorescentia monoica vel dioica. Andræcia in dorso frondis. Antheridia vel dispersa vel in soros aggregata nuda, ostiolis verruciformibus, purpureis. Carpocephala longe vel longissime pedunculata, pedunculo - strato hypoporo recedente, ex apice costæ orto, postice sulco singulo profundo instructo, basi paleaceo. Capitula parva, vertice convexa alteque papulosa, stomatis compositis ut in Reboulia, breviter quadriloba. Involucra (sub lobis evoluta, haud interlobulares) normaliter 4 , e margine loborum orta, oblique descendentia, monogyna, inflata, tempore maturitatis late hiantibus. Perianthia nulla. Capsula sphærica, brevipedicellata, bulbo magno inserta, operculo bene definito dehiscens, annulo distincto. Calyptra tenera. Elateres breves, fusiformes 3 spiri. Sporæ magnæ, laxe reticulatæ, areolis convexo-prominulis vel bullosis.

\section{Grimaldia dichotoma Raddi i. c.}

\section{Syn. G. angustifolia (Necker) Lindb.}

Monoica et dioica, fusco-viridis, dense gregaria. Frons usque ad $3 \mathrm{~cm}$. longa, anguste ligulata, interdum furcata (præcipue in fronde $\sigma^{7}$ ) pro more simplex, apice (rarissime postice) innovata, crassa, antice canaliculata, postice convexa; costa humilis, carina postica minus distincta; stratum anticum altum, filis chlorophylliferis longis, usque ad epidermidem protractis. Stomata anguste alteque papulosa, poro parvo sex cellulis conicis, 4-5̆ seriatis circumdato. Cellulæ epidermidis haud incrassatæ. Squamæ posticæ magnæ, purpureæ, appendiculis geminatis remotis e lata basi anguste lanceolatis; tertia squamarum series mediana interdum costæ insidens. 
Carpocephala plus minus longe pedunculata, pedunculus e fundo nudo ortus, basi paucis paleis armatus, apice pro more nudus, compressus, varie humiliterque costatus, canali parvo subcylindrico percursus; capitula parva vertice rotundata, stomatis humilibus, normaliter quadriloba. Involucra parum divergentia, ore integerrimo. Capsulæ celiulæ basales teneræ $17 \times 68 \mu$, annuli $25 \times 25 \mu$ operculi validæ $55 \times 68 \mu$. Sporæ $60 \mu$, brunneæ alte papulosæ. Elateres concolores, tenues $170 \mu$ longi. Androcia in fronde repetita, sæpe regulariter seriata vel in soros plus minus regulares aggregata.

Hab. Germania, Tirol. Gallia austr. (Montagne). Græcia (Heldreich), Portugal (Moller), Algeria (Trabut), Abyssinia (Schimper, Schweinfurth), Tenerifa (Aurel Krause), Madeira (Fritze), Insulæ Canarienses (De la Perrandière), Himalaya, Chitral (Harris) et Ralan Valley (Duthie), Caucasus (Brotherus).

\section{G. capensis St. n. sp.}

Monoica, minor, fusco-viridis, postice subatra. Frons usque ad $150 \mathrm{~mm}$. longa, $2 \mathrm{~mm}$. lata, linearis, parum ramosa, crassa, fragilisque, postice valde convexa, longe rhizifera, antice plana, marginibus attenuatis adscendentibus. Stratum anticum anguste cavernosum, stomata parum elevata, minima, 6 cellulis parvis biseriatis formata. Cellulæ epidermidis maxime incrassatæ, trigonis magnis, sæpe confluentibus. Squamæ posticæ magnæ, imbricatæ, oblique semilunatæ, apice breviter bifidæ, laciniis anguste lanceolatis, sinu lato acuto discretis, flexuosis, parvicellularibus, interdum cellula prominente paucidentatis. Androcia in fronde feminea repetita, antheridiis biseriatis, alternantibus, ostiolis parvis, nudis. Carpocephala breviter pedunculata, pedunculo e fundo apicali costæ orto, margine paleaceo, paleis purpureis lanceolatis apice filiformibus. Capitula parva, ceterum iis G. dichotomæ simillima, basi paucipaleacea, paleis linearibus purpureis, brevissimis. Capsulæ cellulæ basales teneræ, hyalinæ $17 \times 34 \mu$, annuli $17 \mu$ similes; operculum magnum brunneum, bene definitum, cellulis magnis $35 \times 35 \mu$ validis formatum. Elateres breves usque ad $140 \mu$, trispiri, fusiformes, flavescentes. Sporæ $50 \mu$ rufæ, in facie convexa reticulatimpapulosæ, papulis parum convexis, ala angusta lævi.

Hab. Transvaal, Blœmfontein (Rehmann).

Bene distincta stomatis minutis et sporis rufis parum papulosis. 
3. G. californica St. n. sp.

Dioica, pallide-virens, gregarie crescens. Frons usque ad $25 \mathrm{~mm}$. longa, $4 \mathrm{~mm}$. lata, interdum furcata, pro more ex apice innovata, ramulis femineis a latere costæ ortis, crassa, antice subplana, marginibus acutis erectis, costa valida (duplo tamen humilior quam stratum anticum) postice convexa mediaque carinatim angustata, in carina ipsa solum radicellifera.

Stratum anticum altum, lamellis confertis, fila chlorophyllifera longissima gerentibus. Stomata parva, minus convexa, 6-8 cellulis conicis, in lumen pori obtuse prominulis circumdata, circulo proximo cellularum late insidentibus; cellulæ epidermidis trigonis validis sæpe confluentibus incrassatæ. Squamæ ventrales magnæ, purpureæ, appendiculis geminatis (interdum solitariis) armatæ, e lata basi acuminatis, varie curvatis, irregulariter dentatis vel spinosis. Carpocephala semper in ramulo postico obcordato, e latere costæ orto, apicalia, e fundo nudo costæ longe pedunculata; pedunculus basi purpureus, superne decoloratus, usque ad $25 \mathrm{~mm}$. longus, [basi paleis parvis lanceolatis hirtus, ceterum omnino nudus, parum sulcatus, canali parvo angusto percursus, in sectione transversa ellipticus. Capitula parva, stomatis papulosa, alte umbonata, vertice rotundata, breviter 3-4 loba; involucra valde attenuata, parum divergentia, ore amplo integerrimo. Capsula fusco-rubra, cellulis basalibus validis; operculum haud vidi. Sporæ $60 \mu$, fusco-rufæ, papulis numerosis minus alte convexis. Elateres concolores, 3 spiri, spiris laxe tortis. Antheridia haud seriata sed in parvos soros aggregata.

Hab. California Yosemite Valley (Bolander). Primo visu distinguenda squamis grosse armatis.

4. G. pilosa (Horn.) Lindb. Musci. scand., 1879, p. 1.

Syn. : Duvalia pilosa Lindb. in Hartm. Fl. Scand. X, p. 4 əั4.

Marchantia pilosa Hornem. FI. Dan. VIII, p. 24.

Grimaldia carnica Mass. Ann. Inst. bot. Rom. II, p. כ̌4.

Monoica, minor, pallide viridis. Frons usque ad $2 \mathrm{~mm}$. longa, repetito irregulariterque ramosa, ramis masculis postico-lateralibus, antice canaliculata, postice convexa, costa angusta, abrupte producta, carinatim angustata, subacuta; stratum anticum altum, lamellis minus confertis, fila chlorophyllifera breviora epidermidem haud attingentia, e cellulis inflatopapulosis formata. Stomata magna, maxime bullosa, in æatate ubique rupta, poro parvo, a 6 cellulis conicis sexseriatis circumdato. Squamæ posticæ magnæ, purpureæ, margine repando-angulatæ et cellulis clavatis 
dense ornatæ, appendiculo solitario, hyalino, anguste lanceolato, basi cellulis prominulis dentato, superne longe filiformi. Carpocephala e fundo nudo apicali orta, pedunculo ubique, præsertim basi apiceque longe paleaceo, paleis subdentatis, subcylindrico, sulco amplo profundo percurso. Capitula magna vertice rotundata, papulosa, stomatis multo minoribus et minus elevatis, involucra brevia, parum divergentia, ore integer-

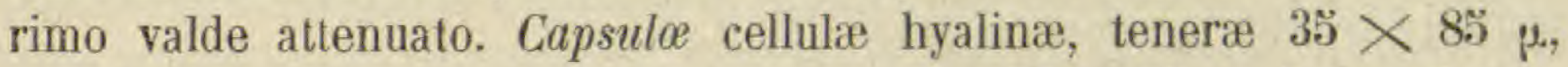
annuli $3 \ddot{\Xi} \times 3 \check{\Xi} \mu$, operculi brunneæ, validæ $3 \tilde{a} \times 8 \check{~} \mu$. Sporæ flavescentes $68 \mu$ alte papulosæ. Elateres concolores, trispiri, fibra crassa, laxe torta, $240 \mu$ longi, ubique fere æquilati.

Andræcia in ramulo parvo postico e latere costæ orto (semper?).

Hab. Norvegia, Suecia (Arnell) Lapponia, Fennia, Sibiria, Amur (Maximowicz), Jenisei (Arnell), Italia Belluno.

Bene distincta magnis capitulis longe barbatis, Andrœciis parvis ventralibus et squamarum appendiculo dentato.

\section{ร. G. fragrans (Balbis) Corda.}

Syn. Marchantia fragrans Balbis. Act. Taur. X et XII.

Grimaldia inodora Wallr. Linnæa XVI, p. 686.

Grimaldia sessilis Sull. Hep. Am. sept., t. VII.

Grimaldia barbifrons Bisch. Nova Acta XVIII, p. 1028.

Dioica, parva, gregarie crescens. Frons usque ad $20 \mathrm{~mm}$. Ionga, late oblonga, pro more simplex, interdum furcata vel postice innovata, crassa, antice profunde canaliculata, marginibus erectis; costa alta (dimidium altit. frondis), postice valde angustata, dein alte obconica, medio infimo obtuso radicellifero. Stratum anticum conferte lamellatum, fila chlorophyllifera longa, usque ad epidermidem fere protracta, e cellulis longis cylindricis formata. Stomata parva, minus papulosa, poro a 6 cellulis obconicis 3 seriatis circumdato. Cellulæ epidermales valde incrassatæ, trigonis sæpe confluentibus, minus distinctis. Squamæ posticæ, præsertim in frondis apice, maximæ, imbricatæ, frondem longe superantes, purpureæ, appendiculis geminatis longissimis, hyalinis, lanceolatis, integerrimis. Carpocephala breviter pedunculata, pedunculus subcylindricus, sulco profundo angusto percursus, basi apiceque dense paleaceus, paleæ hyalinæ, basales comatæ breviores, apicales e basi angusta longeque lineari lanceolatæ acutæ, varie tortæ. Capitula parva, centro parvo hemisphærico bene definito, valde papuloso, normaliter quadriloba, involucris divergentibus, ore tenui integerrimo. Capsula dilute-brunnea cell. basales $25 \times 70 \mu$, annuli $25 \times 25 \mu$, operculum humile, vix $1 / 4$ altit. capsulæ, cell. 
$50 \times 50 \mu$, valde incrassatæ. Elateres $200 \mu$ trispiri, laxe torti. Sporæ $50 \mu$ papulis minoribus minusque elevatis. Androcia in soros irregulares aggregata.

Hab. Germania Harz, Schlesien, Nordhausen, Halle, Baden. Mähren, Tirol, Italia, Gallia (Montagne), Helvetia Wallis (Bernet, Solms.), Norvegia (Kaalaas), Fennia (Lindb), Caucasus (Boissier, Brotherus), Sibiria, Jenisei (Arnell), America septentr. (Rau) (Eggert).

6. G. graminosa (Griff). Schffn. Engl. et P. Hep., p. 32.

Syn. Reboulia graminosa Griff. Notulæ II, p. 336.

Dioica. Frons ex angusta basi oblonga, simplex vel furcata, antice viridis, margine purpurea, squamis remotis purpureis acutis. Carpocephala longe pedunculata, pedunculo e fundo nudo apicali orto, basi paleaceo, sulco singulo percurso, antice stomatis rudimentariis instructo, apice paleis villoso. Capitula conico-globosa, papulosa, radiatim quadriloba, involucris profunde solutis unifloris, bivalvis, membranaceis; perianthio nullo (" ovario nudo "). Capsula sphærica, bulbo inserta, ore irregulariter dentata, ut videtur circumscissa, parielibus unistratis (" cellulis simplicibus. ") Stomata haud elevata, superficiales, stratum anticum sat altum, cellulis vel filis erectis dense repletum. Sporæ reticulatim cristatæ.

Hab. Afganistan, Otipore (Griffith).

Die vorstehend in ihren Erfordernissen übersetzte Diagnose kaun vielleicht ein Wiedererkennen der Pflanze ermöglichen; es existieren keine Exemplare derselben in Europa. Nach der Beschreibung sollte man die Pflanze für eine Grimaldia halten; wenn aber die pedunculi an ihrer dorsalen Seite wirklich rudimentäre Lufthöhlen tragen, so passte sie schlecht in dieses Genus.

\section{NEESIELLA Schffn.}

in Engler et Pr. Hep., p. 32.

Syn. Duvalia Nees. in Magazin Berl. Ges. Nat. Fr. VIII, p. 271.

Plantæ frondosæ, arcte repentes, rupicolæ, parvæ, spongiosæ, dilute virides. Frons linearis, furcata vel ex apice innovata, apice profunde inciso-biloba, antice subplana. Costa crassa, postice plano-convexa; stra- 
tum anticum duplo altius, cavernosum, cavernæ amplæ, unistratæ, lamellis accessoriis auctæ. Stomata simplicia, e cellulis 6-7 radiatís superficialibus et vix convexis formata, poro parvo; epidermis tenera, facile rupta, cavernis dein late apertis. Squamæ posticæ irregulariter distributæ, violaceæ, sæpe dentatæ facillime evanidæ. Inflorescentia monoica. Andræcia disciformia, paleis minutis circumdata, ostiolis papilliformibus. Carpocephala plus minus longe pedunculata, pedunculus strato hypoporo recedente e costæ apice ortus, crassus, sulco profunde singulo percursus, basi apiceque interdum etiam in medio paleaceus; capitula hemisphærica, cavernis bullatim inflatis, stomatis compositis ut in Reboulia, normaliter quadriradiata, radiis decurvis, subtus ad pedunculum concurrentibus ibidemque ad annulum vaginæforme (pedunculum obvelantem) conjunctis, ceterum crassis, postice multo angustioribus. Involucra e margine radiorum orta, id est interradiala, tenera, tempore maturitatis valde inflata, ore tamen capsulæ diametro angustiore. Perianthia nulla. Capsula sphærica magna, brevipedicellata, bulbo magno inserta, operculo rupta. Cellulæ basales elongatæ teneræ, operculares interdum bistratæ, minores, valde æqualiterque incrassatæ, annulo parvo cellulari distincto. Elateres vix attenuati trispiri, Sporæ tetrædræ, grosse papulosæ. Androcia flori fem. approximata, in ramis parvis lateralibus, funde nudo apicali inserta minima, disciformia, paucis paleis cincta, ostiolis papilliformibus.

\section{Neesiella rupestris (Nees.) Schffn. 1. c.}

Syn. Duvalia rup. Nees. 1. c.

Monoica, mediocris, gregarie crescens. Frons usque ad $2 \mathrm{~cm}$. longa, plus minus ramosa, interdum ex apice innovata; costa crassa, plano convexa, stratum anticum quam costa triplo altius, laxe cavernosum; stomata parva subplana, poro a 6 cellulis angustis 2 vel 3 seriatis circumdato; cellulæ epidermidis haud incrassatæ. Squame posticæ valde variabiles et irregulares, appendiculo singulo acuminatæ vel bilobæ, lobis varie obtuseque dentatis, apice sæpe breviter bis bifidis. Carpocephala valida, longe pedunculata, pedunculus compresso-cylindricus, lævis, sulco profundo angusto percursus, labiis obtusis, basi apiceque paucis paleis hyalinis et lanceolatis armatus. Capitula hemisphærica, alte papulosa; involucra brevissima, tenera, capsulæ egressu rupta. Capsulæ cellulæ basales, $3 \check{5} \times 68 \mu$, annuli $25 / 25 \mu$, operculi $68 \times 68 \mu$. Sporæ $60 \mu$. Elateres $240 \mu$. Androcia in ramis parvis apicalibus, ad latera carpocephali ortis, ovato-disciformia, paleis hyalinis cincta.

Hab. Europa, Japonia (Faurie), Amer. septentr. (Rau). 
2. N. chilensis (Mont) Steph.

Syn. Grimaldia chilensis Mont in d'Orbigny Voy. Amér. mérid. Bot., p. วั3.

Monoica, pusilla, fusco-viridis, postice subatra, dense stratificata; frons 3-4 mm. longa, simplex, in planta fructifera inæqualiter furcata, ramulo femineo brevi, altero increscente longiore, crassa, magis alta quam lata, costa maxime producta, strato antico fere triplo altior, frons itaque altissime radicellifera, antice plana, marginibus angustis tenerrimis adscendentibus. Stratum anticum anguste cavernosum. Stomata parva, ore ๖̈-6 cellulis magnis circumdato, parietibus radialibus (ut in Cleveis) trigone incrassatis, trigonis acutis, haud longe attenuatis. Squamæ posticæ valde irregulares, sub lente fusco-violaceæ, in sicco atræ, oblique ovatæ, grosse lobato-dentatæ, appendiculo abrupte angusteque lanceolato, aliæ parvæ, varie lobatæ lacinulatæque. Carpocephala parva, breviter pedunculata, pedunculus, e fundo apicali frondis, ubique nudus, basi crassus, superne valde attenuatus, compressus, varie costatus, sulco profundo angusto, labiis tenerrimis. Capitula alte umbonata, papulosa, radiis validis ad vaginam posticam late descendentibus; involucra magna, multo magis evoluta quam in reliquis, valida, oblique divergentes, ore amplo, capsulæ egressu haud rupto. Sporae $3 \check{\mu}$. fusco-brunneæ, alte papulosæ. Elateres concolores, trispiri, spiris anguste tortis, Andracia pedunculo plus minus approximata, sæpe totam superficiem frondis occupantia, ostiol a hyalina obtuse conica parum prominula. Capsulam ipsam haud vidi.

Hab. Chile. Quillota (Bertero).

Ohne allen Zweifel gehört diesa Pflanze nicht zu Grimaldia, sondern steht Neesiella, am nächsten, besonders in der Bildung des Fruchtkopfes; auch die violetten Ventralschuppen sind typisch für Neesiella; ganz abweichend dagegen sind die sternförmig verdickten Stomata; ich habe schon bei Plagiochasma, wo ähnliche vorkommen, darauf hingewiesen, dass ihr Bau kein zuverlässiges generisches Merkmal abgiebt und dass sie der Anpassung unterliegen wie alle vegetativen Organe.

\section{N. longiseta St.}

Syn. : Duvalia longiseta St. Bull. Herb. Boiss., V, p. 88.

Duvalia intermedia? Aust. Ac. Phila,, 1869.

Monoica, minor, muscicola, pallide-virens. Frons tenuis, plana, usque ad $15 \mathrm{~mm}$. longa, oblongo-obcuneata, ramis longe coalitis sæpe latissima, apice profunde biloba, marginibus longe attenuatis. Costa plano-convexa, fronde plus duplo angustior, bene producta, abrupte sub alas desinens; 
radiculis sæpe interrupte vel omnino violaceis. Stratum anticum costæ plus triplo altius, laxe cavernosum; stomata minima, 6 cellulis tenerrimis circumdata. Cellulæ epidermidis trigonis magnis incrassatæ. Squamæ posticæ integerrimæ, appendiculo longo, laxe reticulato, basi maxime constricto superne lanceolato acuto. Carpocephala longissime pedunculata; pedunculus $6 \mathrm{~cm}$. longus capillaceus, subteres, varie obtuseque costatus, canali amplo profundoque percursus, labiis obtusis, basi apiceque paucis paleis longis linearibus hyalinis ornatus. Capitula parva $(2 \mathrm{~mm}$. in diam.) hemisphærica, alte papulosa, radiis angustis subtus ad brevem vaginam confluentibus; involucra brevia tenerrima, ore parvo, quam capsula multo angustiore. Capsulæ cellulæ basales $25 \times 70 \mu$ annuli $25 \times$ $25 \mu$, operculi valde æqualiterque incrassatæ, subatræ, bistratæ, $34 \times$ $34 \mu$. Sporæ $60 \mu$, grosse conico-papulosæ. Elateres $340 \mu, 3$ spiri, spiris fusco-rufis, confertim tortis. Andracia disciformia, rotunda, minuta, subnuda.

Hab. Japonia, Nemuro (Faurie), 

Extrait du Bulletin de l'Herbier Boissier.

Tome VII. No 2. Février 1899.

\section{SPECIES HEPATICARUII}

AUCTORE

Franz STEPHANI

(Suite.)

\section{FIMBRIARIA Nees.}

in Hor. phys. Berol., p. 45, 1820.

Plantæ frondosæ, terrestres, arcte repentes, minores vel parvæ, virides vel purpurascentes. Frons linearis, rarius furcata, pro more ex apice innovata, ramis posticis, præcipue floriferis, haud raris, tenuis vel tenerrima, rare crassa, antice plana vel parum canaliculata, apice inciso biloba præsertim in ramis femineis. Costa bene evoluta, sæpe angusta, interdum carinatim acutata, antice fere semper valde convexa. Stratum hypoporum vel anticum humile, rarius magis evolutum, cavernæ angustæ, sæpe valde irregulares, lamellis accessoriis numerosis, sub poro sæpe filiferis. Stomata simplicia, parum convexa, rare alte conica. Squamæ posticæ in utroque latere costæ uniseriatæ, longe appendiculatæ, radiculas punctatim incrassatas e basi paginaque proferentes. Inflorescentia monoica vel dioica. Androcia disciformia, strato antico recedente sessilia, nuda, pedunculo approximata vel in ramulis parvis posticis, in plantis dioicis sæpe linearia. Antheridia numerosa, alveolis monandris, ostiolis brevibus vel brevissimis. Capitula plus minus longe pedunculata, pedunculo, strato hypoporo recedente, ex apice costæ orto, sulco singulo percurso, basi apiceque paleaceo, antice convexa vel conica vel alte umbonata, cavernis inflatis papulosa, stomatis duplicatis vel compositis i. e intus cellulis BULL, HERB, BOISS., février 1899. 
conico conniventibus subclausis; normaliter quadriradiata, lobi interradiales, ad discum connati vel discreti, convexi. Involucra e margine loborum orta, tenera, cum lobis infundibulum apice cupulatum vel campanulatum formantia. Perianthia monogyna, ovata vel oblonga, apice obconica, interdum tubuloso-rostrata, longitudinaliter plurifissa, hyalina vel purpurascentia, laciniis apice cohærentibus, in ætate liberis, basi immersa integra, tenerrima, apice cellulis valde incrassatis fragilia. Calyptra tenerrima, basi sæpe pluristrata. Capsula brevipedicellata, magno bulbo inserta, unistrata, tenera, operculo magno cellulis maxime incrassatis formato. Sporæ tetrædræ, in facie convexa reticulatim lamellatæ lateque limbatæ, pro more flavæ. Elateres breves, simplices vel furcati, vix attenuati, mono-vel bispiri.

Diese Gattung ist hier nach der Form der Capitula in eine Anzahl Abtheilungen gespalten, da diese Fruchtknöpfe das sicherste Merkmal zur Bestimmung der Arten darstellen; nicht selten ist nur ein Perianth fertil und da die Ausbildung der Capitula von der Befruchtung abhängig ist und sterile Involucra ganz rudimentär bleiben, so sind solche Köpfe zur sicheren Bestimmung nicht zu verwerthen. Neben den Capitulis sind die Höhe der luftführenden Schicht im Vergleich zur Höhe der Costa, ferner diese selbst und ihr ventraler Zuschnitt, auch der Bau der Stomata und Oberhaut die besten, weil konstantesten Merkmale. Die Frons selbst kann in ziemlich weiten Grenzen variiren und ist an schattigen Standorten erheblich dünner, so dass die Maasse, welche bei den Riccien sehr zuverlässig sind und das Verhältnis der Dicke der Frons zu ihrer Breite angeben, bei unserer Gattung nicht benutzt werden können.

Der Blüthenstand ist vielleicht bei allen Arten der Gattung monœecisch, auch bei denen, die hier als dioceisch beschrieben worden sind; das Material ist leider nicht immer so erhalten, dass man in allen Fällen die männlichen Aeste als Glieder der weiblichen Frons auffinden kann, sei es, dass sie von anderen bereits gereinigt und die männlichen Aeste abgebrochen worden sind, sei es, dass die Pflanzen in ihren älteren Theilen schon zerstört und die Verbindungen zusammengehöriger Aeste unterbrochen worden sind.

Wenig zuverlässig sind die Farben des Pedunculus und des Perianths; an sonnigen Standorten haben viele Arten intensive Farben an diesen Organen, die im Schatten verbleichen. Auch die Spreuschuppen am Pedunculus sind leicht vergänglich und mögen bei manchen Arten existiren, ohne dass ich sie gesehen habe. Sehr variabel ist Dicke und Länge des Pedunculus, so dass man auf den ersten Blick eine ganz 
Fimbriaria. FRANZ STEPHANI. SPEGIES hEPATICARUM.

andere Art vor sich zu haben glaubt; endlich varïren auch die Elateren in ihrer Länge ganz ausserordentlich innerhalb ein und derselben Kapsel.

\section{Uebersicht der Arten.}

\section{A. Capitula disciformia.}

a. appendicula squamarum brevia, subovata.

1. F. leptophylla

2. ") incrassata

3. „ venosa

4. „) Raddii.

b. appendicula lanceolata.

5. F. Blumeana

6. „ Zollingeri

7. $)$ viridis.

c. appendicula dentata vel laciniata.

8. F. angusta

9. ) maculata

10. „) Wallichiana.

d. appendicula setacea.

11. F. atrispora.

e. capitula maxima, squame ignota.

12. F. gigantea.

B. Capituli centrum hemisphoricum.

f. appendicula dentata vel lacerata.

13. F. Lindmanii

14. „) Volkensii

15. „ nepalensis

16. ") africana

17. ") Pringlei

18. „ muscicola

19. \# Wrightii

20. ") persica.

g. appendicula maxima, late ligulata, acuta.

21. F. Drummondii

22. ") longebarbata.

h. appendicula brevia, oblonga vel ovata.

23. F. Macounii
24. ") canelensis

25. " angolensis

26. " innovans

27. " vulcanica.

i. appendicula lanceolata.

28. F. tenera

29. "n dissoluta

30. " parvipora

31. „ Wilmsii

32. i) marginata.

33. " Boryana

34. " Khasiana

3อ̃. „) Bachmannii

36. n violacea

37. y pilosa

38. ") vesiculosa.

k. appendicula setacea.

39. F. californica

40. " echinella

41. ") abyssinica

42. ") sanguinea

43. " multiflora

44. ") elegans

4ว. " cubensis

46. "Bolanderi

47. „s Stahlii

48. " lateralis

49. „ linearis

50. D commutata

51. ") Austini.

C. Capitula distincte conica (haud alte umbonata).

1. appendicula magna, ovata, obtusa. ว2. F. Mülleri

53. „) australis

54. " conocephala 
อั5. ") Whiteleggeana.

m. appendicula lanceolata.

56. F. caucasica

57. " tasmanica

ร8. " subplana

59. » tenella

60. ") Mandoni

61. " macropoda.

$\mathrm{n}$. appendicula setacea.

62. F, Lindenbergii
63. ") setisquama

64. ” Preussii.

o. appendicula dentata.

65. F. chilensis.

D. Capitula alte umbonata.

66. F. alpina

67. ") fragrans

68. " nudata

69. ') Palmeri.

\section{a. Capitula disciformia.}

1. Fimbriaria leptophylla Mont. Ann. sc. nat. 1842, XVII, p. 19.

Monoica, dilute viridis, postice hyalina, minor et tenerrima. Frons ad $7 \mathrm{~mm}$. longa et $2 \mathrm{~mm}$. lata, ex apice innovata, ramis masculis semper posticis, antice plana, postice leniter convexa, alis validis, leniter attenuatis, costa fronde duplo angustior. Stratum anticum in medio frondis humile, quam costa duplo humilius, cavernis minus angustis; fila libera nulla. Stomata magna, parum convexa, poro magno, 8 cellulis triseriatis circumdato, ultimæ in lumen pori rotundatim prominulæ. Epidermis tenerrima. Squamæ remotæ, roseæ, parvæ, appendiculo ovato-oblongo breviter acuminato parvicellulari. Pedunculus ad $13 \mathrm{~mm}$. longus, alte lamellatus, compressus, apice paleis brevibus hyalinis linearibus barbatus. Carpocephala disciformia, quadriloba, centro subplano, lobis vix ad 1/5 solutis plano-convexis, margine decurvulis; involucra lobis æquilonga inflata. Per. subrecte patula, subhorizontalia, hyalina, oblongo-ovata, ad $2 / 3$ exserta. Elateres longissimi $270 \mu$, filiformes, dilute flavescentes bispiri, spiris laxe tortis, ligulatis. Sporæ dilute flavæ, ad $63 \mathrm{~mm}$. latæ, alis latis tenerrimis, crenulatim repandis.

Androecia in ramulis parvis posticis. Hab. India orient, Nilgherry $\mathrm{M}^{\mathrm{s}}$ (Perrottet).

\section{Fimbriaria incrassata St. n. sp.}

Monoica, mediocris vel parva, viridis, postice purpurea, tenuis sed robusta et dura, ramis floriferis tamen flaccidis tenerrimis. Frons ad $10 \mathrm{~mm}$. longa, $5 \mathrm{~mm}$. lata, ex apice vel e latere costæ innovata, antice parum concava, medio postico parum incrassato; costa frondi æquilata, 
medio postico leniter carinatim acutata, sensim in alas attenuata, grandicellularis, infima parte postica cellulis duplo minoribus ædificata. Stratum anticum bene definitum, humile, cavernis parvis dense filiferis. Stomata parva, alte conica, 6 cell. quadriseriatis formata; cellulæ epidermidis maxime incrassatæ, trigonis maximis sæpe confluentibus et indistinctis ob parietum incrassationem. Squamæ posticæ purpureæ, appendiculo subcirculari vel late ovato brevissimo, hyalino, margine crenulatim papuloso tenerrimo, vix constricto. Pedunculus brevissimus $3 \mathrm{~mm}$. longus, ubique nudus. Carpocephala disciformia antice fere plana vel parum convexa, integra, i. e lobis ad discum indivisum confluentibus, margine papulis prominentibus lobulatis. Involucra tenerrima, disco sublongiora, valde inflata. Perianthia ad $2 / 3$ immersa, marginem disci parum superantia, hyalina, subhorizontalia. Capsula tenerrima, dilute brunnea. Sporæ sulphureæ, alis angustis, integerrimis $72 \mu$. Elateres $170 \mu$, angusti, bispiri spiris validis. Andrœcia in ramulis parvis apicalibus, femineis approximatis magna.

Hab. Abyssinia Schoa (Schimper).

3. Fimbriaria venosa L. L. in Lehm. Pug. Pl. IV, p. 29.

Monoica, major, intense viridis, postice hyalina. Frons ad $25 \mathrm{~mm}$. longa, $4 \mathrm{~mm}$. lata, repetito furcata, interdum ex apice innovata, tenuis et valida, antice plana, costa fronde quintuplo angustior abrupte prominens et valde convexa, alæ tenues, ubique æquicrassæ, acutæ, stratum anticum humile, fere triplo humilius quam costa, cavernis amplis, filis nullis. Stomata parva ( $34 \mu$ in diametro) 4 -ə̆ cellulis angustis biseriatis formata, subplana, cellulæ epidermidis teneræ. Squamæ posticæ parvæ, remotæ, roseæ, appendiculo valde constricto parvo oblongo acuto, magnis cellulis purpureis formato. Pedunculus ad $2 \mathrm{~cm}$. longus compressus, varie profundeque costatus, barba apicalis brevis, paleis hyalinis lanceolatis. Carpocephala parva, leniter convexa, disciformia, lobis haud discretis sed ope radiorum ad discum integrum conflatis, radii e centro communi versus marginem sensim ampliati ibidemque rotundato prominentes; involucra brevissima ad laminam parvam basalem reducta, perianthia discum capituli vix superantes late ovata, breviter acuminata, acutissima, hyalina, oblique patentia vel fere horizontalia. Capsula tenerrima rufescens. Sporæ $72 \mu$, alis latis repandis asperis, rufescentes. Elateres flvaescentes $270 \mu$ tenues, flexuosi, bispiri, spiris validis. Andræcia pedunculo approximata parva, ostiolis grossis purpureis.

Hab. Brasilia (Sellow, Puiggari, Ule). Siehe auch F. Zollingeri. 
4. Fimbriaria Raddii Corda. in Nees. Hep. Eur. IV, p. 289.

Monoica? Minor, viridis, margine posticeque purpurea, tenuis. Frons ad $10 \mathrm{~mm}$. longa, $3 \mathrm{~mm}$. lata, sublinearis, simplex, antice plana, costa fronde triplo angustiore, postice convexa, bene producta, alis abrupte attenuatis, tenerrimis, subintegris. Squamæ breves, roseæ. Cellulæ epidermidis validæ. Stomata parum convexa. Stratum anticum humile, cavernis subamplis. Pedunculus ex apice frondis ortus, sparsim paleaceus, aurantiacus, brevissimus, crassus, basi apiceque barbatus, paleis brevibus, hyalinis linearibus. Carpocephala parva, disciformia, parum convexa, viridia, papulosa, lobis brevissimis haud discretis, rotundatim prominulis, discum rolundato-quadratum formantibus. Perianthia oblique patula, ovato-conica, brunnea, usque ad basin fere 14-16 fida, capsula fuscobrunnea, operculo parvo. Elateres flavescentes, vix attenuati, spiris brunneis duplicatis, laxe tortis. Sporce flavo-brunneolæ; Androcia ignota.

Hab. Italia, Firenze (Raddi).

Die Pflanze ist im Berliner Museum nicht aufzufinden; da sie bis jetzt auch nicht wieder gesammelt worden ist, habe ich die Diagnose nach Nees Beschreibung 1. c. übersetzt; sie ist eine so detaillirte, dass nicht daran zu zweifeln ist, dass wir eine gute Art vor uns haben, die ganz fremdartig unter den europäischen Species dasteht.

5. Fimbriaria Blumeana Nees. Syn. Hep., p. 564.

Monoica, parva, viridis, tenera. Frons ad $10 \mathrm{~mm}$. longa, obcordata, ex apice innovata, plana, medio postico late convexa, alis attenuatis, costa angusta, fronde triplo angustior, humillima, strato antico plus duplo humilior, cavernæ amplæ, filis liberis subnullis. Stomata parum convexa, poro magno, 6 cellulis biseriatis circumdato; cellulæ eptdermidis trigonis magnis incrassatæ. Squamæ parvæ remotæ, roseæ, appendiculo lanceolato, acuto, vel longius acuminato, interdum cellulis conico-prominulis dentato. Pedunculus ad $10 \mathrm{~mm}$. longus, basi purpureus, apice paleis brevibus lanceolatis pupureis barbatus, irregulariter profundeque costatus. Carpocephala disciformia, leniter convexa, viridia, lobis rotundatim e disco prominulis, sinu lato et parum profundo discretis, leniter decurvis, venosis; involucra tenerrima lobis breviora, saccata. Perianthia oblonga, hyalina semiexserta, oblique vel subhorizontaliter patula, Capsula hyalina, tenerrima, operculi cellulæ maxime incrassatæ. Sporæ $72 \mu$, alis lobatim erenatis, aurantiacæ. Elateres $260 \mu$, flavescentes, spiris duplicatis validis. Androecia pedunculo approximata, ostiolis brevibus hyalinis. 
Hab. Java (Zollinger) N. W. Himalaya (Stolitzka, Duthie, Gamble) $8000^{\prime}$ engl.

\section{Fimbriaria Zollingeri St. n. sp.}

Syn. : F. venosa L. und L. (ex parte).

Monoica, viridis, flaccida, minor. Frons ad $20 \mathrm{~mm}$. longa, כै mm. lata, ex apice innovata vel furcata, antice plana, postice leniter convexa; costa postice haud producta, fronde sextupto angustior, antice maxime convexa, stratum anticum supra costam itaque humillimum, cavernis laxis, alæ sensim attenuatæ haud tenerrimæ, sed ob cavernas magnas flaccidæ et perlucentes. Stomata magna, parum convexa, 9 cellulis 4 seriatis conflata. Cellulæ epidermidis teneræ. Squamæ posticæ roseæ, appendiculo lanceolato, acuto vel obtuso, in medio 4 cellulas lato. Pedunculus $25 \mathrm{~mm}$. longus, subteres, humiliter costatus, apice paleis hyalinis linearibus breviter barbatus. Carpocephala parva, parum convexa, diseiformia, lobis obconicis profunde solutis, margine ob cavernas inflatim-protractas profunde lobatis, convexo-explanatis; involucra multo breviora, perianthia oblongo-ovata, basi involucro parum tecta, sub lobis fere occulta, subhorizontalia, hyalina, apice lobos solum superantia. Capsula tenera, rufescens. Sporæ $90 \mu$, rufescentes, alis latis integerrimis, asperrimis. Elateres $216 \mu$, tenues, bispiri, spiris validis. Androcia parva, hyalina, pedunculo approximata.

Hab. Java (Zollinger, Stahl, Schiffner).

F. venosa ist als brasilianische Pflanze publizirt; später hat man eine javanische, äusserlich ähnliche Pflanze dazu gezogen, die aber zweifellos verschieden ist und daher einen andern Namen erhalten musste.

7. Fimbriaria viridis L. und L. in Lehm. Pug. PI. IV, p. 6.

Monoica, dilute viridis, tenera. Frons ad $15 \mathrm{~mm}$. longa, $3 \mathrm{~mm}$. lata, ex apice innovata, alis adscendentibus late canaliculata, alæ tenerrimæ, margine irregulariter crenulatæ. Costa fronde quadruplo angustior, maxime et abrupte producta, postice in sectione semirotunda, stratum anticum humillimum, cavernis angustis, in alis multo amplioribus, fila libera numerosa, bicellularia; stomata minima, 6 cellulis triseriatis angustis formata, parum prominentia. Squamæ parvæ, purpureæ, appendiculo squama longiore, lanceolato, magnis cellulis formato, apice filiformi. Pedunculus $2 \mathrm{~mm}$. longus (semper?) apice barbatus paleis brevissimis, lanceolatis, acutis, hyalinis. Carpocephala disciformia, centrum parvum, vix prominulum, stomatis grosse papulosis, quatuor radios latos et decur- 
vos proferens; lobi radiis breviores, validi excisi cum involucro parum longiore pileolum hiantem formantes, haud campanulatim penduli sed ad latera aperti; perianthia itaque subrecte patula ovata longeque exserta, ore breviter tubuloso. Capsula tenerrima, hyalina, parietibus radialibus valde incrassatis, operculo parvo similiter incrassato. Sporæ fuscobrunneæ $72 \mu$, lobato-cristatæ, asperrimæ. Elateres dilute-flavescentes $144 \mu$, bispiri, spiris angustis laxe tortis. Androcia antica in soros aggregata vel in fronde feminea vel in ejus ramo ex apice innovante.

Hab. Nepal (Wallich).

Eine sehr interessante Pflanze, insofern hier die Radien des Kopfes mächtig entwickelt sind; sie bilden ein Kreuz und zwischeu ihnen stecken, wie kleine Hüte, die kurzen, weit klaffenden Involucra; das ist nur zu sehen, wenn man die Perianthien herausgezogen hat, aber dann auch bei sehr geringer Vergrösserung in völliger Klarheit.

\section{Fimbriaria angusta St. n. sp.}

Dioica, mediocris, viridis, margine posticeque atropurpurea, valida et tenax. Frons ad $20 \mathrm{~mm}$. longa, $3 \mathrm{~mm}$. lata, ex apice innovata, subplana, medio postico valde convexa, alis validis sensim ad marginem acutum attenualis, costa fronde triplo angustior. Stratum anticum in medio frondis quam costa duplo humilius, cavernis amplis, fila libera longa. Stomata magna, 6-cellulis triseriatis formata. Cellulæ epidermidis validæ æqualiter incrassatæ. Squamæ magnæ, sanguineæ vel violaceæ, appendiculo longo apice sæpe inæqualiter bifido. Pedunculus brevissimus, $2 \mathrm{~mm}$. longus, crassus, teres, apice barbatus, ubique paleaceus, paleis lanceolatis brevibus patulis. Carpocephala disciformia, parum convexa, lobis usque ad apicem fere connatis, alte papulosis, parum decurvis, cum involucro æquilongo cupulatis. Perianthia purpurea subhorizontaliter patula, ovata, $\mathrm{ad}^{2} / 3$ exserta ore anguste tubiformi. Capsula subhyalina. Sporæ ad $63 \mu$,

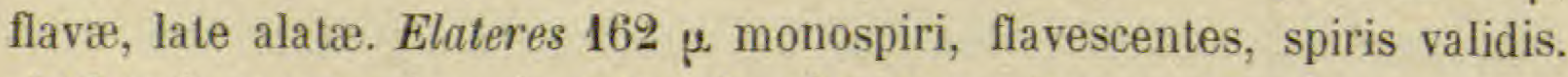
Andrœcia magna, linearia, totam frondem masculam occupantia, purpurea, vallatim ampliata, ostiolis brevissimis.

Hab. India orientalis, Coory (Lowrie).

\section{Fimbriaria maculata St. n. sp.}

Monoica, viridis, subtus hyalina, major. Frons ad $20 \mathrm{~mm}$. longa, $3 \mathrm{~mm}$. lata, linearis, ex apice innovata, antice plana, postice leniter convexa, costa fronde 3-plo angustior, postice late carinatim prominens. Stratum anticum, in medio frondis, costæ æquialtum, cavernis angustis sub poro 
fila libera conferta gerens. Stomata magna, 8-9 cellulis triseriatis formata. Cellulæ epidermidis maxime incrassatæ, parietibus trabeculatis, trigonis magnis subnodulosis. Squamæ posticæ oblique ovatæ, medio infero purpureo (unde nomen "maculata ") supero hyalino, appendiculum squamæ æquilongum, lanceolatum spina singula supra basin armatum, apice setaceum. Pedunculus brevis (๖ mm,) crassus stramineus, subteres, laxe cellulosus, ubique paleis longis hyalinis hirtus, barba apicalis paucipaleacea. Carpocephala disciformia, parum convexa parva, lobis centro æquilongis, haud solutis, grosse papulosis, emarginatis, ob papulas prominentes margine lobulatis, cum involucro æquilonga et similiter lobuato obconico-hiantibus, margine crispatulis. Perianthia ovato-oblonga, acuminata, ore breviter rostrato-tubuloso. Capsula dilute brunnea, operculo trigonis magnis incrassato. Sporæ $70 \mu$, fusco-brunneæ, alis angustis, crenato-lobulatis. Elateres $\mathbf{1 4 4} \mu$, crassi, stricti, æquilati, rufo-brunnei, monospiri, spiris ligulatis. Androcia in ramulis parvis posticis minuta.

Hab. Himalaya, Sansidara. $3000^{\prime}$ engl. (Duthie).

10. Fimbriaria Wallichiana L. und L. Pug. PI. IV, p. 4.

Dioica? major, viridis, postice purpurascens, tenera. Frons ad $25 \mathrm{~mm}$. longa et $\check{5} \mathrm{~mm}$. lata, ex apice vel e latere costæ innovata, rarius furcata, antice subplana, postice plano-convexa, costa fronde ら̋-plo angustior bene producta, alis attenuatis, venosis, margine crenulatis et plicatulo-erispatis. Stratum anticum in medio frondis costæ æquialtum, cavernis angustissimis, sub poro fila libera longa valdeque aggregata gerentibus; stratum hypoporum itaque quasi ut in Ricciis. Stomata magna, 6-cellulis quadriseriatis formata, valde convexa; cell. epidermidis teneræ. Squamæ posticæ magnæ, purpureæ, imbricatæ, appendiculo magno lanceolato simplici vel plus minus grosse laciniato, laciniis filiformibus e margine appendiculi ortis. Pedunculus brevis (semper) $3 \mathrm{~mm}$. longus, apice barbatus, paleis brevibus, lanceolatis hyalinis vel purpureis. Carpocephala disciformia, parum convexa, grosse papulosa, lobis profunde diseretis brevibus recte patulis cum involucro æquimagno ad annulum reductis, Perianthia itaque longe (ad $2 / 3)$ exserta, ovata, sat longe acuminata, recte patentia. Capsula tenera rufescens, operculo valde incrassato. Sporæ $63 \mu$, fusco-brunneæ repando-alatæ. Elateres breves $180 \mu$ mono-vel bispiri. Androecia ignota.

Hab. Birma (Wallich) Bhotan (Griffith) Ind. orient. Bhor Ghat (Schiffner). 
Fimbriaria.

\section{Fimbriaria atrispora St.n. sp.}

Monoica, mediocris, viridis, margine posticeque purpurea. Frons ad $25 \mathrm{~mm}$. longa, $4 \mathrm{~mm}$. lata, ex apice innovata, ramis floriferis semper posticis, antice plana, medio postico late plano-convexa alis tenerrimis. Costa fronde 4-plo angustior, postice haud producta. Stratum anticum in medio frondis quam costa duplo humilius, cavernis angustis haud filiferis. Stomata magna alteque convexa, 6-cellulis, 4-こ̌ seriatis formata. Cellulæ epidermidis tenerrimæ. Squamæ posticæ magnæ, purpureæ imbricatæ, appendiculo (interdum geminato) longo, lanceolato superne sæpe longe lineari (2-cellulas lato). Pedunculus tenuis, subteres et lævis, apice paleis hyalinis anguste linearibus longe barbatus. Carpocephala disciformia, antice vix convexa grosse papulosa, integra, i. e, lobis haud discretis sed omnino confluentibus, crassis, involucra tenerrima usque ad marginem disci protracta, perianthia ad $2 / 3$ tegentia. Perianthia ovata hyalina, horizontalia, marginem capituli vix superantia. Capsula flavescens. Elateres $230 \mu$, crassi, stricti, dilute brunnei, bispiri, spiris validis. Sporæ $108 \mu$ subnigræ, alis angustis asperis.

Androcia minima, sæpe ad $\mathbf{2}$ antheridia tantum reducta.

Hab. Mexico (Schaffner] [Maury).

\section{Fimbriaria gigantea St. n. sp.}

Monoica, pallida, tenera, inter muscos sparsim crescens. Frons ex apice innovata, $2 \mathrm{~cm}$. longa, e basi angusta oblonga, apice profunde inciso-biloba, ceterum plana; costa angusta, pro planta tenuis, maxime et abrupte producta, late obconica, medio infero radicellis longissimis repens; stratum anticum humile; stomata magna, poro magno cellulis angustis prærupte 4-seriatis circumdato; cellulæ stomatum et epidermidis tenerrimæ, incrassatio angulosa nulla. Squamæ paucæ, magnæ purpureæ, tenerrimæ, appendiculo? (destructo). Carpocephala maxima, longe pedunculata, pedunculo $45 \mathrm{~mm}$. longo, valido, inferne colorato, basi nudo, apice breviter barbato, paleis lanceolatis hyalinis apice filiformibus. Carpocephala discoidea $1 \mathrm{~cm}$. lata, antice parum convexa, vertice vix umbonata, rufo-brunnea, papulosa, fere ad medium quadriloba, lobis truncato-rotundatis, subplanis, leniter declivibus, involucris intra marginem loborum ortis, tenerrimis, amplis et humilibus, perianthia vix ad medium cingentibus. Perianthia late ovato-conica, parva, basi tenerrima, medio supero cellulis validis hyalinis formata. Calyptra tenerrima; capsula rufobrunnea, cellulis validis, Operculum magnum, cellulis bistratis parvis, trigone incrassatis formatum. Sporæ $93 \mu$, lobatim cristatæ, asperæ. 
Elateres $340 \mu$, bispirj, filiformes, spiris latis, anguste tortis. Androcia pedunculo approximata, ostiolis magnis hyalinis.

Hab. Africa trop. Kilimandscharo (leg. ?).

\section{b. Gapituli centrum hemisphæricum.}

\section{Fimbriaria Lindmanii St. Acad. suec. 1897, p. 17.}

Monoica, pallide virens, tenerrima, flaccida. Frons parva, ad $10 \mathrm{~cm}$. longa, $3 \mathrm{~mm}$. lata, furcata vel ex apice innovata, antice posticeque plana, costa solum valde convexo-prominula, fronde 3-plo angustior; alis ubique æquicrassis, margine truncalis-decurvulis. Stratum anticum costæ duplo humilius in medio, cavernis amplis haud filiferis. Stomata parva, haud vel vix prominula, 4 cellulis biseriatis formata; cellulæ epidermidis teneræ. Squamæ hyalinæ superne purpureæ oblique ovatæ, appendiculo grandicellulare inæqualiter bifido, laciniis brevibus, majore oblongo acuto altero spiniformi subæquilongo. Pedunculus ad $4 \mathrm{~mm}$. Iongus, apice breviter paleaceus subteres et vix costatus. Carpocephali centrum parvum, hemisphæricum, haud conico-angustatum, lobis oblique patulis ad medium solutis oblique decurvis, centro capituli æquilongis cum involucro breviter campanulatis. Perianthia e basi ovata longe acuminata ad medium exserta, hyalina. Capsula hyalina, sporce $54 \mu$, flavescentes; Elateres $220 \mu$, filiformes flavescentes, bispiri, spiris laxe torlis. Andræcia ad basin pedunculi parva, hyalina.

Hab. Brasilia Porto Alegre (Lindman).

\section{Fimbriaria Volkensii St. n. sp.}

Monoica, pallide-virens vel omnino purpurascens, spectabilis, flaccida. Frons ad $25 \mathrm{~mm}$. longa, $6 \mathrm{~mm}$. lata, furcata, rami postici nulli, interdum ex apice innovata, antice ample canaliculata, medio postico valde producto, prærupte in alas tenerrimas attenuata; costa in infima parte convexitatis parva et humilis (strato antico quam costa duplo altiore); cavernæ ampliores, filis liberis nullis; stomata magna, alte elevata, 6 cellulis sexseriatis formata. Cellula epidermidis magnæ $(54 \times 72 \mu)$ haud incrassatæ. Squamæ posticæ imbricatæ, late lunatæ appendiculo lanceolato purpureo, breviusculo, haud constricto. Pedunculus crassus, compressus, parum costatus, apice paleis brevibus hyalinis et lanceolatis barbatus. Centrum carpocephali parvum, hemisphæricum, lobis duplo 
longioribus, ad $2 / 8$ connatis, oblique decurvis, cum involucro inflato æquilongo bene campanulatis. Perianthia itaque parum exserta ovata, ad $2 / 3$ immersa, hyalina. Capsula rufescens. Elateres $230 \mu$, flavescentes, bispiri, spiris validis. Sporæ $100 \mu$, aurantiacæ, alis angustis, repandis, asperis. Andrœcia in fronde feminea, a pedunculo remota, magna, ostiolis brevissimis, purpureis.

Hab. Kilimandscharo (Volkens).

15. Fimbriaria nepalensis Taylor, Linn. Soc. 1837, XVII, p. 387. Monoica, parva, flavo-virens, margine purpurascens, tenera. Frons ad $7 \mathrm{~mm}$. longa, $2 \mathrm{~mm}$. lata, e latere costæ vel ex apice innovata, antice plana, postice late convexa, costa lata, postice plano-convexa, fronde subduplo angustior, alis attenuatis ob cavernas perlucentes venosis. Stratum anticum in medio frondis costæ æquialtum, cavernis majoribus, sub poro filis liberis brevibus. Stomata magna, parum convexa, 8 cellulis triseriatis formata; cellulæ epidermidis trigone incrassatæ. Squamæ posticæ parvæ, roseæ, tenerrimæ et facile evanidæ, appendiculo lanceolato vel ligulato, apice inæqualiter breviterque bifido. Pedunculus brevis (3-4 mm.) apice longe barbatus, ubique paleaceus maximeque hirtus, paleis hyalinis anguste lanceolatis, recte patulis et sursum curvatis, ceterum teres et lævis, Carpocephala plano-convexa, centro parvo, grosse papuloso, lobis subhorizontaliter patulis, inflatis, centro capituli æquımagnis, ore leniter decurvo, usque ad apicem connatis, teneris et venosis, margine ob cavernas prominentes lobulatis, cum involucro tenerrimo æquilongo cupulatis. Perianthia ovata, apice angustata dictincte rostrata, hyalina oblique patula. Capsula flavescens. Sporæ $72 \mu$ rufæ, alis angustis repandis, asperulis. Elateres flavescentes $170 \mu$, spiris filiformibus duplicatis. Androcia pedunculo approximata, sæpe totam frondem fere obtegentia, in ejus medio vallatim ampliata, ostiolis brevibus hyalinis.

Hab. Nepal. (Wallich) N. W. Himalaya (Gollan, Gamble).

16. Fimbriaria africana Mont. in Webb. et Berth. Descr. Ins. Canar., p. 61.

Syn. Rhacotheca azorica Bisch. in Hochstetter et Seuber.Fl. Azor, p.12.

Monoica, mediocris, viridis margine posticeque purpurascens, Frons ad $20 \mathrm{~mm}$. longa, $4 \mathrm{~mm}$. lata, furcata vel ex apice innovata subtenuis, antice plana; costa bene producta, abrupte prominens postice rotundata, stratum solidum ad infimam partem costæ reductum. Stratum anticum in medio frondis itaque sat altum, anguste cavernosum; stomata magna, 
valde convexa, poro magno a 6 cellulis quinqueseriatis circumdato. Cellulæ epidermidis teneræ, haud incrassatæ. Squamæ posticæ purpureæ imbricatæ, appendiculo constricto oblique ovato, acuto obtuse dentato. Carpocephala parum convexa breviter pedunculata, pedunculo paleis linearibus sparsis hirto, apice paleis similibus barbato, ceterum subtereti, superficie varie obtuseque costato. Capitula e centro parvo hemisphærico ad medium 4-loba, lobis optime cuneatis, apice truncato-rotundatis, umbellatim patulis, attenuatis et laxissime cavernosis, margine ob cavernas prominentes repando-angulato. Involucra late campanulata, postice tenerrima. Perianthia primo (e basi inflata) longe rostrata, laciniis fissis itaque longe angusteque acuminatis, hyalinis. Capsula dilute brunnea cellulis magnis in operculo brunneo multo minoribus. Sporæ ad $85 ٌ \mu$ fulvæ vel rufescentes, asperæ grosse lobatim alatæ. Elateres $370 \mu$, tenues et attenuati, laxe bispiri. Andrœcia pedunculo approximata, parva ostiolis longis hyalinis.

Hab. Insulæ canarienses (Perrandière), Ins. Açores (Hochstelter), Madeira (Saera, Fritze, Mandon), Algeria (Herb. Montagne).

\section{Fimbriaria Pringlei Und. Bot. Gaz. XX, p. 64.}

Monoica, minor, tenuis, viridis subglauca, in ætate purpurascens. Frons usque ad $2 \mathrm{~cm}$. longa, $4 \mathrm{~mm}$. lata, interdum furcata, pro more ex apice innovata, rami feminei semper e latere costæ orti, alis adscendentibus antice leniter canaliculata, costa bene producta, strato antico subtriplo humilior, plano-convexa, sensim in alas atlenuata; alæ subhyalinæ optime crispato-plicatulæ, margine grosse inciso-lobulatæ; stratum anticum costæ æquialtum, cavernis angustis; stomata minima, poro parvo, 6 cellulis biseriatis prærupte superpositis circumdato. Squamæ magnæ purpureæ vix imbricatæ oblique ovatæ, appendiculo hyalino, magno oblongo acuminato, hic illic spina armato, basi pro more vix constricto. Carpocephala longius pedunculata, pedunculo ad $2 \mathrm{~cm}$. longo, purpureo, tenui, basi apiceque nudo; capitula subglobosa $3 \mathrm{~mm}$. in diam. valde papulosa, stomatis valde convexis, poro interno 6-cell. conicis inflatis circumdato, quadriloba, lobis parvis ob margines ad posticum incurvos ore angustatis. Perianthia ad medium immersa, ovata, obtusa, hyalina, capsula operculo bistrato fusco rumpens. Sporæ nigræ, grosse tuberculatæ, $102 \mu$; elateres dilute brunnei $250 \%$ vermiculares 1 vel 2 spiri. Androcia in frondis ramulo proprio (haud ventrali) parva, oblonga, ostiolis brevibus purpureis.

Hab. Mexico, Guadalajara (Pringle, mense Sept. cum fructu maturo). 
18. Fimbriaria muscicola St. Hedwigia 1892, p. 121.

Monoica, minor, atropurpurea, crassa et robusta. Frons ad $10 \mathrm{~mm}$. longa, furcata, ramis posticis nullis, postice carinatim convexa, antice alis adscendentibus late canaliculata, costa humili in sectione conicorotundata, fronde sextuplo angustiore, in medio triplo humiliore. Stratum anticum itaque totam fere frondem occupans, laxe cavernosum, filis liberis nullis. Stomata minuta, 6 cellulis conicis parum convexis formata. Squamæ posticæ atropurpureæ: appendicula parum constricta, sensim acuminata, apice 6 cellulis superpositis subulata, basi marginibus plus minus setosa vel laciniatim pinnata. Pedunculus crassus, $10 \mathrm{~mm}$. longus, aurantiacus, in sectione trilobatus, lobis æquimagnis, rotundatis, posticus anguste canaliculatus, labiis truncatis appressis, lobi antici magnis cavernis vacuis instructi. Carpocephala parva, alte hemisphærica, grosse papulosa, lobis hrevibus valde declivibus cum involucro breviter hiantibus. Perianthia itaque fere pendula, longius exserta, parum tamen longiora quam lata, apice truncato rolundata, apiculata vel fere umbilicata. Androcia pedunculo contigua, ostiolis hyalinis longis.

Hab. Transvaal Spitzkop (Wilms).

\section{Fimbriaria Wrightii Underw. Bot. Gaz. XX, p. 64.}

Monoica, mediocris, margine posticeque purpurea. Frons ad $10 \mathrm{~mm}$. longa, $3 \mathrm{~mm}$. lata, ex apice innovata, canaliculata, alis adscendentibus tenerrimis, margine crispato-plicatulo. Costa plano-convexa, fronde fere triplo angustior. Stratum anticum costæ æquialtum, anguste cavernosum, cavernæ filis dense repletæ; stomata magna, parum convexa, poro 6 cellulis triseriatis circumdato; cellulæ epidermidis validæ, æqualiter incrassatæ. Squamæ magnæ, contiguæ, oblique lunatæ, longissime appendiculatæ, appendiculo e basi lanceolata longe cuspidato, interdum spina singula magna armato, Carpocephala terminalia in fronde vel in ramulis parvis posticis. Pedunculus $15 \mathrm{~mm}$. longus, purpureus, superficie varie acuteque costatus, apice longe barbatus, paleis linearibus ( 2 cell. latis, cell. 6-7 mm. longis). Carpocephala e centro hemisphærico alte papuloso quadriloba, radiis alte papulosis in dorso involucrorum longe decurrentibus; lobis oblique patulis attenuatis, margine repandis usque ad basin fere solutis, cuneatis apice truncatis vel emarginatis; involucr a tenerrima sat longa. Perianthia ovata, hyalina vel purpurea, ore breviter tubulosa. Capsula subhyalina. Operculum minimum, parietibus radialibus maxime incrassatis. Sporæ $102 \mu$ aurantiacæ, Iate alatæ, alis flavescentibus mar- 
gine asperrimis. Elateres $270 \mu$, bispiri, spiris angustis. Androcia in ramulis parvis posticis vel in fronde dorsalia.

Hab. Cuba (Wright).

\section{Fimbriaria persica St. Hedwigia. 1894, p. 7.}

Monoica, major, robusta, omnino purpurea. Frons ad $20 \mathrm{~mm}$. longa, $5 \mathrm{~mm}$. lata, ex apice innovata, ramis floriferis semper posticis, antice plus minus canaliculata, postice plano convexa, costa haud prominens, fronde triplo angustior et 3-plo humilior quam stratum anticum; cavernæ angustissimæ, sub poro dense longeque filiferæ. Stomata magna, 6 cellulis quadriseriatis conflata. Epidermidis cellulæ æqualiter incrassatæ. Squamæ magnæ atropurpureæ, imbricatæ, longe appendiculatæ, appendiculis geminatis, subremotis, filiformibus basi grosse paucispinosis. Pedunculus ad $7 \mathrm{~mm}$. longus crassus, purpureus, compressus varie humiliterque costatus, apice paleis hyalinis anguste lanceolatis barbatus. Carpocephala magna, centro plano-convexa lobis duplo longioribus, decurvis, profunde solutis cum involucro æquilongo cupuliformibus. Perianthia late ovata, apice inflato-rotundata obtusissima. Capsula valida fusco rufa, opereulo maxime incrassato. Sporæ subnigræ, alis angustis asperrimis, $108 \mu$. Elateres $130 \mu$, fusco-rufi, bispiri, spiris validis, laxe tortis. Androcia in ramulo parvo postico.

Hab. Persia (Hausknecht).

21. Fimbriaria Drummondii Taylor. I. of Bot. 1844, p. כ774.

Monoica, major, crassa et robusta, viridis margine posticeque purpurea. Frons ad $15 \mathrm{~mm}$. longa, $4 \mathrm{~mm}$. lata, interdum furcata, pro more ex apice innovata, ramis floriferis semper posticis, antice subplana, ventre late et humiliter convexa, alis breviusculis validis attenuatis acutis, integerrimis. Costa fronde triplo angustior, haud producta, strato antico mediano æquialta, cavernæ angustissimæ, sub poro longe filiferæ; stomata magna, 8 cellulis quinqueseriatis formata; cellulæ epidermidis teneræ, trigonis magnis incrassatæ, duplo fere altiores quam latæ. Squamæ posticæ magnæ, oblique ovatæ purpureæ, appendiculo hyalino basi haud constricto squamæ fere xquilato, longe ligulato apice oblique breviterque acuminato. Pedunculus ad $2 \mathrm{~cm}$. longus, purpureus, crassus, apice paleis anguste lanceolatis breviter barbatus. Carpocephala magna, centro parvo leniter convexo, grosse papuloso, lobis quam centrum multo longioribus, latissimis, crassis, similiter papulosis, umbellatim patulis cum involucro æquilongo cupuliformibus. Perianthia ovata, semiexserta hyalina, inter- 
dum purpurea; capsula rufescens, operculo maxime incrassato; Sporæ magnæ flavescentes, ad $\mathbf{1 6 2} \mu$, latissime alatæ, alis integris vel grosse lobatis, asperis. Elateres ad $250 \mu$ flavescentes, bispiri, spiris validis. Andrecia magna disco bene definito nigro-purpureo.

Hab. Australia, Victoria (Luchmann, Curran, Turner, Mc. Cann.) Swan River (Drummond. Miss Sewell) New Zealand (Kirk).

\section{Fimbriaria longebarbata St. Hedwigia 1889, p. 156.}

Monoica, viridis, margine posticeque purpurea, valida. Frons ad $2 \mathrm{~cm}$. longa, $4 \mathrm{~mm}$. lata, subplana, furcata vel ex apice innovata. Costa fronde quintuplo angustior, postice valde convexa, lateribus sensim in alas validas abeuntibus. Stratum anticum in tergo costæ humile, cavernis angustis, fila libera 2-3 cellulas longa, sub poro conferta. Stomata numerosa, magna et valde convexa, 6-cellulis 4-ö-seriatis formata. Squamæ posticæ magnæ, purpureæ, appendiculo magno, rotundato, acuto vel obtuso, grandicellulari, hyalino. Pedunculus ad $10 \mathrm{~mm}$. longus, purpureus, apice longe-barbatus, paleis linearibus, hyalinis, obtuse costatus. Carpocephala parva vertice convexa et parum papulosa, lobis capituli centro æquimagnis, profunde solutis, cuneatis, apice truncato-rotundatis, decurvopatulis, involucro tenerrimo, duplo breviore. Perianthia oblique patula oblonga, longe exserta (ad $3 / 4$ ). Capsula tenerrima viridis. Sporæ $90 \mu$ flavescentes, anguste alatæ, alis integerrimis. Elateres concolores, $170 \mu$ bispiri, dilute flavescentes. Andræcia in furcis vel in ramulo parvo postico, magna, oblonga, valde convexa, purpurea, ostiolis brevibus.

Hab. Queensland (Amalie Dietrich, Bowman, Bailey).

\section{Fimbriaria Macounii St. n. sp.}

Syn. : F. tenella Pearson (non Nees) in Selwyn, Survey, 1890, p. 27.

Monoica, pusilla. Frons simplex, interdum ex apice innovata, $\breve{~ m m . ~}$ longa, $1 \mathrm{~mm}$. lata, anguste ligulata (rami o solum latiores), crassa; cavernis subamplis, antice inflatis, fila nulla; costa latissima, alis crassis obtusis adscendentibus valde concava. Stomata humillima, 6 cellulis biseriatis formata. Epidermis haud incrassata. Squamæ vix imbricatæ, purpurea, appendiculo hyalino, parvo, oblongo apice rotundato, integerrimo. Pedunculus $10 \mathrm{~mm}$. longus, haud barbatus, pro planta crassus, sublævis nudusque. Carpocephala e centro hemisphærico quadriloba, lobis longe connatis, margine breviter solutis, fusco purpureis, attenuatis. Involucra longe fissa margine repando-lobata. Perianthia longe rostrata, segmentis fissis longe attenuatis. Capsula viridis, laxe cellulosa, operculo 
maximo, quam capsulæ dimidium majore, optime circumscisso, cellulis $42 \mu$, unistratis formato. Sporæ כ̆1 $\mu$ cristis regulariter minuteque lobulatis, sulphureæ. Elateres $170 \mu$, trispiri. Andrœcia pedunculo approximata, parva.

Hab. Insula Vancouver, Macoun (mense majo c. f. mat.).

24. Fimbriaria canelensis Spruce in Edinb. bot. Soc. XV, p. 564 . Monoica, pallide-virens, tenera. Frons ad $25 \mathrm{~mm}$. longa, $7 \mathrm{~mm}$. lata, ex apice innovata, subplana (planta in locis minus humidis inventa forsan minus flaccida minusque plana). Costa fronde quadruplo angustiore, convexo-prominula, alæ valde attenuatæ; stratum anticum humile, sub poro cavernis amplis, reliquis parvis. Stomata magna, a 6 cellulis quinque seriatis formata, parum elevata. Squamæ posticæ parvæ, roseæ, appendiculo ovato-oblongo, obtuso, cellulis magnis formato. Pedunculus ad $10 \mathrm{~mm}$. longus, tenuis, apice maxime barbatus, paleis purpureis anguste linearibus, profunde acuteque costatus. Carpocephala juniora globosa, adulta a centro parvo hemisphærico quadriloba; Involucra brevia, tenerrima, integra. Perianthia purpurea, longe exserta. Capsula pallide rufescens, operculo magno. Sporæ fusco-brunneæ $90 \mu$, reticulatim alatæ, alæ integerrimæ. Elateres $340 \mu$, bispiri, spiris latis. Androcia in ramulis parvis posticis, minutis.

Hab. Andes quitenses (Spruce).

\section{2.. Fimbriaria angolensis St. n. sp.}

Dioica, major, tenuis, viridis, postice hyalina. Frons ad $2 \mathrm{~cm}$. longa, $5 \mathrm{~mm}$. lata, ex apice repetito innovata, antice plana, medio postico parum incrassata, leniter convexa, alis leniter adscendentibus, plano-convexis. Costa haud producta, fronde quintuplo angustior, in sectione bene definita et elliptica, quam stratum anticum duplo altior. Cavernæ angustæ, filis liberis nullis. Stomata parva, parum elevata, 6-cellulis biseriatis formata. Cellulæ epidermidis teneræ. Squamæ roseæ, remotæ, oblique oblongolunatæ, appendiculo tenerrimo, magno, ovato, hyalino, grandi-cellulari. Pedunculus tenuis, ad $8 \mathrm{~mm}$. longus, apice dense breviterque barbatus, paleis linearibus purpureis. Centrum capituli hemisphæricum, lobis centro æquimagnis, oblique patentibus, profunde solutis, cum involucro æquilongo campanulatis. Perianthia hyalina, oblongo ovata, ad $3 / 4$ exserta. Reliqua desunt.

Hab. Angola Huilla Cataract (Newton).

BULL. HERB. Borss., février $1899 . \quad 113$ 
Fimbriaria.

26. Fimbriaria innovans (Austin) Evans, Conn. Acad. VIII, 1891, p. 8.

Syn. : Marchantia innovans. Aust. Torr. B. Cl, V, p. 14.

Monoica, mediocris, flavo-virens. Frons ad $15 \mathrm{~mm}$. longa, $3 \mathrm{~mm}$. lata, ex apice innovata, ramis floriferis semper posticis, antice plana, postice leniter convexa, costa haud producta, fronde triplo angustior, alis attenuatis. Stratum anticum quam costa duplo humilius (in medio frondis), cavernis amplis, fila libera nulla. Stomata magna, alte convexa, 8-cellulis quinque-seriatis angustis formata, poro maximo (36 «). Cellulæ epidermidis validæ, æqualiter incrassatæ. Squamæ posticæ minutæ, remotæ, hyalinæ, appendiculo oblongo, parum acuminato, purpureo. Pedunculus ad $7 \mathrm{~mm}$. longus, compressus, varie et humiliter costatus, apice paleis filiformibus longis sparsim barbatus. Carpocephala parva, centro alte convexo, lobis centro æquimagnis, umbellatim patulis, teneris, grosse papulosis, margine decurvis, usque ad basin liberis; involucra breviora, tenerrima, perianthia itaque oblique pendula, ovata, hyalina ad medium exserta. Capsula flavescens, operculo maxime incrassato. Sporæ flavorufæ, $90 \mu$, alis angustis, crenato-lobulatæ. Elateres $216 \mu$, flavescentes, spiris duplicatis, ligulatis. Andræcia in ramulis minutis magna, totum fere ramulum tegentia.

Hab. Hawai (Baldwin, Bishop).

\section{Fimbriaria vulcania (Schffn.) St.}

Syn. : Hypenantron vulcanicum Schffn. Acad. Vindob., 1898, LXVII, p. 155 .

Dioica, major, robusta, viridis, margine posticeque atrorubens. Frons ad $20 \mathrm{~mm}$. longa, $5 \mathrm{~mm}$. lata, antice plana, furcatim ramosa, rarius ex apice innovata (" e ventre continua "Schiffner). Squamæ ventrales atrorubentes, appendiculo ovato-oblongo, obtuso vel subacuto, integerrimo. Pedunculus gracilis, ad $23 \mathrm{~mm}$. longus, sparsim paleaceus, apice paleis rubris longe barbatus. Carpocephala alte hemisphærica, dense papulosa. Perianthia longe dependentia, conica, pallida, apice tubuloso. Andrceia ignota.

Hab. Java in monte Gunung Guntur $800 \mathrm{~m}$ (Schiffner).

Ipse non vidi. Sine dubio bona species nova.

28. Fimbriaria tenera Mitt. Fl. Nov. Zel. II, p. 170.

Monoica, intense viridis, subtus hyalina. Frons ad $15 \mathrm{~mm}$. longa, $4 \mathrm{~mm}$. lata, tenera, flaceida carnosa tamen, anlice subplana, furcata et 
ex apice innovata, rami postici rariores. Costa lata, fronde 3-plo angustior, plano convexa, alis attenuatis margine obtusis. Stratum anticum humile, quam costa duplo humilius, laxe cavernosum, fila libera subnulla. Stomata magna, parum convexa, 6 cellulis triseriatis formata. Epidermis antica tenerrima, haud incrassata. Squamæ posticæ tenerrimæ, oblique ovatæ, hyalinæ longe appendiculatæ, appendiculo ubique 2-cellulas lato, purpureo, breviter acuminato, grandicellulari. Pedunculus ad $15 \mathrm{~mm}$. longus, subteres, humiliter costatus, labiis crassis rotundatis, ceterum nudus, hyalinus, in ætate plus minus purpurascens, apice breviter barbatus, paleis occultis anguste lanceolatis. Carpocephala juniora viridia conica lobis pedunculo appressis, in ætate brunneola, centro subplano parum papuloso, lobi 4 , cuneati, subrecte patuli, usque ad medium soluti (radiis cuneatis, bene conspicuis) valde papulosi, subplani apice truncatorotundati valdeque decurvi; involucra duplo breviora, tenera. Perianthia subpendula, hyalina, brevissima, involucrum parum superantia, facile in lacinias soluta. Capsula maxima, dilute brunnea, vertice maxime incrassata. Sporæ brunneæ $63 \mu$, reticulatim alatæ, alis latis asperis. Elateres $270 \mu$, tenues, bispiri, spiris laxe tortis, validis. Andrœcia pedunculo approximata, ostiolis hyalinis.

Hab. New Zealand (Colenso, Knight, Petrie, Kirk, Helms, Cheeseman), Tasmania teste Mitten.

\section{Fimbriaria dissoluta St. in Engler, Ostafrica V,} p. 62.

Monoica, major, dilute viridis, interdum omnino purpurascens. Frons ad $3 \mathrm{~cm}$. longa, $1 \mathrm{~cm}$. lata, furcata, ramis masculis posticis numerosis, apice sæpe vegetativis multiramosa, crassa, antice subplana, margine abrupte acuta, postice plano-convexa vel alis decurvis concava, alæ crassæ, spongiosæ, costa minima, vix prominula, fronde octuplo angustior, paucas cellulas alta; stratum anticum itaque totam frondem occupans, cavernis magnis antice bullatim prominulis formatum. Stomata magna, 6 cellulis sexseriatis conflata; squamæ posticæ purpureæ, late oblique ovatæ, appendiculo solitario æquilongo late lineari acuto, margine angulato. Pedunculus vix $2 \mathrm{~cm}$. longus, crassus, ubique nudus, purpureus subteres. Carpocephala magna, hemisphærica, alte grosseque papulosa, lobis ad medium solutis, centro capituli æquimagnis, validis decurvis, involucro æquilongo. Perianthia late ovata, hyalina, acuta, ad medium exserta. Capsula hyalina, valida. Sporæ fulvæ $72 \mu$, anguste alatæ. Elateres $300 \mu$ pallide flavescentes, bispiri, angusti, ubique æquilati, sæpe ramosi, spiris latis, 
laxe tortis. Andrœcia semper in ramis parvis posticis, parva, ostiolis longis purpureis.

Hab. Kilimandscharo (Volkens).

30. Fimbriaria parvipora St. n. sp.

Monoica, parva, fusco-viridis, postice subatra. Frons ad $7 \mathrm{~mm}$. longa, $2 \mathrm{~mm}$. lata, valde canaliculata, simplex vel ex apice innovata, costa planoconvexa, latissima, fronde duplo solum angustior, alis valde attenuatis; stratum anticum in medio frondis humillimum, cavernis angustis paucilamellosis, subvacuis, fila libera nulla. Stomata parva, 6 cellulis superficialibus formata, vix prominula. Cellulæ epidermidis teneræ. Squamæ posticæ parvæ, atropurpureæ, magno appendiculo e lata basi acuminato, basi haud vel minime constricto. Pedunculus pro planta longus (10 mm.) apice paucis paleis hirtus, purpureus, triquetrus. Carpocephala hemisphærica, stomatis parvis papulosa, lobis centro æquilongis ob radios elongatos ad medium connatis, abrupte oblique patulis, antice inflatis, tenerrimis, apice decurvis, crenato-lobulatis. Perianthia oblongo-ovata, $\mathrm{ad}^{2} / 3$ exserta. Capsula? Sporæ flavescentes $70 \mu$, alis repando-lobulatis, angustis. Elateres concolores, $360 \mu$ bispiri, attenuati, spiris in medio confertim, versus apicem laxe tortis. Andrœcia in furcis frondis, parva, ostiolis hyalinis brevissimis.

Hab. Kaschmir Liddar Valley $13000^{\prime}$ engl. (Duthie).

\section{Fimbriaria Wilmsii St. Hedwigia 1892, p. 122.}

Monoica, major, robusta, viridis, margine posticeque interdum purpurascens. Frons ad $4 \mathrm{~cm}$. longa, $10 \mathrm{~mm}$. lata, ex apice innovata, postice parum convexa, costa parum prominente, lata, triplo tamen angustiore quam frons. Stratum anticum humile (in medio frondis 3-plo humilius quam costa) cavernis valde numerosis, angustissimis. Stomata magna, parum convexa, 6 cellulis quinqueseriatis formata; cellulæ epidermidis valde et æqualiter incrassatæ. Squamæ posticæ magnæ, purpureæ appendiculis (interdum geminatis) magnis oblongis vel lanceolatis acutis, margine angulatis. Pedunculus ex apice frondis ortus, crassus, ad $2 \mathrm{~cm}$. longus, subteres, labiis attenuatis, duplicatis, alterne imbricatis, apice paleis purpureis lanceolatis breviter barbatus. Carpocephala hemisphærica, lobis attenuatis, margine grosse lobatis, plano convexis, declivibus ad medium solutis, cum involucro æquilongo, valido integerrimoque late campanulatis. Perianthia oblique pendula, ovato-oblonga, longius exserta, hyalina vel purpurascentia. Capsula subhyalina, tenera, operculo magno. 
Sporæ luridæ, $120 \%$ crenulatim alatæ. Elateres $170 \mu$, sæpe ramosi, mono- vel bispiri, spiris validis. Androecia in ramulis parvis posticis.

Hab. Transvaal (Wilms, Maclea), Mozambique (Braga), Madagascar (Baron.) (Caussèque) Cap. Kumakala (Breutel).

32. Fimbriaria marginata Nees. in Hor. phys. Berol. $\mathbf{1 8 2 0 ,}$ p. 44.

Monoica, pallide-virens, margine posticeque purpurea. Frons ad $150 \mathrm{~mm}$. longa, $4 \mathrm{~mm}$. lata, valida, ex apice innovata, antice subplana; costa fronde 6-plo angustior, humilis in sectione anguste elliptica, alæ validæ, margine integerrimæ. Stratum anticum in medio frondis magis altum quam costa, cavernis amplis, fila libera subnulla. Stomata minima, parum elevata, 6 cellulis biseriatis formata, poro minimo. Squamæ posticæ parvæ, purpureæ, appendiculis longis, geminatis, strictis atque lanceolatis acutisque. Pedunculus brevis (3-4 mm. longus) apice breviter barbatus, paleis lanceolatis. Carpocephali centrum hemisphæricum, stomatis bullatim prominulis, lobi breviores subhorizontaliter patuli, similiter alte papulosi, cum involucro magno late hiantes, perianthia itaque oblique patula, ad $2 / 3$ exserta, late ovata obtusa. Capsula tenera, dilute brunnea, operculo magis fusco, valde incrassato. Sporæ $90 \mu$ fusco-brunneæ, anguste alatæ, alis integerrimis. Elateres $170 \mu$ flavescentes, monospiri. Andrœcia in ramis parvis posticis, sæpe repetito innovatis, omnibus innovationibus masculis.

Hab. Africa australis. Albany (Drège), Capetown (Ecklon, Mc. Owen), Caledon River (Rehmann), Devilspeak (Rehmann), Transvaal (Mc. Lea).

\section{Fimbriaria Boryana Mont. Ann. sc. nat. 1838, IX, p. 41.}

Dioica, viridis, magna et valida postice margineque purpurea. Frons ad $30 \mathrm{~mm}$. longa et $6 \mathrm{~mm}$. lata, ex apice innovata, rarius furcata antice subplana, postice valde convexa, costa fronde triplo angustior, haud vel parum producta, alæ crassæ, sensim attenuatæ. Stratum anticum costæ æquialtum (in medio frondis), cavernis angustis; fila libera subnulla. Cellulæ epidermidis teneræ, trigonis parvis incrassatæ. Stomata magna, parum convexa 7 - vel 8 cellulis, 6 -seriatis ædificata. Squamæ posticæ parvæ, oblique ovatæ, appendiculo longissimo (quam squama sæpe duplo longiore) lanceolato, basi vix constricto, apice acuminato acuto, intense sanguineo. Pedunculus ad $4 \mathrm{~cm}$. longus, validus purpureus, subteres et parum costatus, apice paleis purpureis longo barbatus. Centrum carpocephali parvum convexum, lobi centro longiores oblique patuli cum 
involucro æquilongo bene campanulati. Perianthia purpurascentia, oblongo-ovata, ad $2 / 3$ exserta. Capsula rufescens. Sporæ $100 \mu$, flavescentes alis latis repandis. Elateres $270 \mu$ dilute flavescentes, bispiri, spiris laxe tortis, filiformibus. Andræcia in dorso frondis aggregata, sæpe 3-vel plura consecutiva.

Hab. Mascarenæ Insulæ (Bory de S. Vincent, Rodriguez, Richard, Boivin, de l'Isle).

34. Fimbriaria Khasiana (Griff.) Mitt. Hep. Ind. or., p. 126, in Linn. Soc. V.

Syn. Octoskepos Khasianus. Griff. Not. tab. 69 D, fig. II.

Monoica, minor, tenera, pallide virens. Frons ad $15 \mathrm{~mm}$. longa, $3 \mathrm{~mm}$. lata, parum canaliculata in fronde adulta postice purpurea, in novellis hyalina, costa minima, postice valde producta, in sectione hemisphærica, alis tamen tenerrimis, laxissime cavernosis; stratum anticum ceterum totam fere frondem occupans, filis liberis nullis. Stomata magna, parum convexa, 6 cellulis triseriatis formata. Squamæ parvæ purpureæ, appendiculo anguste lanceolato breviter acuminato integerrimo. Pedunculus ad $10 \mathrm{~cm}$. longus, nudus, subteres. Carpocephala pro planta maxima, centro minimo, convexo, stomatis longissime utriculatis quasi hirto, lobi similiter sed sparsius utriculati, margine stomatis longe productis longe angusteque inciso lobati, ceterum umbellatim expansi, involucra humilia, tenera. Perianthia parva, ovata, hyalina; Capsula tenera superne dilute rufescens, basi hyalina, opereulo magno valde incrassato (parietes radiales). Sporæ $90 \mu$, humiliter cristatæ. Elateres $102 \mu$. bispiri. Androcia pedunculo approximata, ostiolis hyalinis, longis.

Hab. Himalaya (Hooker et Thomson).

Die Beschreibung ist nach dem Hoockers'schen Original no 1677 gefertigt, da Griffith keine Pflanzen dieser Art nach Europa gelangen liess.

\section{3ั. Fimbriaria Bachmannii St. Hedwigia, 1894, p. 7.}

Dioica, major, robusta, pallide virens, subtus hyalina. Frons ad $3 \mathrm{~cm}$. longa, こ̆ mm. lata, ligulata, ex apice vel e latere costæ innovata, antice plana, postice leniter convexa, costa haud producta, fronde plus triplo angustior, alæ validæ, parum acuminatæ, ipso margine abrupte acutæ; stratum anticum in tergo costæ humile, duplo humilius quam costa, cavernis angustis, filis liberis subnullis. Stomata parva, parum convexa, 8 cellulis parvis biseriatis formata. Cellulæ epidermidis teneræ; squamæ 
posticæ remotæ, purpureæ, triangulares, acutæ, pro more tamen appendiculatæ, appendiculo hyalino tenerrimo oblongo vel lanceolato acuto, basique constricto, parum breviore quam squama. Pedunculus $10 \mathrm{~mm}$. longus, tenuis, compressus vel subteres, parum costatus, apice dense barbatus, paleis longioribus hyalinis, anguste linearibus. Carpocephala hemisphærica alte angusteque papulosa, profunde quadriloba, lobis centro capituli æquimagnis, valde decurvis, margine - magnis stomatis prominentibus - grosse lobulatis, cum involucro æquilongo breviter campanulatis. Perianthia hyalina, ovato-conica, obtusa, ad $1 / 2$ exserta, pendula; capsula flavescens, tenerrima opercu'o valde incrassato. Sporæ $90 \mu$, alis angustis integerrimis, asperulis, flavescentes. Elateres breves, $136 \mu$, concolores, bispiri, æquilati, obtusi, spiris validis. Androcia in planta propria terminalia, magna, oblonga valde convexa, ostiolis magnis purpureis.

Hab. Transvaal (Bachmann) (Mc. Lea).

\section{Fimbriaria violacea Austin. Torr. Bot. Cl. III, p. 17.}

Monoica, minor, pallide viridis, postice hyalina. Frons ad $2 \mathrm{~cm}$. longa, ex apice innovata, $2 \mathrm{~mm}$. lata, crassa, costa latissima, convexa, alis angustis costam parum superantibus subhyalinis; stratum anticum medio costæ æquialtum, anguste cavernosum, filis usque ad epidermidem elongatis. Stomata magna, valde convexa, poro a 6 cellulis angustis quadriseriatis circumdato; cell. epidermidis haud incrassatæ. Squamæ posticæ fusco-purpureæ, imbricatæ, appendiculo singulo elongato, anguste lanceolato. Capitula in ramulo postico terminalia, breviter pedunculata, pedunculo crasso, subtereti, humiliter costato, basi purpureo, superne expallescente, paucis paleis hirto, apice barbato, paleis hyalinis sublinearibus. Carpocephala purpureo maculata, e centro majore alte rotundato crassoque longe quadriloba, lobis ad medium discretis, oblique decurvis, capitulo duplo longioribus. Involucra itaque late tubulosa. Perianthia ovatoobconica, ad medium immersa, hyalina (secundum Auct. violacea) capsula subhyalina, apice incrassata (parietes radiales). Operculum haud vidi. Sporæ magnæ, $102 \mu$, rufæ, lobatim cristatæ, cristis tenerrimis asperis. Elateres $270 \mu$, flavescentes, bispiri, spiris angustis, laxe tortis. Andrcecia in ramulis lateralibus minutis.

Hab. California (Jepson, Bolander, Coulter, Howe).

Austin beschreibt diese Pflanze als recept. subconoidea tragend; diesen Eindruck erhält man auch, wenn man die schief abstehenden lobuli mit in Betracht zieht; dass die Perianthien an den Jepson'schen Pflanzen hyalin sind und nicht violett, halte ich für kein wichtiges Unterschei- 
dungszeichen, da je nach dem mehr oder weniger belichteten Standort die Farben der Marchantiaceen mehr oder weniger roth ausfallen und an ein und derselben Art erheblich variiren können. Im Uebrigen ist die Diagnose Austins zu einer sicheren Bestimmung zu unvollständig und ich habe die Beschreibung, da Originalpflanzen nicht zu erhalten waren, nach dem Jepson'schen Exemplar gefertigt, das wohl Howe bestimmt hat.

37. Fimbriaria pilosa (Wahl.) Taylor Linn. Soc. XVII, p. 386.

Syn. Marchantia pilosa Wahlbg. Flora lapponica 1810, p. 399. F. nana Ldbg. Syn. Hepat. Europ., p. 110 (?).

Monoica, parva, pallide viridis. Frons simplex vel ex apice innovata, antice subplana, crassa, marginibus breviter acuminatis acutis, leniter adscendentibus, triplo latior quam alta. Costa latissima, humilis, postice plano convexa sensim attenuata. Stratum anticum laxe cavernosum, cavernis altis (triplo altioribus quam costa), fila libera nulla. Stomata magna, convexa, 6 cellulis triseriatis formata. Epidermis haud incrassata, parietibus validis. Squamæ magnæ, imbricatæ, purpureæ, appendiculo lineari, longo sed breviter acuminato, striclo. Carpocephala parva, centro hemisphærico, ipso vertice parum majus prominente, humiliter papuloso. Pedunculus ad $3 \mathrm{~cm}$. longus, purpureus, profunde irregulariterque costatus haud barbatus. Lobi brevissimi, cum involucro fere ad annullum membranaceum reducti, ob radios elongatos ad posticum incurvos haud soluti, oblique extrorsum nutantes, lamina involucri interdum fissa; perianthia dein oblique patula, ovato-oblonga, longe exserta, laciniis longe acuminalis. Capsula tenera, flavo-rufescens; operculum magnum, bene definitum, validum, cellulis altis brunneis, valde incrassatis formatum. Sporæ $72 \mu$, profunde lobato-alatæ pallide flavescentes. Elateres $290 \mu$ tri- quadrispiri, spiris angustis, arcte tortis. Andræcia ad basin pedunculi parva purpurea.

Hab. Germania, Sudeten, Helvetia (Schleicher), Suecia (Arnell), Grænlandia (Vahl, Vanhœffen), Japonia (Faurie), Fennia, Lapponia (Lindberg), Sibiria (Arnell), Norvegia (Kaalaas), Am. sept. Vancouver Island (Macoun), California (Coville), Washington Terr. (Brandegee).

Die letztgenannten drei Standorte führt Underwood an. Washington soll wohl Wash. Territ. heissen?, denn bei der Stadt dieses Namens wird die Pfianze wohl schwerlich vorkommen; es ist eine alpine und arctische Art, und Californien ist deshalb auch zweifelhaft. 
38. Fimbriaria vesiculosa Austin. Acad. Phila. 1869.

Monoica, mediocris, pallide virens, in sicco flavescens, maxime crassa. Frons ad $15 \mathrm{~mm}$. longa, $3 \mathrm{~mm}$. lata, repetito breviterque furcata, apice sæpe 4-6 ramulos nascentes gerens, ante apicem itaque latissima ob ramulos nondum separatos, antice valde concava, postice leniter convexa, ubique fere æquicrassa, alis parum attenuatis; costa latissima, frondi fere æquilata, in alis attenuatim excurrens. Stratum anticum cosiæ æquialtum, cavernis antice convexo-prominulis, amplis, prismaticis, fila libera nulla; stomata parva, numerosa, parum convexa, poro magno 6 cellulis parvis circumdato. Epidermidis cellulæ æqualiter incrassatæ, validæ. Squamæ magnæ, roseæ, oblique triangulares, longe acuminatæ, nusquam constrictæ. Pedunculus ad $10 \mathrm{~mm}$. Iongus, validus, in sectione compresso ellipticus, apice paleis hyalinis longe filiformibus sparsim barbatus. Carpocephala centro hemisphærica, lobis quam centrum duplo breviorıbus oblique patulis cum involucro rquilongo cupulatis usque ad basin liberis. Perianthia ovata, distincte acuminata, laciniis longe cuspidatis, hyalina ad $2 / 3$ exserta. Capsula medio infero cellulis elongatis, supero magnis cellulis incrassatis formata, hyalina. Sporæ $54 \mu$ flavescentes, anguste alatæ. Elateres subhyalina $180 \mu$, spiris duplicatis filiformibus. Andracia pedumculo approximata. Antheridia longe seriata totum ramulum fere percurrentia.

Hab. Patria? North Pacific Exp. (Rodgers).

Eine ausgezeichnete Art, welche an ihrer dicken, schwammigen Frons leicht wieder zu erkennen sein wird.

39. Fimbriaria californica Hampe in Austin. Hep. Bor. Am., p. $13 \%$.

Monoica, major, robusta, fusco-viridis, margine posticeque purpurascens. Frons simplex vel ex apice innovata, ad $2 \mathrm{~cm}$. longa, $12 \mathrm{~mm}$. lata, crassa. antice subplana, costa late convexa, fronde duplo angustior, sensim in alas attenuata, humilis; alæ tenues, crispato-plicatulæ. Stratum anticum sat altum, cavernis angustis; stomata magna, hyalina, valde concava, cellulis triseriatis formata, poro amplo. Cellulæ epidermidis aqualiter incrassatæ. Squamæ posticæ purpureæ, magnæ, semilunatæ, appendiculis (2 vel 3) brevibus, basi valde constrictis, lanceolatis, hyalinis. Capitula dilute viridia, longe pedunculata, pedunculo ad $2^{1 \prime}{ }_{2} \mathrm{~cm}$. longo, valido. superne stramineo, basi flavo-rufescens, nudo, apice barbato, paleis longissimis, hyalinis, linearibus vel lanceolatis, e cellulis elongatis ædificatis. Carpocephala centro hemisphærico, ad medium quadriloba, lobis 
oblique patentibus, magnis apice inciso bilobis. Involucra itaque optime bilabiata, labiis rotundatis integerrimis. Perianthia hyalina, ovato-conica, semiexserta, ore breviter tubuloso. Calyptra tenerrima, cellulis magnis $(50 \times 120 \mu)$ formata. Capsula tenera, dilute brunnea, cellulis trigone incrassatis. Operculum haud vidi. Sporæ $120 \mu$, fulvæ, late lobatim-cristatæ cristis asperrimis. Elateres $200 \mu$, mono- vel bispiri. Andræcia in ramulis posticis minuta.

Hab. California (Howe, Boländer, Bauer, Bigelow).

40. Fimbriaria echinella G. Hepat. Mex., p. 271.

Monoica, minor, viridis, purpureo marginata. Frons ad $15 \mathrm{~mm}$. longa, $4 \mathrm{~mm}$. lata, concava, alis adscendentibus, attenuatis, ex apice innovata. ramis posticis floriferis valde numerosis. Costa angustissima, fronde multoties angustior, postice leniter convexa et vix producta. Stratum anticum humile, cavernis solum sub poro amplioribus, reliquis minutis; fila brevissima, sæpe ad unam cellulam reducta. Stomata parva, 6 cellulis triseriatis prærupte superpositis formata. Cellulæ epidermidis æqualiter incrassatæ, validæ. Squamæ parvæ purpureæ; appendiculis disco squamæ æquilongis, anguste lanceolatis, integerrimis. Pedunculus ad $7 \mathrm{~mm}$. longus, teres, paucis paleis hyalinis, linearibus obsitus, apice similiter et sparsim barbatus. Carpocephala, hemisphærica, stomatis maxime utriculatim elongatis quasi spinosa, lobi capitulo æquilongi, oblique patuli, cum involucro campanulati, antice similiter sed sparsim utriculati, margine stomatis grosse lobati. Capsula hyalina, tenerrima. Operculum parvum bistratum hyalinum, parietibus radialibus maxime trabeculatim incrassatis. Elateres $200 \mu$ dilute flavescentes, bispiri spiris angustis. Sporæ rufæ, $63 \mu$, lobato cristatæ. Andrcecia in ramulo parvo postico.

Hab. Am. sept. Arkansas (leg. Trécul), Mexico (Fr. Müller), Texas (Wright. teste Underwood).

41. Fimbriaria abyssinica G. Syn. Hep., p. 569.

Monoica, viridis, postice purpurea, robusta, crassa, gracilis. Frons ad $15 \mathrm{~mm}$. longa, $3 \mathrm{~mm}$. lata, linearis, ex apice innovata, antice subplana, postice valde convexa, costa fronde subtriplo angustior, haud producta. alis crassis, sensim attenuatis, margine acutis integerrimis. Stratum anticum in medio frondis costæ æquialtum, cavernis angustis, sub poro filis longis confertis. Stomata magna, 8-cellulis quadriseriatis formata. Cellulæ epidermidis validissimæ. Squamæ posticæ late lunatæ, appendiculo æquilongo stricto, lanceolato longeque acuminato, basi haud constricto. 
Fimbriatia. FRANZ STEPHANI. SPECIES hepatiGarum.

Pedunculus ad $10 \mathrm{~mm}$. longus purpureus, ubique longe paleaceus, paleis linearibus, apice magis numerosis. Carpocephala pro planta magna. centro hemisphærico grosse papuloso, lobis oblique decurvis centro eapituli æquilongis, papulosis, cum involucro æquilongo et valido late campanulatis, profunde solutis. Perianthia late ovata, apice inflato-obtusata, hyalina, vix ad medium exserta. Capsula valida, flavescens operculo valde incrassato. Sporæ $90 \mu$, alis angustis, integris, asperis. Elateres $150 \mu$, flavescentes, bispiri, spiris angustis; Andrœcia (in planta propria ex apice ramulo femineo innovata) in medio frondis irregulariter aggregata, ostiolis brevissimis, crassis, purpureis.

Hab. Abyssinia (Kotschy, Schimper).

(A suivre.) 
Extrait du Bulletin de l'Herbier Boissier.

Tome VII. No 3. Mars 1899.

\title{
SPECIES HEPATICARUM
}

AUGTORE

\author{
Franz STEPHANI
}

(Suite.)

42. Fimbriaria sanguinea L. L. in Lehm. Pug. IV, p. है.

Monoica, minor, antice viridis, postice atrosanguinea, gracilis. Frons ad $15 \mathrm{~mm}$. longa, $3 \mathrm{~mm}$. lata, ubique linearis, ex apice innovata (rami feminei minimi e latere costæ orti), subplana, costa fronde quadruplo angustior, leniter convexa, alis validis laxe cavernosis, stratum anticum, in tergo costæ, humile, anguste cavernosum, fila libera ad cellulas conicoprominulas reducta. Stomata magna, valde convexa, 6 cellulis quinque seriatis formata; epidermidis cellulæ teneræ. Squamæ posticæ lunatæ, longissime appendiculatæ, appendiculis geminatis, approximatis, linearibus, apice subulatis, grosse cellulosis. Pedunculus brevis, ad $5 \mathrm{~mm}$. longus, stramineus, perfecte teres, ubique (præsertim in apice) paleis linearibus hyalinis hirtus. Carpocephala parva, hemisphærica, lobis centro eapituli æquimagnis, decurvis, involucro æquilongo. Perianthia oblonga, ad $2 / 3$ exserta. Andræecia semper in fronde primaria dorsalia, disciformia ostiolis purpureis numerosis. Reliqua desunt.

Hab. Nepal (Wallich); Simla (Griffith).

\section{Fimbriaria multiflora St. n. sp.}

Monoica, pallide virens, mediocris, valida. Frons ad $10 \mathrm{~mm}$. longa, $2 \mathrm{~mm}$. lata, ex apice innovata, ramis femineis posticis versus apicem plantæ aggregatis, antice parum concava, postice convexa, costa haud producta, angustissima, fronde triplo angustior, alis parum attenuatis, 
crassis. Stratum anticum in medio frondis costæ æquialtum, cavernis amplis, filis liberis numerosis. Stomata magna, leviter convexa, 8 cellulis 5 seriatis formata. Epidermidis cellulæ teneræ. Squamæ parvæ, longe appendiculatæ, appendiculo anguste lanceolato, 2 cellulas lato, apice setaceo. Pedunculus ad $10 \mathrm{~mm}$. longus subteres et parum costatus, ubique paleis filiformibus hyalinis hirtus apice barbatus. Carpocephala vertice plano-convexa, profunde quadriloba, centro parvo papuloso, lobis umbellatim patulis, centro multo majoribus, usque ad basin liberis, cum involucro æquilongo campanulatis. Perianthia ad $2 / 3$ exserta, ovata, obtusa, apice sæpe purpurascentia. Capsula flavescens, tenerrima, operculo magno, valde incrassato. Sporæ sulphureæ $544 \mu$ alis angustis integerrimis. Elateres $170 \mu$, flavescentes, monospiri spiris filiformibus. Andræcia in apice frondis, rotunda.

Hab. N. W. Himalaya (Duthie, Gamble).

\section{- 44. Fimbriaria elegans Sprengel. Syst, Veg. IV, p. 230 .}

Monoica, mediocris vel parva, viridis, margine posticeque purpurea. Frons ad $15 \mathrm{~mm}$. longa et $3 \mathrm{~mm}$. lata, ex apice innovata, ramis floriferis minutis semper posticis, antice subplana, postice late convexa, alis valde attenuatis, costa parva, fronde 4 plo angustior, postice haud producta, sat alta et strato antico duplo crassior, cavernæ angustæ, sub poro longe filiferæ. Stomata parum convexa, magna, 6 cellulis 4-כ̆ seriatis formata. Cellulæ epipermidis teneræ. Squamæ posticæ purpureæ, margine cellulis clavatis numerosis obsitæ, appendiculo longo filiformi (ubique $\mathbf{2}$ cellulas lato) apice acuto. Pedunculus ad $15 \mathrm{~mm}$. longus subteres, apice paleis linearibus hyalinis longe barbatus. Centrum carpocephali alte papulosum, hemisphæricum parvum, lobis decurvis profunde solutis, centro longioribus, cum involucro tenerrimo longe campanulatis. Perianthia oblongoovata, fere ad $2 / 3$ exserta, hyalina. Capsula rufescens, operculo valde

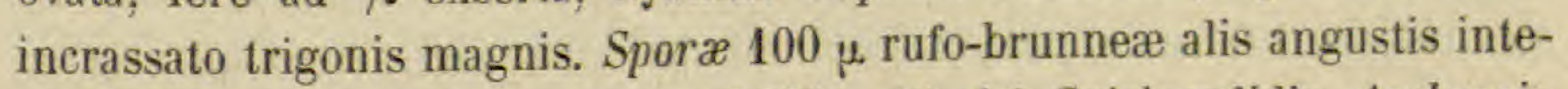
gerrimis, asperis. Elateres brunnei $230 \mu$, bispiri. Spiris validis. Androcia minima, in ramulo parvo postico.

Hab. Sto Domingo (Eggers), Cuba (Wright), Costarica (Wendland), Mexico (F. Müller), Andes Quitenses (Spruce), California (Brandegee). Soll nach Underwood auch in Südamerica und Europa vorkommen.

45. Fimbriaria cubensis Lehm. in Ramon, Hist. Cuba, IX, p. 489.

Syn. : F. elegans var. $\gamma$. cubensis Syn. Hep., p. 563. 
Monoica, minor, angusta, viridis, postice hyalina. Frons ad $12 \mathrm{~mm}$. longa, $3 \mathrm{~mm}$. lata; margine subintegerrima, ex apice innovata, rami $\delta$ interdum postici, antice subplana, postice parum convexa, alis longe attenuatis; costa parva, fronde 5 plo angustior, strato antico æquicrassa, postice convexo-prominula. Cavernæ angustæ, sub poro breviter filiferæ. Cellulæ epidermidis teneræ. Stomata magna, parum convexa, 6 cellulis こ̃ seriatis formata. Squamæ posticæ parvæ, purpureæ, appendiculo (sæpe geminato) Iongissimo, anguste lanceolato apice setaceo. Pedunculus tenuis, $10 \mathrm{~mm}$. longus, apice paleis longiusculis linearibus hyalinis barbatus, compressus. Centrum carpocephali parvum hemisphæricum alte papulosum, lobis longioribus, alte papulosis, decurvo-patulis cum involucro æquilongo campanulatis. Perianthia oblonga, fere ad $2 / 3$ exserta, hyalina, oblique patula; capsula rufa. Sporæ $90 \mu$, fusco-rufæ, alis anguste alte papillatis. Elateres $180 \mu$, dilute brunnei bispiri, spiris validis. Andrœcia vel terminalia vel in ramulo postico laterali, magna, valde convexa, subnigra, ostiolis brevibus.

Hab. Cuba (Otto jun, Wright, Underwood).

Proxima $F$. eleganti, quæ differt ramis floriferis semper posticis, appendiculo squamarum anguste lineari, usque ad apicem fere $\mathbf{2}$ cell. lato, sporis et elateribus multo majoribus. F. Wrightii differt capitulo multo minus longe papuloso, pedunculo crasso el squamarum appendiculo spinam magnam basalem gerente.

\section{Fimbriaria Bolanderi Austin, Ac. Phila, 1869, p. 230.}

Monoica, minor, viridis, postice purpurea. Frons linearis, $15 \mathrm{~mm}$. longa $2 \mathrm{~mm}$. lata, ex apice innovata, antice late canaliculata, ventre valde convexa, costa fronde plus duplo angustior alis adscendentibus, crassis, attenuatis. Stratum anticum (in medio frondis) costæ æquialtum, cavernis angustis, fila libera subnulla. Stomata magna, parum convexa, 8 cellulis quadriseriatis formata, poro magno. Cellulæ epidermidis haud incrassatæ. Squamæ posticæ purpureæ, imbricatæ, late lunatæ, appendiculo filiformi, inferne $\mathbf{2}$ cellulas lato, apice longe setaceo. Pedunculus in ramulo parvo postico purpureus, tenuis, in sectione ovalis, humiliter costatus, apice longe barbatus, paleis purpureis linearibus pendulis. Carpocephala parva, hemisphærica, stomatis parvis papulosa, lobi oblique patuli, centro capituli sublongiores, ore angustato basique leniter constricta, cum involucro inflato-tubulosa. Perianthia oblongo-ovata, ad ${ }^{2} / \mathrm{s}$ exserta, tenerrima, hyalina. Capsula flavo-virens, tenerrima, operculo magnis trigonis incrassato. Sporæ sulphureæ $72 \mu$, alis angustis remote crenulatis. Elateres $180 \mu$ 
ubique æquilati bispiri, spiris validis. Andrecia in ramulis parvis posticis minuta purpurea.

Hab. California (Boländer, Howe).

\section{Fimbriaria Stahlii St. n. sp.}

Monoica? Minor, tenera, viridis. Frons ad $2 \mathrm{~cm}$. longa, $2 \mathrm{~mm}$. lata, in planta feminea duplo latior, antice subplana, alis tenerrimis; costa angusta (fronde quadruplo angustior) bene producta et valde convexa, strato antico æquialta; stratum hypoporum angustissime cavernosum, cavernarum superficies omnino fere stomatis occupata. Stomata valde convexa, fere bullata, 6 cellulis 4-5 seriatis prærupte superpositis formata. Epidermidis cell. haud incrassatæ. Squamæ posticæ magnæ, appendiculo singulo longe lineari. Pedunculus carpocephali ad $7 \mathrm{~mm}$. longus, pro planta crassus, nudus, fuscus, compressus. Carpocephala giobosa (perfecta haud vidi), stomatis numerosissimis alte papilliformibus obsita. Lobis umbellatim patulis, tenerrimis, venosis, cum involucro breviter campanulatis; perianthia oblongo-ovata, hyalina, involucro 3 plo longiora, longe exserta. Capsula dilute brunnea, operculo parvo. Elateres $190 \mu$, bispiri, fusci, æquilati $(12 \mu)$. Sporæ $8 \check{\mu} \mu$, subnigræ, humiliter cristatæ, cristis crenulatis. Andracia in ramulis angustis longe seriata, ostiolis hyalinis longis.

Hab. Guatemala (Bernoulli), Mexico (Stahl, Bourgeau).

48. Fimbriaria lateralis Howe. Torr. Bot. Cl. XXV, p. 189.

Monoica, minor, viridis, margine posticeque purpurea. Frons crassa, ad $15 \mathrm{~mm}$. longa, $4 \mathrm{~mm}$. lata, ex apice innovata, profunde canaliculata; costa angusta subconico-convexa, alæ crassæ, marginibus tamen valde attenuatis; stratum anticum sat altum, anguste cavernosum, fila libera brevissima 3 cellulas alta, conferta. Stomata parum convexa, 6 cellulis quadriseriatis formata. Epidermidis cellulæ validæ. Squamæ purpureæ, imbricatæ, appendiculo lanceolato longe acuminato, apice subulato. Carpocephala numerosa, semper in ramulis parvis posticis; pedunculus subhyalinus, ad $15 \mathrm{~mm}$. longus ubique paleaceus, paleis linearibus hyalinis, apice longissimis, ceterum subteres. Carpocephala parva, vix $\mathbf{2} \mathrm{mm}$. Jata, e centro parvo convexo quadrilobata, lobis profunde discretis, plano-convexis, ob cavernas perlucentes striolatis margineque crenatis, capituli centro æquilongis; involucra parum breviora, tenerrima, longe intra margines loborum orta. Perianthia ovata, semiexserta, hyalina. Capsula rufa, cellularum parietes ubique validæ, versus apicem maxime æqua- 
literque incrassatæ. Operculum? Sporæ rufæ $72 \mu$ alis subintegerrimis. Elateres $180 \mu$, concolores, ubique aquilati, bispiri, spiris angustis. Androcia in ramulo parvo postico.

Hab. Mexico (Rose) (Schaffner).

49. Fimbriaria linearis St. in Engler, Bot. Jahrb. XX, p. 302.

Dioica, minor, pallide virens, in ætate flavescens, postice purpurea, gracilis, valida. Frons ad $15 \mathrm{~mm}$. longa, innovationis repetitione persæpe triplo longior, $2 \mathrm{~mm}$. lata, linearis, sub flore $q$ solum ampliata, lobis majoribus obcordata, nusquam furcata, ex apice vel e latere costæ ramosa, antice leniter canaliculata, postice subcarinatim-convexa, costa valde convexa, fronde quadruplo angustior, alæ attenuatæ validæ integerrimæ. Stratum anticum in tergo costæ humile, cavernæ angustæ, lamellis accessoriis valde numerosis, confertis, fila libera subnulla. Stomata sparsa, parum convexa, 6 cellulis bi-vel triseriatis formata; cellulæ epidermidis validæ, trigonis nullis. Squamæ posticæ purpureæ, oblique ovatæ, longe appendiculatæ, appendicula geminata, approximata, anguste lanceolata, cellulis elongatis formata. Pedunculus ad $10 \mathrm{~mm}$. longus, compressus, irregulariter costatus, apice longe paleaceus, paleis hyalinis, linearibus; carpocephala parva, hemisphærica, alte papulosa, lobis capituli centro æquimagnis, profunde solutis, decurvis, papulosis, involucro tenero æquilongo; perianthia fusiformia, ad $3 / 4$ exserta, hyalina. Capsula? Sporæ $63 \mu$, flavescentes anguste alatæ. Eleateres $144 \mu$, concolores. Androecia in ramulis magnis posticis, apice sæpe vegetativis, parva, ostiolis brevibus purpureis.

Hab. Usambara (Holst.), Bourbon (Rodriguez).

50. Fimbriaria commutata St. n. sp.

Syn. : F. violacea Pearson, non Austin, in Selwyn, Survey, 1890, p. 7.

Monoica, minor, viridis margine posticeque purpurascens. Frons semper ex apice innovata, ad $2 \mathrm{~cm}$. longa, $4 \mathrm{~mm}$. lata, ramis o late obcordatis. antice ob alas oblique adscendentes, ample canaliculata; costa angusta, optime obconica, valde producta, lateribus in alas attenuatas longe excurrentibus. Stratum anticum humillimum, subanguste cavernosum, stomatis itaque numerosis, magnis, bullatim prominentibus, poro 6 cellulis prærupte quadriseriatis circumdato. Squamæ posticæ magnæ, purpureæ, imbricatæ, appendiculis geminatis, approximatis, brevibus, anguste linearibus, hyalinis, Carpocephala parva, minus longe pedunculata, pedunculo $1 \mathrm{~cm}$. longo ubique sparsim paleaceo, paleis subfiliformibus, hyalinis 
apice magis numerosis longioribus. Capitula e centro hemísphærico parvo ad medium quadriloba, lobis decurvo-patulis, valde convexis, a basi tenerrimis et laxissime cavernosis dilute brunneis rotundato-truncatis, apice breviter incisis. Involucra ad laminam brevem tenerrimam reducta, lobis triplo breviora. Perianthia intense purpurea, persepe expallescentia, basi hyalina, ovata, obtusa, semiexserta, oblique patula. Capsula subhyalina, basi tenera, superne magnis trigonis incrassata, operculo parvo bistrato, cellulis internis maximis brunneis instructo. Sporæ $68 \mu$, fiavorufescentes, grosse lobatim alatæ, alis tenerrimis facile destructis. Elateres $170 \mu$, vermiculares i. e ubique æquilati valdeque flexuosi, sæpe ramosi, bispiri, spiris angustis laxe tortis. Andrcecia pedunculo plus minus approximata, antheridiis seriatis, ostiolis magnis purpureis.

Hab. Am. sept. Canada, Selkirk ms. (Macoun).

\section{s1. Fimbriaria Austini Und. Bot. Gaz. XX, p. 64 .}

Dioica? pallide-viridis, tenera, mediocris. Frons ad $15 \mathrm{~mm}$. longa, 5 mm. lata, ex apice vel e ventre innovata, antice subplana, postice leniter convexa; costa fronde quintuplo angustior abrupte carinatim producta et optime obconica in sectione transversa, alis tenerrimis maxime attenuatis. Stratum anticum in medio frondis duplo humilius quam costa, cavernis angustis sub poro dense breviterque filiferis. Stomata parum convexa, 6 cellulis triseriatis formata. Cellulæ epidermidis teneræ. Squamæ posticæ hyalinæ, teneræ, oblique ovatæ appendiculo longissimo simplici anguste lanceolato medio supero filiformi, purpureo. Pedunculus ad $10 \mathrm{~mm}$. longus, validus, subteres et parum costatus, paleaceus, apice paleis longis filiformibus dense barbatus. Carpocephala matura centro parvo convexo, grosse papuloso, lobis profunde solutis, parum patulis subpendulis, valde attenuatis, venosis, centro longioribus. Perianthia oblongo-ovata semiexserta pendula. Andræcia in frondis facie antica magna, disciformia vel in ramulis parvis posticis minuta ad pauca antheridia reducta. Reliqua desunt.

Hab. Cuba (Wright).

\section{c. Gapitula distincte conica (haud alte umbonata).}

\section{Fimbriaria Mülleri G. ms.}

Monoica, viridis, margine posticeque atropurpurea, mediocris. Frons ad $18 \mathrm{~mm}$. longa, $3 \mathrm{~mm}$. lata, linearis vel oblonga, ex apice innovata, 
ramis floriferis utriusque sexus posticis, parvis, antice subplana, costa fronde 3 plo angustior, sat convexa, sensim in alas attenuata, alæ tenerrimæ, venosæ; stratum anticum humillimum, costa duplo humilins, anguste cavernosum, filis sub poro longis confertis; stomata magna, valde convexa, 6 cellulis quinqueseriatis formata. Epidermis tenera. Squamæ posticæ, lunatæ, in appendiculum late breviterque ligulatum transeuntes. Pedunculus $20 \mathrm{~mm}$. longus, crassus et tenax, purpureus, apice paleis brevibus hyalinus barbatus, compressus varie profundeque costatus. Carpocephala conica, obtusa, papulosa, lobis centro vix brevioribus, oblique patulis inflatis, cum involucro æquilongo subtubulosis. Perianthia late ovata, hyalina, ad medium exserta, oblique patula. Capsula rufescens, operculo trigonis magnis incrassato. Sporæ $\mathbf{1 0 8} \mu$, late alatæ, rufescentes. Elateres $180 \mu$, monospiri. Androcia magna elongata, valde convexa, ostiolis brevibus.

Hab. Australia Lindos Valley (F, von Müller).

๑3. Fimbriaria australis Taylor. J. of B. 1844, p. 573.

Monoica, major, fusco-viridis, postice marginibusque purpurea. Frons ad $3 \mathrm{~cm}$. longa, $\breve{\mathrm{mm}}$. lata, interdum furcata, pro more ex apice innovata, crassa, antice plana, marginibus validis integerrimis; costa convexa, bene producta, triplo angustior quam stratum anticum, sensim in alas attenuata; stratum anticum costæ æquialtum. Stomata magna, hyalina, valde convexa, poro amplo 6 cellulis bi-vel triseriatis circumdato, cellulie epidermidis trigonis magnis incrassatæ; squamæ posticæ magnæ, vix imbricatæ, semilunatæ, purpureæ, appendiculo maximo ovato obtuso, hyalino, basi valde constricto integerrimo. Carpocephala in fronde vel in parvis ramulis posticis terminatia, pedunculo ad $15 \mathrm{~mm}$. longo, inferne purpureo, basi nudo apice sparsim longeque barbato, paleis lanceolatis vel subfiliformibus. Capitula late conica, vertice obtusa, fere ad medium quadriloba, lobis oblique patulis, cono centrali fere æquilongis, involucra itaque late tubulata, ore bilabiatim incisa, labiis rotundatis, integerrimis. Perianthia longe exserta, involucro 3 plo longiora, oblique patula, oblongo ovata, apice breviter tubulosa, hyalina.

Calyptra tenerrima. Capsula viridis, tenuis, operculo bistrato, cellulis trigone incrassatis. Sporæ flavo-virescentes, humiliter reticulatim cristatæ $51 \mu$. Elateres pallidi, mono-vel bispiri, ad $200 \mu$. Andræcia semper in ramulo postico, ostiolis brevibus purpureis.

Hab. Nova Zelandia, Thames (Kirk, Colenso). 
54. Fimbriaria conocephala St. n. sp.

Dioica, major, viridis vel purpurascens. Frons ad $2 \mathrm{~cm}$. longa, fureata vel ex apice innovata, oblongo-cuneata, parum concava; costa angustissima, postice abrupte producta, Ieniter convexa, alæ tenerrimæ, plicatocrispatæ. Stratum anticum humillimum, cavernis angustis; stomata magna 6 cellulis sexseriatis formata, valde convexa. Cellulæ epidermidis haud incrassatæ; squamæ posticæ magnæ, roseæ, appendiculo late ligulato, hyalino, obtuso, valde variabili, longo vel perbrevi, angusto vel latiore, parum vel haud constricto. Pedunculus ad $2.0 \mathrm{~mm}$. longus, subteres, parum costatus, nudus, apice barbatus, paleis comatis validis, brevibus et occultis, breviter lanceolatis acutis. Carpocephala magna, centro conico umbonato, hemisphærico-subconico, profunde quadriloba, lobis subconicis, plano-concavis, decurvulis, cum involucro æquilongo breviter campanulatis. Perianthia ovato-oblonga, hyalina, longe exserta, ore breviter tubuloso ; capsula tenera, flavo-rufescens, operculum haud vidi. Sporæ $108 \mu$, late reticulatim-alatæ, alis integerrimis. Elateres $170 \mu$, bispiri, spiris angustis. Androcia in soros parvos aggregata.

Hab. Australia Geographe Bay (Berthoud), Marrego River (Bäuerlen), Grampians (Sullivan), Rockhampton (Ferd. v. Müller), Tasmania (Fitzgerald).

วัง. Fimbriaria Whiteleggeana St. Hedwigia 1889, p. 8.

Monoica, minor, valida, viridis, sæpe omnino purpurea. Frons ad $10 \mathrm{~mm}$. longa, $2 \mathrm{~mm}$. lata, ex apice innovata, antice ample canaliculata, medio postico valde convexa; costa fronde triplo angustior, strato antico æquialta, cavernæ angustæ, filis liberis subnullis. Stomata magna, 6 cellulis 4-5 seriatis formata. Cellulæ epidermidis haud incrassatæ. Squamx posticæ purpureæ, hyaline-marginatæ, appendiculo ovato, hyalino tenerrimo, basi plus minus constricto. Pedunculus ad $2 \mathrm{~cm}$. longus fusco-purpureus, apice barbatus, paleis brevibus lanceolatis, hyalinis. Centrum carpocephali optime late conico-umbonatum, lobis umbellatim patulis, centro æquilongis, cum involucro æquilongo longius campanulatis, ad $2 / 3$ solutis. Perianthia hyalina, ovata, ad medium exserta, pendula. Capsula flavescens. Sporæ flavidæ magnæ, $126 \mu$, alis latis, integerrimis. Elateres $216 \mu$ mono-vel bispiri, spiris laxe tortis, angustis. Androecia parva, in dorso frondis femineæ, a pedunculi basi remota, ostiolis magnis purpureis.

Hab. Australia New South Wales (Whitelegge) (Sullivan). Queensland (Bailey), Peel River (Nusson), Wimmera (Eckert), Stewart River (Johnson). 
วั6. Fimbriaria caucasica St. n. sp.

Monoica, mediocris, margine posticeque purpurea. Frons ad $2 \mathrm{~cm}$. longa, $3 \mathrm{~mm}$. lata, furcata vel ex apice innovata, anguste ligulata, parum canaliculata, rami of solum latiores. Stratum anticum humillimum. cavernis parvis filisque brevissimis. Costa abrupte producta (alis ab initio tenerrimis) in sectione quasi pendula. Stomata magna, 6 cellulis quadriseriatis formata, alte conica. Epidermis haud incrassata. Squamæ magnæ purpureæ, imbricatæ, appendiculo magno lanceolato acuminato. Pedunculus 15 mm. longus, purpureus, breviter barbatus, paleis anguste lanceolatis, hyalinis. Carpocephala alte conica, ad medium quadriloba, lobis umbellatim divergentibus. Involucra campanulata ore truncato integerrimo. Perianthia oblongo-ovata, hyalina, ore breviter tubuloso. Capsula hyalina valida, basi pluristrata; operculum parvum bistratum. Elateres $220 \mu$, sporæ $136 \mu$, late alato-cristatæ, stramineæ, alis integerrimis. Andrecia pedunculo approximata.

Hab. Caucasus (Moyston).

\section{Fimbriaria tasmanica St. n. sp.}

Monoica, viridis, subtus fusco-purpurea, valida. Frons ad $150 \mathrm{~mm}$. longa, $5 \mathrm{~mm}$. lata, ex apice innovata, antice valde concava, marginibus erectis. Costa fronde quadruplo angustior, postice plano-convexa, alis crassis, acutis. Stratum anticum (in medio frondis) costæ æquialtum cavernis angustis, dense lamellatum, stomata magna, parum convexa, 6 cellulis triseriatis formata; cellulæ epidermidis teneræ. Squamæ posticæ purpureæ oblique ovatæ, in appendiculum lanceolatum, apice subulatum attenuatæ. Pedunculus brevis, ad $7 \mathrm{~mm}$. longus, crassus purpureus, apice breviter barbatus, paleis anguste lanceolatis hyalinis occultis. Carpocephala pro planta magna, late conica, papulis humilibus, lobi profunde soluti capituli centro æquilongi eoque contigui (haud divergente-patuli) cum involucro longius campanulati, perianthia itaque ad medium immersa, ovata, purpurascentia. Capsula haud matura. Androcia in ramulis parvis pesticis.

Hab. Tasmania (Weymouth).

58. Fimbriaria subplana St. Hedwigia 1894, p. 8.

Monoica, viridis, major, valida, postice purpurea. Frons ad $30 \mathrm{~mm}$. longa, $6 \mathrm{~mm}$. lata, antice subplana, postice plano-convexa ; costa lata haud producta, fronde duplo solum angustior; stratum anticum costæ æquialtum, cavernis angustis sub poro filiferis. Stomata alte convexa, 6 cel- 
lulis quadriseriatis formata; epidermidis cellulæ teneræ. Squamæ posticæ magnæ sanguineæ longe appendiculatæ, appendiculis geminatis approximatis, fere contiguis, late lanceolatis breviter acuminatis, acutis. Pedunculus ad $10 \mathrm{~mm}$. Iongus maxime irregulariter costatus, apice breviter barbatus, paleis hyalinis; carpocephala parva, conico-rotundata, lobis brevibus decurvis. Perianthia oblonga, longe exserta. Reliqua desunt. Androecia in ramo magno postico disciformia, ostiolis confertis purpureis.

Hab. Australia occid. (Areo Eillinna Well) leg. Helms, Elder Explor. Exped.).

59. Fimbriaria tenella (L.) Nees. Hep. Eur. IV, p. 271.

Syn. : Marchantia tenella L. Sp. PI., p. 1137.

Fimbriaria mollis Taylor J. of Bot. V, p. 414 (1846).

Monoica, parva, viridis, subtus haud colorata. Frons ad $20 \mathrm{~mm}$. longa, $3 \mathrm{~mm}$. lata, furcata vel (raro) ex apice innovata, crassa, antice plana vel in partibus junioribus subcanaliculata, postice convexa, marginibus integerrimis obtusis; costa parva, fronde triplo angustior, crassa, in alas validas attenuata, bene sed haud abrupte producta, medio infimo solum radicellifera; stratum anticum costæ æquialtum, cavernis angustis; fila libera fere nulla. Stomala humillima, poro majusculo 6 cellulis biseriatis circumdato. Cellulæ epidermidis trigonis magnis incrassatæ. Squamæ inagnæ purpureæ, contiguæ, appendiculo magno oblique triangulari, acuminato, acuto, hyalino. Carpocephala parva, breviter pedunculata, pedunculo ad $3 \mathrm{~mm}$. longo, inferne purpureo, humiliter costato, apice breviter barbato, paleis lanceolatis purpureis inclusis, ceterum subtereti. Capitula conico-hemisphærica, ad $1 / 3$ quadriloba, lobis oblique declivibus, crassis, margine altenuatis laxeque cavernosis, margine angulatim repandis; involucra magna, inciso biloba tenera. Perianthia oblongo ovata, semiexserta, hyalina. Capsula tenerrima subhyalina, cellulis magnis formata. Operculum haud vidi. Sporæ $70 \mu$, grosse lobato-cristatæ fulvæ, asperæ. Elateres $200 \mu$, flavescentes, spiris angustis, laxe tortis. Androcia in soros aggregata vel longe biseriata, pedunculo plus minus approximata, ostiolis longis hyalinis vel coloratis.

Hab. America septentr. haud rara.

\section{Fimbriaria Mandoni St. n. sp.}

Monoica, major, robusta. Frons ex apice innovata, ramis posticis floralibus numerosis, ad $3 \mathrm{~cm}$. longa, $5 \mathrm{~mm}$. lata, antice leniter concava 
purpurea. Frons ad $2 \mathrm{~cm}$. longa, $4 \mathrm{~mm}$. lata, linearis, ex apice innovata, ramis femineis parvis posticis, antice subplana. Costa fronde triplo angustior, late convexa, distincte (haud abrupte) producta, alæ crassæ, acutæ. Stratum anticum costæ æquialtum, maxime lamelliferum, cavernis angustis, filis liberis nullis. Stomata parva, parum convexa, 6 cellulis biseriatis angustis formata; epidermis æqualiter maximeque incrassata, trigonis nullis. Squamæ contiguæ, purpureæ, oblique lunatæ, apice in setam longam hyalinam attenuatæ. Pedunculus ad $3 \mathrm{~cm}$. longus, purpureus, superne longe paleaceus, apice barbatus, paleis purpureis, linearibus, rectangulatus vel subteres. Carpocephala late conica, obtusa, grosse papulosa, lobis oblique patulis, papulosis, centro capituli subæquilongis, cum involucro æquilongo breviter campanulatis. Perianthia hyalina, ovata, obtusa, ad $2 / 3$ exserta, pendula; capsula dilute brunnea. valida. Operculum? Sporææ luridæ, $108 \mu$ anguste alatæ. Elateres breves, $144 \mu$, flavescentes, bispiri, spiris angustis, laxe tortis. Andræcia magna, pulvinata, ostiolis magnis hyalinis, in planta propria ex apice repetito innovata, innovationibus brevibus masculis.

Hab. Kamerun (Preuss'), Angola (Welwilsch).

6. Fimbriaria chilensis Mont. Ann. sc. nat. 1838, IX, p. 44. Monoica, minor, viridis, postice hyalina, crassa. Frons ad $10 \mathrm{~mm}$. longa, $2 \mathrm{~mm}$. lata, furcatim ramosa vel ex apice innovata, antice plana, postice subconvexa; costa fere plana, duplo tantum fronde angustior, sensim in alas attenuatas excurrens. Stratum anticım costæ æquialtum, laxe cavernosum, fila libera nulla. Stomata parva, parum convexa, poro magno 6 cellulis triseriatis angustis circumdato. Epidermis tenera. Squa$m \dddot{x}$ parvæ appendiculo longo lanceolato, longe acuminato, interdum spina magna basali armato. Pedunculus brevis, ad $\mathbf{1 0} \mathrm{mm}$. longus, tenuis vel brevior et magis crassus, teres, humiliter paucicostatus, apice paucis paleis longe filiformibus, hyalinis barbatus. Carpocephala breviter conica, vertice obtusa, lobis umbellatim patulis, teneris, venosis, vix ad medium solutis, apice decurvis, cum involucro breviter campanulatis, ore angustato. Perianthia brevissima, lobos parum superantia, late ovata, capsulæ pressura inflata, apice mucronata. Capsula hyalina; spor $84 \mu$, alis latis, asperis, flavescentes. Elateres $210 \mu$, hyalini, spiris duplicatis filiformibus. Androcia pedunculo approximata, ostiolis hyalinis, brevibus.

Hab. Chile (Gay. Dusén.) 


\section{d. Capitula alte umbonata.}

\section{Fimbriaria alpina St.•n. sp.}

Monoica, fusco-viridis, margine posticeque atro-purpurea, minor. Frons ad $13 \mathrm{~mm}$. longa, $3 \mathrm{~mm}$. lata, furcata vel ex apice innovata, ramis femineis semper posticis, antice late canaliculata, crassa sub alis brevissimis constricta, duplo solum latior quam alta, ventre maxime incrassata, costa lata, strato antico æquialta, postice plano-convexa, lateribus valde rotundatis, ampliatis. Cavernæ angustissimæ. Stomata itaque creberrima, alte convexa, parva 5 cellulis prærupte biseriatis formata; epidermidis cellulæ teneræ. Squamæ posticæ imbricatæ purpureæ, appendiculo longo, stricto, anguste lanceolato. Pedunculus ad $2 \mathrm{~cm}$. longus, compressus. Carpocephali centrum parvum, alte umbonatum. vertice vix angustatum lateque rotundatum, lobis pendulis centro capituli subbrevioribus, per totam longitudinem connatis, inflatis, cum involucro æquilongo tubulosis, ore angustato. Perianthia parva subcylindrica, 3 plo longiora quam lata, apice obtusa. Capsula tenerrima, flavescens. Spor:e $90 \mu$, reticulatim lamellatæ, alveolis parvis angulisque longius papillatis (ut in Ricciis). Elateres $180 \mu$, flavescentes, bispiri. Androcia ad basin pedunculi parva, longe ostiolata, purpurea.

Hab. Bolivia (Mandon).

67. Fimbriaria fragrans (Schleich.) Nees, in Hor. phys. Berol.. p. 4.9.

Syn. : Marchantia fragrans Schleich. Exsicc. III, no 64.

Marchantia umbonata Wallr. Linnea. XIV. p. 6.

Monoica, parva, viridis, margine interdum purpurea. Frons ad $2 \mathrm{~cm}$. longa, $3 \mathrm{~mm}$. lata, furcata vel ex apice innovata, sape simplex; antice alis erectis profunde canaliculata, costa in sectione alte obconica; stratum anticum sat altum, quam costa tamen 3 plo humilius, cavernis angustis, sub poro longe et confertim filiferis. Stomata alte convexa, 6 cellulis quinqueseriatis conflata. Cellula epidermidis teneræ, trigonis magnis incrassatæ. Squamæ posticæ magnæ purpureæ, marginem superantes, hyaline limbatæ, celluis prominulis irregulariter crenatæ, appendiculo longo hyalino lanceolato apice cuspidato. Pedunculus ad $6 \mathrm{~mm}$. longus, subteres, apice subnudus, basi paleis hyalinis filiformibus dense longeque villo- 
Fimbriaria.

8

sus. Carpocephali centrum alte umbonatum subcylindricum, rarius conicoangustatum, vertice semper rotundatum minute papulosum, lobis centro longioribus oblique pendulis, profunde solutis, papulosis, cum involucro aquilongo tubulosis. Perianthia oblongo-ovata, duplo longiora quam lata, hyalina; capsula tenerrima, dilute virescens, obovata. Spor $\mathscr{X}$ flavescentes $90 \mu$, alis latis integerrimis asperis. Elateres breves $144 \mu$, ubique æquilati, stricti, flavestentes, bispiri, spiris validissimis. Androecia in frondis medio antico, antheridiis paucis approximatis; ostiola brevia purpurea.

Hab. Italia, Appeninæ Mtes; Helvetia, Martigny (Bernet); Græcia, Achaia (von Heldreich); Germania, Nordhausen (Wallroth, Vocke), (Mexico, Idaho, Alaska teste Underw.).

Die nordamerikanischen Pflanzen habe ich nicht gesehen.

\section{Fimbriaria nudata Howe, Erythea I, p. 112.}

Monoica, minor, fusco-viridis, margine posticeque atro-purpurea; frons ad $10 \mathrm{~mm}$. longa, simplex vel e latere costæ innovata, valde carnosa, antice ob margines adscendentes canaliculata. Costa maxime et abrupte producta, parum latior quam alta, fronde triplo angustior, medio postico subcarinatim angustata, lateribus curvatim adscendentibus, abrupte in alas excurrens; alæ validæ, margine acutæ. Stratum solidum humile ad infimam partem costæ reductum; stratum anticum dein maxime evolutum, cavernis confertis, angustissimis, poris itaque valde numerosis. Stomata parva, parum convexa, poro amplo, cellulis prærupte biseriatis circumdato, parietibus radialibus (ut in Clevea) attenuatim incrassatis ; cellulæ epidermidis haud incrassatæ. Squamæ posticæ magnæ, marginem frondis superantes, atropurpureæ, imbricatæ, margine varie profundeque laceratæ, sæpe geminatim appendiculatæ, appendiculis irregulariter laceratis. Carpocephala breviter pedunculata, pedunculo stramineo basi apiceque nudo; capitula alte angusteque conica, quadriloba, lobis valde declivibus, parum inflatis usque ad marginem fere connatis; involucra tamen intus longe libera, ad basin coni inserta, late tubulosa et apicem pedunculi longe quasi vaginatim obvelantia. Perianthia oblonga triplo longiora quam lata, ad medium exserta, ore breviter tubuloso. Capsulæ cellulæ superiores trabeculatim incrassatæ, cell. basales teneræ. Sporæ らั1 $\mu$ fusco-brunneæ, humiliter repando-cristatæ. Elateres breves $120 \mu$, monovel bispiri, flavescentes. Androcia basi pedunculi approximata, ostiolis Iongis hyalinis.

Hab. California (Howe, Hansen, Jepson Mc. Clatchie).

Diese Pflanze zeigt durch die enorme Entwicklung des assimilirenden 
Gewebes in der Höhe, grade wie bei Riccia, die Anpassung an ein trocknes Clima, welches die Entwicklung einer dünnen Frons in die Breite verbietet.

\section{Fimbriaria Palmeri Austin. Torr. Bot. Cl. VI, p. 47.}

Monoica, viridis, postice margineque purpurea, major, robusta, capitula maxima. Frons ad 15 כ̆ mm. longa, כั mm. lata, antice subplana vel parum concava, crassa, 3 plo solum latior quam alta. Costa postice plano convexa, lateribus oblique adscendentibus; alæ breves, crassæ, late attenuatæ, postice concavæ, antice planæ. Stratum anticum costæ æquialtum, cavernæ angustæ, regulariter prismaticæ, lamellis accessoriis et filis liberis omnino nullis. Stomata numerosa, parva, こั-6 cellulis conico-conniventibus formata. Epidermis tenera; squamæ magnæ, subdentatæ, purpureæ, appendiculis (interdum geminatis) lanceolatis, margine apiceque varie longeque fimbriatis. Pedunculus ad $3 \mathrm{~cm}$. longus, nudus, crassus, subrufus, in sectione profunde trilobatus, lobus ventralis profunde bilabiatus canalem amplum includens. Carpocephala magna, centro optime alteque conico-umbonato, vertice rotundato, radiis (4-6) distinctis usque ad apicem loborum decurrentibus, lobi itaque haud liberi, antice parum inflati, haud divergente patuli sed penduli, attenuati cum involucro tenerrimo æquilongo breviter tubulosi. Perianthia oblongo-ovata, ad medium exserta, parva, hyalina. Capsula dilute brunnea. Sporæ ad $90 \mu$ in facie convexa vermiculariter lamellata, lamellis humilibus, inciso-lobatis, liberis (haud confluentibus) ceterum fusco brunneæ. Elateres $180 \mu$. dilute brunnei, crassi $(14 \mu)$ spiris duplicatis laxe tortis, filiformibus, stricti ubique fere æquilati. Andrecia parva, pedunculo approximata.

Hab. California (Palmer).

Unbekannt geblieben sind mir :

Fimbriaria gracilis. Colenso in Trans. N. Zeal. Institule 1884, XVI, p. 359 und

Fimbriaria pallide virens Colenso. 1. c., p. 360.

Diese Pflanzen hat der Autor nicht an das Museum in Kew geschickt und bei der völligen Unzuverlässigkeit dieses verdienten Sammlers, dessen meiste und zahlreiche Species novæ einzuziehen gewesen sind, unterlasse ich eine Copie seiner Beschreibungen, die ganz unzureichend sind, hierherzusetzen.

Zu kassiren sind ferner :

Fimbriaria saccata (Wahlbg.) Nees, welche schon Lindberg zu Grimaldia pilosa (Horn.) Lindb. stellte und 
Fimbriaria Kiærii (Asterella) Kaalaas, welche der Autor neuerdings selbst als eine etiolirte sterile Form von Conocephalum conicum erkannt hat.

\title{
CONOCEPHALUM Necker.
}

\author{
Elem. bot. III, p. 344 .
}

Syn. : Fegatella Raddi Opusc. se. II, p. 3 כ̋.

PJantæ frondosæ, majores vel maximæ, terrestres vel paludicolæ, in latas plagas expansæ arcteque repentes, normaliter fusco-olivaceæ. Frons repetito furcata vel monopodialiter ramosa (alternatim pinnata) ex apice innovata, tenax et valida, antice subplana; costa lata, medio postico abrupte producta, cellulis brunneis valde æqualiterque incrassatis formata; stratum anticum humillimum, cavernæ amplæ, fila conferta simplicia gerentes; fila hypopora unicellularia, anguste cylindrica, acuminata, reliqua 2-3 cellulis superpositis inflato-obconicis ædificata (cellulæ opuntiacæ Lindbergii).

Stomata simplicia, maxima, alte inflato-conica, poro amplo 6-cellulis, 8 seriatis circumdato. Squamæ posticæ pro planta parvæ, pallide-violaceæ vel purpureæ. teneræ, appendiculo constricto subrotundo, laxe reticulato. integerrimo, normaliter sub fronde occultæ. Inflorescentia dioica. Androcia disciformia, in apice ramuli abbreviati sessilia, nuda, strato antico recedente vaginatim circumvallata. Carpocephala longe pedunculata; pedunculus e fundo nudo apicali frondis ortus, strato antico recedente in valvas coriaceas mutato circumvallatus, debilis, sublævis teres vel compressus, canali profundo (interdum nullo) percursus, labiis obtusis conniventibus, apice nudus vel paucis paleis brevibus barbatus. Capitula mitræformia, symmetrica, vertice conico-obtusa, inferne campanulata, normaliter 8 radiata; involucra interradialia, e margine radiorum orta. tempore maturitatis inflata, monogyna, superne cavernis magnis inflatis formata, fila chlorophyllifera tamen nulla; stomata capituli complicata (interne cellularum circulo aucta).

Capsula longius pedicellata, parvo bulbo inserta, fusco- brunnea, clavato-pyriformis pendula, maturitate apice longitudinaliter fissa, laciniis revolutis, pariete annulatim incrassato. Calyptra valida, basi cellulis 4-อ̃ stratis formata; sporæ magnæ, asperæ, pluricellulares. Elateres breves. fusiformes, quadrispiri. 
1. Conocephalum conicum (L.) Necker. 1. c.

Syn. : Marchantia conica L. Spec. Pl. II, p. 1604.

Fegatella conica Raddi. 1. c.

Fusco viridis, postice fusco-violacea; frons ad $18 \mathrm{~cm}$. longa, $25 \mathrm{~mm}$. lata, omnium hepaticarum maxima, parum canaliculata, alis plano-convexis longe attenuatis, apice biloba, furcata vel ex apice (interdum geminatim) innovata, antris inflatis antice reticulatim rugulosa, stomatis magnis pallidis obsita. Cellulæ epidermidis haud inerassatæ. Squamæ posticæ oblique lunatæ, longissime in costam decurrentes, margine interdum repando-angulatæ, appendiculo parvo. Carpocephala longe vel longissime pedunculata; pedunculus ad $12 \mathrm{~cm}$. longus, inferne parum coloratus, superne hyalinus, vagina basalis magna, fusca, labiis attenuatis coriaceis plus minus erecto-incurvis. Capitula pro planta parva, 5 mm. longa, vertice optime obconica, fusco brunnea, inferne pallidiora, tempore maturitatis longitudinaliter sulcata. Sporæ $8 \Xi \mu$. Elateres $170 \mu$. (plus minus longiores) fusiformes vel filiformes, valde irregulares. Androcia sæpe in innovatione parva, ob furcas haud solutas subrotunda, disco ovato valido, fusco, $7 \mathrm{~mm}$. longo, ostiolis brevibus, strato antico frondis arete circumvallata.

Hab. Europa, America et Asia septentrionalis ubique, præcipue in montosis communis. Italia, Hispania (Moller), Coimbra (Henriques), Algeria (Trabut), Madeira (Fritze), Azores (Krause), Batum (Levier), Kaschmir (Duthie), Japonia (Faurie), Florida (Rau), Alaska (Krause), Sibiria (Arnell).

2. Gonocephalum supradecompositum (Lindb.) St. Bull. Herb. Boiss. V, p. 82.

Syn. : Sandea supradecomposita Lindb. Acta soc. F. Fl. fenn. II, no 5 . Minor, graeilis valde ramosa, fusea vel dilute viridis, normaliter repetito furcata in flabellam expansa, sæpe ramis elongatis pinnatis; frons ad $3 \mathrm{~cm}$. longa, $3 \mathrm{~mm}$. lata, linearis, integerrima vel marginibus subdentatis crispatulis. Costa abrupte producta, sæpe fusco-brunnea, hieme magnum tuber ex apice proferens; tubera sessilia, in adspectu elliptica, utroque latere apiculata ibidemque squamis appressis obtecta, antice plana, postice alte convexa, magis lata quam longa; alæ frondis attenuatæ, interdum tenuissimæ, papyraceæ. Cavernæ magnæ, humillimæ, stomata magna, multo minus convexa quam in C. conico. Cellulæ epidermidis valde æqualiterque incrassatæ. Squamæ posticæ oblique ligulatæ, appendiculo æquilato, subrotundo, dilute purpureo, cellulis multo minoribus quam in 
C. conico. Carpocephala ad $4 \mathrm{~mm}$. longa, vertice rotundata et vix angustata, campanulata, pedunculo ad $\mathbf{2} \mathrm{cm}$. longo, apice nudo; vagina basalis pro planta spectabilis, brunnea, dura, semiglobosa ore angustato rotundo.

Capitula iis C. conici simillima, calyptra basi pluristrata; sporæ tamen multo minores $68 \mu$, pallide rufæ, elateres $170 \mu$. Androecia in fronde terminalia utroque latere pinnula innovata, parva, purpurea, strato antico frondis humiliter cincta.

Propagula in ramis terminalia (1-6) facillime decidua, parva, haud stipitata, horizontalia, plana, breviter et latissime spathulata, rotundatoobtusissima, integerrima, basi unam alteramve squamam posticam minutam gerentia, haud radicellifera (Lindberg).

Hab. Japonia (communis in regione subtropica) (Faurie, Makino, Savatier, Miyabe, Inouë, Tokubuchi); China, Prov. Schensi (Giraldi).

Die Pflanze ist je nach dem Standort sehr variabel, auf sandigem nassem Boden dünn und stark etioliert; das Laub ist dann fahlgelb, das dunkle Gewebe der Rippe ist hyalin, die Verzweigung bleibt (wohl aus Nahrungsmangel) trotz der Etiolirung zurück und man findet am Ende der Hauptäste eine verbreiterte Laubscheibe mit zahlreichen gedrängt stehenden Vegetationspunkten, deren jeder mit weit hervorragenden purpurfarbenen Schuppen geschützt ist, die keine Spitzenanhängsel tragen und spitz auslaufen; die Gemmen tragende Form habe ich nicht gesehen. Die terminale Knolle dieser Art entspricht dem ruhenden Winterspross unseres $C$. conici, der auch 2 Vegetationspunkte hat, woher die befremdliche Erscheinung rührt, 2 Innovationen aus der Spitze eines Thallus entspringen zu sehen.

Meine schon früher publizirte Fegatella japonica ist bisher in Frucht nicht gefunden worden; es ist eine Riesenpflanze, die ich in Exemplaren von $22 \mathrm{~cm}$. Länge besitze; ohne die Fructificationsorgane ist aber eine definitive Entscheidung nicht möglich; ich zweifle, dass sie eine gute Art ist.

\section{LUNULARIA Micheli.}

Nov. Gen., p. 4.

Plantæ trondosæ, terrestres, validæ, glauco-virentes, arcte repentes. Frons ad $2 \mathrm{~cm}$. longa regulariter furcata vel ex apice innovata, ramis planis, late ligulatis apice breviter bilobis; costa in medio postico parum 
producta sensim in alas attenuata. Stratum anticum humillimum, fila chlorophyllifera, 3 cellulas longa, opuntiaca. Stomata hyalina, simplicia, valde convexa, poro magno, 6 cellulis quinqueseriatis circumdato; epidermis antica laxe cellulosa, cellularum parietibus validis angulisque trigone incrassatis. Squamæ posticæ tenerrimæ, hyalinæ vel roseæ, late lunatæ (quadruplo latiores quam longæ) appendiculo magno parum constricto, rotundato, integerrimo, vel pauci-dentato, cellulis oleiferis numerosis punctatæ.

Carpocephala in ramis abbreviatis terminalia, fronde uno latere increscente quasi lateralia, longe pedunculata, pedunculus e costæ fundo nudo ortus, ad $3 \mathrm{~cm}$. longus, hyalinus nudus vel paleis capillaceis hirtus, haud canaliculatus, superficie varie sulcatus, apice paucis paleis capilliformibus armatus, basi squamis magnis vaginatim erectis hyalinis obtectus; squamæ pluriseriatæ, externæ maximæ, $3 \mathrm{~mm}$. latæ, reniformes, internæ sensim minores, intimæ ligulatæ longissime capillaceo-fimbriałæ.

Capitula ㅇ parva, juvenilia disciformia, quadrifoveolata, foveola bilabiata labiis horizontalibus, tri-quadrigyna, adulta 4 involucra cruciatim inserta gerentia, strato antico nullo. Perianthium nullum. Involucrum e margine foveolæ ortum, cylindricum, tenue sed pluristratum, ore angustato bilabiato. Calyptra magna tenera. Capsula 'ovata, magno bulbo inserta, longe pedicellata longeque exserta, pedicello crasso, usque ad basin fere quadrivalvis, valvulæ rufo-brunneæ, angustæ, apice cellulis parvis bistratis magis incrassatis instructæ, reliquæ cellulæ magnæ rectangulares, æqualiter incrassatæ, haud annuliferæ. Elateres $340 \mu$. laxe bispiri.

Sporæ rufæ, minutæ, ad 17 mm., læves. Androcia disciformia, sessilia, nt capitula terminalia, fronde uno latere increscente quasi lateralia rotundo vel oblonga, e fundo nudo costæ - strato antico recedente orta, paleis nullis, limbo lato attenuato circumdata, ostiolis mamillatim productis. Propagula antica discoidea, e fundo nudo costæ orta, breviter pedicellata, reniformia, a tergo squama carnosa semilunata nutante obtecta, mucore inundata.

1. Lunularia cruciata (L.) Dum. Com. bot., p. $\mathbf{1 1 6 .}$

Syn. : Marchantia cruciata L. Sp. Pl., p. 1604.

Lunularia vulgaris Mich. I. c.

Hab. Europa et Africa mediterranea, Madeira, Tenerifa. Abyssinia (Beccari), Kilimandscharo (Hans Meyer), Chile (Hahn, Dusén), Queensland (Bailey). Ausserdem durch Blumenerde überallhin verschleppt.

BULL. HERB. BOISS., mars $1899 . \quad 143$ 


\title{
EXORMOTHECA Mitt.
}

\author{
in Godman Hist. Azores, p. 325.
}

Plantæ thallosæ, parvæ, teneræ vel majores et robustæ, virides vel flavicantes, in una hyalinæ. Frons simplex vel parum ramosa, linearis vel ligulata, antice subplana, stratum anticum vel humile stomatis alte cylindricis instructum vel altissimum (stomatis confluentibus); in fundo strati lamelliferi adsunt fila chlorophyllifera simplicia, maxime aggregata. Costa postice valde producta. Squamæ posticæ magnæ, dense imbricatæ, obtusæ vel acuminatæ, sub apice in facie externa appendiculo filiformi vel dendroideo instructæ. Inflorescentia monoica et dioica. Andracia in medio frondis pulvinata, bene definita, haud tamen disciformia neque paleis cincta. Carpocephala pedunculata vel sessilia, e fundo nudo alveoli apicalis, sæpe ante sinum dichotomiæ orta; pedunculo sulco profundo percurso, apice nudo. Receptacula globosa, vertice haud stomatifera, strato chlorophyllifero tecta. Archegonia plura (1-5̃) seriata. Involucra geminata, opposita; recte patentia cupuliformia vel conchæformia, ore plus minus late aperta, subtus vaginatim angustata vel aperto-decurrentia. Capsula sphærica irregulariter valvatim rumpens, pedunculo perbrevi, bulbo magno inserta; pariete unistrato, annulatim incrassato, rufo-brunneo. Operculum cellulis majoribus distinctum, intus cellulas elateriformes pendulas maximeque incrassatas gerens. Elateres flavescentes, laxe bi- tri-spiri. Sporæ in facie convexa vel primatice areolatæ et angustatæ, læves vel minute papulosæ.

\section{Exormotheca pustulosa Milt. 1. c.}

Monoica vel dioica. Frons viridis, parva, usque ad $12 \mathrm{~mm}$. longa, simplex vel furcata, linearis, canaliculata vel subplana, crassa, marginibus attenuatis; cost $a$ postice valde producta lateque rotundata, sensim in alas excurrens; squamæ posticæ marginem haud excedentes, hyalinæ vel purpureæ, late lunatæ, apice duplo angustiores lateque rotundatæ vel obtuse breviterque bilobæ, margine obtuse denticulatæ, appendiculo filiformi, apice geniculatim erecto. Stratum anticum humile; epidermis ob stomala confertissima nulla. Stomata conico cylindrica, 3 plo longiora quam lata contigua, ore parvo elliptico, parvis cellulis cincto; fila chlorophyllifera brevia dense aggregata, sub antris longiora et in lumen stomatorum pro- 
tracta. Androcia pulvinulata, bene definita, haud disciformia, in dorso frondis, a tergo carpocephali vel in ramulo proprio, interdum in planta propria, ostiolis purpureis aggregatis. Carpocephala plus minus longe pedunculata, pedunculo usque ad $20 \mathrm{~mm}$. longo, basi apiceque nudo, subtereti, profunde sulcato. Receptaculum horizontaliter eylindricum, $4 \mathrm{~mm}$. latum, subtus in vaginam plus minus longam, pedunculum amplectentem protractum. Involucra 2 , ex utroque receptaculi parte extrema orta, cupuliformia, tenera, ore truncato, labiis crispatulis. Capsula longius pedicellata, subexserta. Elateres 2-3 spiri, spiris laxe tortis. Sporæ $51 \mu$, flavidæ, læves, laxe areolatæ et prismatice angulatæ.

Hab. Ins ${ }^{c e}$ Madeira (Johnston, Fritze), Tenerifa (Aurel Krause), Africa occid. Angola (Welwitseh), Africa orient. Abyssinia. Bogos, ad ripas flum. Insaba (Beccari).

2. Exormotheca fimbriata (Nees) Solms. Bot. Ztg. 1897.

Syn. : Riccia fimbriata Nees in Mart. Fl, bras. I, p. 301.

Myrriorhynchus fimbriatus Lindb. Soc. F. Fl, fenn, 1884.

Dioica, major, robusta, viridis. Frons usque ad $15 \mathrm{~mm}$. longa, $4 \mathrm{~mm}$. lata, simplex vel parum ramosa, ramis late ligulatis, antice subplana, costa latissima strato antico æquilata, postice leniter convexa, sensim ad margines atlenuata. Stratum anticum humillimum, cavernis anguslis. Stomata alte conico-cylindrica, omnino discreta sed conferta, epidermide interjecta angusta, antice truneata parum convexula. Fila chlorophyllifera conferta, longa in stomatum cavitatem elongata. Squamæ posticæ magnæ, dense imbricatæ, utroque latere costæ uniseriatæ, marginem frondis longe superantes, hyalinæ, ex obliqua basi late ligulatæ, superne acuminatæ, obtusæ vel breviter obtuseque bilobæ, margine parum erosulæ hic illic crenatæ, sub apice appendiculatæ, appendiculo dendroideo i. e. medio infero simplici, superne ramosissimo.

Andræcia (leste Solms) in medio antico frondis; antheridia seriata, ostiolis angustis. Reliqua desunt.

Hab. Brasilia. Minas Geraes, Serra de Piedade (Martius).

\section{Exormotheca Holstii St. n. sp.}

Dioica. Frons parva, hyalina, usque ad $10 \mathrm{~mm}$. longa, simplex vel furcata, linearis, antice plana, crassa. Costa maxima, strato antico æquilata, postice valde rotundata, lateribus convexo-adscendentibus. Squamæ posticæ magnæ, cellulis longissimis $(31 \times 253 \mu)$ formatæ, uno latere ad basin grosse lacinulatæ, oblique oblongæ acuminatæ obtusæ, sub apice 
vel apice ipso appendiculatæ, appendiculo a basi multifido, parum ramoso, filis ramisque squarrose divergentes. Stratum anticum costæ æquialtum, in fundo fila aggregata gerens. Stomata densissima altissima, ad $2 / 3$ coalita, tertio supero libera, cylindrica, obtusa, vertice poro rotundato perforata. Andrœcia ignota. Carpocephala in fundo alveoli nudo, strato antico recedente et ante dichotomiam frondis. Receptacula sessilia globosa, vertice haud porosa stratoque chlorophyllifero tecta, subtus obconico-angustata, utroque latere involucrata; involucra 2 , opposita, capituli vertice convexoprominente separata, oblique adscendentia, conchæformia, antice subearinata, subtus apiceque aperta, labiis late hiantibus usque ad basin decurrentibus; capsula longius pedicellata, irregulariter quadrivalvata, valvæ rufo-brunneæ, maxime incrassatæ. Sporæ $136 \mu$, rufæ, ubique minute papulosæ, papulis sæpe rostratis. Elateres ignoti.

Hab. Africa orient. Muse, regio campestris, in locis arenosis humidis (Holst.).

\section{Exormotheca Welwitschii St.}

Syn. : Riccia bullosa Link in Ldbg. Syn. Hep. Eur., p. 119 ex parte.

Major, robusta, in sicco flavo-rufescens, valde spongiosa. Frons usque ad $20 \mathrm{~mm}$. longa, $3 \mathrm{~mm}$. lata, furcata, ramis linearibus, apice tuber clavatum maximum ubique rhiziferum horizontaliter proferentibus. Stratum anticum altissimum, costæ plus triplo altius, cavernis amplis, sub 6 in diametro frondis, epidermide convexa clausis; stomata itaque haud discreta parva, parietibus haud incrassatis. Stratum chlorophylliferum humile, filis minus dense aggregatis, 3 cellulas altis. Costa valida, in sectione late trigona i. e. postice carinatim ampliata, medio infimo solum rhizifera, lateribus nudis sensim adscendentibus sensimque attenuatis. Squamæ posticæ hyalinæ, parvæ, occultæ, oblique triangulatæ apice celluloso dentatæ, acuminatæ, appendiculo filiformi, 8 cellulas longo, haud ramoso. Reliqua desunt.

Hab. Portugal, prope Vendas in ripas flum. Tajo in solo argilloso (Welwitseh).

Diese ausgezeichnete Art ist die extremste Form hinsichtlich der bei dieser Gattung riesenhaft entwickelten Stomata. E. fimbriata hat sie noch getrennt inserirt und die sie tragende Epıdermis ist zwischen ihnen horizontal und deutlich erkennbar, flach über das Assimilationsgewebe hinweglaufend; bei E. pustulosa ist die Epidermis nicht höher gestellt, die Stomata sind aber bereits schlauchartig verlängert und berühren sich mit ihren Basen; die Epidermis trill nicht mehr in die Erscheinung. 
E. Holstii zeigt die Stomata gedrängt, zu langen Schläuchen ausgebildet und diese sind bis auf das obere Drittel bereits miteinander verbunden; bei $\boldsymbol{E}$. Welwitschii endlich hat die Verschmelzung den ganzen Schlauch ergriffen; sie haben eine gemeinsame ununterbrochene Epidermis, die Schläuche sind im Querschnitt 6eckig, jeder trägt auf schwacher Wölbung einen Porus.

\section{CRYPTOMITRIUM Austin.}

in Underwood Bull. III. St. Labor. II, p. 36.

Plantæ frondosæ, terrestres, tenues et teneræ, minores, virides, arcte repentes. Frons oblonga, repetito furcata vel monopodialiter ramosa (ramuli fertiles breves, steriles solum increscentes) raro ex apice innovata vel e latere costæ. Costa valida, angusta, sub alis evanida, alæ latissimæ valde attenuatæ margine tenuissimo. Stratum anticum humile, cavernosum, cavernæ amplæ, vacuæ i. e. filis vel laminulis liberis nullis. Stomata parum elevata, parva 5 -6 cellulis conicis formata, poro minimo. Cellulæ epidermidis haud incrassatæ. Squamæ posticæ biseriatæ, parvæ, remotæ, purpureæ vel violaceæ, late ovatæ, varie lobatæ, lobis ultimis appendiculo filiformi (8 cellulis superpositis formato) armatis. Inflorescentia monoica. Androcia pedunculo continua, linearia; ostiola hyalina anguste conica, nuda, triseriata. Carpocephala plus minus longe pedunculata; pedunculus ex apice costæ - strato hypoporo recedente - ortus, basi apiceque nudus, teres vel compressus, superficie lævi vel varie profundeque costatus, canali singulo vel duplicato percursus. Capitula disciformia, circularia, antice leniter convexa, maxime papulosa, centro crassa, ad margines attenuata, integerrima vel brevissime 6 lobata, postice subplana. Involucra normaliter 6 , omnino postica, radiatim inserta, capituli marginem haud attingentia, interradialia, radiis in adspectu minus distinctis, in sectione tangentiali facile observandis, ovalia, parva, inflata, tri-quadrigyna, longitudinaliter fissa, ore quam involucrum breviore, labiis conniventibus quasi clausa. Perianthia nulla. Calyptra tenuis, basi bistrata. Capsula sphærica, vix exserta, bulbo sphærico affixa, pedunculo subnullo, operculo bistrato, bene definito. Cellulæ basales $34 / 31$, annuli $20 ّ \mu$, hyalinæ, operculi brunneæ $17 \mu$. æqualiter incrassatæ. Elateres longi, fusiformes $400 \mu$. 
flexuosi, interdum ramosi, bi-vel trispiri. Sporæ $50 \mu$, brunneæ, tetraèdræ, reticulatim lamellatæ, dilute limbatæ.

Gryptomitrium tenerum (Hook.) Austin I. c. Syn. : Marchantia tenera Hook. in Kunth. Syn. pl. 1, p. 45.

Duvalia tenera G. Syn. Hep., p. כัऽ̆4.

Duvalia brevipedunculata Mont. Cent. V, no 79.

Duvalia Gayi Mont. Ann. sc. nat. 1845, p. 354 .

Platycoaspis Lindb. in Sv. Vet. Ak. Handl. XXIII, p. 11.

Hab. Mexico (Humbold), California, Chile (Gay. Dusén).

Howe hat zuerst (Erythea IV, p. 50, 1896) darauf aufmerksam gemacht, dass die Pflanze nicht monogyne Hüllen hat, wie ich nach einem reife Kapseln tragenden Fruchtknopf, an dem sterile Pistille nicht erhalten waren, angenommen hatte; in demselben Aufsatz betont auch Howe, dass der Pedunculus nur eine Wurzelrinne habe, während ich zwei gefunden hatte. Neues gutes Material, von Dusén in Chile gesammelt, zeigte nun dasselbe Verhalten, d. h. auch die chilenische Pflanze enthält in ein und demselben Rasen Fruchtstiele, die bald ein, bald zwei Wurzelrinnen haben, ein Vorkommnis, das ieh noch bei keiner Marchantiacee beobachtet habe, für unsere Pflanze aber typisch zu sein scheint; die Hüllen dieser chilenischen Exemplare trugen je 1-4 junge Capseln.

\title{
DUMORTIERA R. BI. Nees.
}

\author{
Nova Acta Acad. Leop. VII, p. 410.
}

Plantæ frondosæ, spectabiles, terrestres, rupicolæ vel paludicolæ, pervirides, repentes, in latas plagas expansæ. Frons furcata vel ex apice angustatim innovata, apice breviter- sub innovationibus profunde biloba, tenuis antice subplana, margine setosa; costa valde producta; stratum anticum epidermide evanida ad cellulas parvas globosas chlorophylliferas reductum, rudimentis parietum cavernarum reticulatum.

Stomata itaque nulla, in frondi juvenili solum videnda, minuta, poro parvo a 4 cellulas circumdato, sæpe ad rimam irregularem mutato. Squamæ posticæ valde evanidæ valdeque irregulares, acuminatæ cellulisque elongatis liberis laceratæ. Inflorescentia dioica. Carpocephala longe pedunculata, pedunculus bicanaliculatus, basi nudus, apice paleacens, 
paleis crassis, sæpe bifidis. Capitula e centro umbonato 8-12 radiata. radiis apice plus minus furcatis, furcis utroque involucro proximo distributis. Involucra itaque interradialia, antice duabus radiorum furcis approximatis percursa, crassa, ovata, usque ad marginem pluristrata, plus minus setosa, rima verticali rotundato-bilabiata. Calyptra valida, cellulis pluristratis crassa. Capsula longe pedicellata, annulatim incrassata quadrifissa, basi interna utriculis crassis elateriformibus pendulis aucta. Elateres longi, valde attenuati. Sporæ parva, papillatæ. Andræecia sessilia, disciformia, crassa. margine setosa, paleis posticis hyalinis longeque prominentibus villosa, antice e centro umbilicatim immerso convexa, nuda, antheridiis numerosis, ostiola ad mammam humilem reducta.

Die Bildung des Carpocephalum erfordert eine weitere Erläuterung, obgleich sie Leitgeb bereits kurz geschildert hat. Die in der Pflanze sichtbaren Lappen des Fruchtkopfes entsprechen nicht den Radien des Fruchtkopfes von Marchantia; sehr deutlich sieht man das an ganz jungen Köpfen, welche 8 Einkerbungen tragen, in jeder derselben steht eine Gruppe Pistille und zwischen den Gruppen wölbt sich der junge Radius vor. An Pflanzen, deren Involucra voll entwickelt sind. gabelt sich der Strahl in der Mitte seiner Gesamtlänge und giebt nach rechts und links den beiden benachbarten, von ihm getrennten Hüllen, je 1 Gabelast ab. Da jeder Strahl diese zwei Aeste hat, erhält auch jede Hülle deren zwei; bei $D$. trichocephala verlaufen sie als parallele schmale Wülste bis zur Spitze der Hülle; bei D. hirsuta sind dagegen die beiden Gabeläste durch Laubsubstanz verbunden, die zwischien ihnen ausgespannt ist; es bildet also der vordere verbreiterte Teil des Strahls ein Dreieck, dessen Hypothenuse nach der Peripherie des Kopfes zu liegt; die Ecken des Dreiecks sind hier schmal ausgezogen und verlaufen in ähnlicher Weise, wie oben, parallel genähert auf der dorsalen Seite des Involucrums. Ein vertikaler Querschnitt durch eine Hülle zeigı daher auf ihrer dorsalen Seite 2 Wülste oder Kämme, zwischen denen die viel dünnere Laubsubstanz des Involucrums liegt. Zwischen diesen Aesten des Strahls liegt also auf der Oberseite der Hülle eine mehr oder weniger breite Furche, die stets nackt ist; die Aeste aber sind fast immer stark zweizeilig behaart.

Die Randborsten des Laubes übernehmen an Stelle der äusserst reduzierten Ventralschuppen den Schutz des Vegetationspunktes und sind beiderseits zusammenneigend über denselben hinweggebogen. Später fallen die Borsten ab oder wachsen an feuchten Orten wohl auch hie und da zu Wurzelhaaren aus. 
1. Dumortiera trichocephala (Hook.) Nees Hep. Eur. IV, p. 499.

Syn. : Marchantia trichocephala Hook. Icon. pl. II. t. 158.

Frons bene evoluta valida, magis crassa, costa medio postico abrupte producto, in alas excurrens. Carpocephala spinis validis maxime setosa, pedunculo ad $5 \mathrm{~cm}$. longo, interdum setoso, præcipue in medio infero. Capitula valde convexa, centro ruguloso, radiis ad medium furcatis, furcæ vallatim ampliatæ carnosæ valdeque spinosæ in proximis involucris anguste decurrentibus; involucra itaque antice duabus furcis crassis approximatis longeque attenuatis percursa, margine et superficie setis strictis longis maxime hirta. Capsula longius pedicellata, exserta. Sporæ pallide rufæ, 20 \%. Elateres Iongissimi ad $600 \mu$. bispiri, maxime attenuati.

Hab. Tonkin (Balansa), Birma (Stolitzka), Java (Junghuhn, Solms, Schiffner), Tahiti (Nadeaud), Samoa (Reinecke), Hawai (Remy).

Diese Pflanze ist bisher allgemein als $D$. hirsuta ausgegeben worden; ich selbst habe sie daher früher dafür gehalten, und da mir gute Capitula damals von der amerikanischen Pflanze nicht zu Gebote standen und deren Identität mit der europäischen $D$. irrigua mir daher verborgen blieb, die Ueberzeugung ausgesprochen, dass D. hirsuta und D. irrigua 2 verschiedene Arten seien; das Original von D. hirsuta stammt aber aus Jamaica und im tropischen Amerika und Africa kommt keine andere vor; sie ist aber auch in Japan, Nepal und auch in Java gefunden worden, scheint aber viel seltener im Sunda Archipel zu sein, während ich D. trichocephala im ganzen tropischen Asien und Oceanien als gemein bezeichnen kann.

2. Dumortiera hirsuta (Sw.) R. Bl. Nees. I. c.

Syn. : Marchantia hirsuta Swartz. Prodr. FI. Ind. occ., p. 140

D. irrigna (Wilson) Nees. Hep. Eur. IV, p. 1599.

D. nepalensis (Taylor) Nees. Hep. Eur. IV, p. 169.

Frons valde variabilis, bene evoluta minus crassa quam in $D$. trichocephala; costa postice valde producta, sensim in alas attenuata. Carpocephala minus hirta, centro sæpe omnino nudo, longe pedunculata; pedunculus multo validior quam in D. trichocephala, sæpe maxime crassus, nudus; capitula sæpe maxima, minus convexa, centro umbonato parvo, ruguloso, radii furcati, apice solum piliferi, triangulariter ampliati, excisotruncati, angulis attenuatis in utroque involucro proximo decurrentibus. Involucra itaque antice duabus cristis depressis attenuatisque percursa, 
crassa, margine et superficie plus minus hirta. Capsula minus longe pedicellata, tempore maturitatis parum exserta, una tantum evoluta, interdum 2 vel 3. Sporæ pallide rufescentes, $34 \mu$. Elateres breviores, $380 \mu$ ad $500 \mu$.

Hab. Guadeloupe (l'Herminier), Bogota (Lindig), Brasilia (Ule, Glaziou 7234, Puiggari, Lindman), Mexico (Liebman), Africa, Reunion (Gaudichaud), Usambara (Holst 3247), Kamerun (Dusén 36, Preuss 1080), St. Thomé (Moller), Java (Stahl) (Herb. Univ. Lips.), Japonia (Makino, Inouë), Nepal (Wallich), Tahiti (Remy, Vesco), Italia (Bottini, Arcangeli) Hibernia.

- 3. Dumortiera velutina Schffn. Acad. sc. Vindob. LXVII, p. 156. Frons ad $15 \mathrm{~cm}$. longa, $12 \mathrm{~mm}$. lata, tenuis, mollis, antice intense viridis, cellulis anticis chlorophylliferis dense velutina. Pedunculus carpocephali ad $3 \mathrm{~cm}$. longus, nudus, apice paleis lanceolatis hyalinis breviter denseque barbatus. Capitula hemisphærico-conica, vertice obtusa, nuda vel sparsim setulosa, regulariter 5-8 lobata, lobis convexis, margine rotundatim prominulis ibidemque levi sinu discretis, apice breviter inciso-bilobis, ante apicem canaliculato-depressis. Involucra omnino postica, haud prominentia. Androcia haud setulosa. Reliqua ut in D. hirsuta.

Hab. Java, Sumatra (Schiffner).

Superficie frondis densissime papillosa et carpocephali forma distinguenda (Schiffner).

Die gut erhaltene dorsale Schicht freier kugeliger Zellen lässt auf eine Schattenform schliessen, da sie bei allen exponirten Pflanzen leicht zu Grunde gehen; alle Arten dieser Gattung führen diese typischen, der Epidermis entbehrenden Zellen und ein unterscheidendes Merkmal können sie für unsere Art nicht abgeben. Die Carpocephala aber sind sehr abweichend, da die Radien des Fruchtkopfes mit den lobulis hier vollständig zu einer glatten Gewebefläche verschmolzen sind, die nach den Rändern zu wellig verbogen ist. Die Pflanze macht den Eindruck einer forma luxurians.

(A suivre.) 

Extrait du Bulletin de l'Herbier Boissier.

Tome VII. No รั. Mai 1899.

\title{
SPECIES HEPATICARUM
}

AUCTORE

Franz STEPHAvI

(Suite.)

\section{WIESNERELLA Schffn.}

\author{
Oest. Bot. Zeitschr., 1896, p. 1.
}

Plantæ frondosæ, spectabiles, terrestres, dilute virides postice pallidæ, repentes, in latas plagas expansæ, teneræ. Frons ad $10 \mathrm{~cm}$. longa, $10 \mathrm{~mm}$. lata, late linearis, monopodialiter ramosa, hic illic dichotoma, antice subplana, marginibus undulatis integerrimis. Costa strato antico requilata, triplo crassior, plano-convexa, sub alis attenuata, Squamæ posticæ oblique lunatæ, magnæ, hyalinæ, utroque latere costæ uniseriatæ, appendiculo magno subrotundo arcte constricto, margine repando et paucidenticulato. Stratum anticum humillimum, cavernis amplis, filis opuntiacis brevibus dense repletis. Stomata numerosa, magna, valde convexa, 6 cellulis quadriseriatis formata. Cellulæ epidermidis teneræ. Pedunculus capituli terminalis, e frondis sinu angusto profundo ortus, ad $4 \mathrm{~cm}$. longus sape multo brevior, tenuis, hyalinus, nudus vel apice paucis paleis lanceolatis et facile evanidis barbatus, breviter bicanaliculatus, cavernis anticis valde rudimentariis. Carpocephala parva, centro convexo parvo papuloso, stomatis compositis intus 4 cellulis magnis clausis, poro parvo subquadrato, ceterum 5 -8 (normaliter 6 ) radiata, radiis longis angustissimis; lobi interradiales antice parum convexi, late triangulares, stellatim patuli, parum decurvi, acuminati, obtusi. Involucra e margine loborum orta, tenerrima, basi inflata, medio supero carinata, subinde ibidem fissa, bila- 
biata, labiis integris. Perianthia nulla. Pistilla ad 4. Capsula longe pedunculata longeque exserta, sphærica, ad medium irregulariter 46 fissa, valvulæ revolutæ, cellulis annuliferis rubro-fuscis. Sporæ $40 \mu$, reticulatim alatæ, alis latis, lobatis, asperis. Elateres $340 \mu$, longe attenuati, fibris duplicatis anguste tortis. Andræcia in furcis propriis frondis o terminalia, brevissime pedunculata, subsessilia, disciformia crassa, paleis dilute brunneis brevibus cincta.

1. Wiesnerella denudata (Mitten) St.

Syn. Dumortiera denudata Mitt. Linn. Soc. V, p. 12\%.

Wiesnerella javanica Schfîn. I. c.

Hab. Himalaya, Kumaon $5000^{\prime}$ engl. (Strachey et Winterbottom.), Java (Stahl, Schiffner, Massart), Hawai (Baldwin), Japonia (Miyike).

\section{PREISSIA Corda, 1828 in Opitz Beiträge, p. 647.}

Plantæ frondosæ, terrestres, rupicolæ vel paludicolæ minores, repentes in latas plagas expansæ, solum calcareum diligentes. Frons viridis, postice sæpe purpurascens, tenuis, ad $3 \mathrm{~cm}$. longa, pro more ex apice innovata, rarius furcata, ramis ligulatis apice profunde bilobis, antice subplanis, costa postice valde producta, subcarinatim prominens, sensim in alas attenuata. Stratum anticum humillimum, cavernæ filis chlorophylliferis 3-4 cellularibus repletum. Stomata parva, composita, poro antico amplo, 6 cellulis angustis biseriatis circumdato, poro interno cruciato, 4 cellulis circumdato. Squamæ magnæ purpureæ, imbricatæ, late lunatæ, appendiculo parvo angusto basi valde constricto, interdum geminato. Inflorescentia dioica el monoica. Carpocephala terminalia, sub flore semper innovata, longe pedunculata, pedunculo ad $4 \mathrm{~cm}$. longo bicanaliculato, varie costato, nudo, apice dense barbato, paleis rubescentibus e lata basi anguste lanceolatis. Capitula hemisphærica, quadriradiata, radii rectangulatim cruciati, angusti, crassi, involucris vix longiores, capitula itaque subintegerrima. Involucra interradialia, e margine radiorum orta, crassa, antice colorata cavernosa, stomatis ut in fronde, postice hyalina, magis tenues, 2-3 cellulas tantum crassa, ore late aperto integerrimo.

Pistilla $3-6$, transverse (haud longitudinaliter) inserta. Perianthium 
inflatum, apice abrupte anguslatum subrostratum, ore minimo, basi e margine bulbi ortum, tenue. Capsula longius pedicellata, vix exserta, subglobosa, magno bulbo inserta, 4 valvulis rumpens, pariete dense annulatim incrassata, sub apice utriculis magnis brevibus annuliferis et in lumen capsulæ pendulis aucta.

Calyptra tenerrima, basi bistrata. Elateres $170 \mu$, flavescentes, bispiri, subfiliformes. Sporæ $60 \mu$, reticulatim Iobato-cristatæ, rufo-brunneæ. Androcia breviter pedunculata, capitulo disciformi, cavernoso, margine attenuato crispato-plicatulo, centro antheridia aggregata gerente, ostiolis brevissimis, squamæ posticæ hyalinæ. tenerrimæ margine varie laceratæ.

1. Preissia commutata (Ldbg.) Nees. Hep. Eur. IV. p. 117.

Syn. : Marchantia commutata Ldbg. Hep. Eur., p. 101.

Preissia quadrata (Scopoli) Nees. I. c., p. 133..

Preissia mexicana St. Hedwigia 1883. IV, p. 1.

Hab. Europa, Am. sept. et Asia sept. haud rara, Groenlandia (Vanhœeffen), Alaska (Kranse), Sibiria (Arnell), Japan (Miyoshi, Faurie), Italia, Hispania in montosis, Himalaya (Duthie), Mexico (Juergensen).

\section{MARCHANTIA L., 1753}

Sp. pl. II, p. 1063.

Plantæ frondosæ, terrestres, arcte repentes, majusculæ vel magnæ, validæe et coriaceæ. Frons plus minus late ligulata, furcata (fureis secundariis solum floriferis) antice plana, apice profunde inciso-biloba. Costa bene evoluta, lata humilisque, rarius abrupte producta, pro more in alas tenues sensim attenuata. Stratum hypoporum semper humile, cavernis amplis, filis chlorophylliferis opuntiacis confertis. Stomata composita, antice conico prominula, humilia, poro magno aperto, postice conico-cylindrica, in lumen cavernarum pendula, poro interno plus minus parvo, subquadrato vel quadrifisso vel crueiformi vel filifero. Squamæ posticæ utroque latere triseriatæ, series prima costæ insidens, parva, canali rhizifero submarginalis, series secunda magna, appendiculata, series tertia margini frondis approximata, ligulata. Inflorescentia semper dioica. Andrœcia pedunculata vel disciformia crenatoque lobata vel profunde palmatifida, ventre squamuligera; antheridia numerosissima, radiatim seriata, alveolis 
monandris, ostiolis brevissimis. Pedunculus capitulorum ex apice frondis ortus, basi interdum magnis squamis vaginatim involucratus, facie antica cavernis filiferis et stomatiferis instructus, postice duobus sulcis profundis percursus, in planta feminea paleis apicalibus filiformibus barbatus. Capitula 우 vel symmetrica, lobos æquimagnos gerentia vel asymmetrica, lobis inæqualibus, basalibus profundius discretis, sæpe hastatim divergentibus majoribusque, interdum subelobata, hemisphærica, margineque crenulata vel integerrima, antice stomatis (semper compositis) papulosa et cavernis filiferis instructa. Involucra semper interradialia, conchæformia, longe bilabiata, rarius ore angustato bilabiato; labiis sæpe armatis vel crispatis, ad latera magnis squamis ovatis vel lanceolatis obtecla. Pistilla numerosa. Perianthia monogyna, ovata, plicatulo-angustata, ore parvo, interdum rostrato vel plurifido el fimbriato. Calyptra tenera. Capsula longius pedunculata, matura exserta pendula, fusco-brunnea, sæpe fere ad basin regulariter quadrivalvata, parietibus crebre annulatim incrassatis, apice facile diffusis, operculo definito nullo. Sporæ minutæ, tetrædræ, in facie convexa irregulariter lamellulosæ. Elateres semper simplices, longissimi, angusti et longissime attenuati, bispiri.

Die Gattung Marchantia ist eine durch den Bau der Capitula, Spaltöffnungen und Brutbecher von den übrigen Marchantiaceen scharf getrennte und leicht zu erkennende; es sind meist ansehnliche Pflanzen, die aber nur im tropischen und subtropischen Asien und Oceanien einen grösseren Arten-Reichthum entfalten, während die übrigen Gebiete wesentlich ärmer an Arten sind, die dafür aber oft ein ungeheures Gebiet besiedelt haben (March. polymorpha das ganze nördliche Waldgebiet der Erde und die höheren Gebirge des tropischen Asiens und Amerikas, March. chenopoda das tropische Amerika, March. cephaloscypha das antarctische Gebiet Chile, Australien, Neu Seeland).

Die Verzweigung und der Bau der Frons ist von der grössten Gleichmässigkeil, nur die schmalen Formen haben eine etwas höher ausgebildete assimilierende Schicht; die Gründe dafür wurden schon bei Riccia erwähnt; alle Arten haben eine Lichtform, mit kräftiger, ventral of gefärbter Frons und eine Schattenform mit breiterer, schlaffer Frons, meist lebhafter grün gefärbt, auch auf der ventralen Seite.

Die Stomata sind meist wenig gewölbt, oft kaum über die Oberfläche der Frons hervortretend; ihre Grösse ist bei ein und demselben Individuum sehr variabel und kann zur Diagnose daher nicht benutzt werden; grosse Unterschiede aber zeigt der Bau der inneren Porenöffnung, welche 
der chlorophyllführenden Fadenschicht zugewendet ist und deren Schliessung und Oeffnung (durch Quellung) regulatorisch wirkt, wie dem Eindringen fremder Körper ein Hindernis entgegenstellt. Es sind vier Typen in dieser Hinsicht zu unterscheiden, die keine Uebergänge zeigen und daher zur Unterscheidung der Arten ein vorzügliches Merkmal bilden; die innere 0effnung ist danach entweder von vier wurstförmigen

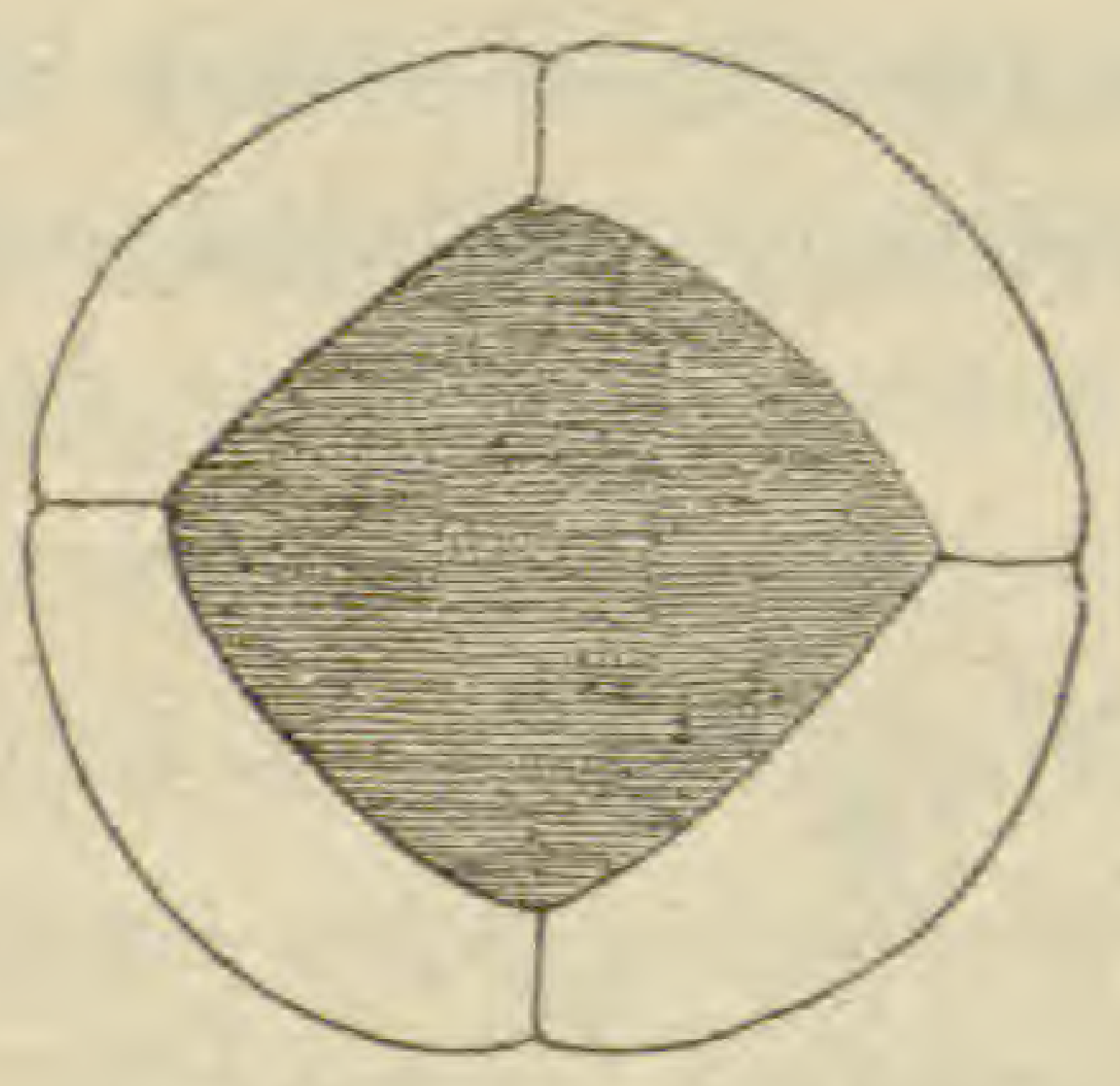

Fig. $a$.

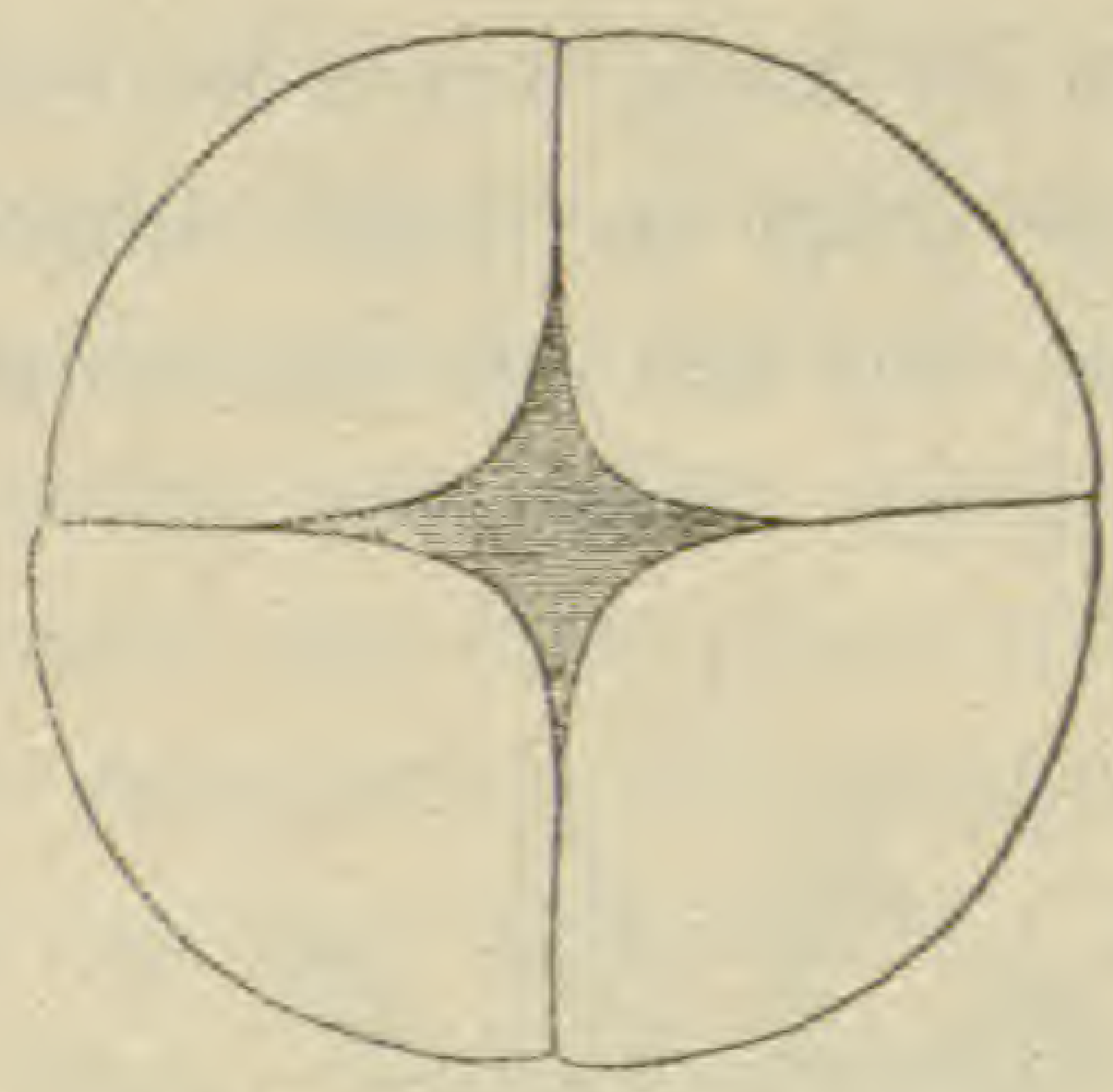

Fig. $b$.

Zellen gesäumt, die sich durch Quellung nur wenig verändern (Fig. a) oder es sind vier flach-konische Zellen, welche radial mit den gerundeten Spitzen zusammenneigen, in der oberen Hälfte frei sind und eine kleine, in vier glatte Spalten ausgezogene Oeffnung frei lassen (Fig. b); sie können dieslbe fast vollständig verschliessen. Ein dritter Typus ist bereits von Preissia her bekannt; die vier konischen Zellen lassen eine kreuzförmige Oeffnung entstehen, die durch Quellung vollständig geschlossen

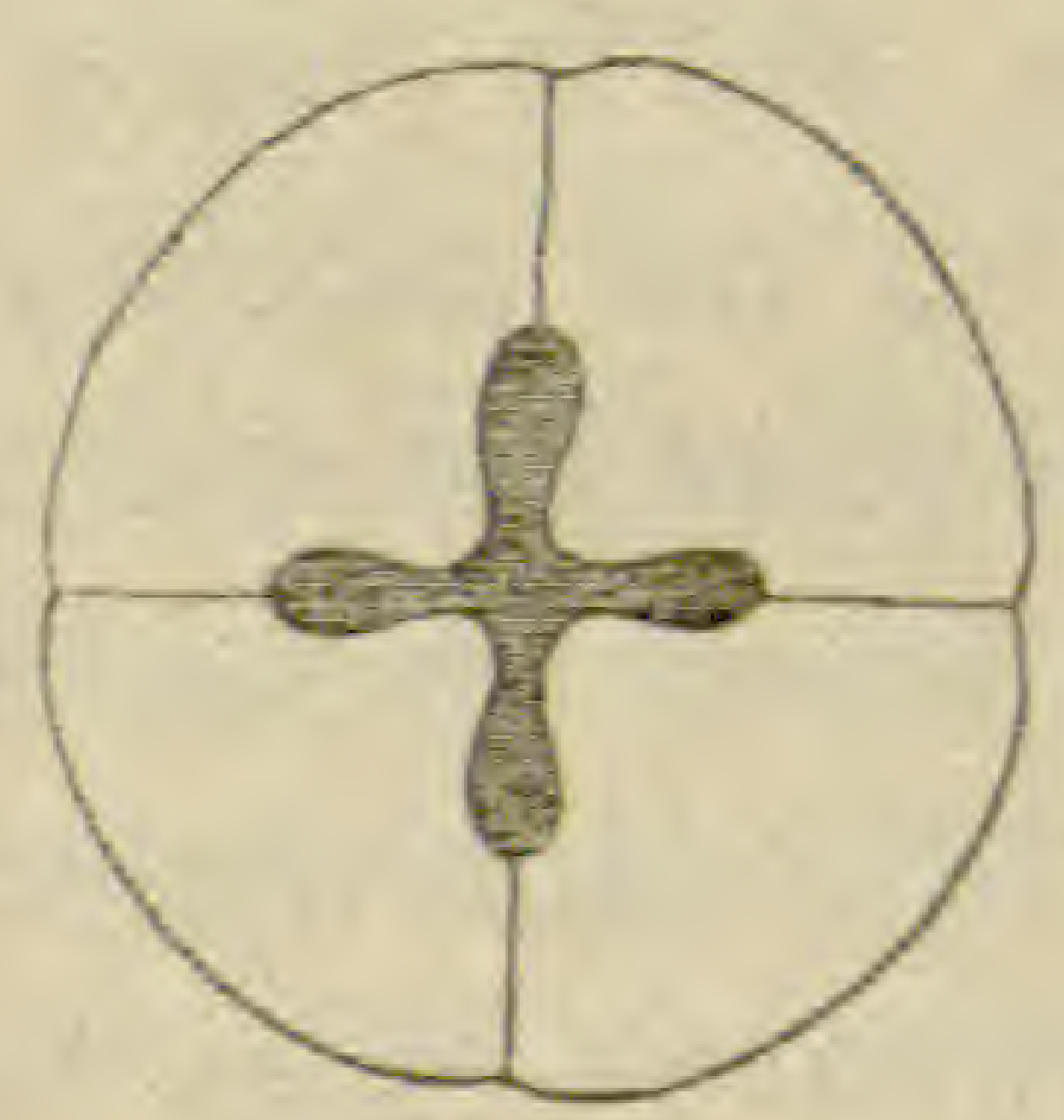

Fig. $c$.

wird, die vier Lappen schieben sich dabei übereinander (Fig. c); eine ganz abweichende Form, als vierten Typus, hat die innere Oeffnung des Porus von M.macropora (aus Neuseeland); die kleinen zahlreichen Zellen, welche sie umsäumen, wachsen hier zu fädigen Schläuchen aus, die dem Centrum der Oeffnung radial zustreben, sich dicht übereinanderschieben und 
so die abnorm grossen Stomata wirksam gegen eindringende Fremdkörper schützen (Fig. d).

Bei manchen Arten unserer Gattung ist die dorsale Epidermis aus 2-3 Zelllagen gebildet und bei $M$. Treubii trägt sie grosse, stumpf-conische, hyaline Papillen; im übrigen ist die Oberhaut sonst einschichtig und glatt, je nach dem Klima mit stärkeren oder schwächeren Zellwandungen versehen.

Die Costa ist meist wenig hervortretend und dann nie sehr stark entwickelt; sie trägt in ihrer ventralen Mediane einen engen und wenig tiefen Canal, der mit den zu einem starken Strang vereinigten verdickten

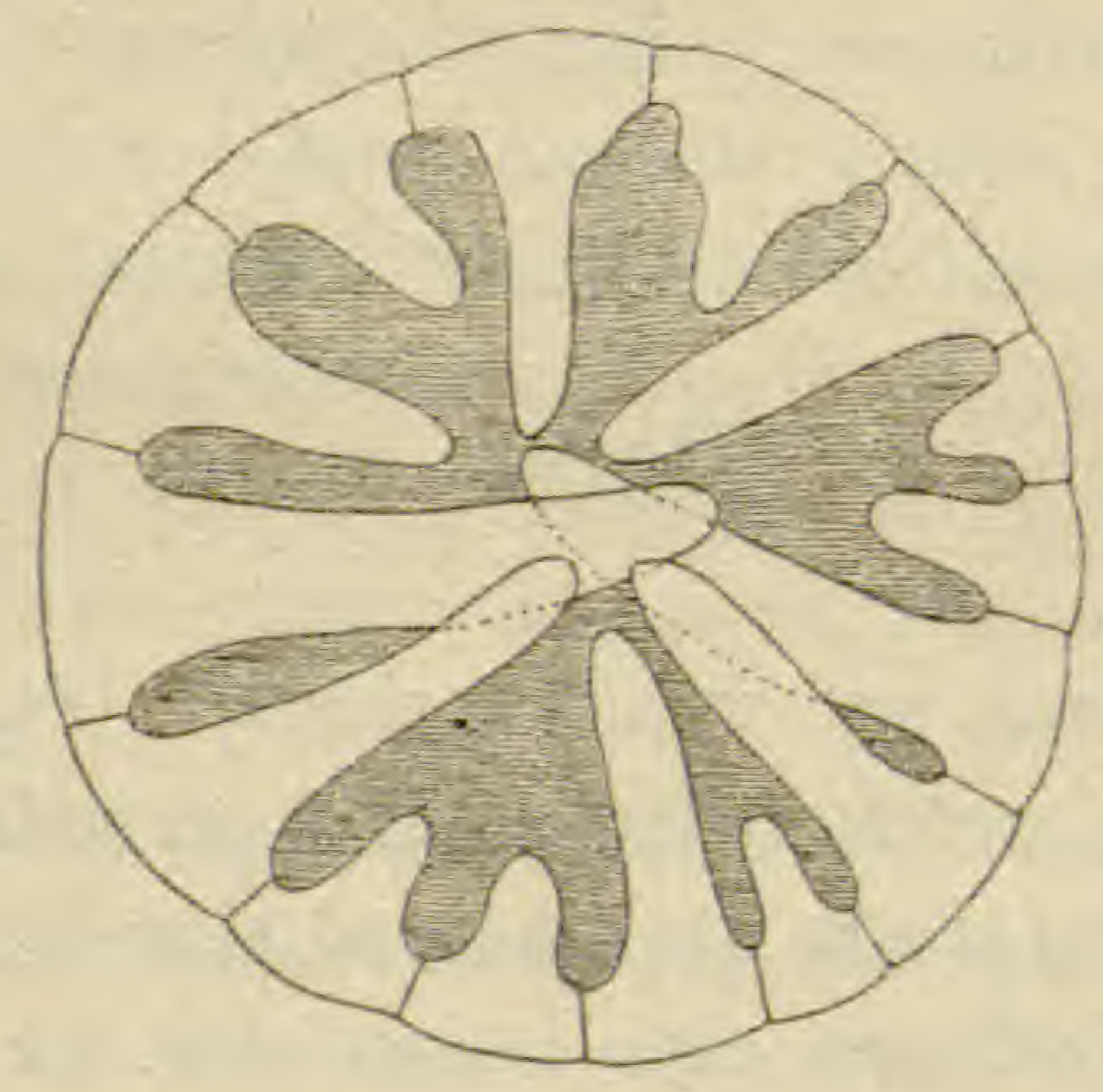

Fig. $d$.

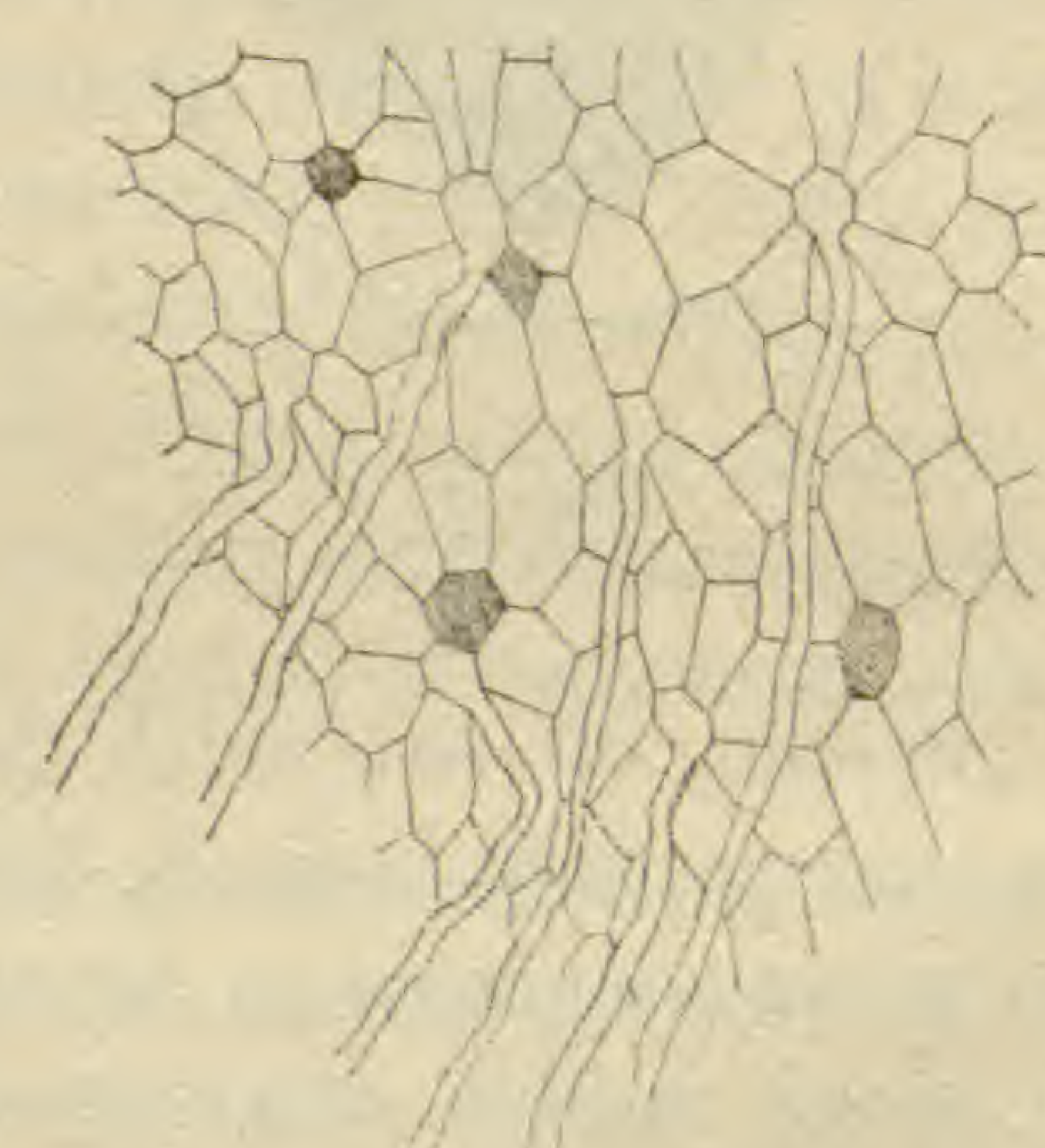

Fig. $e$.

Rhizoiden gefüllt ist; auch die Rhizoiden des Capitulums, welche durch den Pedunculus hinabsteigen, sind in diesem Bündel eingeschlossen, wie es denn leicht ist, dasselbe an der abgestorbenen Basis der Pflanze zu fassen und bis an den Fruchtkopf unverletzt herauszuziehen; sie verteilen sich hier radial nach jedem Involucrum zu, dessen Hüllschuppen stets zahlreiche abgerissene Rhizoiden tragen; die unverdickten Wurzelhaare, welche allein die Funktionen eines Haft- und Ernährungsorgans ausüben, entspringen rechts und links von dem erwähnten Mittelkanal und zwar in nur geringer Breite; sie erreichen bei manchen Arten eine bedeutende Länge; die Wasserversorgung der Ventralschuppen und der dünnen Seitenteile der Frons führt ein anderes System von verdickten Rhizoiden aus, das teils der Basis, teils der Fläche der Schuppen (Fig. e) entspringt und, schon zur Zeit ihrer Entwicklung in der Vegetationspitze, in den Mittelkanal eintritt. Die Mittelrippe enthält nicht selten Sclerenchymstränge, welche sich durch Maceration leicht herauspräpa- 
rieren lassen; es sind mässig lange, geschlossene Gänge mit buchtigen Erweiterungen, deren Wände braun gefärbt und stark verdickt sind; ihr Lumen übertrifft das der übrigen Zellen nur wenig; sie verlaufen parallel der Längsaxe der Pflanze.

Bei vielen Arten, besonders solchen trockener Gebiete, enthält die Costa zahlreiche Schleim führende Gänge, welche ebenfalls longitudinal gelagert sind; bei einzelnen Arten ist die Schleimentwicklung so stark, dass aufgekochte Schnitte vertikal schwimmen und es nicht möglich ist, sie auf die Schnittläche zu legen, wegen des an derselben haftenden, weit herausgequollenen, zähen Schleimes; auch die Capitula führen diese Schleimgänge. Durch Grösse und Färbung der Zellen kann man zwei scharf getrennte Schichten in der Costa unterscheiden, eine niedrige ventrale und eine grössere, welche der hypoporen Schicht zunächst liegt; sie ist dorsal sehr convex und gegen das laxe Gewebe der seitlich angrenzen, dünneren Seitenteile der Frons meist zienalich deutlich abgesetzt; zweifellos dienen diese Zellcomplexe bestimmten Funktionen, doch ist bis jetzt darüber, so viel ich weiss, nichts publiziert worden.

Der Stiel der Fruchtköpfe ist zwar hinsichtlich seiner Länge, Dicke und der Ausbildung der Lippen seiner Wurzelkanäle sehr verschieden, aber schon bei ein und derselben Art, oft innerhalb desselben Rasens, so verschieden, dass diese Momente zur Diagnose schwer zu verwenden sind; ebenso ist es mit dem Zellbau der Ventralschuppen, die in Folge der Pressung, welche sie in der Scheitelfurche erfahren, sehr ungleiche und verzerrte Zellformen aufweisen; bei manchen Arten sind die der Basis des Pedunculus benachbarten Schuppen mächtig entwickelt und bilden eine grosse mehrblättrige Vagina.

Die Capitula sind das wertvollste Moment zur Unterscheidung der Arten und auf ihre Ausbildung stützt sich daher die hier folgende Anordnung des gesammten Materials; sterile Pflanzen sind somit in vielen Fällen nicht bestimmbar. Dennoch ist auch die Verwertung der Capitula mit Vorsicht zu benutzen, da es nicht selten vorkommt, dass die Anzahl der Lappen des Capitulums variirt, sei es, dass die Pflanze bei schwacher Ernährung eine ausgiebige und normale Ausbildung nicht zu vollbringen vermochte, sei es, dass die Gabelung eines Astes des Capitulums hier und da unterblieb oder später eintrat, wo dann ein stärkerer Ast an die Stelle von zwei schmäleren trat, so dass die Anzahl der Lappen des ganzen Carpocephalums wesentlich variirt.

Auch gehört eine grössere Kenntnis dieser Pflanzen dazu. ganz sterile Capitula, deren Organe wegen der mangelnden Befruchtung nicht ihre 
volle Ausbildung erreichten, oder jüngere, noch unbefruchtete Fruchtköpfe zu deuten. Jedenfalls sind die auf pag. 5 und 6 dieses Werkes genannten Präparations-Methoden anzuwenden.

Die fädigen Schuppen, welche das obere Ende des Pedunculus umgeben, sind fast stets gering an Zahl und, da sie dem jungen Fruchtkopf, als er noch auf dem Laube sass, zur Hülle dienten, später wertlos und oft nicht mehr ganz erhalten; ganz abweichend hiervon sind die breiteren, oft in ungeheurer Anzahl entwickelten Schuppen, welche das muschelförmige Involucrum beiderseits umgeben und ihm allein zur Hülle dienen; dieses Involucrum steht stets zwischen zwei Lappen und ist jedem derselben mit einer Hälfte inseriert; in den Fällen, wo es unter einem Lappen zu stehen scheint, ist derselbe als ein noch ungegabelter Ast zu betrachten, der aber fast stets an seiner Spitze eine Einkehrbung zeigt, die eine bereits eingetretene, aber wenig fortgeschrittene Zweiteilung andeutet.

Die Elateren und Sporen sind von grosser Gleichförmigkeit, so weit ich sie gesehen; leider sind sie von vielen Arten nicht bekannt und ist bei dieser durchweg dioecischen Gattung viel, und mehr als das reiche vorhandene Material erwarten liess, nachzutragen.

Mit Bezug auf die hier folgenden Beschreibungen habe ich nur zu bemerken, dass ich den Teil der unsymetrischen Capitula, welcher in den Pedunculus übergeht, die Basis genannt habe; die Epidermis, mit welcher stets die dorsale gemeint ist, bezeichnete ich mit valida in allen Fällen, wo deren Zellen starke Wandverdickungen zeigen, im Gegensatz zur Epidermis tenera mit unverdickten Zellwänden, wie ich in gleicher Weise, um Wiederholungen zu vermeiden, für die ringförmigen Verdickungen der Kapselwand kurzweg capsula laxe oder crebre annulata gewählt habe.

\section{Marohantia.}

\section{A. Capitula of symmetrica.}

1. Capituli lobi convoluto-teretes (in una carinati).

a. Porus internus cruciatus.

1. Marchantia cephaloscypha app. magna, integerrima.

2. Marchantia Kirkii app. parva, integerrima.

3. Marchantia lamellosa app. crebre denticulata. 
b. Porus internus quadratus, cell. angustis formatus.

4. Marchantia polymorpha capit. of symmetrica.

5. Marchantia tabularis capit. $\sigma^{\top}$ palmatifida.

6. Marchantia plicata app. grandicellularia.

7. Marchantia amboinensis lobi capil. carinats:

II. Capituli lobi plano-lineares.

a. Capituli centrum integrum magnum.

8. Marchantia planiloba app. dentata.

9. Marchantia foliacea app. subintegra.

10. Marchantia multiloba, lobi angustissimi numerosi.

b. Capituli centrum integrum parvum.

11. Marchantia grossibarba.

12. Marchantia assamica.

III. Gapituli lobi plano-obcuneati.

a. Capitula parva, valde convexa, lobis gibbosis.

13. Marchantia papillata.

b. Capitula parva, lobis planis.

a. Porus internus cruciatus.

14. Marchantia squamosa. Capitula parva.

15̈. Marchantia planipora. Capitula magna.

$\beta$. Porus internus 4 cellulis conicis clausus.

16. Marchantia Wilmsii.

\%. Porus internus Quadratus 4 cell. angustis circumdatus.

17. Marchantia cuneiloba app. Ionge fimbriata.

18. Marchantia domingensis app. acuta, invol. fimbriata.

19. Marchantia Elliottii app. acuta, invol, integ. plana.

20. Marchantia globosa app. acuta, invol, integ. crispa.

21. Marchantia rubribarba app. obtusa, denticulata.

22. Marchantia simlana app. obtusa, minute crenulata.

23. Marchantia subandina app. obtusa grosse papulosa.

\section{Capitula breviloba vel subintegra.}

a. Porus internus crucialus.

24. Marchantia fusca capitula hemisphærica.

2.. Marchantia paleacea capit. plano-convexa.

b. Porus internus quadratus, 4 cell. angustis formatus.

26. Marchantia brasiliensis capit. subintegra.

27. Marchantia Pappeana capit. breviloba barba tenuis.

28. Marchantia umbellata capit. breviloba, barba maxima.

29. Marchantia Miqueliana capit. ignota.

c. Porus internus cellulis plano-conicis clausus.

30. Marchantia parviloba app. cordata, acuta.

31. Marchantia viridula app. maxima, oblonga. 
32. Marchantia subintegra eapit. hemisphæriea 4 loba.

33. Marchantia Bescherellei eapit, subplana, crenato-lobata.

34. Marchantia crenata capit, hemisphærica, 6 crenata.

\section{B. Capitula ㅇ asymetrica.}

\section{Gapituli lobi lineares.}

35. Marchantia geminata capit. prof. 4 loba app. ovata acnta.

36. Marchantia sciaphila capit. prof. 4 loba, app. lanceulata.

37. Marchantia Treubii capit. prof. 4 loba epid, papillata.

38. Marchantia macropora cap. prof. 4 loba, Stomata filifera.

39. Marchantia vitiensis cap. breviter 5 loba app. parva cuspidata.

40. Marchantia Wallisii cap. ad med. 8 loba app. subintegra.

41. Marchantia Fargesiana cap. ad med. 9 loba app. magna denticulata.

42. Marchantia diptera cap. ad med. 11 loba app. cordif. integerrima.

\section{Gapituli lobi obcuneati.}

a. Porus internus cruciatus.

43. Marchantia nepalensis cap. 9 lobata, lobis truncatis.

44. Marchantia nitida cap. 9 lobata, lobis bifidulis.

45. Marchantia tholophora eap. alte conica.

b. Porus internus cellulis conicis clausus.

46. Marchantia tosana capit. 6 loba, lobis truncatis.

47. Marchantia disjuncta capit. 10-11 loba, lobis rotundato-truncatis.

c. Porus internus quadratus, cell. angustis formatus.

48. Marchantia Schadenbergii append. fimbriata.

49. Marchantia palmata cap. lobi sublineares, invol. integra crispata.

50. Marchantia linearis cap. lobi sublineares, invol. ciliata.

š1. Marchantia Lecordiana cap. Iobr stipitati abrupte ampliati.

52. Marchantia caracensis cap. lobi late obeuneati.

53. Marchantia Kærnbachii cap. lobi ad $2 / 3$ liberi, bifiduli.

54. Marchantia angusta cap. lobi ad $1 / 2$ liberi, bifiduli.

วั5. Marchantia furciloba cap. lobi ad $1 / 3$ liberi, bifiduli.

\section{Capitula disciformia breviloba.}

56. Marchantia chenopoda cap. breviter Jे loba, lobis rotundatis.

57. Marchantia hexaptera cap. breviter 6 loba, lobis bifidulis.

58. Marchantia pileata cap. breviter 6 loba, lobis obtusis.

59. Marchantia samoana cap. breviter 6 loba, lobis truncatis.

60. Marchantia subgeminata cap. plana, 9 loba, lobis breviss, bifidulis.

61. Marchantia peruviana cap. ignota.

62. Marchantia Notarisii cap. ignota.

\section{Incertæ sedis.}

a. Porus internus cruciatus.

63. Marchantia oregonensis. Amer. septentr. 
b. Porus internus cellulis conicis clausus.

64. Marchantia pallida. Australia.

65. Marchantia vaginata. Japonia.

c. Porus internus quadratus, cell. angustis formalus.

66. Marchantia acaulis. Malacca.

67. Marchantia cata ractarum. Java.

\section{a. Capitula fem. symmetrica.}

I. Gapituli lobi convoluto-teretes in una carinati.

1. Marchantia cephaloscypha St. Hedwigia 1883, no 4, p. 3. Major vel maxima, robusta et tenax, olivacea vel fusco-viridis. Frons ad $6 \mathrm{~cm}$. longa, $15 \mathrm{~mm}$. lata, costa crassa haud producta, sensim in alas crassas attenuata. Epidermis valida. Stomata parva, creberrima, parum prominula, ore interno cruciato. Appendicula squamarum magna, cordiformia vel late ovata, cellulis a centro ad marginem sensim sensimque minoribus, ipso margine minimis, integerrima rosea vel hyalina. Pedunculus carpocephali 9 ad $4 \mathrm{~cm}$. longus, validus, apice paleis lanceolatis hyalinis sparsim barbatus. Capitula fem. 9 radiata, centro parum umbonato, radiis leniter decurvis haud papillatis. Involucra dimidio loborum breviora, hyalina, lobulata, lobulis irregulariter fimbriatis. Per. hyalina, ore parvo integerrimo. Capsula fusco brunnea, creberrime annulata. Sporæ $18 \mu$, glaberrimæ. Elateres $440 \mu$. Capitula $\sigma^{7}$ symmetrica, brevipedunculata, femineis submajora, ad 1/s octolobata, lobis ovatis latiuscule marginatis. Scyphuli crassi, nodulosi i. e. basi apiceque contracti, apice ipso plano-discoidei ibidemque margine spinosi.

Hab. Australia, Tasmania, Nova Zelandia, Fuegia, Patagonia, Chile, ubique haud rara.

\section{Marchantia Kirkii St. n. sp.}

Major, valida, olivacea, postice concolor. Frons ad ร̌ $\mathrm{cm}$. Ionga, $7 \mathrm{~mm}$. lata, costa crasșa, bene producta, sensim in alas validas attenuata. Stomata parva, ore interno cruciato. Epidermis valida i. e. æqualiter incrassata. Appendicula squamarum subparva, ovata, acuta, integerrima, cellulis ubique æquimagnis formata, arete constricta. Pedunculus carpocephali validus, ad $3^{1 / 2} \mathrm{~cm}$. longus, in statu juniore lanatus, subinde 
fere nudus, apice paleis hyalinis vel purpureis dense barbatus. Capitula fem. magna, 9 lobata, (radiata) lobis angustis, subteretibus, centro integro umbonato plus duplo longioribus; haud papillatis. Involucra lobis capituli parum breviora, parvilobulata, lobis breviter ciliatis, coloratis. Per. ore parvo contracto-plicatulo. Capsula viridis usque ad basin fere regulariter 4 valvata, valvulis creberrime annulatis. Elateres $670 \mu$. Sporæ $13 \mu$, læves, sulphureæ. Capitula on parva, 6 lobata, lobis rotundatis integerrimis parum discretis. Scyphuli breviter dentato-ciliati.

Hab. New Zealand (Helms) Stewart-Island (Kirk.).

M. cephaloscyphæ simillima; differt præcipue squamis parvi-appendiculatis, appendiculis æqualiter reticulatis, acutis.

\section{- 3. Marchantia lamellosa Hpe. et G. Syn. Hepat., p. Ј27.}

Maxima, ad $7 \mathrm{~cm}$. longa et $15 \mathrm{~mm}$. lata, viridis vel olivacea. Frons pro planta tenuis, costa humilis et alis parum validior, margine plicatulodentato. Stomata parva, humillima, ore interno cruciato. Epidermis tenera. Squamæ ventrales magnæ, appendiculo magno subrotundo, irregulariter denticulato, cellulis a centro ad marginem decrescentibus, ipso margine exiguis, ceterum pluriseriatæ late insertæ et totam superficiam posticam tegentes (unde nomen "lamellosa".

Pedunculus carpoc. ad $6 \mathrm{~cm}$. longus, maxime crassus $(1 \mathrm{~mm}$. in diametro) subniger, nudus, apice paucis paleis filiformibus barbatus. Capitulu fem. 11 lobata (radiata) lobis subteretibus e lata basi sensim acuminatis, papillatis. Involucra ad medium loborum protracta, hyalina, profunde inciso-lobata, lobis irregulariter fimbriatis. Perianthia hyalina, ore contracto parvo integerrimo, Capsula dilute brunnea, annulis minus validis, haud coloratis. Sporæ $14 \mu$ pallide brunneolæ, læves. Elateres $740 \mu$, concolores. Capitula of brevius pedunculata, parva, disciformia, brevissime 8 lobata, lobis rotundo-prominulis.

Hab. Andes quitenses (leg. ?). Columbia (Moritz).

\section{Marchantia polymorpha L. Sp. pl. II, p. 1603.}

Major, viridis, medio antico sæpe linea fusca notata. Frons ad $4 \mathrm{~cm}$. longa, $10 \mathrm{~mm}$. lata, valida, costa parum crassa, longe in alas validas attenuata. Stomata subparva, parum prominula, ore interno 4 cellulis angustis circumdato. Cellulæ epidermidis validæ. Appendicula squamarum hyalina vel plus minus colorata, subrotunda, minute crenulata, cellulis marginalibus multo minoribus. Pedunculus carpocephali validus, ad $3 \mathrm{~cm}$. longus, nudus, apice paleis hyalinis filiformibus sparsim barbatus. Capitula fem. 
novem lobata, lobis vix acuminatis, subteretibus, papillatis. Involucra usque ad medium radiorum protracta, lobata, lobis profunde bifidis, spinoso-ciliatis, sæpe fere pinnatim spinosis. Perianthia hyalina, ore parvo integro, Capsula fusco-brunnea, valvulis crebre annulatis. Sporæ $13 \mu$ flavæ. Elateres $400 \mu$. Capitula $\sigma^{\varnothing}$ minus longe pedunculata, pro more pedunculo $15 \mathrm{~mm}$. longo, magis tenui quam in capit. femineo, disciformia, 8 lobata, lobis apice rotundatis, vix ad medium solutis. Scyphuli margine breviter lobati, lobis triangulatis, acuminatis, basi breviter spinulosis.

Hab. Europa, Asia et America septentrionalis. Japonia (Sapporo Faurie Makino), Himalaya (Hooker, Duthie), Java (Junghuhn), Alaska (Krause), Costarica (Pittier), Labrador (Ahles), Acores (W. H. Brown), California (Bolander), Caucasus (Levier).

5. Marchantia tabularis Nees. Hep. Eur. IV, p. 71.

Syn. : M. Berteroana L. et L. in Lehm. Pug. VI, p. 21 (teste Schiffner).

Major, tenuis, viridis, margine rubescens; costa bene evoluta el multo crassior quam alæ. Frons ad $4 \mathrm{~cm}$. longa, $10 \mathrm{~mm}$. lata. Stomata parsa, majora tamen quam in M. polymorpha, parum prominula, ore interno minimo, 4 cellulis plano-conicis circumdato. Epidermis tenera. Squamx posticæ hyalinæ, appendiculo roseo magno, reniformi, integerrimo, cellulis parvis 3 seriatis marginato. Pedunculus carpoc. ad $3 \mathrm{~cm}$. longus, validus, apice paucis paleis hyalinis filiformibus barbatus. Capitula fem. 9 lobata, majora quam in M. polymorpha, lobis basi angustis superne clavatim ampliatis, haud papillatis, profunde discretis, teretibus. Involucra radiis parum breviora, hyalina, breviter lobata, lobis breviter fimbriatis. Per: magna, ore amplo plicatim contracto integro. Capitula mascula brevipedunculata, palmatim sex lobata, lobis late ligulatis, ad medium soluti-; margine crispatulis. Scyphuli patelliformes, margine profundius lobati, lobis longe setaceis, basi grosse spinosis. Capsulæ maturæ ignotæ.

Hab. Prom. bon. spei. (Preiss. Ecklon. Drège, Rabenhorst fil.), Transvaal (Rehmann), St. Helena (W. H. Brown).

6. Marchantia plicata N. et M. Ann. se. nat. IX, p. 43.

Major, viridis, tenuis. Frons ad $7 \mathrm{~cm}$. longa, $8 \mathrm{~mm}$. lata, margine minute plicatula; costa minime producta, alis validis vix crassiore. Stomata numerosa, humillima, majora, ore interno quatuor cellulis angustis circumdato. Cell. epidermidis teneræ. Squamæ posticæ pluriseriatæ, late insertæ, appendiculis magnis, subrotundis, obtusis, margine 
crebre irregulariterque denticulatis, cellulis centralibus amplis, versus marginem diminutis, ipso margine multoties minoribus. Pedunculus fem. ad $4 \mathrm{~cm}$. longus, validus nudus, apice paleis linearibus, longis lanatim contortis barbatus. Capitula fem. magna, 9 lobata, lobis anguste teretibus, haud papillatis, acuminatis, ad $8 \mathrm{~mm}$. longis. Involucra lobis duplo breviora, hyalina, breviter lobata, lobis angustis, contiguis, remote pinnatim laciniatis sæpe purpureis. Capitula $\sigma^{\pi}$ minora, disciformia, 9-11 lobata, lobis ligulatis, ad $1 / 2$ solutis. Scyphuli "margine grosse serrati, extus minute papillosi " (Spruce).

Hab. Quito (Ortoneda, Spruce) Nova Granada (Lindig), Peru(d'Orbigny), Merida (Moritz).

7. Marchantia amboinensis Mont. Ann. sc. nat. 1838, p. 43. Major, sed minus lata, gracilis, flavovirens, tenuis. Frons ad $5 \mathrm{~cm}$. longa, $4 \mathrm{~mm}$. lata, multiramosa; costa angusta, leniter producta, sensim in alas attenuatas excurrens. Stomata magna, vix prominula, ore interno magno 4 cellulis angustis circumdato. Epidermis tenera. Squamæ posticæ parvæ, purpureæ, appendiculo ovato, eircumcirea dense angusteque spinosa, spina terminali longiore. Pedunculus carpocephali brevis, ad $10 \mathrm{~mm}$. longus, tenuis breviter paleaceus, paleis linearibus, purpureis, breviter barbatus. Capitula o pro more solum 4 lobata, normaliter 8 lobata, lobis in plano anguste triangulatis, ob latera decurva conduplicatim carinatis, profunde solutis, apice sensim attenuatis. Involura magna lobis parum breviora, hyalina, ore amplo crispato-plicatulo, integerrimo. Reliqua desunt.

Hab. Amboina (La Billardière).

Ich habe das Original in Händen gehabt und an den zahlreichen Capitulis keinen gefunden, welcher mit der Beschreibung der Synopsis übereinstimmt; alle diese Capitula waren unbefruchtet und mangelhaft enlwickelt, so dass bessere Exemplare hierüber erst Licht verbreiten müssen; jedenfalls sind aber die lobi capituli cuneatim angustati und nicht obcuneati, wie bei so vielen anderen Arten.

\section{Capituli lobi plano-lineares.}

8. Marchantia planiloba St. in Engler, Bot. Jahrb. VIII, p. 90. Major, dilute viridis, tenuis. Frons ad $4 \mathrm{~cm}$. longa, $5 \mathrm{~mm}$. lata, costa parum prominente, sensim in alas attenuatas abeunte; cellulæ epider- 
midis teneræ. Stomata majuscula, ore interno 4-ă cellulis plano-conicis circumdato. Appendicula squamarum parva, subrotunda, margine dentata, cellulis subæquimagnis majusculis formata. Pedunculus carpocephali fem. validus, ad $3^{1 / 2} \mathrm{~cm}$. longus, ubique brevipaleatus, barba apicalis longa, hyalina, paleis linearibus. Capitula fem. novemlobata, disco centrali magno alte convexo, lobis disco duplo brevioribus, late linearibus, subplanis, recte truncatis. Involucra hyalina, ore fimbriato. Perianthia hyalina, ore contracto-plicato breviter fimbriato. Capsula fusco-brunnea, parietibus laxe annulatim incrassatis. Sporæ $20 \%$, vermiculariter lamellatæ. Elateres $680 \mu$. Capitula masc. palmatifida, lobis 6-7 usque ad basin fere solutis, lanceolatis, $12 \mathrm{~mm}$. longis. Scyphuli margine lobati, lobis triangularibus acutis.

Hab. Africa, Insa. San Thomé (Moller, Quintas), Angola (Welwitsch), Kamerun (Dusẻn, Preuss, Staudt, Zenker), Togo (Büttner), Kilimandscharo (Volkens), Undussuma (Stuhlmann), Runssoro (Stuhlmann).

\section{Marchantia foliacea Mitt. Fl. N. Zel. II, p. 168.}

Major, dilute viridis, postice fusco-purpurea; Frons ad है $\mathrm{cm}$. longa, $10 \mathrm{~mm}$. lata, crassa, costa lata, valde producta et omnium maxima, in alas validas sensim abeunte. Epidermidis cellulæ teneræ. Stomata magna ore interno subquadrato, 4 cellulis ovalibus circumdato. Appendicula squamarum majuscula, sanguinea, ovata, apiculata, margine integerrima, repando angulata, cellulis majusculis subæqumagnis formata. Pedunculus carpocephali validus ad $3 \mathrm{~cm}$. longus, paucipaleatus, coloratus, apice breviter barbatus, paleis linearibus, purpureis; paleæ involucrales purpureæ lanceolatæ, cuspidatæ. Capitula fem. magna, 9 lobata, centro magno valde convexo, Iobis disci diametro duplo brevioribus, breviter linearibus, recte truncatis, sæpe valde irregularibus ad 2 vel 3 confluentibus; involucra 8 , fusco-purpurea, ore magno breviter lobato, lobis longe fimbriatis, laciniis haud pinnatim dispositis. Perianthia colorata, ore fisso, laciniis brevibus fimbriatis. Capitula $\delta$ parva, brevipedunculata, disciformia, sexloba, lobis ovatis ad medium solutis. Scyphuli dentatociliati.

Hab. New Zealand (Colenso, Kirk, Petrie, Helms), Tasmania (Weymouth).

10. Marchantia multiloba St. n. sp.

Mediocris, fusco-viridis, postice haud colorata. Frons ad $2 \mathrm{~cm}$. longa, $3 \mathrm{~mm}$. lata, angusta, valida; costa lata, bene producta, alis tenuibus 
costæ æquilatis. Epidermidis cellulæ teneræ. Stomata magna, humilia,

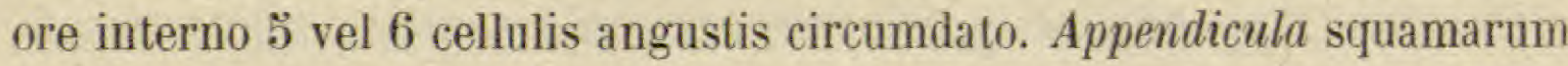
fusco-purpurea, majuscula, oblonga, acuta, margine irregulariter spinosa et dentata, cellulis oblongo-hexagonis æquimagnis formata. Pedunculus carpocephali tenuis, ad $₫$ $\mathrm{mm}$. longus, ubique paucipaleatus, barba apicalis paleis filiformibus brevibus formata, paleæ involucrales breviter lanceolatæ, violaceæ cuspidatæ sæpe longe bifidæ, margine repandoangulatæ. Capitula fem. majuscula, 11-13 lobata, centro integro magno valde convexo, late conico, lobis centri diametro parum brevioribus, anguste linearibus, apice truncatis. Involucra integerrima hyalina, cellulis prominulis crenulata. Capitula masc. femineis æquimagna usque ad centrum fere sexloba, lobis angustis divergentibus. Scyphuli margine crebre dentati, dentibus $6-8$ cellulas longis, basi 3 cell. latis Reliqua desunt.

Hab. Nova Guinea (Macgregor, Armit, Lauterbach, Hellwig), Luzon (Loher).

11. Marchantia grossibarba St. Soc. nat. Cherbourg XXIX, p. 221.

Mediocris, gracilis, dilute viridis, postice haud colorata. Frons ad $3 \mathrm{~cm}$. longa, $3 \mathrm{~mm}$. lata, tenuis; costa humili, haud producta, sensim in alas validas abeunte. Epidermis tenera. Stomata majuscula, parum prominentia, ore interno 4 cellulis angustis circumdato. Appendicula squamarum majuscula, late ovata, obtusa, margine crebre denticulata, cellulis marginalibus quam reliquæ multo minoribus. Pedunculus carpocephali validus, ad $2.5 \mathrm{~mm}$. longus, nudus, apice paleis filiformibus barbatus; paleæ involucrales numerosissimæ, confertissimæ, oblongo lanceolatæ, lobatæ et plurifissæ, laciniis denticulatis purpureis. Capitula fem. minora, 11 lobata, centro parvo, convexo, lobis centri diametro longioribus, anguste linearibus, truncatis. Involucra hyalina, ore amplo integerrimo. plicatulo-crispato. Perianthia purpurea, ore parvo, integro, contracto plicatulo. Scyphuli creberrime minuteque denticulati, dentibus 1-2 cellulas longis.

Hab. China, Yuennan (Delavay).

12. Marchantia assamica Griff. Notulæ, p. 327 c. ic.

Major, magnitudine M. polymorphæ squamis posticis magnis, imbricatis, purpureis, appendiculo magno, rotundato acuto. Capitula feminea longe pedunculata, pedunculis crassis, apice purpureo paleatis, 10 lobata, centro 
convexo subconico, lobis apice plano-explanatis, truncatis vel obsoleteemarginatis.

Hab. India orient. ad Flum. Burramputer et Koondil (Griffith).

Die Pflanze liegt in keinem europäischen Herbar; ich habe die Diagnose excerpirt und nach den Abbildungen einiges hinzugefügt, so dass es vielleicht möglich sein wird, die Pflanze wiederzuerkennen, falls aus jenem selten bereisten Gebiete etwas nach Europa gelangt.

\section{Capituli lobi plano-obcuneati.}

13. Marchantia papillata Raddi. Soc. It. Modena XIX, p. 44 .

Minor, angusta, fusco-viridis, postice fuscescens. Frons ad $3 \mathrm{~cm}$. longa, $4 \mathrm{~mm}$. lata, valida, costa crassa, pro planta latissima, postice plano-convexa, abrupte in alas breves validas transeunte. Epidermis tenera. Stomata majuscula, ore interno 6 cellulis angustis circumdato. Appendicula squamarum majuscula, late ovata, acuta, regulariter parvidentata, cellulis parvis marginata. Pedunculus carpocephali validus, ad $3 \mathrm{~cm}$. Iongus, paleis brevibus hirtus, apice paleis filiformibus barbatus, paleæ involucrales valde numerosæ, late lanceolatæ, acuminatæ. confertissimæ, purpureæ, margine dentatæ. Capitula fem. parva, 9 lobata, centro convexo, medio conice umbonato, lobis contiguis obconicis, apice truncato-rotundatis vel leniter emarginatis, decurvis, medio gibbis, apice plano-patulis. Involucra hyalina, cellulis longius prominentibus crenato-papulosa. Scyphuli minule denticulati.

Hab. Brasilia Rio Janeiro (Roosmalen, Ule), Paraguay (Balansa), Mexico (C. H. Schultz).

\section{Marchantia squamosa L. L. in Lehm. Pug. IV, p. 12.}

Mediocris, antice dilute viridis, postice fusco-purpurascens. Frons ad $200 \mathrm{~mm}$. longa, 气 $\mathrm{mm}$. lata, tenerrima, costa angusta, haud crassa sed bene producta et abrupte in alas tenerrimas abeunte. Epidermis tenera. Stomata parva, parum prominentia, ore interno cruciato. Appendicula squamarum maxima, cordiformia, parum repanda, subintegerrima, cellulis majusculis æquimagnis conflata. Pedunculus carpocephali validus ad $15 \mathrm{~mm}$. longus, ubique lanatim paleaceus, barba apicalis et involucralis paleis similibus longis et anguste linearibus formata. Capitula fem. parva, 9 lobata, centro parvo, lobis sublinearibus, apice cuneatim dilatatis 
recte truncatis decurvulis. Involucra hyalina longe fimbricata. Reliqua desunt.

Hab. Brasilia (Raddi).

\section{5.. Marchantia planipora St. nsp.}

Major, viridis, postice fusco-purpurascens. Frons ad $ら \mathrm{~cm}$. longa, $7 \mathrm{~mm}$, lata, costa valida, lata, late convexo-producta, sensim in alas validas excurrens. Epidermis tenera; stomata parva, numerosa, vix prominula, ore interno cruciato. Appendicula squamarum magna, cordata, rotundata, basi valde constricta, integerrima, parvis cellulis marginata, cellulis centralibus multo majoribus. Pedunculus carpocephali crassus, longissimus (ad $7 \mathrm{~cm}$.) paucis paleis barbatus, ceterum nudus. Capitula $q$ magna, 9 lobata, centro majusculo, lobis centro longioribus, oblongo-obcuneatis, contiguis, sub apice repando-angulatis, subdenticulatis, ceterum validis convexo-costatis. Involucra hyalina, breviter ciliata. Perianthia hyalina, ore parvo integro. Capsula brunnea, crebre annulata. Sporæ ignotæ. Elateres $640 \mu$. Reliqua desunt.

Hab. Japonia (Ahlburg, Jnouë).

16. Marchantia Wilmsii St. Hedwigia, 1892, p. 126.

Major, dilute viridis, postice fuscescens. Frons ad $4 \mathrm{~cm}$. longa, $7 \mathrm{~mm}$. lata, tenuis; costa haud crassa, sed distincte convexo producta sensim in alas tenues excurrens. Epidermis tenera. Stomata majuscula, parum prominentia, ore interno 4 cellulis plano-conicis circumdato, Appendicula squamarum late cordiformia, acuta, margine regulariter breviterque dentata, cellulis majusculis subæquimagnis conflata. Pedunculus carpocephali validus ad $3 \mathrm{~cm}$. longus, nudus, apice paleis filiformibus brevibus barbatus, paleæ involucrales breves, confertæ et numerosissimæ, late lanceolatæ acuminatæ vel longe b1-trifidæ. Capitula fem. magna 9 lobata, centro magno valde convexo, lobis ex angusta basi optime cuneatim ampliatis, apice rotundatis contiguis, basi sinu rotundato discretis. Involucra margine cellulis prominulis longe papulosa. Perianthia hyalina, ore contracto integro. Capsula fusco-brunnea, crebre annulata. Sporx sulphureæ papillatæ 3 u. Elateres flavescentes 600 ш. Capitula mascula femineis æquimagna, brevius pedunculata, palmatifida, 8 lobata, lobis vix ad medium solutis, ut in femineis sinu rotundato discretis. Scyphuli margine creberrime breviterque ciliati, ciliis 3 cellulas longis.

Hab. Transvaal (Wilms, Maclea). 


\section{Marchantia cuneiloba St. nsp.}

Mediocris, antice viridis, postice concolor. Frons ad $4 \mathrm{~mm}$. longa, $5 \mathrm{~mm}$. lata, crassa, postice subplana; costa vix producta, alæ crassæ, margine breviter acuminatæ. Epidermis valida. Stomata majuscula, valde convexa. ore interno quator cellulis angustis circumdato. Appendicula squamarum purpurea, magna oblonga vel anguste oblonga, apice longe setacea, margine magnis laciniis subpinnata, cellulis elongatis ubique æquimagnis ædificata. Pedunculus carpocephali validus, paleaceus, ad $2 \mathrm{~cm}$. longus, apice paucis paleis filiformibus barbatus, paleæ involucrales purpureæ. oblongæ, cuspidatæ, sæpe profunde bifidæ, grosse dentatæ. Capitula fem. majora, 9 lobata, disco centrali magno, valde convexo, lobis remotiusculis, disci diametro brevioribus, apice leniter cuneatim ampliatis decurvulis. Involucra discum parum superantia, ore integro, rotundatim lobato, crispato. Capitula mascula femineis majora, palmatifida, lobis ad 9, ad $3 / 3$ solutis angustis, apice palmatim approximatis, basi hastatim divergentibus. Scyphuli minute dentato-ciliati.

Hab. Japonia, Liu-Kiu Insulæ (Makino, Ferrié), Formosa (A. Henry).

18. Marchantia domingensis L. et L. in Lehm. Pug. VI, p. 22. Syn. : Marchantia inflexa M. et N. Ann. sc. nat. IX, p. 43.

Marchantia linearis L. et L. pp. (quoad pl, americanam).

Minor, dilute vel flavo viridis, postice fusca. Frons ad $2 \mathrm{~cm}$. longa, $4 \mathrm{~mm}$. lata, valida, costa parum prominens, sensim in alas validas attenuata. Epidermis valida, interdum 2 cellulas crassa. Stomata magna, ore interno quadrato, 4 cellulis angustis circumdato. Appendicula squamarum magna, ovato-oblonga, cuspidata, irregulariter, crenato-denticulata, cellulis minoribus marginata. Pedunculus carpocephali tenuis, $15 \mathrm{~mm}$. longus, paleis hyalinis hirtus, apice similiter barbatus, paleæ involucrales lanceolatæ, cuspidatæ vel longe setaceæ. Capitula fem. parva, 9 lobata, centro integro majusculo, lobis divergentibus, linearibus, apice parum obcuneatis, truncatis vel 2 vel 3 dentatis, centri diametro subæquilongis. Involucra lıyalina, breviter fimbriata. Reliqua ignota.

Hab, Insulæ Indiæ occid. St Christoph (Breutel), Sto Domingo (Eggers), Dominica (Eggers), Puerto Rico (Sintenis), Martinique (Sieber, Belanger, Mẻrat, Plée), Haïti (Ehrenberg), Mexico (C. H. Brandt).

M. Domingensis liegt im Herb. Nees auch unter dem Namen M. palmat ex Insula Java leg. Sieber, in Folge des bekannten Irrtums Siebers, der die Herkunft seiner Pflanzen auf der Reise nicht notiert und sie später ad libitum dazu gesetzt hat. 
19. Marchantia Elliotii St. n. sp.

Minor, dilute viridis vel flavo-virens, postice haud colorata. Frons ad 2.5 $\mathrm{mm}$. longa, $4 \mathrm{~mm}$. lata. Costa angusta, bene producta, alis tenuibus. Epidermis tenera, stomata humillima, majora, ore interno, 4 cellulis angustis circumdato. Appendicula squamarum magna, subrotunda, arete constricta, margine dense regulariterque spinosa, spinis brevibus validis, Pedunculus carpocephali validus ad $3 \mathrm{~cm}$. longus, paleis filiformibus hirtus, apice similiter barbatus, paleæ involucrales late lanceolatæ, cuspidatæ vel longe setaceæ. Capitula fem. majuscula, 9 lobata, centro integro lato, medio umbonata, lobis centri diametro duplo brevioribus, sinı rotundato discretis, basi convexis apice applanatis, cuneatim dilatatis. Involucra hyalina, ore integerrimo haud crispato. Perianthia ovata, ore rostrato, flavescentia. Capsula fusco-brunnea, crebre annulata. Sporæ $27 \mu$, flavæ asperæ. Elateres 660 u. Scyphuli creberrime ciliolati, ciliis 2-3 cellulas longis. Reliqua desunt.

Hab. Dominica (Elliot.).

\section{Marchantia globosa Bridel. Syn. Hep., p. 531.}

Minor, gracilis, antice pallide-virens, vel pallide flavicans, postice purpurea. Frons $4 \mathrm{~cm}$. longa, $6 \mathrm{~mm}$. lata, costa crassa, valde producta, sensim in alas tenues excurrente. Epidermis valida. Stomata magis prominula, ore interno subquadrato, 4 cellulis ovalibus circumdato. Appendicula squamarum majuscula late ovata acuta, crebre et valide spinosa, dilute

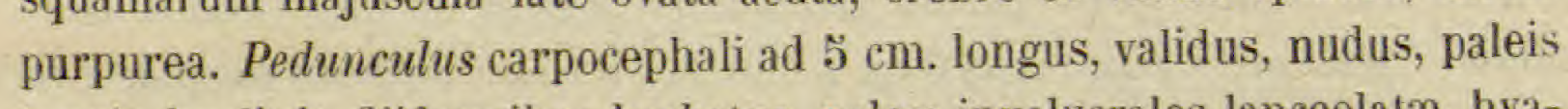
longis hyalinis filiformibus barbatus, paleæ involucrales lanceolatæ, hyalinæ, apice longe setaceæ. Capitula fem. minora, 9 lobata, centro magno 9 costato, lobis centri diametro æquilongis, late linearibus, apice cuneatim dilatatis, rotundato-truncatis. Involucra hyalina, magna, margine integerrima crispatulo-plicata. Perianthia hyalina, ore contracto integerrimo.Sporæ $28 \mu$ brunneæ, vermiculariter lamellatæ. Elateres 5ร0 $\mu$. Capsula profunde quadrivalva, fusco brunnea, parietibus creberrime annulatis. Capitula $\sigma^{\pi}$ femineis submajora, brevius pedunculata, fere ad centrum sexlobata, lobis linearibus divergentibus. Scyphuli patelliformes, margine integerrimi.

Hab. Insulæ Mascarenæ (Delessert, Robillard), Mayotte (Boivin), NossiBé (Boivin), Africa orient. Butumbi, Uluguru, Undussuma, Bukoba (Stuhlmann).

\section{Marchantia rubribarba St. n. sp.}

Major, viridis, flaccida. Frons ad $4 \mathrm{~cm}$. longa, $6 \mathrm{~mm}$. lata, tenuis. Costa 
haud producta, sensim in alas attenuata. Epidermis tenera. Stomata humillima, poro interno quatuor cellulis angustis circumdato. Appendicula squamarum magna, subrotunda, grosse obtuseque dentata, cellulis æquimagnis formata. Pedunculus fem. tenuis, $15 \mathrm{~mm}$. longus, nudus, apice paleis lanceolatis purpureis brevibus barbatus. Capitula feminea symmetrica, 9 lobata, lobis radiatim contiguis, late obcuneatis, apice truncatis, tenerrimis, viridibus, lamellis perlucentibus striolatim reticulatis, centro umbonato parvo. Involucra hyalina, breviter incisa vel repanda, lobulata, lobis parvicrenulatis. Perianthia ore parvo tubuloso. Scyphuli crebre ciliati, ciliis 5-6 cellulas longis. Reliqua desunt.

Hab. Nova Guinea (W. Fitzgerald) in rupibus humidis.

\section{Marchantia simlana St. n. sp.}

Minor, dilute viridis, postice purpurascens. Frons ad $2 \mathrm{~cm}$. longa, $4 \mathrm{~mm}$. lata, tenuis. Costa humilis, haud prominens, sensim in alas validas attenuata. Epidermis tenera. Stomata majuscula, parum prominentia, ore interno 5̃ cellulis angustis circumdato. Appendicula squamarum majuscula, late ovata, acuta, margine minute crenulata, cellulis parvis marginata. Pedunculus carpocephali tenuis, brevis, ad $1 \mathrm{~cm}$. longus, nudus, apice paleis filiformibus barbatus; paleæ involucrales late lanceolatæ cuspidatæ vel longe setaceæ. Capitula fem. parva, 9 lobata, centro integro majusculo, lobis centri diametro æquilongis, linearibus, remotiusculis subplanis, apice leniter cuneatim ampliatis. Involucra hyalina, lobulata, lobis fimbriatis; reliqua desunt.

Hab. Himalaya, Simla (Brandis).

23. Marchantia subandina Spruce. Edinb. Bot. Soc. 188\%, p. ร61.

Minor, gracilis, viridis, postice haud colorata. Frons ad $4 \mathrm{~cm}$. longa, $3 \mathrm{~mm}$. lata, valida, costa lata, convexo-producta, sensim in alas æquilatas attenuata. Epidermis tenera. Stomata minuta et humillima, ore interno quatuor cellulis angustis circumdato. Appendicula squamarum parva, late ovata, obtusa, margine cellulis longis prominulis grosse papulosa, cellulæ centrales marginalibus majores. Pedunculus carpocephali tenuis ad $2 \mathrm{~cm}$. longus, nudus, paleis purpureis filiformibus barbatus; paleæ involucrales lanceolatæ, crenulatæ, subdentatæ, apice setaceæ. Capitula feminea parva, 9 lobata, centro integro majusculo, convexo, lobis centri diametro parum brevioribus, lineari-obcuneatis, subplanis, apice truncato-rotundatis. Involucra hyalina, ore integerrimo. "Perianthia apice inæqualiter 5" fida. BULL. неRв. воIsS., mai 1899. 
Capsula rufa, trabeculata. Sporæ fulvæ, scaberulæ, mediocres. Elateres elongati, monospiri " (teste Spruce). Capitula mascula femineis multo majora, breviter pedunculata, 6-8 radiata, centro integro parvo, lobis diametro centri duplo longioribus, linearibus, divergentibus, geminatim approximatis.

Hab. Andes Peruviani ad flum. Huallaga (Spruce).

\section{Capitula breviloba vel subintegra.}

\section{Marchantia fusca St. n. sp.}

Magna, fusco-viridis, postice fusco-purpurascens. Frons ad $4 \mathrm{~cm}$. longa, $10 \mathrm{~mm}$. lata, margine sæpe crispata, valida. Costa crassa, haud tamen producta, sensim in alas valde attenuatas excurrens. Epidermis tenera. Stomata parva, parum prominula, ore interno parvo cruciato. Appendicula squamarum magna, ovato-rotunda, obtusa, integerrima, cellulis mediocribus ubique fere æquimagnis formata. Pedunculus carpocephali brevissimus, ad $7 \mathrm{~mm}$. longus, paleis longis purpuress hispidus, apice paleis similibus longe barbatus; paleæ involucrales late lanceolatæ, longe cuspidatæ, apice setaceæ, valde numerosæ confertissimæ. Capitula fem. magnitudine mediocri, hemisphærica, omnino elobata, margine perfecte integerrimo. Involucra hyalina, margine profunde lobata, lobis maxime laceratis, fimbriatis. Reliqua desunt.

Hab. N. Zealand (Petrie).

20. Marchantia paleacea Bertol. Opusc. scient. Bol. I, p. 242. Major, glauco-viridis, marginibus sæpe purpurascentibus, postice haud colorata. Frons ad $5 \mathrm{~cm}$. longa, $8 \mathrm{~mm}$. lata, tenuis; costa valida, parum convexa, in alas longe attenuata. Epidermis valida. Stomata parva, parum prominula, ore interno cruciato. Appendicula squamarum magna, cordiformia, obtusa, irregulariter repando-angulata vel hic illic denticulata, cellulis ubique fere æquimagnis, majusculis. Pedunculus carpocephali crassus, ad $4 \mathrm{~cm}$. longus, paleis filiformibus hirtus, apice similiter breviterque barbatus, Capitula 9 magna, disciformia, e centro parvo prominulo 9 costata, costæ in lobos continuatæ breves, lato sinu obtuso disdiscretos, apice truncatos, planiuseulos. Involucra purpurea, irregulariter breviterque lobata, lobulis pinnatim lacinulatis. Perianthia hyalina, ore parvo plicatim contracto. Scyphuli margine triangulatim lobati, lobis acutis, basi minute denticulatis. Reliqua desunt. 
Hab. Italia (De Notaris, Arcangeli, Moggridge), Hispania (Willkomm), Portugal (Moller), Acores Ins ${ }^{c e}$ (Simroth, Carreiro).

26. Marchantia brasiliensis L. L. in Lehm. Pug. IV, p. 32.

Mediocris, dilute viridis vel flavicans, postice fusco-purpurea. Frons ad $3 \mathrm{~cm}$. longa, $10 \mathrm{~mm}$. lata, sæpe sub flore simpliciter innovata. Cosia lata, bene producta, sensim in alas validas excurrens. Epidermis valida. Stomata majora, bene prominula, ore interno magno, 5 cellulis angustis circumdato. Appendicula squamarum minora, ovata, acuminata, omnino integerrima, cellulis mediocribus ubique fere æquimagnis formata. Pedunculus carpocephali maxime crassus, ad $2 \mathrm{~cm}$. longus, paleis fuscis ramosis hirtus, apice paleis lanceolatis purpureis et pendulis maxime villosus. Capitula fem. majuscula, valde convexa, brevissime $4-6$ lobulata, lobis vix discretis, vallibus interfluentibus notatis. Involucra hyalina, margine haud lobata, breviter fimbriata. Capitula mas. peltata, brevius pedunculata (ipse haud vidi).

Hab. Brasilia (Sellow, Guillemin), Sto Domingo (Eggers).

M. chenopoda ist eine viel grössere Pflanze, welche unsymmetrische Capitula hat und sich schon durch die gezähnten appendicula leicht unterscheiden lässt.

27. Marchantia Pappeana Lehm. Pug. X, p. 21.

Mediocris, viridis, postice purpurascens. Frons ad $4 \mathrm{~cm}$. longa, $7 \mathrm{~mm}$. lata, tenuis. Costa parum producta, sensim in alas validas excurrens. Epidermis tenera. Stomata magna, parum prominula, ore interno magno, quadrato, 4 cellulis angustis circumdato. Appendicula squamarum magna, cordiformia, acuta, margine repando-angulata et crenata, cellulis æquimagnis mediocribus formata. Pedunculus carpocephali validus, $3 \mathrm{~cm}$. longus, nudus, apice paleis hyalinis linearibus longissime barbatus, Capitula fem. disciformia, plano-convexa, breviter 11-12 lobata, lobis planis, sinu rotundato discretis, duplo fere brevioribus quam latis, apice truncatis. Involucra hyalina, breviter lobata, lobis ciliatis. Perianthia hyalina, ore parvo contracto. Capsula fusco-brunnea, crebre annulata. Sporæ $25 \%$, flavæ. Elateres $680 \mu$. Scyphuli margine crebre dentati, dentibus 3 cellulas longis, basi $2-3$ cellulas latis.

Hab. Caput bon. sp. (Pappe). Adhuc nusquam reperta.

28. Marchantia umbellata St. in Engler, Bot. Jahrb. 1893, p. $30 \%$, 
Major, tenuis, pallide-virens, margine purpurascens, postice haud colorata. Frons ad $6 \mathrm{~cm}$. longa, $6 \mathrm{~mm}$. lata ; costa angusta, haud producta, sensim in alas tenues excurrens. Epidermis cellulis æqualiter incrassatis valida. Stomata minora, ore interno 4 cellulis angustis circumdato. Appendicula squamarum magna, cordata, apice Iongispina, ceterum irregulariter parvidentata, cellulis parvis marginata, cell. centrales multoties majores.

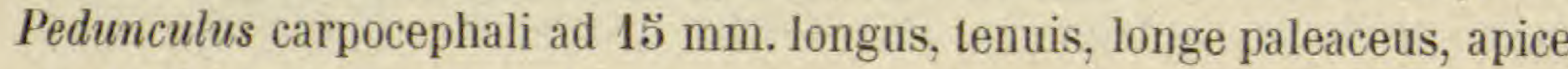
atque ad involucra paleis longis, hyalinis, filiformibus maxime barbatus. Capitula fem. minora, disciformia, plano convexa, 9 lobata, lobis brevibus rotundatis (in planta juvenili et solum pistillifera). Capitula masc. femineis æquimagna, disciformia, 9 radiata, radiis usque ad apicem connatis acute tamen prominentibus, lamina interradialis leniter excisa (unde nomen "umbellata "). Scyphuli parvi, margine dense longeque ciliati.

Hab. Africa orient. Usambara (Holst.).

\section{Marchantia Miqueliana Lehm. Pug. X, p. 20.}

Major, tenuis, viridis, postice fuscescens. Frons ad 3 ä mm. longa, $7 \mathrm{~mm}$. lata. Costa humilis, haud producta, sensim in alas tenues excurrens. Epidermis tenera. Stomata maxima, parum prominula, ore interno magno quadrato, quatuor cellulis angustis circumdato. Appendicula squamarum purpurea, basi valde constricta, ovato-oblonga, acuminata, acuta, margine varie lobulata, basi subdentata, cellulis minoribus æquimagnis formata. Capitula masc. magna, longe pedunculata, pedunculo crasso, fusco, $3 \mathrm{~cm}$. longo, nudo, palmatifida, lobis ad 6 , usque ad basin fere liberis, angustis, crispato alatis, 6-7 mm. longis, validis, divergentibus. Reliqua haud vidi. Scyphuli margine valide spinosi, spinis 7-8 cellulas longis, basi 3 cellulas latis.

Hab. Java (Miquel).

Lehmann beschreibt die capitula fem. wie folgt : "hemisphærico-umbilicata, centro pedunculata, ambitu brevissime decemfida, subtus breviter fibrillifera, involucris oligocarpis, ore lacero-fimbriatis. Involucella membranacea, quadrifida. Capsula matura, subexserta, vertice dehiscente, demum profunde quadfipartita ". Die Pllanze scheint also eine gute Art zu sein, da eine Species mit capituli lobis brevissimis und einem capitulo hemisphærico symmetrico aus Java nicht bekannt ist. Lehmann'sche Originalpflanzen sind zum Teil im Herb. der Universität Rom (Herb. De Notaris) vorhanden. Wo aber ist der Rest seiner wertvollen Sammlung geblieben? 
Marchantia. FRANZ STEPHANI. SPECIES HEPATICARUM.

30. Marchantia parviloba St. in Engler, Bot. Jahrb. 1895, p. 305 .

Magna, tenuis, antice viridis, postice purpurascens. Frons ad $6 \mathrm{~cm}$. longa, $6 \mathrm{~mm}$. lata ; costa humilis, lata, tertiam latitudinis partem tenens, sensim in alas validas excurrens. Epidermis tenera. Stomata maxima, parum prominula, ore interno magno, 丂̆-6 cellulis plano-conicis circumdato. Appendicula squamarum magna, cordata, subrotunda, arcte constricta, acuta, margine repando-angulata vel irregulariter dentata, cellulis majusculis, marginalibus duplo minoribus. Pedunculus carpocephali validus, ad $3 \mathrm{~cm}$. longus, nudus, apice paleis filiformibus longius barbatus; paleæ involucrales lanceolatæ, cuspidatæ, integerrimæ. Capitula O magna, plano-convexa, disciformia, 9 lobata, lobis sinu rotundato diseretis, brevibus, subquadratis, apice truncatis. Involucra hyalina, breviter lobata, lobis fimbriatis. Perianthia hyalina, ore parvo tubuloso paucidentato. Capsula fusco-brunnea, laxe annulata. Sporæ $27 \mu$, flavo-virescentes. Elateres $720 \mu$. Scyphuli magni, minute ciliati, ciliis 3 cellulas longis; ciliæ similes in externa facie patellæ sparsæ.

Hab. Africa orient. in Mte Runssoro (Stuhlmann $2800 \mathrm{~m}$.).

31. Marchantia viridula L. L. in Lehm. Pug. IV, p. 33.

Magna, robusta, viridis, postice fusco purpurascens. Frons ad $5 \mathrm{~cm}$. longa, $10 \mathrm{~mm}$. lata, coriacea. Costa angusta, parum producta, sensim in alas validas attenuata. Epidermis tenera. Stomata minora, parum prominula, ore interno 4 cellulis plano-conicis circumdato. Appendicula squamarum maxima, normaliter oblongo-ovata, interdum breviora et magis rotundata, ubique breviler denticulata, cellulis parvis marginata (centralibus multo majoribus). Pedunculus carpocephali validus, ad $25 \mathrm{~mm}$. longus, apice paleis lanceolatis dense barbatus. Capitula $ᄋ$ magna, 9-11 lobata, lobis valde devexis, antice costatis, ad $1 / 3$ solutis, dense contiguis apice rima angusta breviter incisis, lobulis truncato rotundatis, planis. Involucra hyalina, margine minute crenato-denticulata. Perianthia hyalina, ore parvo integro. Capsula fusco-brunnea, dense annulifera. Sporæ $20 \%$ $\mu$, flavæ. Elateres $660 \mu$. Capitula masc. femineis minora, palmatifida, brevius pedunculata, 8 lobata, lobis angustis, per paria approximatis, ad medium solutis. Scyphuli breviler denticulati, dentibus 2 cellulas longis basi $\mathbf{2}$ cell. latis.

Hab. Ins ${ }^{e}$ Mascarenæ (Rodriguez, Boivin, Armange, Garnier. Inse Comoræ (Humblot) Madugascar (Pervillé). 
32. Marchantia subintegra. Mitt. Linn. Soc. V, p. 125.

Minor, angusta, pallide viridis vel flavicans, postice fuscescens. Frons ad $3 \mathrm{~mm}$. lata, $3 \mathrm{~cm}$. longa, crassa. Costa latissima, bene convexa, alis brevissimis sensim attenuatis. Epidermis tenera. Stomata parva, humilia, ore interno 4 cellulis plano-conicis conniventibus subclauso. Appendicula squamarum magna, basi valde constricta, ovata, angusta, acuminata, angulatim repanda, celllulis marginalis parum minoribus. Pedunculus carpocephali ad $2 \mathrm{~cm}$. longus, validus, ubique sparsim lanatus, apice paleis longis filiformibus purpureis barbatus; paleæ involucri lanceolatæ, dentatæ, apice longe attenuatæ, interdum bi-vel trifidæ vel dentatæ. Capitula 오 symmetrica, hemisphærica, quadriloba, lobis ad medium liberis ovatis, decurvis. Involucra sub lobis inserta, hyalina, margine breviter lobulata, lobis rotundatis, creberrime et purpureo fimbriatis. Capitula $\sigma^{7}$ asymmetrica, 8 radiata, radiis connatis, levi sinu acuto diseretis. Reliqua desunt.

Hab. Assam (Griffith), Himalaya (Hooker et Thomson), Darjeeling (Wichura).

Hinsichtlich der Stellung der Involucra unter (nicht zwischen) den lobulis, siehe die Einleitung zum Genus Marchantia.

33. Marchantia Bescherellei St. Rev. bryol. 1888, p. 86.

Major, fusco-viridis, postice fusco-purpureus. Frons ad $4 \mathrm{~cm}$. longa, $10 \mathrm{~mm}$. lata, tenuis. Costa angusta, bene producta, late convexa, abrupte in alas tenerrimas excurrens. Epidermis tenera. Stomata magna, alte prominula, ore interno 6 cellulis conicis circumdato. Appendicula squamarum parva, rosea, ovata, angulatim repanda. Pedunculus carpocephali validus, ad $2 \mathrm{~cm}$. longus, nudus, apice paleis roseis, lanceolatis, cuspidatis barbatus. Capitula fem. magna, disciformia, fusco-viridia, tenera et venosa, centro plano-convexo, 9 lobata, Iobis planis usque ad apicem fere connatis, apice rotundatim prominentibus, incisura brevissima itaque distinctis. Involucra hyalina, parvilobulata, irregulariter breviterque fimbriata. Perianthia hyalina, ore contracto breviter rostrata. Capsula fusco-rufa, laxa annulata. Sporæ llavæ, $23 \mu$. Elateres $720 \mu$. Capitula masc. femineis æquimagna, palmatifida, lobis 4 latis ad medium liberis. Scyphuli desunt.

Hab. Brasilia, Rio Janeiro (Glaziou, Ule).

34. Marchantia crenata Austin. Torrey Bot. Cl. V, p. 14.

Minor, fusco-viridis, postice purpurascens. Frons ad $3 \mathrm{~cm}$. longa, כ̆ $\mathrm{mm}$. 
lata, crassa, magnis et numerosis ductibus muciferis percursa. Costa valida, haud tamen producta, sensim in alas validas excurrens. Epidermis tenerrima. Stomata maxima, ore interno $\breve{5}-6$ cellulis plano-conicis circumdato. Appendicula squamarum purpurea, ovato-lanceolata vel ovato-oblonga, acuta, cellulis mediocribus ubique fere æquimagnis formata. Pedunculus carpocephali validus, brevis, $10 \mathrm{~mm}$. longus, paleis linearibus valde hirsutus, apice similiter barbatus, paleis involucralibus tamen brevioribus, roseis, lanceolatis. Capitula fem. parva, hemisphærica, crenato-sexlobata, lobis brevibus, rotundatis, apice brevissime bilobis. Involucra parva, margine parvilobulata, lobis irregulariter ciliatis. Reliqua desunt. Scyphuli parvi, margine dentati, dentibus parvis, triangulatis, acutis, integerrimis.

Hab. Hawai (Mann et Brigham, Baldwin). 

Extrait du Bulletin de l'Herbier Boissier.

Tome VII. No 7. Juillet 1899.

\title{
SPECIES HEPATICARUM
}

AUCTORE

\author{
Franz STEPHANI
}

(Suite.)

\section{b. Capitula fem. asymmetrica.}

V. Capituli lobi lineares.

\section{- 33. Marchantia geminata Nees, Nova Acta XII, p. 194.}

Major, viridis vel subglauca. Frons ad $7 \mathrm{~cm}$. longa, multiramosa, ramis $5 \mathrm{~mm}$. latis. Costa valde et abrupte producta, angusta, alis crassis, sensim attenuatis. Stomata majuscula, ore interno 4 cellulis plano-conicis circumdato. Appendicula squamarum magna, valde constricta, ovato-oblonga, breviter acuminata, margine irregulariter brevidentata. Pedunculus carpocephali ad $3 \mathrm{~cm}$. longus, validus, sparsim et longe paleaceus, apice paleis linearibus longe barbatus; paleæ involucrales lanceolatæ, dentatæ, longe attenuatæ. Capitula fem. asymmetrica, uno latere ad $2 / 3$ trilobata, centro gibboso, lobis linearibus, sinu acuto divergentibus, planis, apice breviter bifidis (unde nomen ageminatas). Involucra sub lobis inserta et sub fissura apicali desinentia, a dorso itaque haud videnda, magna, vix colorata, versus basin conico-angustata, ore amplo integerrimo. Perianthia brunnea. Capsula fusco-rufa, annulis creberrimis incrassata. Sporæ $28 \mu$, glaberrimæ, dilute flavescentes. Elateres filiformes, $300 \mu$. Scyphuli parvi, irregulariter brevidentati, subspinosi. Capitula $\sigma^{\top}$ asymmetrica, 6 radiata, radiis usque ad basin fere solutis, alis costæ æquilatis tenerrimis crispatis.

Hab. Java (Blume, Jagor, Solms, Warburg, Schiffner), Sumatra (Schiffner), India orient (Wichura). 
36. Marchantia sciaphila Schffn. Kais. Akad. Wien. LXVII, p. 161.

Frons mediocris, ad $10 \mathrm{~cm}$. longa, $8 \mathrm{~mm}$. lata, antice læte viridis, postice rubescens. Costa parum prominula, sensim in alas attenuatas excurrens. Epidermis antica tenera. Stomata humilia, parva, ore interno parvo, quatuor cellulis plano-conicis circumdato. Appendicula squamarum magna, oblonga, lanceolata, apice setacea, parum dentata. Pedunculus carpocephali ad $2.5 \mathrm{~mm}$. longus, subnudus, tenuis, apice paleis lanceolatis longeque setaceis barbatus. Capitula ㅇ parva, 3-4 lobis palmatim unilateralibus asymmetrica, centro parum convexo, lobis late linearibus, usque ad centrum liberis, sulcatis, apice breviter bifidulis. Involucra hyalina, minute crenato-denticulata. Perianthia ore constricto integerrimo. Capsula brunnea, crebre annulata. Sporæ $27 \mu$. Elateres $630 \mu$. Andræcia ignota.

Hab. Java in Mte Salak (Schiffner).

37. Marchantia Treubii Schffn. Kais. Akad. Wien. LXVII, p. 160.

Minor, antice viridis, postice haud colorata. Frons ad $6 \mathrm{~cm}$. longa, $7 \mathrm{~mm}$. lata, valida; costa latiuscula, parum convexo-producta, sensim in alas validas abeunte. Epidermis valida, bistrata, papillas magnas hemisphæricas hyalinas gerens. Stomata parva, parum prominula, ore interno parvo subquadrato, 4 cellulis angustis circumdato. Appendicula squamarum maxima, lanceolata, apice longe setacea, basi arcte constricta. Pedunculus carpocephali ad $2 \mathrm{~cm}$. longus, paleaceus, apice paleis filiformibus purpureis barbatus; paleæ involucrales maximæ, lanceolatæ, purpureæ, longe cuspidatæ. Capitula breviter palmatifida, quadriloba, centro parvo convexo, lobis quadratis, medio sulcatis, apice truncatis, breviter incisis. Involucra rufescentia, margine purpurea, crispato-lobulata, irregulariter dentata; cellulæ limbi valde incrassatæ. Capitula masc. magna, palmatifida, lobis 3-8, profunde solutis. Scyphuli breviter spinosodentati, dentibus 4 cellulas longis, basi 2 cell. latis.

Hab. Java (Schiffner, Stahl), Timor (Forbes).

\section{Marchantia macropora Mitt. Flora N. Zel. II, p. 169.}

Minor, gracilis, crassa et dura, subfragilis, antice flavo-virens vel rubescens, postice purpurascens. Frons ad $3 \mathrm{~cm}$. longa; $3 \mathrm{~mm}$. lata; costa angusta, abrupte producta, haud tamen crassa, alis validis, margine acutis. Epidermis antica cellulis bistratis formata, maxime æqualiterque incras- 
sata, trigonis nullis. Stomata omnium maxima, purpureo marginata, late conica et valde elevata, 6 cellulis sexseriatis ædificata, ore interno maximo, cellulis numerosis, biseriatis, conicis, subinde elongatis et filiformibus, in lumen pori concentrice et imbricatim conniventibus clauso. Appendicula squamarum purpurea, majora, subrotunda, obtusa, integerrima, cellulis minoribus marginata; cellulæ rentrales multo majores. Pedunculus carpocephali brevis, $10 \mathrm{~mm}$. longus, tenuis, apice dense breviterque barbatus, paleis roseis lanceolatis, acuminatis. Capitula parva, palmatim 4 fida, disco integro altissime stomatifero, stomatis fusco marginatis, lobis disci diametro æquilongis, contiguis, late linearibus, apice cuneatim leniterque ampliatis, truncatis breviterque incisis. Involucra tubulosa, ore minore, rotundo, lobulato, lobulis breviter fimbriatis. Perianthia hyalina, ore breviter tubuloso. Capitula mas. parva, brevissime pedunculata, palmatim quadrifida, lobis usque ad basin solutis.

Hab. New Zealand (Sinclair, Knight, Kirk).

\section{Marchantia vitiensis St. n. sp.}

Frons ad $3 \mathrm{~cm}$. longa, $5 \mathrm{~mm}$. lata, valida, antice fusco-viridis, postice fusco-purpurea. Costa plano-convexa, haud producta, sensim in alas attenuatas excurrens. Epidermis antica æqualiter incrassata. Stomata parum prominula, ore interno magno, subquadrato, 4 cellulis angustis circumdato. Squamarum appendicula profunde constricta, basi rotundata, superne sensim angustata, acuminata, paucis dentibus validis armata. Pedunculus carpocephali tenuis, ad $2 \mathrm{~cm}$. longus, paleaceus, paleis filiformibus apice dense breviterque barbatus et paleis lanceolatis purpureis villosus. Capilula fem. parva, asymmetrica, basi aloba, ceterum quinqueloba, lobis latis breviter discretis, apice truncatis vel exciso truncatis, medio costatis, costis ad centrum umbonatum concurrentibus. Involucra 4, margine breviter lobata, lobis dense dentatis vel spinosis. Scyphuli parvi, dentati, dentes 2-3 cellulas longi. Reliqua desunt.

Hab. Insulæ Viti (Græffe, C. Weber).

\section{Marchantia Wallisii Jack et St.}

Syn. : M. macropora J. et St. (non Mitten), Hedw., 1892, p. 22.

Parva, fusco-viridis, postice fusco-purpurea. Frons ad $2 \mathrm{~cm}$. longa, $3 \mathrm{~mm}$. lata, valida. Costa lata, convexo-producta, alis brevibus validis; cellulæ epidermidis æqualiter incrassatæ. Stomata magna, valde prominentia, ore interno quadrato, 4 cellulis angustis cireumdato. Appendicula squamarum ovata, subintegerrima, acuta, parvicellularia. Pedunculus car- 
pocephali validus, $2 \mathrm{~cm}$. longus, purpureus, paleis setaceis hirtus, apice paleis lanceolatis barbatus. Capitula fem. asymmetrica, valde convexa, uno latere quadriloba, lobis profunde bifidis, laciniis late linearibus, interdum spathulatis. Involucra 4, magna, ore integerrimo, optime crispato, rubescente. Perianthia purpurea, ore angustato, plicatulo. Scyphuli breviter dentato-ciliati.

Hab. Insulæ Philippinæ (Wallis, Semper).

\section{Marchantia Fargesiana St. n. sp.}

Magna, glauco-viridis, postice fusco-rufescens. Frons ad $5 \mathrm{~cm}$. longa, $10 \mathrm{~mm}$. lata, costa bene producta, valde convexa, sensim in alas excurrens. Epidermis antica æqualiter incrassata, valida. Stomata bene producta, ore interno cruciato. Appendicula squamarum maxima, e basi cordata sensim angustata, oblonga, acuminata acuta, irregulariter eroso denticulata, hic illc dente validiore armata, cellulis marginalibus multo minoribus. Pedunculus carpocephali crassus, validissimus, subnudus, apice paucis paleis brevibus filiformibus barbatus; paleæ involucrales lanceolatæ. Capitula fem. rufescentia, asymmetrica, uno latere aloba, ceterum 9 lobata, lobis late linearibus valde convexis, apice truncatis, ad medium liberis, centro parvo umbonato. Involucra parva, multifissa, laciniis pinnatim longius fimbriatis. Perianthia magna, hyalina, alata, alis apice longe liberis, ore contracto, fimbriato. Scyphuli magni crebre lobati, lobis trigonis, longe cuspidatis, basi spinis minoribus patulisque armatis.

Hab. China, Sutchuen orient. (Farges).

42. Marchantia diptera Mont. Ann. sc. nat. 1843, p. 243.

Syn. : M. calcarata St. Bull. Herb. Boiss. 1897, p. 98.

Major, robusta, viridis, margine posticeque purpurascens. Frons ad $4 \mathrm{~cm}$. longa, $8 \mathrm{~mm}$. lata, costa parum incrassata, in alas valde attenuatas excurrens. Epidermis tenera. Stomata parva, numerosa, ore interno minimo, 4 cellulis conicis radiatim conniventibus subclauso. Appendicula squamarum magna, cordato-rotunda, purpurea, subintegerrima, cellulæ marginales centralibus æquilongæ, angustiores. Pedunculus carpocephali validus, $\check{5} \mathrm{~cm}$. longus, subnudus, paleis purpureis filiformibus barbatus, basi magnis squamis vaginatim involucratus. Capitula 우 asymmetrica, uno latere exciso-hastata, ceterum 9 lobata, lobis disco integro capituli æquilongis, linearibus, truncatis, regulariter distributis, Involucra margine lobata, lobis purpureis fimbriatis. Perianthia ore constricto plicatulo integerrimo. Reliqua desunt. 
Marchantia. FRANZ STEPHANI. SPEGIES HEPATIGARUM.

Hab. Japonia Bussenil, Makino, Savatier, Faurie).

Das Original von $M$. diptera ist fruchtend nicht zu beschaffen; nur einen sterilen Thallus konnte ich prüfen, der in allen Teilen mit meiner M. calcarata übereinstimmt, so dass ich diesen Namen eingezogen habe.

\section{Gapituli lobi obcuneati.}

43. Marchantia nepalensis L. et L. in Lehm. Pug. IV, p. 10. Major, viridis, postice fusco-purpurea. Frons ad $4 \mathrm{~cm}$. longa, $10 \mathrm{~mm}$. lata; costa lata, haud producta, humilis et longe in alas excurrens. Epidermis tenerrima. Stomata parva, parum elevata, ore interno cruciato. Appendicula squamarum magna, cordata, acuta, repandula, cellulis marginalibus multo minoribus. Pedunculus carpocephali validissimus (basi $1 \mathrm{~mm}$. in diametro) ad $4 \mathrm{~cm}$. longus, coloratus, basi squamis magnis vaginatim involucratus, paleis brevibus filiformibus purpureis barbatus. Capitula fem. asymmetrica, centro parvo umbonato, basi laciniis divergentibus hastata, ceterum 9 lobata, lobis radialiter distributis, ad medium liberis, linearibus, antice valde convexis (costatis) apice truncato parum latioribus. Involucra hyalina, breviter lobata, lobis longe fimbriatis. Perianthia hyalina, ore contracto integerrimo. Capsula brunnea, annulis confertis validissimis incrassata. Sporæ brunneæ, granulatæ 24 ‥ Elateres $440 \mu$. Androcia capitulis $9 æ q u i m a g n a$, breviter pedunculata, disciformia, radiis vel lobis usque ad apicem fere conjunctis, antice varie tortis et rugulosis. Scyphuli margine purpureo dentati (ipse haud vidi).

Hab. Nepal (Wallich), Himalaya (Gollan 7000').

\section{Marchantia nitida L. et L. in Lehm. Pug. IV, p. 11.}

Major, robusta, viridis, margine posticeque purpurascens. Frons ad $4 \mathrm{~cm}$. longa, $5 \mathrm{~mm}$. lata. Costa bene producta, sensim in alas validas excurrens. Epidermis antica cellulis æqualiter incrassatis valida. Stomata parva, numerosa, ore interno cruciato. Appendicula squamarum magna, cordata, margine crenulata, cellulæ marginales multo minores. Pedunculus carpocephali ad $2 \mathrm{~cm}$. longus, paucipaleatus, apice paleis longis purpureis filiformibus barbatus. Capitula fem. asymmetrica, basi late emarginata, ceterum 9 lobata, lobis ad medium solutis, ex angusta basi cuneatim ampliatis, contiguis, apice inciso-bilobis. Involucra hyalina, late aperta, irregulariter lobata, lobis varie fimbriatis. Perianthia hyalina, ore contracto parvo. Capsula annulis remotiusculis incrassata. Calyptra 
valida. Sporæ $28 \mu$, minute papillatæ, flavescentes. Elateres $460 \mu$. Capitula masc. "minus longe pedunculata, peltata, rugosa, margine adscendente octoloba " (Lindenberg), Scyphuli margine grosse lobati, lobis sub 25 plano conicis, contiguis, longe acuminatis, medio infero patulospinulosis.

Hab. Nepal. (Wallich), Java (Schiffner).

Die Pflanze aus dem Nilgherry-Gebirge habe ich nicht gesehen.

45. Marchantia tholophora Bisch. Nova Acta XVII, p. 989.

Major, dilute viridis, postice purpurascens, tenuis, medio antico, costa fusca perlucente, notata. Frons ad $4 \mathrm{~cm}$. longa, $12 \mathrm{~mm}$. lata; costa lata, humilis, postice plano convexa, sensim in alas tenerrimas excurrens. Stomata parva, ore interno cruciato. Epidermis tenera. Appendicula squamarum magna, cordato-rotundata, valde constricta, purpurea, integerrima, cellulis marginalibus duplo minoribus. Pedunculus brevis, $10 \mathrm{~mm}$. Iongus, paleis filiformibus sparsim hirtus, apice similiter longeque barbatus, basi squamis magnis prominentibus validis vaginatim involucratus. Capitula alte umbonata centro anguste conico, septemlobata, lobis (juvenilibus) decurvis, convexis, in statu explanato obcuneatis, truncatis, 2 basalibus multo majoribus profunde solutis et hastatim divergentibus. Reliqua desunt.

Hab. Mexico, 0axaca (Sommerschuh).

Bischoff l. c. führt noch an : Involucra fimbriata, pilis longis densissimis. Scyphuli ciliato-denticulati.

\section{Marchantia tosana St. Bull. Herb. Boiss. 1897, p. 99.}

Minor, gracilis, fusco-viridis, postice fuscescens. Frons ad $2 \mathrm{~cm}$. longa, $3 \mathrm{~mm}$. lata, crassa; costa latissima, valde evoluta et bene producta, sensim in alas breves et validas excurrens. Epidermis valida. Stomata parva, alte prominula, ore interno 4 cellulis plano-conicis circumdato. Appendicula squamarum parva, valde constricta, ovata, breviter acuminata, margine remote valideque brevispinosa, cellulis majoribus, a basi ad marginem magnitudine decrescentibus. Pedunculus carpocephali validus, ad $2 \mathrm{~cm}$. longus, sparsim longeque paleaceus, apice paleis purpureis filiformibus barbatus; paleæ involucrales oblongo-lanceolatæ, apice setaceæ. Capitula fem. parva, 6 lobata, disco centrali parvo, convexo, lobis divaricatis, disci diametro plus duplo longioribus, linearibus, apice cuneatim dilatatis, truncatis, basalibus magis divergentibus. Involucra tenerrima, hyalina, ore integerrimo, crispato-plicatulo. Perianthia 
purpurea, ore parvo contracto. Capitula mas. palmatifida, disco integro magno, lobis 8, disci diametro æquilongis, leniter divergentibus, basi elobulata.

Hab. Japonia (Jnouë, Faurie).

47. Marchantia disjuncta Sull. Musci Allegh., p. 67.

Mediocris, viridis, postice fusco-rubescens. Frons ad $25 \mathrm{~mm}$. longa, $5 \mathrm{~mm}$. lata, valida. Costa optime producta, sensim in alas tenues attenuata. Epidermis tenerrima. Stomata parva, bene prominula, ore interno parvo 5 cellulis plano-conicis circumdato. Appendicula squamarum magna, late ovata, acuta, rubescentia, margine eroso-denticulata vel subciliata, cellulis majusculis subæquimagnis formata. Pedunculus carpocephali validus, ad $2 \mathrm{~cm}$. longus, nudus, apice paleis ovato-oblongis varie laceratis purpureis barbatus. Capitula fem. magna, 9 lobata, disco integro magno, convexo, lobis decurvulis, sinu obtuso discretis, linearibus, apice cuneatim dilatatis, rotundato-truncatis; lobi basales sinu lato discretis, hastatim divergentibus. Involucra hyalina, breviter lobulata, lobis paucidentatis, dentibus triangulatis parvis. Capitula mascula femineis minora, brevius pedunculata, palmatifida, lobis sub 8 , geminatim approximatis, ad medium liberis; lobi basales late divergentes.

Hab. America septentr.: Alabama, Arkansas, Texas, haud rara. Mexico (C. Müller, Stone, Bourgeau, C. Mohr), Cuba (Wright), Jamaica (Wilson, James).

\section{Marchantia Schadenbergii St. n. sp.}

Minor, fusco virens, postice rufescens. Frons ad $3 \mathrm{~cm}$. longa, $3 \mathrm{~mm}$. lata, medio valde incrassata; costa tamen haud producta, plano convexa, sensim in alas attenuata. Épidermis cellulis æqualiter incrassatis valida. Stomata parva, ore interno magno, 4 cellulis angustis circumdato. Appendicula squamarum purpurea, oblonga, margine regulariter longeque fimbriata. Pedunculus carpocephali ad $12 \mathrm{~mm}$. longus, tenuis, paleis filiformibus hirtus, apice similiter barbatus. Capitula fem. usque ad basin fere 9 fida, Iobis planis, ex angusta basi ampliatis, apice truncatis. Involucra integerrima, crispata, cellulis oleiferis ubique creberrime punctata, paleis lanceolatis ovato-acuminatis el dentatis tecta. Perianthia purpurea. Capitula mas. asymmetrica, palmatim sexfida, lobis profunde solutis, contiguis, ala marginali crispata.

Hab. Insula Luzon (Schadenberg). 
49. Marchantia palmata Nees. Nova Acta XII, p. 193, Syn. : M. emarginata Nees. Hep. Jav. Nova Acta XII, p. 192-400.

Minor, gracilis, viridis, postice fuscescens. Frons ad $3^{1 / 2} \mathrm{~cm}$. Ionga, $3 \mathrm{~mm}$. lata; costa valde producta, alæ tenerrimæ. Epidermis cellulis æqualiter incrassatis valida. Stomata bene prominula, ore interno amplo, 4-らّ cellulis angustis formato. Appendicula squamarum parva, ovata, paucidentata, cellulis æquimagnis ædificata. Pedunculus tenuis, nudus vel sparsim paleaceus, apice paleis filiformibus longius barbatus; paleæ involucrales oblongæ, longe sæpe abrupte setaceæ, dentatæ vel spinosæ. Capitula fem. asymmetrica, ad $2 / 3$ lobata, lobis $9-11$ angustis, planis, confertis, ex angusta basi cuneatim ampliatis, truncatis, vel leniter emarginatis, basalibus hastatim divergentibus, brevioribus. Involucra hyalina, integerrima, crispatula. Perianthia purpurea, ore parvo integro. Capsula fusco-brunnea, annulis numerosis incrassata. Sporæ $27 \mu$, flavescentes. Elateres $480 \mu$. Capitula mas. brevius pedunculata, magna, palmatifida, lobis ad 8 , usque ad basin liberis, angustis, ambitu clavatis. Scyphuli creberrime ciliolati, ciliis 2 cellulas longis.

Java (Junghuhn, Hillebrand, Jagor, Solms, Stahl, Schiffner), Japan (Dönitz, Miyoshi), Philippinæ Inse (Wichura), Tonkin (Balansa), China (Wichura), Himalaya (Brandis).

๊0. Marchantia linearis L. et L. in Lehm. Pug. IV, p. 8.

Minor, gracilis, flavo-viridis, postice fuscescens. Frons ad $4 \mathrm{~cm}$. longa, $3 \mathrm{~mm}$. lata ; costa angusta, convexo-producta, alæ tenues, ob epidermidis cellulas incrassatas validæ, plano explanatæ. Stomata parva, parum prominula, ore interno subquadrato, 4 cellulis angustis circumdato. Appendicula squamarum valde constricta, rotundata, acuta, margine varie spinosa. Pedunculus carpocephali ad $3 \mathrm{~cm}$. longus, tenuis, paleis filiformibus hirtus, apice similiter longeque barbatus; paleæ involucrales hyalinæ, oblongæ, magnæ, numerosæ et confertissimæ, margine longe fimbriatæ. Capitula fem. 10 lobata, Iobis centro capituli duplo longioribus, anguste obcuneatis, contiguis, convexis, apice truncatis. Involucra hyalina, margine lobulata, lobulis creberrime breviterque ciliatis. Capitula masc. magna in apice ramorum sessilia, profunde palmatifida, lobis ad sex. Reliqua desunt.

Hab. Nepal (Wallich).

Quoad plantam americanam vide March. domingensis.

\section{Marchantia Lecordiana St. n. sp.}

Minor, viridis, postice fuscescens, angusta et gracilis. Frons ad $3 \mathrm{~cm}$. 
longa, $4 \mathrm{~mm}$. lata; costa distincte producta, convexa, alæ tenues. Epidermis valida. Stomata parva, parum prominula, ore interno subquadrato, 4 cellulis angustis formato. Appendicula squamarum valde constricta, ovata, acuta, parvicellularia, margine plus minus longe spinoso-dentata. Pedunculus carpocephali $\mathbf{2} \mathrm{cm}$. longus, tenuis, paleis lanceolatis ubique hrrtus, magis in apice pedunculi. Capitula fem. asymmetrica, basi anguste hastata, ceterum quinqueloba, lobis basi valde angustatis, quasi stipitatis, apice abrupte obconicis, truncatis. Involucra hyalina, integerrima, crispatula. Capitula mascula symmetrica, usque ad basin bis-quadrifida, pedunculo subnudo breviore, $8 \mathrm{~mm}$. longo. Reliqua desunt.

Hab. Nova Caledonia, Ouraï (Lecord).

\section{Marchantia caracensis St. n. sp.}

Minor, angusta, gracilis, olivacea, postice fuscescens. Frons ad $20 \mathrm{~mm}$. longa, $3 \mathrm{~mm}$. lata, crassa. Costa bene producta, sensim in alas validas excurrens. Epidermis tenera. Stomata magna, creberrima, bene producta, ore interno magno, quadrato, 4 cellulis angustis circumdato. Appendicula squamarum magna, rosea, late ovata, acuta, arcte constricta, cellulis a basi ad marginem valde decrescentibus, margine eroso-denticulata. Pedunculus carpocephali tenuis, ad $45 \mathrm{~mm}$. longus, paleis longis hirtus, apice similiter barbatus; paleæ involucrales late lanceolatæ, cuspidatæ, dentatæ vel lacinulatæ, omnes purpureæ. Capitula fem. parva, $ّ$-6 lobata, centro integro parvo, convexo, lobis ex angusta basi oplime obcuneatis, contiguis, diametro centri duplo longioribus, convexis, decurvulis, apice truncato rotundatis. Involucra hyalina, margine lobulata, lobis breviter fimbriatis. Perianthia hyalina, ore contracto integro. Capsula fusco brunnea, crebre annulata. Reliqua desunt.

Hab. Caracas (Gollmer), Mexico (Wawra).

\section{5ั3. Marchantia Kærnbachii St. n. sp.}

Frons parva, angusta, gracilis, ad $2^{1 / 2} \mathrm{~cm}$. longa, $3 \mathrm{~mm}$. lata, crassa. Costa lata, abrupte producta, postice plano convexa. Epidermis antica validissima, cell. parietibus æqualiter incrassatis. Stomata parva, numerosa, ore interno quadrato, 4 cellulis angustis circumdato. Appendicula squamarum magna, oblonga, laxe reticulata, margine regulariter spinosodentata, apice obtusa. Pedunculus carpocephali ad $20 \mathrm{~mm}$. longus, subtenuis, apice paucis paleis pendulis et filiformibus barbatus. Capitula fem. excentrica, uno latere 9 lobata, lobis regulariter radiatis, ex angusta basi conico-ampliatis, approximatis, apice breviter bifidulis vel excisis vel 
truncatis; paleæ involucrales lanceolatæ, breves. Involucra late conchæformia, rufo-brunnea, integerrima, crispula. Perianthia hyalina, ore parvo contracto. Capsula dilute brunnea, annulis crebris instructa. Sporæ $27 \mu$, rufo brunneæ. Elateres $430 \mu$, validi, medio $7 \mu$. lati valde attenuati. Reliqua desunt.

Hab. Nova Guinea, Butanang (Kärnbach).

\section{5้4. Marchantia angusta St. n. sp.}

Minor, valde angusta, gracillima, pallide virens, postice fuscescens. Frons ad $4 \mathrm{~cm}$. longa, $2 \mathrm{~mm}$. lata, multiramosa, valida. Costa haud producta, sensim in alas crassas excurrens. Epidermis tenera. Stomata magna, parum prominentia, ore interno magno, 5 - 6 cellulis angustis circumdato. Appendicula squamarum magna, ovata, acuta, spinis validis, numerosis armata, valde constricta, cellulis æquimagnis majusculis formata. Pedunculus carpocephali tenuis, ad $25 \mathrm{~mm}$. longus, nudus, apice paleis lance0latis breviter barbatus. Capitula fem. parva, 9 lobata, lobis basalibus acuminatis, sinu latissimo divergentibus, reliquis optime obcuneatis, sinu obtuso discretis, disci centralis diametro brevioribus, apice truncatis emarginatis vel inciso bilobis. Involucra ad medium loborum protracta, ore integerrimo crispato-plicatulo. Perianthia hyalina vel flavescentia, ore integro. Capsula rufo-brunnea, laxe annulata. Sporæ $28 \mu$, flavæ. Elateres $660 \mu$. Capitula mas. femineis minora, subdisciformia, 8 lobata, lobis per paria approximatis, usque ad apicem connatis, lamina interlobularis plus minus profunde acuteque insisa, circumscriptione itaque valde irregulari. Scyphuli margine denticulati, dentibus conico-prominentibus, unicellularibus.

Hab. Tonkin (Bon. Balansa).

\section{วิอิ. Marchantia furciloba St. n. sp.}

Mediocris, viridis, postice rufo-purpurascens. Frons ad 30 mm. longa, $5 \mathrm{~mm}$. lata. Costa parum producta, leniter convexa, in alas validas excurrens. Epidermis tenera, cellulis haud raro bistratis formata. Stomata magna, numerosa, bene exserta, ore interno magno, $\check{b}$ cellulis angustis circumdato. Appendicula squamarum e basi rotundata profundeque constricta, ovata, acuminata, cellulis subæquimagnis formata, margine subintegra. Pedunculus carpocephali $1 \mathrm{~cm}$. Iongus, nudus, paleis linearibus breviter barbatus; paleæ involucrales lanceolatæ, longe cuspidatæ, purpureæ. Capitula fem. dilute glauco-viridia, asymmetrica, basi aloba, ceterum 9 lobata, lobis ad $1 / 3$ liberis, apice profunde bifidulis, centro 
leniter umbonato. Involucra valida, brunnea, margine integerrimo planoque, parietibus cellularum æqualiter incrassatis. Capitula mas. magna, asymmetrica, $\breve{5}-6$ loba, usque ad basin palmatifida, lobis inæqualibus. Reliqua desunt.

Hab. Hawaï (Baldwin).

VII. Capitula disciformia breviloba.

\section{Marchantia chenopoda L. Sp. pl. II, p. 1603.}

Syn. : M. cartilaginea L. et L. teste Schiffner. Lehm. Pug. plant. IV, p. 31.

M. Dillenii Lindb. Krit. Gransk. Dill. Hist. 1883, p. 47.

Minor, gracilis, fusco-viridis, margine sæpe purpurascens, postice fuscopurpurea. Frons ad $3 \mathrm{~cm}$. longa, $5 \mathrm{~mm}$. lata. Costa latiuscula, optime et abrupte producta, alæ tenues, costæ æquilatæ. Epidermis valida. Stomata minora, parum prominula, ore interno quadrato, 4 cellulis angustis circumdato. Appendicula squamarum submagna, late cordato-ovata, acuta, integerrima vel plus minus dentata, cellulis majusculis subæquimagnis formata. Pedunculus carpocephali tenuis, ad $3 \mathrm{~cm}$. longus, paleis longis purpureis hirtus, apice similiter barbatus; paleæ involuerales anguste lanceolatæ setaceæ. Capitula fem. asymmetrica, parva, valde convexa, brevissime quinqueloba, lobis rotundatim prominulis, sinu acuto discretis, decurvulis, basalibus oppositis, capitula basi dein truncata. Involucra 4, hyalina, lobulata, lobulis breviter fimbriatis. Perianthia hyalina, ore constricto quadrifido, lobis papulosis. Calyptra rufescens, cellulis maxime incrassatis valida. Capsula nigro-brunnea, creberrime annulata. Sporæ flavæ $25 \%$ ‥ Elateres ad $720 \mu$. Capitula masc. magna, femineis multoties majora, palmatifida, 4-7 lobata, lobis ad $\mathbf{1 0} \mathrm{mm}$. Iongis, angustis, fere ad basin usque liberis. Scyphuli parvi, regulariter breviterque dentati, dentibus $\mathbf{1 - 2}$ cellulas longis.

Hab. America tropica ubique communis; subtropica Chile et Mexico.

57. Marchantia hexaptera Rchdt. Verh. zool. bot. Ver. Wien, XVIII, p. 960.

Mediocris, viridis, postice fuscescens. Frons ad $3 \mathrm{~cm}$. longa, $5 \mathrm{~mm}$. lata. Costa parum producta, sensim in alas attenuata. Epidermis tenera. Stomata parva, parum prominula, ore interno parvo quadrato, 4 cellulis angustis circumdato. Appendicula squamarum magna, late ovata, repandoangulata vel breviter dentata, apice acuta, cellulis minoribus ubique æqui- 
magnis formata. Pedunculus earpocephali ad $10 \mathrm{~mm}$. longus paleaceus, apice paleis lanceolatis sæpe bifidis maxime barbatus. Capitula fem. disciformia asymmetrica, centro integro magno, umbonato, convexim 8 costato, basi omnino elobulata lateque frondiformia integerrima, ceterum 8-10 lobata, lobis brevibus, sinu parvo obtuso discretis, obcuneatis, apice late truncatis vel repandis vel leniter emarginatis, plano-patulis. Involucra 8, angusta, ore cellulis longis angustissimis crebre ciliato. Perianthia brunneola, valida, ore parvo contracto integro. Capsula fusco-brunnea, laxe annulata. Sporæ flavæ, $28 \mu$. Elateres $660 \mu$. Capitula mas. femineis æquimagna, brevipedunculata, palmatifida, lobis ad 6 , usque ad basin liberis, angustis. Scyphuli brevissime denticulati, dentibus 2 cellnlas longis.

Hab. Tahiti (Exped. Novara, Didrichsen, Vesco, Lépine, Thiébault, Vieillard et Panchet, Nadeaud).

Die Beschreibung des Autors stimmt so wenig mit seiner Figur überein, dass es bisher nicht möglich war, die Pflanze wieder zu erkennen. Obige Beschreibung derselben ist nach den Originalpflanzen im Wiener Museum gefertigt.

58. Marchantia pileata Mitten. Fl. N. Zel. II, p. 169.

Major, robusta, tenax, fusco-virens, postice purpurascens. Frons ad $7 \mathrm{~cm}$. longa, $7 \mathrm{~mm}$. lata; costa angusta, parum producta, sensim in alas validas excurrens. Stomata parva, ore interno subquadrato, 4 cellulis anguste ellipticis circumdato. Epidermis valida, Squamarum appendicula magna, late ovata, apice rotundata, margine crebre irregulariterque denticulata, cellulis anguste hexagonis formata, marginalibus parum minoribus. Pedunculus carpocephali ad $15 \mathrm{~mm}$. longus, tenuis, nudus, apice paleis linearibus sparsim barbatus; paleæ involucrales late lanceolatæ, longe cuspidatæ, fuscescentes, integerrimæ. Capitula fem. valde convexa, subhemisphærica, basi lobis longioribus divergenti-hastata, ceterum breviter 5 loba, Iobis latis truncatis vel rotundatis, interdum leniter emarginatis. Involucra lacerata (ipse haud vidi). Reliqua desunt (adhuc nusquam reperta).

Hab. New Zealand (Colenso).

\section{Marchantia samoana St. n. sp.}

Mediocris, dilute viridis, subtus purpurascens. Frons ad $4 \mathrm{~cm}$. Ionga, $6 \mathrm{~mm}$. lata, tenuis. Costa humilis, longe in alas tenues excurrens. Stomata parum prominula, poro interno 4 fisso, 4 cellulis planis, conico-rotundatis formato. Epidermis valida. Appendicula squamarum maxima, late ovata, cuspidata, margine irregulariter dentata et breviter spinosa, cellulis 
marginalibus parum minoribus, omnibus breviter hexagonis. Pedunculus carpocephali ad $10 \mathrm{~mm}$. longus, tenuis, paleis longis filiformibus fusco purpureis villosus; barba apicalis similis; paleæ involucrales lanceolatæ, longe attenuatæ. Capitula fem. basi late rotundata, omnino elobulata, apice breviter $50-6$ lobata, lobis contiguis, truncatis, sinu parvo rotundato discretis. Involucra breviter inciso-lobata, lobis repando-angulatis. Capitula mas. brevius pedunculata, plus minus regulariter peltata, lobis 5 ad 7 , usque ad basin fere solutis.

Hab. Samoa (Græffe), Viti (Græffe).

60. Marchantia subgeminata St. n. sp.

Major, antice glauco-virens, postice purpurascens. Frons ad $7 \mathrm{~cm}$. longa, $7 \mathrm{~mm}$. lata. Costa crassa, haud tamen producta, sensim in alas excurrens. Epidermis tenerrima. Stomata parva, parum elevata, ore internỏ cruciato. Appendicula squamarum maxima, cordiformia, leniter repanda, minuteque crenulata, cellulis minimis marginata, centralibus multoties majoribus. Pedunculus carpocephali ad $3 \check{\mathrm{mm}}$. longus, basi squamis magnis vaginatim involucratus ibidemque maxime crassus, versus apicem valde attenuatus, ubique paleis tortis lanatus; barba apicalis sanguinea, paleis late linearibus apice setaceis, margine repandoangulatis. Capitula fem. glauco-viridia, disciformia, asymmetrica, basi recto angulo incisa, ceterum 9 loba, lobis sinu brevi angustoque discretis, apice emarginato-bilobis, parum convexis; centro lato, umbonato. Involucra hyalina, profundius lobata, lobis truneatis, irregulariter et longius lacinulatis, purpureis.

Hab. Celebes leg.?

61. Marchantia peruviana (Mont.) Nees. Syn. Hep., p. 538.

Syn. : Grimaldia peruviana Mont. in d'Orbigny. Voy. Botan., p. 63.

Minor, gracilis, viridis, postice fusco-purpurea. Frons ad $4 \mathrm{~cm}$. longa, $4 \mathrm{~mm}$. lata, tenuis. Costa humilis, haud producta, sensim in alas tenues attenuata. Epidermis tenera. Stomata magna, bene prominula, ore interno magno, כ cellulis angustis circumdato. Appendicula squamarum rosea, minora, subrotunda, acuta, margine paucidenticulata, cellulis parvis, marginalibus duplo minoribus formata.

Reliqua haud vidi.

Hab. Peru (d'Orbigny).

In der Synopsis sind noch folgende Charactere gegeben, die ich zur Vervollständigung hier hinzufüge : 
Capitula fem. integra, subglobosa, subtus brevipilosa; pedunculus brevipilosus. Capitula mas, discoidea sessilia. (??)

Montagne hat in seinem Sylloge, p. 91, den alten Namen Grimaldia peruviana restituirt, zweifellos mit Unrecht, da die Pflanze jedenfalls eine Marchantia ist und wahrscheinlich zu M. chenopoda gehört; ein fruchtendes Exemplar ist aber nicht erhalten, weder im Pariser Museum (Herb. Montagne), noch im Strassburger (Herb. Nees).

\section{Marchantia Notarisii Lehm. Pug. X, p. 22.}

Mediocris, tenuis, antice fusco-viridis, postice fusco-purpurascens. Frons ad $3 \mathrm{~cm}$. longa, $\check{5} \mathrm{~mm}$. lata. Costa oplime producta, angusta, abrupte in alas tenerrimas excurrens. Epidermis tenera. Stomata parum prominula, magna, ore interno $\check{5}$ cellulis angustis circumdato. Appendicula squamarum magna, rosea, late ovata, acuminata, margine grosse dentata vel subspinosa. Capitula mascula palmatifida breviter pedunculata, pedunculo tenui, $12 \mathrm{~mm}$. longo, quadriloba, lobis oblongis, ad medium solutis, divergentibus, ala angustissima circumdatis. Scyphuli margine minute et creberrime ciliati, ciliis $\mathbf{2}$ cellulas longis; plantam 우 haud vidi.

Hab. Chile Valparaiso (Lehmann filius).

Lehmann beschreibt die capitula fem. als : «dimidiato-semicircularia, centro obtuse umbonato, pedunculo fibrilligero, excentrice affixo, subtus barbata, brevissime 4-כ̆ loba, lobis obtusis, fornicatis. Involucra ore minute fimbriato denticulato, oligocarpa;» darnach gehört die Pflanze jedenfalls in die nächste Nachbarschaft von $\boldsymbol{M}$. chenopoda, wenn beide nicht gar identisch sind.

\section{c. Incertæ sedis.}

63. Marchantia oregonensis St. Hedwigia, 1893, p. 318.

Mediocris, tenuis, viridis, postice haud colorata. Frons ad $3 \mathrm{~cm}$. longa, $5 \mathrm{~mm}$. lata; costa humilis, haud producta, sensim in alas longe attenuatas excurrens. Epidermis valida. Stomata majuscula, ore interno cruciato. Appendicula squamarum rosea, magna, reniformia, margine varie remoteque dentato-spinosa, cellulis parvis subæquimagnis formata. Capitula mascula parva, brevipedunculata, disciformia, 4-8 crenatim lobata, lobis rotundo-prominulis. 
Hab. America sept. Mt Hood. (Röll.)

Von allen nordamerikanischen Arten unterscheidet sich diese Pflanze schon allein durch die kreuzförmige Oeffnung des inneren Porus stomatum.

Wenn ich diese und einige andere Arten unserer Gattung, obwohl ich weibliche Pflanzen nicht kenne, hier einfügte, so geschieht es, weil sie in Gebieten gefunden worden sind, in welchen die Gattung nur mit wenigen Arten vertreten ist, so dass es ohne Schwierigkeit möglich sein wird, sie später zu identifiziren. Eine grosse Anzahl Pflanzen habe ich leider unerwähnt lassen müssen, weil sie aller Reproduktionsorgane entbehren, obwohl manche gut charakterisirte darin enthalten sind.

64. Marchantia pallida St. Hedwigia 1889, p. 266.

Mediocris, pallide flavo-virens, postice fuscescens. Frons ad $4 \mathrm{~cm}$. longa, $5 \mathrm{~mm}$. lata. Costa bene producta, late convexa, sensim in alas tenerrimas excurrens. Epidermis tenera. Stomata humilia, parva, ore interno $\check{5}$ cellulis plano-conicis fere clauso. Appendicula squamarum rosea, magna, cordata, acuta, margine remote obtuseque denticulata, cellulis oblongis subæquimagnis formata. Scyphuli parvi, margine mamillatim armati, mamillæ geminatim approximatæ. Reliqua desunt.

Hab. Australia, Hume River (Miss Campbell).

Die Gattung ist in dem australischen Continent äusserst spärlich vertreten und unsere Pflanze wird nach dem oben Gesagten jedenfalls wiederzuerkennen sein.

\section{6.ั. Marchantia vaginata St. n. sp.}

Major, valida, coriacea sed tenuis, viridis, margine posticeque purpurascens. Frons ad כ cm. longa, ob ramos longe coalitos latissima, frondem parum dissectum formans, margine valde crispata. Costa parum producta, latissima, canales muciferos numerosos gerens. Epidermis tenerrima, Stomata minima et numerosa, parum prominentia, poro interno 4 cellulis plano-conicis circumdato. Appendicula squamarum magna, cordata rotundata, margine minute obtuseque denticulata. Pedunculus masculus tenuis, $10 \mathrm{~mm}$. longus, basi squamis magnis purpureis, apice cucullatis involucratus. Capitula mascula disciformia, symmetrica, 8 lobata, lobis sinu acuto discretis, rotundatis, parum prominulis. Scyphuli grosse lobati, lobis contiguis, triangulatis, longe cuspidatis, medio infero margine spinulosis. Reliqua desunt.

Hab. Japonia (Faurie, Makino, Miyoshi). 


\section{Marchantia acaulis St. n. sp.}

Major, robusta, tenax et dura, fusco-viridis, postice fuscescens, crassa. Frons ad $4 \mathrm{~cm}$. longa, $5 \mathrm{~mm}$. lata. Costa valida, bene et abrupte producta, radicellis longissimis repens, canalibus muciferis ubique percursa (in costa alisque). Epidermidis cellulæ anticæ maxime æqualiterque incrassatæ, ubique fere bi-vel tristratæ. Stomata humilia, ore interno quadrato, 4 cellulis angustis circumdato. Appendicula squamarum magna, subrotunda, acuta, varie crenato-dentata, cellulis marginalibus haud minoribus. Capitula mascula asymmetrica, subsessilia, pedunculo minimo, palmatifida, lobis angustis ( 5 vel 6 ) ad medium connatis.

Hab. Malacca, Perak (Ridley).

Die Pflanze ist dem ganzen Bau nach einem sehr trockenen Standorte angepasst; darauf deuten die mächtig verdickten Epidermiszellen, welche in 2 bis 3 Lagen übereinander liegen. Die Frons ist ferner von einer grossen Anzahl longitudinal verlaufender Canäle durchzogen, welche eine grosse Menge zähen, durchsichtigen Schleims enthalten, der Wasser aufspeichert, um dasselbe allmählig wieder an die Pflanze abzugeben; die männlichen Capitula endlich sind sitzend und liegen mit ihren schmalen Abschnitten dem Boden ausgebreitet an, was sie natürlich leichter vor dem Vertrocknen schützt, als wenn sie auf einem Stiel in die Luft ragten biologisch ist diese Art jedenfalls die interessanteste der Gattung.

\section{Marchantia cataractarum Schffn. Kais. Ak. Wien LXVII,} p. 158.

Major, valida, viridis, postice purpurea. Frons ad $5 \mathrm{~cm}$. longa, $9 \mathrm{~mm}$. lata. Costa crassa, maxime producta, abrupte in alas validas excurrens. Epidermis tenera. Stomata maxima, bene prominentia, ore interno giganteo, quadrato, 4 cellulis angustis circumdato. Appendicula squamarum parva, ovata, acuminata, acuta, cellulis mediocribus formata, marginalibus duplo minoribus, margine irregulariter paucidentata, hic illic spinosa. Reliqua desunt.

Hab. Java (Schiffner).

Eine gute Art, welche an den riesengrossen Stomatis leicht zu erkennen ist.

Die nachstehenden zwei Arten sind ganz verkümmerte Pflanzen, ohne jeden Werth, die ich nicht beschreibe und die zu streichen sind.

Es sind: $M$. quinqueloba Nees. Syn. Hep., p. 526.

M. pusilla N. et M. Syn. Hep., p. 526. 
Extrait du Bulletin de l'Merbier Boissier.

Tome VII. No 9. Septembre 1899.

\section{SPECIES HEPATICARUM}

AUCTORE

Franz STEPHAVI

(Suite.)

\section{SPHEROCARPUS Micheli, 1729.}

Plantæ frondosæ, parvæ, lerricolæ, virıdes, planæ et tenerrimæ, arcte repentes, dichotome multiramosæ, radicellis longiusculis solo affixæ, apice profunde inciso-bilobæ ibidemque cellulis curvatim-erectis clavatis obtectæ. Costa lata, haud producta, $2-3$ cellulas crassa, sensim in alas tenerrimas attenuata. Rami adventivi antici, e cellulis alarum orti. Inflorescentia dioica. Flores feminei antici, valde numerosi. Involucru pro planta maxima, monogyna, interdum bi vel trigyna, oblique inserta et versus apicem plantæ nutantia, plus minus pyriformia vel subcylindrica, ore apicali plus minus angustato. Calyptra basi bistrata, apice unistrata, facile destructa et ante capsulæ maturitatem evanida. Capsula chlorophyllifera sphærica, pariete unistrata magnisque cellulis formata, pedicello parvo chlorophyllifero facile destructo. Sporæ tetraedræ, cuticula valida, varie lamellata, plus minus hirta. Sporæ juveniles ante maturitatem capsulæ in glebam aggregatæ, parietibus capsulæ haud adhærentes, in fluido capsulari aggregatim natantes. Elateres nulli; adsunt tamen cellulæ steriles sporis mixtæ et minores, oleiferæ, sphæricæ, pariete tenera, nutriculæ sporarum. Flores masculi antici in fronde minore et longius ramosa, e medio costæ orti, sæpe in ramulis nascentibus aggregati et marginem dense tegentes. 
Antheridia sphærica, breviter pedicellata, pedicello frondis substantiæ immerso. Involucra mascula femineis multo minora, rubescentia, inferne inflata, medio supero cylindrice rostrata.

Die Pflanzen dieser Gattung wachsen alle auf leichtem und lockerem Boden; der Thallus ist von dem denkbar einfachsten Bau; da er bei den meisten Arten dicht mit den schlauchförmigen Involucris bedeckt ist, so übernehmen diese hauptsächlich die Assimilation und Ernährung, wozu die vielen Hüllen eine bedeutende assimilierende Oberfläche darstellen, wie sie nur Riccia in anderer Form wieder erreicht.

1. S. terrestris (Mich.) Smith. Engl. Bol. 1790, tab 299.

Syn. : Sphærocarpus terrestris minima Mich. Nov. Gen. p. 4.

Sphærocarpus Michelii Bellardi. Acta Taur. 1792. V, p. 246.

Dioica, involucris maxime confertis, maturis vix duplo longioribus quam latis, interna facie lævibus, inferne obcuneato-inflatis, tertio supero late acuminato, ore parvo truncato, vix crenulato. Sporæ ad $90 \mu$, grosse reticulatim lamellatæ, lamellis breviter echinatis.

Hab. Germania (rhenana), Britannia, Gallia, Europa et Africa mediterranea, America septentr.

2. S. Donnellii Austin. Torrey B. CI. VI, p. 157.

Dioica, involucris confertissimis, maturis subcylindricis, basi vix angustatis, apice conico-hemisphæricis, ore angusto integerrimo, facie interna lævi; sporæ ad $100 \mu$ reticulatim lamellatæ, lamellis in lobulos plano-conicos obtusos vel acutos divisis, sporæ itaque grosse lobiferæ.

Hab. America septentr. (Florida, New Jersey).

Die Pflanze von New Jersey (Closter) hat Austins eigenhändige Aufschrift; diese Art hat also eine bedeutende Verbreitung.

3. S. texanus Austin. Torrey B. Cl. VI, p. 158.

Ipse haud vidi; secundum descriptionem Underwoodii : Thallus est minor, lobulis leniter acuminatis. Involucra apice minus obtusa. Sporæ duplo minores (quam in $S$. terrestri). Coccus $63 \mu$ in diam.

Hab. Texas (Wright).

Die sehr kleinen Sporen werden ermöglichen die Art wieder zu erkennen; diese Pflanze liegt nicht im Herbar Austin's in Manchester. Sie scheint ganz verloren gegangen zu sein. 
4. S. Berteroi Mont. Ann. sc. nat. Series II. IX, p. 39.

Dioica. Frons involucris minus dense obtecta, centro adulto nudo, utriculis solum in ultimis lobis, ceterum involucra ovata vel ovato-oblonga, longe acuminata, apice truncata, interna facie cellulis hamatim decurvis hirta, ore similibus cellulis armata, basi longe pedicellata, pedicello juvenili minimo, cum involucro sensim sensimque increscente, tempore maturitatis dimidium longitudinis utriculi metiente. Sporæ maturæ ignotæ. Capsula brevissime pedunculata, pedunculo basi inflatæ utriculorum inserto, pedicellum utriculi haud percurrente. Plantæ masculæ quam femineæ multo minores, utriculis purpureis, ut in S. terrestri superne Jonge rostratis.

Hab. Chile, Quillota (Bertero).

Der Pedicellus utriculi ist keineswegs hohl, wie Lindenberg sagt (Nova Acta 1836, XVIII, p. こั04 i.), sondern aus einem durchaus gleichmässigen Gewebe aufgebaut und schief nach vorn geneigt inseriert.

5. S. californicus Austin. Torrey Bot. Cl. VI, p. 30 .

Dioica, involucris confertis, duplo longioribus quam latis, ubique diametro æquali, apice conico hemsphærico, ore parvo crenato. Sporæ ferrugineæ ad $110 \mu$ in diam, alte reticulatim cristatæ, cristis valde irregularibus, breviter incisis et lobatis vel leniter emarginatis, ubique erosulis et distincte minuteque papillatis, nusquam spinosis.

Hab. America septentr., Louisiana (Langlois), Missisippi (Hall), California (Bolander).

6. S. cristatus Howe. Torrey Bot. CI, VII, p. 66.

Dioica. Involucra conferta, humilia, obovata, interna facie lævia, apice rotundata, poro parvo haud prominente. Sporæ e cocco tacile solutæ, flavorufescentes, sub $80 \mu$, lamellis radiatim divergentibus, interdum ramosis vel anostomosantibus oblectæ.

California (Campbell, Howe).

Eine ausgezeichuete Art, welche an den groben, etwas entfernt gesteliten, langen Lamellen der Sporen sofort erkennbar ist.

\section{S. Jamesii Austin.}

Diese Pflanze ist mir nur dem Namen nach bekannt; ein Exemplar derselben ist nirgend erhalten; sie wurde in Mexico gesammelt. 


\section{RIELLA}

\section{Mont. Ann. se. nat. 3. XVIII, p. 11.}

Plantæ thallosæ, pro more parvæ vel mediocres in paucis magnæ et spectabiles, omnes tenerrimæ, dilute virides, in aqua erectæ basique radicantes, interdum aqua recedente in limo humido repentes; radicellæ capillares haud incrassatæ, e costæ basi bulbiformi ceterum e ventre costæ ortæ. Ramificatio repetito furcata, in paucis superne magis densa umbellatimque expansa. Costa in sectione elliptica, cellulis centralibus elongatis, corticalibus tamen parenchymaticis, stricta, nusquam (?) spiraliter torta, apice plus minus falcata. Ala e dorso costæ orta, unistrata, tenerrima, nuda, basin versus sensim angustata, superne magis evoluta apiceque falcato rotundata, margine ceterum integerrima vel parum inciso lobata, plana vel plus minus undulata, costæ nusquam spiraliter inserta. Bracteæ costales anticæ, ad dextram et sinistram alæ insertæ, apicem plantæ floresque femineos tegentes, valde variabiles, vel rudimentariæ vel maxime evolutæ et folia fingentes. Antheridia margini alarum immersa, seriata, breviter pedicellata, ovoidea, vagina arcte circumdata, ostiolis haud productis. Flores fem. e costæ dorso orti. Involucra magna, sporangio multo majora, unistrata, ovoidea, superne plus minus inflato-acuminata, ore minimo. Calyptra valida, bistrata. Capsula sphærica, pariete unistrata, pedicello perbrevi, basi clavatim incrassato. Sporæ magnæ, tetrædræ, minute reticulatim lamellatæ, lamellis ex angulis papillatæ vel setosæ. Cellulæ steriles capsulæ sporis parum minores, pellucidæ amyliferæ, sine fibra spirali.

Die Gattung Riella, 1843 als Duriæa publiziert, wurde erst 1854 durch Hofmeister näher bekannt, der die Entwicklungsgeschichte einer Art (R. Reuteri) in meisterhafter und einwandsfreier Darstellung (Verhandl. der Königl. Sächs. Ges. der Wiss. II, p. 92) publizierte. Diese Arbeit enthält alle Momente, welche diese Gattung so scharf von allen übrigen Verwandten trennt, ich meine den Aufbau der Pflanze in der Verticalebene, wie Goebel treffend es nennt (Botan. Ztg. 1893, p. 104 fi.). Hofmeister hatte den Thallus unserer Gattung mit dem einer Marchantia verglichen, der der eine Flügel fehlt; dieser Vergleich und diese Folge- 
rung aus sonst richtigen Beobachtungen ist bereits von Leitgeb (Untersuch. über die Lebermoose, siehe Riella, p. 4.5) widerlegt worden. Der Marchantia Thallus baut sich vorwiegend aus lateralen Segmenten der Scheitelzelle auf, während bei Riella im Gegenteil eine verticale Ausbildung stattfindet; auch müsste, wäre Hofmeisters Ansicht zutreffend, die eine Seite des Flügels, z. B. die rechte, und die daran stossende rechte Seite der Rippe die Oberseite der Pflanze sein und allein Sexual-0rgane produzieren, was nicht der Fall ist, da o Blüten rechts und links vom Flügel aus der Rippe entspringen, demnach die Flügelseite die morphologische Oberseite sein muss, der übrigens auch entgegengesetzt die ventrale Wurzelrinne verläuft.

Leitgeb betrachtete daher den Flügel als eine dorsale Wucherung der Rippe, eine Ansicht die Gœebel bestreitet, da der Flügel an seinem ganz jungen Adventivspross vorhanden war, ehe die Rippe an demselben zur Entwicklung gekommen war (1. c. p. 105̈); hierzu ist aber zu bemerken, dass nicht selten-die Gabelung von der Rippe allein ausgeführt wird und die Flügel sich erst später entwickeln. Dieser Flügel wird von den älteren Autoren und auch von Leitgeb als spiralig verlaufend geschildert, indem die Rippe selbst eine Torsion zeigt. Niemand nach ihm hat das aber wieder beobachtet. Die Flügel, welche bei einigen Arten sehr breit entwickelt sind, werfen Falten, weil die Insertionsbasis am Stengel kürzer ist als die Länge ihres freien Randes und laden an der senkrecht wachsenden Pfianze seitlich aus, wie es die turgescente Flügelfläche fordert; hierdurch erhält der obere Teil des Stengels bei längeren Exemplaren eine leichte Torsion, welche aber nur eine rein mechanische Einwirkung auf ein durchaus gerade gewachsenes und sehr biegsames Organ ist; die Stengelzellen selbst verlaufen nicht spiralig; das ist alles an der gut entwickelten lebenden Pfianze und an überreichem Material beobachtet; es bedarf daher der Aufklärung, unter welchen Verhältnissen die Pflanzen tordieren und ob, wie Gobel I. c. andeutet, etwa Lichtverhältnisse hierbei eine Rolle spielen.

Die schuppenförmigen Blättchen, welche dem Schutze des Vegetationspunktes dienen, sind rein dorsalen Ursprungs und decken natürlich ebenso die jungen Pistille; bei $R$. Parisii sind sie aber so zahlreich und gross, dass sie den Habitus der Pflanze beeinflussen und sicherlich bei ihrem Stofiwechsel eine wesentliche Rolle spielen.

Die Gattungen Sphærocarpus und Riella stehen hinsichtich der sterilen Kapselzellen und auch sonst der Gattung Corsinia nahe; doch bilden die 
übrigen Marchantiaceen wegen des Baues der vegetativen Organe ein so gleichförmiges zusammenhängendes Ganze, dass man unsere zwei verwandten Gattungen nicht wohl in jene hineinschieben kann; es lässt sich eben, was sich aus dichotomer Abstammung neben einander entwickelt hat, nicht wohl hintereinander anordnen.

\section{RIELLA}

\section{A. Monoic.e.}

1. R. Reuteri Mont. Ann. sc. nat. 3. XVIII, p. 12.

Frons pusilla, ad $6 \mathrm{~mm}$. longa, simplex vel furcata, ala plana, vix undulata; squamæ costales valde variabiles, minutæ et filiformes vel lanceolatæ vel subovatæ. Antheridia pauca in furcis propriis, neque in planta propria. Involucra in apice plantæ aggregata, ovoidea acuminata, cellulis prominulis alte papulosa. Sporæ rufæ, ad $60 \mu$ spinosæ, spinis breviusculis, multo brevioribus quam in $R$. gallica et $R$. Battandieri.

Hab. Helvetia, Lac Léman prope Genthod; nuperius haud reperta, in loco classico destructa (Reuter).

R. Battandieri Trabut in Schiffner. Botan. Centralbl. 1886.

Frons mediocris, ad $2 \mathrm{~cm}$. longa, erecta vel adscendens; ala bene evoluta, undulata, plus minus repanda, apice falcato-rotundata; squamæ costales lanceolatæ acutæ minores. Antheridia pauca, ad 2 vel らั seriata. Involucra ovoidea, acuminata, papulosa, apice valde angustato alte papuloso. Sporæ $60 \mu$ hispidissimæ, spinis longe acuminatis.

Hab. Alger (Battandier).

\section{B. Dioicæ.}

a. Sporis echinatis.

3. R. gallica Balansa in Trabut. Rev. gén. Bot. III, p. 4500.

Frons mediocris, ad $5 \mathrm{~cm}$. longa, inferne pauciramosa, superne repetito furcata, submersa erecta, in limosis repens; ala angusta, plana, apice falcato-rotundata; squamæ variabiles, minutæ vel ad $2 \mathrm{~mm}$. longæ. Antheridia ignota. Involucra ad $\mathbf{2} \mathrm{mm}$. longa, ovoidea, lævia, apice tantum papulosa. Sporæ brunneæ, $80 \mu$, spinosæ, spinis attenuatis.

Hab. France, Roquehaute (Balansa 1866). Nuperius haud reperta. 
4. R. Notarisii Mont. Ann. sc. nat. 3. XVIII, p. 11.

Syn. : Duriæa Notarisii Bory et Mont. Ann. sc. nat. 1844, p. 229.

Mediocris. Frons ad $6 \mathrm{~mm}$. longa, repens vel erecta; ala bene evoluta, $3 \mathrm{~mm}$. lata, superne desinens. Squamæ costales apicem plantæ obtegentes, pro planta magnæ, lineares, obtusæ, ad $3 \mathrm{~mm}$. longæ, aggregatæ; squamæ basales multo minores oblongæ vel ovatæ. Involucra ex angusta basi oblongo-oviformia, longius acuminata, lævia. Sporæ $60 \mu$, hispidissimæ. Antheridia ignota.

Hab. Insula Sardinia, prope Pula (De Notaris), Græcia, Phalerus (Chaboisseau).

5. R. Parisii Gottsche. Hepat. Exsicc. G. et Rab. No $375 \%$.

Syn. : R. Clausonis Let. in Trabut. Atlas Fl. d'Alger 1886, p. 13.

Spectabilis, ad $20 \mathrm{~cm}$. Ionga, læte viridis, dense ramosa; ala lata undulata in trunco ramisve ad basin subnulla, haud rare interrupta. Squamæ magnx, cordiformes, ob insertionem duplicatam conduplicatim concava, decurva. Involucra late oviformia, subsphærica apice breviter acuminata subapiculata, lævia, Sporæ $60 \mu$ hispidæ. Andræcia ignota.

Hab. Alger, pluribus locis (Clauson, Paris).

Die Pflanze ist durch ihre Ausgabe in dem Exsiccatenwerk von Gottsche et Rabenhorst unter No 375 selbstverständlich als rite publiziert $z u$ betrachten.

\section{b. Sporis truncato-papillatis.}

6. R. helicophylla Mont. Ann. sc. nat. 3. XVIII, p. 11.

Syn. : Duriæa helicophylla Bory et Mont. Ann. sc. nat. 1844, p. 229.

Spectabilis. Frons ad $10 \mathrm{~mm}$. longa, parum ramosa; ala latissima (ad $4 \mathrm{~mm}$ ) valde undulata haud tamen spiraliter inserta. Squamæ costales parvæ variiformes. Involucra ovoidea obtusa, superficie lævi. Sporæ $80 \mu$, longe papillatæ, papillis apice incrassatis truncatis. Andræcia in apice alarum, antheridiis valde numerosis longeque in margine seriatis.

Hab. Alger, Senia (Durieu).

7. R. Cossoniana Trabut. Atlas fl. d'Alger, 1886, p. 6 .

Mediocris. Frons subsimplex, erecta, ad $3 \mathrm{~cm}$. longa; ala $2 \mathrm{~mm}$. lata, undulata, apice falcato-rotundata. Squamæ costales parvæ, oblongæ vel lanceolatæ. Involucra ex angusta basi globosa vel late pyriformia, apice rotundata, 8 angulis meridionaliter percurrentibus lateque alatis instructa, alis integerrimis, vertice basique attenuatim excurrentibus. Sporæ $70 \mu$, 
papillatæ, papillis brevibus truncatis. Antheridia in margine alæ longius seriata.

Hab. Oran, El Kreider (Trabut).

\section{ANEURA Dum.}

$$
\text { Sylloge } 1831 \text {, p. } 85 .
$$

Plantæ frondosæ, terrestres corticolæ vel rupicolæ, exiguæ, mediocres vel giganteæ, virides vel rufescentes, persæpe olivaceæ, semper carnosæ rigidæque, erecto-vel depresso-cæspitosæ, stolonibus affixæ, in paucis arcte in solo repentes (A. pinguis et affines). Frons pro more anguste linearis, monopodialiter ramosa, sæpe optime pinnata et gracillima, pinnis sæpe unilateralibus, altero latere stoloniformibus. Truncus semper fere biconvexus, interdum subteres (ramis semper minus crassis), in paucis latus, planus, ubique æquicrassus. Costa nusquam abrupte definita, in alas ubi adsunt plus minus latas attenuata. Costæ cellulæ centrales elongatæ, corticalibus fere semper multoties ampliores; epidermis lævis, in paucis verrucosa vel pubescens vel lamellata. Cellulæ alarum ad costam maximæ, versus marginem sensim minores, marginales integerrimæ, interdum papuloso-alte-prominulæ, in paucis dentiformes. Ramorum apices cellulis clavatis, sæpe maxime muciferis obtecti. Inflorescentia dioica, rarius monoica. Rami feminei in trunco vel solitarii vel oppositi, simplices vel furcati, interdum innovati, semper ex apice pinnularum orti, basi itaque steriles, apice pro more decurvi vel nodulosi, interdum disciformes, margine erecto semper armato, lacinulato vel pilifero; pistilla biseriata, alternantia, breves, cellulis vel squamulis interjectis tecta. Calyptra cylindrica vel clavata, parietibus valde carnosis, lævis vel plus minus hirta, mamilla apicali coronata, inferne pistilia sterilia gerens. Capsula breviter pedicellata, oblongo-cylindrica, usque ad basin quadrivalvis; valvulæ bistratæ annulatim incrassatæ, apice elateribus cylindricis adhærentibus barbatæ. Elateres decidui monospiri, breves, e medio ampliore maxime attenuati. Sporæ parvæ, læves vel asperulæ. Rami masculi ex apice pinnarum orti, (basi itaque steriles) solitarii vel oppositi vel regulariter pinnatin consecutivi, pro more pinnis pinnulisque ultimis inserti, angusti, breves strictique vel longiores et sub fronde curvatim occulti, in una fere circinati, simplices vel furcati, interdum ex apice vege- 
tativi, margine pro more papulosi; Antheridia biseriata (in una solum seriata), alternantia, in paucis tri-quadriseriata, magna globosa subsessilia. Propagula haud rara, cellulis solutis deciduisque vel marginalibus vel corticalibus orta.

Die Verzweigung der Gattung Aneura ist eine monopodiale, d. h. jede neue Gabelung der Frons lässt (abwechselnd nach rechts und links) einen Fiederast stehen; diese Gabelungen wiederholen sich aber derartig, dass in vielen Fällen immer je 2 Fiedern gegenständig inseriert erscheinen, was sie natürlich thatsächlich nicht sind, obgleich ich in den Diagnosen diese Bezeichnung der Kürze halber benutzt habe; nicht selten bleiben aber auch solche Aeste unentwickelt, als knotige Anschwellungen (ruhende Astanlagen Leitgebs) in unregelmässiger Anordnung am Hauptstamm zurück; sie wachsen späler meist zu weiblichen Aesten aus, bleiben aber auch wohl für immer unentwickelt oder entwickeln bei Verletzungen der Stammspitze eine neue sterile Frons. Im Uebrigen findet die Verzweigung bei gut entwickelten Pflanzen meist in der Weise statt, dass der Stamm wenig oberhalb der Basis einen gleich starken Gabelast entwickelt, zuweilen auch noch in der Folge einen solchen Hauptast treibt, die alle sich dadurch als solche kennzeichnen, dass sie mit dem Truncus oder Hauptstamm gleiche Stärke zeigen, ganz wie dieser verzweigt sind und auch, wenn jener ungeflügelt ist, ihrerseits keine Flügel tragen; ist nun der nicht gegabelte Stamm z. B. bipinnatus, so habe ich wegen dieser Hauptäste keineswegs die Pflanze tripinnatus genannt, da es ja oft vorkommt, dass sie solche Hauptäste nicht trägt und dann die Diagnose falsch wäre. Alle meine Angaben über den Terzweigungsmodus beziehen sich also auf den einfachen ungegabelten Truncus primarius.

Da die schmalen Aneura-Formen meist aus einem oberirdischen kriechenden Rhizom entspringen, dieses aber beim Sammeln oft nicht beachtet worden und nicht erhalten ist, so ist die diøecische Inflorescenz vielleicht in einzelnen Fällen nicht zutreffend, wie ich das bei monœecischen Arten erfahren habe, die durch das Abreissen oder Absterben basaler Stammverbindungen diœcisch erschienen. Leider sind uns von den allermeisten Arten reife Kapseln nicht zugängig, so dass ich die Sporen und Elateren für die Beschreibungen nicht angeben konnte. Obwohl alle Formen dieser Gattung zu ihrer Entwicklung sehr feuchte Standorte nötig haben, so giebt es doch auch etiolierte Formen, wie z. B. A. cataractarum Spruce eine solche ist, die besser nicht publiziert wäre; in den Sümpfen Patagoniens sind solche Formen häufig; in den Tropen 
und auch in gemässigten Klimaten finden sie sich nur zwischen Laubmoosen. Da sie ihren Habitus völlig ändern, meist ganz steril bleiben. so sind sie nicht zu identifizieren.

Als die konstantesten und daher zuverlässigsten Merkmale dieser Pflanzen sind zu betrachten, die Verzweigung, welche selbst bei ärmlichen Exemplaren wohl an einem guten Stämmchen zu beobachten ist; ferner der Bau des Thallus, d. h. sein Querschnitt, die Breite der Flügel und deren Zellbau; sehr konstant ist auch die Stellung der männlichen Aeste, bald am weiblichen Aste selbst, bald in dessen Nähe, bald als konstant unterste Fieder eines Seitenastes u. s. w. Die Länge der männlichen Aeste ist aber je nach dem Alter verschieden; nach dem oft spärlich vorhandenen Material habe ich genau beschrieben, was ich fand und diese $\sigma^{7}$ Aeste bald als stricti, bald als curvati, geschildert; ich habe aber die Vermutung, dass die jungen Aeste alle gekrümmt sind und die älteren ausgewachsenen gerade gestreckt; jedenfalls ist das bei vielen Arten der Fall. Die Calyptra ist bei allen Arten sehr fleischig, aus vielen Zelllagen aufgebaut und giebt die darin gesammelten Reservestoffe allmählig an das sich entwickelnde Sporogonium ab. Die Oberfläche ist nur an jungen Exemplaren normal; im Alter fallen die Haarbildungen der Calyptra ab und sie erscheint dann sehr abweichend, überhaupt ist die Gattung eine ziemlich schwierige wegen der grossen Aehnlichkeit ihrer Formen und des grossen Artenreichtums; man wird daher nur ältere gut entwickelte Pflanzen mit Sicherheit bestimmen können.

Unser genus ist ein vorwiegend tropisches und subtropisches, denn von der grossen Anzahl Arten gehören nur wenige dem ausgedehnten Waldgebiet der nördlichen gemässigten Zone an; das antarctische Gebiet ist dem gegenüber viel reicher und zum Teil mit riesenhaften oft wunderbaren Formen ausgestattet; zwei dieser antarctischen Arten (A. stolonifera aus Neu-Seeland und A. prehensilis aus Fuegia und Patagonien) sind auch in Java gefunden worden (leider ohne nähere Standortsangabe); dies erinnert an Psiloclada und Zoopsis, die zuerst als Bürger der Antarctis beschrieben, später in den Molukken und SundaInseln ebenfalls auftauchten. Im Nachfolgenden sind im Ganzen 1551 Arten beschrieben, von denen

6 dem nördlichen Waldgebiet angehören,

53 dem tropischen und subtropischen Asien und Oceanien,

43 dem tropischen Amerika,

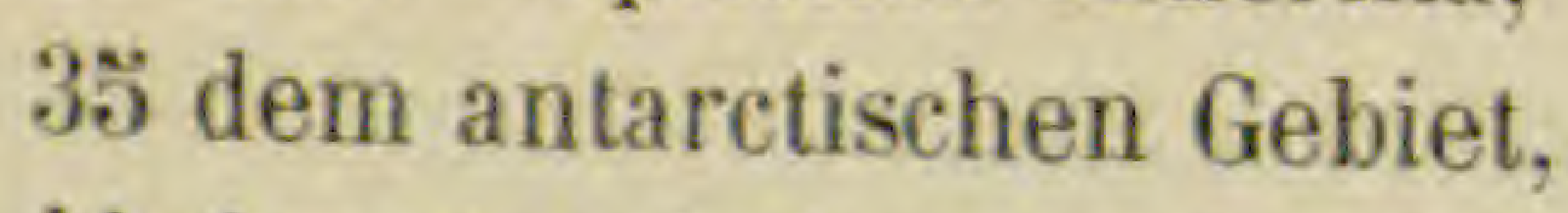

14 dem tropischen und subtropischen Afrika. 


\section{Aneurat.}

\section{A. Rami alati.}

a. Cuticula armata.

1. Aneura fuegiensis (Mass) Fretum magellan.

2. Aneura aberrans St. Nova Granada.

3. Aneura prehensilis (Tayl) Fretum magell.

4. Aneura eriocaula (Hooker) N. Zealand.

5. Aneura tamariscina St. Java.

b. Cuticula lavis.

\section{Truncus exalatus.}

๔. Monolce.

6. Aneura bogotensis G. Amer. tropica.

7. Aneura emarginata St. Brasilia.

8. Aneura Græffei St. Samoa. N. Guinea.

9. Aneura Regnellii (Angstr.) Brasilia.

10. Aneura saccatiflora St. Bourbon.

11. Aneura multifidioides (Schffn.) Java.

12. Aneura androgyna (Schffn.) Java.

$\beta$. Dioic...

\section{Plantø elatø.}

13. Aneura cæspitans St. Kamerun.

14. Aneura calva Schffn. Fretum magellan.

15.. Aneura Jackii (Schffn.) Java.

16. Aneura laticostata Spr. Dominica.

17. Aneura plumæformis Spr. Andes.

18. Aneura plumosa (Mitt.) Viti, Java.

19. Aneura amboinensis St. Amboina.

20. Aneura Ridleyi (Schffn.) Singapore.

21. Aneura Zollingeri St. Java.

22. Aneura distans Spr. Dominica.

23. Aneura fucoides (Sw.) Antillæ Ins.

24. Aneura grossidens St. Guadeloupe.

25. Aneura papillata (G.) N. Granada.

26. Aneura squarrosa St. N. Granada.

27. Aneura algoides (Tayl.) Peruvia.

28. Aneura virgata G. Guadeloupe.

29. Aneura cervicornis Spr. Andes. Costarica.

30. Aneura dicrana St. n. sp. Sumatra.

31. Aneura hymenophylloides (Schffn.) Sumatra.

32. Aneura crispa Schffn. Fret. magell.

\section{Plantø mediocres.}

33. Aneura andina Spr. Andes. Guatem.

34. Aneura humilis (G.) Mexico. 
3ّ̋. Aneura diablotina Spr. Dominica.

36. Aneura decrescens St. n. sp. Japonia.

37. Aneura fuscescens St. Tahiti, Samoa.

38. Aneura Poeppigii (L. et L.) Peruvia

39. Aneura hymenophytoides Spr. Andes.

40. Aneura nobilis St. Borneo. N. Guinea.

41. Aneura ramosissima St. Bourbon.

\section{Plantæ parvœ vel exigum.}

42. Aneura minima (C. et P.) Australia.

43. Aneura gogolensis St, n. sp. N. Guinea.

44. Aneura crassiretis (Schfin.) Sumatra.

45. Aneura samoana St. Samoa, Viti, Hawai.

46. Aneura tenuicula Spr. Brasilia.

47. Aneura macrostachya Spr. Brasilia.

\section{Truncus alatus.}

๔. Monoic..

48. Aneura crenulata St. Japan.

49. Aneura autoica St. n. sp. Chile.

50. Aneura Fendleri St. Trinidad.

51. Aneura intermedia St. n. sp. Brasilia.

52. Aneura leptophylla Spr. Venezuela.

5ี3. Aneura erosa St. San Thomé (Afr.)

ß. Diогс.ж,

\section{Plantæ elatæ, spectabiles.}

54. Aneura elata St. Java.

อัธั. Aneura Glaziovii Spr. Am. trop.

56. Aneura trichomanoides Spr. Andes.

57. Aneura lepidomitra Spr. N. Granada.

๖8. Aneura Wallisii St. N. Granada.

59. Aneura pallida Spr. Andes.

60. Aneura multifida (L.) Dum. Europa, Am. sept.

61. Aneura tjibodensis (Schffn.) Java.

62. Aneura tahitensis St. n, sp. Tahiti, N. Guinea.

63. Aneura tenuis St. Java.

64. Aneura ciliolata Spr. Andes.

6.̈. Aneura heteroclada (Schffn.) Java, Sumatra.

\section{Plantœ mediocres.}

66. Aneura alata St. n. sp. Brasilia.

67. Aneura planifrons Spr. Dominica.

68. Aneura limbata St. Kamerun.

69. Aneura longispica St. Réunion.

70. Aneura nudiflora St. Maurice.

71. Aneura reticulata St. S. Thomé (Afr.)

72. Aneura fastigiata (L. et L.) Caput bon. sp.

73. Aneura flaccidissima (Schffn.) Java.

74. Aneura Loriana St. n. sp. N. Guinea. 
75. Aneura Wettsteinii (Schffn.) Java, Sumatra.

76. Aneura Makinoana St. n. sp. Japan.

3. Plantæ parvœ vel exiguæ.

77. Aneura amazonica Spr. Amazonas.

78. Aneura Stephanii Besch. n. sp. Congo.

79. Aneura tenuicostata (Schffn.) Java, Singapore.

80. Aneura vitiensis St. Viti.

\section{B. Rami exalati.}

a. Cuticula armata.

81. Aneura scabra (Schffn.) Java, Sumatra.

82. Aneura stolonifera St. New Zealand, Australia, Java, Luzon.

83. Aneura tasmanica St. n. sp. Tasmania.

84. Aneura Colensoi St. New Zealand.

85. Aneura spinulifera (Mass.) Fret. magellan.

b. Cuticula lavis.

\section{Plantæ biconvexæ.}

๔. Monoic..

86. Aneura portoricensis St. n. sp. Puertorico.

87. Aneura platyclada (Schffn.) Java, Sumatra.

88. Aneura singapurensis (Schffn.) Singapore.

89. Aneura nitida Col. New Zealand.

90. Aneura æquitexta St. New Zealand.

91. Aneura papulosa St. New Zealand.

92. Aneura inconspicua St. Kamerun.

93. Aneura perpusilla Col. New Zealand.

३. Diоicж.

\section{Plantæ elatæ, ramis gracillimis.}

94. Aneura cataractarum Spr. Paraguay.

93. Aneura corralensis St. n. sp. Chile.

96. Aneura micropinna St. New Zealand.

97. Aneura pauciramea St. Hawai.

98. Aneura Baldwini St. Hawai.

\section{Plantw spectabiles, robustø, coriaceœ.}

99. Aneura dilatata Spr. Dominica.

100. Aneura comosa St. Bourbon.

104. Aneura Lepervanchei St. n. sp. Réunion.

102. Aneura Kowaldiana St. n. sp. N. Guinea.

103. Aneura pectinata Aust. Hawai.

104. Aneura polymorpha Col. New Zealand.

105. Aneura longiflora St. n. sp. Tasmania.

106. Aneura spectabilis St. n. sp. Fuegia.

107. Aneura Spegazziniana (Mass.) Fuegia.

108. Aneura Negeri St. n. sp. Chile.

\section{Plantw mediocres.}

109. Aneura pinnatifida Dum. Europ. Am. sept.

110. Aneura digitiloba Spr. Am. trop. 
111. Aneura stipatiflora St. Martinique.

112. Aneura conimitra St. n. sp. Chile.

113. Aneura floribunda St. n. sp. Fret. magell.

114. Aneura marginata Col. New Zealand.

115. Aneura Nadeaudii St. n. sp. Tahiti.

116. Aneura latifrondoides (Schffn.) Singapore.

117. Aneura Levieri Schffn. ms. India orient.

118. Aneura singalangana (Schffn.) Sumatra.

119. Aneura subexalata (Schffn.) Java.

120. Aneura barbiflora St. China.

\section{Plantæ parvae vel exiguae.}

121. Aneura gracilis St. n. sp. Tasmania.

122. Aneura oppositiflora St. N. Zealand.

123. Aneura metzgeriæformis St. n. sp. Brasilia.

124. Aneura palmata (Hedw.) Dum. Eur. Am. sept.

12.. Aneura parvula (Schffn.) Java.

\section{Plantæ filiformes, subteretes.}

126. Aneura subsimplex St. Cuba.

127. Aneura alcicornis (Tayl) Fuegia.

128. Aneura tenax St. n. sp. Fret. magell.

129. Aneura compacta St. Caput bon. spei.

130. Anenra attenuata St. Hawai.

131. Aneura diminuta (Schffn.) Java, Sumatra.

132. Aneura sumatrana (Schffn.) Sumatra.

133. Aneura calcarea St. n. sp.

III. Plantæ latæ, planæ, arcte repentes.

134. Aneura Karstenii St. Amboina.

135. Aneura albomarginata St. Amboina.

136. Aneura erecta St, n. sp. Tasmania.

137. Aneura latifrons (Lindb.) Europa, Japan.

138. Aneura incurvata (Lindb.) Fennia.

139. Aneura Breutelii St. n. sp. St. Christoph.

140. Aneura canaliculata (Nees.) Java.

141. Aneura cochleata (H. et T.) Fret. magell.

142. Aneura maxima (Schffn.) Java.

143. Aneura alterniloba Tayl. New Zealand.

144. Aneura dentata St. New Zealand.

14วั. Aneura lobata (Schffn.) Java.

146. Aneura coronopus De Not. Borneo.

147. Aneura granulata St. Fret. magellan.

148. Aneura pallidevirens St. n. sp. Fuegia.

149. Aneura pinguis (L.) Dum. Europa.

150. Aneura viridissima (Schffn.) Java.

151. Aneura Schwaneckei St. Puertorico. 
Ignotæ.

Aneura australis (Lehm.) Australia.

Aneura bipinnata (Swartz) Jamaica.

Aneura brasiliensis (Angstr.) Brasilia.

\section{A. Plantæ ramis alatis.}

a. Cuticula armata.

\section{Aneura fuegiensis (Mass.).}

Syn. : Riccardia fuegiensis Mass. Diar. bot. 1885, p. $25 \%$.

Pseudoneura fuegiensis Schffn. Exped. Gazelle, p. 40.

Dioica, magna vel gigantea, dense depresso cæspitans. Frons ad $12 \mathrm{~cm}$. longa, repens, normaliter densissime tripinnata, flaccida. Truncus fuscobrunneus, anguste alatus, validus, rigidus, postice planus, antice convexus, cristulis erectis, parallelis filiferis dense obtectus, medio 12 cellulas crassus. Pinnæ oppositæ, approximatæ, ad $12 \mathrm{~mm}$. longæ, oblique patulæ, normaliter dense imbricatæ, ambitu late ovatæ, densissime bipinnulatæ; costa ut in trunco lamellifera; laciniaæ ultimæ anguste costatæ, lamellis anticis parvis interruptis; alæ valde pellucidæ, ad 6 cellulas latæ, margine maxime irregulares, repandæ vel lobulatæ et fere interruptæ, papulosæ hic illic dentatæ. Cellulæ alarum ad $30 \mu$ ad costam majores, margine minores, trigonis magnis incrassatæ.

Rami feminei in trunco oppositi vel solitarii, parvi, margine foliacei, irregulariter breviterque ciliolati; calyptra magna, $5 \mathrm{~mm}$. Ionga, clavata, cellulis papulosis aspera, mamilla parva. Rami masculi numerosi in pinnis pinnulisque, sæpe in apice ultimarum laciniarum, parvi, curvatim sub pinnula occulti, late alati, ali erectis irregulariter papulosis, antheridiis ad 8 jugis.

Hab. Fuegia et Patagonia australis (Spegazzini, Cunningham, Savatier, Naumann, Dusén).

\section{Aneura aberrans St. Hedwigia 1893, p. 18 .}

Menoica, elata, flavicans, dense profundeque cæspitosa. Frons ad $6 \mathrm{~cm}$. longa, supra basin repetito furcata, furcis longis, bipinnatis, rare tripinnatis, Truncus $1 \mathrm{~mm}$. latus, plano-convexus, medio 12 cellulas crassus, cellulis subcorticalibus valde incrassatis, ubique anguste alatus (alis sæpe 
destructis). Pinnæ approximatæ, oblique patulæ, oppositæ, alatæ, ambitu late ovalæ, subplanæ. Pinnulæ opposilæ, pro planta breves, late lineares, cosła lata, sensim in alas attenuata, alæ 3 cellulas latæ, cellulis irregulariter prominulis erosæ, ipso margine grosse verrucosæ, cuticula minute transverse lamellata, lamellis anostomosantibus. Cellulæ alarum ad $46 \times 76 \mu$, aliis multo minoribus mixtæ. Rami feminei in trunco oppositi, parum concavi, margine lacerati, e ventre innovati; calyptra magna clavata, valde tuberculata, mamilla fere rostrata. Rami masculi brevissimi, ovati, crassi, recurvo-occulti, uno latere innovati, margine paucilobato incurvo. Antheridia 2, seriata (haud transverse geminata), magna.

Hab. Nova Granada, Antioquia (Wallis).

3. Aneura prehensilis (Taylor) Mitten (sub Sarcomitrium) $18 \% 3$ in Hooker. Antarctic Toyage II, p. 505.

Syn. : Aneura Savatieri St. Hedwigia, 1893, p. 26.

Metzgeria prehensilis Tayl. I. of Bot., 1844, p. 480.

Psendonenra prehensilis G. Hepat. Mex., p. 259.

Dioica, parva et dense depresso cæspitosa vel longissima profundeque pulvinata, flavescens, pro more flavo-rufescens, interdum fusco-olivacea, gracilis. Frons ad $10 ̈ \mathrm{~cm}$. longa, superne interdum furcata, bipinnata. Truncus primarius usque ad basin alatus, fuscus, alte biconvexus, validus, apice maxime muciferus, cellulis subcorticalibus maxime incrassatis rufis, corticalıbus bi-vel tristratis tenerrimis, ultimis conico-productis; pinnæ primariæ breves, patulæ, suboppositæ, approximatæ, ambitu ovatooblongæ, pinnulis brevibus strictis vel decurvulis, late alatis validis, medio 5 cellulas, in alis tres cellulas crassis, hyaline marginatis, crenulatis; ramorum cellulæ centrales reliquis haud majores, cell. corticales depresso imbricatulæ, in trunco patulæ, planta itaque sub lente pubescentehirta.

Rami masculi in pinnis primariis dense pinnatim seriati, decurvi, fusci stricti, breves, canaliculati, cellulis prominulis hirti, antheridiis ad 6 jugis; rami $\rho$ in trunco vel pinnis laterales solitarii, parvi, crassi, margine foliacei, varie profundeque fissi, lobis subspinosis. Calyptra magna, subcylindrica crassa, alte et creberrime papulosa, apice grosse mamillata.

Hab. Fretum magellanicum (Hooker, Cunningham, Spegazzini, Savatier, Hatcher, Dusén. Chile, Arique [Lechler], Valdivia [Hahn], Corral [Krause]).

Die Abbildung in Hooker Antarclic Voyage stellt eine ganz verkümmerte Form dar. In Neu-Seeland kommt die Pflanze nicht vor. Mitten 
hat sie in Hooker, Handbook of the N. Zealand Flora aufgeführt und nicht richtig beschrieben; diese neuseeländischen Pflanzen haben zu einem weitverzweigten Irrtum Anlass gegeben, so dass man sie in allen Herbarien unter dem Namen A. prehensilis findet; sie gehören mehreren ähnlichen Arten an.

\section{Aneura eriocaula (Hooker).}

Syn. : Jungermannia eriocaula Hook. Musi. exot. t. 72.

Metzgeria eriocaula Hook. Syn. Hepat. p. 50๖ั.

Pseudoneura eriocaula G. Hep. Mex. p. 259.

Dioica, major, plus minus dilute olivacea, inferne rufescens, laxe cæspitosa. Frons ad $4 \mathrm{~cm}$. longa, erecta vel procumbens, tripinnata; truncus superne sæpe furcatus, rufo-brunneus, validus, haud alatus, in sectione ovalis, cellulis subcorticalibus brunneis valde incrassatis, corticalibus teneris, papulosis, cellula magna cylindrica vel clavata recteque patula coronatis; truncus itaque maxime pubescens. Pinnæ oppositæ breves, ad $4 \mathrm{~mm}$. longæ homomallæ, pinnulæ confertæ, angustissimæ, in sicco capillares, oblique patulæ, late costatæ, decurvæ, cellulis corticalibus oblique patulis hirtæ, alis angustis 3 cellulas latis, papulose crenulatis. Rami feminei in trunco oppositi, parvi, margine breviter setulosi vel subfimbriati; calyptra $3 \mathrm{~mm}$. longa, papulosa cellulisque patulis hirta, mamilla parva. Rami masculi numerosi, ad basin pinnularum occulti, maxime incurvi, subcirculares, multo magis crassi quam lati, profunde canaliculati, marginibus late alatis, alæ $\mathbf{0}-6$ cellulas latæ, tenerrimæ, pellucidæ, erectæ, margine repando-angulatæ vel dentatæ.

Hab. New Zealand (Menzies, Knight, Helms, Kirk, Beckett). Tasmania (Moore).

Ab A. prehensili præsertim et tacile distinguenda pinnulis ultimis quadruplo angustioribus alisque angustis et pellucidis.

\section{Aneura tamariscina St. Hedwigia 1893. p. 26.}

Dioica, mediocris vel major, flavo-virens, procumbens vel erecta. Frons ad $5 \mathrm{~cm}$. longa, ambitu oblongo-linearis regulariter bipinnata, ubique alata et papillis confertis aspera. Truncus pro more simplex, interdum furcatus, in sectione acute biconvexus, medio 5 cellulas crassus, anguste alatus. Pinnæ pinnulæque confertæ, oppositæ, trunco parum angustiores, multo minus crassæ; costa angusta, cellulis centralibus perlucentibus reticulata, in ultimis evanida, alis ad 5 cellulas latis, integerrimis; cellulæ alarum $38 \mu$, ad costam majores, margine multo minores, 
papulosæ, haud incrassatæ. Rami feminei in trunco oppositi, brevissimi, margine longius denseque fimbriati, laciniis incurvis.

Hab. Java (Stahl).

\section{b. Cuticula læovis.}

\section{Truncus exalatus.}

«. Monolce.

\section{Aneura bogotensis (Gottsche).}

Pseudoneura bogotensis. G. Ann. sc. nat. 1864, p. 90.

Aneura pectinata Spr. Edinb. Bot. Soc. 1885ั, p. כั46.

Aneura Sprucei St. Herb. Boissier 1897, p. 844.

Monoica, minor, dilute olivacea, humilis, laxe cæspitosa. Frons erecta, basi tantum radicans, ad $2 \mathrm{~cm}$. longa, superne tripinnata. Truncus validus, in sectione ovalis, medio 16 cellulas crassus, haud alatus, cellulis subcorticalibus brunneis, valde incrassatis. Pinnæ oppositæ, contiguæ, oblique patulæ, decurvæ, ambitu late deltoideæ, alatæ. Pinnulæ confertæ. subcontiguæ, lanceolatæ oblusæ; costa angusta, bene distincta, humilis, alis ad 8 cellulas latis, valde chlorophylliferis et minus pellucidis; cellulæ alarum $27 \times 57 \mu$, subæquimagnæ, validæ, trigonis itaque minus distinctis. Rami feminei in trunco oppositi, margine breviter lacimulati vel spinosi, calyptra apice breviter mamillata, cellulis grosse papulosis hirta. Rami masculi ad basin pinnarum breves, sub pinna occulti, vix alati, papulosi, antheridiis ad $ّ$ jugis.

Hab. Bogota (Lindig), Brasilia subtropica (Ule), Guadeloupe (I'Herminier), Cuba (Wright), Sto Domingo (Eggers).

Die Pflanzen Spruces aus der Ebene des Amazonas sind klein und ihre Frons ist dünn; der Unterschied der A. bogotensis gegenüber ist gross und ich habe früher diese Pflanze für eine gute Art gehalten und den Namen Spruces, der schon früher von Austin für eine andere Pflanze benutzt war in A. Sprucei geändert; durch Slater erhielt ich jetzt Exemplare aus Spruces Sammlung, welche keinen Zweifel lassen, dass seine A. pectinata mit A. bogotensis identisch ist; sie ist im tropischen Amerika und Westindien weit verbreitet.

7. Aneura emarginata St. Hedw, 1893, p. 20.

Monoica, mediocris, fusco-olivacea, humilıs, laxe cæspitans, erecta vel procumbens, Frons ad $气 \mathrm{~cm}$. longa, $\check{\Xi} \mathrm{mm}$. lata, valde regulariter bipin- 
nata. Truncus validus, medio 8 cellulas crassus, fusco-brunneus, in sectione acute alteque biconvexus, haud alatus. Pinnæ remotiusculæ, oppositæ, ambitu late triangulares, imbricatæ, $4 \mathrm{~mm}$. longæ, oblique patulæ, late alatæ. Pinnulæ approximatæ, lineares vel spathulatæ, costa angusta, valida et bene definita, alæ latissimæ, 8 cellulas latæ, margine repandæ, versus apicem irregulariter dentatæ, ipso apice late emarginatæ; cellulæ alarum $38 \mu$, versus marginem parum minores. Rami feminei in trunco oppositi, parvi, decurvi, margine breviter fimbriati; calyptra magna, clavata, apice haud mamillata, lacinulis hirta. Rami masculi ad basin pinnarum oppositi, flori femineo semper vicini, breves, curvatim sub pinna occulti, margine longis cellulis liberis armati. Antheridiis 4-อ̆ jugis.

Hab. Brasilia, Caraca (Weinio), Apiahi (Puiggari).

8. Aneura Græffei St. Hedwigia 1893, p. 21.

Monoica, mediocris, flaccida, viridis vel fusco-virens, dense depresso cxespitosa. Frons ad $2 \mathrm{~cm}$. longa, bipinnata, superne late alata. Truncus e basi subfiliformi sensim ampliatus, anguste linearis, uno latere dense stoloniferus, altero bipinnatus, biconvexus, medio 6 cellulas crassus, haud alatus; cellulæ internæ multo majores perlucentes. Pinnæ e basi angusta exalata optime lanceolatæ trunco latiores simplices vel palmatim trifidæ i. e supra basin pinnulas oppositas gerentes, late alatæ. Pinnulæ similiter lanceolatæ, juniores sublineares obtusæ; alæ 3-与̆ cellulas latæ, cellulis parvis subæqualibus margine papulosis formatæ; costa ubique lata versus apicem angustata. Rami feminei in trunco oppositi, solitarii, breves, margine ciliis grosse cellulosis intricatis armato. Calyptra parva clavata, lævis, superne magnis cellulis decurvo-patulis hirta, mamilla elongata, cylindrica papulosa. Rami masculi femineis approximati breves, stricti, margine erecto lacinulato. Antheridia ad 5ั juga.

Hab. Samoa (Græffe), Nova Guinea (Kärnbach).

\section{Aneura Regnellii (Angstr.).}

Syn. : Pseudoneura Regnellii Angstr. Musci brasil. 1876, p. 90.

Synoica, mediocrís, tenerrima, pallide flavo-virens, dense depresso cespitans. Frons ad $15 \mathrm{~mm}$. longa, late breviterque bipinnata, superne tantum bipinnatim lobata. Truncus $1 \mathrm{~mm}$. latus, plano-biconvexus, medio ò cellulas crassus, cellulis internis majoribus, exalatus, sæpe uno latere stoloniferus, apice solum regulariter bipinnatus; rami trunco parum angustiores, medio 3 cellulas crassi, alati, alis 4 cellulas latis, cellulæ 
alarum $57 \mu$, margine angustiores, haud incrassatæ. Rami feminei brevissimi, lati, margine breviter lacinulati, uno vel utroque latere spicam masculam minimam gerentes. Antheridia quadrijuga. Calyptra clavata superne magnis cellulis utriculatis sparsim obtecta, mamilla nulla.

Hab. Brasilia, Caldas (Regnell), Rio Grande do Sul (Lindman 138 proparte).

10. Aneura saccatiflora St. Hedwigia 1892, pag. 200.

Monoica, mediocris, dilute olivacea, in umbrosis fusco-viridis, in cortice late expansa. Frons ad $15 \mathrm{~mm}$. longa, irregulariter ramosa, pinnata, rarius bipinnata, magnis cellulis internis perlucentibus reticulata. Truncus stoloniferus, alte biconvexus, margine acutus, 8 cellulas crassus, haud alatus. Pinnæ pinnulæque confertæ, sæpe contiguæ, longæ, teneræ et planæ, trunco æquilatæ, sæpe abbreviatæ et in frondem palmatifidam plano-congestæ, ex apice innovatæ et frondem secundariam magnam gerentes, 4 cellulas crassæ, margine in alas unistratas, 3 cellulas latas attenuatæ. Cellulæ alarum 5ั6 $\mu$, ad costam majores, margine multo minores, haud papulosæ. Rami feminei in trunco oppositi, breves, crassi, ventre saccatim ampliati, facie antica prærupta fere perpendiculari, margine apicali hyalino laciniato, laciniis 4 cellulas longis recurvis. Squama dorsalis magna, profunde papulosa. Calyptra optime clavata, cellulis accumbentibus papulosa, sub apice longis laciniis foliaceis papulosis pendulis velata; mamilla longa, cylindrica, truncata. Rami masculi in trunco oppositi, stricti anguste lineares, usque ad basin fertiles, margine haud alato, breviter papuloso, erecto. Antheridia ad 8 juga.

Hab. Insula Bourbon (Rodriguez), Madagascar, Diego Suarez(Chenagon).

Die Androecien sind meist auf eigene Hauptäste verteilt und sehr selten mit 우 Blüten auf demselben Fiederast zu finden.

\section{Aneura multifidioides (Schffn.).}

Syn. : Riccardia multifidioides Schffn. Kais. Ak. Wien LXVII, p. 166.

Synoica, monoica et dioica, mediocris, pallide viridis, dense depressocæspitosa. Frons ad $15 \mathrm{~mm}$. longa subregulariter bipinnata vel (trunco abbreviato) subpalmatifida. Truncus haud alatus ad basin plano ellipticus, ad 6 cellulas crassus, superne acute plano-convexus, medio 气̆ cellulas crassus; cellulæ corticales papulosæ, centrales majores. Pinnæ pinnulæque approximatæ, patulæ, trunco simillimæ, breves, 3 cellulas crassæ, cellulis magnis internis perlucentibus reticulatæ; alæ ubique 3-4 cellulas latæ, cellulis 57 $\mu$ ad costam majoribus margineque minoribus. Rami sexuales 
in trunco laterales, masculi parvi, subplani, anguste alati, crenati, antheridiis ad है jugis; feminei brevissimi, margine breviter lacinulati, calyptra cellulis vel filis septatis brevibus utriculatis patulo-hispida.

Hab. Java 1560-296ə m. (Schiffner).

12. Aneura androgyna (Schffn.).

Syn. : Riccardia androgyna Schiffn. Kais. Ak. Wien LXVII, p. 164. Riccardia elongata Schffn. ibidem

Paroica vel monoica vel dioica, mediocris, laxe cæspitosa, pallide viridis, infra brunnescens. Frons suberecta, flaccida (valde etiolata) ad $4 \mathrm{~cm}$. longa, simpliciter pinnata. Truncus ex angusta basi ad $1 \mathrm{~mm}$. latus, planobiconvexus, medio ad 8 cellulas crassus, cellulis corticalibus multo minoribus quam internæ, ceterum haud alatus, superne sæpe furcatus. Pinnæ plus minus remotæ, suboppositæ, semper fere simplices, subrecte patulæ, trunco parum angustiores, tenues, alatæ, versus apicem incrassatæ vel subteretes radicantes, angustæ Alæ tres cellulas latæ, cellulis $37 \times 74 \mu$, haud incrassatis. Ram $i$ $ᄋ$ in trunco laterales, breves, squama dorsali nulla, margine crenati apice subciliati. Calyptra glaberrima, mamilla humilis et lævis. Antheridia in tergo rami feminei, quadrijuga (ramis omnino masculis rarissimis.

Hab. Java Tjibodas $2140 \mathrm{~m}$. (Schiffner).

\section{Dioic..}

1. Plantæ elatæ.

13. Aneura cæspitans St. Hedwigia 1892, p. 198.

Dioica, mediocris, valida, fusco-rufa, laxe cæspitosa. Frons ad $3 \mathrm{~cm}$. longa, pinnata, superne alata. Truncus repetito furcatus, biconvexus, medio 10 cellulas crassus; cellulæ internæ corticalibus multo majores, perlucentes, ceterum haud alatus; pinnæ inferne irregulares, superne oppositæ, trunco parum angustiores, medio 6 cellulas crassæ oblique patulæ, lineares breves alatæ, alis 3 cellulas latis, cellulis alarum marginalibus sub $27 \mu$, medianis $27 \times 40 \mu$ ad costam $38 \times 577 \mu$, parietibus validis. Rami feminei breves, disciformes, usque ad costam in lacinias longas angustas hamatim incurvas dissecti. Calyptra longe clavata, ubique laciniis pluri- et grosse- cellularibus patulis præcipue versus apicem maxime hirta; mamilla magna, discoidea, papulosa, constricta; rami masculi ignoti.

Hab. Kamerun (Dusén). 
14. Aneura calva Schffn. Exped. Gazelle. 1889, p. 42.

Dioica, major, rigidissima, rufo-brunnea, apice olivacea, muscis consociata. Frons ad $5 \mathrm{~cm}$. longa, bipinnata. Truncus validus haud alatus, acute biconvexus, medio 15 cellulas crassus, ipsa basi ovalis in sectione, plus minus regulariter pinnatus, pinnis oblique patentibus, sæpe confertis, imbricatis, suboppositis, valde acuminatis, strictissimis, basi trunco primario æquilatis, apice multoties angustioribus et magis tenuibus, versus marginem valde attenuatis, ala unistrata tamen nulla. Pinnulæ breves, suboppositæ, parum divergentes, strictæ, lineares, obtusæ, tenues, valide et abrupte costatæ, costæ cellulis internis parvis, late limbatæ, limbo 4 cellulas lato, integro, 3 cellulas crasso, cellulis internis multo majoribus. Rami feminei brevissimi, crassi, margine breviter lacinulati.

Hab. Fretum magellan. Tuesday Bay (Exped. Gazelle).

\section{5.. Aneura Jackii (Schffn.).}

Syn. : Riccardia Jackii Schffn. Kais. Ak. Wien. 1898, p. 163.

Dioica, major, dense depresso cæspitosa, viva læte viridis. Frons ad $3 \mathrm{~cm}$. longa, bipinnata. Truncus procumbens, late ligulatus, acute biconvexus, medio 8 cellulas crassus, haud alatus, cellulis internis magnis perlucentibus grosse reticulatus. Pinnæ oppositæ confertæ, imbricatæ, trunco simillimæ, parum angustiores, medio こ̌ cellulas crassæ, oblique patentes, haud alatæ, paucipinnulatæ; pinnulæ versus apicem breviores, pinnis vix angustiores, late lineares, planæ $3-4$ cellulas crassæ, alis unistratis 3 cellulas latis; cellulæ alarum $37 \mu$, marginales minores crenulatæ. Rami feminei in trunco solitarii, parvi, margine dense lacinulati; calyptra pro planta parva, magnis cellulis papulosa, mamilla parva, cellulis utriculatis effuse prominulis. Rami masculi in pinnis laterales, haud raro utroque latere pinnatim consecutivi, magni, stricti, late alati, alis grosse cellulosis, plano-explanatis, margine grosse papulosis. Antheridia ad 12 juga.

Hab. Java 1200-163å m (Schiffner; Massart.).

$\mathrm{Zu}$ dieser Pflanze gehört wohl als etiolierte Form Aneura flaccidissima Schffn.; selbstverständlich ist deren Verzweigung eine andere elioliert-verlängerte; der sonstige Bau der Pflanze und die grossen papulosen Ränder der männlichen Aeste lassen die Identität vermuten.

16. Aneura laticostata Spruce. Linn. Soc. XXX, p. 367.

Dioica, major, laxe depresso cæspitans, brunnea vel rufescens, corticola. Frons ad $3 \mathrm{~cm}$. longa, tripinnata. Truncus basi angustus versus apicem 
sensim ampliatus, haud alatus nisi alis e margine pinnarum in trunco parum decurrentibus, superne sæpe repetito furcatus, furcis divergentibus in flabellam expansis, in sectione acute biconvexus, medio 15 cellulas crassus, cellulæ subcorticales bistratæ, maxime incrassatæ, fusco brunneæ centralibus et corticalibus minores. Pinnæ oppositæ, approximatæ, late alatæ, ambitu late deltoideæ lateque imbricatæ, pinnulis linearibus vel lanceolatis; alæ 4-־ cellulas latæ, integerrimæ vel repandulæ, cellulis æquimagnis $(37 \mu)$ formatæ; cellularum parietes validissimæ, angulis distincte incrassatæ. Rami feminei in trunco oppositi, e basi communi 3-4 fidi, lobis decurvulis canaliculatis, marginibus erectis crebre laciniatis hispidissimis. Reliqua desunt.

Hab. Insula Dominica (Elliott) in monte Diablotin.

17. Aneura plumæformis Spruce. Edinb. Bot. Soc. 1885 , p. $\breve{48 .}$

Dioica, magna, erecta, laxe cæspitosa, valida, flavo-virens vel olivacea. Frons ad $6 \mathrm{~cm}$. longa, supra basin sæpe furcata, tripinnata; truncus primarius crassus, in sectione ovalis, haud alatus, fusco-brunneus, superne magis dilutus, basi ramis numerosis descendentibus radicans. Pinn: oppositæ, late alatæ, primariæ remotiusculæ sed imbricatæ, ambitu ovatotriangulares vel late deltoideæ, plano-convexulæ, reliquæ contiguæ, lineares, planæ, costa optime distincta, alis pellucidis grosse cellulosis, 5 cellulas latis, cellulæ alarum ad costam $45 \mu$ versus marginem decrescentes, ipso margine multoties minores, $18 \mu$, omnes magnis trigonis acutis incrassatæ. Cuticula lævis. Rami feminei in trunco laterales, oppositi, trifid, margine crenulati, calyptræ itaque ad 6 aggregatæ, longissimæ, lacinulis maxime hirtæ. Rami masculi ad basin pinnæ primariæ, sæpe oppositi, stricti, angusti, adulti longe spicati, alveolis ad 20 jugis, anguste alati, alis erectis repandis.

Hab. Columbia, Cauca (F. C. Lehmann No 3260) $\sigma^{2}$, in Monte Abitagua (Spruce) ठ', Rio Verde (Wallis) ㅇ, Costarica (Pittier).

\section{Aneura plumosa (Mitten).}

Syn, : Sarcomitrium plumosum Mitt. Flora Viti, p. 418.

Aneura Gobelii Schffn. Nova Acta Ac. Leop. 1893, LX, p. 273.

Dioica, major, flavo-rufescens, Frons ad $12 \mathrm{~cm}$. longa, valida, erecta, optime denseque tripinnata. Truncus crassus, in sectione transversa late ovalis (medio 15 cellulas crassus), haud alatus. Pinnæ alternantes, confertæ, imbricatæ, ambitu late uvatæ, dense breviterque bipinnatæ, haud alatæ. Pinnulæ confertæ, leniter acuminatæ, obtusæ humiliter costatæ, 
costa 3-4 cellulas crassa, cellulis internis bistratis magnis in adspectu perlucentibus reticulata, late alatæe, alis $3-4$ cellulas latis, subæqualiter cellulosis (cell. $4.5 \mu$, haud incrassatæ) margine repandis. Rami feminei in trunco primario, brevissimi, margine longe fimbriati, laciniis lanatim intricatis. Reliqua desunt.

\section{Hab. Insulæ Viti (Seemann).}

Hierher gehört wahrscheinlich A. Goebelii Schffn., die im Habitus und allen vegetativen Organen völlig mit $A$. plumosa übereinstimmt; da letzlere aber fertil nicht gesammelt worden ist, muss die definitive Entscheidung offen bleiben. Schiffner beschreibt die rami feminei wie folgt : " margine membranaceo laciniato-inciso, ibidemque squamulis laciniatodentatis ornato, nonnullæ squamulæ etiam inter archegonia. Calyptra ad $3 \mathrm{~mm}$. longa, $1 \mathrm{~mm}$. lata, lævis; planta $\sigma$ ignota ".

Java, in Monte Pangerango (Gœebel, G. Karsten).

\section{Aneura amboinensis St. n. sp.}

Dioica, major, gracilis, flavicans. Frons erecta, ad $4 \mathrm{~cm}$. Ionga, tripinnata. Truncus dilute brunneus, rigidus, in sectione ovalis, haud alatus, cellulis subcorticalibus fuscis, valde incrassatis, medio 12 cellulas crassus. Pinnæ oppositæ, remotæ, haud imbricatæ, oblique patulæ, ad $5 \mathrm{~mm}$. longæ, basi haud alatæ, ambitu ovato-deltoideæ, planæ. Pinnulæ oppositæ, simplices, basales tantum pinnulatæ, lineares, tenerrimæ, integerrimæ; costa latiuscula, humillima, parum distincta, alæ 3 cellulas latæ, cellulis subæquimagnis, haud incrassatis, $27 \times 37 \mu$. Rami masculi in pinnulis terminales, angusti, alis angustis papulosis subdentatis. Antheridia ad 12 juga.

Hab. Amboina, Wawani Hila (G. Karsten).

20. Aneura Ridleyi (Schffn.). St.

Syn. : Riccardia Ridleyi. Schffn. Kais. Ak. Wien. 1898, p. 172.

Dioica, major, superne pallide virens, inferne fusco-olivacea. Frons ad $4 \mathrm{~cm}$. longa, bipinnata, erecta, ipsa basi solum radicans. Truncus fuscobrunneus, validus, in sectione ovalis vel subteres, medio 12 cellulas crassus, haud alatus. 'Pinnæ approximatæ, oppositæ, valde regulares, ambitu late triangulares, breves breviterque pinnulatæ, pinnulis tenerrimis, conferlis angustis, late alatis, crenulatis; alæ 6 cellulas latæ cellulisque transversis marginatæ; cellulæ alarum ad costam maximæ $(27 \times 63 \mu)$, versus marginem sensim minores, trigonis magnis incrassatæ, ipso margine $12 \mu$, parietibus crassis. Rami feminei in trunco oppositi, breves, apice foliacei, profunde 3 -ă fidi, lobis basi angustatis superne pinnatim 
lobulatis, incurvis, squama dorsalis brevis, profunde laciniata. Rami masculi semper ad basin pinnæ primariæ, longe spicati, solitarii vel oppositi, leniter curvati, anguste alati, crenulati, antheridiis usque ad 20 jugis.

Hab. Singapore Chan Chu Kan (Ridley 288), Bukit Timah (Schiffner 194), N. Guinea, Moroka, Moresby (Loria).

Die Pflanze ist leicht an den grossen Zellen zu erkennen, welche in den dünnen Endfiedern beiderseits der Mittelrippe anliegen; sie wurde von mir bereits $1893 \mathrm{~A}$. Ridleyi $\mathrm{St}$. benannt und ausgegeben.

21. Aneura Zollingerii St. Hedwigia 1888, p. 277.

Syn. : Jungermania fucoides Nees. Hep. Jav. p. 12.

Riccardia rigida Schffn. Kais. Ak. Wien 1898, p. 172.

Dioica, major, robusta et rigida, gracilis, olivacea. Frons ad $4 \mathrm{~cm}$. longa, tripinnata. Truncus basi valde stoloniferus, superne repetito-furcatus, compresso-cylindricus, medio 16 cellulas crassus, haud alatus; pinnæ primariæ approximatæ, alternantes, $5 \mathrm{~mm}$. longæ, ambitu obovato-triangulares, dense bipinnatæ, late alatæ, alæ 3 -4 cellulas latæ, cellulis $18 \mu$, angulis valde incrassatis, marginalibus minoribus, pinnulis ultimis angustissimis, costa よ̃ cellulas crassa præditis. Cuticula lævis. Rami feminei in trunco laterales, alternantes, crassi, brevissimi, subnodulosi, margine profunde dissecti, laciniæ filis longis simplicibus vel ramosis, lanatim intricatis instructæ; calyptra grosse tuberculata, mamilla parva, rugosa. Ramuli masculi in pinnis pinnulisque numerosi, adulti spicati, late alati, ala 3 cellulas lata, tenerrima, margine repanda papulose-crenata. Antheridia ad 6 juga.

Hab. Java (Zollinger, Sulp. Kurz 478), in Monte Gedé (Solms), Sumatra in Monte Singalang (Schiffner).

22. Aneura distans Spruce. Linn. Soc. XXX, p. 367.

Dioica, magna, gracillima, fusco-olivacea, in sicco subnigra, corticola. Frons ad $9 \mathrm{~cm}$. longa, procumbens, flaccida, basi solum radicans, bipinnata. Truncus tenuis, subteres, exalatus, medio 12 cellulas crassus, fuscobrunneus vel subniger, regulariter remoteque pinnatus; pinnæ suboppositæ, superne interdum alternæ, 7-10 mm. longæ, oblique patulæ, basi haud alatæ, paucis pinnulis brevibus instructæ, pinnulæ alternæ, anguste lineares, apice sublatiores, margine repandæ, apicem versus subdenticulatæ, alis 4-7 cellulas latis; cellulæ alarum subæquimagnæ $37 \times \Xi 6 \mu$, marginales valde æqualiterque incrassatæ. Rami masculi ad 
basin pinnarum solitarii, breves, patuli, haud alati, subteretes, antheridiis ad 5 jugis. Reliqua desunt.

Hab. Dominica (Elliott 763, 1440).

Die weiblichen Blütenäste fehlen; bis solche gefunden werden, lasse ich die Entscheidung ausstehen, ob diese Pflanze nicht eine sehr laxe Form von Aneura fucoides ist.

\section{Aneura fucoides (Sw.) St.}

Syn. : Jungermannia fucoides Sw. Prodr. fl. ind. p. 4 ö.

Metzgeria fucoides Mont. Exp. voy. d'Orbigny. p. 60.

Pseudoneura fucoides G. Hepat. Mex. p. 259.

Dioica, major vel maxima, fusco-olivacea vel brunneola, rigida laxeque cæspitans vel inter hepaticas erecta flaccida interdum longissima. Frons ad $8 \mathrm{~cm}$. longa, basi radicans, tripinnata. Truncus subniger, superne interdum furcatus, pro more simplex, in sectione ovalis vel subteres, ad 14 cellulas crassus, haud alatus. Pinnæ remotæ, oppositæ oblique patulæ, ad $10 \mathrm{~mm}$. longæ, ambitu late deltoideæ, plano decurvæ, haud imbricatæ. Pinnulæ remotiusculæ, sæpe alternantes vel oppositæ, lineares, late alatæ, costa angusta, bene distincta; alæ 7 cellulas latæ, pellucidæ margine repandulæ, integræ vel apice subdentatæ; cellulæ alarum $37 \mu$, ad costam majores, ipso margine duplo minores, haud incrassatæ. Rami feminei in trunco oppositi vel solitarii, breves, margine breviter lacinulati. Calyptra magna ( $5 \mathrm{~mm}$.) clavata, cellulis vel lacinulis hirta, mamilla parva. Rami masculi ad basin pinnularum oppositi numerosi, breviusculi, curvatim sub pinna occulti (adulti stricti), anguste alati, alis integerrimis, adscendentibus. Antheridiis ad 8 jugis.

Hab. Jamaica (Swartz, Hansen, Harris), Guadeloupe (l'Herminier, Funck et Schlim, Husnot, Beaupertuis), Martinique (Perrottet, Husnot), Puertorico (Sintenis), Grenada (Broadway), Dominica (Elliott), Costarica (Pittier), Brasilia, Apiahy (Puiggari), Rio de Janeiro (Ule, Schenck).

\section{Aneura grossidens St. Hedwigia, 1893, p. 23.}

Dioica spectabilis, gracilis, rufescens. Frons erecta vel procumbens, basi radicans, ad $12 \mathrm{~cm}$. longa, laxe bipinnata. Truncus fusco-brunneus, validus, tenuis, in sectione ovalis, 12 cellulas crassus, haud alatus. Pinnæ remotæ, oppositæ, oblique vel subrecte patulæ, ad $10 \mathrm{~mm}$. longæ, ambitu late ovatæ, basi simplici exalatæ, superne pinnulatæ; pinnulæ remotiusculæ, oblique patulæ, anguste lanceolatæ, costa valida, alis subæquilata, alæ valde pellucidæ, 6 cellulas latæ, papulosæ crenatæ plus minus valide den- 
tatæ, apice interdum flagelliferæ i. e. pinnulæ alis deficientibus costaque tantum increscente radicantes. Cellulæ alarum magnæ, $57 \mu$, parietibus validis, marginales valde incrassatæ, ubique æquimagnæ. Rami feminei in trunco oppositi, breves, canaliculati, decurvi, margine irregulariter dentati vel lacinulati. Calyptra magna, ad $6 \mathrm{~mm}$. longa, cellulis papulosis vel clavatis hirta, mamilla parva coronata. Rami masculi ad basin pinnarum oppositi breves, leniter decurvi, alis angustis adscendentibus, irregulariter crenulatis, antheridiis ad 8 jugis.

Hab. Guadeloupe (l'Herminier), Dominica (Elliott).

\section{Aneura papillata (G.) St.}

Syn. : Pseudoneura papillata G. Ann. sc. nat. 1864, p. 91.

Dioica, major, laxe stratificata, apice dilute flavo-virens, basi rufobrunnea; frons ad $8 \mathrm{~cm}$. longa, tripinnata; truncus fusco-brunneus, validus, acute biconvexus, medio 12 cellulas crassus, haud alatus, superne interdum furcatus; pinnæ remotiusculæ, suboppositæ, primariæ ambitu oblongæ, omnes flaccidæ anguste alatæ, parum acuminatæ; cellulæ alarum subæquimagna $\mathbf{1 8} \mu$. Cuticula lævis. Rami feminei in trunco oppositi, semper e basi innovati, margine breviter lacinulati; calyptra maxima, ad $7 \mathrm{~mm}$. longa, apice grosse mamillata, ubique lacinulis maxime hirta. Elateres rufi, ad $630 \mu$ longi, maxime attenuati. Sporæ rufæ, ad $14 \mu$, læves. Rami masculi ad basin pinnularum breves, interdum furcati, stricti, patuli, anguste alati, margine papulose-crenati, foveolis ad 12 jugis.

Hab. Bogota (Lindig, Pehlke).

Die $q$ Aeste entspringen nicht etwa am unteren Ende eines Astes; dieser entwickelt sich erst später aus der Basis des Fruchtastes und stellt also eine wirkliche Innovation dar, die an sterilen wie fertilen ${ }^{+}$Aesten zu finden ist.

\section{Aneura squarrosa St. Hedw. 1893, p. 26.}

Dioica, magna, fusco-brunnea, ramis dilutioribus. Frons ad $7 \mathrm{~cm}$. longa, quadripinnata; truncus anguste linearis, validissimus, subniger, alte, biconvexus, in medio $\mathbf{1 0}$ cellulas crassus, superne repetito furcatus, hand alatus; pinnæ regulariter alternantes, remotæ, Jongiusculæ subrecte patulæ, anguste alatæ, pinnulis squarrose remoteque patulis, decurvis, ultimis angustissimis, omnibus valide costatis, anguste et tenerrime alatis, alæ $3-4$ cellulas latæ, cellulis $45 \%$. Cuticula lævis. Rami masculi magni, maxime reflexi late et tenerrime alati, alæ cellulis irregulariter prominulis dentatæ; antheridia ad 12 juga, magna. Reliqua desunt.

Hab. N. Granada, Paramo de Sonson, 10,000' (Wallis). 
27. Aneura algoides (Taylor) St.

Syn. : Metzgeria algoides Taylor. I. of. Bot. 1846, p. 410.

Dioica, elata vel longissima, gracillima, dilute flavo-virens, pendula. Frons ad $15 \mathrm{~cm}$. longa, tripinnata. Truncus fusco-brunneus, validus, haud alatus, a basi ad apicem latitudine increscens, ipso apice $0,5 \mathrm{~mm}$. latus, ibidemque setis longis unicellularibus obtectus, in sectione late ellipticus, medio 16 cellulas crassus, cellulis subcorticalibus valde incrassatis; pinnæ suboppositæ, remotiusculæ, ad $\mathbf{1 5}$ mm. longæ, oblique patulæ, haud imbricatæ, basi haud alatæ, tenues, attenuatæ, apice capillares, ambitu longe deltoideæ. Pinnulæ suboppositæ, remotæ, angustissimæ, attenuatæ, ultimæ capillares, costa angusta, alis ad 4 cellulas latis, pellucidis, crenatis, apice subdenticulatis; cellulæ alarum $20 \times 46 \mu$, ad costam $30 \times 57 \mu$, parietibus parum æqualiterque incrassatis. Rami feminei in trunco laterales, e basi communi brevissime quadrifidi, utroque latere innovati, margine spinosi. Calyptra clavata, mamilla parva acutiuscula, cellulis papulosis aspera. Rami masculi in pinnulis ultimis penduli, valde curvati, magni, breves late alati, alis tenerrimis, erectis, crispatis. Antheridia ad 8 juga.

Hab. Quito (Jameson).

28. Aneura virgata G, in Steph. Hedwigia 1888, p. 277.

Dioica, longissima, gracillima, rufescens, laxe profundeque cæspitosa. Frons erecta, ad $15 \mathrm{~cm}$. longa, tripinnata. Truncus superne interdum furcatus, validus subteres, exalatus, pinnæ remotæ, ad $15 \mathrm{~mm}$. longæ, suboppositæ, attenuatæ, apice subcapillares, ambitu lanceolatæ, i. e. pinnulis brevibus, suboppositis, versus apicem brevissimis; alæ pinnularum 2 cellulas latæ, valde pellueidæ sæpe interruptæ, cellulis marginalibus $57 \mu$, ad costam $9 \check{\mu} \mu$ longis, parietibus crassis. Rami] feminei in trunco oppositi, breves, margine breviter lacinulati. Calyptra $6 \mathrm{~mm}$. longa, clavata, lævis, mamilla parva obtusa. Rami masculi parvi, in pinnis pinnulisque laterales, basi sterili subštipitati, simpfices vel ramosi (geminati vel terni) plani, alis pătulis crenatis pellucidis. Antheridia ad こั juga.

Hab. Guadeloupe (I'Herminier), Martinique (Duss), Jamaica (Herb. George Davies).

Mit $A$. algoides (Taylor) zu vergleichen.

29. Aneura cervicornis Spruce. Edinb. Bot. Soc. 1885 , p. 5ั0.

Dioica, major, plus minus elata, rigida, erecta, olivacea vel rufescens, laxe cæspitosa. Frons ad $4 \mathrm{~cm}$. longa, tripinnata, superne anguste limbata. 
Truncus simplex vel furcatus, fusco-brunneus, durus, subteres, haud limbatus, cellulis subcorticalibus valde incrassatis. Pinnæ decurvulæ, magnæ, oppositæ, approximatæ et imbricatæ, ambitu late deltoideæ, trunco multoties angustiores, limbatæ, biconvexæ, medio 6 cellulas crassæ; Pinnulæ angustissimæ, pinnis ceterum simillimæ, limbo pellucido 2 cellulas lato, cellulis subæquimagnis, oblonga-hexagonis $(19 \times 38 \mu)$ formato. Rami feminei in trunco oppositi, e basi innovati, steriles valde elongati, late ligulati et decurvo- penduli, margine regulariter pinnatim lobati. Calyptra magna, clavata, lobulis magnis patulis pluricellularibus ubique dense obtecta, mamilla magna humilis, papulosa. Rami masculi (ipse haud vidi) ad basin pinnarum oppositi, breves, limbo incurvo acute plurilobulato. Antheridia sub 8 juga.

Hab. Andes quitenses (Spruce), Costarica 2800 m. (Pittier).

\section{Aneura dicrana St. n. sp.}

Dioica, major, dilute olivacea, rigida, laxe cæspitosa. Frons ad $3 \mathrm{~cm}$. onga, erecta vel procumbens pinnisque teretibus elongatis sæpe fere ad frondis apicem usque radicans, tripinnata. Truncus crassus in sectione alte ovalis, dilute brunneus, haud alatus. Pinnæ alternæ, ad こ̆ mm. longæ, basi haud alatæ rigidæque, hamatim decurvæ, ambitu late ovatæ. Pinnulæ confertæ, contiguæ, apice angustatæ, alis integerrimis quam costa angustioribus, 4 cellulas latis. Cellulæ alarum ad costam multo majores $23 \times 76 \mu$, reliquæ $19 \mu$, marginales minores subcrenulatæ, omnes exincrassatæ; cellulæ costæ internæ magnæ perlucentes, costa itaque reticulata. Rami masculi in pinnulis brevibus terminales, longe spicati, stricti, alis angustis recte patulis, repandis, papulosis, pellucidis. Antheridia $\mathbf{1 6}$ juga.

Hab. Sumatra, Insula Engano (Modigliani).

\section{Aneura hymenophylloides (Schffn.).}

Syn, : Riccardia hymenophylloides Schffn. Kais. Ak. Wien LXVII, p. 17. Aneura decipiens Schfin. ibidem, p. 176.

Dioica, major, viridis, inferne fuscescens, dense cæspitosa. Frons procumbens, ad $35 \mathrm{~mm}$. longa; truncus fusco-brunneus, rigidus, simplex vel furcatus, densissime tripinnatus, validissimus, teres, haud alatus, cellulis subcorticalibus valde incrassatis. Pinnæ oppositæ imbricatæ, homomallæ, ambitu late deltoideæ, a basi crebre pinnulatæ, pinnulis anguste costatis, canaliculatis, alis 8 cellulas latis, margine interrupte inflexis, crispatis, repandis denticulatisque. Cellulæx alarum $37 \mu$, ad costam 
majores, parietibus validis, æqualiter incrassatis. Rami feminei in trunco solitarii, rarius oppositi, breves margine foliaceo, varie laciniati dentatique. Calyptra $2 \mathrm{~mm}$. longa, clavata, cellulis quasi e contextu solutis asperula, mamilla parva acuta. Rami masculi ad basin pinnarum, numerosi, sub pinna decurvo-occulti, late alati, margine irregulariter subdenticulati. Antheridia ad 10 juga.

Hab. Sumatra, in monte Singalang $2000 \mathrm{~m}$., Java in monte Salak $1300 \mathrm{~m}$. ad truncos putridos (Schiffner No 223-227).

Aneura decipiens Schffn, ist nur eine niedrige Form von A. hymenophylloides; man findet in den Rasen junge kräftige Sprosse, wie gewöhnlich bei Aneura, mit ganz unausgebildeten jugendlichen Fiedern; an diesen Sprossen ist der Truncus auch fast stielrund, die reichere Verzweigung wird an ihnen jedenfalls auch eintreten, wie das bei dieser Gattung allgemein zu finden ist, so dass die Unterschiede, welche der Autor hervorhebt, wohl sicher nur die des Alters derz wei Pflanzen sind.

32. Aneura crispa Schffn. Exped. Gazelle 1889. IV, p. 41.

Syn. : Aneura umbrosa Schffn. ibid. (forma juvenilis).

Dioica, fusco-brunnea vel fusco rufa, dense cæspitosa, spectabilis sed humilis. Frons ad $\check{5} \mathrm{~cm}$. longa, flaccida, dense interdum densissime quadripinnata. Truncus latus, plano-biconvexus, haud alatus, simplex vel superne repetito furcatus, furcis 10 cellulas crassis, cellulis æquimagnis, haud incrassatis. Pinnæ approximatæ $4 \mathrm{~mm}$. longæ, plus minus dense imbricatæ, ambitu late deltoideæ. Pinnulæ tenerrimæ, subrecte patentes, decurvæ varie hamatæ, subcircinnatæ, costa humilis et angusta, alis 4 cellulas latis, pellucidissimis ; cellulæ alarum $37 \mu$, ad costam duplo longiores, margine papulosæ. Rami masculi breves, in pinnis pinnulisque solitarii vel oppositi, alis angustis, papulosis. Antheridia 4 juga. Reliqua ignota.

Hab. Fretum magellanicum, haud rara (Nauman, Savatier, Cunningham, Dusẻn, Hatcher).

\section{Plantæ mediocres.}

33. Aneura andina Spruce Edinb. Bot. Soc. 1885 , p. כั48.

Dioica, mediocris, olivacea, laxe cæspitans. Frons erecta vel procumbens, basi tantum radicans, ad $25 \mathrm{~mm}$. longa, bipinnata, rigida. Truncus fuscobrunneus, validus, compresso-subteres, ad $\mathbf{1 6}$ cellulas crassus, haud alatus, cellulæ subcorticales brunneæ, valde incrassatæ; pinnæ plus minus ap- 
proximatæ, suboppositæ, imbricatæ, anguste alatæ, oblique patulæ, decurvulæ, ambitu latissime deltoideæ. Pinnulæ lineares, suboppositæ, plus minus approximatæ, alis 5 cellulas latis, cellulæ $38 \times 54 \mu$ ad costam parum majores, margine vix minores, trigonis distinctis. Rami feminei in pinnis oppositi, breves, margine irregulariter spinosi. Calyptra magna, cylindrica vel subclavata, albida, papillis breviusculis scabra. Rami masculi in pinnis oppositi, alis suberectis latiusculis crenulatis. Antheridia ad 20 juga.

Hab. Andes orientales sylvaticos, pluribus locis (Spruce), Guatemala, Alta Vera Paz, prope Coban (v. Türckheim).

\section{Aneura humilis (G.) St.}

Syn. : Pseudoneura humilis G. Hep. Mexic., p. 260.

Dioica, mediocris, olivacea. Frons ad $150 \mathrm{~mm}$. longa, bipinnata, superne alata. Truncus subteres, nigro-olivaceus, superne furcatus, exalatus. Pinnæ decurvæ ad รั mm. longæ, imbricatæ, dense pinnulatæ, pinnulis 3-4 jugis, linearibus oblique patulis, contiguis, late costatis, alæ 5 - 6 cellulas latæ. Rami feminei in trunco suboppositi, margine laciniato-dentati. Calyptra cellulis prominulis sub apice uncinatim recurvis tuberculatoaspera, mamilla conica fuscescente.

Hab. Mexico, Hacienda de Mirador. 3000' (Liebmann).

Diese Pflanze habe ich nicht gesehen und daher die Diagnose nach des Autors Beschreibung zusammenstellen müssen; Aneura andina Spruce steht ihr sehr nahe oder ist mit derselben identisch; Spruce zog Aneura humilis nicht zum Vergleich heran, obgleich die Diagnosen sich im wesentlichen decken.

\section{3\%. Aneura diablotina Spruce. Linn. Soc. XXX, p. 366.}

Dioica, humilis dense ramosa ad $15 \mathrm{~mm}$. longa vel magis elata laxeque ramosa ad $\check{5} \mathrm{~cm}$. longa, fusco olivacea vel pallide virens, basi rufescens, laxe caspitans. Frons erecta vel procumbens, tenax, bipinnata, rigida. Truncus plus minus fuscus, in sectione ovalis, ad $\mathbf{1 6}$ cellulas crassus, haud alatus, cellulis subcorticalibus brunneis valde incrassatis. Pinnæ plus minus approximatæ, suboppositæ, ambitu late deltoideæ, imbricatæ, oblique patulæ, decurvulæ, basi minus alatæ. Pinnulæ remotiusculæ, suboppositæ, lanceolatæ, costa lata, alæ 6 cellulas latæ, integerrimæ, apice repandæ (cellulis solutis erosæ). Cellulæ alarum $37 \times 72 \mu$, trigonis magnis sæe fuscis incrassatæ, subæquimagnæ. Rami feminei oppositi, ramosi bi-vel trifidi, margine crebre spinosi, spinis 3 cellulas longis. 
Rami masculi in pinnulis basalibus terminales, parum curvati, longi, alis angustis, erectis, papulosis. Antheridia ad 12 juga.

Hab. Dominica (Elliott), Sto. Domingo (Eggers).

\section{Aneura decrescens St. n. sp.}

Dioica, mediocris, flaccida, dilute flavo-virens, depresso cæspitans. Frons ad $2 \mathrm{~cm}$, longa, dense ramosa, superne flabellatim expansa, bipinnata. Truncus superne repetito-furcatus, $1 \mathrm{~mm}$. latus, postice planus, antice convexus, medio 7 cellulas crassus, margine acuto haud alato; cellulæ internæ corticalibus multo majores perlucentes. Pinnæ oppositæ, medio こ̊ cellulas crassæ, confertæ sæpe contiguæ, valde imbricatæ, 4-こ̆ mm. longæ, oblique patulæ, alis 3 cellulas latis. Pinnulæ pinnis simillimæ, angustiores, 3 cellulas crassæ, costa sub apice evanida; cellulæ alarum ad costam $57 \times 76 \mu$, margine $38 \mu$, valde papulosæ. Rami feminei in trunco furcisque oppositi innovati, majusculi, disciformes, margine dense grosseque piliferi; pilis longis lanatim tortis intricatisque; calyptra longissima (6-7 mm.) clavata, squamulis patulis hirta; mamilla parva, cylindrica; rami $\sigma^{\pi}$ ignoti.

Hab. Japonia, Awa (Makino).

Die Pflanze steht unserer europäischen Aneura multifida sehr nahe ist aber in den Fi€derästen viel dünner gebaut und wesentlich dichter beästet; die Aeste lassen unsere Pfianze sofort erkennen.

37. Aneura fuscescens St. Hedwigia, 1893, p. 21.

Dioica, mediocris, pallide olivacea, dense depresso stratificata. Frons ad $3 \mathrm{~cm}$. longa, procumbens, pinnata. Truncus postice planus, antice convexus, margine acutus, haud alatus, medio 6 cellulas crassus, cellulis internis multo majoribus, uno latere pinnatus altero stoloniferus. Pinnæ approximatæ vel confertæ, simplices, adultæ lanceolatæ, medio 3-4 cellulas crassæ, late alatæ, alis 4-อ̆ cellulas latis, crenulatis; cellulæ alarum $57 \mu$, margine minores, ad costam majores. Rami feminei in trunco solitarii, brevissimi, cupuliformes, breviter lacinulati. Calyptra parva, clavata, superne cellulis papulosis vel utriculatis hirta; mamilla parva, conica papulosa.

Hab. Tahiti (Nadeaud), Andaman Insulæ (E. H. Man).

Aneuræ reticulatæ (ex Insula afric. San Thomé) simillima, quæ differt trunco alato, cellulis marginalibus minimis etc. 
38. Aneura Pœppigii (L. L.) St.

Syn. : Jungermannia Poppigii L. L. Pugill. VI, p. 23.

Metzgeria Poppigii Ldbg. Syn. Hepat., p. 506.

Pseudoneura Poppigii G. Hepat. Mex., p. 261.

Dioica, minor, laxe depresso-cæspitans, fusco-olivacea. Frons ad $2 \mathrm{~cm}$. longe, supra basin furcata, furcis divergentibus bipinnatis. Truncus fuscobrunneus, haud alatus, in sectione ovalis 8 cellulas crassus; pinnæ primariæ breves, oppositæ, approximatæ, interdum simplices attenuatæ. radicantes, promore breviter paucipinnulatæ, pinnulæ ultimæ trunco parum angustiores, tenerrimæ, late alatæ, alarum cellulæ haud incrassatæ ad $30 \mu$, valde chlorophylliferæ. Rami feminei in trunco oppositi, parvi. margine fimbriati, calyptra $1 \mathrm{~mm}$. longa, clavata, lacinulis hirta. Rami masculi in pinnis primariis oppositi, sæe seriati vel totum ramulum pinnatim-occupantes, ceterum breves, decurvuli, anguste alati, margine papulose crenati, antheridiis ad 7 jugis.

Hab. Peruvia (Poppig).

Die Pflanzen von der Insel St. Vincent und Mexíco, welche in der Syn. Hepat. erwähnt werden, habe ich nicht gesehen.

39. Aneura hymenophytoides Spruce. Edinb. Bot. Soc. 1885 , p. อั49.

Dioica, major sed humilis, dilute olivacea, vel rufula, erecta, laxe cæspitosa. Frons ad $10 \mathrm{~mm}$. longa, basi solum radicans, bipinnata, rigida. Truncus validus, fusco-rufescens, in sectione ovalis, medio 8 cellulas crassus, haud alatus, basi sæpe nudus, apice paucas pinnulas, interdum unam pinnam apicalem gerens; pinnæ oppositæ, parum patulæ, decurvæ, laciniis 3-6 subpalmatifidæ, laciniæ medianæ longiores, subeontiguæ. lineares, basi angustiores, late costatæ lateque alatæ, repandæ, alis 6 celIulas latis, pellucidis; cellulæ alarum magnæ $37 \mu$, marginales minores, valde et æqualiter incrassatæ. Rami feminei in trunco oppositi (steriles longiores), canaliculati, alati, alæ adscendentes, usque ad costam fere incisæ, laciniis plus minus longis, subulatis vel filiformibus, sæpe hamatim incurvis; calyptra ad $3 \mathrm{~mm}$. longa, clavata, apice crasse angusteque mamillata, cellulis inflatis vel clavatis dense armata. Capsula ovalis, valvulis ut in congeneribus bistratis, stratum internum semiannulatim incrassatum, externum tenerrimum hyalinum. Sporæ $13 \mu$, rufæ, læves. Elateres concolores, attenuati, monospiri, spira lata, anguste torta.

Hab. Andes quitenses, in monte Campana (Spruce). 
40. Aneura nobilis St. Hedw. 1893, p. 24.

Dioica, major sed humilis, procumbens, dilute olivacea. Frons vix $3 \mathrm{~cm}$. longa, tripinnata, e ramulis parvis basalibus radicans. Truncus tenuis, atrorubens, plano-biconvexus, haud alatus, remote pinnalus. Pinnæ oppositæ, subrecte patulæ, ambitu late deltoideæ, ob pinnulas basales deficientes quasi stipitatx; pinnulæ contiguæ, ligulatæ, oblique porrectæ, tenerrimæ, late et humiliter costatæ lateque alatæ, alis 6 celIulas latis, minute crenulatis; cellulæ alarum $36 \mu$, marginales $18 \mu$, valde incrassatæ. Rami feminei in trunco laterales, parvi, margine pauciciliati. Calyptra parva, clavata, tuberculosa.

Hab. Borneo_(Beccari).

Die Fiederäste erster Ordnung gleichen wegen der langen Internodien wirklichen Blättern; dieser Eindruck wird noch erhöht durch den stielförmigen Basalteil jener Aeste, die im übrigen dicht zweizeilig gefiedert sind; von allen frondosen Formen der Lebermoose ist diese Pflanze einer Blätter tragenden am ähnlichsten.

\section{Aneura ramosissima St. Hedwigia 1892, p. 200.}

Dioica, parva, gracillima subfiliformis, rufescens, densissime pulvinata. Frons ad $10 \mathrm{~mm}$. longa, angustissima, a basi longe et creberrime subfasciculatim ramosa, superne alata. Truncus in sectione ovalis, ad 9 cellulas latus, medio 7 cellulas crassus, cellulis internis majoribus, magis latis quam altis, inæqualiter longe ramosus, ramis trunco subæquilatis, furcatis biconvexis, medio 4 cellulas crassis, alæ 2-3 cellulas latæ, cellulis marginalibus $28 \mu$, parietibus validis. Rami feminei brevissimi, margine breviter lacinulati, calyptra mediocris, clavata, lævissima, mamilla constricta, discoidea, papulosa.

Hab. Insula Bourbon (Rodriguez).

\section{Plantæ parvæ vel exiguæ.}

42. Aneura minima (C. et P.) St.

Syn. : Riccardia minima C. et P. Linn. Soc. N. S. Wales. 1887, p. 105̈3̈).

Dioica pusilla, rigida, olivacea, pulvinata. Frons ad $7 \mathrm{~mm}$. longa, basi valde stolonifera, stolonibus valde ramosis, bipinnata, superne alata. - Truncus e basi subfiliformi sensim ampliatus, haud alatus, postice planus, antice valde convexus, medio 7 cellulas crassus, cellulis internis haud majoribus, superne furcatus, furcis irregulariter bipinnatis; pinnæ plus minus longæ, lanceolatæ, juniores obtusæ, furcatæ vel paucis ramulis 
oppositis pinnulatæ, anguste alatæ, medio 4 cellulas crassæ; alæ 2 vel 3 cellulas latæ, papuloso-crenatæ, cellulis marginalibus 57 $\mu$. Rami feminei pro planta magni, disciformes, margine longe piliferi, pilis confertis hamatim conniventibus; pistilla ad 10 juga. Reliqua desunt.

Hab. Australia N. S. Wales (Whitelegge), Illawarra (Kirlon), Tasmania, Mount Wellington (Weymouth).

\section{Aneura gogolensis St. n. sp.}

Dioica, minor, viridis, flaccida, corticola. Frons ad $7 \mathrm{~mm}$. longa, bipinnata, superne alata. Truncus anguste linearis, postice planus, antice con-

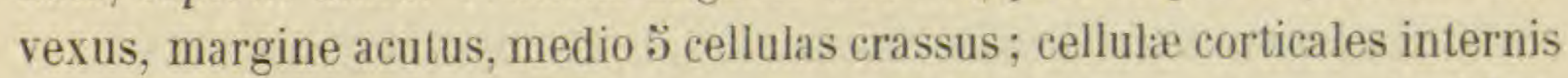
multoties minores; pinnæ unilaterales, remotiusculæ ex angusta basi late obcuneatæ, superne breviter palmatim bis-bifidæ, laciniis linearibus tenerrimis; alis 3 cellulas latis, margine papuloso-parvicellulari. Rami feminei parvi, breviter lacinulati. Calyptra parva, e basi angustissima optime clavata, superne cellulis utriculatis strictis erectisque maxime horrens. Rami masculi longissimi, in pinnis solitariis apicales, margine parvis cellulis hyalinis alteque papulosis graciliter limbati. Antheridia ad 14 juga.

Hab. Nova Guinea ad flumen Gogol (Lauterbach).

\section{Aneura crassiretis (Sehffn.) St.}

Syn. : Riccardia crassiretis Schffn. Kais. Ak. Wien. 1898. LXVII, p. 173.

Dioica, exigua, rigida, fusco-viridis, pulvinulata. Frons ad $3 \mathrm{~mm}$. longa, erecta, stolonibus numerosis radicans. Truncus angustus, haud alatus, in sectione ellipticus, 4-อ̃ cellulas crassus, rami ex angusta basi sensim latiores, superne furcati, æquilongi, lineares, trunco æquicrassi, limbo unistrato 2 cellulas lato bene difinito, cellulis valde incrassatis, marginalibus $18 \mu$, haud papulosis. Cellulæ centrales $28 \times 70 \mu$, corticalibus multo majores, perlucentes, parietibus maxime incrassatis. Rami feminei parvi ad basin ramorum. margine celluloso-dentato; calyptra pro planta maxima, cylindrica, cellulis breviter utriculatis sparsim obsita, mamilla parva obtusa. Rami masculi breves, limbo angusto incrassato grandicellulari; Antheridia ad 6 juga.

Hab. Sumatra, in monte Singalang, terricola $2000 \mathrm{~m}$. (Schiffner).

\section{Aneura samoana St. Hedwigia, 1893, p. 2.}

Dioica, minor, pallide olivacea, tenera, in cortice dense depresso-cæspitans. Frons ad $10 \mathrm{~mm}$. longa, e caudice repente flabellatim ramosa, cellu- 
lis internis perlucentibus grosse reticulata. Truncus latus, planus, medio 3 cellulas crassus, haud alatus, pinnis trunco æquilatis, confertis, optime flabellatim expansis, 3 cellulas crassis, alis angustis. Pinnulæ apice sæpe radicantes vel in stolones breves mutatæ, paucæ, alternantes, duplo angustiores, lineares, obtusæ, 2 cellulas crassæ, tertia cellula singula centralis. Rami feminei ad basin pinnularum parvi, margine irregulariter lacinulati. Calyptra cylindrica , papulosa, apice magnis cellulis utriculatis radiatim divergentibus hispida. Reliqua desunt.

Hab. Samoa (Græffe, Powell, Reinecke), Hawai (Baldwin),

46. Aneura tenuicula Spruce. Edinb. Bot. Soc. 1885, p. 5ૅ.0ั.

Dioica, pusilla, viridis, in cortice dense imbricatim repens. Frons ad $4 \mathrm{~mm}$. longa, vage ramosa, tenerrima. Truncus exalatus, こั cellulas latus, medio 3-4 cellulas crassus, plano-biconvexus; rami latiores, tenerrimi, medio 3 cellulas crassi, limbo lato unistratoso; cellulæ internæ magnæ, elongatæ, corticales multo minores, papulosæ. Rami feminei breves, margine erecto digitatim lacinulato. Calyptra clavata, superne papulosa. Rami masculi breves, margine papulosi. Antheridia ad 6 juga.

Hab. America merid., Amazonas, Rio Negro, Uaupes et Huallaga (Spruce).

47. Aneura macrostachya Spruce. Edinb. Bot. Soc. 1885, p. อัอ0.

Dioica, exigua, fusco-virens, dense depresso-cæspitosa. Frons $4 \mathrm{~mm}$. longa, stolonifera, simpliciter pinnata, superne alata. Truncus haud alatus, repetito furcatus, furcis divergentibus, uno latere stoloniferis, altero pinnatis, apice solum regulariter opposito-pinnatis, plano-biconvexis, medio 4-5े cellulas crassis; cellulæ internæ multo majores. Pinnæ oblique patentes, lineares vel lanceolatæ, obtusæ, medio $\mathbf{2}$ cellulas crassæ, late alatæ, alis 3-4 cellulas latis, cellulæ marginales $38 \mu$ ad costam majores. corticales valde chlorophylliferæ. Rami masculi in trunco laterales. lineares, sæpe longissimi, longitudinem totius plantæ longe superantes, limbati, papuloso-crenati. Antheridia ad 30 juga.

Hab. Brasilia, Rio Negro (Spruce).

\section{Truncus alatus.}

«. Monorce.

48. Aneura crenulata St. Bull. Herb. Boissier. 1897, p. 85 .

Monoica, mediocris, dilute flavo-virens, dense depresso cæspitosa. Frons ad $15 \mathrm{~mm}$. longa, e caudice repente flagellifero unilateraliter - apice solum 
bilateraliter ramosa, celerum tripinnata, alata. Truncus postice planus, antice convexus, medio 6 cellulas crassus; alæ 3 cellulas latæ. Pinnæ approximatæ, ambitu triangulares, imbricatæ, trunco vix angustiores æquicrassæ. Pinnulæ anguste lineares, 3 cellulas crassæ, ala solum 2 cellulas lata, margine optime papuloso-crenulata; cellulæ internæ corticalibus vix majores, in costa trunci solum longiores. Rami feminei brevissimi, margine breviter lacinulati, calyptra cylindrica, superne papulosa vel cellulis elongatis hirta, mamilla nulla. Rami masculi flori fem. approximati, sæpe oppositi, anguste lineares, margine papuloso. Antheridia ad 30 juga.

Hab. Japonia (Faurie).

\section{Aneura autoica St. 11. sp.}

Autoica, minor, corticola, olivacea, dense depresso intricata, Frons procumbens, ramulis stoloniformibus radicans, ad $15 \mathrm{~mm}$. Ionga bipinnata. Truncus latus in sectione plano-biconvexus, vel late triquetrus, i. e. antice planus, postice late carinatus, medio 10 cellulas crassus, alatus, altero latere ramosus, altero stolonifero radicans; pinnæe itaque unilaterales, confertæ, $3 \mathrm{~mm}$. longæ, imbricatæ, sæpe quatuor laciniis palmatifidæ vel longiores et magis distincte pinnulatæ. Pinnulæ contiguæ, lineares vel apice parum angustatæ, truncatæ; costa valida alis æquilata, sensim in alas altenuata; alæ 6 cellulas latæ, integerrimæ, cellulis $45074 \mu$, ad costam parum majoribus, haud incrassatis. Rami feminei parvi, breviter lacinulati, utroque latere e basi communi ramulum masculum gerentes; calyptra maxima, crassa, lævis, mamilla magna basi constricta. Rami masculi interdum ad basin pinnularum solitarii, substricti angusti, vix alati, margine papulosi, antheridiis ad 10 jugis.

Hab. Chile anstralis (Dusén).

50. Aneura Fendleri St. Hedwigia 1893, p. 20.

Monoica, mediocris, olivacea, dense depresso-cæspitans. Frons ad $15 \mathrm{~mm}$. longa, pinnata et bipinnata, anguste alata. Truncus repetitofurcatus, anguste linearis, plano-biconvexus, medio כ̌ cellulas crassus, anguste alatus, alæ 2-3 cellulas latæ; pinnæ unilaterales (in frondis apice solum regulariter pinnatim dispositæ) simplices vel longe furcatæ, trunco æquilatæ el vix minus crassæ, parum acuminatæ, alis 3 cellulas latis; cellulæ alarum $40 \mu$, ad costam majores, margine minores, haud incrassatæ. Rami feminei in trunco solitarii breves, margine erecto hamatim Iobulato; calyptra parva, apice longe papulosa, mamilla parva, cellulis 
clavatis dense obtecta. Rami masculi ad basin pinnarum laterales, lineares, breves, stricti, margine erecto subintegerrimo. Antheridia ad 6 juga.

Hab. Trinidad (Fendler), Guadeloupe (Marie).

\section{Aneura intermedia St. n. sp.}

Monoica, mediocris, flavo-rufescens, apice dilute virens, dense depresso caspitans et maxime intricata. Frons arcte repens (pinnulis radicantibus affixa) ad $2 \mathrm{~cm}$. longa, multiramosa et late dilatata, rigida. Truncus ad $1 \mathrm{~mm}$. latus, plano-biconvexus, medio 8 cellulas crassus, anguste alatus, alis 3-4 cellulas latis, irregulariter ramosus, rami altero latere breviter pinnati, altero pinnis attenuatis radicantes; pinnæ subcontiguæ, ramis floriferis sæpe interruptæ, digitatim trifidæ, lacinïs vel pinnulis ultimis lanceolatæ, humiliter costatæ, late alatæ, alis costæ æquilatis, 8 cellulas latis; cellulæ alarum magnæ $(40 \mu)$, haud incrassatæ, marginales haud minores. Rami feminei in trunco oppositi, brevissimi, margine lacinulati, laciniis valde irregularibus, longis, capillaceis vel brevibus ad spinam reductis; calyptra $3 \mathrm{~mm}$. longa, clavata, lævis, mamilla apicali parva. Rami masculi solitarii, ex apice pinnulæ sterili orti, parvi, femineis approximati, margine magnis cellulis denticulati, stricti, antheridiis quadrijugis.

Hab. Brasilia, Apiahy (Puiggari).

52. Aneura leptophylla Spruce. Edinb. Bot. Soc. 1885, p. 5̆44.

Monoica vel dioica, pusilla, tenella, flaccida, olivacea, valde chlorophyllifera, dense depresso stratificata. Frons ad $5 \mathrm{~mm}$. longa, regulariter bipinnata, late alata. Truncus pro planta latus, plano-biconvexus, 4 cellulas crassus, margine cellulis triseriatis alatus, cellulæ internæ corticalibus multo majores, alarum $27 \mu$, ad costam majores, margine crenulato. Pinnæ breves, approximatæ, trunco duplo angustiores, apice pinnulis oppositis patentibus quasi palmatim trifidi. Rami feminei in trunco pinnisque solitarii, breves fere cupuliformes, margine cellulis digitiformibus crenulati, plus minus inciso-lobati. Calyptra parva, $1 \mathrm{~mm}$. longa, superne cellulis utriculatis hirta, mamilla cellulis similibus penicillatis formata. Rami masculi breves, margine erecto papuloso. Antheridia ad 8 juga.

Hab. Venezuela, San Carlos del Rio-Negro (Spruce), Cuba (Wright).

53. Aneura erosa St. Hedwigia 1891, p. 269.

Monoica, exigua, dilute olivacea, pellucida, tenerrima, in cortice expansa. Frons ad $3 \mathrm{~mm}$. longa, basi stolonifera, superne furcata vel palmatim 
divisa vel paucipinnata, ramulis trunco æquilatis, linearibus, medio 3 cellulas crassis, alis $3-4$ cellulas latis, margine irregulariter papulosis quasi erosis. Rami feminei brevissimi, margine hamatim papuloso. Calyptra pyriformis, lævis, mamilla discoidea, papulosa. Rami masculi longissimi, sæpe frondi subæquilongi, lineares, tenues, margine hamatim papulosi. Antheridia ad 150 juga.

Hab. Africa occid. Insula S. Thomé (Quintas).

\section{B. DoIC.E.}

1. Plantæ elatæ, spectabiles.

\section{5\%. Aneura elata St. Hedwigia 1893, p. 19.}

Dioica, major, plus minus fusco-olivacea, laxe cæspitans. Frons ad $19 \mathrm{~cm}$. longa, rigida, erecta vel procumbens, basi tantum radicans, tripinnata. Truncus latus, validus, fusco-brunneus, in sectione alte biconvexus, medio 10 cellulas crassus, anguste alatus; cuticula lævis. Pinnæ plus minus remotæ suboppositæ, ambitu late deltoideæ, oblique in planum patentes, ad $12 \mathrm{~mm}$. longæ, alatæ, acuminatæ; pinnulæ oppositæ remotiusculæ, obtusæ, costa lata; alæ pellucidæ, ご cellulas latæ, cellulis $28 \mu$, ad costam multo majoribus, versus marginem sensim minoribus, ipso margine circiter $7 \mu$, parietibus validis, angulisque incrassatis. Cellulæ costæ corticales parvæ, internæ multo majores, perlucentes, rami itaque optime reticulati. Rami feminei in trunco oppositi, steriles elongati, interdum furcati, late alati, alis usque ad costam lobatis varieque incisis (nusquam lanatim piliferis). Calyptra clavata sublævis, mamilla parva, Rami masculi ad basin pinnarum oppositi, interdum ramosi bi-trifidi, curvatim sub pinna occulti, canaliculati, crenulati. Antheridiis ad 8 jugis.

Hab. Java (Stahl, Schiffner).

Aneura Zollingeri differt trunco haud alato, pinnulis alternis, alarum cellulis multo minoribus, præcipue ramis femineis lanatim piliferis.

ธ๊รั. Aneura Glaziovii Spruce. Bull. Soc. bot. 1889, XI, p. 201.

Syn. : Aneura tripinnata St. Soc. bot. belg. 1892, p. 175.

Dioica, major, gracilis, superne flavo-virens, inferne rufescens. Frons ad $6 \mathrm{~cm}$. longa, tripinnata; truncus antice planus, postice convexus, medio 12 cellulas crassus, cellulis æquimagnis formatus, anguste alatus; pinnæ breves, alternantes, decurvæ, remotiusculæ, ambitu ovato-deltoideæ, pinnulis brevibus confertis, latissime alatis, ala integerrima cellulis magnis $(36 \times 54 \mu)$ formata. Cuticula lævis. Rami feminei in trunco sparsi, 
parvi margine crenulati. Calyptra magna, trunco primario æquilata, clavata, apice grossemamillata, lacinulis sparsis hirta. Elateres rufi, monospiri, maxime attenuatæ. Sporæ rufæ $13 \mu$, læves. Rami masculi in pinnulis ultimis laterales, numerosi, parvi, parum canaliculati, curvatim sub ramo occulti, tenues et pellucidi, margine irreguIariter papulosi, antheridiis $6-7$ jugis,

Hab. Costarica (Pittier et Durand 6075), Brasilia subtropica (Ule 204, 433), Rio Janeiro (Glaziou 7069).

Spruce beschrib seine Pflanze (nach sehr schlechten Exemplaren) als bipinnata, was ein Wiedererkennen der Pflanze verhinderte.

56. Aneura trichomanoides Spruce. Edinb. Bot. Soc. 1885 , p. 5ั47.

Dioica, elata, erecta vel dense stratificata, pallide viridis vel rufescens. Frons ad $6 \mathrm{~cm}$. longa, tripinnata. Truncus validus, superne repetito longe furcatus, plano-biconvexus, medio 10 cellulas crassus, alatus, alæ subdentatæ, sæpe interruptæ. Pinnæ כ̃ mm. longæ, alternantes vel suboppositæ, oblique patulæ, planæ, ambitu late triangulares, subcontiguæ, pinnulæ suboppositæ, lineares vel lanceolatæ, contiguæ, angustæ, costa angusta, apice 2 cellulas lata, bene distincta, alæ latissimæ, pellucidæ, ad 7 cellulas latæ, margine repandæ, erosæ, plus minus dentatæ; cellulæ alarum $37 \mu$, ad costam majores. Rami masculi ad basin pinnarum solitarii, interdum furcati, alii apice vegelativi, alis latis tenerrimis, adscendentibus, margine irregulariter denticulatis, antheridiis ad 12 jugis.

Hab. Andes quitenses, in sylva Canelos et in monte Abitagua (Spruce).

57. Aneura lepidomitra Spruce. Edinb. Bot. Soc. 1885̆, p. כ̋49.

Dioica, major, rufescens, erecta vel procumbens. Frons ad כ̋ $\mathrm{cm}$. longa, gracilis, subflaccida, bipinnata. Truncus fusco-rubens, late linearis, in sectione plano-biconvexus, medio 6-7 cellulas crassus, ubique anguste alatus (alis 5̈-6 cellulas latis). Pinnæ dissitæ, breves, 3 mm. longæ, suboppositæ, oblique patulæ, hamatæ, paucis pinnulis brevibus contiguis instructæ; costa latissima, in pinnulis ultimis angustior, late alata, alis 5-6 cellulas latis, margine repandis; cellulæ alarum $18 \mu$, parietibus validis angulisque incrassatis. Rami feminei in trunco oppositi, lati brevissimi, margine longe et anguste laciniati. Calyptra alte mamillata, facie papillis neenon squamulis membranaceis conspersa.

Hab. Andes quitenses, in monte Guayrapata, $2800 \mathrm{~m}$. in cortice, Nova Granada, Paramo de Sonson (Wallis). 
Aneura.

58. Aneura Wallisii St. Hedwigia 1893, p. 28.

Dioica, major, rufescens, valida. Frons ad $6 \mathrm{~cm}$. longa, inter muscos irregulariler ramosa, tripinnata. Truncus plano-biconvexus, medio 8 cellulas crassus, alatus; pinnæ breves oppositæ, approximatæ, paucipinnulatæ, late alatæ, ala tenerrima, integerrima, valide costatæ, cellulæ alarum parvæ, $18 \mu$. Rami feminei in trunco oppositi, brevissimi, trifidi, margine foliacei, longe fimbriati, laciniis valde irregularibus, sæpe dentatis, lanatim intricatis. Reliqua desunt.

Hab. Nova Granada, Paramo de Sonson (Wallis).

Die $q$ Aeste sind zuerst gabelig und einer der Gabeläste hat sich dann nochmals geteilt; jeder Ast trägt die Pistille in der gewöhnlichen zweizeiligen Anordnung.

(A suivre.) 

Extrait du Bulletin de l'Herbier Boissier.

Tome VII. No 10. Octobre 1899.

\title{
SPECIES HEPATICARUII
}

\author{
AUCTORE \\ Franz StTEPHANI
}

(Suite.)

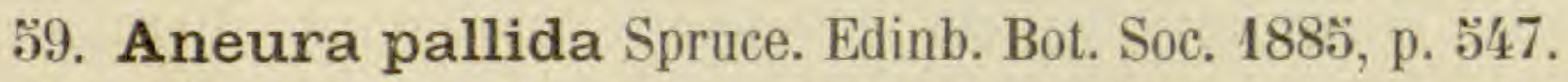

Dioica, elata, pallide rufescens vel pallide-virens, gracilis, cæspitans. Frons ad $6 \mathrm{~cm}$. longa, erecta vel pendula, in planum bipinnata. Truncus plano-biconvexus, medio 12 cellulas crassus, usque ad basin anguste interrupteque alatus. Pinnæ remotæ, oppositæ, ad $4 \mathrm{~mm}$. longæ, oblique patulæ, trunco multoties angustiores, ambitu late triangulares. Pinnulæ anguste lineares, costa angusta percursæ, alis 4 cellulas latis pellucidis unistratis subintegerrimis; cellulæ alarum $27 \times 46 \mu$, ad costam parum majores. Rami feminei ad basin pinnarum laterales, breves, alis angustis in lacinias subulatas vel subfiliformes fissis, hamatim conniventibus. Calyptra pyriformis, clavata, tuberculis vel papillis perraris conspersa, apice angustiuscule mamillata (ipse haud vidi). Rami masculi ad basin pinnarum oppositi, pellucide alati, cellulis irregulariter prominulis subdentati. Antheridia 10 juga.

Hab. Andes quitenses, in monte Chimborazo et Abitagua (Spruce).

60. Aneura multifida (L.) Dum. Comment. p. 145.

Syn. : Jungermannia multifida L. Sp. pl., p. 1602).

Dioica, major, gracilis, olivacea, depresso-cæspitans. Frons ad $3 \mathrm{~cm}$. longa, optime regulariter bi-vel tripinnata, alata. Truncus superne repetito-furcatus, furcæ anguste lineares ubique æquilatæ plano-biconvexæ medio 6 cellulas crassæ, anguste alatæ, cellulæ internæ corticalibus multo majores optime perlucentes. Pinnæ ad $6 \mathrm{~mm}$. longæ, trunco multo angustiores late alatæ, suboppositæ, approximatæ, haud tamen imbricatæ, 
ambitu oblongæ, pinnulis suboppositis, 4 jugis, anguste linearibus, interdum lanceolatis, basalibus sæpe furcatis, late alatis; cellulæ alarum triseriatæ, ad costam $76 \mu$, versus marginem minores, ipso margine papulosæ. Rami feminei in trunco oppositi, breves, crassi, margine breviter lacinulati. Calyptra ad $\check{~} \mathrm{~mm}$. longa, squamosa, mamilla parva papulosa. Rami masculi in trunco pinnisque oppositi, breves, alati, alis crenulatis. Antheridia ad 6 juga.

Hab. Europa, Asia, America sept., Japonia (Faurie).

\section{Aneura tjibodensis (Schffn.).}

Syn. : Riccardia tjibodensis Schffn. Kais. Ak. Wien. LVII, p. 163.

Sterilis, major, gracilis, inter muscos erecta vel laxe cæspitosa, læte viridis, inferne brunnescens. Frons ad $5 \mathrm{~cm}$. longa, ubique anguste alata. Truncus basi tenuis, superne dilatatus, repetito furcatus, furcis acute biconvexis, medio $ّ$ cellulas crassis, ob pinnarum alas decurrentes interrupte alatis. Pinnæ remotiusculæ, pro planta brevissimæ, alternantes, patulæ, rigidæ, lineares, alis 3 cellulas latis. Pinnulæ pinnis simillimæ, angustiores tamen; cellulæ alarum ad costam $22 \times \check{50} 6$, marginales multo minores valdeque irregulares, papulosæ. Nusquam invenire potui alam undulatam (in plantis bene emollitis et acido lactico tractatis).

Hab. Java, Tjibodas, $2140 \mathrm{~m}$. (Schiffner).

\section{Aneura tahitensis St. n. sp.}

Dioica, major, flavo-viridis, dense stratificala. Frons ad $6 \mathrm{~cm}$. longa, simpliciter pinnata. Truncus simplex, superne interdum furcatus, ex angusta basi ad $1 \mathrm{~mm}$. latus, plano-biconvexus, anguste alatus, medio 8 cellulas crassus, cellulis internis quam corticales multo majoribus; pinnæ in planta bene evoluta valde regulariter dispositæ, breves, diametro trunci duplo longiores, duploque angustiores, lineares, rarissime pinnula solitaria auctæ, 4 cellulas crassæ, cellulis internis perlucentibus optime grosseque reticulatæ, limbo unistrato 2 cellulas lato. Rami $\sigma^{7}$ in pinnis laterales, solitarii, breves strictique, margine vix alati, papulosi, antheridiis ad 6 jugis; cetera ignota.

Hab. Tahiti (Nadeaud).

63. Aneura tenuis St. Hedwigia 1893, p. 28.

Dioica, gracillima, dilute olivacea, profunde cæspitosa. Frons ad $5 \mathrm{~cm}$. longa, regulariter bipinnata. Truncus tenuis, basi subteres, superne ellipticus, medio 8 cellulas crassus, 12 cellulas latus, cellulæ internæ corti- 
calibus parum majores, ceterum basi haud alatus, superne ramorum alis decurrentibus interrupte alatus. Pinnæ pinnulæque breves, subremotæ, oppositæ, lanceolatæ, trunco parum angustiores, alis ad 3 cellulas latis, versus apicem ramorum magis magisque reductis, ipso apice evanidis; cellulæ alarum $19 \mu$, ubique æquales et parum incrassatæ. Rami feminei in trunco oppositi, breves, alæ latissimæ usque ad costam regulariter laciniatæ, laciniis lanceolatis hamatim incurvis. Reliqua desunt.

Hab. Java (Solms) in cacumine montis Gedeh (Stahl), in monte Pangerango $2780 \mathrm{~m}$. (Schiffner).

Die mit einem häutigen Flügel versehenen Arten der Gattung Aneura zeigen denselben an der Spitze meist stark entwickelt; er bildet hier über dem im Grunde eines tiefen Einschnittes befindlichen Vegetationspunkte zusammenneigend einen wirksamen Schutz; unsere Pflanze dagegen entwickelt im Gegenteil den Flügel erst späler, er fehlt der wachsenden Spitze ganz und ist auch an älteren Fiedern daselbst wenig entwickelt.

64. Aneura ciliolata Spruce. Edinb. Bot. Soc. 1885, p. 5ั47.

Dioica, elata, fulva vel badia, laxe cæspitosa. Frons erecta (inter muscos) ad $12 \mathrm{~cm}$. Ionga, alata, repetito furcata, ramis fastigiatis bipinnatis. Truncus inferne exalatus, superne alatus, alis interruptis quasi in foliola ciliata dissolutis, postice planus, antice leniter convexus, medio 8 cellulas crassus. Pinnæ dissitæ, oppositæ vel subalternæ, $4 \mathrm{~mm}$. longæ, ambitu deltoideæ, æquimagnæ. Pinnulæ breves, subtrijugæ, infimæ iterum divisæ, lineares, medio 6 cellulas crassæ, pinnulæ pinnæque omnes late alatæ, alis ad 5 cellulas latis, pellucidis ciliolatis, ciliæ 1-3 cellulas longæ, plus minus recte patulæ; cellulæ alarum magnæ $76 \times 38 \mu$ ad costam majores, margine duplo minores. Rami masculi ad basin pinnarum oppositi, late alati, alis setosis vel ciliolatis incurvis. Antheridia ad 4 juga.

Hab. America trop., in monte Mulmul (Spruce), Paramo de Sonson Columbiæ, $10,000^{\prime}$ (G. Wallis).

\section{- 6อ̈. Aneura heteroclada (Schffn.).}

Syn. : Riccardia heteroclada Schffn, Kais. Ak. Wien. LXVII, p. 17 .

— Riccardia serrulata Schffn.. ibid., p. 174.

Dioica, major, robusta, dilute olivacea, arcte repens. Frons ad 5 cm. longa, crassa, rigida, superne bipinnata, inferne quadripinnata. Truncus olivaceus, ad $2 \mathrm{~mm}$. latus, acute biconvexus, medio ad 14 cellulas crassus; cellulæ internæ corticalibus multo majores, æquimagnæ, nusquam incras- 
satæ, truncus ceterum angustissime alatus, superne interdum repetito furcatus, alis papulosis vel regulariter denticulatis. Pinnæ approximatæ, alternæ, trunco similes, duplo tamen angustiores et latius alatæ. Pinnulæ primariæ lineares, ad 3 in utroque latere pinnæ, crassæ, alis 3 cellulas latis, basales iteratim bipinnatæe, pinnulis secundariis tenerrimis, longis, late expansis, pro parte trunco incumbentibus, linearibus; costa angustissima, alis valde pellucidis, margine lobatis, crispatis vel spiraliter tortis, folia fingentibus; cellulæ alarum $37 \times 74 \mu$, marginales breviores, papulosæ integerrimæ. Rami feminei in axilla anteriore pinnarum basique pinnæ inserti, ex angusta basi communi trifidi, lobis divergentibus, late alatis, alis erectis usque ad costam laceratis. Calyptra lacinulis patulis hirta, alte mamillata. Rami masculi solitarii vel geminati, ad basin pinnarum pellucidarum, curvati, alis latis crenato-dentatis. Antheridia ad 12 juga.

Hab. Java, Sumatra, 1200-2500 m. (Schiffner), Penang (Herb. Mitten),

Einen spezifischen Unterschied zwischen A.heteroclada und A. serrulata habe ich nirgends finden können.

\section{Plantæ mediocres.}

66. Aneura alata St. n. sp.

Dioica, minor, humilis, flavicans, dense depresso cæspitosa. Frons ad $2 \mathrm{~cm}$. longa, bipinnata (in plantis magis robustis hic illic tripinnata). Truncus validus, rigidus, basi fuscus, in sectione acute biconvexus, 10 cellulas crassus, usque ad basin anguste alatus. Pinnæ suboppositæ, remotiusculæ, parum oblique vel subrecte patulæ, parum devexæ, $3 \mathrm{~mm}$. longæ, ambitu oblongo-deltoideæ, alatæ. Pinnulæ approximatæ, latæ, trunco parum angustiores, versus apicem distincte angustatæ, integerrimæ, costa angustissima, alis latissimis, valde pellucidıs, ad 7 cellulas latis; cellulæ alarum $37 \times 46 \mu$, ad costam parum majores, parietibus validis, trigonis minus distinctis. Rami feminei oppositi, breves, margine foliacei, ut squama dorsalis profunde lacerati; calyptra cellulis grosse papulosis maxime hirta, mamilla parva. Rami masculi in pinnis laterales ibidemque regulariler pinnatim consecutivi, curvatim occulti, breves, alis planis latis papulosis. Antheridia ad 10 juga.

Hab. Brasilia, Apiahy (Puiggari).

67. Aneura planifrons Spruce. Linn. Soc. XXX, p. 368.

Dioica, minor, pallide-virens, matrici appressa, vel procumbens, tenera et flaceida. Frons ad $3 \mathrm{~cm}$. longa, vage multiramosa, ramis trunco parum 
angustioribus, tam trunco quam pinnis prælate costatis, costa 2 vel 3 cellulas tantum crassa, limbo angusto unistrato, 3-4 cellulas lato, integerrimo, cellulis magnis $(8 \Xi \mu)$ formato. Cellulæ haud incrassatæ, ad costam majores, ipso margine minores. Rami feminei breves, margine laciniati (ipse haud vidi). Reliqua desunt.

Hab. Insula $S^{t}$ Vincent, in monte $S^{t}$ Andreas ad Musarum vaginas marcescentes. Insula Dominica (Elliott).

\section{Aneura limbata St. Hedw. 1891, p. 203.}

Dioica, mediocris, flavicans vel rufescens, flaccida, supra muscos putridos expansa, basi solum radicans, superne procumbens denseque stratificata. Frons ad $2 \mathrm{~cm}$. longa, bipinnata. Truncus late linearis, repetito furcatus, tenuis, 4 cellulas crassus, quarum intimæ multo majores, anguste alatus; alæ 4-气̆ cellulas latæ, quam costa triplo angustiores, tenerrimæ, integræ cellulis æquimagnis $(40 \mu)$ formatæ. Pinnæ (in planta sterili) approximatæ, longæ, alternantes, sæpe simplices, apice hic illic paucis pinnulis instructæ, in planta $q$ ramis floriferis interjectis minus regulariter et brevius pinnulatæ, costa ubique latissima 3 cellulas crassa, alis ut in trunco. Rami feminei sparsi, brevissimi, subplani, vel decurvi, late marginati, limbo tenerrimo profunde inciso et crispato, ut squama dorsalis cellulis papulosis vel clavatis armato. Calyptra (juvenilis) cellulis magnis patulis hirta, apice grosse mamillata.

Hab. Kamerun (Dusén).

\section{Aneura longispica St. Hedwigia 1892, p. 199.}

Dioica, mediocris, tenera, flaccida, fusco-olivacea, dense depresso expansa. Frons ad $2 \mathrm{~cm}$. longa, bipinnata, anguste limbata, parum stolonifera. Truncus ad $1 \mathrm{~mm}$. latus, plano-biconvexus, medio 6 celIulas crassus, limbo unistrato 2 cellulas lato. Pinnæ parum angustiores, unilaterales, longe ligulatæ, simplices vel fureatæ vel breviter pinnulatæ, pinnulis medio 4 cellulas crassis, cellulæ internæ majores. Rami feminei in trunco solitarii, brevissimi, margine breviter lacinulati, calyptra parva, clavata, sublævis, mamilla parva disciformis. Rami masculi regulariter pinnatim consecutivi, simplices vel furcatim geminati, sæpe longissimi, attenuati. Antheridia ad 20 juga.

Hab. Mascareignes (Boivin, de l'Isle, Rodriguez), Comores (Humblot), Madagascar (Perrot), Kamerun (Dinklage). 
70. Aneura nudiflora St. Hedwigia 1892, p. 199.

Dioica, mediocris, rigida, olivacea, dense depresso cæspitosa. Frons ad $10 \mathrm{~mm}$. longa, procumbens, stolonifera, pinnata, anguste alata. Truncus basi furcatus, plano biconvexus, medio 4 cellulas crassus, cellulis internis parum majoribus, limbo 2-3 cellulas lato, acuto. Pinnæ suboppositæ, remotiusculæ, lanceolatæ, trunco æquicrassæ, parum angustiores. Rami feminei in trunco solitarii, disciformes, decurvi, alis tenerrimis, late explanatis profundeque laceratis; pistilla longe seriata; calyptra ignota. Rami masculi minimi, anguste lineares, margine erecto subintegro. Antheridia ad 6 juga.

Hab. Insula Maurice (Robillard), Madagascar (Perrot).

\section{Aneura reticulata St. Hedwigia 1891, p. 204.}

Dioica, mediocris, pallide-olivacea, dense stratificata. Frons ad $3 \mathrm{~cm}$. longa, pinnata et bipinnata, procumbens, stolonibus affixa. Truncus planobiconvexus, medio 8 cellulas crassus; cellulæ internæ corticalibus multoties majores, perlucentes, fronde itaque optime grosseque reticulata, cellulis marginalibus minimis distincte et abrupte limbata. Pinnæ trunco æquilatæ medio 4 cellulas crassæ plus minus longæ, alternæ, sæpe unilaterales, altero latere stolonibus compensatæ, rare oppositæ, similiter limbatæ. Rami feminei majusculi, valde concavi, margine late et tenerrime alati, alæ adscendentes, lobatæ, cellulis digitiformibus profunde crenatæ. Pistilla trijuga, squamulis transversis interjugalibus protecta; calyptra magna, clavata, cellulis utriculatis hirta, mamilla magna, alta, similibus cellulis confertis et parum divergentibus formata. Rami masculi longissimi, angustissimi, stricti, margine cellulis papulosis grosse limbati. Antheridia ad 25 juga.

Hab. Africa occid. tropica, Insula San Thomè (Quintas), Kamerun (Dusén, Staudt), Loango (Micholitz).

\section{- 72. Aneura fastigiata (L. et L.) Syn. Hepat. p. 500.}

Syn. : Jıngermannia fastigiata L. et L. Linnæa. IV, p. 370.

Dioica, mediocris, flaccida, olivacea vel flavo-rufescens, dense depressoexpansa. Frons ad $2 \mathrm{~cm}$. longa, anguste alata, regulariter denseque bipinnata, nusquam fastigiata. Truncus ad $1 \mathrm{~mm}$. latus, plano-biconvexus, medio 5 cellulas crassus; cellulæ internæ corticalibus multo majores, perlucentes; alæ 1-2 cellulas latæ; pinnæ breves lineares confertæ oblique patulæ, trunco duplo angustiores, vix minus crassæ; pinnulæ bijugæ pinnis simillimæ subæquilatæ, breviores, alis 3 cellulas latis; 
cellulæ alarum $57 \mu$, ad costam majores, marginales minores haud papulosæ. Rami feminei breves breviterque lacinulati. Calyptra ignota. Rami masculi anguste lineares, breves, stricti, integerrimi. Antheridia ad quadrijuga.

Hab. Africa australis, Table Mountain (Ecklon, Mac 0wen), Devilspeak. (Ecklon), Boschberg (Nac Owen).

Aneura multifida unterscheidet sich durch dickeren Truncus, schmälere Aeste, die entfernter stehen und durchsichtiger in den Flügeln sind.

\section{Aneura flaccidissima (Schffn.).}

Syn. : Riccardia flaccidissima Schffn. Kais, Ak. Wien 1898. LXVII, p. 167.

Dioica, mediocris flaccida (valde etiolata) viva læte viridis. Frons ad $24 \mathrm{~mm}$. longa, pinnata. Truncus pro more simplex, rarius furcatus, ligulatus, plano biconvexus, medio 4 cellulas crassus, alis unistratis 3-4 cellulas latis; cellulæ alarum $74 \mu$, haud papulosæ, cellulæ costæ elongatæ, internæ multo majores et longiores; pinnæ suboppositæ, breves, remotæ, duplo angustiores, medio 3 cellulas crassæ, similiter alatæ. Rami masculi in trunco solitarii, breves, limbo angusto cellulis magnis inflatis crenulato. Antheridia ad 6 juga.

Hab. Java, in faucibus torrentis Tjiapus (Schiffner).

Die Pflanze ist so etioliert, dass sich ihre normale Form schwerlich wiedererkennen lassen wird.

\section{Aneura Loriana St. n. sp.}

Dioica, mediocris, viridis, tenuis, flaccida, dense depresso cæspitans. Frons ad $15 \mathrm{~mm}$. longa, dense bipinnata. Truncus plano-biconvexus, 6 cellulas crassus, alis $\mathbf{2}$ cellulas latis; frondis cellulæ internæ corticalibus multo majores. Pinnæ oppositæ, confertæ, longiusculæ, oblique porrectæ, trunco fere æquilatæ, biconvexæ, alatæ, alis 3 cellulas latis. Cellulæ marginales minimæ, optime papuloso-prominulæ, cellulæ alarum basales (i. e. costæ contiguæ) marginalibus multoties majores valdeque conspicuæ. Pinnulæ plus minus confertæ, pinnis duplo angustiores, ceterum simillimæ. Rami feminei in trunco solitarii, parvi, margine breviter lacinulati. Calyptra parva, clavata, lavis, mamilla parva, conica, obtusa.

Hab. Nova Guinea, Moresby (Loria).

\section{Aneura Wettsteinii (Schffn.).}

Syn. : Riccardia Wettsteinii Schffn. Kais. Ak. Wien. 1898. LXVII, p. 162. BULL. HERB. BOrss., octobre 1899. 
Dioica, mediocris, viridis, in sicco nigrescens, depresso cæspitosa. Frons ad $2 \mathrm{~cm}$. longa, repens, latiuscula, irregulariter ramosa, ubique anguste alata, ramis primariis bipinnatis, antice plana, postice convexa, versus marginem longe attenuata, medio 12 cellulas crassa, cellulis internis haud latioribus. Pinnæ minus crassæ, parum angustiores, alis magis distinctis, repandis, 2-4 cellulas latis. Cellulæ alarum ad 450 parietibus maxime æqualiterque incrassatis. Rami feminei ad basin ramorum, breves valde concavi, marginibus erectis, tenuibus, crispatis breviter lacinulatis, papulosis, Calyptra cylindrica, lævis, mamilla bene difinita, cellulis confertis papulosis quasi verrucosa. Rami masculi ad basin pinnarum solitarii vel geminati, breves, alis crispatis, interrupte incurvis, papulosis. Anthendia ad 8 juga.

Hab. Java, Sumatra, 670-2890 m. (Schiffner).

\section{Aneura Makinoana St. n. sp.}

Dioica, mediocris, fusco-viridis, flaccida, depresso-cæspitans. Frons ad $10 \mathrm{~mm}$. longa, longe pinnata, ubique late alata. Truncus basi stoloniferus, anguste linearis, plano-biconvexus, medio ă cellulas crassus, cellulis internis multo majoribus. Pinnæ oblique patentes approximatæ, longe lanceolatæ, obtusæ, medio 3 cellulas crassæ; alæ pellucidæ, 3-4 cellulas latæ; cellulæ alarum ad costam $38 \times 76 \mu$ versus marginem sensim minores, ipso margine $27 \mu$, papuloso-prominulæ. Rami feminei majusculi, margine longissime lacinulati. Calyptra parva, grosse cylindrica, superne cellulis magnis patulis vel decurvis hirta, mamilla parva, humilis, cellulis similibus erectis conflata. Androcia desunt.

Hab. Japonia, Tosa, prope Kochi (Makino).

\section{Plantæ parvæ vel exiguæ.}

77. Aneura amazonica Spruce. Edinb. Bot. Soc. 1885, p. 54 כ̆.

Dioica, pusilla, tenuis, flaccida, flavo-virens, inferne rufescens, intricata et stratificata. Frons ad $10 \mathrm{~mm}$. longa, pinnata et bipinnata, late alata. Truncus angustus plano biconvexus medio $4-50$ cellulas crassus, cellulæ internæ corticalibus in sectione vix majores; ala 2-3 cellulas lata, truncus ceterum repetito furcatus, furcis recte divergentibus; pinnæ pinnulæque paucæ remotæ recte patulæ, oppositæ, trunco æquilatæ, juniores apice incisobilobæ, adultæ sæpe attenuatæ radicantes; costa valde conspicua, angusta sub apice evanida, alis 5 cellulas latis; cellulæ alarum $39 \mu$, ad costam majores, marginales minores, papulosæ; cellulæ costæ corticales oblongo- 
hexagonæ. Rami feminei parvi, margine usque ad costam lacinulati, laciniis angustis, ramosis. Calyptra clavato-cylindrica, papulosa, alte mamillata. Rami masculi ad basin pinnarum, limbo incurvo crenato-lobato. Antheridia ad 12 juga.

Hab. America tropica, Amazonas et Rio Negro (Spruce), Rio Grande (Puiggari), Rio Janeiro (Glaziou).

\section{Aneura Stephanii Besch. n. sp.}

Dioica, pusilla, flaccida et tenera, pallide virens, in cortice dense stratificata. Frons ad $5 \mathrm{~mm}$. longa, pinnata vel bipinnata, cellulis internis perlucentibus grosse reticulata. Truncus basi angustatus superne pro plantæ magnitudine latus, medio 3 cellulas crassus; alæ 3 cellulas latæ, cellulis magnis, margine minoribus. Pinnæ longæ, lineares, remotæ divergentes, simplices, interdum furcatæ, in apice frondis pro more approximatæ et flabellatim divergentes, alæ ubique 2 cellulas latæ, cellulis marginalibus majoribus obtusæ. Rami masculi pro planta longissimi, in pinnis ultimis, terminales, interdum $e x$ apice vegetativi et iteratim fertiles, valde numerosi, sæpe omnes ramorum pinnulas occupantes, lineares tenerrimi et maxime fragiles, margine erecto profunde papuloso vel subdenticulato. Antheridia ad 18 juga. Reliqua desunt.

Hab. Africa, Congo, Brazzaville (TholJon).

\section{Aneura tenuicostata (Schffn.).}

Syn. : Riccardia tenuicostata Schffn. Kais. Ak. Wien. LXVII, p. 166. Aneura crenulata Schffn., ibidem, p. 173.

Dioica, parva, dilute viridis, dense depresso expansa. Frons ad $7 \mathrm{~mm}$. longa, vage multiramosa, tenuis. Truncus inferne angustus, superne latior, plano-biconvexus, medio 6 cellulas crassus, apice sæpe dense pinnatus, subpalmatifidus; rami vix angustiores, medio 3 -4 cellulas crassi, limbo in trunco ramisve unistrato ubique 2-4 cellulas lato, margine optime papuloso; costæ cellulæ corticales magnæ $(36 \times 72 \mu)$ internis æquimagnæ, limbi cellulæ minores, marginales $12 \mu$. valde æqualiterque incrassatæ. Rami feminei in trunco et ramis numerosi, brevissimi, valde concavi, fere saccati, marginibus tenuibus, clavatim cellulosis vel sublacinulatis. Calyptra magna, cylindrica, cellulis utriculatis hirta, mamilla similibus cellulis confertis formata. Rami $\delta^{7}$ longissimi, interdum geminati, angusti, substricti, valde canaliculati, limbo angusto crenato.

Hab. Singapore, in monte Bukit Timah, $150 \mathrm{~m}$., Java, $1120-2140 \mathrm{~m}$. (Schiffner, Solms). 
Aneura crenulata (der Name war schon früher benutzt) ist zweifellos identisch mit A. tenuicostata; letzlere ist nur nicht so schön entwickelt, meist steril, ärmlicher und etwas etioliert; doch findet man an den oberen Theilen des Rasens stets Aeste, welche die sehr auffallenden, derben, crenulierten kleinzelligen Ränder zeigen; übrigens zitiert der Autor die A. crenulata auch vom Standort der anderen.

\section{Aneura vitiensis St. Hedwigia 1893, p. 28.}

Dioica, parva, pallide-virens, dense depresso-cæspitosa. Frons ad $3 \mathrm{~cm}$. longa, fasciculatim radicans arcleque repens, anguste alata, valde pellucida, irregulariter multiramosa, ramulis remotis vel magis approximatis, apice sæpe subfasciculatis, linearibus vel apice dilatatis, trunco parum angustioribus. Frons ubique plana, tenuis, medio 3-4 cellulas crassa; cellulæ internæ corticalibus multo majores perlucentes, planta itaque in adspectu laxe reticulata. Rami feminei brevissimi, in trunco solitarii, margine paucis cellulis clavatis armati. Calyptra clavato-pyriformis, lævis, mamilla cellulis magnis clavatis aggregatis, basi liberis formata. $\sigma^{7}$ ignota.

Hab. Viti, Ovalu (Græffe).

\section{B. Rami exalati.}

\section{a. Cuticula armata.}

\section{Aneura scabra (Schffn.).}

Syn. : Riccardia scabra Schffn. Kais. Akad. Wien 1898. LXVII, p. 161.

Dioica, mediocris, depresso-cæspitosa, fusco-viridis, opaca, fere velutina. Frons ad $2 \mathrm{~cm}$. longa, irregulariter ramosa, haud alata, trunco stolonifero, valido, subnigro, in sectione elliptico, medio 8 cellulas crasso, cellulis internis magnis; rami in trunco plus minus remoti, unilaterales, simplices vel irregulariter pinnati, pinnis linearibus, 4 cellulas crassis, obtusis; cellulæ internæ magnæ $(50 \times 108 \mu)$ perlucentes, rami itaque in adspectu optime grosseque reticulati; cuticula aspera, alæ nullæ; cellulæ corticales parvæ, valde æqualiterque incrassatæ, marginales $18 \mu$. Rami feminei breves, margine dense breviterque lacinulati. Calyptra cellulis utriculatis hirta, mamilla crassa. Rami $\delta^{\lambda}$ ad basin ramorum plerumque geminati, angusli, juveniles, valde curvati, marginibus erectis vel conniventibus canaliculati, grosse crenulati. Antheridia ad 8 juga.

Hab. Java, Sumatra, 800-2180 m. (Schiffner). 
- 82. Aneura stolonifera St. Hedwigia 1889. Heft 2.

Syn. : Aneura striolata St. I. Linn. Soc. 1892. Vol. 29. p. 263.

Dioica, major el robusta, olivacea, inferne fusco badia, dense depresso cæspitans vel inter muscos adscendens. Frons crassa, ad $8 \mathrm{~cm}$. longa, maxime ramosa maximeque stolonifera, haud alata, cuticula dense minuteque lamellifera. Truncus primarius ad $1 \mathrm{~mm}$. latus, versus apicem repetito et confertim furcatus, postice planus, antice convexus, medio ad 10 cellulas crassus, marginibus acutis; cellulæ corticales parvæ, internæ versus centrum sensim majores; furcæ pinnatæ ut truncus numerosis stolonibus apice ramosis radicantes. Pinnæ oppositæ longæ, furcis duplo angustiores, remotæ, oblique patentes, in planta muscicola sæpe irregulares et male evolutæ, ceterum plano-biconvexæ, medio ad 6 cellulas crassæ, margine acutæ. Rami feminei in trunco solitarii sæpe geminati, brevissimi, margine breviter inciso, papuloso; squama dorsalis brevis similiter incisa ; calyptra magna, anguste clavata, papulosa, mamilla nulla (vel destructa?). Rami $\widetilde{\gamma}$ in trunco, in ramis et stolonibus solitarii, breves, crassi, margine grosse papuloso. Antheridia ad อ̃ juga.

Hab. Australia, Illawarra (Kirton), Queensland (Walker), N. Zealand (Colenso, Helms, Kirk), Fret. Magellan. (Cunningham), Java (leg ?), Luzon (Semper).

Die $\sigma^{7}$ Pflanze aus Queensland ist wesentlich kürzer und robuster, da sie nicht zwischen Moosen wuchs. Die zentralen Zellen ihrer Frons sind kleiner als an der etwas etiolierten Illawarra Pflanze; da beide die sehr auffallende lamellose Cuticula besitzen, auch sonst sehr ähnlich sind, so ist an ihrer Identität nicht zu zweifein; ich lege besonderen Wert auf die Beobachtung, dass Aneura in der Grösse der internen Fronszellen variieren kann (ganz wie bei Phanerogamen Pflanzen von nassen Standorten). Haben wir also den inneren Bau der Aneura Frons als konstant angesehen, so sind wir durch obige Variation an zweifellos identischen, aber an verschiedenen Standorten gesammelten Pflanzen um ein wertvolles Moment für die Diagnose ärmer und um eine Schwierigkeit reicher.

\section{Aneura tasmanica St. n. sp.}

Dioica, mediocris, olivacea, dense depresso cæspitosa, lateque expansa, corticola vel terricola. Frons ad $10 \mathrm{~mm}$. longa, haud alata, irregulariter multiramosa. Truncus e caudice repente maximeque stolonifero procumbens, basi angustus, superne sensim ampliatus, apice latissimus ( $1 \mathrm{~mm}$. in diametro) sæpe uno latere stoloniferus, altero pinnatus; rami trunco angustiores, valde irregulares, longi et lineares vel breves, ad 
lobulum reducti, sæpe ex apice anguste innovati et magnam frondem similiter irregularem gerentes, ceterum ut truncus plano-biconvexi, medio 8 cellulas crassi ; cellulæ internæ magnæ, corticales multo minores valde chlorophylliferæ, incrassatæ, papillis conico prominulis obtectæ; frons dein ubique creberrime aspera, marginibus minute denticulatis. Rami feminei breves, margine anguste limbati, limbo cellulis digitiformibus profunde crenato. Calyptra gigantea, grosse cylindrica, papulosa, mamilla subnulla. Rami masculi in trunco ramisve numerosi, sæpe geminati, crassi, valde canaliculati, limbo angusto crenulato, antheridiis ad 6 jugis, magnis.

Hab. Tasmania, Hobarttown, Mt Wellington (Weymouth).

\section{Aneura Colensoi St. I. Linn. Soc. XXIX, p. 264.}

Dioica, major, tenuis, flaccida, terricola vel supra muscos expansa. Frons ad $25 \mathrm{~mm}$. longa, dense breviterque bipinnata, haud alata. Truncus $3 \mathrm{~mm}$. latus, basi stoloniferus plano biconvexus, medio 6 cellulas crassus, cellulæ corticales multo minores, papillis anguste conicis recteque patulis longe et densissime hirtæ. Pinnæ plus minus confertæ, interdum contiguæ, breviter lineares vel lobuliformes, trunco multoties angustiores, pinnulis minutis dentiformibus. Rami feminei in trunco oppositi, breves, crassi, geminati vel terni, margine posticeque ciliis brevibus confertissimis hirti. Reliqua desunt.

Hab. New Zealand (Colenso, Beckett).

\section{Aneura spinulifera (Mass.).}

Syn. : Riccardia spinulifera Mass. Diar. bot. 1885, p. 254.

Spinella magellanica Schffn. Exp. Gazelle 1889, p. 42.

Monoica, minor, gracilis, Lepidoziis simillima, pallide virens, aliis hepaticis consociata, erecta. Frons ad $10 \mathrm{~mm}$. longa, tripinnata, haud alata, ubique squamulis oblique patulis foliiformibus obtecta; squamx antice posticeque cellulis conicis armatæ, margine longe interdum pinnatim spinosi; frondis cuticula intersquamalis dense paraphyllifera, paraphyllis vel spiniformibus vel pluricellularibus, plus minus latis et spinulosis. Truncus simplex vel furcatus, in sectione plano-ellipticus, medio 8 cellulas crassus, cellulis internis parvis haud incrassatis; pinnæ remotiusculæ, supoppositæ, fere recte patentes, pro planta longæ, versus apicem frondis sensim minores, trunco parum angustiores, pinnulæ breves, remotæ, anguste lineares, in sectione biconvexæ. Rami feminei in trunco solitarii, brevissimi, margine longe lobati, lobis foliaceis bipin- 
natim spinosis. Calyptra clavata, alte papulosa, mamilla parva. Rami masculi in pinnis solitarii, crassi, hispidissimi, ambitu ovales, marginibus erectis. Antheridia quadrijuga.

Hab. Fuegia, Basket Island (Spegazzini), Insula Desolacion (Savatier).

\section{b. Cuticula lævis.}

\section{Plantæ biconvexæ.}

๔. Monoicæ.

\section{Aneura portoričnsis St. n. sp.}

Monoica, mediocris, fusco-olivacea, laxe caspitans. Frons ad $15 \mathrm{~mm}$. longa, bipinnata, haud alata. Truncus plano-biconvexus, medio ã cellulas crassus, cellulis internis multo majoribus perlucentibus, uno latere stoloniferus, altero apiceque regulariter pinnatus vel bipinnatus; pinnæ breves, trunco parum angustiores et vix minus crassæ, simplices vel furcatæ, late lineares. Rami feminei breves, margine breviter piliferi, solitarii vel uno vel utroque latere ramulo masculo perbrevi suffulti. Antheridia quadrijuga. Calyptra ignota.

Hab. Puertorico (Schwanecke).

\section{Aneura platyclada (Schfin.).}

Syn. : Riccardia platyclada Schffn. Kais. Ak. Wien. 1898. LXVII, p. 167.

Polyoica, mediocris, humilis, pallide viridis, laxe cæspitosa. Frons ad $14 \mathrm{~mm}$. longa, haud alata, trunco stolonifero procumbente, uno latere pinnato, acute plano-biconvexo, medio 8 cellulas crasso; cellulæ internæ corticalibus multo majores. Pinnæ confertæ, simplices vel furcatæ, lanceolatæ, planæ, normaliter 3 cellulas - medio 4 cellulas - crassæ interdum in pinnulis junioribus limbo unistrato instructa. Rami femine breves, margine breviter lacinulati; calyptra magna, pinnis subæquilonga, lævis, mamilla angusta longe producta, cellulis utriculatis aggregatis vel effusis formata. Rami masculi solitarii, breves, plani, crenulati, antheridiis ad 6 jugis, interdum apice femineis.

Hab. Java, Sumatra 230-1860 m. (Schiffner).

\section{Aneura singapurensis (Schffn.).}

Syn. : Riccardia singapurensis Schffn. Kais, Akad. Wien. 1898, LXVII, p. 165.

Monoica hypogyna, mediocris, pallide virens, dense stratificata. Frons 
ad $2 \mathrm{~cm}$. longa, bipinnata, haud alata. Truncus simplex vel furcatus, latus, postice planus, antice leniter convexus, medio 6 cellulas crassus, margine acutus integerrimus. Pinnæ oppositæ, confertæ, patulæ, imbricatæ, trunco parum angustiores, medio 4 cellulas crassæ. Pinnulæ paucæ, breves, remotæ, pinnis simillimæ, medio 3 cellulas crassæ. Rami sexuales in trunco laterales, breves, basi masculi, antheridiis $3-4$ jugis, magnis, apice feminei margineque breviter paucilaciniati. Calyptra?

Hab. Singapore in Monte Bukit Timah (Schiffner).

89. Aneura nitida Col. Trans. N. Zeal. Inst. 1883̈. XVIII.

Autoica, mediocris, crassa, rigida, pallide flavo-virens, in cortice arcte repens. Frons ad $2 \mathrm{~cm}$. longa, bipinnata, haud alata. Truncus plus $1 \mathrm{~mm}$. latus, plano-biconvexus, medio 8 cellulas crassus, margine obtusus, cellulis internis majoribus, simplex et longe prorepens vel repetito furcatus et flabellam oblongam formans. Pinnæ confertæ, interdum unilaterales, in apice frondis oppositæ, brevissimæ, pinnulis aggregatis divergentibus subpalmatifidæ; pinnulæ trunco sextuplo angustiores, lineares, medio 5 cellulas crassæ, margine obtusæ. Rami feminei in trunco pinnisque laterales, hrevissimi, cupuliformes, margine breviter lacinulati; calyptra parva, clavata, celluloso-verrucosa, mamilla parva late conica, obtusa. Rami masculi e latere rami $q$ orti, brevissimi, valde canaliculati, acuminati, decurvi, papulosi. Antheridia 3-4 juga.

Hab. New-Zealand (Colenso).

Cum Aneura papulosa comparanda.

\section{Aneura æquitexta St. I. Linn. Soc. XXIX, p. 263.}

Monoica, mediocris, valida, flavo-virens, in ligno decorticato arete repens. Frons ad $2 \mathrm{~cm}$. longa, ubique valde stolonifera, bipinnata, haud alata. Truncus plano-biconvexus, inferne 8 cellulas crassus, cellulis internis haud majoribus, margine obtuso, superne acuto, ceterum furcatus, furcis in planta bene evoluta regulariter pinnatus. Pinnæ alternantes vel suboppositæ, trunco parum angustiores, medio 6 cellulas crassæ, oblongæ, obtusæ hic illic atlenuatæ radicantes et in novam frondem bipinnatam abeuntes. Pinnulæ breves oblongæ, apice obtusæ, juniores apice breviter inciso bilobæ, medio 4 cellulas crassæ. Rami feminei ad basin pinnarum vel in ipso trunco solitarii, breves breviterque lacinulati; calyptra magna, clavata, superne cellulis utriculatis longe recteque patulis hirta, mamilla angusta longe producta cylindrica, truncata. 
Rami masculi femineis oppositi, sæpe in stolonibus laterales, breves subcylindrici, margine papulosi. Antheridia 4 juga.

Hab. New Zealand (Colenso, Knight).

\section{Aneura papulosa St. Hedwigia 1893, p. 25.}

Monoica, minor, fusco-rufa, apice viridis, in ligno decorticato arete repens. Frons ad $10 \mathrm{~mm}$. longa, quadripinnata, haud alata. Truncus latus repetito furcatus, ad instar Ricciarum stellatim expansus, basi 12 cellulassuperne है cellulas crassus, antice canaliculatus, postice alte convexus, margine abrupte acutus. Pinnæ trunco simillimæ, latæ oppositæ, parum divergentes, tripinnatæ, pinnulæ angustissimæ, subrecte patentes, lineares, 6-7 cellulas latæ, 4 cellulas crassæ, postice valde convexæ, antice planæ, cellulis corticalibus anticis optime papulosis. Rami feminei brevissimi, margine paucilacinulati; calyptra parva, vix $2 \mathrm{~mm}$. longa, cylindrica, papuloso-verrucosa, mamilla magna papulosa. Rami masculi magni, valde decurvi, canaliculati, margine grosse papulosi. Antheridia 15 juga.

Hab, New Zealand (Colenso).

Der Unterschied zwischen den Fiederästen erster und zweiter Ordnung ist so gross, dass man beim ersten Anblick glaubt, zwei verschiedene in einem Rasen durcheinander gewachsene Arten zu sehen.

92. Aneura inconspicua St. Hedwigia 1893, p. 23.

Monoica, exigua, tenerrima, dilute olivacea, densissime cæspitans, in ligno decorticato late expansa. Frons $1 \mathrm{~mm}$. Ionga, haud alata e caudice repente erecta, pauciramosa, ramis trunco æquilatis, medio 2 cellulas crassis, linearibus, כ̃-6 cellulas latis, fere hyalinis, integerrimis. Rami feminei ad basin ramorum, pro planta magni, hamatim decurvi, margine densissime longeque lacinulati, laciniis incurvis. Rami masculi longissimi, interdum plantæ longitudinem superantes, erecti, lineares, margine cellulis papulosis incurvis crenati. Antheridia ad 12 juga.

Hab. Kamerun (Dusén, Jungner).

93. Aneura perpusilla Col. New Zeal. Inst. 1889. V, p. 22.

Syn. : Zoopsis lobulata Col. Trans. N. Zeal. Inst. 1885.

Monoica, pusilla, dilute virens, terricola vel corticola, dense depresso caspitans. Frons ad $2 \mathrm{~mm}$. Ionga, haud alata, e caudice repente procumbens, a basi fasciculatim ramosa; truncus communis brevis, subteres, cellulis ubique æquimagnis formatus; rami repetito furcati, æquilongi, postice plani, antice convexi, medio ä cellulas crassi, cellulis corticalibus 
haud minoribus, papulosis, marginibus acutis decurvis. Rami feminei breves, margine profunde laciniati, laciniis lanceolatis margine celluloso dissectis. Calyptra cylindrica pro planta maxima, lævissima, mamilla rotundata, parva, papulosa. Rami masculi in trunco sæpe furcatimgeminati, femineis approximati, breves, stricti, margine papulosi. Antheridia parva, こ̌ juga.

Hab. New Zealand (Colenso), Tarawera (Lauterbach).

\section{ß. DIOIC.E.}

1. Plantæ elatæ, ramis gracillimis.

94. Aneura cataractarum Spruce. Soc. bot. d. France. 1889. p. 195.

Dioica, mediocris, crassa, fragilis, albicans vel plus minus viridis, in saxis rivulorum cæspitans et humilis vel fluitans elongataque. Frons 1-4 cm. longa, plus minus regulariter pinnata et bipinnata, haud alata. Truncus anguste linearis, biconvexus, medio 6 cellulas crassus, cellulæ internæ corticalibus multo majores, optimeque perlucentes. Pinnæ suboppositæ, basi sæpe angustiores, breves trunco simillimæ sed angustiores, simplices vel paucis pinnulis minutis instructæ. Rami feminei in trunco solitarii decurvi, disciformes, margine tenui varie lobatim inciso. Calyptra magna cylindrica papulosa. Rami feminei in pinnis solitarii, lineares, recte patuli, stricti, margine papulosi. Antheridia ad 12 juga.

Hab. Paraguay (Balansa), Brasilia subtropica (Ule), Dominica (Elliott).

\section{Aneura corralensis St. n. sp.}

Dioica, mediocris, gracilis, rigida, pallide-virens, dense cæspitosa, procumbens vel erecta, Frons ad $25 \mathrm{~mm}$. longa, regulariter bipinnata, haud alata. Truncus angustus (ad $0,30 \mathrm{~mm}$. in diametro), simplex vel furcatus, biconvexus, medio 10 cellulas crassus, margine acutus; cellulæ internæ corticalibus majores. Pinnæx angustiores, suboppositæ vel alternantes, patulæ, 2-3 mm. longæ, remotiusculæ, decurvæ, acuminatæ, paucis pinnulis similibus et angustioribus instructæ; pinnæ pinnulæque biconvexæ ultimæ medio 4 cellulas crassæ, margine acutæ; costa sub apice evanida. Rami feminei in trunco oppositi, brevissimi, margine tenero breviter lacinulato. Calyptra cylindrica, crassa, glaberrima, apice rotundata, mamilla nulla. Rami masculi in trunco laterales, magni, ambitu late oblongo, canaliculati margine tenero, magnis cellulis alte papuloso. Antheridia magna ad 6 juga.

Hab. Chile, Corral (Dusẻn). 
96. Aneura micropinna St. Hedwigia 1893, p. 24.

Dioica, magna, olivacea vel brunnea, profunde cæspitosa. Frons ad $6 \mathrm{~cm}$. longa, rigida, gracillime tri-vel quadripinnata, haud alata, cellulis internis multo majoribus. Truncus inferne subteres valde stoloniferus, superne ad $2 \mathrm{~mm}$. latus, plano-biconvexus, medio 12 cellulas crassus, margine acutus. Pinnæ oblique patulæ, suboppositæ, interdum fere alternantes, ambitu late triangulares, approximatæ, haud imbricatæ, trunco multoties angustiores, longe acuminatæ, medio 8 cellulas crassæ. Pinnulæ basales longæ, validæ, superne breviores angustissimæ fere filiformes, acuminatæ, juniores lineares obtusæ, anguste limbatæ, limbo 2 cellulas lato, quarum marginales multo minores. Rami feminei in trunco oppositi, ex axilla pinnarum orti, crassi, brevissimi, margine breviter lacinulati;

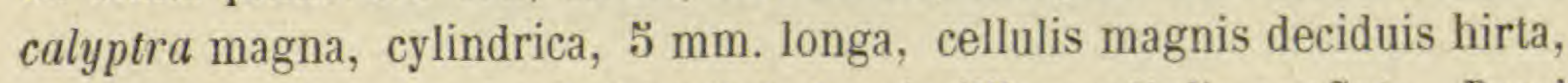
mamilla maxima, profunde bi-trilobata, similibus cellulis conflata. Rami masculi in pinnis primariis propriis aggregati, tolam pinnam occupantes regulariterque consecutivi, canaliculati, oppositi, parum divergentes, ambitu lanceolati, anguste limbati, irregulariter papulosi. Antheridia ad 6 juga.

Hab. New Zealand (Helms, Knight, Kirk, Petrie, Cheeseman, Raoul, Beckett).

97. Aneura pauciramea St. Bull. Herb. Boissier. 1897, p. 84 כั. Sterilis, gracilis, major, fusco-viridis, dense profundeque pulvinatim cæspitosa. Frons ad $6 \mathrm{~cm}$. longa, tenera, flaccida, tripinnata, haud alata. Truncus simplex, interdum furcatus, basi solum radicans, furcis longis, plano-biconvexis, medio ad $\mathbf{1 0}$ cellulas crassis; cellulæ internæ corticalibus multoties majores, perlucentes, planta itaque optime reticulata. Pinnæ remotæ, breves, כั mm. longæ, angustæ, 6 cellulas crassæ, ambitu late ovatæ, dense bipinnatæ, pinnulis 4 cellulas crassis, decurvo hamatis.

Hab. Hawai (Baldwin).

\section{Aneura Baldwini St. nom, nov.}

Syn. : Aneura tamarisci St. Bull. Herb. Boissier 1897, p. 841.

Dioica, mediocris, gracilis, dense depresso cæspitosa, in sicco fere nigra. Frons ad $2.0 \mathrm{~mm}$. longa, regulariter denseque bipinnata. Truncus ex angusta basi latus, medio 6 cellulas crassus, haud alatus, plano biconvexus. Pinnæ confertæ, oppositæ, oblique patulæ, longæ, versus apicem frondis sensim breviores, optime attenuatæ; pinnulæ similes, breviores et angustiores, valde regulariter dispositæ, omnes exalatæ. Ramuli feminei 
in trunco solitarii, brevissimi, margine breviter lacinulati, calyptra longissima, optime clavata, ubique laciniis brevibus crispulis patulisque creberrime hirta. Mamilla apicalis magna, flabellatim dilatata. Rami masculi in pinnis laterales, opposili, regulariter pinnatim consecutivi, breves, patuli strictique, lineares, alis angustis papulosis. Antheridia ad 7 juga.

Hab. Hawai (Baldwin).

Diese Pflanze wurde irrtümlich A. tamarisci genannt, obwohl ein sehr ähnlicher Name, A.tamariscina, bereits für eine andere Art benutzt worden war, so dass eine Abänderung eintreten musste.

\section{Plantæ spectabiles, robustæ, coriaceæ.}

99. Aneura dilatata Spruce. I. Linn. Soc. XXX, p. 368.

Dioica, spectabilis, flaccida, olivacea, laxe cæspitans. Frons ad $4 \mathrm{~cm}$. longa, regulariter pinnata et bipinnata, haud alata, cellulis hyalinis uniseriatis limbata, basi valde stolonifera, ambitu deltoideo-oblonga. Truncus $1 \mathrm{~mm}$. latus, postice planus, antice convexus, medio 8 cellulas crassus, cellulis internis majoribus, margine obtuso. Pinnæ trunco fere æquilatæ, medio 6 cellulas crassæ, inferiores curvatim-patulæ, $7 \mathrm{~mm}$. longæ, apice furcatæ vel paucipinnatæ, superiores sensim breviores, simplices oblique patentes, strictæ et angustiores, medio 4 cellulas crassæ. Rami feminei in stolonibus numerosi, steriles longi, decurvi late ligulati, margine profunde denseque cristato-incisæ; pistilla longe biseriata; calyptra et rami masculi ignoti

Hab. Insula Dominica (Elliott).

100. Aneura comosa St. Hedwigia 1892, p. 199.

Dioica, major, tenuis, flaccida, viridis vel flavo-virens, supra muscos late expansa. Frons ad $7 \mathrm{~cm}$. longa, bipinnata, haud alata, angustissime limbata. Truncus repetito furcatus, $2 \mathrm{~mm}$. latus, plano-biconvexus, medio 6 cellulas crassus, cellulæ internæ corticalibus multo majores, limbo cellulis angustis hyalinis uniseriatis formato. Pinnæ confertæ ad $7 \mathrm{~mm}$. longæ, trunco duplo angustiores, lineares, simplices vel paucis pinnulis brevibus angustisque instructæ. Rami feminei in trunco furcisque laterales simplices vel furcatim-geminati, crassi, ambitu ovati, e facie postica radicantes; antice pilis longis unicellularibus e margine ramorum ortis maxime comosi. Pistilla haud rare triseriata. Reliqua desunt.

Hab. Africa, Insulæ Maurice, Bourbon (Rodriguez, de l'Isle). 


\section{Aneura Lepervanchei St. n. sp.}

Dioica, major, valida, crassa, coriacea, olivacea, ætate rufo-brunnea, depresso cæspitans lateque expansa. Frons ad $4 \mathrm{~cm}$. longa, stolonibus unilateralibus repens, superne tantum regulariter bipinnata, haud alata. Truncus ad $1 \mathrm{~mm}$. latus, biconvexus, medio 8 cellulas crassus, margine acutus; cellulæ internæ majores, parietibus validis. Stolones breves, valde numerosi valdeque ramosi. Pinnæ lineares, approximatæ, irregulares, plus minus longæ, regulariter consecutivæ vel interruptæ, simplices vel furcatæ, trunco angustiores vel subæquilatæ, medio 8 cellulas crassæ. Rami masculi in pinnulis brevibus disciformibus aggregati, terni vel quaterni, e margine disci orti breves, valde curvatim occulti, margine erecto papuloso. Antheridia ad 5ँ juga. Reliqua desunt.

Hab. Réunion (Lepervanche).

\section{Aneura Kowaldiana St. n. Sp.}

Sterilis, major, valde robusta, coriacea, glauco-virens, dense depresso intricata. Frons ad $4 \mathrm{~cm}$. longa, basi stolonifera, recto angulo divergentifurcata, bipinnata, ubique biconvexa medioque 8 cellulas crassa, margine acuta, haud alata. Cellulæ internæ majores, corticales valde incrassatæ. Pinnæ breves, sæpe lobuliformes, aliæ melius evolutæ ad 5 mm. longæ, subrecte patulæ, paucis pinnulis brevibus ramosæ.

Hab. Nova Guinea, Yule Mountains (Kowald).

\section{Aneura pectinata Austin. Torrey B. Cl. V, p. 15.}

Syn. : Aneura hamatiflora St. Bull. Herb. Boiss. 1897, p. 844.

Dioica, major, valida, coriacea, rufo-brunnea, dense stratificata. Frons ad $6 \mathrm{~cm}$. longa, bipinnata, exalata. Truncus semper fere simplex, crassus, alte acuteque biconvexus, medio ad $\mathbf{1 2}$ cellulas crassus, cellulis internis majoribus. Pinnæ confertæ, inferne breves simplices, sæpe in stolones abeuntes, superne multo longiores, regulariter pectinatæ, hamato-decurvæ, in sicco involutæ, optime lanceolatæ, apice sæpe furcatæ, furcis similiter acuminatis, ubique 4 cellulas crassis, in sectione transversa itaque linearibus. Rami feminei in trunco oppositi, breves, crassi, margine breviter alati, alis lobatim incisis; calyptra longe acuminata, subacuta, cellulosoverrucosa, subnigra, mamilla parva papulosa. Rami masculi in trunco ramisve solitarii breves, crassi, stricti, anguste alati, alis tenerrimis explanatis laceratis. Antheridia ad 10 juga.

Hab. Hawai (Baldwin). 
104. Aneura polymorpha Col. Trans. N. Zeal. Inst. 1889. XXII. Syn. : Aneura bipinnatifida. Col. ibidem.

Dioica, major, flaccida, dilute olivacea, dense cæspitosa, terricola. Frons ad $\breve{c m}$. longa, bipinnata, exalata. Truncus $1 \mathrm{~mm}$. latus, tenuis, postice planus, antice convexus, medio 8 cellulas crassus, margine acutus, cellulis internis parum majoribus, medio infero breviter pinnatus, superne optime regulariterque bipinnatus. Pinnæ lineares, confertæ, suboppositæ, ad $10 \mathrm{~mm}$. longæ, versus apicem trunci sensim breviores, trunco parum - angustiores. Pinnulæ pinnis simillimæ, subæquilatæ, breves, lineares, medio כั cellulas crassæ, in planta muscicola minus validæ, sæpe tenerrimæ. Rami feminei ad basin pinnarum oppositi, parvi, brevissimi, valde concavi, margine breviter laciniati, subdentati. Calyptra parva, clavata, cellulis alte papulosis puberula, apice late rotundata, haud mamillata. Rami masculi ad basin pinnarum oppositi vel solitarii, breves, stricti, lineares vel subovati, limbo angusto integro tenerrimo. Antheridia magna, quadrijuga.

Hab. New Zealand (Colenso, Kirk).

\section{Aneura longiflora St. n. sp.}

Dioica, major, flaccida, rufo-brunnea, dense cæspitosa, procumbens. Frons ad $4 \mathrm{~mm}$. longa, $3 \mathrm{~mm}$. lata, haud alata, superne furcata, furcis pinnatim lobulatis. Truncus plano-biconvexus, parum stoloniferus, medio 12 cellulas crassus, cellulis internis majoribus, margine acuto. Pinnæ breves vel brevissimæ, trunco subæquimagnæ, duplo tamen angustiores, oblique patuli, simplices interdum furcatim bifidi, obtusi, juniores apice profunde inciso-bilobi; stolones e basi ramorum orti, ramosi, validissimi. Rami feminei in trunco laterales, breves, crassi, margine grosse profundeque lacerati, postice radicantes, a latere innovati. Calyptra ad $8 \mathrm{~mm}$. longa, cylindrica, cellulis papulosis puberula, mamilla parva alte papulosa. Rami masculi ignoti.

Hab. Tasmania (Weymouth).

\section{Aneura spectabilis St. n. sp.}

Dioica, magna, rigida, procumbens vel inter muscos erecta, superne dilute olivacea, inferne rubescens. Frons ad $5 \mathrm{~cm}$. longa, regulariter bipinnata, haud alata. Truncus validus, $1 \mathrm{~mm}$. latus, plano-biconvexus, medio 12 cellulas crassus, cellulis internis majoribus, margine acutus, exalatus. Pinnæ breves subrecte patulæ, optime acuminatæ, fere pungentes, trunco multo angustiores, superne multo longiores densèque pinnulatæ, 
versus apicem plantæ sensim breviores. Pinnulæ pinnis simillimæ ubique breves decurvæ, acuminatæ, plano-biconvexæ, medio 8 cellulas crassæ. Rami feminei ad basin trunci brevissimi, late inserti marginibus lateralibus late incurvis, margine apicali rotundato, late limbato, limbo tenerrimo profundeque papuloso-crenato. Calyptra juvenilis cellulis inflatis papulosa; mamilla nulla? Rami masculi numerosi in pinnis laterales, breves, sub fronde curvatim occulti, maxime crassi, valde canaliculati, margine erecto tenui, crenulato. Antheridia ad 4 juga.

Hab. Tierra del Fuego et Insula Desolacion (Dusén).

\section{Aneura Spegazziniana (Mass.).}

Syn. : Riccardia Spegazziniana Mass. Diar. bot. 1880̃, p. 254.

Dioica, maxima, maximeque robusta, coriacea, fusco brunnea, in sicco subnigra, inter muscos erecta. Frons ad $13 \mathrm{~cm}$. longa, bipinnata, haud alata. Truncus simplex, interdum furcatus, $3 \mathrm{~mm}$. latus, plano-biconvexus, margine obtusus, medio 12 cellulas crassus, cellulis ubique validis, corticalibus multo minoribus, brunneis maximeque incrassatis. Pinnæ oppositæ, in planta bene evoluta valde regulares, confertæ, oblique patulæ, breves, decurvulæ, e lata basi longe acuminatæ, trunco multo angustiores. Pinnulæ paucæ, breviter acuminatæ vel longiores et spiniformes, medio 6 cellulas crassæ, biconvexæ, margine acutæ. Rami feminei in pinnulis laterales, brevissimi, crassi, valde decurvi, margine apicali tenero alte papuloso.

Hab. Fretum magellanicum et Insulæ adjacentes (Spegazzini, Hahn, Savatier, Hatcher, Dusén).

\section{Aneura Negeri St. n. sp.}

Sterilis, magna, robusta, coriacea, olivacea depresso-cæspitans. Frons ad $7 \mathrm{~cm}$. longa, antice convexa, postice concava, pinnata, exalata. Truncus inferne simplex, superne repetito furcatus, sæpe fasciculatim ramosus, $1 \mathrm{~mm}$. latus, in sectione longe-ellipticus, marginibus itaque rotundatis. Cellulæ internæ frondis corticalibus multo majores. Pinnæ remotiusculæ, inferne breves decurvæ, superne longiores (ad $6 \mathrm{~mm}$. longæ) versus apicem sensim breviores, trunco æquicrassæ, duplo tamen angusliores similiterque convexæ. Reliqua desunt.

Hab. Chile australis (Dr Neger).

Sehr ausgezeichnet durch die überall gleichartig ausgebildete Frons, deren Ränder breit gerundel sind. 
3. Plantæ mediocres.

109. Aneura pinnatifida Dum. Rec. d'observ. 183อ̆, p. 26.

Syn. : Aneura major Lindb. Musci Scand. p. øै.

Dioica, mediocris, viridis, saxicola, in latas plagas expansa, sæpe immersa. Frons ad $2 \mathrm{~cm}$. longa, irregulariter multiramosa, haud alata. Truncus repetito furcatus, furcæ ex angusta basi sensim ampliatæ, obtusæ, bipinnatæ, superne $1 \mathrm{~mm}$. latæ, antice leniter canaliculatæ vel planæ, postice convexæ, medio 6-7 cellulas crassæ, marginibus obtusis; cellulæ corticales internis multo humiliores sed fere æquilatæ. Pinnæ pinnulæque remotæ, furcis parum angustiores, breves, obtusæ, sæpe unilaterales, altero latere trunci rudimentariæ vel in stolones mutatæ. Rami feminei longiusculi, angusti, in trunco laterales, margine foliaceo, integerrimo, profunde papuloso. Calyptra ad $4 \mathrm{~mm}$. longa, clavata, papulosa, mamilla parva. Rami masculi ignoti.

Hab. Europa, America, Asia sept., Japonia (Faurie, Makino, Inoue). Caucasus (Levier). Portugal (Henriques). Madeira (Fritze).

\section{Aneura digitiloba Spr. Soc. bot. France. 1889, p. 201.}

Dioica, pusilla, pallide virens, in solo argilloso densissime depressocæspitans lateque expansa. Frons ad $5 \mathrm{~mm}$. longa, e caudice repente maximeque stolonifero procumbens, pinnata, vel fasciculatim ramosa, haud alata. Truncus biconvexus, medio 6 cellulas crassus, cellulis internis multo majoribus perlucentibus. Pinnæ vix angustiores longe linearidigitiformes, simplices, medio 4 cellulas crassæ. Rami feminei ad basin trunci oppositi, brevissimi, margine breviter lacinulati. Calyptra grosse breviterque cylindrica, squamulis angustis patulis hirta, mamilla parva papulosa. Rami masculi in trunco vel stolonibus solitarii, curvati, cylindrici, margine papulosi. Antheridia ad 8 juga.

Hab. Brasilia, Rio Janeiro (Glaziou), Apiahy (Puiggari), Puertorico (Schwanecke), Dominica (Elliott), Guadeloupe (Funk et Schlim, Lefebvre).

\section{Aneura stipatiflora St. Hedwigia. 1893. p. 26.}

Dioica, mediocris, valida, fusco-brunnea, procumbens el dense stratificata. Frons ad $4 \mathrm{~cm}$. longa, pinnata vel bipinnata, exalata. Truncus $1 \mathrm{~mm}$. latus, furcatus, furcis pinnisque valde stoloniferis, stolonibus sæpe in novam frondem abeuntibus, planta itaque maxime composita, truncus ceterum plano biconvexus, medio 10 cellulas crassus, cellulis internis 
majoribus, margine obtusus. Pinnæ ad $5 \mathrm{~mm}$. longæ, approximatæ, trunco fere æquilatæ, adultæ lanceolatæ, juniores obtusæ, alternantes, interdum furcatæ, ultimæ medio 6 cellulas crassæ, margine obtusæ. Rami feminei in trunco stolonibusque oppositi, quasi stipati (parte basali angusta, longiore) interdum furcati, apice ad discum ovalem dilatati, margine dense longeque ciliati, ciliis diametro disci æquilongis, explanatis, apice incurvis, squama dorsalis foliacea, integerrima, brevis. Reliqua desunt.

Hab. Martinique (Duss, Hahn), Dominica (Elliott).

\section{Aneura conimitra St, n. sp.}

Dioica, minor, flaccida, fusco-viridis, dense depresso-cæspitosa. Frons ad $10 \mathrm{~mm}$. longa, bipinnata, haud alata, limbata, limbo hyalino, cellulam lato valdeque conspicuo. Truncus pro planta latus, in sectione anguste ellipticus, medio 6 cellulas crassus, cellulis tenerrimis, anticis multo minoribus quam posticæ. Pinnæ oppositæ, magnæ, trunco æquilatæ, maxime attenuatæ, biconvexæ, pinnulis longis similibus angustioribus, hamatim decurvis. Rami feminei brevissimi, margine breviter lobulati; calyptra lævis, subcylindrica; mamilla magna, lævis, conico-angustata, obtusa, cellulis magnis connatis radialiter dispositis, superne brevioribus conflata. Rami masculi maximi, late lineares, calyptræ fere æquilongi, margine cellulis magnis hyalinis sublobulati. Antheridia ad 5 juga, magna.

Hab. Chile australis (Dusén).

\section{Aneura floribunda St. n. sp.}

Dioica, mediocris flaccida, superne olivacea, inferne rufo-brunnea, dense pulvinata. Frons erecta, ad $3 \mathrm{~cm}$. longa, tenuis et flaccida, irregulariter pinnata haud alata. Truncus $1 \mathrm{~mm}$. latus, hic illic stoloniferus, plano-biconvexus, spongiosus, cellulis internis maximis perlucentibus, trunco itaque in adspectu grosse reticulato. Pinnæ trunco duplo angustiores, æquicrassæ lineares, valde irregulares, breves vel longæ, regulariter insertæ vel uno latere trunci deficientes. Rami feminei ad basin pinnarum solitarii, breves margine papulosi, calyptra longissima grosse celluloso-verrucosa, mamilla parva. Rami masculi in trunco subsimplici regulariter pinnatim consecutivi, sæpissime furcatim geminati, brevissimi, margine papuloso. Antheridia quinquejuga.

Hab. Fretum magellanicum, communis (Cunningham, Dusén).

114. Aneura marginata Col. Trans, N. Zeal. Inst. 188 Э.

Dioica, minor, valida, rigida, pallide virens, pulvinata. Frons ad $15 \mathrm{~mm}$. BULL. HERB. BoIss., octobre 1899. 259 
longa, erecta, simplex vel furcata, basi valde stolonifera, superne ampliata, apice inciso-biloba, vix unquam ramulnm lateralem edens, haud alata, plano-biconvexa, medio 4 cellulas crassa, cellulis internis multo majoribus bistratis, margine acuta. Rami feminei breves, e basi sæpe stoloniferi, margine paucilobulati. Calyptra parva, clavata, magnis cellulis inflatoclavatis obsita, mamilla magna, similibus cellulis erectis conflata. Rami masculi ad basin frondis numerosi, oppositi, simplices, sæpe geminati, interdum terni, divergentes, breves, decurvi, margine erecto anguste limbato, antheridiis magnis 4-

Hab. New Zealand (Colenso), Australia, Queensland, Daintree River (Pentzke).

\section{Aneura Nadeaudii St. n. sp.}

Dioica, mediocris, tenuis, rigida, fusco-olivacea, dense depresso cæspitosa. Frons ad $2 \mathrm{~cm}$. longa, squarrose bipinnata, hand alata. Truncus anguste linearis, postice planus, antice valde convexus, margine acutus, medio 6 cellulas crassus, cellulis internis quam corticales multo majoribus. Pinnæ unilaterales, altero latere in stolones mutatæ, breves, trunco parum angustiores, subrecte patulæ, apice bifidæ, medio 4-ら̆ cellulas crassæ, ut truncus antice solum convexæ. Rami feminei in trunco oppositi, breves, disciformes, margine maxime longeque lacerati, laciniis confertis, strictis, filiformibus, sæpe ramosis, explanatis. Calyptra ignota. Rami masculi ex apice pinnæ abbreviatæ furcatim geminati, furcis late divergentibus, anguste linearibus, cellulis papulosis limbatis. Antheridia magna ad 9 juga.

\section{Hab. Tahiti (Nadeaud).}

Die Pflanze ist nach einem verdienstvollen Sammler benannt, welcher als Arzt auf Tahiti wirkte und reiche botanische Kollektionen nach Europa geschickt hat.

\section{Aneura latifrondoides (Schffn.).}

Syn. : Riccardia latifrondoides Schffn. Kais. Ak. Wien LXVII, p. 168.

Dioica, mediocris, pallide virens, radicicola. Frons ad $15 \mathrm{~mm}$. longa, pinnata vel vage ramosa, haud alata. Truncus procumbens stolonibus numerosis validis radicans, latus, postice planus, antice convexus, medio 6 cellulas crassus, marginibus ob cellulas marginales maximas obtusis; cellulæ corticales in sectione transversa $40 \mu$, internæ $90 \mu$. Pinnæ fere recte patentes, breves, trunco simillimæ, æquilatæ, sæpe acuminatæ, 4 cellulas crassæ, marginibus obtusis, cellulis internis perlucentibus 
optime grosseque reticulatæ. Rami feminei parvi, in trunco solitarii, margine usque ad costam lacerati, laciniis grosse cellulosis, simplicibus vel ramosis vel apice fasciculatis. Calyptra cylindrica ubique magnis cellulis utriculatis patulis villosa. Rami masculi magni in trunco ramisve sparsi, curvatim patuli, alis angustis papulosis. Antheridia ad 20 juga.

Hab. Singapore in monte Bukit Timah (Schiffner).

\section{Aneura Levieri (Schffn. ms.).}

Syn. : Riccardia Levieri Schffn. ms.

Dioica, mediocris, valida, olivacea, laxe et depresso cæspitans. Frons ad $10 \mathrm{~mm}$. longa, vage ramosa, superne flabellatim bipinnata, haud alata. Truncus fusco-brunneus, alte biconvexus, medio 15 cellulas crassus, cellulis parvis ubique æquimagnis; superne repetito furcatus, furcis brevibus, basi stoloniferis, superne flabellatim bipinnatis, i. e. pinnæ pinnulæque confertæ, æquilatæ et æquilongæ, pro more sub 8 in flabellam planam expansæ, ultimæ medio 6 cellulas crassæ. Rami feminei in trunco solitarii, brevissimi, crassi, margine late foliacei, profunde inciso lobati, lobis varie lacinulatis. Calyptra magna, grosse cylindrica, maxime crassa, apice truncato-rotundata, squamulis foliaceis dense villosa. Rami ơ ignoti.

Hab. Himalaya Bootang. 6000' (Durel).

\section{Aneura singalangana (Schffn.).}

Syn. : Riccardia singalangana Schffn. Kais, Ak. Wien LXVII, p. 174.

Dioica, minor, brunnea, rigidissima, fragilis, humilis, dense fere pulvinatim cæspitans. Frons ad $\check{~} \mathrm{~cm}$. longa, bipinnata. Truncus repetito furcatus, antice planus, postice convexus, medio ad 20 cellulas crassus, haud alatus, margine obtusatus. Pinnæ confertæ oppositæ, trunco simillimæ, parum angustiores. Pinnulæ 1 vel 2, patulæ, rare oppositæ, promore unilaterales, pinnis similes lineares, medio 8 cellulas crassæ, cellulis parvis internis haud majoribus (in frondis parie adulta). Rami feminei in trunco laterales, breves, curvati, margine papulosi vel breviter obtuseque Iacinulati. Calyptra (juvenilis) alte papulosa, mamilla parva rotundatim producta.

Hab. Sumatra, in monte Singalang, $2800 \mathrm{~m}$. (Schiffner).

Sollte diese Pflanze nicht eine Form von Aneura subexalala Schffn. sein?

\section{Aneura subexalata (Schffn.).}

Syn. : Riccardia subexalata Schffn. Kais. Ak. Wien LXVII 1898, p. 163. 
Dioica, valida et robusta, dense stratificata. Frons ad $150 \mathrm{~mm}$. longa, regulariter bipinnata, nusquam alata. Truncus simplex vel furcatus, repens, $1 \mathrm{~mm}$. latus, plano biconvexus, medio 15 cellulas crassus; cellulæ corticales internis subæquimagnæ, parvæ. Pinnæ suboppositæ, remotæ, recte patentes, trunco æquilatæ atque simillimæ. Pinnulæ breves, parum angustiores, lobuliformes medio 8 cellulas crassæ. Rami feminei in trunco laterales, brevissimi, crassi, margine foliacei, irregulariter lobulati, lobis lanceolatis acutis vel ligulatis obtusis. Calyptra cellulis irregulariter prominulis scabra; mamilla parva, conica, obtusa. Rami masculi in pinnis oppositi, sæpe regulariter pinnatim consecutivi, interdum e basi communi geminati, breves, crassi anguste limbati, limbo tenui erecto. Antheridia ad こ̃ juga.

Hab. Java, 1400- $296 \Xi$ m. (Schifinner).

120. Aneura barbiflora St. Mém. Soc. bot. Cherbourg XXIX, p. 209.

Dioica, mediocris, flavo-virens vel rufescens, inter muscos adscendens. Frons ad $3 \mathrm{~cm}$. longa, bipinnata, haud alata. Truncus angustus, planobiconvexus, medio 9 cellulas crassus, simplex vel furcatus; pinnæ breves, remotæ, trunco duplo angustiores, minute pinnulatæ, ultimæ medio 6 cellulas crassæ, cellulis internis haud majoribus. Rami feminei breves, disciformes, margine maxime longeque lacerati. Calyptra pro planta longissima ( $4 \mathrm{~mm}$.) anguste cylindrica, squamulis ciliatis, remotiusculis obtecta, mamilla magna, constricta, disciformis, papulosa. Reliqua desunt.

Hab. China, Yünnan (Delavay).

\section{Plantæ parvæ vel exiguæ.}

121. Aneura gracilis St. n. sp.

Dioica, pusilla, gracilis, viridis, terricola depresso cæspitosa. Frons ad $15 \mathrm{~mm}$. longa, bi-vel tripinnata, haud alata. Truncus superne furcatus angustissime linearis, basi subfiliformis, biconvexus, medio 5 cellulas crassus, margine cellulis minoribus hyalinis papulosis limbatus, reliquæ cellulæ frondis ubique æquimagnæ i. e. corticales haud minores. Pinnæ breves furcatæ vel paucis pinnulis instructæ, hic illic minute bipinnatæ, omnes trunco æquilatæ et similiter limbatæ. Rami masculi in pinnulis terminales, geminati, breves, margine papulosi. Antheridia 4 juga.

Hab. Tasmania, Mt Wellington (Weymouth).

Mit A. minima $\mathrm{C}$. et $\mathrm{P}$. zu vergleichen. 
122. Aneura oppositiflora St. J. Linn. Soc. XXIX, p. 265.

Monoica vel dioica, mediocris, dilute olivacea, dense depresso cæspitosa, corticola. Frons ad $2 \mathrm{~cm}$. longa, in planta bene evoluta regulariter bipinnata, haud alata, basi stolonifera superne procumbens. Truncus simplex vel furcatus, superne $1 \mathrm{~mm}$. latus, plano-biconvexus, medio 8 cellulas crassus, margine acutus, cellulis internis quam corticales majoribus. Pinnæ oppositæ, trunco angustiores, subrecte patulæ, obtusæ, lineares, pinnulæ pinnis multo angustiores, breves, biconvexæ, medio 4-こ̃ cellulas crassæ. Rami feminei in trunco pinnisque oppositi, margine papulosi. Calyptra ignota. Rami masculi in pinnis oppositi, numerosi breves, stricti, ex apice interdum vegetativi, margine tenerrimo crenulato, antheridia ad š juga.

Hab. New Zealand, Colenso.

\section{Aneura metzgeriæformis St. n. sp.}

Dioica? minor, gracillima, flaccida, pallide virens vel albicans, dense depresso caspitosa. Frons angustissima, haud alata, procumbens, ad $15 \mathrm{~mm}$. longa, simpliciter pinnata vel persæpe repetito-furcata, furcis late divergentibus Metzgeriis simillima. Truncus basi stoIoniferus, anguste linearis, biconvexus, medio כั cellulas crassus, cellulis internis magnis, perlucentibus optime reticulata; pinnæ, ubi adsunt, trunco æquicrassæ, parum angustiores, oppositæ. Reliqua desunt.

Hab. Brasilia (Glaziou 45ั66).

124. Aneura palmata (Hedw.) Dum. Comment. p. 115.

Syn. : Jungermannia palmata Hedw. 1790.

Dioica, pusilla, humillima, viridis, in cortice pulvinata vel late expansa, interdum terricola. Frons ad 弓̆ mm. longa, normaliter bipinnata, ramis sterilibus sæpe palmatifidis, haud alata. Truncus stoloniferus, postice planus, antice leniter convexus, medio 7 cellulas crassus, cellulis internis majoribus. Pinnæ erectæ vel procumbentes, trunco æquilatæ, oppositæ, a basi furcatæ, furcis approximatis linearibus æquilongis quasi palmatifidæ, in planta fertili alternantes, regulariter pinnulatæ, pinnulis patulis, apicalibus brevioribus, \& cellulas erassis. Rami q in trunco oppositi vel solitarii, breves, cupuliformes, margine tenui parvilobulato. Calyptra magna, cylindrica, celluloso-verrucosa ; mamilla magna, hemisphærica, papulosa. Rami masculi in trunco pinnisque laterales, numerosi, magni, crassi, ambitu oblongi, haud alati, margine crenulati. Antheridia 8 juga.

Hab. Europa, America, Asia septentr., Japonia. 
125. Aneura parvula (Schffn.).

Syn. : Riccardia parvula Schffn. Kais. Ak. Wien. 1898. LXVII, p. 172.

Dioica, pusilla, dense depresso cæspitosa, dilute viridis, corticola. Frons rigida, ad $5 \mathrm{~mm}$. longa, stolonifera, repens, pinnata et bipinnata. Truncus simplex vel furcatus apice duplo latior quam basi, acute biconvexus, medio 7 cellulas crassus, cellulis internis quam corticales parum majoribus, haud alatus. Pinnæ pinnulæque remotiusculæ, alternæ, plus minus breves, irregulares, trunco duplo angustiores, biconvexæ, medio 4-ə̆ cellulas crassæ, haud alatæ. Rami feminei in trunco solitarii, breves, margine breviter lacinulati. Calyptra cellulis breviter utriculatis patulis hirta, mamilla bene definita, magna, utriculis similibus erectis formata. Rami masculi arcuati, limbo crenulato, antheridiis 8 jugis.

Hab. Java, in monte Pangerango, $2960 \mathrm{~m}$. (Schiffner).

\section{Plantæ filiformes, subteretes vel sectione ovali.}

126. Aneura subsimplex St. Hedwigia 1893, p. 26.

Dioica, parva, gracillima, dilute viridis, dense depresso-cæspitans. Frons ad $8 \mathrm{~mm}$. longa, longe et simpliciler pinnata, rarissime ramulo accessorio bipinnata, haud alata. Truncus procumbens, valde angustus, ubique $\check{5}$ cellulas crassus, margine obtusus, cellulis internis quam corticales multo majoribus, uno latere regulariter stoloniferus, altero longe ramosus; rami recte patuli, trunco parum angustiores, 4 cellulas crassi, longe lineares, apice obtusæ, ramulis masculis oppositis pinnati. Rami masculi longiusculi, recte patuli, stricti, anguste lineares, limbo hyalino crenulato. Antheridiis ad 12 jugis.

Hab. Cuba (Wright).

Optime distincta frondis conformatione simplici et absentia pinnularum.

127. Aneura alcicornis (Tayl.) H. et T. Syn. Hep. p. 499.

Syn. : Jungermannia alcicornis Tayl. J. of Bot. 1844. p. 479.

Dioica, minor, rigida, gracillima, fusco-brunnea, laxe cæspitosa. Frons ad $10 \mathrm{~mm}$. longa, erecta, multiramosa, filiformis, haud alata. Truncus basi solum stoloniferus, repetito furcatus, superne sensim dilatatus, teres, furcis regulariter bipinnatis; pinnæ confertæ oblique patulæ, in sectione elliptic $\mathfrak{x}$ pauci-breviterque pinnulatæ. Rami feminei in furcis laterales, brevissimi, margine paucilobulati, calyptra vix millimetrum longa, sub- 
cylindrica, tuberculata, apice rotundata, mamilla nulla. Rami masculi in pinnulis laterales, lineares, margine papulosi. Antheridia ad 4 juga.

Hab. Fretum magellanicum (Hooker), Fuegia (Spegazzini, Savatier).

\section{Aneura tenax St. n. sp.}

Dioica, tenax, mediocris, dilute olivacea vel rufescens, dense depresso cæspitosa vel pulvinatim erecta. Frons ad $20 \mathrm{~mm}$. longa, bipinnata. Truncus fuscus, durus, in sectione ellipticus, medio 9 cellulas crassus, cellulis internis multo longioribus, uno latere pinnatus, altero stoloniferus. Pinnæ pinnulæque remotiusculæ, trunco simillimæ sed angustiores, strictæ et rigidæ, trunco vix minus crassæ, alte biconvexæ, margine $o b$ tusæ, limbo unicellulari in ultimis pinnulis solum distincto. Rami feminei in trunco solitarii, breves, margine breviter lacinulati. Calyptra cylindrica, papulosa, mamilla parva obtusa. Rami masculi in trunco vel ramis vel stolonibus solitarii, pro planta magni, trunco æquilati, oblongi, interdum regulariter pinnalim dispositi, valde canaliculati, apice profunde bilobi, marginibus erectis foliaceis papuloso-crenatis. Antheridia ad ร̈ juga.

Hab. Fretum magellanicum (Cunningham, Dusén), Insula Desolacion (Dusén).

129. Aneura compacta St. Hed wigia. 1893, p. 19.

Dioica, minor, rigida, gracillima, dura, fusco-rufa, dense depressocæspitosa vel compacte pulvinata. Frons ad $10 \mathrm{~mm}$. longa, tenuis fere filiformis, haud alata, repetito furcata, furcis longis, in sectione ellipticis, medio 8 cellulas crassis, pinnæ vix aliter conformatæ suboppositæ, longe lineares, basales sæpe descendentes et stoloniformes, radicantes. Cellulæ corticales valde incrassatæ internæ corticalibus vix majores. Rami masculi in pinnis superioribus laterales oblongi, recurvuli, margine papulosi. Antheridia ad 6 juga.

Hab. Africa austr. Cap. bon. spei (Exped. Novara leg. Jelinek).

130. Aneura attenuata St. Bull. Herb. Boiss. 1897, p. 844 .

Dioica, major, rigida, glauco-virens, ætate rufescens, dense depresso cæspitans. Frons ad $3 \mathrm{~cm}$. longa, bipinnata, haud alata. Truncus e caudice repente simplex, rare furcatus, anguste linearis, biconvexus, medio 10 cellulas crassus, margine obtusus, cellulis internis vix majoribus, inferne irregulariter pinnatus, pinnis unilateralibus, altero latere stoloniferus, superne utroque latere regulariter bipinnatus, pinnæ ad $7 \mathrm{~mm}$. longæ, longe attenuatæ, hamato-decurvæ, paucis pinnulis similibus ins- 
tructæ, ultimæ in sectione ellipticæ, 4 cellulas crassæ, quarum corticales optime papulosæ. Rami feminei magni, disciformes subplani, margine longe angusteque lacerati. Reliqua desunt.

Hab. Hawai (Heller).

\section{— 131. Aneura diminuta (Schffn.).}

Syn. : Riccardia diminuta Schffn. Kais. Ak. Wien. 1898. LXVII, p. 170.

Dioica, mediocris, rigida, læte viridis, in sicco fusca, dense depresso cæspitans. Frons ad $\mathbf{1 5} \mathrm{mm}$. longa, bipinnata, caudice altero latere stolonibus repente, altero ramifero, in sectione plano-ovali, 8 cellulas crasso. Truncus procumbens, caudice vix minus crassus, haud alatus, plano biconvexus, marginibus obtusis; pinnæ oppositæ, remotæ, trunco æquilatæ eoque fere parallelæ, deinde imbricatæ, כ̋ cellulas crassæ, margine obtusæx, lineares. Pinnulæ pinnis simillimæ ubique 3 cellulas crassæ, ala unistrata nulla; cellulæ corticales ubique parvæ, teneræ, internæ multo majores et longiores, valde æqualiterque incrassatæ. Rami masculi breves, ad basin pinnarum oppositi, curvatim occulti, limbo crenulato. Antheridia ad 10 juga. Rami feminei breves, cupuliformes, margine lacinulati; calyptra lævis, mamilla alta.

Hab. Java, Sumatra, 800-3כ00 m. (Schiffner).

Plantam $ᄋ$ haud vidi.

\section{Aneura sumatrana (Schffn.).}

Syn. : Riccardia sumatrana Schffn. Kais. Ak. Wien. 1898. LXVII, p. 173.

Dioica, exigua, in sicco fusco-brunnea, fere nigra, dense pulvinata. Frons ad $7 \mathrm{~mm}$. longa, tenuissima, filiformis, crassa et rigida, haud alata, pinnata, ubique æquilata, in sectione elliptica, medio 4 cellulas crassa, cellulis internis haud latioribus; pinnæ remotiusculæ, sat regulares, pro planta longæ, sæpe subrecte patulæ. Rami feminei parvi, in trunco solitarii, margine paucis laciniis armati; calyptra cellulis brevibus grosse papulosis aspera, mamilla angusta, alte papulosa. Rami masculi in trunco solitarii, breves, curvati, marginibus erectis papulosis. Antheridia ad trijuga.

Hab. Sumatra, in cacumine montis Singalang, corticola $2800 \mathrm{~m}$. (Schiffner).

\section{Aneura calcarea St. n. sp.}

Diese kleine Pflanze wurde von Gœebel bei Tovar (Venezuela) gesammelt und von Ruge (Flora 1893, Heft IV, p. 33) wegen ihrer Keim- 
körnerbildung als Aneura n. $s p$. erwähnt; sie ist völlig steril, wächst auf einem schneeweissen Detritus und vermehrt sich anscheinend nur durch Keimkörner, wie man das auch an anderen Lebermoosen beobachten kann, die auf einem ungünstigen Substrat noch vegetieren können, zu einer Blütenbildung aber nicht gelangen. Die Frons ist bis ร̈ mm. lang, unregelmässig verzweigt, mit kurzen Gliedern und hat überall einen elliptischen Querschnitt, der eine kleinzellige Epidermis und grosse in zwei Schichten geordnete zentrale Zellen zeigt; da ich auf Goebels Wunsch dieser Pflanze einen Namen gab, führe ich sie hier auf, obgleich sie völlig steril ist und daher schwer zu identifizieren sein wird; charakteristisch ist die Dicke selbst der jungeren Fiederäste.

\section{Plantæ latæ vel latissimæ planæ arcteque repentes.}

134. Aneura Karstenii St. Hedwigia. 1893, p. 23.

Dioica, magna, flaccida, flavescens vel Havo-virens, in ligno decorticato arctissime repens lateque expansa. Frons ad $8 \mathrm{~cm}$. longa, $1 \mathrm{~cm}$. lata, plana, ubique 8 cellulas crassa, antice dense grosseque papillata, margine crenata, superne repetito-furcata, furcis parallelis late ligulatis, apice inciso-bilobis. Rami feminei breves plani radicantes, ambitu obcuneati, apice late truncati decurvi ibidemque maxime pilosi, pilis longis strictis simplicibus; pistilla pauca pilis circumdata et omnino obvelata. Calyptra magna, crassa, pilis sparsis longiusculis hirta. Rami masculi breves, pro more furcati, margine papulosi vel breviter lacinulati. Antheridia ad 6 juga.

\section{Hab. Amboina (G. Karsten).}

13อ. Aneura albo-marginata St. Hedwigia. 1893, p. 18.

Dioica, mediocris, flavescens, late stratificata. Frons ad $2 \mathrm{~cm}$. longa, repens, haud stolonifera, ex angusta basi dilatata, repetito furcata, furcis $3-4 \mathrm{~mm}$. latis late breviterque lobatis, approximatis vel contiguis, flabellam undulatam irregularum lichenoidem formantibus, postice leniter convexis, medio $\breve{5}$ cellulas crassis, late limbatis, limbo unistrato, unam cellulam lato, hyalino et valde perspicuo, cellulis magnis rectangulatis, magis longis quam latis $(38 \times 66 \mu)$. Rami feminei basi constricti substipitati, disciformes, cordati, margine cellulis digitiformibus denticulati, apice profunde inciso-bilobi, plani, marginibus lateralibus erecto-incurvis; pistilla 6 juga, nuda, squama dorsalis nulla. Reliqua desunt.

Hab. Amboina (G. Karsten). 
136. Aneura erecta St. n. sp.

Sterilis, mediocris, crassa, crispata, flavo-virens, humilis, in cortice compacte cæspitans. Frons e caudice repente erecta, basi angusta, repetito-breviterque furcata, furcis dilatatis, $2 \mathrm{~mm}$. latis, apice obcuneatis, lobato-incisis, lobis contiguis vel imbricatis, rotundatis, concavis, sæpe fere infundibulatim contortis, ceterum medio 6 cellulis crassa, versus marginem parum attenuata ipso margine magnis cellulis pellucidis quadratis vel rectangulatis maximeque incrassatis limbata. Cellulæ internæ frondis maximæ $16 \Xi \mu$, corticales $38 \mu$.

Hab. Tasmania, Mt Wellington (Weymouth).

\section{Aneura latifrons (Lindb.).}

Syn. : Riccardia latifrons Manip. musc. II, p. 372.

Autoica vel paroica, minor, humilis, dilute olivacea, dense cæspitosa. Frons ad $2 \mathrm{~cm}$. longa, irregulariter pinnata et bipinnata, canaliculata, haud alata, medio 5 cellulas crassa, cellulis magnis, oblongo hexagonis, internis haud majoribus. Truncus pro planta latissimus, basi valde stoloniferus, repetito breviterque furcatus, furcis superne dilatatis, cervicornutis, lobatim pinnatis, pinnulis trunco parum angustioribus, basalibus sæpe angustis in stolones mutatis. Rami feminei in trunco solitarii, margine apiceque longe fimbriati. Calyptra pro planta maxima, $3 \mathrm{~mm}$. longa, papuloso-verrucosa, mamilla humilis, subdisciformis. Sporæ ad $14 \mu$, viridi-bruuneolæ, minute asperæ. Rami masculi femineis approximati, breves decurvi, margine grosse papuloso. Antheridia pro more ad 6 juga, interdum multo longiora.

Hab. Europa et America sept., Japonia(Makino, Faurie), Açores(Simroth).

\section{Aneura incurvata (Lindb.)}

Syn. : Riccardia incurvata Lindb., Musei scand., p. こั.

Dioica, minor, rigida, pallide virens, arhiza, muscicola. Frons ad $10 \mathrm{~mm}$. longa, optime canaliculata, pinnata, haud alata. Truncus anguste linearis, in sectione transversa semilunatus, medio 4 -5̆ cellulas crassus, margine parum attenuato obtuso. Cellulæ internæ corticalibus majores. Pinnæ remotiusculæ, sæpe omnino deficientes, suboppositæ vel alternæ, trunco angustiores, subrecte patulæ, similiter canaliculatæ. Rami feminei in trunco laterales, parvi, margine breviter lacinulati. Calyptra grosse cylindrica, lævis, æatate desquamans, mamilla discoidea papulosa. Rami masculi in trunco solitarii, magni, valde canaliculati, persæpe ex apice innovati, marginibus attenuatis papulosis. Antheridia ad 8 juga. 
Hab. Fennia, Suecia (Lindberg).

Die Originalpflanzen, welche ich geprüft habe und die keineswegs als " exiguæ " zu bezeichnen sind, sind aufrecht zwischen Laubmoosen wachsende etiolierte wurzellose Exemplare, welche höchst unregelmässig verzweigt, oft ganz ohne Aeste sind; auch die aus der Spitze der männlichen Aeste sprossenden innovationen sind ein ächtes Zeichen intensiver Etiolierung und abnormer Standortsverhältnisse; immerhin führe ich sie hier als gute Art auf, da erst aus kultivierten Exemplaren festzustellen sein wird, ob dieselben vielleicht zur Aneura pinguis auswachsen, was ich vermute. Sporen und Elateren sind durchaus diejenigen von A. pinguis, auch in der Farbe.

\section{Aneura Breutelii St. n. sp.}

Dioica, minor, crassa, crispata, olivacea, in cortice densissime intricatim stratificata. Frons ad $12 \mathrm{~mm}$. longa, lobatim pinnata. Truncus pro planta latus, valde canaliculatus, ubique $4-\check{\text { }}$ cellulas crassus, margine parum attenuato obtuso, pinnis brevibus, confertis, sæpe imbricatis, tortis, trunco æquicrassis et vix angustioribus, similiter canaliculatis, apice sæpe dilatatis et 4 vel 6 ramulos nascentes gerentibus ibidemque limbo angusto hyalino marginatis. Rami masculi breves, crassi, margine papuloso. Antheridia ad 4 juga.

\section{Hab. Insula St Christoph (Breutel).}

Die jüngeren Fiederlappen tragen an ihrer Spitze 2-3 junge Astanlagen, die überall je eine Gabelung zeigen und somit 4-6 Vegetationspunkte enthalten; der Mittellappen, welcher jede Gabelung einleitet, ist an der Basis scharf abgeschnürt und nach vorn spatelig verbreitert, während die dazu gehörenden Seitenlappen infolge der Pressung der benachbarten Astanlagen aus ihrer horizontalen Lage gebracht werden und muschelförmig die junge Gabelung von rechts und links schützen; diese Verhältnisse sind die Ursache, dass die Frons ganz abnorm dicht rasig verwachsen ist und von oben gesehen kraus wie ein Flechtenthallus ist.

140. Aneura canaliculata Nees. Syn. Hep. p. 500.

Syn. : Jungermannia canaliculata Nees. Hep. Jav. p. 10.

Monoica, mediocris, pallidevirens, corlicola. Frons ad $12 \mathrm{~mm}$. longa, $3 \mathrm{~mm}$. lata, arcte repens, tenuis, plana, marginibus erectis vel incurvis, præcipue in ramis nascentibus. Truncus simplex vel furcatus, ramis juvenilibus pinnatim lobulatus, है cellulas crassus, abrupte limbatus, limbo unistrato hyalino, tenerrimo, $3-4$ cellulas lato, irregulariter profundeque 
crenato, interdum sublobulato, maxime incurvo, cellulis valde incrassatis tormato. Rami feminei breves, valde decurvi, similiter limbati, pistilla numerosa longeque biseriata, limbo lato, lacerato et connivente omnino velata. Calyptra clavata, papulosa, mamilla magna, celluloso fimbriata, comosa. Rami masculi breves, valde concavi; antheridia ad 4 juga, marginibus late incurvis occulta.

Hab. Java, Tjibodas (Schiffner).

\section{Aneura cochleata (H. et T.)}

Syn. : Riccia cochleata H. et T. J. of B. IV, p. 96.

Sterilis, major, crassa, coriacea, in solo turfoso gregarie crescens. Frons ad $2 \mathrm{~cm}$. longa, $\breve{\mathrm{mm}}$. lata, irregulariter lobata, lobis parum productis, canaliculatis, apice planis, frondis margo interlobularis erectus, planta itaque fere crispata, ubique tamen carnosa, plano-biconvexa, medio ad 12 cellulas crassa, marginibus acutis. Cellulæ internæ corticalibus majores. Flores haud vidi.

Hab. Lord Aucklands Islands (Hooker, Krone).

\section{Aneura maxima (Schffn.).}

Syn. : Riccardia muxima Schffn. Kais. Ak. Wien LXVII, p. 177.

Dioica, maxima, lignicola, arcte repens, in sicco dilute olivacea, viva atroviridis. Frons ad $10 \mathrm{~cm}$. longa, furcata, furcis lobatim ramosis, ad $12 \mathbf{m m}$. latis, planis, medio $\mathbf{1 6}$ cellulas crassis, apice profunde inciso bilobis, versus marginem sensim attenuatis, ipso margine unam cellulam crassis. Rami feminei e sinu apicali orti, lobis adjacentibus basi reflexis et fimbriatis obtecti, re vera lobulo nascenti inserti, disciformes, crassi, pistillis in disci apice declivi aggregatis, margine latissime alati, alis erectis usque ad costam laceratis, laciniis irregularibus, foliaceis vel piliformibus, curvatis sæpe ramosis, lanatim intricatis, pistilla itaque - similibus laciniis a tergo tecta - omnino immersa. Calyptra maxima, ad $15 \mathrm{~mm}$. longa, ad $2 \mathrm{~mm}$. crassa, sublævis vel pauci-villosa, apice subumbonata.

Hab. Java, Sumatra, 1500-2400 m. (Schiffner).

143. Aneura alterniloba Taylor. J. of. Bot. 1844 , p. 527.

Syn. : Aneura epibrya Col. Trans. N. Z. Inst. vol. 18, 188 3.

Dioica, maxima, coriacea, pallide-virens, vel olivacea vel brunnea, in ligno decorticato expansa. Frons ad $5 \mathrm{~cm}$. longa, $1 \mathrm{~cm}$. lata, plana, margine undulata, repetito-furcata, furcis $\breve{~ m m}$. latis, pinnatim lobulatis, lobuli rotundati, interdum parum elongati, apice profunde inciso bilobi. 
Rami feminei brevissimi, radicantes, crassi, margine brevidentati, squama dorsalis brevissima similiter dentata, dentibus crassis. Calyptra clavata $4 \mathrm{~mm}$. longa, plus $1 \mathrm{~mm}$. in diametero, maxime crassa, fusco-brunnea, maxime longeque setosa. Rami masculi ad 3 vel 4 in frondis lobulo parvo rotundato marginales, divergentes, sæpe totum frondis marginem apicalem occupantes, radicellis longis radicantes, crassi, ambitu ovato-oblongi, limbo lato tenerrimo, eroso, erecto. Antheridia parva, ad 6 juga.

Hab. New Zealand (Hooker, Colenso, Sinclair, Helms, Petrie).

\section{Aneura dentata St. J. Linn. Soc. XXIX, p. 264.}

Sterilis, spectabilis, valida, flaccida, dilute olivacea, arcte repens, haud stolonifera. Frons ad $4 \mathrm{~cm}$. longa, כ̋ mm. lata, plana, ubique $7-8$ cellulas crassa, margine acuto, superne divergenti furcata lobatimque pinnata, lobis contiguis, plus minus brevibus (ad $4 \mathrm{~mm}$. longis) trunco duplo angustioribus, rotundatis, ceterum margine ubique (præsertim ad apicem) grosse dentata, dentibus remotiusculis, plano-conicis, acuminatis, 2 vel 4 cellulas longis; frondis cellulæ internæ corticalibus multo majores.

Hab. New Zealand (Colenso).

\section{Aneura lobata (Schffn.).}

Syn. : Riccardia lobata Schffn. Kais. Ak. Wien. LXVII, p. 178.

Dioica, magna, arcte repens, fusco-olivacea. Frons ad $7 \mathrm{~cm}$. longa, late expansa. Truncus ad こ̆ mm. latus, planus, medio 10 cellulas crassus, cellulis internis magnis, versus marginem sensim attenuatus, ipso margine 1 cellulam crassus, ceterum repetito furcatus, lobatim pinnatus, pinnis oblique patentibus, late linearibus, plus minus longis, apice truncato-rotundatis, breviter inciso-bilobis. Rami feminei e fundo rimæ apicalis orti, utroque latere lobis ciliatis conniventibus obtecti et squama dorsali magna crassaque similiter ciliata a dorso tecti, disciformi, crassi, pistilla in disci apice declivi aggregata ibidemque ciliis strictis divergentibus protecta. Calyptra crassa, apice profunde umbilicata, verrucisque circumdata, ubique pilis strictis longis rufisque maxime hirta.

Hab. Java, Sumatra, 600-2200 m. (Schiffner), Nova Caledonia (Deplanche).

146. Aneura coronopus De Not. in Steph. Hedwigia 1893, p. 19. Sterilis, major, tenera, flaccida, arcte repens, rufescens. Frons $3 \mathrm{~cm}$. longa, furcata, furcæ divergentes, late ligulatæ, $4 \mathrm{~mm}$. latæ, ramulis numerosis dense consecutivis in fundo exeisurarum frondis quiescentibus, 
unde margo furcarum grosse lobato-dentatus evadit; planta celerum subplana medio 3 cellulas crassa; cellulæ centrales corticalibus multo majores perlucentes.

Hab. Borneo (Beccari).

147. Aneura granulata St. Hedwigia. 1893, p. 21.

Dioica, mediocris, flaccida, fuscescens, cæspitans. Frons repens, ad $3 \mathrm{~cm}$. longa, irregulariter pauciramosa $3-4 \mathrm{~mm}$. lata, marginibus obtusis erectis profunde canaliculata, ubique 4 cellulas crassa, cellulis centralibus majoribus, antice posticeque cellulis conicis plus minus prominulis et apice incrassatis aspera. Rami masculi numerosi, parvi, ambitu oblongi, marginibus asperis parum elevatis. Antheridia 4 juga.

Hab. Patagonia, Staten Island (Spegazzini).

\section{Aneura pallidevirens St. n. sp.}

Dioica, major, pallide flavo-virens, muscicola, late expansa. Frons repens, ad $3 \mathrm{~cm}$. longa, plana, tenuis, valde fragilis, pinnata, stolonibus nullis. Truncus $2 \mathrm{~mm}$. latus, ubique 4 cellulas crassus, margine obtusus; cellulæ corticales $17 \times 85 \mu$ parietibus validis, internæ $34 \mu$ in sectione transversa. Pinnæ trunco simillimæ, parum angustiores, suboppositæ, patulæ, lineares apice truncatæ. Ramuli feminei in trunco vel pinnis oppositi, magni, valde carnosi, profunde canaliculati, marginibus erectis integerrimis, papuloso-crenatis, bractea dorsali nulla.

Hab. Fretum magellanicum, Insula Desolacion (Dusén).

\section{Aneura pinguis (L.) Dum. Comment. p. 115.}

Syn. : Jungermannia pinguis L. Sp. pl. II. p. 1602.

Aneura sessilis Sprengel Syst. Veg. IV. p. 232.

Aneura latissima Spr. Trans. Edinb. B. Soc. 1885. p. こ̌44.

Riccardia fuscovirens Lindb. Musci. scand. 1879, p. ๖.

Dioica, late linearis vel ligulata, crassa, viridis vel flavo-virens, in latas plagas expansa. Frons ad $\mathbf{2} \mathrm{cm}$. longa, furcata, radicellis numerosis arcte repens, furcis divergentibus, simplicibus, canaliculatis, $3 \mathrm{~mm}$. latis, costa lata, 8 cellulas crassa, postice bene producta planaque, abrupte in alas attenuatas abeunte; alæ obtusæ, integerrimæ, adscendentes, crispatæ; cellulæ internæ frondis corticalibus multo majores. Rami masculi in trunco ramisve pseudo-laterales, radicantes, breves, sæpe furcato-geminati vel terni, ambitu ovati, alis tenuibus explanatis 3 cellulas latis. Antheridia 4 juga, magna, interdum 3 seriata. Rami feminei in trunco furcisque 
pseudo-laterales, apice breviter el tenerrime lacinulati, sub frondis lobis occulti, calyptra cylindrica, tempore maturitatis $8 \mathrm{~mm}$. longa, lævis, mamilla parva, alte papulosa. Sporæ rufæ, minute papillatæ $18 \mu$. Elateres ad $200 \mu$, rufescentes, laxe torti, apicibus longe et anguste attenuatis ut in congeneribus.

Hab. Europa, Asia, America sept,, Japonia (Inoné, Faurie), Grœnland, Umanakfjord $71^{\circ}$ (Vanhöffen), Himalaya (Duthie), Java (Karsten, Solms), Australia, Victoria (Whitelegge, Luchmann), New Zealand(Helms), Africa, Mascareignes (de l'Isle, Rodriguez), Kamerun (Dusén, Staudt), Angola (Welwitsch), San Thomé (Moller), Mexico (Egeling), Brasilia (Puiggari, Glaziou, Ule), Rio Negro (Spruce), Insulæ Indiæ occid. (Wright, Duss, Elliot, l'Herminier).

\section{1วั0. Aneura viridissima (Schffn.).}

Syn. : Riccardia viridissima Schffn. Kais. Ak. Wien 1898. LXVII, p. 176.

Dioica, major, latissima, viridis, subvernicosa, in sicco subfuscescens, laxe cæspitans, habitu Pelliæ epiphyllæ. Frons ad ə̃ $\mathrm{cm}$. longa, ad $8 \mathrm{~mm}$. lata, pauciramosa, sæpe simplex, ad 10 cellulas crassa, cellulis internis majoribus, late canaliculata, marginibus undulatis vel subcrispatis, longe attenuatis, haud alatis. Rami feminei brevissimi, carnosi, disciformes, antice sub lobis ramuli materni occulti, postice creberrime radicelliferi, margine paucilacinulati; calyptra cylindrica, lævis (interdum grosse lacinulata). Rami masculi in trunco laterales, solitarii vel geminati, breves, radicantes, carnosi, marginibus erectis sublobatis erosis. Antheridia 3 vel 4 seriata.

Hab. Java, 250-1730 m. (Schiffner).

151. Aneura Schwaneckei St. Hedwigia 1888, p. 278.

Dioica, mediocris, tenera, pallide-virens, laxe cæspitans, corticola. Frons ad 15 mm. longa, procumbens, uno latere ramosa, altero stolonifera, apice solum regulariter bipinnata. Truncus $1 \mathrm{~mm}$. latus, antice posticeque planus, margine acutus; pinnæ breves, contiguæ, pinnatim lobatæ; rami trunco simillimi, æquilati, 4 cellulas crassi, apice profunde inciso-bilobi; cellulæ corticales internis multo minores, marginales limbum hyalinum bene definitum formantes. Rami feminei parvi, decurvo occulti, margine breviter lobulati, squama dorsalis bene evoluta similiter lobulata. Reliqua desunt.

Hab. Puertorico (Schwanecke), Rio Grande (Lindman). 
Unbekannt sind mir geblieben :

Aneura australis (Lehm) als Sarcomitrium australe Lehm. Pug. X, p. 19, beschrieben; leg. Preiss, Australia, Swan River.

Aneura bipinnata (Swartz) als Jungermannia bipinnata Sw. Prodr. Fl. Ind. occ. III, p. 1877 beschrieben; leg. Swartz, Jamaica.

Aneura brasiliensis(Angstr.) als Pseudoneura brasiliensis, Angstr. Kongl. Vet.-Ak. 1876, p. 91, beschrieben; leg. Widgren, Brasilia, Caldas.

Aneura crassa (Schwägr.) Nees. Syn. Hepat. p. こ000. Syn. Jung. crassa Schwägr. Prodr. p. 31 .

Die Beschreibungen vorstehender Pflanzen sind unzulänglich, auch bei Angström, obgleich seine Diagnose ausführlicher ist.

Exemplare dieser Arten sind nirgends zu erhalten gewesen. 


\title{
SPECIES HEPATICARUI
}

A UCTORE

\author{
Franz STEPHANI
}

(Suite.)

\section{METZGERIA Raddi.}

Plantæ frondosæ, teneræ, pallidæ, in umbrosis virides, in tropicis interdum flavo-rufescentes, statu morbido hic illic cœruleæ, violaceæ vel purpureæ, pro more corticolæ, rarius rupicolæ vel foliicolæ, vulgo dense stratificatæ vel effuse inter fruticum ramulos nidulantes, radicellis posticis e costa, ex alis vel marginibus ortis repentes, monopodialiter repetitofurcatæ, furcis linearibus, ultimis rare acuminatis, late divergentibus, in paucis frondes alternatim pinnatæ vel pinnatim decompositæ, semper fere convexæ, in umbrosis subplanæ, apice rotundatæ cellulisque clavatis muciferis obtectæ.

Costa tenuis, sæpe tenuissima, sub bifurcatione solum dilatata (duplicata) in * Furcatis * ceterum ubique rquilata, in * Pinnatis * attenuata i. e. in trunco primario maxime crassa, in pinnis pinnulisque sensim sensimque angustata. Costæ cellulæ corticales internis majores, posticæ plus minus longe setosæ, in paucis nudæ, antice rarissime setulosæ.

Alæ utroque latere æquilatæ, interdum tamen asymmetricæ vel versus apicem attenuatæ, vel margine lobatæ, semper fere convexæ vel revolutæ, nudæ vel hirtæ in paucis crassæ, versus marginem unistratæ, marginibus semper fere armatis, in umbrosis irregulariter setosis vel nudis.

Inflorescentia monoica vel dioica. Rami sexuales postici, e latere costæ orti, brevissimi; feminei ex angusta basi obcordatim ampliati, medio crassi, 
alis tenuibus margine posticeque setosis, antice pauca pistilla biseriata et alternantia gerentes. Calyptra plus minus magna, vulgo clavato-pyriformis, valde carnosa, pistillis sterilibus haud obsita, plus minus dense longeque hispida. Capsula fusco-brunnea, breviter pedicellata, oblongoovalis, ad basin usque quadrivalvis, valvulis bistratis, cellulis internis vulgo semi-annulatim incrassatis. Sporæ parvæ, sphæricæ, læves vel minute papillatæ. Elateres decidui tenues, longe attenuati, monospiri, fibrà spirali lata, ligulata. Elateres remanentes sub apice valvarum affixæ, reliquis validiores penicillatim aggregatæ patulæque.

Rami masculi nudi, cucullati, costam distinctam et cellulas clavatas apicales gerentes. Antheridia pauca, biseriata, alternantia, in pedicello perbrevi sphærica.

Die Arten dieser Gattung sind von grosser Einförmigkeit, nur wenige fremdartige Formen vermögen das Interesse zu fesseln; ihr Bau ist ein höchst einfacher, rudimentärer, so dass man genötigt ist, zu ihrer Beschreibung und Unterscheidung die Anzahl der Zellen einzelner Theile zu Hilfe zu nehmen; diese Zahlen (der Rindenzellen der Mittelrippe etc.) sind so konstant, dass die Bestimmung dadurch sehr erleichtert wird; unvollkommen entwickelte Exemplare, wie sie an sehr nassen Standorten oder in tiefdunklen Wäldern häufig sind, bieten aber grosse Schwierigkeiten, weil die Behaarung des Thallus, die eine hervorragend gute und sichere Handhabe zur Unterscheidung der Arten bietet, dann sehr unregelmässig wird und oft ganz fehlt. Zum Festhalten von Wasser ist also die Behaarung jedenfalls bestimmt; die Gattung ist aber, so sehr sie bei der Zartheit aller Organe konstanter Feuchtigkeit bedarf, eine durchaus lichtbedürftige; sie gedeiht am besten an gut beleuchteten Standorten, welche aber dem direkten Sonnenlicht nicht ausgesetzt sind; hier zeigt sie auch stets ihre normale bleiche Farbe; sehr grüne Exemplare werden stets von einem zu nassen Standort stammen und der Bestimmung die grössten Schwierigkeiten entgegenstellen.

Die Geschlechtsäste entspringen, wie im Vorstehenden bereits gesagt, aus der Seite der Mittelrippe unter der Ventralseite der Flügel; hierdurch weicht Metzgeria wesentlich von Aneura ab, deren Sexualäste bekanntlich terminal aus ruhenden Vegetationspunkten entwickelt werden. Metzgeria steht also der Gattung Hymenophytum sehr nahe; diese drei zu einer Gruppe zu vereinigen, wie es geschehen ist, scheint mir ganz unmöglich.

In der Synopsis Hepaticarum sind nur $\breve{~ w a h r e ~ M e t z g e r i a-A r t e n ~ a u f-~}$ 
geführt, während im Nachfolgenden deren 64 beschrieben werden, welche sich auf die Florengebiete wie folgt vertheilen :

2 Arten sind Cosmopoliten;

1 Art gehört dem nördlichen Waldgebiet der Erde an;

8 Arten dem tropischen Asien und Oceanien;

9 " dem tropischen und subtropischen Africa;

29 " dem tropischen America;

15. "dem antarctischen Gebiel.

Die Standortsangaben beziehen sich, wie immer, nur auf Pflanzen, die ich selbst untersuchen konnte.

Leider sind reife Kapseln auch bei dieser Gattung nur von wenigen Arten bekannt, da dieselbe fast durchgängig diœeisch ist; auch hier ist also, wie bei Aneura erwähnt, noch viel nachzutragen.

Die von Lindberg angeführten, als subspecies zu M. furcata gestellten zwei Pflanzen $M$. subundulata Austin und M. crassipilis Lindb. habe ich nicht erlangen können.

Vetzgereria Raddi.

Die Bruchziffern hinter dem Worte costa zeigen kurz

die Zahl der Rindenzellen der Mittelrippe an; die obere und untere Ziffer entsprechen der dorsalen und ventralen Seite.

\section{A. Pinnatæ.}

a. Frondes antice setosa.

1. Metzgeria pubescens Raddi.

2. Metzgeria frontipilis Lindb.

b. Frondes antice nudee.

3. Metzgeria decrescens St. costa adulta $5 / 7$.

4. Metzgeria corralensis St. costa adulta $4 / 8$.

๖. Metzgeria terricola St. costa adulta $6 / 6$.

6. Metzgeria acuminata St. costa adulta $8 / 6$.

7. Melzgeria longiseta St. costa adulta $6 / 8$.

8. Metzgeria Liebmanniana L. et G. costa adulta $6 / 8$.

9. Metzgeria filicina Mitten. costa adulta ${ }^{12} / 15$.

10. Metzgeria rigida Lindb. costa adulta $6 / 8$.

\section{B. Furcatæ.}

a. Frondes omnino nuda.

11. Metzgeria Elliotii St. $\operatorname{costa}^{2} / 2$.

12. Metzgeria inflata St. $\operatorname{costa} 2 / 2$.

13. Metzgeria crassicostata St. costa $4 / 6$.

14. Metzyeria imberbis J. et St. costa $5 / 6$. 
b. Frondes margine simpliciter setosa.

\section{Costa hirta $2 / 2$.}

15. Metzgeria chilensis St. alæ nudæ.

16. Metzgeria Lindbergii Schffn, alæ nudæ.

17. Metzgeria aurantiaca St. alæ hirtæ.

18. Metzgerıa Perrotana St, alæ hirtæ.

II. Costa nuda $2 / 2$.

19. Metzgeria comata St. alæ nudæ.

20. Metzgeria glaberrima St. alæ nudæ.

21. Metzgeria sinuata Loitl. alæ nudæ.

22. Metzgeria longitexta St. alæ hirtæ.

III. Costa hirta $2 / 4$.

23. Metzgeria convoluta St. alæ nudæ.

24. Metzgeria patagonica St. alæ nudæ.

2ə. Metzgeria Jackii St. alæ setulosæ.

26. Metzgeria furcata Lindb. alæ setosæ.

IV. Costa nuda $2 / 4$.

27. Metzgeria saccata Mitten.

\section{Costa hirta $4 / 4$.}

28. Metzgeria Lechleri St.

VI. Costa nuda $4 / 4$.

29. Metzgeria Dusenii St.

VII. Costa $4 / 6$.

30. Metzgeria dichotama (Sw.) Nees.

VIII. Costa $6 / 6$.

31. Metzgeria linearis (Sw.) Austin.

IX. Costa $8 / 8$.

32. Metzgeria effusa St.

c. Frondes margine geminatim-setosce.

\section{Costa hirta $2 / 2$.}

\%. Alæ HIRT. .

33. Metzgeria angusta St. alæ breviter setulosæ.

34. Metzgeria madagassa St. alæ breviter setulosæ.

3ə. Metzgeria rufula Spruce alæ breviter setulosæ.

36. Metzgeria Renauldii St. alæ longe setosæ.

37. Metzgeria camerunensis St. alæ longe setosæ.

38. Metzgeria fuscescens Mitten. alæ pilosæ.

39. Metzgeria hamatiformis Schffn. alæ pilosæ.

40. Metzgeria procera Mitten. alæ pilosæ.

41. Metzgeria papulosa St. alæ pilosæ.

42. Metzgeria scobina Mitten. alæ pilosæ.

3. Ale NUde.

43. Metzgeria consanguinea Schffn. costa setulosa.

44. Metzgeria nitida Mitten. costa setulosa.

45. Metzgeria thomeensis St, costa setulosa.

46. Metzgeria albinea Spruce costa setosa. 
47. Metzgeria leptoneura Spruce costa pilosa.

48. Metzgeria recurva St, costa pilosa.

49. Metzgeria hamata Lindb. costa pilosa.

II. Costa nuda $2 / 2$.

50. Metzgeria atrichoneura Spruce.

III. Costa $2 / 4$.

51. Metzgeria adscendens St. alæ nudæ, costa nuda.

ว2. Metzgeria conjugata Lindb. alæ nudæ, costa setosa.

э3. Metzgeria Wallisiana St. alæ nudæ, costa pilosa.

ว̌4. Metzgeria Sandei Schffn. alæ setulosæ, costa setulosa.

วัอ. Metzgeria leptomitra Spruce alæ setosæ, costa setosa.

ə6. Metzgeria crenata St. alæ pilosæ, costa pilosa.

37. Metzgeria quadrifaria St. alæ pilosæ, costa pilosa.

IV. Costa hirta $4 / 4$.

58. Metzgeria fruticola Spruce alæ nudæ.

59. Metzgeria clavæflora Spruce alæ setosæ.

60. Metzgeria bracteata Spruce alæ villosæ.

V. Costa hirta $4 / 6$.

61. Metzgeria Uleana St. alæ setulosæe.

62. Metzgeria muscicola St. alæ setosæ.

d. Frondes margine set is ternis armatie.

63. Metzgeria polytricha Spruce costa $2 / 2$.

64. Metzgeria myriopoda Lindb. $\operatorname{costa}^{2} / 8$.

\section{A. Pinnatæ.}

1. Metzgeria pubescens Raddi. Mem. Mod. XVIII. p. 45.

Dioica, major, rigida, pallida, spongioso-cæspitans in rupibus calcareis, rarius corticola. Frons ad $3 \mathrm{~cm}$. longa, vix $2 \mathrm{~mm}$. lata, irregulariter alternatim pinnata et bipinnata, ramis ultimis sensim acuminatis obtusis, rarius plana, vulgo varie undulata et torta apiceqee subcrispata, antice et postice breviter setulosa, ventre ramis adventivis flagellisque innovata. Flagella longa serpentina, fere ad costam reducta, alis 2-3 cellulas latis, ubique setulosa apiceque in frondem normalem abeuntia. Alæ interdum interruptie i. e. frons ex apice rotundata abrupte innovata, costam exalatam proferens sensimque in novam frondem excurrens. Costa subteres, antice posticeque alte producta ibidemque setis longioribus hispida, in trunco primario crassa, in pinnis pinnulisque sensim angustata; cellulæ corticales itaque in trunco 26 (utroque latere 13), in pinnis 16 (antice 9 et postice 7), in pinnulis ultimis 10 (antice 6 et postice 4). Cellulæ internæ costarum in sectione corticalibus vix minores. Alæ ad 20 cellulas latæ, 
setulis brevioribus pungentibus obsitæ, margine setulis similibus geminatis vel ternis armatæ. Cellulæ alarum $27 \times 36 \mu$, parietibus validis, trigonis nullis. Rami feminei utroque latere - masculi postice tantum dense pilosi.

Hab. Europa, e Norvegia $63^{\circ}$ lat. bor. in Italia usque, Caucasus (Brotherus, Levier); America sept. Alleghany Montes, Alaska (Krause), Insula Vancouver (Lyall); Asia, Himalaya 8000-12000' (Hooker, Gamble, Duthie), Kashmir 11000' (Duthie); Japonia (Faurie, Makino); China. Yünnan (Delavay), Setschuan (Farges), Schensi (Giraldi).

\section{Metzgeria frontipilis Lindb. Monogr. Metzg. p. 14.}

Dioica, mediocris sed robusta, rigida, sæpe (inter muscos) elongata, pallida, in sicco flavescens, ætate fuscescens, laxe cæspitans, terricola et corticola. Frons ad $5 \mathbf{c m}$. longa, valde concava, geniculatim pinnata i. e. inferne paucis pinnis primariis instructa, pinnis longioribus sat regulariter pinnulatis, pinnulis remotiuseulis, alternantes, breviusculis breviterque acuminatis obtusis. Costa in trunco primario validissima, fere teres, antice convexa, postice maxime producta; cellulæ corticales in sectione 36 (utroque latere sub 18, in pinnis sub 12, in pinnulis sub 6) ceterum dorso ventreque longe setosa. Alæ valde decurvæ, basi cellulis bi vel tristratis crassæ, postice nudæ, antice setis strictis inæquilongis hirtæ, margine setulis brevibus pro more geminatis et late divergentibus armatæ. Cellulæ

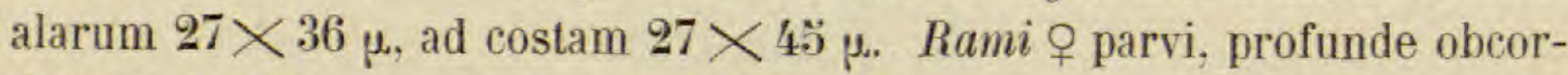
dati, dorso ventreque setulosi. Pistilla 6-7.

Hab. Fretum magellanicum, ubique communis (Lechler, Cunningham. Spegazzini, Savatier, Exped. Gazelle, Hahn, Pehlke, Dusén); Chile australis (Krause, Neger).

Die Costa nimmt vom Truncus primarius an durch alle Verzweigungen allmählig an Stärke ab und ist in den äussersten Fiederästen zugespitzt, so dass sich eine konstante Zahl der Rindenzellen nicht angeben lässt; obige Ziffern sind Durchschnittszahlen, die um weniges differiren können.

\section{Metzgeria decrescens St. n. sp.}

Dioica, major, hyalina, dense cæspitosa. Frons irregulariter pinnatim ramosa, pinnis pinnulisque longis et multo brevioribus mixtis. Costa nuda, in trunco primario crassa, in sectione ovalis, dorso ventreque æqualiter producta ; cellulæ corticales magnæ, internis multo majores, ad 12 (antice 5 , postice 7 ); in pinnis solum 9 (antice 4, postice 5 ); in pinnulis 
ultimis 4 (utroque latere 2 cellulæ). Alæ similiter attenuatæ, e trunco lato in ramis ramulisque sensim angustatæ, in ultimis pinnulis fere 2-plo angustiores, ceterum nudæ et valde recurvæ, marginibus sæpe conniventitangentibus, longe piliferis, pilis strictis crebris simplicibus. Cellulæ alarum $4 \breve{5} \times \mathfrak{3} 4 \mu$, ad costam parum longiores; trigona nulla. Androecia ut in congeneribus.

Hab. Patagonia, ad fretum magellanicum (Dusén).

Wegen der starken Einrollung der Flügel ist die Abnahme der Breite der Frons in den Zweigen gegenüber dem Hauptstamm wenig sichtbar und zeigt sich nur deutlich in Querschnitten; übrigens haben alle Arten mit verdünnt auslaufender Rippe auch dem entsprechend verlaufende Flügel. Lindberg ${ }^{1}$ hat das sonderbarer Weise gar nicht bemerkt, während sich diese Pfianzen ganz wesentlich von der grossen Masse der übrigen Arten unterscheiden, die durchweg eine völlig gleichartige Rippe besitzen, die alle Dichotomien durchläuft (abgesehen natürlich von der Verdoppelung der Rippe dicht unterhalb der Gabelung). Es ist ein wesentlicher Fortschritt jener gefiederten Pflanzen, die mit einem kräftigen Hauptstamm versehen, sich meist hoch in reicher Beästung entwickeln können und ihnen gegenüber erscheinen die dichotomen Arten sehr rudimentär.

\section{Metzgeria corralensis St. n. sp.}

Dioica, mediocris, pallida, dense caspitans. Frons ad $4 \mathrm{~cm}$. longa, subplana, remote pinnata, pinnis brevibus alternantibus apice obtusis, plus $1 \mathrm{~mm}$. Iatis. Costa valida, in sectione ovalis, ventre longius ciliata, ciliis creberrimis, validis, strictis. Cellulæ costæ corticales 12, quarum 4 anticæ latiores, 8 posticæ duplo angustiores. Alæx planæ, ad 12 cellulas latæ. dense ciliatæ; ciliis tenuibus, flaccidis, hamatulis; margine simpliciter ciliata, ciliis validis longiusculis strictis, oblique ad posticum nutantes. Cellulæ alarum $27 \times 36 \mu$, incrassatio nulla, ad costam sæpe duplo fere majores. Rami masculi parvi nudi.

Hab. Chile, Corral (H. Krause).

\section{Metzgeria terricola St. n. sp.}

Dioica, mediocris, pallide-flavicans, ætate fuscescens. Frons ad $2 \mathrm{~cm}$. longa, pinnata et bipinnata, rigida fragilisque, undulata et maxime revoluta. Costa in trunco primario lata, in sectione plano-elliptica, postice magis producta ; cellulæ corticales 12 (utroque latere 6) in pinnis pinnu- 
lisque sensim attenuata, in ultimis 4 tantum cellulis corticalibus tecta (utroque latere 2) ceterum paucisetulosa. Alæ maxime decurvæ frondes itaque sæpe omnino clausæ et depresso-tubulosæ, nudæ, margine tamen longissime et creberrime piliferæ, pilis geminatis substrictis late divergentibus. Cellulæ alarum $36 \times 54 \mu$, trigonis nullis, parietibus validis. Rami $\sigma^{\top}$ parvi, nudi.

Hab. Fretum magellanicum (Savatier, Dusén).

\section{Metzgeria acuminata St. n. sp.}

Dioica, pallide-virens, in ramulis fruticum effuse cæspitans. Frons furcata, furcis tamen pinnatis, plano-decurvis, apice distincte breviterque acuminatis, omnino nudis. Costa crassa, in furcis primariis æquicrassa, subteres, antice valde producta ibidemque cellulis 8 seriatis-postice 6 seriatis-tecta, in pinnis multo angustior et apicem versus attenuata. Alæ planæ, strictæ sed posticum versus nutantes, in fronde adulta latæ in pinnis duplo angustiores et attenuatæ. Cellulæ alarum $18 \times 37 \mu$, tenerrimæ, incrassatio nulla. Rami masculi parvi, nudi. Rami feminei semper innovati. Calyptra pyriformis, basi nuda, superne setulıs longissimis comata.

Hab. Brasilia, Rio Grande (Kunert).

\section{Metzgeria longiseta St. n. sp.}

Sterilis, major, valde elongata, flaceida, flavescens, dense stratificata. Frons ad $8 \mathrm{~cm}$. longa, pinnatim decomposita, maxime ramosa, ramis remotiusculis, haud attenuatis, maxime convexa. Costa a dorso compressa, asymmetrica, antice bene convexa, postice subplana, in ramis ramulisque sensim angustata. Cellulæ corticales in trunco primario antice sex seriati, postice 8 seriatæ, in ramis sensim pauciores, in ultimis antice bi-postice 4 seriatæ. Cellulæ dorsales semper multo majores, inflatæ et convexoprominulæ, ventrales multo minores et internis æquimagnæ; cellulæ internæ triseriatæ, ventrales longe setosæ. Alæ maxime revolutæ, ubique æquilatæ (20 cellulas) nudæ, basi $2-3$ cellulas crass $æ$, versus marginem cellulis sensim humilioribus distincte attenuatæ, margine setis longissimis, ample cylindricis, atlenuatis, simplicibus et hamatis armato. Cellulæ alarum $36 \times 5 \% 4$, ad costam $45 \times 72 \mu$ trigonis nullis. Reliqua desunt. Planta spectabilis, omnium pulcherrima.

Hab. Fretum magellanicum (Herb. Warnstorff).

8. Metzgeria Liebmanniana L. et G. Syn. Hepat. p. 50อ̆.

Dioica, major, elongata, flaccida, pallida vel flavo-virens, superne inter- 
dum brunneo-purpurea, corticola. Frons ad $5 \mathrm{~cm}$. longa et $3 \mathrm{~mm}$. lata, pinnatim pauciramosa, interdum e ventre innovata, parum convexa, undulata. Costa in trunco primario crassa, subteres, in pinnis pinnulisque sensim angustata, cellulæ corticales in sectione trunci 14 (6 anticæ et 8 posticæ) in pinnis longioribus 12 ( 5 anticæ et 7 posticæ) in pinnulis ultimis 10 (4 anticæ et 6 posticæ). Alæ ad 20 cellulas latæ, in ultimis ramulis distincte acuminatæ, postice dense breviterque villosæ, pilis breviusculis flaccidis; margine similiter armatæ, setulis strictis geminatis divergentibus. Cellulæx alarum $36 \mu$, ad costam $37 \times 45 ั \mu$. Rami feminei parvi, ventre et margine longe setosi. Calyptra clavata, setis longis hispida.

Hab. Catena Andium haud rara, Mexico (Liebman, Leibold, Schaffner, Bourgeau), Costarica (Pittier), Brasilia, montes orientales (Ule, Glazion), Argentinia, Tucuman (Lorentz), Chile, Valdivia (Hahn).

9. Metzgeria filicina Mitt. J. of Bot. 18ə̃1, p. 361.

Dioica, magna et valde elongata, pallide viridis vel flavicans, corticola vel rupicola, laxe effuse cæspitosa, sæpe inter fruticum ramulos squarrose nidulans. Frons ad $10 \mathrm{~cm}$. longa, bi-vel tripinnata, valde convexa, subrevoluta, pinnis pinnulisque squarrose patulis, leniter acuminatis, quam truncus multo et sensim angustioribus. Costa nuda, in trunco primario maxime crassa, cellulis corticalibus 27 , quarum 12 anticæ et 15 posticæ; in pinnis longioribus 21 (anticæ 9, posticæ 12) in apice pinnularum 4 (utroque latere 2). Alæ tenerrimæ cellulis $36 \times 54 \mu$, ad costam longiores, trigonis subnullis, margine nudo vel paucis setulis simplicibus armato, ipso apice crebre setuloso. Rami feminei parvi, arcuato-suberecti, alis tamen decurvis, apice rotundata ceterum nudi, margine solum setosi, sæpe innovati. Calyptra magna clavata, superne setis validis strictis et porrectis penicillatim setosa. Capsula late ovalis, fusço brunnea. Sporæ $20 \mu$, brunneæ, minutissime asperæ. Rami masculi ut in congeneribus nudi, pro planta parvi.

Hab. Andes quitenses (Jameson, Spruce), Bolivia, Unduavi (Pearce), Nova Granada, Paramo Choachi__(Lindig).

\section{B. Furcatæ.}

10. Metzgeria rigida Lindb. Monogr. Metzg. p. 43.

Dioica, parva, rigida, tenax et fere cartilaginea, Iurido-pallida, superne corulescens, corticola. Frons ad $125 \mathrm{~mm}$. longa, $3 / 4 \mathrm{~mm}$. lata, dense 
breviterque ramosa, vix linearis sed hic illic angustata, alis adscendentibus antice leniter concava, glaberrima. Costa nuda, paucas radicellas emittens, crassa et rigida, postice magis producta; cellulæ corticales 14 , quarum 6 anticæ et 8 posticæ, in ramis longioribus 9 (antice 4 , postice 5 ) in pinnulis ultimis 7 (antice 3, postice 4). Alæ undulatæ, angustæ, ad 13 cellulas latæ, ubique nudæ; cellulæ alarum $36 \times 54 \mu$, valde æqualiterque incrassatæ. Rami feminei glaberrimi. Calyptra pyriformis, 'glaberrima. Rami masculi nudi.

Hab. Lord Aucklands Islands (Hooker).

Lindberg hat in seiner Monogr. Metzg. nicht berücksichtigt, dass die Costa vor der Gabelung allmählig verdoppelt wird und giebt infolgedessen der Anzahl der Rindenzellen einen Spielraum, der im normalen Gabelast nicht vorkommt; das ist auch die Ursache, dass er die allmählige Verdünnung der Costa bei den gefiederten Arten nicht bemerkt oder wenigstens nicht erwähnt hat (siehe M. decrescens).

\section{Metzgeria Elliotii St. n. sp.}

Sterilis, parva et humilis, dense depresso-cæspitans, in sicco sulphurea, emollita aquam maxime tingens, corticola. Frons ad $15 \mathrm{~mm}$. longa, repetito furcatim ramosa, flabellatim expansa, ramis simplicibus interjectis acuminatis, ceterum Iinearis apiceque obtusa, plano-convexa, omnino nuda, paucis radicellis marginalibus repens. Costa tenuis, cellulis corticalibus in sectione 4, i. e. utroque latere 2 cellulis tecta. Cellulæ alarum $36 \times 45 \%$ ad costam vix majores, margine minores ibidemque maxime incrassatæ.

Hab. Africa centralis, in monte Runssoro $9000^{\prime}$ (Scott Elliot).

\section{Metzgeria inflata St. n. sp.}

Dioica, spectabilis, brevis, flaccida, pallide lurida, optime nitida, muscis consociata. Frons furcata, ad $3 \mathrm{~cm}$. longa, omnino nuda, basi tantum paucis radicellis affixa. Costa tenuis, cellulis corticalibus utroque latere biseriatis tecta, in sectione transversa late ovalis; cellulæ antice et postice magnæ, æquales, internæ multo minores triseriatæ. Alæ apice cucullatæ, ubique maxime irregulariterque revolutx, in sectione valde asymmetricæ. uno latere quadruplo latiores, re vera itaque sinuatim lobatæ, lobis bullosoinflatis, ob flexuram tamen haud discretis. Cellulæ alarum $36 \times \Delta 4^{4} \mu$. parietibus validis, trigonis parvis. Rami feminei parvi, fere conduplicati, margine breviter setosi.

Hab. Guiana britann., in cacumine Montis Roraima (Mac Connell et Quelch.). 
Diese merkwürdigePflanze bildet einen Uebergang zu M. saccata Mitten, deren lobi alarum tiefer getrennt sind, während sie hier durch die Einrollung der Flügel nicht in die Erscheinung treten.

\section{Metzgeria crassicostata St. Hedwigia 1889.}

Dioica, minor et angusta, gracilis, dilute olivacea. Frons furcata, furcis sæpe simplicibus pinnæformibus, apice rotundata, valde convexa, postice hirta. Costa validissima, postice magis producta, 10 cellulis corticalibus tecta (antice 4 majoribus, postice 6 minoribus) ventre breviter setosa, setulis tenuibus strictis crebris. Alæ valde decurvæ, $\mathbf{1 6}$ cellulas latæ, margine nudæ, postice sparsim breviterque setulosæ. Cellulæ alarum $37 \times 40 \ddot{\mu} \mu$, trigonis nullis. Rami feminei obcordati, carinatim concavi, costæ oblique approximati, margine dorsoque longe ciliati.

Hab. Australia, Richmond River (de Camera).

14. Metzgeria imberbis Jack et Steph. Hedwigia 1895, p. 316.

Dioica, major, tenerrima, pallide-virens, laxe cæspilosa (pendula?). Frons regulariter furcata, optime in flabellam latam multiramosam evoluta, in vivo tamen maxime intricata radicellisque inter se affixa, ceterum ad $3 \mathrm{~cm}$. longa, sub $2 \mathrm{~mm}$. lata, omnino plana vel leniter undulata. Costa crassa, postice magis producta ibidemque cellulis corticalibus sexseriatis tecta breviterque setosa, antice nuda cellulis corticalibus 5 seriatis; cellulæ internæ 7 seriatæ reliquis vix minores. Alæ perfecte nudæ, ad 20 cellulas latæ, hic illic postice, rarius e margine radicellas suctorias emittentes. Cellulæ alarum $27 \times 36 \mu$ parietibus æqualiter incrassatis, trigonis nullis. Rami feminei breves margine setulosi semper innovati, tempore maturitatis calyptram longe superantes. Calyptra setis longis validis porrectis penicillatim setosa.

Hab. Argentinia, Rio seco (Lorentz).

\section{Metzgeria chilensis St. n. sp.}

Dioica, parva, angusta; gracilis, pallida, in umbrosis viridis, corticola vel terricola. Frons ad $10 \mathrm{~mm}$. longa, furcata, valde convexa, apice rotundata. Costa tenuis, postice setosa, setis longis, strictis. Cellulæ corticales costæ utroque latere biseriatæ. Alæ fere revolutæ, nudæ, margine solum simpliciter ciliatæ, ciliis confertis, longis, tenuibus strictisque. Cellulæ alarum $36 \times 5 \% \mu$, trigonis nullis. Rami feminei pro planta magni, profunde obcordati, carinatim conduplicati, longe setosi.

Hab. Chile (Dusén), New Zealand, in subalpinis (Colenso). 
16. Metzgeria Lindbergii Schffn. Kais. Akad. Wien. LXVII, p. 182.

Syn. : Metzgeria tahitensis St. ms.

Autoica, mediocris, flaccida, in sicco pallide-flavicans, corticola et terricola. Frons ad $\mathbf{2} \mathrm{cm}$. longa, vix $1 \mathrm{~mm}$. lata, plana, fureata et ramis posticis innovata. Costa tenuis, cellulis corticalibus utroque latere biseriatis tecta, ventre dense breviterque setulosa. Alæ planæ, nudæ, ad 1 ڤ̆ cellulas latæ. Cellulæ alarum $27 \times 36 \mu$, ad costam majores, trigonis majusculis. Setæ marginales simplices, breves, oblique extrorsum nutantes, strictæ. Rami feminei obcordati, parum setosi. Calyptra dense breviterque setosa. Rami masculi nudi.

Hab. Java, Buitenzorg (Schiffner), Tahiti(Vieillard et Panchet, Nadeaud), Insulæ Markesas, Nukahiwa (Ed. Jardin).

\section{Metzgeria aurantiaca St. n. sp.}

Dioica, minor, flavo-rubescens, muscis irrepens. Frons ad $15 \mathrm{~mm}$. longa, furcata, convexa, apice obtusa. Costa tenuis, cellulæ corticales magnæ, in sectione 4 (utroque latere 2) postice setulis crebris hirtæ. Alæ valde decurvæ, ad 12 cellulas latæ, postice ubique et plus minus dense setulosæ, margine setis simplicibus longiusculis strictis dense armatæ. Cellulæ alarum $36 \times 36 \mu$, trigonis nullis. Rami feminei magni, profunde obcordati, cucullatim convexi, dorso margineque setosi. Calyptra subcylindrica, maxime longeque hispida.

Hab. Brasilia, Caraca (Weinio).

\section{Metzgeria Perrotana St. n. sp.}

Dioica, gracilis, minor, angustissima, tenax pallide flavicans, dense depresso cæspitans. Frons ad $25 \mathrm{~mm}$. longa, semimillimetrum lata, repetito-furcata, convexa. Costa angusta et crassa, antice et postice cellulis corticalibus biseriatis et valde incrassatis tecta, ventre setosa, setis longiuseulis angustis et gracilibus, strietis. Alæ ad 13 cellulas latæ, parum decurvæ, postice sparsim setulosæ, margine setulis similiter gracilibus simplicibus armato. Cellulæ alarum $36 \mu$, parietibus crassis, trigonis itaque minus distinctis. Rami masculi minimi, cucullati costæ diametro breviores. Rami feminei pro planta magni, frondis diametro parum angustiores, ventre et margine longe setosi.

Hab. Madagascar (Perrot.), Africa australis, Montagupass (Rehmann).

Der $\boldsymbol{M}$. aurantiaca sehr ähnlich, von der sie sich durch die überall dünnen zierlichen Borsten unterscheidet. 


\section{Metzgeria comata St. n. sp.}

Dioica, major, hyalina, tenerrima, grandicellulosa, foliicola. Frons ad $2 \mathrm{~cm}$. longa, $1 \mathrm{~mm}$. lata, plana, irregulariter furcata, furcis hic illic longis simplicibus. Costa tenuissima, alis æquicrassa dein haud producta, utroque latere cellulis corticalibus biseriatis tecta nuda. Alæ asymmetrica, uno latere costæ multo angustiores (costa itaque haud mediana), omnino planæ, acuminatæ, obtusæ, cellulis tenerrimis maximis $(34 \times 126 \mu)$ formatæ, omnino nudæ, vel margine ciliis longiusculis simplicibus radicantes. Rami feminei longe et valide setosi. Calyptra optime pyriformis. nuda, vertice solum cellulis giganteis clavatis grosse comata.

Hab. Nova Caledonia (Vieillard).

\section{Metzgeria glaberrima St, n. sp.}

Dioica, mediocris, sed elongata hyalina, flaccida, dense depressocæspitosa. Frons ad $80 \mathrm{~mm}$. longa, repetito-furcata, parum vel haud convexa. Costa tenuis, nuda, cellulis corticalibus 4 (utroque latere 2). Alæ nudæ vix decurvæ ad 12 cellulas latæ, sæpe angustiores, cellulis regulariter hexagonis $36 \times 36 \mu$; aliæ multo longiores, trigona nulla. Setæ marginales simplices, costæ diametro duplo longiores, recte patulæ, sæpe subnullæ. Rami feminei magni, profunde obcordati, ventre margineque longe et valide setosi. Calyptra magna, clavata, ubique sparse hirta. Androcia magna globosa nuda.

Hab. Fretum magellanicum (Spegazzini, Dusén, Exped. Gazelle), Chile (Gay, Krause), New Zealand (Knight, Cheeseman, Beckett), Australia, Victoria (Lauterbach).

21. Metzgeria sinuata Loitl. in Szyszylowicz. Diagn. Plant, I, p. 20̈. Sterilis, major, tenerrima, hyalina, apicibus violaceis vel coeruleis, corticola. Frons ad $2 \mathrm{~cm}$. longa, $3 \mathrm{~mm}$. lata, furcata, valde convexa, apice cucullatim clausa. Costa nuda, tenuis, cellulis corticalibus in sectione 4 (utroque latere 2) internis paucis ad filum angustum reductis. Alæ maxime decurvæ, latissimæ, ad 3ə̈ cellulas latæ, nudæ, margine profunde sinuato i. e. interrupte recurvo, ciliis longis strictis recte patentibus dense armato. Cellulx alarum $3 \check{3} \mu$, ad costam Iongiores. Reliqua desunt.

Hab. Peruvia, Cutervo (Jelski).

Die Rippe ist völlig nackt, denn die keulenförmigen Cilien, welche der Autor beschreibt, sind die terminalen Keulenhaare, welche bei allen Metzgeria-Arten den Scheitel schützen, meist bald abfallen und hier nur länger erhalten sind. 


\section{Metzgeria longitexta St. n. sp.}

Sterilis, major, pallide-virens, tenerrima et flaccida, dense stratificata. Frons furcata plana, $2 \mathrm{~cm}$. longa, $1^{1 / 2} \mathrm{~mm}$. lata. Costa tenuis antice et postice cellulis biseriatis corticalibus tecta, ventre longe pilosa, pilis ample cylindricis, flaccidis. Alæ undulatæ, postice sparsim, margine dense pilosæ, pilis ut in costa ubique flaccidis latis et obtusis, margine simplicibus recteque patentibus. Cellulæ alarum elongatæ $2 \tilde{5} \times 68 \mu$, trigonis nullis.

Hab. Insula Dominica (Elliott).

Die Pflanze ist infolge ihres jedenfalls schattigen Standortes schlaff und grün und an einem günstigen Platze wird sie in dieser Hinsicht abweichen; da sie aber sonst gut entwickelt ist und besonders die Behaarung überall auf eine normale Ausbildung schliessen lässt, so konnte sie hier nicht unerwähnt bleiben.

\section{Metzgeria convoluta St. n. sp.}

Dioica, gracilis, longa et angusta, olivacea, dense intricatim cæspitosa. Frons ad $6 \mathrm{~cm}$. longa, repetito-longefurcata, valde convexa, apice obtusa. Costa tenuis, postice breviter setulosa; cellulæ corticales 6 (antice 2 postice 4). Alæ valde decurvæ vel revolutæ, nudæx, margine ciliis simplicibus brevibus crebre armatæ; cellulæ alarum $36 \times 54 \mu$, margine minores, ad costam longiores. Rami feminei dorso margineque longe setosi.

Hab. Brasilia (Glaziou).

\section{Metzgeria patagonica St. n. sp.}

Dioica, major vel mediocris, flaccida hyalina vel pallide flavo-virens, dense stratificata. Frons furcata, ramis posticis numerosis, ad $2.5 \mathrm{~mm}$. longa, $1 \frac{1}{2} \mathrm{~mm}$. lata, statu normali convexa. Costa valida, postice valde producta; cellulæ corticales in sectione 6 (antice 2 , postice 4) ventre longe setosæ. Alæ normaliter valde decurvæ sæpe revolutæ, nudæ, margine setis singulis longis et ample cylindricis crebre armato. Cellulæ alarum $40 \times 8 \tilde{4} 4 \mu$, angulis et in medio parietum valde incrassatæ, ad costam $40 \times 72 \mu$. Rami o parvi, profunde odcordati, margine et postice sparsim setosi.

Hab. Patagonia, Insula Newton (Dusén).

Die Pflanze steht hinsichtlich des Baues der Rippe der M. Wallichiana sehr nahe, die Grösse der Zellen und deren Wandverdickungen unterscheiden beide leicht; im Uebrigen sind die Pflanzen des gesammelten Rasens völlig etioliert und nur an den jüngeren Innovationen ist der wirklich normale Bau der Pflanze erkennbar. 


\section{2อั. Metzgeria Jackii St. n. sp.}

Sterilis, minor et angusta, valida, tenax, dense depresso-cæspitosa, flavo-virens, aquam sulphureo tingens. Frons furcata, ad $15 \mathrm{~mm}$. longa, valde convexa. Costa valida, in sectione ovalis, 6 cellulis corticalibus tecta (2 anticis et 4 posticis), ventre dense breviterque setosa. Alæ valde decurvæ, postice setulis brevibus strictis sparsim hirł, margine creberrime setulosæ, setulis simplicibus reliquis haud diversis. Cellulæ alarum $36 \times 45 \mu$, trigonis magnis incrassatæ, ad costam parum longiores.

Hab. Brasilia, Blumenau (Ule).

An einem der untersuchten Exemplare befanden sich ventrale Innovationen, eine jüngere kurze und eine ältere längere; ihre Frons war schmal, die Mittelrippe trug beiderseits (im Querschnitt) 4 Rindenzellen und der Thallus war, dorsal wie ventral, mit Borsten besetzt; nur der ältere und längere Adventivspross zeigte an seinem vorderen Theile, $d a$ wo er vom Muttersprosse nicht mehr bedeckt war, eine normale Ausbildung. Es giebt kaum eine bessere Illustration zu dem Gesetz, dass erst die Belichtung die Dorsiventralität der Lebermoose erzeugt; die unter M. Uleana bemerkte Missbildung findet aber dadurch noch nicht ihre Erklärung.

26. Metzgeria furcata (L.) Lindb. Monogr. Metzg., p. 3 อ̆.

Syn. : Jungermannia furcata L. Sp. pl., p. 1002.

Metzgeria planiuscula Spruce. Rev. bryol. 1888, p. 34/35̈.

Metzgeria flavo-virens Col. Trans. N. Zeal. Inst. 1888, vol. XXI.

Dioica, minor, pallida, corticola, dense depresso cæspitans. Frons furcata, subplana, apice rotundata. Costa tenuis, cellulis corticalibus 6 (antice 2 , postice 4 minoribus et anguste rectangulatis), ventre longius setosa; alæ vix decurvæ nisi in locis minus humidis, postice plus minus dense setosæ setis longiusculis usque ad marginem distributis, setæ marginales re vera nullæ. Cellulæ alarum $27 \times 36 \mu$, trigonis parvis, ad costam longiores. Rami feminei obcordati plano-convexi, longe et sparsim piliferi. Calyptra clavato-pyriformis, plus minus hispida.

Hab. Europa ubique communis, e confinibus mediterraneis in Lapponiæ alpina regione, Cancasus (Levier), Africa, Abyssinia (Traversi), Natal (Rehmann), Kamerun (Staudt), Chile (Philippi, Lechler), Tasmania (Weymouth), New Zealand (Colenso), Australia, Queensland (Hartmann), Victoria (F. v. Müller, Mrs. Mac Cann).

In Sibirien und Japan scheint die Pflanze nicht vorzukommen, ebenso wenig ist sie aus Nordamerica bekannt.

BULL. HERB. BOISs., décembre 1899. 289 
27. Metzgeria saccata Mitten. Journ. Linn. Soc. 1886. Vol. XXII, p. 145 .

Dioica, minor, rigida, subhyalina, muscis corticolis consociata. Frons furcatim multiramosa, ad $20 \mathrm{~mm}$. longa, vix millimetrum lata, valde convexa. Costa nuda, valida, subteres, postice multo magis producta; cellulæ corticales 6 (antice 2 majores, postice 4 minores); cellulæ internæ quam corticales multo minores, triseriatæ. Alæ decurvæ, profunde incisolobulatæ, lobulis a latere exteriore convolutis, sub fronde occultis, inflatoclavatis, margine ciliis longis simplicibus armatis. Cellulæ alarum $45 \mu$, ad costam longiores, parielibus validis æqualiter incrassatis. Rami feminei pro planta magni, inflato conchæformes, duplo latiores quam longi, margine ventreque setulosi.

Hab. Tasmania (Milligan, Weymouth), New Zealand (Helms).

Der Durchschnitt der Frons, wie der Autor ihn abbildet, ist sicher durch eine Gabelung geführt, wo sich bekanntlich die Rippe verdoppelt; siehe hierüber die Einleitung zur Gattung Metzgeria.

\section{Metzgeria Lechleri St. n. sp.}

Sterilis, major, fiaccida, fusco-virens, aliis hepaticis consociata. Frons longe furcata, ad $30 \mathrm{~mm}$. longa, plus millimetrum lata, subplana. Costa valida, subteres, bene producta, utroque latere 4 cellulis corticalibus, humilibus tecta, ventre setulis longiusculis tenuibus dense obtecta. Alæ vix decurvulæ ad 20 cellulas latæ, postice dense breviterque setulosæ, margine setulis similiter gracilibus, simplicibus crebre armato. Cellulæ alarum $36 \mu$, ad costam longiores, parietibus validis angulisque distincte incrassatis.

Hab. Chile, Arique (Lechler).

\section{Metzgeria Dusenii St. n. sp.}

Dioica, mediocris, pallida, corticola. Frons repetito-furcata, valde convexa, apice obtusa. Costa lata et humilis, antice convexa postice plana, omnino nuda, cellulis corticalibus 8 , quarum 4 dorsales magnæ et valde productæ, 4 ventrales multo minores, centrales paucæ. Alæ revolutæ, conniventi-tangentes nudæ, margine tantum ciliis longis flaccidis simplicibus ornatæ. Cellulæ alarum $36 \times 450$, marginem versus minores, ad costam longiores, trigonis nullis. Rami masculi parvi nudi, ut in congeneribus cucullati.

Hab. Fretum magellanicum, Insula Desolacion (Dusén). 
30. Metzgeria dichotoma (Sw.) Nees. Hep. Eur. III, p. 508.

Syn. : Jungermannia dichotoma Sw. Prodr. Ind. occ. p. 145.

Dioica, mediocris, pallida vel viridula, corticola rarius saxicola, dense depresso cæspitans. Frons regulariter furcata, convexa, apice obtusa. Costa crassa, bene producta, ventre breviter setosa; cellulæ corticales 10 , quarum 4 anticæ et 6 posticæ. Alæ decurvæ, postice breviter et minus dense pilosæ, margine setulis strictis simplicibus oblique patulis armatæ. Cellulæ alarum $27 \times 36 \mu$, margine minores, ad costam majores. Rami feminei profunde obcordati, dorso margineque dense selosi. Calyptra clavato-pyriformis, superne hispidissima.

Hab. Jamaica (Swartz), Cuba (Wright), Brasilia (Beyrich, Glaziou, G. A. Lindberg, Lindman, Puiggari).

31. Metzgeria linearis (Sw.) Austin. Torrey Bot. Cl. VI, p. 18. Syn. : Jungermannia linearis Sw. Prodr. veg. Ind., p. 145.

Dioica, minor, rigida, angusta, olivacea, algoidea, in fruticum ramulis effuse cæspitans. Frons ad $2 \mathrm{~cm}$. longa, vix $1 \mathrm{~mm}$. lata, furcatim multiramosa, ramis adventivis posticis haud raris, parum convexa. Costa nuda, radicellis suctoriis tantum sparsim affixa, crassa, subteres, cellulis corticalibus 12, utroque latere 6 seriatis, centralibus maxime incrassatis lumineque cellularum fere obliterato. Alæ nudæ, ad 20 cellulas latæ, validæ ob cellulas ad angulos trigone incrassatas et limbo maxime incrassato, ex una serie cellularum formato. Ciliæ marginales valde reductæ, dentiformes, breves, valde incrassatæ obtusæ, sæpe deficientes. Cellulæ alarum rhombeo-hexagonæ $18 \times 450$, ad costam latiores, margine $18 \times 117 \mu$, obliquæ seriatæ. Rami masculi pilis numerosis spiniformibus hirti.

Hab. Jamaica (Swartz), Cuba (Wright).

\section{Metzgeria effusa St. n. sp.}

Dioica, mediocris, dilute flavicans vel hyalina in ramulis ultimis fruticum effuse cæspitans maximeque intricata. Frons valde ramosa, repetitofurcata, ramis simplicibus interjectis; rami postici numerosi, sæpe in furca seriati. Costa crassa, in sectione elliptica, bene producta, ventre nuda vel setosa, setis strictis longiusculis; cellulæ corticales costæ $\mathbf{1 6}$ (utroque latere 8); cellulæ internæ らั seriatæ, corticalibus vix minores. Alæ planæ vel undulatæ, 12 cellulæ latæ, nudæ, radicellis hic illic affixæ, margine nudæ vel simpliciter setosæ, setis longiusculis strictis oblique ad posticum nutantes. Cellulæ alarum $18 \times 36 \mu$, ad costam $27 \times 544 \mu$, 
margine $25 \times 25$ ‥ Rami feminei parvi, paucisetosi, semper e basi innovati. Calyptra magna optime pyriformis, apice longe setosa.

Hab. Brasilia (Ule), Guiana britannica (Quelch).

\section{Metzgeria angusta St. n. sp.}

Dioica, mediocris, gracilis viridis vel pallide flavescens, vel rufescens. dense cæspitosa, corticola et terricola. Frons ad $3 \mathrm{~cm}$. longa, repetitofurcata, angusta plus minus convexa, antice nuda, postice ubique setulosa. Costa tenuis, cellulis antice posticeque biseriatis tecta, ventre longius setosa. Alæ ad 8 cellulas latæ, plano-convexæ, setulis sparsim hirtæ, interdum hic illic nudæ, margine similibus ciliis brevibus divergentigeminatis armato. Cellulæ alarum papulosæ, $37 \times 54 \mu$, trigonis parvis distinctis incrassatæ. Rami feminei Ionge setosi. Calyptra ubique longe setosa. Rami masculi parvi, nudi.

Hab. Brasilia tropica et subtropica (Ule, Glaziou, Lindman), Venezuela (Fendler), Chile et Patagonia (Dusén), Trinidad (Crüger), Mexico (Sartorius), Guatemala (Levier), Louisiana (Langlois), Apiahy (Puiggari), Santo Domingo (Eggers).

Die Dusén'schen Pflanzen sind erdbewohnend und in der Grösse äusserst reduziert.

\section{Metzgeria madagassa St, n. sp.}

Dioica, minor, angustissima rigida dilute olivacea, dense stratificata. Frons furcata ad $2 \mathrm{~cm}$. longa, semimillimetrum lata, valde convexa. Costa tenuis, cellulis corticalibus utroque latere biseriatis tecta, ventre crebre et longiuscule setulosa, setulis validis strictis. Alæ valde decurvæ, 12 cellulas latæ, postice ubique breviter setulosæ, cellulis prominulis papulosæ, margine incurvo dense setuloso, setulis breviusculis strictis, divergentigeminatis. Cellulæ alarum 37 p. parietibus validis trigonisque majusculis, ad costam longiores. Rami feminei parvi, margine longesetosi. Calyptra optime clavata ubique longe setosa.

Hab. Madagascar (Besson, Borgen, Sikora), Mascareignes (Robillard, Rodriguez), Usambara (Holst.), Himalaya, Sikkim (Bretandeau).

Das Vorkommen der Pflanze in 0stindien ist nicht auffallend, da wir auch Ptychanthus striatus, Radula Perottetii und andere in gleicher Weise aus beiden Gebieten kennen.

3อั. Metzgeria rufula Spruce. Edinb. Bot. Soc. 1885ั, p. כ̌อั5ั.

Dioica, mediocris, flaccida, pallide rufula, stratificata. Frons furcata, ad 
$4 \mathrm{~cm}$. longa, subplana. Costa tenuis, cellulis corticalibus utroque latere biseriatis, postice dense et longiuscule pilosa. Alæ parum decurvæ, undulatæ, ad 20 cellulas latæ, postice setis sparsis longiusculis, margine geminatis flexuosis hirtæ. Cellulæ alarum $36 \times 544$, trigonis nullis. Rami feminei parvi, margine longiciliati, postice nudi.

Hab. Andes quitenses (Spruce, Wallis).

\section{Metzgeria Renauldii St. n. sp.}

Sterilis, minor, rigida, pallide flavicans, aliis hepaticis consociata. Frons ad $15 \mathrm{~mm}$. longa, valde convexa, furcata. Costa tenuis, cellulis corticalibus utroque latere biseriatis tecta, ventre longe setosa. Alæ valde decurvæ, postice longe setosæ, margine ciliis geminatis breviusculis optime aduncis et late divergentibus armato. Cellulæ alarum $4 \breve{a} \mu$, ad costam $4 \ddot{5} \times 63 \mu$, trigonis magnis incrassatæ.

Hab. Insula Maurice (Rodriguez), Madagascar (Berthieu).

Der M. hamatiformis Schffn. sehr nahestehend; sie unterscheidet sich durch auffallend tief hakig eingekrümmte Randborsten, sowie durch die sehr starken Eckenverdickungen der Flügelzellen, wodureh die Pflanze ihren rigiden Habitus erhält.

\section{Metzgeria camerunensis St. n. sp.}

Dioica, major, elongata, flaccida, pallide flavicans vel virescens, dense stratificata. Frons ad $5 \mathrm{~cm}$. longa, furcata, furcis millimetrum latis, convexis. Costa tenuis, utroque latere cellulis corticalibus biseriatis tecta, ventre setulis tenuibus breviusculis hirta. Alæ decurvæ, ventre setulis longiusculis remotis obsite, margine incurvo breviter setuloso, setulis geminatis, divergentibus strictis, gracilibus. Cellulæ alarum oblongohexagonæ, $36 \times 57 \mu$, trigonis subnullis. Rami feminei parvi, ubique setulis longis gracilibus hispidissimi.

Hab. Kamerun (Dusén).

Der $M$. madagassa St. sehr nahestehend, doch viel ansehnlicher als diese und ihre Zellen viel grösser.

\section{Metzgeria fuscescens, Vitten. n. sp.}

Dioica, major, sæpe longissima, rufescens vel flavo-rufescens, corticola. Frons ad $6 \mathrm{~cm}$. longa, $1 \mathrm{~mm}$. lata, furcata, convexa. Costa tenuissima, antice posticeque cellulis corticalibus biseriatis tecta, ventre setis longis curvatis hirta. Alæ decurvi, postice setis longis flaccidis plus minus dense obtectæ, margine crebre setulosæ, setulis brevioribus, geminatis diver- 
gentibus curvatis, flaccidis. Cellulæ alarum $36 \times 54 \mu$, ad costam longiores. trigonis majusculis incrassatæ. Rami feminei parvi, obcordati, margine crebre et Ionge setiferi.

Hab. Java, in monte Megamendong 6000' (Motley, Paterson, Solms Schiffner).

\section{Metzgeria hamatiformis Schffn. Nova Acta LX, p. 272.}

Monoica, minor et angusta, supra muscos expansa. Frons furcata, ad $4 \mathrm{~cm}$. longa, $12 \mathrm{~mm}$. lata, convexa. Costa tenuis, cellulis corticalibus utroque latere biseriatis, ventre longe pilosa. Alæ valde decurvæ, postice sparsim piliferæ, sæpe nudæ, margine crebre setulosæ, setulis longiusculis hamatis, divergenti-geminatis. Cellulæ alarum 450 $\mu$, ad costam longiores, trigonis nullis; cuticula antica minute papillosa. Rami masculi parvi, nudi, feminei mihi ignoti, auctore ceterum nusquam descripti.

Hab. Java (Junghuhn, Schiffner), Amboina (G. Karsten).

40. Metzgeria procera Mitten in Hooker. Fl. Nov. Zel. II, p. 166. Syn. : Metzgeria hamata var. $\beta$. procera Lindb. Monogr. Metz, p. 28.

Sterilis, spectabilis, sæpe longissima, pallida vel plus minus viridis. stratificata vel pendula. Frons ad $15 \mathrm{~cm}$. longa, $3 \mathrm{~mm}$. lata, valde convexa. furcata, furcis sæpe simplicibus longe attenuatis, rami adventivi postice numerosi. Costa tenuis, cellulis corticalibus magnis, utroque latere biseriatis tecta, ventre sparsim pilifera, pilis longis flaccidis, ample cylindricis. Alæ valde recurvæ, postice sæpe nudæ, normaliter sparsim pilosæ margine pilis longissimis geminatis hamatis flaccidis armatæ. Cellulæ alarum maximæ, alte convexo-prominentes, regulariter hexagonæ $74 \mu$, versus costam sæpe multo longiores (ad $74 \times 117 \mu$ ), trigonis minutis. Reliqua desunt.

Hab. Guadeloupe (Funck et Schlim, l'Herminier), Dominica (Elliott).

Im Vertrauen auf Lindbergs Untersuchungen hatte ich, unbekannt mit dem Original aus Guadeloupe, Pflanzen dieser Art von der Insel Dominica M. latissima genannt und unter diesem Namen mitgeteilt, was also zu korrigieren ist.

\section{Metzgeria papulosa St. n. sp.}

Dioica, major, interdum valde elongata, plus minus pallide-virens, dense stratificata. Frons ad $7 \mathrm{~cm}$. Ionga, plus $1 \mathrm{~mm}$. lata, furcata convexa. Costa tenuis, cellulis corticalibus utroque latere biseriatis tecta, ventre Ionge pilosa, pilis biseriatis. Alæ valde decurvæ, paucipilosæ, margine 
pilis similibus geminatis, hamatis sed inter se divergentibus armatæ. Cellulæ alarum alte papulos $2,36 \times 54 \mu$, ad costam $36 \times 72 \mu$, trigonis nullis. Rami feminei parvi, obcordati, margine ventreque piliferi.

Hab. Hawai (Heller No 2253), Tahiti (Nadeaud), Viti (Græffe).

42. Metzgeria scobina Mitt. Linn. Soc. 1886 . Vol. XXII, No 445.

Dioica, mediocris, flavo-rufescens, dense stratificata. Frons $25 \mathrm{~mm}$. longa, vix $1 \mathrm{~mm}$. lata, furcata, convexa. Costa tenuis, parum producta, ventre longe hamatim pilosa; cellulæ corticales utroque latere biseriatæ, internis majores. Alæ decurvæ, ad $\mathbf{1}$ cellulas latæ, postice sparse pilosæ, pilis longis validis hamatis, margine ciliis longis geminatis, divergentibus vel homomallis armatæ. Cellulæ alarum $45 \%$ ad costam $45 \times 63 \mu$, antice alte conico-prominulæ verticeque maxime incrassato. Rami feminei parvi, profunde obcordato-bilobi, ventre et margine longe pilosi.

Hab. Borneo (Everetl), Sumatra (Kehding).

\section{Metzgeria consanguinea Schffn. Nova Acta LX, p. 271.}

Dioica, mediocris, corticola, pallida, cæspitans. Frons furcata, valde convexa, apice obtusa. Costa tenuis, ventre setulosa, cellulís corticalibus 4 (postice et antice 2). Alæ nudæ, margine solum setulis brevibus divergenti-geminatis armatæ. Cellulæ alarum $36 \times 54 \mu$, trigonis magnis incrassatæ. Rami feminei dorso margineque setosi. Calyptra superne crebre setosa, ad basin nuda.

Hab. Java (Karsten, Schiffner), Japan, Musashi (Makino), Luzon (Semper).

Die vom Autor I. c. beschriebenen hornartig zugespitzten, übrigens aufsteigenden Aeste sind keine nur dieser Art zukommende Eigenthümlichkeit. Man findet dieselbe auch an anderen Arten, besonders wenn die Pflanze auf lebende Blätter gerathen ist; was sie zu dieser Ausbildung so abweichender Aeste veranlasst, ist nur an Ort und Stelle zu entscheiden; wahrscheinlich ist es aber ein Streben nach dem Lichte.

44. Metzgeria nitida Mitt. Linn. Soc. 1886.

Syn. : Metzgeria australis St. Hedwigia, p. 39.

Metzgeria magellanica Schffn. Exped. Gazelle 1889, p. 43.

Metzgeria decipiens? Schffn., ibidem, p. 43.

Dioica, pallide virens, dense stratificata. Frons furcata, sæpe ramulis posticis solum innovata, convexa, marginibus valde decurvis. Costa tenuis, dorso ventreque cellulıs corticalibus biseriatis tecta, postice remote brevi- 
terque setulosa. Alæ nudæ, cellulis prominulis papulosæ, margine geminatim ciliatæ, ciliis longis hamatis divergentibus vel homomallis. Cellulæ alarum $36 \times 45 \mu$, ad costam longiores, trigonis magnis incrassatæ. Rami o maxime cucullati, nudi. Rami feminei carinatim convexi, setulosi. Calyptra clavata, magna, setosa. Sporæ $18 \mu$.

Hab. Australia (Bäuerlen, Camera, Lachmann, Merrah, Maplestone, French, Hartmann, Bailey), Tasmania (Moore, Weymouth), New Zealand (Colenso, Zürn, Helms, Beckett), Fretum magellanicum (Naumann).

Die Beschreibung des Autors ist leider so kurz, dass Niemand die Pflanze wiedererkannt hat. M. decipiens Schffn. gehört wahrscheinlich hierher, ist aber eine jener schlecht entwickelten Formen, die eine sichere Bestimmung überhaupt unmöglich machen; würde man von phanerogamen Pflanzen solche Exemplare zur Schaffung einer neuen Art benutzen? Sicher nicht.

\section{5.. Metzgeria thomeensis St. Hedwigia 1891, p. 271.}

Dioica, major spectabilis, pallide-virens, flaccida, sæpe elongata, dense stratificata. Frons ad $\mathrm{s} \mathrm{cm}$. longa, millimetrum lata, repetito furcata vel furcis simplicibus i. e. nondum in furcas evolutis, hic illic subpinnata. Costa tenuis, in sectione elliptica, utroque latere cellulis corticalibus biseriatis tecta; cellulæ internæ multo minores, posticæ breviter setulosæ. Alæ parum decurvæ, ad $\mathbf{I}$ cellulas latæ, postice similiter remoteque setulosæ, margine omnino nudæ. Cellulæ alarum $4 \partial \ddot{x} \times \check{5} 4 \mu$, parietibus validis. Rami feminei profunde obcordati, inflato-bivalvati, parum setosi. Calyptra superne creberrime et longissime hispida, setis calyptræ subæquilongis.

Hab. Africa occid. Insula San Thomé (Quintas).

Da die Pflanze an ihren Randzellen, und zwar an deren basiskopem Ende, meist zwei kleine Zellen segmentiert hat, die opponiert stehen und aus welchen in bekannter Weise die Randborsten hervorgehen, so ist sie $z u$ den Biciliaten zu stellen; sonderbarer Weise sind diese Cilien nicht entwickelt worden, während oft daneben, aus der übrig geliebenen grösseren Hälfte der Zelle, sich ein Wurzelhaar ausgestülpt hat.

\section{Metzgeria albinea Spr. Soc. bot. de France, 1889, p. CCI.}

Dioica, mediocris, subhyalina, muscicola. Frons ad $2 \mathrm{~cm}$. longa, regulariter furcatim ramosa, antice nuda, postice in costa margineque hirta. Costa tenuis ventre paucisetosa, antice posticeque cellulis biseriatis tecta. Alæ convexæ, nudæ, margine ciliis longis strictis, geminatis et diver- 
gentibus armatæ. Cellulæ alarum $54 \mu$, convexo-prominulæ, trigonis nullis. Calyptra paucisetosa.

Hab. Rio Janeiro (Glaziou 7378).

47. Metzgeria leptoneura Spruce. Edin. Bot. Soc. 1885, p. 5ั5๊อ̆.

Dioica, mediocris, flaccida, tenera, fulvo-viridis, in rupibus stratificata. Frons ad $4 \mathrm{~cm}$. longa, $1^{1 / 2} \mathrm{~mm}$. lata, longe furcata, maxime convexa. Costa tenuis et humilis, cellulis corticalibus utroque latere biseriatis, ventre longe pilifera, pilis flaccidis, bene cylindricis. Alæ nudæ, maxime decurvæ, sæpe omnino revolutæ, cellulis prominulis distincte papulosæ, ceterum margine dense piliferæ, pilis geminatis longis divergentibus flaccidis. Cellulæ alarum magnæ $450 \times 63 \mu$, ad costam vix majores, trigonis nullis. Rami feminei obcordati, margine et ventre pilosi.

Hab. Andes Peruviæ (Spruce), Novæ Granadæ (Wallis), et Boliviæ (Pearce).

M. hamata differt statura 'majore, fronde multo validiore ciliisque marginalibus multo brevioribus.

48. Metzgeria recurva St. in Engler Bot. Jahrb. VIII, p. 90.

Syn. : Metzgeria Warnstorffii St. Engler. Bot. Jahrb. 1890̈, p. 305.

Dioica, minor, gracilis, flavescens, dense stratificata. Frons furcata, ad $2 \mathrm{~cm}$. longa, vix millimetrum lata, valde convexa. Costa tenuis, a dorso compressa, utroque latere cellulis corticalibus biseriatis tecta; cellulæ centrales ad 10 , vix minores, ventrales longe pilosæ. Alæx valde decurvæ sæpe revolutæ, nudæ, margine dense pilosæ, pilis breviusculis, geminatis, ample cylindricis, optime hamatis, divergentibus. Cellulæ alarum $36 \mu$, ad costam hic illic majores $(36 \times \breve{5} 4 \mu)$, parietibus validis. Rami feminei parvi, obcordati, convexo-bivalvati, margine longe pilosi. Rami masculi ignoti.

Hab. Africa occid., Insula San Thomé (Moller), Kamerun (Dusén), Congo, Bourbon (Rodriguez).

M. hamata Lindb., welche unserer Pflanze nahe steht, ist in allen Theilen (Frons, Zellen, Cilien) wesentlich grösser. M. Warnstorffii St. ist nur eine schlecht entwickelte Form; die Standorte der Pflanze zeigen eine ungeheure Verbreitung an, wie wir das bereits an anderen Lebermoosen Africas kennen.

49. Metzgeria hamata Lindb. Monogr. Metz. p. 9 อ̈.

Dioica, major, sæpe valde elongata, flaccida corticola, pallida vel lurida. 
Frons furcata, ad $10 \mathrm{~cm}$. longa, $2^{1} / 2 \mathrm{~mm}$. lata, valde convexa. Costa tenuis, cellulis corticalibus magnis, utroque latere biseriatis, ventre sparsim longe pilosa. Alæ nudæ, maxime decurvæ et sæpe conniventitangentes, margine ciliatæ, ciliis longiusculis geminatim-divergentibus.

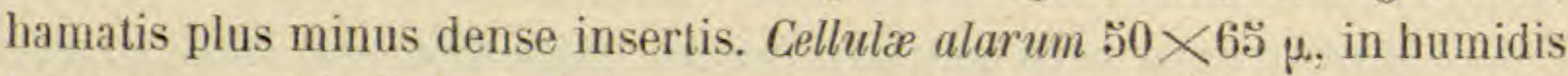
longiores, parietibus validis. Rami feminei parvi, paucis setis hirti. Calyptra longe pyriformis, ubique longe denseque setosa. Rami masculi nudi.

Hab. America tropica, Insulæ antillanæ, Guadeloupe, Martinique, Puertorico, Santo Domingo, Dominica (l'Herminier, Husnot, Sintenis, Eggers, Elliott), Jamaica (Swartz), Guiana brit. (Quelch, in cacumine montis Roraima), Peruvia, Yungas (d'Orbigny), Costarica (Pittier), Patagonia (Dusén), New Zealand (Hooker, Dall), India orient. Sikkim (Hooker. Mrs. Lyell), Nova Guinea, Yule Mtes (Kowald), Moruka $1300 \mathrm{~m}$ (Loria), Java (Zollinger, Schiffner), America septentr., Alleghany Mtes (Sullivant), Britannia, Scotland (Greville), Ireland (Moore, Lindberg).

Lindberg hat eine varietas procera 1 . c. aufgestellt; dies ist aber zweifellos eine gute Art, welche Mitten vor Jahren bereits (Flora Nova Zelandiæ) hervorhob; der enorme Unterschied der Zellgrösse würde allein genügen, die Pflanze nicht zu M. hamata zu stellen; siehe M.procera.

50. Metzgeria atrichoneura Spr. Edinb. Bot. Soc. 1885, p. อั556.

Dioica, minor, sordide albicans, laxe stratificata, supra muscos repens. Frons furcata, maxime convexa, marginibus fere revolutis, apice cucullata. Costa nuda, tenuis, dorso ventreque cellulis biseriatis tecta. Alæ nudæ, margine ciliatæ, ciliis geminatis longis, strictis. Cellulæ alarum $37 \mu$, antice convexo-prominulæ, angulis incrassatis. Rami masculi parvi, nudi. Rami feminei obcordato-reniformes, tenuissimi, nudi, margine solum longe ciliati.

Hab. New Zealand (Lauterbach).

\section{Metzgeria adscendens St. n. sp.}

Dioica, minor, flavo-virens, foliicola. Frons furcata, ramulis numerosis posticis innovata. Alæ subplanæ, nudæx, in ramulis jumioribus adscendentibus valde attenuatæ, apice evanidæ, ceterum decurvo-canaliculatæ, margine setis longiusculis geminatis divergentibus armatæ. Costa tenuis, nuda, hic illic radicellis affixa; cellulæ corticales antice biseriatæ, postice quadriseriatæ. Cellulæ alarum valde irregulares, $27 \times 36 \mu$, aliæ multo majores parietibus validissimis, Rami feminei semper innovati adscen- 
dentes similiter attenuati atque canaliculati, margine nudi vel geminatim setulosi, sæpe radicellis simplicibus arcte repentes. Calyptra (juvenilis) setulis longis hispidissima.

Hab. Guiana, ad flum. Amakuru (Gœbel), Brasilia, Apiahy (Puiggari).

Die aufsteigenden hornartig zugespitzten Aeste sind schwerlich eine besondere Eigenthümlichkeit dieser Pflanze; man findet dasselbe Verhalten auch an anderen Arten (siehe M. consanguinea Schffn.).

ร2. Metzgeria conjugata Lindb. Monogr. Metzg., p. 29.

Monoica, mediocris, dense caspitosa. Frons repetito furcata, convexa, apice obtusa. Costa postice solum producta, 6 cellulis corticalibus tecta, quarum 2 anticæ, 4 posticæ minores longeque setiferæ. Alæ valde decurvæ, nudæ, margine creberrime setulosæ, setis brevibus strictis, divergentigeminatis. Cellulæ alarum $40 \times 6 \Xi ّ$, trigonis nullis. Rami feminei dorso margineque longe setosi; calyptra ubique, præsertim apice, hispida.

Hab. Europa, Asia, Caucasus (Brotherus, Kärnbach, Levier), Celebes, Java (Stahl, Schiffner). Birma (Micholitz), Japonia (Faurie, Makino), Africa, Mozambique (Carvalho), Mascareignes (Rodriguez), Tanganjika (Guillemé), Madugascar (Campenon, Berthieu), Natal(Rehmann), America sept., Washington Terr. (Røell), Louisiana (Langlois), America tropica, Brasilia (Wainio, Ule, Kunert, Glaziou), Argentinia (Lorentz), Chile (Hahn. Neger), New Zealand (Kirk).

\section{Metzgeria Wallisiana St. 1. sp.}

Dioica, major, flaccida, flavo-rufescens, dense caspitosa. Frons furcata, ad $4 \mathrm{~cm}$. longa, valde convexa. Costa valida, subteres, postice multo magis producta ibidemque longe pilosa, in trunco primario multo magis crassa quam in furcis superioribus. ubique tamen 6 cellulis corticalibus tecta, quarum 2 minores anticæ et 4 multo ampliores posticæ; cellulæ internæ parva quadriseriatæ. Alæ valde decurva, sæpe conniventi-tangentes. nuda, margine crebre pilosæ, pilis longissimis, ample cylindricis, flaccidis, ceterum geminatis, hamatim incurvis, inter se divergentibus. Cellula alarum $63 \mu$. haud incrassatæ, ad costam parum longiores. Rami feminei parvi, dense setosi. Calyptra magna et robusta, maxime crassa. cylindrica, superne setis giganteis maxime hispida.

Hab. Nova Granada. Antioquia. Paramo de Sonson (G. Wallis).

ร4. Metzgeria Sandei Schffn. Kais. Akad. Wien. LXVII, p. 181. Dioica, mediocris, angusta, flaccida, pallida, in cortice caspitosa. Frons 
furcata, ad $3 \frac{1}{2} \mathrm{~cm}$. longa, millimetrum lata, subplana. Costa tenuis, ventre setulis longiusculis angustis strictisque hirta. Cellulæ corticales in sectione 6 (antice 2 , postice 4). Alæ parum convexæ (semper?) ad 18 cellulas latæ, postice sparsim hirtæ margineque dense setulosæ, setulis gracilibus ut in costa, margine geminatæ, substrictæ divergentes. Cellulæ alarum $36 \times 4 \breve{~} \mu$, trigonis subnullis. Rami feminei obcordati, margine ventreque setosi. Calytra pyriformis, longe setosa.

Hab. Java (Schiffner), Sumatra (Schiffner).

รัจั. Metzgeria leptomitra Spruce. Ed. Bot. Soc. 1885, p. อัö4.

Dioica, major, tenerrima, dilute flavo-virens, prostrata. Frons ad $5 \mathrm{~cm}$. longa, plus $1 \mathrm{~mm}$. lata, regulariter furcata, parum convexa. Costa tenuis, cellulis corticalibus antice $\mathbf{2}$, postice 4 minoribus, tecta, ventre longius setosa, setis minus confertis recte patulis. Alæ subplanæ, sparsim et longiuscule setosæ, margine decurvo setulis brevibus divergenti-geminatis dense armato. Cellulæ alarum $36 \times \check{4} 4 \mu$, ubique fere æquimagnæ. Rami feminei parvi, obcordati, margine ventreque setosi. Calyptra breviuscula, clavato-oblonga, ubique longe setosa.

Hab. Andes peruviani et quitenses (Spruce), Mexico, Xilitta (Herb. Paris).

Die Pflanze vom Rio Negro habe ich nicht gesehen, bezweifle aber, dass sie hierher gehört, da Spruce von den Metzgerien manches zusammenfasst, was sicher verschieden ist; er giebı mehrfach die ventralen Rindenzellen der Costa nicht an, weil sie wegen der dichten Behaarung nicht ohne Weiteres erkennbar sind.

\section{ั6. Metzgeria crenata. St. n. s.}

Dioica, mediocris, pallide-flavicans, flaccida, corticola. Frons ad $3 \mathrm{~cm}$. longa, furcata, ramís posticis numerosis apice furcatis vel e ventre innovatis irregulariter ramosa, ceterum convexa, postice ubique hirta, apice obtusa. Costa adulta 6 cellulis corticalibus tecta (antice 2 , postice minoribus 4) ventre longe setosa. Alæ 14 cellulas latæ, valde decurvæ, marginibus profunde crenatis, revolutis et tangentibus, postice longe piliferæ, pilis tenuibus, flaccidis. Cellulæ alarum $36 \times 54 \mu$, teneræ, trigonis nullis. Ciliæ marginales geminatæ, longæ, tenues, divergentes flaccidæque. Rami feminei et calyptra maxime setosæ.

Hab. Venezuela (Funk et Schlimm).

Eine höchst ausgezeichnete Art, deren tief gekerbte Ränder aber nur zu sehen sind, wenn man die Pflanze in Milchsäure oder Chloralhydrat aufquellen lässt. 


\section{Metzgeria quadrifaria St. n. sp.}

Sterilis, mediocris, pallide-virens, muscis consociata. Frons repetitofurcata, ad $3 \mathrm{~cm}$. longa, millimetrum lata, convexa. Costa valida, ventre magis producta ; cellulæ corticales antice biseriatæ, postice quadriseriatæ ibidemque pilis longis distincte acuminatis, divergenti-geminatis crebre armatæ. Cellulæ alarum $27 \times 4.5$, , ad costam longiores, trigonis nullis.

Hab. Africa orient. Somali. (G.-D). Riva).

Die Pflanze wiederholt die Gabelung in so kurzen Abständen, dass die Costa zum allergrössten Teile verdoppelt ist und nur am Grunde der Gabeläste die normale Zahl der Rindenzellen zu erkennen ist.

58. Metzgeria fruticola. Spruce. Edinb. Bot. Soc. 188气̃, p. 5ัă4. Dioica, major elongataque, flaccida et tenerrima, pallide-virens, stratificata, valde intricata et vix extrahenda. Frons ad $7 \mathrm{~cm}$. longa, $2 \mathrm{~mm}$. lata, irregulariter multifurcata, furcis maxime convexis. Costa valida, in sectione late elliptica, utroque latere squaliter breviterque producta cellulisque corticalibus quadriseriatis et humilibus tecta, ventre longis pilis flaccidis villosa. Alæ fere revolutæ, marginibus conniventitangentibus subcylindricæ, nudæ, margine longius pilosæ, pilis geminatis hamatim incurvis. Cellulæ alarum papulosæ, $36 \times \check{4} 4 \mu$, aliæ præcipue ad costam multo majores ad $544 \times 90 \mu$, trigonis nullis. Rami feminei, parvi obcordati maxime longeque setiferi.

Hab. Andes quitenses, in mte Tunguragua (Spruce).

59. Metzgeria clavæflora. Spruce. Edinb. Bot. Soc, 1888 . p. อัวั6.

Dioica, major, flaccida, pallide viridis, ad saxa arboresque pendula denseque cæspitosa. Frons ad $10 \mathrm{~cm}$. longa, $16 \mathrm{~mm}$. lata, dichotome ramosa, plana, apice rotundata. Costa valida, in sectione ovalis, postice dense breviterque setulosa ; cell. corticales 8 , dorso ventreque 4. Alæ subplanæ, nudæ vel postice pauciciliatæ, marginibus parum decurvis, ad costam crass , versus marginem attenuatæ, margine creberrime setulosæ, setulis brevissimis, ipso margine divergenti-geminatis, interdum ternis i. e. intra marginem tertia setula auctis. Cellulæ alarum $54 \times 72 \mu$, ad costam longiores, teneræ, parietibus haud incrassatis. Rami fem. parvi, margine dorsoque longe et valide setosi. Calyptra prælonga, clavata, inferne nuda, superne longe et crebre setosa.

Hab. Andes quitenses. (Spruce.) 
60. Metzgeria bracteata. Spr. Edinb. B. Soc. 1885, p. อัวั3.

Dioica, major, pallida, in sicco fulva vel fuscidula, cæspitoso-stratificata. Frons ad $3 \mathrm{~cm}$. longa, $3 \mathrm{~mm}$. lata, repetito-furcata, hic illic undulata vel subcrispula, antice nuda, postice ubique dense villosa. Costa tenuis, parum producta, dorso ventreque cellulis parvis quadriseriatis tecta, breviter setulosa. Alæ plano-convexæ, setulis brevibus flaccidis flexuosisque villosæ, margine cilüs similibus divergenti-geminatis hirtæ. Cellulæ alarum $36 \times 36 \mu$ ad costam $45 \times 45 \%$, parietibus valde æqualiterque incrassatis. Rami \& magni, obcordati dorso margineque setosi, basi utrinque $4-0$ lobulis variiformibus, nudis patulisque instructi. Calyptra pyriformis densissime setosa.

Hab. Andes quitenses (Spruce) Nova Granada (Wallis).

Höchst ausgezeichnet durch die wollige Behaarung der Unterseite und durch die blattförmigen Anhängsel des o Astes.

\section{Metzgeria Uleana. St. n. sp.}

Dioica, omnium latissima, flaccide el tenerrima, in sicco flavo-rufescens, laxe stratificata. Frons ad $4 \mathrm{~cm}$. longa, $3 \mathrm{~mm}$. Iata, parum convexa, undulata, apice rotundata. Costa tenuis, cellulis corticalibus 10 (quarum 4 anticæ et 6 posticæ) ceterum parvis et parum incrassatis, ventralibus creberrime breviterque setiferis. Alæ ad 30 cellulas latæ, postice dense setulosæ, setulis tenuibus breviusculis, costæ diametro æquilongis, marginalibus brevibus strictis geminatim divergentibus, sæpe simplicibus ; cellulæ alarum $27 \times 36 \mu$, trigonis parvis distinctis, ubique fere æquimagnæ. Rami feminei maximi, carinatim convexi interdum innovati, apice retusi, costæ haud accumbentes sed recurvi, alis valde involutis, ceterum nudi marginibus solum longe setosis.

Hab. Brasilia subtropica (Ule).

An dieser Pflanze habe ich eine merkwürdige Missbildung bemerkt; es liegt darunter ein Exempler, welches in der Mitte eine Gabelung zeigt; der eine Gabelast ist, wahrscheinlich beim Präparieren der dicht verflochtenen und aufeinanderwurzelnden Pflanzen, abgebrochen; die Bruchstelle ist jedenfalls nicht veraltet; der andere Gabelast ist wohI erhalten und zeigt den Flügel in normaler Weise vom Haupttrieb ohne jede Unterbrechung in den Gabelast übergehend; auch der übriggebliebene Stumpf des abgebrochenen Astes ist normal mit dem Flügel des erhaltenen Astes verbunden; etwas oberhalb der Gabelung zeigt letzterer nun die Oberseite behaart und auf derselben, resp. auf deren Mittelrippe inserirt, die grossen weiblichen Aeste; die Rippe ist 
daselbst ebenfalls dicht mit kurzen Borsten besetzt, wie sie sonst nur die Unterseite trägt, kurz es ist hier die morphologische Unterseite zur Oberseite geworden; dies ist eingetreten nachdem die Gabelung bereits vollständig entwickelt war; an eine Torsion der Mittelrippe ist nicht zu denken, da deren Zellen sich in ihrem normalen Verlaufe leicht verfolgen lassen; diese Rippe (die ganze Pfianze ist schmächtig und viel schmäler als normale Exemplare) ist insofern anormal gebaut als sie 8 (beiderseits 4.) Rindenzellen hat, während normal deren 10 vorhanden sein sollten ( 4 oben, 6 unten). Es ist also schon in der Rippe der dorsiventrale Unterschied aufgehoben. Siehe auch M. Jackii.

\section{Metzgeria muscicola St. n. sp.}

Syn. : Metzgeria nudifrons St. Hedwigia 1892.

Dioica mediocris, elongata, viridis, muscis irrepens. Frons furcata, ad o $\mathrm{cm}$. longa, millimetrum lata, valde convexa. Costa valida, in sectione longe elliptica, ventre crebre longeque setosa, setis ample cylindricis, strictis; cellulæ corticales anticæ 4, postice 6 , internæ multo minores quadriseriatæ. Alæ valde decurvæ, ad 18 cellulas latæ, setis similibus sparsim hirtæ, margine creberrime armatæ, setis duplicatis ut in costa longis strictis validis, divergentibus. Cellulæ alarum $36 \times 40 \% \mu$, teneræ, trigonis nullis. Rami masculi magni, nudi, cucullati ut in congeneribus.

Hab. Kamerun (Dusén, Jungner) Capetown (Zeyher, Rehmann) Transvaal (Mc Lea).

Metzgeria nuditrons St. ist die forma epilosa dieser vorstehend beschriebenen Pflanze; da der Name das Gegenteil der normalen Ausbildung bezeichnet, kann er nicht beibehalten werden.

63. Metzgeria polytricha Spruce. Edinb. Bot. Soc. 1885, p. อัอง.

Sterilis, fulva, flaccida, dense stratificato-cæspitosa. Frons furcata, ad $3 \mathrm{~cm}$. longa, convexa, tenera. Costa tenuis, ventre pilis flaccidis dense intricatis hirta. Cellulæ corticales utroque latere biseriatæ, magnæ, internæ paucæ ad filum angustum reductæ. Alæ decurvæ ad 22 cellulas latæ, postice sparsim piliferæ, pilis brevibus angustis et flaccidis, margine similiter pilosæ, pilis ad 3-Ð̆ aggregatis, incurvo-hamatis. Cellulæ alarum ad costam $504 \times 90 \mu$, versus marginem $45 \times 45 \%$, in medio alarum $45 \times 63 \mu$ trigonis nullis.

Hab. Andes Peruviæ (Jameson, Spruce). 
64. Metzgeria myriopoda. Lind. Monogr. Metzg., p. 22.

Dioica, minor sed elongata, lurido-pallida vel viridis, corticola et rupicola. Frons furcata, valde convexa. Costa pro planta crassa, cellulis corticalibus in sectione 10 (anticis $\mathbf{2}$ majoribus, posticis 8 parvis) ventre maxime producta longeque setosa; cellulæ internæ costæ cellulis anticis multo minores; Alæ valde decurvæ, conniventi-tangentes, omnino nudi, margine tamen creberrime breviterque setulosi, setulis ternis et quaternis divergentibus, ex acie et facie interna vel postica marginis ortis. Cellulæ alarum $40 \mu$, ad costam majores, trigonis nullis. Rami fem. ventre margineque dense hispidi. Calyptra clavata longius setosa.

Hab. America sept. pluribus locis (Sullivant, Asa Gray, Fredericksson, Drummond), Brasilia, Caldas (G. A. Lindberg) Argentinia, Tucuman (Lorentz). 
Extrait des Mémoires de l'Herbier Boissier.

\section{SPECIES HEPATICARUII}

AUCTORE

Franz STEPHANI

(Suite.)

\section{HYMENOPHYTUM Dum. 1835.}

Plantæ frondosæ, majusculæ, terricolæ, fusco-virides, e caudice subterraneo ramoso rhizifero ortæ. Frons procumbens, simplex i. e. haud furcatim ramosa, ramis posticis, numerosis, e latere costæ ortis recteque patentibus, ceterum late ligulata apice breviter inciso-biloba ibidemque cellulis clavatis muciferis obtecta, interdum apice attenuata ad costam reducta radicans; in aliis erecta inferne pseudopedunculata, exalata ad costam reducta, superne abrupte multifurcata, horizontaliter umbellatim expansa. Costa in omnibus valida, plano-biconvexa, interdum postice magis producta, sensim in alas unistratas attenuata, fasciculo fibrovasali brunneo anguste cylindrico percursa. Rami fertiles brevissimi, postici, e latere costæ orti, breviter pedunculati vel sessiles; feminei disciformes, apice late alati. Involucrum compresso-bilabiatum, labiis inæqualibus, postico minore, antico lacinulis accretis carnoso. Perianthium longe exsertum, carnosum, plano-cylindricum vel pluriplicatum apice breviter lacinulatum. Calyptra duplo brevior, carnosa, pistillis sterilibus obsita. Capsula oblongo-cylindrica, usque ad basin quadrivalvis, cellularum parietes radiales brunneæ valde incrassatæ; incrassatio annulosa nulla;

MÉMOIRES DE L'HERBIER BOISSIER, no 11,30 avril 1900. 
valvulæ apice elateribus persistentibus barbatæ; elateres decidui longi, capillacei, attenuati, bi- vel trispiri, spiris validis anguste tortis. Sporæx parvæ, sphærico-tetrædræ, rufescentes. Rami masculi brevissimi. basi haud pedicellati, disciformes, anguste alati, antice involucris reticulatim connatis obtecti; involucra superne libera, inflata. plus minus rostrata, monandra. Antheridia magna, sphærica (ad 10-12) brevissime pedicellata.

Die Arten dieser Gattung enthalten zwei vegetative scharf getrennte Gruppen : Podomitrium mit niederliegendem ungeteiltem Thallus und Umbraculum mit einer schirmförmig ausgebreiteten vielfach gegabelten Frons auf einem langen vertikal aufgerichteten ungeflügelten Träger; da die sexuellen Organe beider völlig übereinstimmen, so ist eine Trennung nicht möglich; man kann die erwähnten Gattungen nicht einmal als subgenera verwerten.

Der als caudex bezeichnete Teil der Pflanzen ist meist subterran, fleischig und von dem axilen Bündel brauner Zellen durchzogen; er stellt also nur den unterirdischen ungeflügelten Teil des Thallus dar, der mit zahlreichen Rhizoiden allseitig besetzt ist. Dieser rudimentäre Fibrovasalstrang ist ein schmal cylindrischer von dem umgebenden parenchymatischen Gewebe scharf getrennter Körper, der aus langen prosenchymatischen Zellen gebildet ist; die Zellwände zeigen zahlreiche Tüpfel; mit der Gabelung der Frons (wo solche eintritt) geht er in jeden Gabelast über, worin er sich von anderen verwandten Gattungen unterscheidet, bei denen jede Gabelung ihren Strang in den Mutterspross hinabsendet, der demgemäss (wie auch die dazwischen liegenden Gabelungsglieder) mehrere Stränge zeigt, die, dem Gange der Astbildung entsprechend also nachträglich - angelegt werden. Die intercalare Zweigbildung ist bei den Arten der Untergattung Podomitrium eine rein ventrale, seitlich aus der Mittelrippe entspringende; der Fibrovasalstrang des Muttersprosses tritt nicht in den Zweig ein; er bildet sich vielmehr in ihm später und oberhalb der Basis. Die fertilen Aeste aller Arten enthalten keinen solchen Strang; wenigstens habe ich ihn hier, entgegen den Angaben Leitgebs, nie gesehen.

Die Gattung Hymenophytum ist von Dumortier bereits 183ã sehr gut charakterisirt worden; in der Synopsis sind diese Merkmale aber völlig unbeachtet (oder unbekannt) geblieben und deren Autoren haben nicht einmal bemerkt, indem sie die Pflanzen zu Symphyogyna stellten, dass Hymenophytum einen Kelch hat. 
Hymenophytum. FRANZ STEPHANI. SPEcies hepaticarum.

Obgleich Dumortier ebenfalls eine Symphyogyna (S. Hymenophyllum) zu seiner Gattung stellte, ist die Diagnose doch dadurch nicht beeinflusst worden, so dass zweifellos von ihm zuerst diese Gattung gut und rein dargestellt worden ist.

Hymenophytum Dum.

A. Frons simplex, procumbens. Perianlhium plicatum.

- 1. Hymenophytum Phyllanthus (Hooker).

Syn. : Jungermannia Phyllanthus Hook. Musci exot. t. 95.

Blyttia Phyllanthus Nees. Syn. Hep. p. 478.

Blyttia cladorrhizans Taylor. Syn. Hep. p. 476.

Diplolæna cladorrhizans Taylor. I. of. Bot. 1844, p. 570.

Symphyogyna Phyllanthus Taylor. Fl. Ant., p. 167.

Podomitrium Phyllanthus Mitt. Fl. N. Zeal. II, p. 164.

Dioica, robusta, fusco-viridis, dense cæpitosa. Frons ad $2 \mathrm{~cm}$. longa, late ligulata, tenera, symmetrice alata. Costa minus crassa, planobiconvexa, alæ flaccidæ, undulatæ. Cellulæ alarum valde irregulares, usque ad $27 \times 54 \mu$, versus marginem minores, haud incrassatæ. Rami fem. breviter pedunculati, superne late alati, alis subintegerrimis. Involucra maxime profundeque lacerata, subfimbriata. Perianthium plus minus purpureum, usque ad basin pluriplicatum, apice breviter lobatum, lobis ciliatis. Sporæ $17 \mu$. Rami masculi oblongi, limbo angusto dentato circumdati. Involucra subcampanulata, apice truncata varie profundeque lacerata.

Hab. New Zealand (Colenso, Kirk); Australia: Gippsland (Tysdale), Port Phillip (Maplestone), Melbourne (Luchmann); Tasmania (Weymouth).

Die Pflanze ist gar nicht selten, liegt aber in den Herbarien meist als Symphyogyna bezeichnet, da man die sehr häufig sterilen Sexualäste, welche unter dem Thallus verborgen liegen, nicht beachtet hat.

2. Hymenophytum malaccense St. Hedwigia 1895 , p. 46.

Dioica, major, robusta, rigida, fusco-viridis dense depresso-cæspitosa. Frons ad $3 \mathrm{~cm}$. longa apice pro more attenuata et radicans. Costa validissima, fusca, postice magis producta. Alæ sæpe asymmetricæ, altero latere ad limbum angustum reductæ vel omnino deficientes, altero bene evolutæ, sæpe in plano falcatæ. Cellulæ alarum magnæ ad $65 \times 130 \mu$, margine valde incrassatæ. Rami fem. breviter pedunculati, superne alati, 
alis plus minus profunde laceratis. Involucri labia usque ad basin fere regulariter laciniata, laciniis linearibus vel lanceolatis multo magis robustis quam in precedente. Reliqua desunt.

Hab. Singapore (Ridley, Schiffner); Nova Caledonia (Lecord).

Durch die Verdickung der Randzellen und die starke Mitlelrippe erhält der Thallus die auffallende Rigidität; die unsymmetrische Ausbildung desselben ist sehr auffallend und kann nicht vom Mangel des Lichts herrühren, da $H$. Phyllanthus ganz ebenso rasig wächst und ganz symmetrische Ausbildung zeigt; die sichelförmige Krümmung der Frons aber ist eine Folge des stärkeren Wachstums der einen Flügelseite; an symmetrisch gebauten Pflanzen fehlt die Krümmung; diese Verhältnisse erinnern an Riella, wo jedoch der Flügel dorsal ist.

B. Frons pseudopedunculata, multifurcata. Per. læve.

\section{Hymenophytum flabellatum (Hooker).}

Syn. : Jungermannia flabellata Hook. Musei exot., t. 13.

Symphyogyna flabellata Mont. Voy. au pôle sud, I, p. 216.

Umbraculum flabellatum G., Ann. sc. nat. 1864, p. 180.

Umbraculum Mülleri G., ms.

Dioica, robusta, fusco-olivacea, gregarie crescens. Frons longe pedunculata, pedunculo ad 2 vel $3 \mathrm{~cm}$. longo, superne multi (quinquies-) furcata, furcis brevibus, ligulatis integerrimis, planis, contiguis, horizontaliter in flabellam umbellatam expansis; flabella subrotunda, usque ad $25 \mathrm{~mm}$. in diam., haud rare multo minor et minus ramosa; costa in furcis primariis valida, in furcis sequentibus sensim sensimque attenuata, in ultimis tenerrima sub apice evanida; cellulæ alarum sub $38 \mu$, parietibus æqualiter incrassatis. Rami fem. haud pedunculati, sessiles, alis angustis. Involucrum depresso-bilabiatum, labiis inæqualibus, postico majore reniformi irregulariterque spinoso, antico profunde lacerato et laciniis filiformibus ciliato. Perianthium longe exsertum, crassum planocylindricum, ad $10 \mathrm{~mm}$. longum, apice leniter contractum, lacinulatum. Sporæ $18 \mu$. Involucra mascula superne inflata, breviter rostrata. Ore dentato.

Hab. Australia: Sydney (Whitelegge), Melbourne (Luchmann), Port Phillip (Maplestone), Gippsland (Tysdale), Apollo Bay (F. v. Müller), Queensland (Bailey); New Zealand (Colenso, Wilhelmi, Kirk, Beckett, Petrie); Tasmania (Oldfield, Bufton, Weymouth). 
4. Hymenophytum leptopodum (Taylor).

Syn. : Symphyogyna leptopoda Tayl. J. of Bot. 1844, p. 571.

Umbraculum leptopodum ${ }^{\approx}$ G. Ann. sc. nat. 1864, p. 180.

Dioica, præcedenti simillima, minus robusta, sæpe tenera et flaccida, dilute olivacea. Frondis pedunculus sæpe valde elongatus (ad $10 \mathrm{~cm}$.) flabella ut in $H$. flabellato, sæpe tamen multo minus regularis, furcis basalibus pinnatim patulis, reliquis multo longioribus, basi sæpe exalatis; costa semper excurrens. Cellulæ alarum $46 \times 76 \mu$, æqualiter incrassatæ, versus marginem minores. Rami feminei in furcis primariis et secundariis dispersi, involucro magno bilabiato, labio postico magno reniformi integerrimo, antico minore simillimo. Sporæ vix minores. Reliqua ut in præcedente.

Hab. New Zealand (Colenso. Knight, Helms, Zürn, Kirk, Beckett Petrie); Tasmania (Weymouth).

\section{PALLAVICINIUS Gray. 1821.}

Plantæ mediocres, frondosæ, teneræ, virides vel olivaceæ, terricolæ interdum corticolæ, plus minus dense stratificatæ, e caudice repente subterraneo procumbentes, simplices, rarius furcatæ, ex apice attenuato radicante continuatæ vel postice e latere costæ innovatæ; aliæ inferne ad costam reductæ, plus minus longe stipitatæ, stipite erecto subtereti, superne abrupte multifurcatæ, furcis alatis flabellatim expansis. Costa angusta, biconvexa, postice sæpe magis producta, in alas attenuata, cellulis angustis elongatis formata, fasciculo fibrovasali centrali simplici angusto et brunneo percursa. Alæ latæ et teneræ in plantis procumbentibus vel angustæ et crassæ in erectis, subplanæ rarius crispatæ, integerrimæ vel dentatæ, apice breviter inciso-bilobæ ibidemque cellulis clavatis muciferis dense obtectæ, margine cellulis longis rectangulatis limbatæ, in plantis procumbentibus haud rare asymmetricæ (uno latere angustiores).

Inflorescentia semper dioica. Involucra feminea antica, medio frondis vel ad basin furcæ primariæ erecta, plus minus longe cupulata, ob squamas externe accretas crassa, superne itaque duplicatim laciniata, laciniis valde irregularibus. Perianthia subhyalina, interdum colorata, cylindrica, valida, basi crassa, longe exserta, ore lobato vel laciniato vel 
ciliato. Calyptra valida, basi incrassata, perianthio plus minus longe coalita, basi atque in facie sua pistilla sterilia numerosa gerens, perianthio ceterum multo brevior. Capsula plus minus longe pedicellata, oblongo-cylindrica, normaliter quadrivalvis, valvulis apice semper coalitis, sæpe plurifidis, statu juvenili bistratis, ætate unistratis; cellulæ valvarum elongatæ, pariete interna tenera; parietes reliquæ valde incrassatæ, brunneæ. Sporæ parvæ, minute papillatæ. Elateres longi, filiformes, longe attenuati, spiris duplicatis, anguste ligulatis angusteque tortis.

Andrœcia antica, sæpe in fronde angustiore, semper fere secus costam biseriata, bracteis monandris, cucullatis, confertis vel remotiusculis vel ad cristam depressam coalitis, margine varie dentatis. Antheridia breviter stipitata, magna.

Es wird kaum ein zweites Genus im Pflanzenreich geben, dessen Name mehr gewechselt hat als das vorstehend beschriebene. Lindberg hat dieser confusen Materie eine besondere Arbeit gewidmet und es ist ein glücklicher Zufall, dass wir den ältesten Namen ohne Weiteres beibehalten können, da die demselben angefügte Diagnose die Gattung recht gut erkennen lässt.

Zum guten Teile verdankt das Genus diesen Namenreichtum dem Umstande, dass es lange Zeit und bei manchen Autoren bis auf den heutigen Tag, aus zwei Gattungen bestanden hat, nehmlich aus dem Genus Pallavicinius (typus P. Lyallii) dem irrtümlicher Weise bisher auch die 2 europäischen Arten : Jungermannia Blyttii, Mörch und Jung. hibernica, Hooker hinzugezählt wurden, die aber zur Gattung Calycularia gehören.

Diese letztere Gattung, die nur wenige exotische Arten enthält, war bisher wenig bekannt und da die Unterblätter (Amphigastria) an unseren zwei europäischen Species klein und bald zerstört sind, hat Niemand bisher ihre Identität bemerkt.

Die Gattung Pallavicinius besitzt ein die costa als einfachen Strang durchziehendes dünnes Bündel fibrovasaler Zellen, die braun, sehr fest, lang und schmal und stark verdickt sind; ihre Längswände sind mit feinen spiralig angeordneten Tüpfeln bedeckt; gleiche Stränge besitzt auch Symphyogyna, eine Gattung, die der unsrigen sehr nahe steht und sich durch ein kleines schuppenförmiges Involucralblatt sowie durch den Mangel eines Perianths unterscheidet. Pallavicinius hat dagegen bei sterilen $q$ Blüten ein ringförmiges, nach erfolgter Befruchtung becherförmiges Involucrum, das offenbar aus 2 concentrischen Reihen von Schuppen entstanden ist, die von dem gemeinsamen Basalgewerbe ver- 
eint in die Höhe gehohen wurden, daher daselbst dick und fleischig ist, oben aber zweizeilig gestellte Lacinien zeigt.

Die Haube ist an der Basis mit dem Perianth mehr oder weniger verwachsen und trägt je nach dem Alter der jungen Frucht die sterilen Pistille mehr oder weniger auf ihrer Oberfiäche emporgehoben; bei allen Arten beteiligt sich eben das basale Gewebe des Fruchtstandes am Aufbau der Haube und eine Abtrennung derjenigen Arten (unter dem Namen Mittenia) wo diese Beteiligung eine intensivere, die Verwachsung eine deutlichere ist, wird schon deshalb unmöglich sein, weil es alle möglichen Uebergänge - oft innerhalb ein und desselben Rasens - gibt.

Die Kapsel trägt an der Spitze ein hyalines oder braunes konisches Konnektiv; es sind die obersten Zellen der Klappen, die nach dem Lumen der Kapsel zu durch ein inneres Gewebe verstärkt sind; dieses Konnektiv ist die Ursache, dass die Klappen stets an der Spitze verbunden sind; ihre Zahl ist selten 4; meist ist die Kapsel longitudinal zerfetzt und der Inhalt hängt in diesem glockenförmigen Siebe, langsam mit dem Wechsel der Feuchtigkeit die Sporenmasse entlassend.

Der Thallus unserer Gattung zeigt 2 scharf getrennte vegetative Gruppen; die eine umfasst die Formen mit einfachem Thallus, der selten einmal gegabelt isı, zuweilen an der verschmälerten und flügellosen Spitze wurzelt und zur neuen Frons auswächst, sich sonst aber meist durch ventrale Seitensprosse verzweigt und nicht selten weit ausbreitet; die andere Gruppe zeigt uns eine aufrechte langgestielte Frons, die sich an der Spitze des Stieles plötzlich mit mehrfach sich folgenden kurzen Gabelzweigen schirmartig ausbreitet, wir haben diese 2 vegetativen Formen bereits bei Hymenophytum gesehen und Symphyogyna besitzt sie ebenfalls.

Eine Anzahl Arten besitzt mehr oder weniger lange Randzähne, welche am Vegetationspunkte hakig zusammen neigen; diese Gestalt behalten sie auch später bei; ohne Zweifel dienen sie lediglich zum Schutz des jungen apicalen Gewerbes und ersetzen die Amphigastrien anderer Lebermoose; wir werden bei Symphyogyna sehen, wie sich diese Zähne zu Thalluslappen umgebildet haben.

\section{Pallavicinius Gray.}

\section{A. Procumbentes.}

a. Dentatie vel ciliatie.

1. Pallavieinius ambiguus (Mitten), India orient.

2. Pallavicinius innovans St., New Zealand. 
3. Pallavicinius longispinus St., Japan.

4. Pallavicinius piliferus St., San Thomé.

5. Pallavicinius spinosus (G.), Australia.

6. Pallavicinius xiphoides (Tayl.), New Zealand.

7. Pallavicinius Levieri Schffn., Java, Hawai.

8. Pallavicinius tenuinervis (Tayl.), New Zealand.

9. Pallavicinius indicus Schffn., Java, Tahiti.

b. Integerrima.

10. Pallavicinius crispatus (Mont), India orient.

11. Pallavicinius attenuatus St., Réunion.

12. Pallavicinius himalayensis Schffn. ms., Himalaya.

13. Pallavicinius Lyellii (Hooker), Kosmopolit.

14. Pallavieinius Husnoti St., Guadeloupe, Cuba.

15.. Pallavicinius cylindricus (Austin), Hawai.

16. Pallavicinius procumbens (Taylor), St. Helena.

17. Pallavicinius radiculosus (Sande), Java.

18. Pallavicinius pisicolor (Taylor), Fret. magellan.

19. Pallavicinius erimonus St., Japonia.

20. Pallavicinius latifrons St., Java.

B. Dendroideæ.

a. Dentate vel ciliatce.

21. Pallavicinius crythropus (G.), Andes.

22. Pallavicinius Wallisii St., Andes.

23. Pallavicinius Zollingeri (G.), Java.

24. Pallavicinius Stephanii Jack., Natal.

20̈. Pallavicinius connivens St., New Zealand.

26. Pallavicinius decipiens (Mitt.), Ceylon.

b. Integerrime.

27. Pallavicinius crassifrons St., Kerguelen.

28. Pallavicinius subflabellatus Besch., Fret. magell.

29. Pallavicinius difformis (Nees), Brasilia.

\section{A. Procumbentes.}

a. dentatæ vel ciliatæ.

\section{Pallavicinius ambiguus (Mitt.) St.}

Syn. : Steetzia ambigua Mitt. Linn. Soc. Vol. 5̈, p. 123.

Dioica, minor, gracilis, rigida, brunnea. Frons ad $\mathbf{2} \mathrm{cm}$. longa, vix millimetrum lata, lanceolata, plana, monopodialiter pauciramosa, ramis posticis numerosis. Costa fusco-brunnea, pro planta lata, (fere 1/5 dia- 
metri frondis) postice valde et abrupte producta; alæ 9 cellulas latæ, margine repando-lobatæ, lobis remotis, spinosis; spinæ 5 cellulas longæ in plano incurvæ; cellulæ alarum $27 \times 54 \mu$, maxime incrassatæ. Involucra (sterilia) brevissima, cupulata, crassa, ad medium laciniata, laciniis validis irregularibus, late lanceolatis.

Hab. India orient. Khasia Montes (Hooker); Insula Luzon (Loher).

\section{Pallavicinius innovans St. n. sp.}

Dioica, parva, rigida, procumbens, lurida dense et compacte cæspitosa. Frons ad $4 \mathrm{~mm}$. longa, simplex, ex apice decurvo et abrupte attenuato innovans, ramis posticis numerosis. Costa pro planta lata, crassa, antice canaliculata, postice maxime producta; alæ erectæ, conniventes, basi pluristatæ, margine grosse remoteque spinosæ, spinis breviusculis. Cellulæ alarum $46 \times 46 \mu$. margine angustiores. Involucrum breviter cupulatum crassum, superne breviter irregulariterque inciso-lobulatum, lobulis paucidentatis, hic illic spinosis vel solum angulatim repandis. Perianthium maximum, thallo fere æquilongum, late cylindricum, tenuis, longe plicatum, are amplo repando dentato-ciliato, ciliis remotiusculis hamatim incurvis. Calyptra libera, tenera, perianthis parum brevior, pistillis sparsis obsita. Capsula breviter pedicellata, oblongocylindrica. Sporæ $18 \mu$ grosse papillatæ. Andræcia in planta angustiore curvatim procumbente, bracteis secus costam biseriatis, remotis, dentatis.

Hab. New Zealand (Kirk), Campbell Island (Kirk).

3. Pallavicinius longispinus St. Bull. Herb. Boissier 1897, p. 102.

Dioica, mediocris, flaccida, procumbens, olivacea, dense depressocaspitans. Frons ad $7 \mathrm{~cm}$. longa, $5 \mathrm{~mm}$. lata, simplex, interdum furcata, sæpe e ventre innovata; costa angusta, crassa, antice subplana, postice magis producta, sensim in alas attenuata. Alæ tenerrimæ, margine regulariter sinuatæ, sinubus lunatis, lobis rotundatis spina hamatim incurva apice setacea armatis. Cellulæ alarum $36 \times 72 \mu$, ipso margine longiores. Involucra (sterilia) e basi alte tubulosa abrupte dilatata, profunde incisolobulata, longe dentato-ciliata, ciliis strictis validis pungentibus. Androcia in planta angustiore, bracleis secus costam biseriatis, inflatis, grosse spinosis.

Hab. Japonia, Tosa (Inouë).

Hierher gehört vielleicht P. subciliatus (Austin); leider war ein Exemplar nirgends zu erhalten. 
4. Pallavicinius piliferus St. Hedw. 1891, p. 271.

Dioica, mediocris, flaccidissima, dense depresso cæspitans, dilute olivacea. Frons procumbens ad $2 \mathrm{~cm}$. longa, כ̆ $\mathrm{mm}$. lata, undulata, late ligulata, basi breviter stipitata, ex apice angustato continuata vel e latere costæ innovata. Costa angusta, plano-biconvexa, tenuis, medio 8 cellulas crassa, sensim in alas excurrens. Alæ tenerrimæ margine piliferæ, pilis 4-כ̃ cellulas longis, hamatulis; cellulæ alarum $405 \times 72 \mu$ parietibus tenerrimis. Involucra parva, conico-cupulata, humilia (in statu sterili) margine longe fimbriata, laciniis filiformibus ramosis, lanatim intricatis.

Hab. Africa trop. occid. Insula S. Thomé (Quintas).

5. Pallavicinius spinosus (G.) St.

Syn. : Blyttia spinosa G. Linnæa XXVIII, p. כ̌60.

Mittenia spinosa G. Ann. sc. nat. 1864, p. 84.

Dioica, minor, tenuis, fusco-virens vel brunneola, dense depresso cæspitans. Frons procumbens, ad $15 \mathrm{~mm}$. longa, simplex vel furcata vel e latere costæ ramosa, ramis anguste linearibus, millimetrum latis, planis. Costa angustissima, alte biconvexa, postice magis producta, abrupte in alas desinens. Alæ tenues margine grosse spinosæ, spinis approximatis, hamatim incurvis, basi 4 cellulas latis, acuminatis setaceis. Cellulæ alarum ad costam 36/72, medio 36/\%4, margine $12 / 43 \mu$, parielibus validis. Involucra crassa, ad medium multifida, laciniis acutis vel emarginatobifidis, extus squamulis accessoriis lanceolatis obsitis, margine cellulis longis digitiformibus crenato. Perianthia magna, $8 \mathrm{~mm}$. longa, fusco brunnea, superne plicata, ore plus minus profunde fisso, laciniis margine apiceque ciliatis. Calyptra valida, brunnea, basi crassa ibidemque perianthio breviter coalita. Capsula in pedicello $9 \mathrm{~mm}$. longo parva, cylindrica, apice rotundata. Sporæ $18 \mu$, rufescentes, asperæ. Elateres breves, ad $216 \mu$ longi, parum attenuati, spiris 3 , laxe tortis. Andrœcia in ramulis posticis longe spititatis, breviter disciformibus maximeque spinosis; bracteæ aggregatæ (๖-6) cucullatæ, margine $3-4$ spinosæ, monandræ.

Hab. Australia, Gippsland. (Ferd, von Müller).

6. Pallavicinius xiphoides (Taylor) St.

Syn. : Diplolæna xiphoides Tayl. J. of Bot. 1844, p. 569. Blyttia xiphoides Syn. Hep., p. 476.

Dioica, valida, gracillima, longe procumbens denseque stratificata, olivacea. Frons ad $7 \mathrm{~cm}$. longa, repetito-furcata, furcis sæpe irregularibus, brevibus pinnæformibus, aliis longissimis simplicibus; rami postici 
rariores. Costa pro planta latissima, antice leniter concava, postice convexa, abrupte in alas angustissimas attenuata. Alæ strictæ, margine crebre dentatæ, subserratæ, dentibus validis, e lata basi acutatis, incurviusculis. Involucra campanulata. fere ad medium inciso-lobata, lobis valde irregularibus lanceolatis vel profunde bifidis vel ligulatis; planta communis sed semper sterilis inventa.

Hab. New Zealand (Hooker, Zürn, Kirk, Cheeseman, Beckett).

- 7. Pallavicinius Levieri Schffn. Kais. Ak. Wien. LXVII, p. 184.

Dioica, major, tenerrima, procumbens, dilute viridis, corticola et muscicola. Frons ad $7 \mathrm{~cm}$. longa, $\check{5} \mathrm{~mm}$. lata, plana vel undulata, margine pilis brevibus armata, furcata vel postice innovata. Costa angusta, medio $\breve{~}$ cellulas crassa, antice subplana, postice magis producta, abrupte in alas excurrens. Alæ flaccidissimæ, integerrimæ; cellulæ alarum ad costam $37 / 410 \mu$, medio $37 \times 90 \mu$, margine $27 \times 74 \mu$. Involucrum cupulatum, profunde laciniatum, laciniis angustis dense ramoso-capillaceis. Perianthium longe cylindricum, ad $10 \mathrm{~mm}$. longum, apice ciliatum, capsula cylindrica, sæpe bivalvata. Sporæ $18 \mu$, rufo-fuscæ, granulatæ. Elateres longissimi longeque attenuati, spiris laxe tortis. Androecia in planta minore et angustiore linearia, costam plus minus tegentia, bracteis profunde incisis.

Hab. Java, Sumatra 1000-2120 m. (Schiffner), Hawai (Baldwin), Tahiti (Lépine).

\section{Pallavicinius tenuinervis (Tayl.) St.}

- Syn. : Diplolæna tenuinervis Tayl. J. of B. 1844, p. 477.

Dioica, mediocris, gracilis, tenuis, longe proeumbens et cæspitans, pallide flavo-virens. Frons ad $5 \mathrm{~cm}$. longa, $3 \mathrm{~mm}$. lata, linearis, simplex vel e ventre innovata. Costa angusta, humilis, in sectione fusiformis. Alæ tenerrimæ ad costam bistratæ, basi longe attenuatæ, margine remote denticulatæ, dentibus 1-2 cellulas longis, facile deciduis, ab auctore prætervisis. Cellulæx alarum $36 \times 54 \mu$, margine multo angustiores, omnes tenerrimæ. Involucra cupulata, ad $2 \mathrm{~mm}$. Ionga, margine ad 1/5 incisolobulata, lobulis irregulariter breviterque fimbriatis. Perianthia ad $4 \mathrm{~mm}$. longa, basi crassa, apice longe et creberrime spinoso-ciliata, ciliis concoconniventibus. Calyptra perianthio breviter coalita, crassa, pistillis sterilibus usque ad apicem obsita. Androcia breviter linearia, bracteis remotiusculis, paucispinosis.

Hab. New Zealand (Colenso, Helms). 
9. Pallavicinius indicus Schffn. Kais. Akad. Wien LXVII, p. 183.

Dioica, major, flaccida, procumbens, læte viridis. Frons ad $4 \mathrm{~cm}$. longa, ad $4 \mathrm{~mm}$. lata, sæpe angusta, lanceolata vel linearis, simplex vix unquam furcata. sæpe ex apice prolifera. Costa angusta, medio 10 cellulas crassa, in sectione plano-biconvexa. Alæ subplanæ, margine brevissime dentatæ, dentibus bicellularibus, facile deciduis. Cellulæ alarum $37 \times 74 \mu$, margine $27 \times 74 \mu$, incrassatio parietum nulla. Involucrum (fertile) cupulatum, margine inciso-lobatum, lobis longe ciliatis ciliisque interdum ramosis. Perianthium anguste cylindricum, ore longe dentato-ciliato. Calyptra usque ad apicem pistillis sterilibus obsita, Capsula subcylindrica, pedicello ad $23 \mathrm{~mm}$. longo. Sporæ flavescentes, minute papillatæ. Elateres utriculo hyalino scabro, fibris geminatis brunneis. Androcia in planta graciliore linearia, secus costam biseriata, bracteis sæpe ad cristam dentatam confluentibus.

Hab. Java, Sumatra, 200-2120 m. (Schiffner); Tahiti (Lépine, Nadeaud); Nepal (Wallich).

\section{B. Integerrimæ.}

\section{Pallavicinius crispatus (Mont.) St.}

Syn. : Diplolæna crispata Mont. Ann. sc. nat. 1842, p. 16.

Blyttia crispata Nees. Syn. Hep., p. 476.

Dioica, minor, flaccida, procumbens, fusca-viridis, dense stratificata.

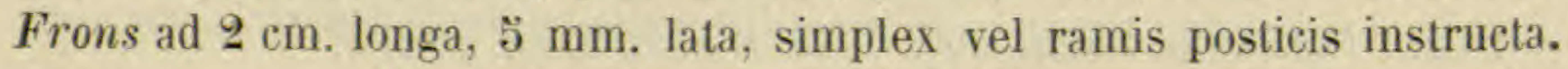
Costa ventre valde producta, abrupte in alas excurrens, angusta. Alæ undulatæ, apice crispatæ, integerrimæ; cellulæ alarum $46 \times 92 \mu$, versus marginem minores ipso margine angustiores. Involucrum crassum, breviter cylindricum, ad medium 4-5̆ lobatum, lobis varie longeque lacinulatis. Perianthium oblongo-cylindricum, ore breviter inciso-lobatum, lobis varie lacinulatis, laciniis margine crenatis vel irregulariter minuteque setulosis. Calyptra perianthio breviter (sæpe uno latere tantum), accreta, pistillis sterilibus usque ad medium obsita. Andræcia linearia, bracteis secus costam sparsim biseriatis, cucullatis varieque incisis.

Hab. India orient. Nilgherry Montes (Perrottet).

11. Pallavicinius attenuatus St. Soc. bot. belge 1893, p. 108. Dioica, major, flaccida, procumbens, fusco-viridis, dense depresso- 


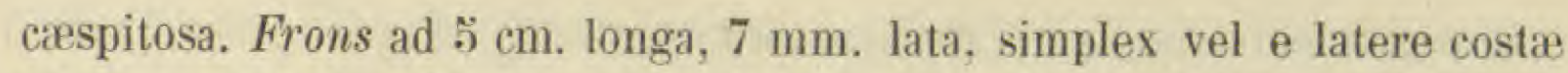
ramosa, anguste oblonga, apice semper angustata, obtusa, marginibus late ad anticum revolutis integerrimis. Costa latiuscula $(1 / 3$ fere diametri frondis) in sectione biconvexa, postice magis producta. Cellulæ alarum $34 \times 50 \mu$, margine $17 \times \supset 0 \mu$, haud incrassatæ. Involucrum humile, crassum, subintegrum. Perianthium (juvenile) humile, crassum, apice longe ciliatum, ciliis usque ad basin fere cellulis uniseriatis formatæ. Reliqua desunt.

Hab. Insula Réunion (de l'Isle).

12. Pallavicinius himalayensis (Schffn. ms. sub Pallavicinia).

Dioica, mediocris, subvalida, procumbens, fusco-viridis. Frons ad $4 \mathrm{~cm}$. longa, כ̌ mm. lata, vulgo simplex vel postice ramosa, vix unquam furcata, apice leniter angustata breviterque inciso-biloba, sæpe e margine longe radicans. Costa angusta, postice valde producta, medio 8 cellulas crassa, abrupte in alas excurrens. Fasciculum fibrovasale tenuissimum. Alæ integerrimæ, teneræ, cellulis $405 \times 90 \mu$, margine $16 \times 90 \mu$, parietibus æqualiter incrassatis. Involucra fertilia ad 1 1/2 mm. longa, obconicocylindrica, ore breviter lobata, lobis longe piliferis. Perianthia $8 \mathrm{~mm}$. longa, flavo-rubescentia, anguste cylindrica, ore dense breviterque setulosa. Capsula ad $\check{\mathrm{mm}}$. longa, subacuta, vulgo bivalvata; sporæ $18 \mu$ papillatæ. Elateres ad $4000 \mu$ medio $6 \mu$ in diam., valde attenuati, spiris anguste tortis. Andrecia ignota.

Hab. Himalaya, Kurseong, 6800' (Decoly et Schaul).

$P$. byssophorus (L. et L.) St.

Syn. : Jungermannia byssophora L. et L. Pug. IV, p. 36.

Blyttia byssophora Nees Syn. Hep. p. 478 von der Insel Bourbon, steht obiger Art sehr nahe; da wir Bürger der ostindischen Flora mehrfach auch von den Mascarenen kennen, wäre es wohl möglich, dass beide identisch sind.

Leider scheint $P$. byssophorus ganz verloren gegangen zu sein; ein Exemplar war nirgends zu erhalten und ich kenne die Pflanze nur aus einer recht guten Zeichnung Gottsche's, die aber nur ein Habitusbild ist.

13. Pallavicinius Lyellii (Hook.) Gray. Nat. Arr. 1821.

Syn. : Jungermannia Lyellii Hook. Brit. Fl. V, p. 127.

Dillæna Lyellii Dum. Rec. d'obs., p. 25.

Blyttia Lyellii Nees. Hep. Eur. III, p. 344.

Symphyogyna Schweinitzii M. et N. Syn. Hep., p. 484.

Symphyogyna oblonga (Schweinitz) Syn. Hep., p. 483. 
Dioica, mediocris, laxe cæspitans, dilute viridis. Frons procumbens, flaccida ad $4 \mathrm{~cm}$. longa. $4 \mathrm{~mm}$. lata, simplex, ex apice radicante continuata, ramis adventivis posticis haud raris. Costa angusta, abrupte in alas excurrens, postice parum producta, alæ integerrimæ, subplanæ, basi in costam nudam longe decurrentes. Cellulæ alarum haud incrassatæ, $27 \times 45 \mu$, margine $27 \times 63 \mu$. Involucra fertilia cupulata, crassa, superne breviter laciniata, laciniis lanceolatis inæqualibus, hamatim incurvis vel porrectis. Perianthia longe cylindrica, apice longe et dense ciliata, ciliis strictis conniventibus. Capsula cylindrica, acuta. Sporæ rufobrunneæ, papillatæ $28 \mu$. Elateres ad $600 \mu$, filiformes, parum attenuati, spiris anguste tortis. Androcia paucibracteata, bracteis secus costam sparsim biseriatis, spinosis.

Hab. Europa: Britannia, Germania, Italia, Portugal, Græcia, Madeira ; Amer. sept. : ubique rara; Amer. trop. Jamaïca (Hansen); Dominica (Elliott); Cuba (Whright); Portorico (Sintenis); Guadeloupe (Husnot); Brasilia (Lindman, Ule); Andes Peruviæ (Spruce); Java (Stahl, Kurz, Solms, Semper); Singapore (Ridley); Tonkin (Balansa); Philippinæ Insulæ (Wichura, Micholitz, Loher); Neu Hannover (Exped. Gazelle); Japonia (Nakino, Faurie); Viti (Græffe); Transvaal (Rehmann); New Zealand (Kirk); Chile (Hahn).

Im Herbarium Nees u, Esenbeck liegen eine Menge Pflanzen, welche mit dem Namen Diplomitrium Lyellii bezeichnet sind; die Forma $\alpha$ hielt Nees für die normale Form; die mit $\beta$ bezeichneten tragen vielfaç den Namen Diplomitrium Flotowianum; die dritte $\gamma$ ist als Forma hibernica etiquettirt; obwohl nun ein steriles Stengelchen von B. Lyellii, von Hooker selbst geschickt, mit darunter enthalten ist, das sehr deutlich den dunklen dünnen Fibrovaselstrang zeigt, so ist ihm doch die Abwesenheit desselben in allen seinen Exemplaren, die übrigens sämmtlich im schlesischen Randgebirge gesammelt sind, entgangen; er besass also tatsächlich kein einziges fertiles Exemplar der wahren B. Lyellii und alle seine Exemplare gehören entweder zu Diplomitrium hibernicum oder D. Blyttii.

Sehr schöne Exemplare unserer Pflanze mit ausgetretener Frucht liegen im Strassburger Herbar aus Varel leg Dr. Friedr. Müller, die Pflanze ist sonst in Deutschland wahrscheinlich sehr selten; da ich aber keine Flora von Deutschland zu geben im Begriffe bin, so habe ich auch nicht die Herbarien nach dieser Pflanze durchsucht.

\section{Pallavicinius Husnoti St. n. sp.}

Dioica, major, tenerrima, dilute olivacea, corticola. Frons ad $3 \mathrm{~cm}$. 
longa, $5 \mathrm{~mm}$. lata, plana, integerrima, simplex vel postice ramosa; costa angusta, plano-biconvexa, medio 10 cellulas crassa, postice magis producta, abrupte in alas attenuata; alæ tenerrimæ, subplanæ, cellulis in medio alarum $36 \times 54 \mu$, ad costam multo majores $36 \times 90 \mu$, margine angustæ, omnes exincrassatæ. Involucra cupulata, minus crassa, superne maxime lacerata, laciniis longis filiformibus, sæpe pinnatim ramosis. Perianthia anguste cylindrica, ad $7 \mathrm{~mm}$. longa, apice profunde inciso lobata, lobis dentato-ciliatis, conniventibus. Capsula in pedicello $12 \mathrm{~mm}$. longo parva, $1^{1 / 2} \mathrm{~mm}$. longa, valvulis apice cohærentibus varie fissis. Sporæ $19 \mu$ rufæ, minute asperæ. Elateres $370 \mu$, attenuati, spiris laxe tortis. Androcia in planta vix graciliore, longe linearia, bracteis secus costam biseriatis, magnis foliiformibus, vel ad cristam depressam confluentibus, margine varie incisis, plus minus longe dentato-ciliatis.

Hab. Guadeloupe (Husnot); Cuba (Wright).

15. Pallavicinius cylindricus (Austin) Evans Connect. Acad. 1891, p. 7.

Syn. : Steetzia cylindrica Aust. Torrey, Bol. CI. V, p. 17.

Dioica, major. flaccida, procumbens, olivacea. Frons ad $5 \mathrm{~cm}$. Ionga, $5 \mathrm{~mm}$. lata, plana, integerrima, sæpe ex apice innovata; costa angusta postice parum prominens, sensim in alas attenuata. Cellulæ alarum ริ $\times 90 \mu$, margine $27 \times 110 \mu$. Involucrum humile, crassum profunde dissectum, laciniis superne duplicatis, cupulatim erectis, valde irregularibus, lanceolatis vel ligulatis plus minus longe spinosis, validis et nusquam ciliatis.

Hab. Hawai (Hillebrand).

Der Autor sagt in seiner Beschreibung, die Pflanze unterscheide sich von P. Lyellii durch zweihäusigen Blütenstand; das ist aber ein Irrtum, da beide diœeisch sind. - Da fertile Exemplare nicht bekannt sind, so ist es fraglich, ob die Pflanze nicht nur eine Form der kosmopolitischen P. Lyelli ist.

\section{Pallavicinius procumbens (Taylor) St.}

Syn, : Diplolæna procumbens Tayl. J. of Bot. 1845े, p. 93.

Blyttia procumbens Tayl. Syn. Hep., p. 477.

Dioica, minor, valida, procumbens, flavo-viridis. Frons ad $3 \mathrm{~cm}$. longa, $3 \mathrm{~mm}$. lata, simplex vel postice ramosa, anguste lanceolata, apice acuminato radicans, subplana. Costa angusta, sensim in alas excurrens, postice magis producta; alæ basi (ad costam) pluristratæ, limbo unistrato $\mathbf{1 5}$ cel- 
lulas lato, tenero, integerrimo; cellulæ alarum $544 \mu$ basi margineque longiores, ipso margine $27 \times 72 \mu$, parietibus maxime incrassatis. Androcia linearia, bracteis creberrimis, depresso-cupulatis, margine grosse paucispinosis.

Hab. Insula St. Helena. Dianas Peak (Hooker).

17. Pallavicinius radiculosus (Sande), Schffn. Kais. Ak. Wien LXVII. p. 183.

Syn. : Blyttia radiculosa Sande. Syn. Hep. Javan., p. 93.

Dioica, magna, sæpe gigantea, tenuis, viridis, sæpe flavo-virens, dense stratificata longeque procumbens. Frons ad $10 \mathrm{~cm}$. longa, $5 \mathrm{~mm}$. lata, plana, integerrima, ligulata, apice sæpe angustata, interdum furcata, pro more simplex atque ventre ramosa vel repetito ramosa. Costa pro planta angusta, postice bene producta, abrupte in alas attenuata, postice ubique radicellis brevibus rufescentibus dense villosa. Alæ angustæ, integerrimæ, haud rare irregulares, uno latere angustiores vel omnino deficientes. Cellulæ alarun $27 \times 54 \mu$, margine angustiores. Involucrum cupulatum, crassum, superne maxime laceratum, laciniis irregularibus varieque hamatis subvillosum. Perianthia crassa, cylindrica, $8, \mathrm{~mm}$. longa, apice breviter lobulata, lobulis breviter ciliatis. Calyptra crassa, basi solum connata, pistillis sterilibus usque ad apicem obsita. Capsula oblongo cylindrica, valvulis valde incrassatis. Elateres こ๊ฐ๊0 $\mu$, sporis validis. Sporæ 150 , asperæ. Andrœcia in planta graciliore linearia, bracteis secus costam biseriatis, repandis vel truncatis sæpe in cristam depressam confluentibus. Antheridia magna.

Hab. Java (Junghuhn, Teysmann, Kurz, Solms, Stahl, Schiffner); Tenasserim. Insula Mergui (Griffith).

Trotz der dichten Bekleidung mit Wurzelhaaren, findet man die Pflanze meist nicht anhaftend, sondern nur lang hingestreckt. Die mangelhafte Beschreibung des Autors und besonders der Vergleich miț Blyttia crispata und Bl. hibernica veranlasste mich (Hedwigia 1893, p. 146) eine Pflanze, die Stahl in Java gesammelt hatte, zu P. radiculosus zu ziehen und diesen Namen in Calycularia radiculosa umzuändern. Später erhaltene Original-Exemplare zeigten aber, dass beides sehr verschiedene Pflanzen sind, so dass beide Namen bestehen bleiben können.

18. Pallavicinius pisicolor (Taylor) St.

Syn. : Diplolæna pisicolor Taylor J. of Bot. 1844, p. 478. Blyttia pisicolor Taylor Syn.'Hep., p. 478. 
Sterilis, mediocris, rigida, flavo-rufescens. Frons ad $3 \mathrm{~cm}$. longa, e caudice repente multiramoso procumbens vel adcendens, furcata vel e latere costæ ramosa, furcis sæpe brevissimis, linearibus, sub recto angulo divergentibus planis vel leniter canaliculatis. Costa haud prominens sensim in alas crassas excurrens; fasciculum fibrovasale simplex. Alæ usque ad marginem fere pluristratæ, limbo tenui 8 cellulas tantum lato, ceterum subintegerrimæ vel angulatim repandæ, basi in costa nuda longe attenuatim decurrentes. Frondis cellulæ corticales valde incrassatæ, in sectione $14 \mu$, internæ et limbi cellulæ multo majores, in sectione $36 \mu$.

Hab. Fretum magellanicum (Hooker).

Ob die Pflanze wirklich hierher gehört ist natürlich fraglich, da sie völlig steril ist. Die Abbildung in der Flora antarctica ist eine sehr irreführende, besonders da auch in der Beschreibung l. c. gesagt wird, dass die Pflanze aufrecht wachse; das ist jedenfalls nicht zutreffend, denn der Thallus liegt an der aufgeweichten und völlig turgescenten Pflanze in der Ebene des kriechenden Rhizoms, eine knieförmige Aufrichtung ist nirgends zu bemerken.

In der Abbildung ist das Rhizom überall mitgezeichnet, was den Eindruck macht, als wäre das eine grosse strauchartig verzweigte Pflanze, während der Thallus selbst nur eine Länge von $3 \mathrm{~cm}$ erreicht und aus den umhüllenden Moosen hier und da heraustritt.

\section{Pallavicinius erimonus St. n, sp.}

Dioica, magna, pallide-flavo-virens, longe lateque stratificata. Frons ad $6 \mathrm{~cm}$. longa, $8 \mathrm{~mm}$. lata, late ligulata vel lanceolata apiceque radicans, simplex vel postice ramosa, tenera subflaccida, undulata, margine repanda integerrina. Costa valida, colorata, angusta, postice magis producta, abrupte in alas unistratas attenuata, fasciculum fibrovasale duplicatum. Cellulæ alarum $36 \times 90 \mu$, teneræ. Involucrum magnum, usque ad basin fere plurifidum, laciniis lanceolatis, superne longe attenuatis vel emarginato biciliatis, grosse cellulosis. Perianthium crassum, clavatum, superne inflatum et plicatum, ore contracto breviter lobato, lobis acutis vel obtusis integerrimis. Calyptra perianthio duplo brevior, basi pistillis valde numerosis cincta, paucis in facie calyptræ dispersis. Capsula in

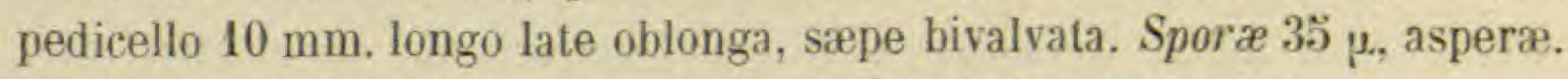
Elateres ad $340 \mu$, spiris laxe tortis. Androcia ignota.

Hab. Japonia : Cap Erimo, Mororan (Miyabe). 
20. Pallavicinius latifrons St. n. sp.

Dioica, magna, flaccida, procumbens et dense cæspitosa, flavo-virens. Frons ad $5 \mathrm{~cm}$. longa, $\mathbf{l} \mathrm{cm}$. lata, nusquam furcata, rami postici numerosi, iterum e ventre ramos proferentes; frondes itaque late expansæ et maxime imbricatæ. Costa angusta medio 12-14 cellulas crassa, antice subplana postice leniter convexa, in alas attenuata, parvitexta. Alæx subplanæ, integerrimæ (pilis apicalibus deciduis), antice posticeque grosse papillatæ. Cellulæ alarum ad costam $450 \times 110 \mu$, medio $450 \times 80 \mu$, margine $18 \times 90 \mu$. Involucrum (sterile) late cupulatum, crassum superne longe et creberrime laciniatum, laciniis duplicatis capillaceis, ramosis, lanatim intricatis.

Hab. Java (Gœebel).

\section{B. Dendroideæ.}

a. dentatæ vel ciliatæ.

\section{Pallavicinius erythropus (G.) St.}

Syn. : Mittennia erythropus G. Ann. sc. nat. 1864, p. 84.

Dioica, mediocris, valida, erecta, gregarie crescens, fusco-viridis. Frons ad $3 \mathrm{~cm}$. longa (stipite ipso $2 \mathrm{~cm}$. longo) flabellatim expansa, repetito (3) furcata, furcis linearibus, profunde solutis, grosse remoteque dentatociliatis, alis basalibus in stipite attenuatim decurrentibus. Costa leniter biconvexa, medio 8 cellulas crassa, sensim in alas attenuata, alæ, planæ, apice brevissime emarginato-bilobæ, pro majore parte bi-tristratæ, limbo unistrato ad 10 cellulas lato; cellulæ corticales internis multo minores. Involucrum ad basin furcarum infimarum, breviter cupulatum, crassum, ore amplo grosse spinoso, spinis 8-10 irregularibus. Perianthia ad $11 \mathrm{~mm}$. longa, crassa, clavata, superne minus valida, pauciplicata, irregulariter inciso-lobata, lobis crebre laciniato-ciliatis conniventibus. Calyptra perianthio vix coalita, pistilla sterilia gerens. Capsula ad 3-4 $\mathrm{mm}$. longa. Sporæ grosse tuberculatæ, flavæ. Elateres ut in congeneribus. Andrœecia linearia, costam tegentia, bracteis plus minus confertis, longe dentatis.

Hab. Andes quitenses (Lindig, F. C. Lehmann.).

Früher habe ich bereits (Journal Linn. Soc. Vol, XXIX, p. 271) die Ansicht geäussert, dass die Verbindung zwischen Haube und Perianth, wenn sonst keine weiteren wichtigen Unterschiede vorhanden sind, nicht genügt, die Gattung Mittenia aufrecht zu erhalten; bei allen Arten des Genus Pallavicinius finden wir die Pistille nicht, oder nicht alle an der Basis der Haube; diese trägt stets mehr oder weniger davon auf ihrer 
Oberfläche; sie sind dahin gelangt, weil sich unterhalb der jungen Blüte ein teilungsfähiges meristematisches Gewebe erhalten hat, das sich nach erfolgter Befruchtung mächtig entwickelt, sich an dem Aufbau der Haube beteiligt und die sterilen Pistille mit in die Höhe trägt; dabei kann die Calyptra mit dem Perianth verwachsen $d$. h. beide werden vereint in die Höhe geschoben; es ist also derselbe Vorgang, der die Pistille auf die Haube trägt und der die Haube mit dem Perianth emporhebt. Trennen wir also die Gattung Mittenia von Pallavicinius, so heben wir lediglich die Intensität eines Vorganges hervor, welcher bei beiden Gattungen zu finden ist; im Uebrigen findet man nicht selten und sogar innerhalb ein und desselben Rasens Perianthien, die frei sind und andere, die an einer Seite auf eine Strecke verwachsen sind; die Spaltung in 2 Gattungen ist also ganz unhaltbar und auch subgenera sind nicht nötig; alle Arten bilden zusammen eine unter sich innig verwandte gut charakterisirte Gruppe von Pflanzen.

\section{Pallavicinius Wallisii. Jack et St. Hedwigia 1892.}

Dioica, mediocris, rigida, gracilis, olivacea inter muscos gregarie crescens. Frons ad $4 \mathrm{~cm}$. longa (stipite ipso $2 \mathrm{~cm}$. longo) superne abrupte trifurcata, furcis anguste linearibus vel lanceolatis, profunde solutis, explanatis vel flabellum leniter concavum formantibus. Costa furcarum humilis, medio 7-8 cellulas crassa, in sectione anguste fusiformis, alis æquilata. Alæ crassæ, ad costam 4 stratæ, limbo tenui 4 cellulas solum lato, margine breviter dentatæ. Involucra breviter cylindrica, crassa, margine irregulariter breviterque, spinosa vel dentata. Perianthia fuscobrunnea, $8 \mathrm{~mm}$. longa, basi 6 cellulas crassa, versus apicem attenuata, plicatula, ore inciso-lobato, lobis regulariter laciniatis laciniisque lanceolatis aculis conniventibus. Calyptra tenuis, basi pistillis sterilibus cincta.

Hab. Nova Granada (Wallis); Guiana: Roraima (Quelch).

Hierher gehört wahrscheinlich Symphyogyna Hymenophyllum Spruce, var. heterogena in Hep. Am. et Andinæ Edinb. Bot. Soc. 1885, p. 536; die Beschreibung des Involucruus passt nicht auf das einer Symphyogyna und ist jedenfalls ein ganz junges cylindrisches Involucrum gewesen, das sich in allen Stadien der Entwicklung bei Symphyogyna nur als flach aufliegende Schuppe zeigt.

23. Pallavicinius Zollingeri (G.) Schffn. Kais. Ak. Wien LXVII, p. 18.ั.

Syn. : Mittenia Zollingeri G. Ann. sc. nat. 1864. p. 85. 
Dioica, mediocris, rigida, erecta, vel adcendens, gracilis, olivacea. Frons ad $6 \mathrm{~cm}$. longa (stipite ipso $4 \mathrm{~cm}$.) superne repetito $(3 \mathrm{vel} 4)$ furcata, furcis profunde solutis late explanatis. Costa furcarum lata, antice plana postice leniter convexa, medio 8 cellulas crassa. Alæ planæ, apice breviter bilobe, ad costam pluristratæ, versus marginem sensim attenuatæ; limbo unistrato 6-8 cellulas lato, margine longe dentato-ciliato, ciliis ad 6 cellulas longis, oblique patulis, leniter hamatis; cellulæ alarum valde irregulares parietibus validis. Involucrum ad basin furcarum, crassum, breviter cupulatum margine breviter irregulariterque lacinulatum, lacinulis duplicatis spiniformibus strictis vel hamatis. Perianthia magna, fusco-brunnea, basi 8 cellulas-apice 3 cellulas crassa ibidemque longe ciliata, ciliis strictis conniventibus. Calyptra tenax, basi 4 cellulas crassa, perianthio uno latere breviter coalita, pistillis sterilibus obsita. Capsula ovali-cylindrica. Sporæ $25 \mu$ brunneæ, minute papillatæ. Elateres $3500 \mu$ fusco-badii. Androecia in planta graciliore linearia, versus apicem thalli aggregata.

Hab. Java (Zollinger, Kurz, Solms, Karsten, Stahl, Schiffner.)

\section{Pallavicinius Stephanii. Jack. Hedw. 1892.}

Dioica, rigida, mediocris, angusta, multifurcata, olivacea, procumbens denseque cæspitans. Frons e caudice ramosissimo orta, ad $45 \mathrm{~mm}$. longa, 3-4 furcata, furcis vix millimetrum latis, linearibus, ultimis sæpe acutis. Costa pro planta lata, medio 5 cellulas crassa, postice parum convexa; alæ crassæ, sensim in costam transeuntes (limbo unistrato 6-8 cellulas lato) margine grosse breviterque dentatæ. Cellulæ alarum $27 \times 45 \%$, parietibus validis, marginalibus valde incrassatis. Involucra ad basin furcarum solitaria breviter cylindrica, erecta crassa, margine ad medium laciniata; laciniis erectis, crassis, irregularibus, lanceolatis vel spiniformibus. Perianthium (juvenile) apice longius laciniatum, laciniis anguste lanceolatis, hic illic furcatis.

Hab. Natal (Wilms).

25. Pallavicinius connivens (Col.) St. Linn. Soc. 1892, p. 270.

Syn. : Symphyogyna connivens. Colenso. Trans. N. Z. Inst. XX, p. 29 4. Dioica, minor, rigida, viridis vel flavo-virens, gregarie crescens. Frons ad $2 \mathrm{~cm}$. longa (stipite ipso ad $15 \mathrm{~mm}$. longo) superne abrupte dilatata, repetito furcata, furcis ambitu subcirculari, sæpe longe coalitis et margine breviter e disco communi prominentibus in aliis magis profunde solutis, 
linearibus, lateribus extremis semper erectis conniventibus fere infundibulatim convolutis, margine grosse spinosis; spinæ strictæ. Alæ plicatulæ ubique fere pluristratæ, limbo unistrato angusto, cellulis tenuibus $(27 \mu)$ formato. Involucra ex angulo furcarum infimarum orta, basi crassa, cylindrica ore lacinulato, laciniis æquilongis plus minus lanceolatis, inæqualibus. Perianthium juvenile ore dentato-subciliato.

Hab. New Zealand (Colenso).

26. Pallavicinius decipiens (Mitten) St.

Syn. : Steetzia decipiens Mitt. Linn. Soc. V, p. 123.

Mittenia decipiens G. Ann. sc. nat. 1864, p. 85 .

Dioica, mediocris, valida, subcrassa, dilute viridis. Frons e caudice repente procumbens, ad $3 \mathrm{~cm}$. longa, basi radicans (stipite ipso ad $15 \mathrm{~mm}$. longo) superne abrupte multifureata, in planta bene evoluta repetito 3 furcata, furcis ultimis itaque 8 , ad brevem lobulum reductis; omnes sub angulo acuto divergentes, ligulatæ vel lanceolatæ, planæ. Costa furcarum plano-biconvexa sensim in alas attenuata. Fasciculum fibrovasale simplex. Alæ ubique fere pluristratæ, limbo tenui paucas cellulas lato, margine dentato, dentibus oblique porrectis $2-3$ cellulas longis, strictis. Cellulæ alarum ad costam $36 \times 74 \mu$, medio $36 \times 5 \% 4$, parietibus tenerrimis; margine $27 \times 63 \mu$ maxime æqualiterque incrassatæ. a Involucrum subcyathiforme, dentatum, perianthio elongato-cylindrico, ore dentato; calyptra usque ad medium perianthii coadunata , (teste Mitten).

Hab. Insula Ceylon (Gardner).

Die Pflanze steht der P. Zollingeri sehr nahe, ist aber durch die kurzen Randzähne des Thallus sogleich zu unterscheiden.

\section{B. Integerrimæ.}

\section{Pallavicinius crassifrons St. n. sp.}

Dioica, minor, maxime crassa et rigida, fusco-viridis, in sicco fere nigra. Frons e caudice multiramoso erecta, inferne longe stipitata stipite ad $3 \mathrm{~cm}$. longo, subtereti, superne abrupte dilatata repetito furcata, furcis erectis, haud discretis, campanulatim conniventibus et perianthia obvelantibus, statu explanato ambitu reniformibus $ّ$ - 6 cellulas crassis, margine ipso 3 cellulas crasso. Involucrum maxime crassum, breviter cupulatum, ore truncato ad $1 / 4$ inciso-multifido, laciniis irregularibus erectis crassis. 
Perianthia magna, frondis flabello apicali æquilonga, erecta, usque ad apicem pluristrata, apice angustata paucis laciniis armata. Calyptra perianthio fere omnino coalita, apice pistillifero solum libero. Capsula oblonga, magno bulbo inserta. Androciu ignota.

Hab. Insulæ Kerguelen (Herb. Kew.).

Das antarctische Clima scheint besonders geeignet, sehr fleischige Formen zu erzeugen; ganz ähnliche Verhältnisse wie oben geschildert finden sich auch bei Aneura Spegazziniana, Aneura cochleata und es wird auch bei anderen Gattungen wiederholt auf diesen Einfluss eines sehr feuchten und rauhen Klimas bei wenig extremen Temperaturen hinzuweisen sein.

28. Pallavicinius subflabellatus Bescherelle n. sp.

Dioica, mediocris, rigida, erecta, dense cæspitosa, olivacea. Frons ad $3 \mathrm{~cm}$. longa (stipite ipso $2 \mathrm{~cm}$. longo) superne abrupte in flabellum dilatata ibidemque tri- vel quadrifurcata; turbinatim concava; furcis brevibus, $3 \mathrm{~mm}$. longis, late ligulatis i. e. latiuscule alatis quapropter minus profunde partitis; alæ integerrimæ, apice profunde inciso-bilobæ, usque ad marginem 4 cellulas crassæ; cellulæ corticales internis multo minores. Costa medio 10 cellulas crassa, plano-biconvexa sensim in alas attenuata; involucra ad basin furcarum infimarum geminata, pro more coalita, breviter cylindrica, maxime crassa. apice breviter lobata, lobis breviter laciniatis, laciniæ duplicatæ, irregulares, lanceolatæ vel piliformes vel spiniformes.

Hab. Fretum magellanicum: Insula Desolacion (Savatier Dusen),Fuegia (Spegazzini).

\section{Pallavicinius difformis (Nees) St.}

Syn. : Jungermannia difformis Nees. Mart. Fl. Bras. I, p. 329.

Symphyogyna difformis M. N. Ann. sc. nat. 1836, p. 69.

Dioica, minor. valida, erecta, flavo-virens vel rufescens. Frons ad $15 \mathrm{~mm}$. longa, stipite subtereti anguste alato, ad $10 \mathrm{~mm}$. longo, superne 3-4 furcata, furcis linearibus anguste alatis, profunde itaque solutis, vix $2 \mathrm{~mm}$. longis, explanatis; alæ integerrimæ apice profunde inciso-bilobæ, 4 cellulas crassæ, limbo unistrato $3-4$ cellulas lato; cellulæ corticales internis multo minores. Costa medio 8 cellulas crassa, sensim in alas attenuata, nusquam producta. Involucrum juvenile (haud bene conservatum) breviter cylindricum, superne longe laciniatum, laciniis lanceolatis. 
Hab. Brasilia (Sellow, Ule).

Die var. $\beta$ der Synopsis Hepat. gehört meiner Ansicht nach zu Symphyogyna brasiliensis; es ist eine ärmlich entwickelte sterile Pflanze, traurige Stückchen, die man vor 50 Jahren mit Sorgfalt aufhob und obwohl damit nichts anzufangen war, sorgsam behütete; daher die vielfachen ganz unwahrscheinlichen Standorte für manche Species, obwohl in diesem Falle beide aus Brasilien stammen.

\section{SYMPHYOGYNA Mont. et Nees. 1836.}

Plantæ frondosæ, mediocres, teneræ vel validæ, vulgo virides vel olivaceæ, interdum flavescentes vel rufescentes, terricolæ, plus minus dense stratificatæ, e caudice repente procumbentes, simplices vel furcatæ, sub flore sæpe radicantes, ex apice attenuato radicante continuatæ vel postice e latere costæ ramosæ; aliæ inferne ad costam reductæ, exalatæ, plus minus longe spititatæ erectæ, superne abrupte multifurcatæ, furcis alatis plus minus flabellatim expansis. Costa angusta, biconvexa, postice pro more magis producta, in alas breviter excurrens vel sensim attenuata, faseiculis fibrovasalibus simplicibus, in paucis duplicatis vel magis numerosis percursa. Alæ latæ et teneræ in plantis procumbentibus, vel angustæ et validæ in erectis, subplanæ vel undulatæ, interdum canaliculatæ, integerrimæ vel dentatæ vel lobulatæ, apice breviter inciso-bilobæ ibidemque [cellulis clavatis muciferis obtectæ. Inflorescentia semper dioica. Involucra feminea antica, medio frondis vel bifurcationis angulo inserta, parva squamæformia, basi solum accreta, lateribus liberis, in una calyptram semiamplectentia, basi lacinulis $e_{e}^{\mathrm{T}}$ dorso accretis crassa, superne varie irregulariterque laciniata.

Perianthia nulla. Calyptra crassa, valida, apice pistillis sterilibus numerosis coronata, interdum cellulis clavatis musciferis obtecta denseque mucosa, involucro semper a dorso breviter coalita. Capsula plus minus longe pedicellata, oblongo vel anguste cylindrica, apice vulgo acuta, valvulis cohærentibus plurifidis, pariete juvenili bistrata, ætate unistrata; cellulæ valvarum elongatæ, pariete interna tenera, ceterum valde incrassatæ rufo-brunneæ. Sporæ parvæ, ferrugineæ, minute papillatæ interdum reticulatim lamellatæ. Elateres longi, filiformis, rarissime 
ramosi, sæpe longe attenuati, spiris duplicatis, rarissime ternis, anguste ligulatis, plus minus anguste tortis.

Andracia in fronde minore et angustiore antica, bracteis monandris, sparsim secus costam biseriatis vel magis confertis et costam tegentibus, margine semper dentatis. Antheridia magna, sphærica, breviter stipitata.

Wie bereits in der Einleitung zur Gattung Pallavicinius gesagt, steht das Genus Symphyogyna jener sehr nahe und unterscheidet sich von ihr hauptsächlich durch die schuppenförmige Ausbildung des Involucrums und den Mangel des Perianths, während die vegetativen Organe denen von Pallavicinius so ähnlich sind, dass sterile Pflanzen sich in vielen Fällen nicht werden bestimmen lassen. Die Grösse des Thallus variirt in weiten Grenzen; auch die Involucralschuppen bieten Schwierigkeiten, da sie im jugendlichen Zustande sehr abweichende Formen haben, so dass es unerlässlich ist, stets ältere Inflorescenzen zu untersuchen.

Die braunen stark verdickten Zellen der Fibrovasalstränge haben, wie bei Pallavicinius, Wandungen mit zahlreichen spiralig angeordneten Tüpfeln; die Stränge sind meist einfach, gabeln sich viel früher als die Gabelung äusserlich in die Erscheinung tritt und laufen eine grössere Strecke in der ungeteilten Frons nahe neben einander her; bei einigen Arten sind 2, 3 und mehr Stränge vorhanden; siehe hierüber die Anmerkungen zu S. trivittata Spruce und S. Hochstetteri M. u. N.

Die niederliegenden Arten unserer Gattung zeigen in der Spitze des Thallus stets die Anlage der jungen Mittelrippe, die bereits kurz hinter der Vegetationsspitze eine beträchlliche Stärke erlangt hat; dagegen verliert sich bei den gestielten, aufrechten Arten die Rippe vor dem Vegetationspunkte, jene haben eben ein unbegrenztes Wachstum; die Pflanzen sterben hinten ab und die Glieder werden zu selbständigen Individuen; die gestielten haben dagegen ein beschränktes Wachstum und erneuern sich lediglich aus dem Rhizom.

Manche Arten besitzen sehr stark entwickelte, aus breiter vielzelliger Basis zugespitzte und eingekrümmte Randzähne am Thallus; sie sind von rechts und links über den Vegetationspunkt hinweggekrümmt und dienen zum Schutz desselben, behalten auch später, wenn sie von der Spitze weit abgerückt sind, ihre Richtung bei.

Vergleicht man die Thallusspitzen solcher Pflanzen mit denen von S. Brogniartii oder einer anderen verwandten Art, deren Thallus in grosse tiefgetrennte Lappen zerschlitzt ist, so fällt sofort die grosse Aehnlichkeit und Uebereinstimmung zwischen Zähnen und Thalluslappen auf; 
beide sind hakig über die Spitze des jungen Triebes hinweg gebogen und beide behalten diese ihre Orientirung auch später bei; sie erfüllen beide offenbar denselben Zweck und ich kann daher die Thalluslappen nur als eine fortgeschrittene Modifikation jener Zähne betrachten, die lediglich wie diese dem jungen Gewebe zum Schutz dienen. Von einem Uebergange der Pflanze zu den beblälterten Formen und von einem Beginn der Blattbildung kann hier nicht die Rede sein, so nahe derartige Speculationen zu liegen scheinen.

Was endlich die Kapsel der Gattung betrifft, so hat sie ganz wie Pallavicinius ein apicales Connectiv, welches die Spitzen der Klappen fest verbindet und (ähnlich wie Fimbriaria) die Sporen nur langsam entlässt; daher ist es denn auch möglich gewesen bei fast allen fruchtenden Exemplaren die Sporen und Elateren zu beschreiben, die aber leider nur sehr geringe Unterschiede bieten.

Manche Arten von Symphyogyna tragen die 우 Blüten stets an der Stelle, wo der Fibrovaselstrang sich gabelt; das erinnert lebhaft an manche beblätterte Gattungen der Hepaticæ, welche stets unter der Blüte 2 Innovationen entwickeln; andere tragen nur eine solche, und in gleicher Weise gibt es auch Arten von Symphyogyna, deren $q$ Blüte mitten auf dem ungegabelten Thallus steht, wo also letzterer gewissermassen mit einfacher Innovation weitergewachsen ist; die Stellung der $\$$ Blüte erscheint demnach quasi terminal bei manchen Arten von Symphyogyna (und auch Pallavicinius), da der betreffende Thallus mit der Blüte abschliesst und unter ihr die jungen Gabeläste divergirend hervorsprossen.

\section{gymphyogym.}

\section{A. Procumbentes.}

a. Dentater.

1. Symphyogyna graudibracteata St., New Zealand.

2. Symphyogyna crassicosta St., New Zealand.

3. Symphyogyna leptothelia Taylor, Brasilia.

4. Symphyogyna rhodina Taylor, Tasmania.

๖. Symphyogyna Lehmanniana M. N., Cape good hope.

6. Symphyogyna atronervia Taylor, Columbia.

7. Symphyogyna rubescens St., Brasilia.

8. Symphyogyna irregularis St., Australia.

b. Integerrima.

9. Symphyogyna marginata St., Dominica.

10. Symphyogyna trivittata Spruce, Guadeloupe. 
11. Symphyogyna digitisquama St., Jamaica.

12. Symphyogyna picta St., Nouv. Calédonie.

43. Symphyogyna canaliculata St., Brasilia.

14. Symphyogyna interrupta C. P., Australia.

15.. Symphyogyna brasiliensis Nees., Brasilia.

16. Symphyogyna subsimplex Mitt., New Zealand.

17. Symphyogyna Gobelii St., Venezuela.

18. Symphyogyna circinata M. N., Fretum magellan.

19. Symphyogyna Volkensii St., Kilimandeharo.

20. Symphyogyna tenuicostata St., Africa.

21. Symphyogyna semiinvolucrata (Austr.), Hawai.

22. Symphyogyna undulata Colenso, New Zealand.

23. Symphyogyna convoluta Taylor, Ascension Island.

24. Symphyogyna Gottscheana M. N., Mascareignes.

25. Symphyogyna Baldwini (Austin), Hawai.

26. Symphyogyna exincrassata St., Tabiti.

27. Symphyogyna vitiensis Jack et St., Viti.

28. Symphyogyna brevicaulis Colenso, New Zealand.

c. Lobatie.

29. Symphyogyna Brogniartii Mont., Am. tropica.

30. Symphyogyna Hochstetteri M. N., Chile, Patagonia.

31. Symphyogyna sinuata (Swartz), Am. tropica.

\section{B. Dendroideæ.}

32. Symphyogyna Hymenopyllum (Hooker), New Zealand.

33. Symphyogyna stipitata St., Chile, Brasilia.

34. Symphyogyna bogotensis (G.), Andes.

35. Symphyogyna rhizobola (Schwägr.). Mascareignes.

36. Symphyogyna podophylla (Thunb.) Africa australis.

37. Symphyogyna spinosa L. G., Africa.

38. Symphyogyna obovata Taylor, Australia, Tasmania.

39. Symphyogvna crassifrons Sull., Tierra del Fuego.

Unbekannt geblieben ist mir S. subcarnosa Lehm. Pug. X. p. 18; die Pflanze ist nirgends zu erhalten gewesen.

\section{A. Procumbentes.}

a. Dentatæ.

\section{Symphyogyna grandibracteata St. n. sp.}

Dioica, major, flaccida, fusco-olivacea. Frons procumbens ad $4 \mathrm{~cm}$. longa regulariter repetito-furcata, furcis ad $10 \mathrm{~mm}$. longis, divergentibus 
ligulatis, ad $\breve{m m}$. latis subplanis. Costa angusta, postice valde producta, medio 10 cellulas crassa, abrupte in alas excurrens. Alæ grosse spinosæ, spinis minus remotis, e lata basi setaceis, in plano incurvis. Cellulæ alarum ad costam $54 \times 72 \mu$, medio $45 \times 54 \mu$, margine $27 \times 72, \mu_{2}$ parietibus æqualiter incrassatis. Squama fem. late inserta, subquadrata, apice truncato-rotundata, ad medium varie lacinulata. Calyptra crassa, maxime mucosa. Capsula ovalis, $2 \mathrm{~mm}$. Ionga in pedicello $2 \mathrm{~cm}$. Iongo, Sporæ $18 \mu$, granulatæ. Elateres ad $600 \mu$ attenuatæ, fibra laxe torta. Androcia linearia, bracteis secus costam biseriatis cucullatis, paucispinosis.

Hab. New Zealand (Colenso, Zürn).

\section{Symphyogyna crassicosta St. n. sp.}

Dioica, parva, rigida, pallde-virens vel flavescens. Frons e caudice maxime ramoso procumbens, simplex vel e latere costæ ramosa, ad $10 \mathrm{~mm}$. longa, vix $3 \mathrm{~mm}$. lata, superne semper attenuata, decurva, ambitu oblonga medio infero subexalato. Costa lata, medio 12 cellulas crassa, postice optime producta, longe in alas attenuata. Fasciculum fibrovasale crassum hyalinum. Alæ crispatæ, basi crassæ, limbo tenui 10 cellulas tantum lato, margine grosse spinoso, spinis confertis, e lata basi attenuatis, in plano incurvis, alæ ad basin frondis in stipite anguste alato et crebre dentato longe attenuatæ. Cellulæ alarum ad costam $45 \times 90 \mu$. medio $45 \times 72 \mu$ margine $27 \times 27 \mu$ vel longiores. Squama fem. late inserta, subquadrata, parum brevilerque lobata, basi crassa, antice lobulis similibus obsita. Androcia secus costam biseriata, bracteis remotis profunde saccatis, apice emarginato-biciliatis, interdum in ramis posticis angustissimis creberrime spinosis crebre biseriata.

Hab. New Zealand (Kirk) in rupibus calcareis irroratis.

3. Symphyogyna leptothelia Tayl. J. of Bot. 1846, p. 408.

Dioica, mediocris, flaccida, viridis. Frons ad $35 \mathrm{~mm}$. longa, $3 \mathrm{~mm}$. lata, simplex vel postice ramosa, procumbens, subplana. Costa angusta, biconvexa, medio 8 cellulas crassa, sensim in alas attenuata. Alæ superne angustatæ, margine breviter dentatæ, dentibus validis remotis, 3 cellulas longis, subrecte patulis. Cellulæ alarum ad costam $63 \times 100 \mu$, medio $54 \times 90 \mu$, margine $27 \times 72 \mu$. Androcia secus costam biseriata, bracteis remotiusculis, profunde excisis, bispinosis.

Hab. Brasilia (Sellow, Wainio, Ule), Peru (Matthews, Spruce). 


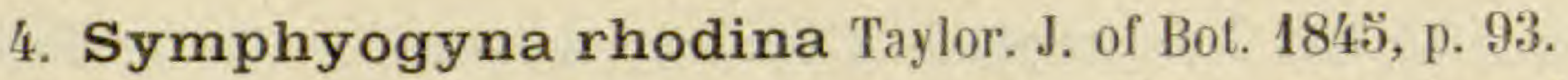

Dioica, minor, tenera, viridis vel roseo-picta. Frons lenerrima, fragilis, ad $10 \mathrm{~mm}$. longa, procumbens, repetito-furcata, furcis brevibus $\breve{~} \mathrm{~mm}$. longis, in plano late ligulatis, $4 \mathrm{~mm}$. latis, canaliculatis, Costa pro planta lata, medio 14 cellulas crassa, ventre late rotundata, sinuatim in alas excurrens. Alæ erectæ vel recurvæ, basi pluristratæ, ceterum tenerrimæ, margine remote spinosæ, spinis validis strictis, brevibus, longe acuminatis, oblique patulis. Cellulæx alarum ad costam $36 \times 72 \mu$, medio $36 \times 54 \mu$, margine $17 \times 54$ ‥ Squama fem. anguste inserta, profunde et irregulariter lobata, lobis basi sæpe constrictis, apice spathulatis et longe grosseque laciniatis, antice lacinulis acutis auctis. Calyptra maxima, $6 \mathrm{~mm}$. longa, crassa. Capsula cylindrica, acuta in pedicello $8 \mathrm{~mm}$. longo. Sporæ $20 \mu$, asperæ. Elateres valde altenuati (medio $9 \mu$ in diam.) fibris anguste tortis. Androcia in planta minore apicalia bracteis confertis emarginato-biciliatis.

Hab. Tasmania (Lyell. Oldfield), New Zealand (Colenso).

๖. Symphyogyna Lehmanniana M. N. Syn. Hep., p. 483.

Dioica, minor, gracilis, tenera, dilute viridis vel flavo-rufescens. Frons ad $3 \mathrm{~cm}$. longa, vix $2 \mathrm{~mm}$. lata, procumbens, subplana, furcata, furcis ad $2 \mathrm{~mm}$. longis, anguste ligulatis apice sæe attenuatis radicantibus, rami adventivi postici numerosi. Costa angusta, tenuis (medio 8 cellulas crassa) plano-biconvexa, sensim in alas attenuata. Alæ normaliter dentatæ, dentibus remotis, brevibus ( $1-2$ cellulas longis). Cellulæ alarum margine $12 \times 72 \mu$, medio $400 \times 63 \mu$, ad costam parum longiores. Squama fem. plus minus incisa, parva, laciniis sæpe capillaceis simplicibus.

Hab. Cape of good hope. (Ecklon, Rehmann, Jelinek).

6. Symphyogyna atronervia Tayl. J. of Bot. 1846, p. 409.

Dioica, major, flaccida, olivacea vel pallide virens, laxe depresso cæspitosa. Frons ad $4 \mathrm{~cm}$. longa, כ̆ mm. lata, procumbens, linearis, sæpe asymmetrica, alis uno latere minus evolutis, nusquam furcata, interdum postice ramosa, subplana. Costa angusta, colorata, postice bene producta, medio 12 cellulas crassa, abrupte in alas attenuata. Alæ tenerrimæ margine remote breviterque dentatæ, dentibus unicellularibus. Cellulæ alarum $45 \times 74$, basi (ad costam) longiores, margine anguste rectangulatæ, longa. Squama fem. parva, anguste inserta, obovata, medio supero laciniata, laciniis plus minus lanceolatis, acutis. Androcia secus costam 
seriata, bracteis remotis paucispinosis. "Capsula cylindrica, valvulis apice cohærentibus, irregulariter fissa "(Taylor).

Hab. Columbia (Jameson).

\section{Symphyogyna rubescens St. n. sp.}

Dioica, minor, tenuis, rubescens. Frons ad $6 \mathrm{~mm}$. longa, in plano $2 \mathrm{~mm}$. lata, subcanaliculata, simplex vel postice ramosa. Costa medio 8 cellulas crassa, postice subangulatim producta, antice concava, sensim in alas atlenuata. Alæ ad basin pluristatæ, adcendentes, sub apice erectæ, inferne curvatim explanatæ, margine paucidentatæ, dentibus parvis 1-2 cellulas longis. Cellulæ alarum ad costam $54 \times 63 \mu$, medio $36 \times 544 \mu$, margine $20 \times 72 \mu$, angulis parum incrassaiæ. Squama fem. magna, late inserta, subquadrata, tenuis, medio supero varie laciniato, laciniis ad 4-5, acuminatis. Calyptra $3 \mathrm{~mm}$. longa, pyriformis, crassa, lacinulis crassis pluricellularibus obsita, apice pistillis sterilibus comata. Capsula ovalicylindrica, regulariter quadrivalvata, pedunculo crasso $12 \mathrm{~mm}$. longo. Sporæ magnæ $(36 \mu)$ optime laxeque reticulatim-lamellatæ, lamellis integerrimis. Elateres breves $(\mathbf{1 8 0} \mu)$ validi (medio $10 \mu$ in diametro) parum attenuati, fibris geminatis, laxe tortis, anguste ligulatis, utroque margine anguste incrassatis. Androcia in planta minore et angustiore, brevia, bracteis confertis cucullatis, apice emarginato bi- trispinosis.

Hab. Brasilia, Apiahy (Puiggari).

Eine sehr ausgezeichnete Art, welche durch ihre kurzen dicken Elateren und die grossen netzig beleisteten Sporen von den übrigen Arten in auffallender Weise abweicht.

\section{Symphyogyna irregularis St. n. sp.}

Dioica, mediocris, rigida, fusco-virens, laxe cæspitans. Frons procumbens, ad $25 \mathrm{~mm}$. longa, basi breviter exalata, superne repetito-furcata, furcis longis ad $2 \mathrm{~mm}$. latis, apice sæpe flagellatim attenuatis, radicantibus. Costa crassa, postice valde producta, medio ad 14 cellulas crassa, abrupte in alas attenuata. Alæ valde irregulares, sæpe utroque latere constrictæ (frondes itaque quasi articulatæ), interdum uno latere deficientes, ceterum undulatæ, margine sparsim dentatæ, dentibus minutis, 2 cellulas longis. Cellul $x$ alarum ad costam $54 \times 108 \mu$ medio $45 \times 90 \mu$, margine $27 \times 80 \mu$, parietibus validis angulisque distincte trigonatis. Squama fem. anguste inserta, profunde lacinulata, laciniis irregularibus, ad 4-5, lanceolatis porrectis. Reliqua desunt.

Hab. Australia, in jugo Bellender Ker (Bailey). 


\section{B. Integerrimæ.}

\section{Symphyogyna marginata St. n. sp.}

Dioica, magna, robusta, fusco-olivacea vel rufo-virens, supra muscos atque in arborum cortice late expansa. Frons procumbens, ad $12 \mathrm{~cm}$. longa, furcata vel postice ramosa, ramis ad $气 \mathrm{~mm}$. latis, subplanis. Costa angusta, tenuis, medio solum 6 cellulas crassa, plano-biconvexa, postice magis producta, sensim in alas attenuata. Alæ unistratæ, integerrimæ validæ, cellulis marginalibus magnis maximeque incrassatis distinctissime limbatæ. Cellulæ alarum ad costam $45 \times 110 \mu$, medio $54 \times 90 \mu$, parietibus æqualiter incrassatis, margine $27 \times 183 \%$ haud rectangulatæ ut in congeneribus sed oblique versus marginem dispositæ. Squama fem. subtriangularis i. e basi angustissime inserta, superne ampliata, margine supero irregulariter breviterque paucidentata. Reliqua desunt.

Hab. Insula Dominica (Elliott).

10. Symphyogyna trivittata Spruce Linn. Soc. Vol. 30, p. 36.

Dioica magna, robusta, flavo-virens vel flavo-rufescens, dense depressocæspitosa. Frons procumbens ad $7 \mathrm{~cm}$. longa, $10 \mathrm{~mm}$. lata, semper e latere costæ ramosa, nusquam furcata, rarissime ex apice prolifera, late linearis vel oblonga apice angustata profundeque inciso-biloba, plana vel parum undulata. Costa lata, medio 20 cellulas crassa, postice planoconvexa, antice leniter concava; fascicula fibrovasalia geminata, in ramis magis robustis terna. Alæ tenues, basi breviter in costam nudam attenuatæ, integerrimæ; cellulæ alarum ad costam $36 \times 90 \mu$, medio $36 \times 72 \mu$ parietibus teneris, margine $54 \times 100 \mu$ parietibus maxime æqualiterque incrassatis sæpe rubescentibus vel purpureis. Squama fem. magna, calyptram semiannulatim amplectens, profunde multilacerata, laciniis simplicibus vel furcatis, lanceolatis longeque attenuatis varie tortis. Calyptra magna, clavata, ad 弓̆ mm. longa, apice pistillis magnis comata.

Hab. Insula Dominica (Elliott); Guadeloupe (1'Herminier).

Die Fibrovasalstränge sind in den meisten Aesten gepaart; unterhalb einer O Inflorescenz findet sich aber ein dritter Strang, der bis an die Basis des Astes zu verfolgen ist; er muss daselbst entstanden sein, da der Ast aus der Spitze eines anderen älteren entsprungen ist, der nur 2 Stränge besitzt; vielleicht ist er nach Anlage der Blüte von dieser aus 
basiscop angelegt worden. Es kommen auch Zweigsysteme vor, deren basaler Spross dreifache, deren mittlerer zweifache und deren terminaler Spross nur einfache Stränge produzirt hat; es ist dabei gleich, ob diese Zweigsysteme aus apical angelegten Gliedern bestehen oder ob diese ventralen Ursprungs sind und sich successive seitlich aus der Mittelrippe des jeweilig älteren Gliedes entwickelt haben. Der dritte Strang hört häufig mitten in einem Gliede auf, weit vor der Spitze.

Die Aeste mit einfachem Strang sind immer die jüngsten; ein Uebergehen der Stränge aus einem älteren Gliede durch die stielförmige Basis des ventralen Seitenastes in dessen Mittelrippe findet nicht statt; der Seitenast hat an der Insertionsstelle gleichmässig parenchymatisches Gewebe und der Strang entsteht erst weit oberhalb der insertion.

Die Pflanze legt offenbar diese Stränge nach Bedürfnis an, wo zwei genügen, hört der dritte auf oder fehlt ganz.

\section{Symphyogyna digitisquama St. n. sp.}

Dioica, spectabilis, flaccida, dilute virens, margine sæpe rubescens, dense cæspitans lateque expansa. Caudex repens, haud subterraneus, antice planus, viridis, postice solum radicans. Frons ad $3 \mathrm{~cm}$. longa, $7 \mathrm{~mm}$. lata, basi radicellis rufescentibus affixa, ceterum procumbens, undulata, margine fere crispata, nusquam furcata, semper e latere costæ ramosa, ramis ex angusta basi spathulatis, æatate late ligulatis, interdum ex apice attenuato prolifera. Costa crassa, angusta, postice maxime producta, abrupte in alas excurrens. Alæ integerrimæ ubique unistratæ; cellulæ alarum ad costam $45 \times 90 \mu$, medio $45 \times 72 \mu$, parietibus vix incrassatis; cellulæ marginales $54 \times 110 \mu$, parietibus maxime incrassatis, limbum sæpe coloratum, 2-3 cellulas latum formantes. Squama fem. parva, crassa. oblonga, tertio supero 3-כ̆ fida, laciniis porrectis, truncato-rotundatis.

Hab. Jamaica (Hansen).

Mit $S$. marginata und S. trivittata zu vergleichen.

\section{Symphyogina picta St. n. sp.}

Dioica, mediocris, rigida, pallide virens. Frons e basi breviter stipitata, linearis, ad $2 \mathrm{~cm}$. longa, $4 \mathrm{~mm}$. lata, pro more simplex, interdum furcata, curvatim procumbens leniterque canaliculata. Costa angusta, medio 8 cellulas crassa, plano-biconvexa, in alas sensim attenuata. Alæ inte-

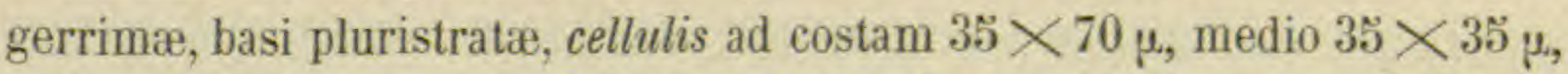
margine $27 \times 70 \mu$, parietibus validis. Squama fem. crassa, lacinulis 
angustis imbricatim connatis formata. Calyptra maxime crassa pyriformis, pistillis giganteis comata. Capsula cylindrica $3 \mathrm{~mm}$. Ionga, acuta, in pedicello $6 \mathrm{~mm}$. longo. Sporæ $27 \mu$, minute papillatæ. Elateres $670 \mu$, medio $8 \mu$ in diam. valde attenuati, fibris laxe tortis. Andrœcia in medio frondis linearia, bracteis confertis purpureis (unde nomen plantæ) margine breviter obtuseque denticulatæ.

Hab. Nova Caledonia (Savès); Hawai (Baldwin).

\section{Symphyogyna canaliculata St. n. sp.}

Dioica, parva, dilute flavo-virens, tenuis in solo argilloso gregarie crescens. Frons ad $10 \mathrm{~mm}$. Ionga, $3 \mathrm{~mm}$. lata simplex vel furcata, optime canaliculata, crispata. Costa pro planta lata, medio 8 cellulas crassa, biconvexa, breviter in alas attenuata. Alæ adscendentes vel incurvæ varie undulatæ, integerrimæ, ubique tenues (unistratæ). Cellulæ alarum ad costam $36 \times 54 \mu$, medio $27 \times 36 \mu$, margine $27 \times 72 \mu$. Squama fem. parva, crassa, apice emarginato bidentula. Calyptra crassa, pistillis magnis obsita.

Hab. Brasilia (Ule, Puiggari); Chile (Bertero).

14. Symphyogyna interrupta C. et P. Linn. Soc. N. S. Wales 1887, p. 1053.

Dioica, mediocris, flaccida, viridis, laxe caspitans. Frons ad $2 \mathrm{~cm}$. longa, repetito-furcata, furcis $4 \mathrm{~mm}$. latis, ramis posticis numerosis, apice interdum attenuata radicans. Costa angustissima, postice bene producta, medio 8 cellulas crassa, abrupte in alas excurrens. Alæ undulatæ vel crispatæ, hic illic constrictæ et sublobatæ, in fronde bene evoluta tamen normaliter contigua integerrima. Cellulæ alarum ad costam $36 \times 90 \mu$. medio $36 \times 72 \mu$, margine $27 \times 82 \mu$, ubique trigonis distinctis incrassatæ. Squama feminea crassa, ambitu late ligulata, superne 4-כ̆ laciniata, laciniis porrectis, lanceolatis vel spiniformibus, integerrimis. Calyptra ad $6 \mathrm{~mm}$. longa ; capsula $3 \mathrm{~mm}$. longa, cylindrica obtusa in pedicello $3 \mathrm{~cm}$. longo. Sporæ $20 \mu$ asperæ. Elateres ad $310 \mu$ vix attenuati, spiris laxe tortis. Androcia in planta graciliore simplici longe linearia, costam tegentia, bracteis confertis, imbricatis, bi- trifidis.

Hab. Australia : Sydney (Whitelegge).

Da gut entwickelte Sprosse keine in Thalluslappen aufgelöste Frons haben, so ist die unregelmässige Entwicklung der Flügel wahrscheinlich ein pathologischer Zustand, oder möglicher Weise auch durch dazwischen wachsende Laubmoose hervorgerufen, welche die glatte Entwicklung gehindert haben. 
15. Symphyogyna brasiliensis Nees. Syn. Hepat, p. 484.

Syn. : Jungermannia brasiliensis Nees. Martius, FI. bras. I, p. 328.

Dioica, major, flaccida, dilute viridis, longe lateque expansa. Frons

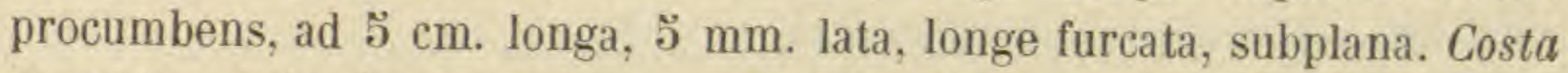
angusta, postice bene producta, medio 9 cellulas crassa, abrupte in alas attenuata. Alæ tenues integerrimæ, interdum hic illic sinuatæ, planoexplanatæ. Cellulæ alarum ad costam $36 \times 72 \mu$, media $27 \times 54 \mu$, margine $18 \times 72 \mu$, omnes teneræ. Squama fem. parva, late ovata Iateque inserta, medio supero dense lacinulata, laciniis porrectis, linearibus vel lanceolatis, sparsim spinosis. Calyptra crassa, כ mm. longa. Capsula cylindrica, acuta, $3 \mathrm{~mm}$. longa in pedicello perbrevi (15 $\mathrm{mm}$.). Sporæ $27 \mu$ grosse papillatæ. Elateres breves $148 \mu$ spiris laxe tortis. Androcia in planta gracillima longe linearia, sæpe in furcas transeuntia, bracteis confertis costam tegentibus, paucidentatis.

Hab. Brasilia tropica et subtropica (Martius, Saint-Hilaire, Sellow, Puiggari, Ule, Wainio, Werner, Lindman), ubique communis; Andes quitenses (teste Spruce).

16. Symphyogyna subsimplex Mitten Fl, N. Zel. II, p. 166

Dioica, major vel maxima, flaccida, dilute olivacea, in costice palmarum procumbens. Frons ad $\check{c} \mathrm{~cm}$. longa, $\Theta$ basi exalata longe linearis, superne ad $5 \mathrm{~mm}$. lata, apice leniter angustata breviterque inciso-biloba, ceterum integerrima, semper simplex (in plantis juvenilibus prostratis vix nuquam furcata) ramificatio ad caudicem reducta. Costa valida, angusta, biconvexa, medio 10 cellulas crassa abrupte in alas excurrens. Alæ planæ, basi longissimæ attenuatæ, teneræ. Cellulæ alarum ad costam $54 \times 90 \mu$, medio $45 \times 63 \mu$, margine $27 \times 72 \mu$. Squama parva, profunde trifida, laciniis tenuibus, obtusis vel longe cuspidatis. Calyptra clavata, ad $5 \mathrm{~mm}$. longa, crassa. Pedunculus capsulæ brevis $(8 \mathrm{~mm}$.) tenuis. Capsula cylindrica $3 \mathrm{~mm}$. longa, apice obtusa. Sporæ $27 \mu$, asperæ. Elateres capillares, vix attenuati, spiris dense tortis. Andrœcia in planta angustiore breviter linearia, ad $4 \mathrm{~mm}$. longa, bracteis magnis confertis secus costam biseriatis, margine varie breviterque laceratis.

Hab. New Zealand (Hooker, Sinclair, Colenso, Helms, Zürn, Kirk, Beckett); Stewart Island (Lyall); Samoa (Reinecke).

Die Zeichnung und Beschreibung Reichards (Reise der Novara) ist bis auf die Calyptra, die er für den Kelch hielt, recht gut; ich bezweifle aber, dass die Pflanze aufrecht wächst; der basale Teil des Thallus ist haardünn und vermag die grosse obere lamina sicher nicht zu tragen; auch spricht 
dagegen, dass die Haube vertikal auf dem Thallus steht, was auf des letzteren horizontale Lage schliessen lässt.

\section{Symphyogyna Gœbelii St, n. sp.}

Dioica, mediocris, dilute viridis, tenuis dense cæspitosa. Frons ad $2 \mathrm{~cm}$. longa, $3 \mathrm{~mm}$. lata, ex apice repetito innovata vel e latere costæ ramosa, ramis curvatim procumbentibus apice decurvo radicante. Alæ itaque erectæ conniventes, integerrimæ, uno latere costæ sæpe ad limbum angustum reductæ vel omnino deficientes. Costa angusta, ventre bene producta, medio 10 cellulas crassa, fasciculo fibrovas. validissimo. Cellulæ alarum ad costam $4.5 \times 110 \mu$, medio $36 \times 90 \mu$, margine $36 \times 95 \mu$ pariete marginali valde incrassata. Squama fem. oblonga, anguste inserta, tertio supero varie lacinulata. Andrœecia secus costam biseriata, bracteis remotiusculis, cucullatis, margine bidentulis.

Hab. America tropica : Guiana brit. (Goebel), Venezuela, Tovar (Gœebel).

18. Symphyogyna circinata M. et N. Syn. Hep., p. 486.

Syn. : Jungermannia circinata Mont. Ann. sc. nat. 1836, p. 69.

Dioica, major, valida, viridis, laxe cæspitosa. Frons procumbens, ad $3 \mathrm{~cm}$. longa, $4 \mathrm{~mm}$. lata, furcata vel postice ramosa, interdum ex apice prolifera et curvatim adscendens (in sicco revoluta unde nomen plantæ) ceterum undulata, integerrima, basi interdum longius exalata. Costa angusta, valida, medio 10 cellulas crassa, sensim in alas attenuata. Alæ ubique fere pluristratæ, limbo tenui ad 12 cellulas lato. Cellulæ alarum ad costam $36 \times 90 \mu$, medio $36 \times 54 \mu$, margine $27 \times 45 \mu$, teneræ, pariete marginali tamen valde incrassata. Squama fem. angusta, longe rectangulata, crassa, inferne squamulis piliferis accretis aucta, apice truncata et breviter lacinulata. Pistilla cellulis clavatis muciferis circumdata. Calyptra matura itaque superne mucosa, ceterum clavata et maxime crassa. Capsula parva in pedicello $12 \mathrm{~mm}$. longo, oblongocylindrica obtusa. Sporæ $30 \mu$, asperæ. Elateres validi parum attenuati, spiris laxe tortis. Andræcia in planta multo angustiore simplici linearia costam dense tegentia, bracteis cucullatis emarginato bi-vel tridentatis.

Hab. Fretum magellan. (Spegazzini, Dusén); Chile : Quillota (Bertero).

Der Thallus ist ganzrandig, da die kleinen einzelligen Zähne der Vegetationsspitze sich nicht erhalten; an der verschmälerten wurzelnden Spitze habe ich mehrfach Einbuchtungen des Randes und breite zahnartig vorstehende Ecken bemerkt. 


\section{Symphyogyna Volkensii St. n. sp.}

Dioica, maxima, flaccida, dilute olivacea. Frons procumbens ad $7 \mathrm{~cm}$. longa, $15 \mathrm{~mm}$. lata, crispata, simplex vel e latere costæ ramosa, late ligulata, apice parum angustata profunde inciso-biloba. Costa angustissima, antice leniter concava, postice bene producta, medio 10 cellulas crassa, abrupte in alas attenuata. Alæ undulatæ margine crispatæ ceterum integerrimæ. Cellulæ alarum ad costam $4 \breve{2} \times 72 \mu$, medio $36 \times 63 \mu$, teneræ, margine $18 \times 63 \mu$ ibidemque trigonis incrassatæ. Squama fem. parva, anguste inserta, obovata, ad medium laciniata, laciniis lanceolatis, margine repandis vel angulatis varieque tortis.

Hab. Africa orient in Monte Kilimandscharo (Volkens).

Omnium maxima et facile distinguenda.

20. Symphyogyna tenuicostata St. Engler's Bot. Jahrb. 1890̈, p. 306.

Dioica, majuscula, tenerrima, dilute-virens, dense depresso-cæspitans. Frons ad $35 \mathrm{~mm}$. longa, $8 \mathrm{~mm}$. lata, procumbens, plana vel undulata, simplex vel postice ramosa, basi attenuatim alata, ceterum late ligulata apice profunde inciso-biloba. Costa angustissima, postice bene producta, medio 10 cellulas crassa, abrupte in alas attenuata. Alæ integerrimæ, cellulis ad costam $45090 \mu$, medio $45 \times 68 \mu$, margine $18 \times 108 \mu$, trigonîs nullis. Squama fem. parva anguste inserta, basi crassa ceterum tenuis (unistrata) oblonga, ad medium bifida, laciniis irregulariter bifidis. Calyptra ad $\check{\beth} \mathrm{mm}$. longa, clavata, crassa. Androcia in planta longiore et angustiore, longe linearia, bracteis confertis costam obvelantibus, alte cucullatis, margine bi- trifidis.

Hab. Usambara (Holst); Kamerun (Jungner); Angola: Huilla (Antunes).

21. Symphyogyna semi-involucrata Austin. Torrey Bot. Club $\mathrm{V}$, p. 15.

Dioica, mediocris, pallide virens vel rufescens, tenera. Frons procumbens, ad $2 \mathrm{~cm}$ longa, $3 \mathrm{~mm}$. lata, undulata, integerrima, postice ramosa, rare furcata, ramis interdum curvatis, apice decurvo radicantibus et alas erectas conduplicatas gerentibus. Costa angusta, postice valde producta, in sectione semicircularis, abrupte in alas attenuata, medio 12 cellulas crassa. Alæ tenerrimæ interdum irregulariter interruptæ et sublobatæ, apice profunde inciso-bilobæ. Cellulæ alarum ad costam $45072 \mu$, medio $45045 \%$, margine $27 \times 45 \%$. Squama fem. parva, plus minus profunde bifida vel trifida, laciniis lanceolatis, irregularibus, 
crassis. Calyptra ad $4 \mathrm{~mm}$. longa, crassa. Capsula cylindrica, acuta in pedicello ad $10 \mathrm{~mm}$. longo. Sporæ magnæ $37 \mu$, alte papillatæ, papillis bidentulis. Elateres validi. longe attenuati, medio $8 \mu$ in diam., fibris laxe tortis. Androcia ignota.

Hab. Hawai (Mann, Heller).

Die Pflanze zeichnet sich durch die ungewöhnlich grossen Sporen aus; der Name rührt von der Haube her, in welcher die bereits geöffnete Kapsel noch halb verborgen steckte; es liegen aber auch Exemplare dabei, an denen die Kapsel bereits weit ausgetreten ist und die Haube auf langem Stiele überragt, so dass der Name recht unglücklich gewählt ist, um so mehr, als die Haube nicht das Involucrum ist; in ähnlichem Reifezustande gesammelte Exemplare einer Pflanze erhielt Austin auch aus Cuba und zog sie zu unserer Art, obwohl sie der Gattung gar nicht angehören und zu Pallavicinius Lyellii zu stellen sind.

\section{Symphyogyna undulata Col. ms.}

Dioica, major, valida, viridis, medio costa fusca notata, in solo argilloso gregarie crescens. Frons procumbens, undulata, ad $25 \mathrm{~mm}$. longa, furcata, furcis ad $\check{\Xi} \mathrm{mm}$. latis. Costa lata, cellulis fusco-brunneis formata, medio 12 cellulas crassa, postice bene producta, abrupte in alas attenuata. Alæ integerrimæ pluristratæ, limbo tenui ad 12 cellulas tantum lato. Cellulæ alarum ad costam $54 \times 80 \mu$, medio $36 \times 54 \mu$, margine $27 \times 60 \mu$. Squamæ fem. in fronde seriatæ approximatæ magnæ, late insertæ, subquadratæ, apice ad medium varie incisæ et laceratæ. Calyptra maxime crassa, ad $5 \mathrm{~mm}$. longa, a basi ad apicem pistillis sterilibus obtecta, cellulis interjectis clavatis muciferis maxime mucosa. Capsula cylindrica, acuta in pedicello tenui ad $10 \mathrm{~mm}$, longo. Sporæ $36 \mu$ papulosæ, rufæ. Elateres longi, validi, bi vel trispiri, valde attenuati, spiris anguste tortis. Andrecia ignota.

Hab. New Zealand (Colenso).

23. Symphyogyna convoluta Tayl. J. of Bot. 1845 , p. 94 .

Dioica, minor, gracilis, rigida, pallide virens, aliis hepaticis cæspilose consociata. Frons ad $15 \mathrm{~mm}$. longa, alis erectis optime canaliculata, e latere costæ ramosa, nusquam furcata vel apice prolifera. Costa angusta, antice concava, postice maxime producta, in sectione semicircularis, medio 12 cellulas crassa, abrupte in alas excurrens. Alæ tenues, integerrimæ, cellulis ad costam $36 \times 72 \mu$, medio $36 \times 63 \mu$, margine $18 \times 63 \mu$. Andræcia in planta graciliore et crispata linearia, bracteis 
Symphyogyna. FRANZ STEPHANI. SPECIES hePaTICARUM.

confertis, magnis, costam tegentibus, grosse inciso-lobulatis et laci niatis.

Hab. Insula Ascension. (Lyall. Gordon).

24. Symphyogyna Gottscheana M. et N. Syn. Hep., p. 484.

Dioica, magna, viridis, flaceida, corticola. Frons procumbens, ad $2 \mathrm{~cm}$. longa, e basi breviter exalata sensim ampliata superne optime lateque obcordata ibidemque ad $7 \mathrm{~mm}$. lata, apice breviter inciso-biloba, lobis late rotundatis, ceterum plana, simplex rarissime furcata, interdum ex apice angustato prolifera. Costa angusta, alte biconvexa, sensim in alas attenuata, medio 14 cellulas crassa. Alæ subplanæ vel parum undulatæ, basi longe attenuatæ. Cellulæ alarum ad costam $54 \times 72 \mu$, medio $36 \times 63 \mu$, margine $27 \times 72 \mu$. Squama fem. anguste inserta, usque ad basin fere laciniata, laciniis oblongis vel late linearibus, margine apiceque anguste lacinulatis. Calyptra ad よ̆ mm. longa, minus erassa. Capsula cylindrica ad $3 \mathrm{~mm}$. longa, obtusa in pedicello tenui $10 \mathrm{~mm}$. Iongo. Sporæ $23 \mu$, minute papillatæ. Elateres validi, medio $9 \mu$ crassi, longe attenuati, fibris dense tortis. Androcia in apice angustato frondis brevia, bracteis magnis, confertis reticulatim connatis grosse lacinulatis.

Hab. Insulæ Mascareigues (de l'Isle, Rodriguez).

\section{Symphyogyna Baldwini (Austin) St.}

Syn. : Steetzia Baldwini Austin. Torrey Bot. CI. VI, p. 303.

? Pallavicinia Baldwini Evans. Connect. Acad. 1891, p. 7.

Dioica, magna, tenuis, pallide virens, in sicco flavicans. Frons ad $5 \mathrm{~cm}$. longa, furcata, furcis ad $10 \mathrm{~mm}$. latis, late linearibus, undulatis, recto angulo divergentibus. Costa angusta, medio 14 cellulas crassa, ventre valde producta abrupte in alas attenuata. Alæ basi pluristratæ ceterum tenerrimæ, integerrimæ, cellulis ad costam $45 \times 72 \mu$, medio $45 \times 54 \mu$, margine $36 \times 54 \mu$. Squama fem. late inserta, subquadrata, basi crassa, ad medium quadrifida, laciniis lanceolatis, tenuibus. Calyptra minus crassa, $8 \mathrm{~mm}$. longa. Capsula cylindrica, $5 \mathrm{~mm}$. longa, acuta, in pedicello perbrevi (16 mm.). Sporæ $27 \mu$, alte papillatæ. Elateres filiformes, parum attenuatæ, spiris anguste tortis. Androcia in planta minore et angustiore, bracteis remoliusculis, secus costam biseriatis, cucullatis, spinosis.

Hab. Hawai (Baldwin).

Das Original, welches ich untersuchen konnte, ist eine Symphyogyna; Evans änderte Austin's Namen in Pallavicinia Baldwini um; ich weiss nicht, ob es eine solche Pflanze gibt oder ob ein Irrtum vorliegt. 


\section{Symphyogyna exincrassata St. n. sp.}

Dioica, major, tenerrima, dilute virens, in cortice palmarum gregarie crescens. Frons procumbens, ad $20 \mathrm{~mm}$. longa, basi breviter stipitata, superne furcata, furcis ad כั mm. latis, apice angustatis, hreviter incisobilobis, subplanis. Costa angusta, antice leniter concava, postice maxime producta, medio 16 cellulas crassa in sectione fere semicircularis, abrupte in alas excurrens. Alæ tenerrimæ, integerrimæ, cellulis ad costam $54 \times 54 \mu$, medio $27 \times 45 \%$, margine $20 \times 27 \mu$, parielibus tenuibus, Squama fem. anguste inserta, oblonga (duplo longior quam lata) tertio supero trifida, laciniis lanceolatis apice longe capillaceis. Calyptra (juvenilis) crassa, pistillis giganteis obtecta. Andræcia in planta parum graciliore longe linearia, bracteis magnis approximatis convexis, varie lacinulatis.

Hab. Tahiti (Jules Lépine.)

27. Symphyogyna vitiensis Jack et St. Bot. Centr. Blatt. 1894, no 43 .

Dioica, major, tenerrima, dilute viridis. Frons procumbens ad $4 \mathrm{~cm}$. longa, simplex vel postice ramosa vel furcata, furcis $3 \mathrm{~mm}$. latis, planis, ligulatis apice late rotundatis breviter inciso-bilobis. Costa angusta, medio 16 cellulas crassa, postice valde producta, in sectione semicircularis, abrupte in alas attenuata. Fasciculum fibrovas. tenue. Alæ integerrimæ a costa leniter adscendentes subinde curvatim explanatæ; cellulæ alarum ad costam $27 \times \check{5} 4 \mu$, medio $27 \times 30 \mu$, margine $18 \times 45 \mu$. Squama fem. parva, late inserta ad $\% / 3$ lacerata, laciniis irregularibus longe capillaceis. Androcia in planta angustiore secus costam biseriata, bracteis remotiusculis alternantibus, inflatis dentatis.

Hab. Viti-Ovalau (Græffe).

28. Symphyogyna brevicaulis Colenso. Trans. N. Z. Inst. 188 อั.

Dioica, mediocris. pallide viridis, tenera. Frons procumbens, ad $20 \mathrm{~mm}$. longa, furcata, furcis כ̌ mm. latis, basi breviter exalata, ceterum undulata, apice profunde inciso-bilboa. Costa angusta, crassa, alte biconvexa, medio 16 cellulas crassa, postice magís producta, abrupte in alas attenuata. Alæ integerrimæ, basi pluristratæ. Cellulæ alarum ad costam $45 \times 90 \mu$, medio $450 \times 54 \mu$, margine $27 \times 544$, ex incrassatæ Squama fem. minima, apice breviter obtuseque lobulata. Calyptra $4 \mathrm{~mm}$. longa, crassa. Capsula oblongo-cylindrica, obtusa in pedicello perbrevi et parum 
exserto (semper?). Sporæ $18 \mu$, asperæ. Elateres validi, spiris anguste tortis. Androcia ignota.

Hab. New Zealand (Colenso).

\section{G. Lobatæ.}

29. Symphyogyna Brogniartii Mont. Ann. sc. nat. 1843, ए. 26 .

Dioica, magna, robusta, viridis, depresso-cæspitans. Frons procumbens, ad $5 \mathrm{~cm}$. longa, interdum simplex, vulgo repetito furcata, furcis divergentibus, sensim sensimque brevioribus, ad $ّ \mathrm{~mm}$. latis subplanis. Costa e basi maxime crassa in apicem multoties angustiorem attenuata, ubique tamen alte biconvexa, postice magis producta, abrupte in alas attenuata, fascicula fibrovas. geminata, in ultimis ramis simplicia, in trunco primario duplicatim geminata (cruciatim opposila $\because \cdot$ ). Alæ profunde sæpe usque ad costam fere lobatim incisæ, lobis rhomboideis vel ovatis, versus apicem plantæ nutantibus, acutis vel apiculatis et angulatim repandis, sinubus acutis vel obtusis. Cellulæ loborum ad costam $36 \times 45 \mu$, medio $36 \times 36 \mu$, margine $27 \times 27 \mu$. Squama fem. late inserta, ambitu subquadrata, crassa, ad medium laciniata, laciniis sat regulariter lanceolatis, integerrimis, hic illic profunde furcatis. Calyptra maxima, ad $20 \mathrm{~mm}$. longa, crassa, cellulis clavatis muciferis obtecta ideoque maxime mucosa. Pedunculus capsulæ ad $6 \mathrm{~cm}$. longus validus. Capsula longa cylindriea, $10 \mathrm{~mm}$. longa, acuta. Elateres ad $610 \mu$ filiformes, attenuati, spiris geminatis anguste ligulatis laxe tortis. Sporæ $18 \mu$ rufæ, asperæ. Andræecia haud vidi.

Hab. America tropica: Brasilia orient. (Ule), Costarica (Pittier), Andes quitenses et peruviani (Spruce).

Die von Spruce gesammelten Pflanzen habe ich nicht alle erhalten können; seine var. pinnati-partita besteht aus 2 Formen, deren eine zu S. Brogniartii, die andere zu S. sinuata zu stellen ist.

30. Symphyogyna Hochstetteri M. et N. Syn. Hep., p. 480. Syn.? : S. subcarnosa Lehm. Pug. X, p. 18.

Dioica, magna, sæpe gracilis, subrigida, dilute viridis vel rufescens. Frons procumbens ad $4 \mathrm{~cm}$. longa, basi breviter exalata, repetito furcata, vix aliter ramosa, furcis longis, angulo acuto divergentibus, flabellum 
contractum formantibus, subplanis. Costa ad basin exalatum frondis subteres, fasciculis fibrovasalibus 6 percursa, in ramis sensim atienuata, fasciculis fibrovasalibus sensim reductis, in ultimis ramis semper geminatis. Alæ margine sinuatæ vel plus minus profunde lobatæ, smubus lunatis, interdum angustis, lobis semper apiculatis, oblique ad apicem frondis nutantibus. Cellulæ alarum ad costam $36 \times 72 \mu$, nedio $36 \times 534 \mu$, margine $27 \times 36 \mu$. Squama fem. anguste inserta, crassa, plus minus profunde laciniata, laciniis ad 4 vel 5 , late lanceolatis, acu'is, sæpe simplicibus. Calyptra ad $10 \mathrm{~mm}$. longa, crassa. Capsula $7 \mathrm{mn}$. longa, apiculata, anguste cylindrica, in pedicello valido $33 \mathrm{~mm}$. longe. Sporæ $27 \mu$, papillatæ. Elateres $420 \mu$, parum attenuati, fibris anguste tortis. Androecia ignota.

Hab. Chile (Gay, Bertero, Krause, Dusén, Neger); Patagonia australis (Savatier).

S. sinuata, zu der Gottsche unsere Pflanze stellte, hat in den terminalen Aesten stets nur einfache Fibrovasalstränge; die Zahl derselben variirt in S. Hochstetteri sehr; man findet terminale Aeste, mit 2 Strängen, deren einer nicht weit hinabreicht; er ist mitten im Ast plötzlich aufgetreten; aus der jüngsten Gabelung laufen in jeden Ast 2, im Ganzen also 4 Stränge aus; sie liegen nebeneinander; die beiden äussersten stammen aus dem älteren Gabelast, die beiden inneren sind erst in der Gabelung entstanden; in älteren Sprossgliedern sind aber die 2 inneren Stränge als aus einem hervorgegangen zu verfolgen; je nachdem die Pflanze kräftig oder schwach entwickelt ist, findet man die Anzahl der Stränge mehr oder weniger reich entwickelt, jedenfalls werden viele der letzteren erst nachträglich angelegt und sind nicht immer das Produkt des Vegetationspunktes.

\section{Symphyogyna sinuata M. et N. in d'Orbigny. Voy. Bot.} p. 61 .

Syn. : Jungermannia sinuata Sw. Prodr. Fl. Ind. occ.; p. 145.

Dioica, magna, flaccida, pallide virens, dense depresso-cæspitosa. Frons procumbens, subplana, tenera, ad $4 \mathrm{~cm}$. longa, $4 \mathrm{~mm}$. lata, simplex, vel fureata, furcis divergentibus. Costa biconvexa, postice magis producta, fasciculis fibrovas, simplicibus, basi tantum geminatis percursa, abrupte in alas attenuata. Alæ profunde lobatim incisæ, sinubus obtusis, lobis ligulatis apice rotundatis vel apiculatis. Cellulæ alarum teneræ, ad costam $57 \times 90 \mu$, medio $57 \times 80 \mu$, margine $36 \times 36 \mu$. Squama fem. anguste inserta, profunde sæpe usque ad basin fere lacerata, laciniis anguste 
ligulatis pinnatim ramosis, ramis porrectis angustissimis. Calyptra ad $7 \mathrm{~mm}$. longa, anguste cylindrica, cellulis clavatis muciferis obtecta ubique mucosa. Capsula $5 \mathrm{~mm}$. Ionga, cylindrica, in pedicello ad $4 \mathrm{~cm}$. longo. Elateres validi, longe attenuati, spiris laxe tortis. Sporæ $18 \mu$, asperæ. Andrœecia in apice plantæ angustioris fusiformia, bracteis confertis, basi apiceque inflorescentiæ sparsis medio magis numerosis costam tegentibus ceterum cucullatis dentato-spinosis. Alæ plantæ masculæ parvi- et anguste lobulatæ.

Hab. America tropica: Brasilia, Rio Grande (Lindman), Rio Janeiro (Glaziou, Lindman, Ule), Caraca (Wainio), Paraguay (Balansa), Ecuador (Eggers), Venezuela (Funk et Schlim, Karsten, Gobel), Cayenne (Möen), Mexico (Mohr, Goebel, G. Karsten), Costarica (Pittier), Jamaica (Swartz, Hansen), Martinique (Perrottet, Hahn), Puertorico (Sintenis), Dominica (Elliott), Guadeloupe (Beaupertuis, l'Herminier).

\section{B. Dendroideæ.}

32. Symphyogyna Hymenophyllum (Hook.) M. et N. Syn. Hep., p. 480.

Syn. : Jungermannia Hymenophyllum Hook. Musci exot., p. 17.

Symphyogyna flavovirens. Colenso. Transact. N. Z. Inst. 1884.

Dioica, mediocris vel parva, tenera vel subrigida, dilute viridis. Frons ad $3 \mathrm{~cm}$. longa (stipite ipso $15 \mathrm{~mm}$. longo) triplo vel quadruplo furcata, furcis sub angulo acuto divergentibus, flabellum ambitu rotundatum (usque ad $30 \mathrm{~mm}$. in diam.) formantibus, ceterum anguste linearibus, apice parum angustatis. Costa a basi ad apicem sensim attenuata, angusta, postice bene producta, abrupte in alas excurrens. Alæ unistratæ subplanæ, ad basin flabelli in stipite longius decurrentes, grosse spinosæ, spinis hamatim in plano incurvis, e lata basi attenuatis. Cellulæ alarum ad costam $36 \times 72 \mu$, medio $36 \times 54 \mu$, margine $27 \times 72 \mu$. Squama fem. late inserta, crassa, subquadrata, margine supero subtruncato plus minus longe spinoso, spinis ad 4-5, late triangulatis, acuminatis vel lanceolatis et magis numerosis. Calyptra ad $5 \mathrm{~mm}$. longa. Capsula vix $3 \mathrm{~mm}$. longa, acuta in pedicello ad $15 \mathrm{~mm}$. Iongo. Sporæ $18 \mu$ papillatæ. Elateres ad $510 \mu$, medio $8 \mu$ in diam. parum attenuati, spiris dense tortis. Androecia ad basin furcarum infimarum, anguste linearia, bracteis confertis, costam tegentibus, cucullatis, bi- vel trispinosis. 
Hab. New Zealand (Colenso, Knight, Zürn, Kirk, Helms, Beckett Cheeseman, Petrie).

Symphyogyna flavovirens Col. ist lediglich eine kleine und wenig gezähnte Form unserer Pflanze.

\section{Symphyogyna stipitata St. n. sp.}

Dioica, mediocris, tenera vel tenerrima, dilute viridis, inter muscos erecta vel dense cæspitosa lateque expansa. Frons ad $3 \mathrm{~cm}$. longa bis vel ter-furcata, furcis profunde solutis, ad $\mathbf{2} \mathrm{mm}$. latis, linearibus, subplanis. Costa angustissima, plano-biconvexa, sensim in alas excurrens. Alæ tenerrimæ, ad basin flabelli decurrentes, margine grosse dentatæ, dentibus 3 cellulas longis oblique patulis. Cellulæ alarum ad costam $45 \times 108 \mu$, medio $45 \times 109 \mu$, margine $18 \times 72 \mu$, trigonis magnis, pariete marginali valde incrassata. Squama fem. parva, anguste inserta, late obovata, medio supero laciniata, laciniis lanceolatis, attenuatis, simplicibus vel bifidis. Calyptra minus crassa, ad $6 \mathrm{~mm}$. longa. Capsula parva, $4 \mathrm{~mm}$. longa, cylindrica, acuta, in pedicello $3 \mathrm{~cm}$. longo. Sporæ $22 \mu$, papillatæ. Elateres validi, longe attenuati. Androecia in planta minore et minus regulariter furcata, bracteis confertis secus costam biseriatis, cucullatis, spinosis.

Hab. Chile (Bauer, Krause, Neger, Dusén); Insula Saint-Paul (de l'Isle); Brasilia subtropica (Ule).

\section{Symphyogyna bogotensis (G) St. n. sp.}

Syn. : S. Hymenophyllum var. bogotensis G. Ann. sc. nat. 1864, p. 87.

Dioica, minor, tenera, dilute viridis. Frons inter muscos erecta, ad $25 \mathrm{~mm}$. longa (stipite ipso $10 \mathrm{~mm}$. longo) superne triplo furcata, furcis primariis vix alatis, reliquis anguste linearibus parum divergentibus subcanaliculatis. Costa angusta, postice bene producta, a basi ad apicem sensim attenuata. Alæ teneræ, ubique unistratæ, margine hamatim spinosæ; cellulæ alarum ad costam $36 \times 63 \mu$, medio $36 \times 54 \mu$, margine $36 \times 45 \mu$, parietibus ubique tenerrimis. Squama fem. angusta tenerrima, ad $2 / \mathrm{s}$ lacerata, laciniis latis fimbriatis. Calyptra ad $5 \mathrm{~mm}$. longa, erassa. Capsula ovalis, ad $2 \mathrm{~mm}$. longa, obtusa. Sporæ $22 \mu$ asperæ. Elateres longi, fibris laxe torlis. Androcia in apice furcarum plantæ procumbentis et vix stipitatæ, bracteis secus costam biseriatis, convexis, inciso bifidis.

Hab. Nova Granada (Lindig). In rivulis ad saxas muscis consociata. Bogota, Chapi, $2700 \mathrm{~m}$. 
Die Pflanze steht der S. Hymenophyllum sehr nahe; die abweichende Bildung der Frons, (die untersten Gabeläste sind fast ungeflügelt) gibt ihr aber einen ganz anderen Habitus.

Spruces S. Hymenophyllum, bei Tarapoto gesammelt (Hep. Amaz. et And. p. 536) gehört nicht hierher und ist jedenfalls ein Pallavicinius; siehe die Anmerkung zu Pallavicinius Wallisii St.

35. Symphyogyna rhizobola (Schwägr.) Nees. Syn. Hepat., p. 483.

Syn. : Jungermannia rhizobola Schwägr. Prodr. p. 31

Dioica, major, valida, viridis, dense cæspitosa. Frons erecta, longe pseudostipitata, ad $3 \mathrm{~cm}$. longa (stipite ipso $15 \mathrm{~mm}$. longo) triplo vel quadruplo furcata, furcis infimis ad $3 \mathrm{~mm}$. longis, mediis ad $5 \mathrm{~mm}$., ultimis ad $12 \mathrm{~mm}$., anguste linearibus, versus apicem leniter angustatis, flabellum late ex-pansum vivo tamen concavum formantibus. Costa furcarum plano-biconvexa, 6-8 cellulas crassa, longe in alas attenuata. Alæ angustæ, planæ, margine dentatæ, dentibus minus remotis, validis, 4 cellulas longis, basi ad 3 cellulas latis, oblique patulis strictis. Cellulæ alarum ad costam $54 \times 90 \mu$, medio $33 \times 66 \mu$, parietibus teneris, marginales et sub marginales tamen maxime æqualiterque incrassatæ, limbum validum formantes et difficile emolliturum ideoque facile perspiciendum. Squama fem. parva, angusta, longe"rectangulata, basi crassa, ad medium quadrifida, sæpe bis bifida, laciniis angustis, simplicibus attenuatis. Calyptra ad $6 \mathrm{~mm}$. longa, crassa. Capsula cylindrica, ad $3 \mathrm{~mm}$. longa in pedicello ad $3 \mathrm{~cm}$. longo, apice subacuta. Sporæ ferrugineæ, $18 \mu$, papillatæ. Elateres $340 \mu$ medio $8 \mu$ lati, longe attenuati, sæpe breves et ramosi, fibris dense tortis. Androcia ignota.

Hab. Insulæ Mascareignes (Du Petit Thouars, de l'Isle).

Die neuseeländische Pflanze, die die Synopis Hep. I. c, erwähnt, gehört jedenfalls nicht zu unserer Pflanze, wie denn auch Mitten fälschlich S. obovata zu derselben stellte; von allen nächst verwandten Formen ist S. rhizobola durch die auffallend verdickten Randzellen zu unterscheiden; dieser limbus ist auch in Hookers Abbildung (Musci exotici tab. 87) abgebildet; dass dessen Pflanze zufällig ein aus der Spitze innovirendes und daselbst wurzelndes Exemplar war, hat jedenfalls dazu beigetragen, S. obovata hierher zu ziehen, obgleich man das an allen Arten dieser Gattung finden kann. 
36. Symphyogyna podophylla (Thunb.) M. et N. Syn. Hep., p. 481.

Syn. : Jungermannia podophylla Thunb. Prodr. fl. Cap II, p. 174.

Symphyogyna Harveyana Tayl. J. of. Bot. 1846, p. 408.

Dioica, major, valida, viridis. Frons inter sphagna erecta, ad $4 \mathrm{~cm}$. longa (stipite ipso $2 \mathrm{~cm}$. longo) superne abrupte plurifurcata, subplana, furcis inæquilongis, ramulis simplicibus hic illic interjectis, flabellum itaque irregulare formantibus, ceterum anguste linearibus, plus minus divergentibus, apice parum angustatis. Costa lata, tenuis, antice concava, postice carinatim producta, sensim in alas attenuata. Alæ leniter adscendentes basi pluristratæ, limbo tenui ad 8 cellulas lato, margine spinoso, spinis oblique patulis, strictis, 3 cellulas longis, Cellulæx alarum ad costam $36 \times 108 \mu$, medio $45 \times 72 \mu$; cellulæ marginales $18 \times 90 \mu$ trigonis magnis incrassatæ. Squama fem. ad basin furcarum infimarum parva, oblonga, apice subtruncata, laciniis numerosis fimbriata. Calyptra ad $3 \mathrm{~mm}$. longa (haud matura).

Hab. Africa australis. Capetown (Thunberg, Krauss, Ecklon, Pappe, Drège, Harvey, Rehmann, Mac 0wen); Natal (Rehmann); Transvaal (Rehmann).

\section{Symphyogyna spinosa L. et G. Syn. Hepat., p. 786.}

Dioica, major, valida, dilute viridis. inter muscos erecta vel procumbens. Frons ad $4 \mathrm{~cm}$. Ionga (stipite ipso $\mathbf{1 5} \mathrm{mm}$. longo) superne quadruplo fureata, furcis dein normaliter $\mathbf{1 6}$, basalibus brevibus, ad discum indivisum congestis, ultimis multo longioribus, ad $2 \mathrm{~cm}$. Iongis, anguste linearibus, millimetrum latis; discus basalis lateribus conniventibus valde concavus, infundibulatus, ramis liberis graciliter curvatim patulis. Costa plano-biconvexa, sensim in alas excurrens; alæ subplanæ, ad costam pluristratæ, limbo unistrato ad $\mathbf{1 0}$ cellulas lato, grosse spinoso, spinis approximatis, e lata basi acuminatis, in plano incurvis. Cellulæ limbi ad costam $27 \times 54 \mu$, medio $27 \times 45 \mu$ margine $18 \times 27 \mu$. Reliqua desunt.

Hab. Insula Réunion (Bory, 'de I'Isle), Africa centr. Kilimandscharo (Volkens), Runssoro (Elliot).

Die Pflanze steht der $S$. podophylla (Thunb.) sehr nahe; die reiche Verzweigung, die aus einer ungeteilten trichterförmigen Basis emporsteigt, unterscheidet unsere Pflanze leicht von der genannten Art, die einen völlig flachen Thallus hat; selbstverständlich kann man das nur an der gut aufgeweichten und völlig turgescenten Pflanze sehen, wesshalb 
den alten Autoren und den meisten neueren solche Unterschiede völlig verborgen geblieben sind.

38. Symphyogyna obovata Taylor. J. of Bot. 1844, p. 581.

Syn. : S. pulchra Tayl, ibidem. 1846, p. 410.

S. rhizobola Mitten (non Nees).

Dioica, mediocris, valida, pro more dense cæspitosa, viridis, interdum roseo picta. Frons erecta ad $3 \mathrm{~cm}$. longa (stipite ipso $15 \mathrm{~mm}$. longo) superne abrupte bis furcata, furcis infimis brevissimis, ultimis oblongis, $10 \mathrm{~mm}$. longis, $3 \mathrm{~mm}$. latis undulatis interdum subcrispatis; rami postici in planta male evoluta vel juvenili et repente numerosi. Costa crassa, postice valde producta, versus apicem furcarum sensim angustata; alæ validæ ad costam 4 cellulas crassæ, limbo unistrato ad $15 ̋$ cellulas lato, remote dentato, dentibus parvis gracilibus, 2 cellulas longis, subrecte patulis. Cellulix alarum ad costam $45 \times 90 \mu$, medio $54 \times 5 ั 4 \mu$, margine $36 \times 108 \mu$, parietibus validis, angulis valde incrassatis. Squama fem. ad basin furcarum ultimarum late inserta lateque ovata, margine grosse dentata vel spinosa. Calyptra ad $10 \mathrm{~mm}$. longa, sæpe rosea vel purpurea, valida (basi 8 cellulas apice 5 cellulas crassa). Capsula oblongo cylindrica acuta. Sporæ rufæ $20 \mu$, reticulatim lamellatæ. Elateres capillares, medio vix ampliores, fibris laxe tortis. Androcia in planta minore, furcis brevioribus et minug profunde solutis instructa, bracteis confertis, costam tegentibus, lacinulatis.

Hab. Tasmania (Hooker, Oldfield, Bufton, Weymouth), Australia Port Phillip (French, Maplestone) New S. Wales, (Whitelegge, Luchmann, Bäuerlen), Mount Cole (Sullivan), Swan River (Drummond), Gippsland (Johnston, Stirling, Tisdale), Queensland (Miss Lamont), New Zealand (Kirk, Colenso).

Fruchtende Exemplare aus New Zealand habe ich nicht gesehen; jedenfalls ist die Pflanze daselbst selten.

\section{Symphyogyna crassifrons Sull. J. of Bot. 1850, p. 317.}

Dioica, mediocris, crassa et rigida, olivacea. Frons adscendens, ad $2 \mathrm{~cm}$. longa, superne breviter furcatim ramosa, ramis anguste linearibus, millimetrum latis, ob furcas nascentes emarginatis vel breviter bilobis, ceterum leniter canaliculatis; basis frondis ad costam reducta, longe stipitiformis, e latere novellas frondes proferens. Costa pro planta latissima et maxime crassa, in sectione fere hemisphærica, abrupte in alas excurrens; fasciculum fibrovasale hyalinum; alæ quam costa triplo 
angustiores, integerrimæ, basi pluristratæ. "Squama feminea laciniata, convoluta. Androecia parva, bracteis ad 9, confertis, imbricatis, margine eroso-dentatis * (teste Sullivant).

Hab. Tierra del Fuego (Hyades).

\section{MONOCLEA Hooker 1820.}

Plantæ frondosæ, magnæ vel giganteæ, crassæ el coriaceæ, dilute olivaceæ vel fusco-virides, terricolæ, arcte repentes. Frons repetito furcata, furcis plus minus profunde solutis, apice breviter inciso-bilobis ibidemque cellulis clavatis muciferis obtectis, subplanis, margine integerrimis vel plicatulis, postice dense rhiziferis; radicellæ medianæ confertissimæ, longæ, ampliores et validiores, marginales tenues ad medium posticum frondis percurrentes. Costa haud definita, crassa, sensim in alas excurrens; alce crassæ, ipso margine pluristratæ, utroque latere epidermide parvicellulari obtectæ; cellulæ internæ multo majores. Inflorescentia dioica. Involucr $q$ ? in axi frondis orta, sæpe oblique versus marginem disposita, alia, ob frondis bifurcationem, lobo mediano furcarum imposita, ceterum frondis paginæ anticæ ubique q⿳assi accreta, cavernam crassam oblongam formantia, intus cellulis muciferis obtecta, primo apice clausa, post fructus egressum rupta. Calyptra crassa, inclusa. Capsulæ (pedicello plus minus longo) solitariæ vel 2 ad 3 aggregatæ, ovalicylindricæ, rima unica dehiscentes, parietibus crassis $(90 \mu$ !) unistratis, semiannulatim maximeque incrassatis. Sporæ parvæ, minute papillatæ, rufo-brunneæ. Elateres longi longeque attenuati, fibris duplicatis anguste ligulatis dense tortis. Androcia immersa; caverna ambitu ovalis vel irregulariter expansa, dorso ventreque plus minus inflatim producta, antheridiorum cavitatibus erectis repleta; cavitates monandræ, ore parvo conico-prominulo. Antheridia parva breviter pedicellata.

Diese Gattung wurde zuerst von Goltsche (Bot. Ztg. 18ä8, p. 281), später von Leitgeb und Lindberg und neuerdings von Ruge (Flora 1893, Heft 4) eingehend beschrieben.

Monoclea dilatata Leitgeb ist wahrscheinlich identisch mit M. Forsteri; denn wenn auch Dumortiera dilatata eine Monoclea ist, so hat der Name Monoclea Forsteri die Priorität; ich habe Dumortiera dilatata, die Originalpflanze, nicht gesehen; nach der Beschreibung möchte ich fast annehmen, 
dass sie zu Anthoceros giganteus gehört. Da Monoclea Gottschei Lindb. zur Zeit Lettgebs als die wahre M. Forsteri galt, hat derselbe die antarctische Monoclea für neu gehalten und sie $M$. dilatata genannt.

Im Uebrigen haben beide Arten viel Gemeinsames. Die Verzweigung ist bei beiden trils gabelig, teils entwickelt sich nur ein Gabelast und da die Blütenstände beider Geschlechter im Vegetationspunkte angelegt werden, mithin in der Mediane des Sprosses liegen, so liegt der $q$ Blütenstand entweder im Mittellappen zwischen den Gabelästen oder, wird nur ein Gabelast entwickelt, der divergirend weiter wächst, schräg gegen den Thallusrand gerichtet, nehmlich in der Achse des nächst älteren Zweiges. Man vergleiche Gottsche's Figur 1 1. c. Tab. VII. Das ist bisher, so viel ich weiss, nirgends berührt worden, obgleich es doch sehr auffallend ist, dass die $O$ Involucra schräg durch den Thallus nach dem Rande $\mathrm{zu}$ orientirt sind, was ein Unicum unter den Lebermoosen wäre.

Die Oberhautzellen beider Arten enthalten je eine kleine KalkkrystallDruse, auf welche Ruge 1. c. aufmerksam gemacht hat. Die Hülle, welche die Pistille bis zur Fruchtbildung und die junge Frucht schützt, habe ich Involucrum genannt, wie der Name allen ähnlichen Gebilden zukommt, die bei den thallosen Lebermuosen die Haube, oder wo ein Perianth vorhanden ist, dieses letztere beschützen. Dieses Involucrum ist bis zur Fruchtreife in Folge des Dickenwachstums an der Spitze fest verschlossen, obwohl natürlich die primäre Spalte, durch welche einst der lange Halsteil der Archegonien herausragte, vorhanden ist; die Frucht öffnet sich später den Weg durch Zerreissung des apicalen Gewebes.

Dieses Involucrum endet stets mit dem Thallusrande, den es nicht überragt und wir haben hier also den Fall eines thallosen Lebermooses, dessen weibliche Blüte terminal ist; die Aeste entwickeln sich stets unterhalb der Blüte (d. h. also am basiscopen Ende der Hülle) wie wir das bei vielen foliosen Formen kennen.

Da in Gottsche's bereits citirter Figur die jüngsten $Q$ Fructificationen terminal sind und Seitenäste nicht mehr entwickelt wurden, so hat die Pflanze ein begrenztes Wachstum; sie schliesst dasselbe hier ab, da sie ventrale Adventiväste nicht produzirt.

Ich verweise hierbei auf das in der Einleitung zur Gattung Symphyogyna gesagte, deren Thallus oft regelmässig unterhalb der $q$ Blüte in Gabeläste übergeht. Trüge die costa von Monoclea Blätter an Stelle der ungeteilten Thallusflügel, so würde Niemand Anstand nehmen, ihre of Blüte als eine terminale zu bezeichnen. 
Der Unterschied zwischen acrogynen und anacrogynen Lebermoosen wird dadurch wesentlich überbrückt.

Sehr auffallend sind bei unserer Gattung die spiralig angeordneten Zellen im Halsteile der Archegonien, auf die Leitgeb hingewiesen hat und welche Ruge neuerdings bestätigen konnte. Die medianen Wurzelhaare, die sehr dick sind und stark verdickte Wandungen haben, dienen zur Befestigung der Pflanze; die marginalen sind viel dünner und haben weniger derbe Wandungen; sie finden sich auch spärlich auf der Unterseite der Thallusflügel und streben alle, wie bei den Marchantiaceen der ventralen Mediane zu, woselbst sie in den dichten Wurzelfilz eintreten; sie dienen vorzugsweise der Wasserversorgung.

Monoclea Hooker.

\section{Monoclea Forsteri Hook. Musci exot. t. 174.}

Dioica, gigantea, crassa et coriacea, dilute olivacea, in sicco fusca. Frons ad $10 \mathrm{~cm}$. longa, ramis ad $21 / 2 \mathrm{~cm}$. latis, longe coalitis, apice solum lobatim prominentibus, medio ad 15 cellulas crassis, versus marginem sensim attenuatis, ipso margine ad 4 cellulas crassis. Radicellæ medianæ validæ, ad $36 \mu$ in diam., marginales multo magis tenues, $9 \mu$ in diam., et minus validis.

Involucra ㅇ magna, crassa, ambitu elliptica ad $20 \mathrm{~mm}$. longa $10 \mathrm{~mm}$. lata, dorso ventreque inflatim producta, ore post capsulæ egressum š mm. lato. Capsulæ (interdum binæ- vel ternæ) $8 \mathrm{~mm}$. longæ in pedicello perbrevi $3 \mathrm{~cm}$. longo, plus minus longe incluso. Sporæ $18 \mu$, asperæ. Elateres ad $440 \mu$ validi, medio $16 \mu$ in diam. Androcia magna, ambitu ovato-rotunda $15 \mathrm{~mm}$. longa $12 \mathrm{~mm}$. lata; caverna parum inflata, ostiolis haud productis, conico-prominulis.

Hab. New Zealand (Forster, Colenso, Kirk. Helms). Patagonia (Dusẻn).

Die Kapseln sind fast immer (in den von mir untersuchten Exemplaren) zu 2 oder 3 in demselben Involucrum. Einzelne Details der Diagnose habe ich fortlassen müssen, teils weil die Exemplare zu schlecht gesammelt waren, teils weil ich dieselben nicht zerschneiden durfte; so fehlt die Untersuchung des inneren ㅇ und $\sigma$ Involucrums und seine Ausstattung mit Schleimhaaren, auch der Vegetationspunkte und deren Behaarung.

2. M. Gottschei Lindb. Rev. bryol. 185\%6, p. 102.

Dioica, spectabilis, multo minus crassa, perviridis, in sicco subnigra. 
Frons ad $6 \mathrm{~cm}$. longa, ramis profunde solutis, late linearibus $(10 \mathrm{~mm}$. latis) planis, margine plicatulis, medio 8 cellulas- margine 3 cellulas crassis. Radicellæ medianæ validæ $27 \mu$ in diam., marginales $9 \mu$, pariete minus valida. Involucra ㅇ minora et multo angustiora $(3: 15 \mathrm{~mm}$.) dorso ventreque inflata, caverna apice longe angustata. Capsulæ ad $5 \mathrm{~mm}$. longæ interdum geminatæ, in pedicello longissimo $(5 \mathrm{~cm}$.). Sporæ $16 \mu$ asperæ. Elateres อัอัว $\mu$, medio $8 \mu$ in diam. Andrœcia sæpe seriata, ovalia $(3 \times 4 \mathrm{~mm}$.) dorso ventreque valde inflata, ostiolis haud productis conicoprominulis.

Hab. America tropica, Costarica (F. C. Lehmann); Guatemala (Wurr.); Caracas (Funk et Schlim, Gobel); Bolivia (Pearce); N. Granada (Lindig); Andes Peruviæ (Spruce); Puertorico (Sintenis); Guadeloupe (I'Herminier); Jamaica (Hansen); Chile (Dusẻn); Japonia (Faurie).

Ob die japanische Pflanze, die ich nur steril kenne, hierher gehört, ist fraglich; vegetativ steht sie der obigen jedenfalls am nächsten. 
Extrait des Mémoires de l'Herbier Boissier.

\section{SPECIES HEPATICARUII}

AUCTORE

Franz s'EPHANI

(Suite.)

\section{CALYCULARIA Mitten 1860.}

Plantæ frondosæ, mediocres vel spectabiles, fragiles, cæspitosæ vel gregarie crescentes, arcte repentes, lurido vel saturate virides, radicellis coloratis, flavidulis vel plus minus purpureis, furcatæ vel ex apice innovatæ, rarissime postice ramosæ, ambitu late ligulatæ, alis adscendentibus canaliculatæ, margine plus minus crispatæ. Costa latiuscula, antice concava, postice valde producta optimeque carinata, sensim in alas attenuata, cellulis elongatis æquimagnis ædificata, versus apicem frondis multo minus crassa, in plantis etiolatis maxime reducta. Alæ e basi crassa sensim attenuatæ, limbo marginali unistrato plus minus lato, margine semper integerrimo, præsertim sub apice plicato-crispato. Cellulæ alarum exincrassatæ, ad costam parum Iongiores. Amphigastria semper præsentia, in apice frondis comata, lanceolata vel subulata, medio infero sæpe pinnatim appendiculata, versus basin angustata, cellula parva basali inserta et facillime decidua. Inflorescentia semper dioica. Flores feminei in pagina antica costæ orti; pistilla numerosa, plus minus aggregata, in flore fecundato toro conico inserta, ceterum hic illic solitaria, bracteis longis, lanceolatis vel foliiformibus valde laciniatis vel spinosis remotis MÉMOIRES DE L'HERBIER BOISSIER, no 16,25 juin 1900. 
et nusquam basi communi annuliformi coalitis circumdata. Perianthia magna, late inserta, post fecundationem evoluta, infundibulata vel campanulata vel inflato-cylindrica, plus minus plicata, sæpe lamellis longitudinaliter jugata, ore late aperto spinoso vel lacerato, basi crassa et bracteis supra descriptis circumdata, superne unistrata. Calyptra magna, toro inserta ideoque quasi stipitata, basi plus minus crassa et pistillis sterilibus cincta, libera, pyriformis. Capsula in pedicello perbrevi late ovalis vel subglobosa, parietibus pluristratis, longitudinaliter fissis, segmentis $5-7$; stratum externum cellulis minoribus brunneis æqualiter incrassatis formatum; cellulæ internæ capsulæ teneræ, in paucis dense semiannulatim incrassatæ. Elateres breves, fusiformes, normaliter bispiri. Sporæ parvæ, papillatæ vel echinatæ. Androcia in pagina antica costæ, bracteis plus minus aggregatis, monandris, erectocucullatis, apice erosis vel dentatis. Antheridia magna subsessilia pedicello unicellulari.

Diese Gattung, von Mitten 1860 aufgestellt, ist Jahrzente lang unbekannt geblieben und obwohl ich 1888 eine Beschreibung der Mitten'schen Art (Cal, cripsula) gab, Lindberg 1889 eine neue Art publizirte und ich selbst $1893 \mathrm{Cal}$. radiculosa veröffentlichte, so hat doch Niemand bemerkt, dass unsere beiden europäischen Arten, Mœrkia Blyttii und Morkia hibernica hierher gehören.

Bei einem Vergleich der hier folgenden Diagnosen ergeben sich als gemeinsame Merkmale: 1. die an der Bauchseite kielig vorstehende costa, welche an ihrer dorsalen Seite stets rinnig-hohl ist; 2. die fleischige Basis der Flügel, die bei allen Arten normal am Rande wellig und faltig kraus sind; 3 , die zahlreichen Amphigastrien, welche auf der ventralen Seite auf derjenigen Linie inserirt sind, welche gebildet wird von dem Uebergange der Costa in die Flügel; 4. die Form dieser Amphigastrien, die mit sehr schmaler Basis inserirt sind; 5 . die zerstreute Anordnung der Pistille, die entweder in lockeren Ständen angeordnet sind oder auch zerstreut auf der Mittelrippe stehen und in solchem Falle stets von einer einzelnen Schuppe vom Rücken her geschützt, sonst aber von einer Anzahl locker gestellter und an der Basis unverbundener Bracteen umgeben sind; aus diesem Grunde findet man bei allen Arten die Mittelrippe mehr oder weniger dicht mit Bracteen bedeckt; 6 . das glockenförmige, mächtig entwickelte Perianth, an der Basis stets fleischig, beiderseits oft mit Lamellen besetzt, welche in eine freie Spitze auslaufen; 7. die Haube, welche stets frei im Grunde des Perianths steht und welche die sterilen 
Pistille an der Basis ringförmig umgeben; 8. der månnliche Blüthenstand, der unbegrenzt die Costa bedeckt und auch in die Aeste übergeht und normal in jeder Schuppe eine grosse fast sitzende Anthere birgt.

Der Bau der Kapselwand und die Ausbildung des. Exospors sind allein nicht übereinstimmend und wir haben 2 Gruppen zu unterscheiden: 1. solche mit Halbringfasern in den inneren Zellen der Kapselwand und langstacheligen Sporen; 2. solche ohne Halbringfasern und papillösen Sporen.

Angesichts der völligen sonstigen Uebereinstimmung des Baues dieser Pflanzen, können die wenigen letztgenannten Unterschiede keinen Anlass geben, diese 2 Gruppen zu trennen; sind doch auch die Kapselwandungen bei Pellia verschieden und die Sporen der Riccien, dieser sehr einheitlichen Gruppe von Pflanzen, von überraschender Mannigfaltigkeit; es unterliegt daher keinem Zweifel, dass die der Ausstreuung der Sporenmasse und der Verbreitung der Sporen dienenden Organe Anpassungen unterworfen sind, welche jene Organe nicht immer wichtig für die systematische Stellung der Pflanzen erscheinen lassen; sie sind zur Charakterisirung des Genus nur mit Vorsicht zu benutzen.

Ich habe wie bisher für das die Calyptra direkt umhüllende Organ den Ausdruck Perianth gebraucht, obwohl der Ursprung desselben rein dorsaler Natur ist. Lindberg wählte deshalb den Namen "caulocalyx ^, der mir wenig sympathisch ist, weil diese Pflanzen einen Stengel nicht besitzen.

\section{Calycularia.}

A. Sporis echinatis.

1. C. crispula Mitt. Linn. Soc. V, p. 122.

Major, valida, cæspitans, pro more muscicola, luride virens, in sicco flavo-rufescens. Frons ad $5 \mathrm{~cm}$. longa, $10 \mathrm{~mm}$. lata, late ligulata, margine optime crispata, radicellis longis et creberrimis subhyalinis repens, simplex vel furcata. Costa valida, sat lata, medio ad 30 cellulas crassa. Alæ plus mirus erectæ, basi valde carnosæ, fragillimæ, cellulæ ad costam longiores. Amph. magna, sæpe purpurea, e basi filiformi lanceolata, papulosa, margine laciniis irregularibus aucta, in apice frondis comata erecta vel arcuatim in dorsum plantæ recurva. Archegonia ad 20, bracteis $6-8$, filiformibus vel lanceolatis varieque lacinulatis a tergo tecta. Perianthia magna, infundibulata, basi crassa, superne parum plicata, utroque latere lanceolata, ore crispato ad $1 / 5$ grosse laciniato, laciniis 
irregularibus longe acuminatis, sæpe hamatis. Calyptra superne tenerrima. Capsula in pedicello brevi et calycem vix superante subglobosa irregulariter bi-tri valvata, valvulæ bi-tri stratæ, cellulis internis dense annulatis. Sporæ 450 , rufescentes, longe echinatæ, echinis laxe dispositis, cylindricis, apice truncato-bidentulis. Elateres et Andræcia haud vidi.

Hab. Himalaya (Hooker, Griffith, Decoly et Schaul).

2. C. laxa Lindb. Svenska Vet. Ac. XXIII, p. 66.

Mediocris, fragilissima, lurido-viridis, dense cæspitosa. Frons ad $25 \mathrm{~mm}$. longa, $12 \mathrm{~mm}$. lata, simplex vel furcata, oblonga, canaliculata, crispata. Gosta ad 12 cellulas crassa, postice dilute violacea, radicellis longis dilute ferrugineis repens. Alæ adscendentes incurvæ vel explanatæ, cellulis ad $40 \mu$, basi longiores. Amph. parva, pallida, lanceolata, subulata, acutissima, medio infero lacinulata. Per. magna, $6 \mathrm{~mm}$. longa, ore $5 \mathrm{~mm}$. lato infundibulata, dilute virescentia, superne sæpe purpurascentia et leniter plicata, lamellis plus minus liberis longitudinaliter aucta, basi externa bracteis lanceolatis vel filiformibus, sæpe pinnatim lacinulatis laxe circumdata, ore late aperto, ad medium multifido, lobis erectis vel incurvis longe acuminatis, pinnatim spinosis. Calyptra crassa, magna pyriformis. Capsula subglobosa, pedicello $2.5 \mathrm{~mm}$. longo, ad basin usque 50-7 valvata, valvulis tristratis; stratum internum semiannulatim incrassatum. Elateres $300 \mu$. Sporæ $40 \mu$, brunneæ, remote echinatæ, echinis conico-cylindricis truncato-bifidulis. Androecia in planta minore et angustiore, bracteis confertis, apice ciliatis vel lobatis.

Hab. Sibiria, Jenisei ad flum. Dudinka (Arnell).

\section{B. Sporis papillatis.}

3. G. radiculosa St. Hedw. 1893, p. 146.

Majuscula, flaccidissima (ulvoidea) saturate viridis, corticola. Frons ad $6 \mathrm{~cm}$. longa, $20 \mathrm{~mm}$. lata, ovato-oblonga, simplex vel furcata, persæpe ramis posticis innovata, radicellis purpureis vel sanguineis arcte repens. Cost $a$ angusta postice maxime producta et optime carinata. Alæ adscendentes, sæpe asymmetricæ vel uno latere omnino deficientes, ad costam 4 cellulas crassæ ceterum unistratæ, tenerrimæ explanatæ, margine plicato-crispulæ, integræ. Cellulæ alarum $35 \times 70 \mu$ ad costam longiores. Amphig. parva, subulata, rubescentia, quatuor cellulis. superpositis formata. Perianthia parva, sæpe seriata, anguste infundibulata, eplicata, 
basi paucis bracteis lanceolalis, dentato-ciliatis, circumdata, ore late aperto truncato breviter inciso irregulariterque pilifero. Pistilla ad 20 in toro subhemisphærico. Calyptra magna, purpurea, libera, crassa. Capsula in pedicello $10 \mathrm{~mm}$. longo ovalis, ad basin usque quadrivalvis valvulis bi-tri stratis, stratum internum cellulis exannulatis formatum. Elateres $440 \mu$. Sporæ purpureæ $22 \mu$, papillatæ Andræcia ignota.

Hab. Java (Stahl. Schiffner) India orient. (Griffith) Borneo (Everett), Samoa (Reinecke).

\section{G. birmensis St. n. sp.}

Mediocris, flaccida, saturate viridis, corticola vel muscicola. Frons ad $4 \mathrm{~cm}$. longa, $7 \mathrm{~mm}$. lata, radiculis dilute ferrugineis arcte repens, late ligulata, undulata, margine crispata, simplex vel ex apice innovata, rarissime furcata. Costa minus crassa (ad 12 cellulas), angusta, frondis diametro triplo angustior, postice convexa, antice concava : alæ e basi adscendente plano-explanatæ, basi pluristratæ, limbo unistrato sat lato. Cellulæ alarum $37 \mu$, sæpe subrectangulares, ad costam longiores. Amph. majuscula, hyalina tenerrima, anguste ligulata, 2-3 cellulas lata, margine alte papulosa, hic illic cellula imposita quasi pinnata. Perianthia ignota. Bracteæ femineæ ad 3-4 tenerrimæ, hyalinæ, amphigastriis configuratione simillimæ, majores tamen. Androcia ignota.

Hab. Birma (Fraser) Sikkim (Decoly et Schaul).

Der Habitus dieser Pflanze ist völlig der von C. radiculosa; die viel grösseren Amphigastrien unterscheiden sie sofort. C. crispula ist eine viel grössere Pflanze, mit mächtigen Amphigastrien, die man mit unbewaffnetem Auge sehen kann.

\section{C. hibernica (Hooker) St.}

Syn. : Jungermannia hibernica Hook. Jung. Brit. t. 88.

Dilæna hybernica Dum. Commentat. 1829.

Blyttia Lyellii var. hibernica Syn. Hep. p. 475.

Morkia hibernica G. Ann. sc. nat. 1864, p. 83.

Mediocris, angusta et gracilis, pallide-virens, muscis consociata rarius gregarie crescens, sæpe paludicola. Frons ad $35 \mathrm{~mm}$. longa, $6 \mathrm{~mm}$. lata, repetito furcata, canaliculata, parum crispata, radicellis flavescentibus arcte repens; costa normaliter ad 30 cellulas crassa, bene producta, in sectione triangularis; alæ e basi crassa adscendentes, sæpe plano-explanatæ integerrimæ, undulatæ, in angulis furcarum plicatulæ. Cellulæ $37 \times 63 \mu$ ad costam longiores. Amph. parva, filiformes, hyalina, 4 cel- 
lulas longa, cellula quinta basalis minima. Perianthia magna, oblonga, inflata, pluriplicata, basi crassa, superne tenera, utroque latere anguste lamellata, ore breviter inciso-multiloba, lobulis crenato- denticulatis; bracteæ basales perianthii valde variabiles; pro more bractea singula magna adest, perianthium a tergo accumbens, subcircularis ad $1 / 3$ anguste lacinulata; bracteæ reliquæ remotæ, lineari-lanceolatæ, ramosæ vel profunde bifidæ. Calyptra lenera, basi tantum crassa. Capsula ovalis in pedicello $25 \mathrm{~mm}$. longo, rufo brunnea, ad basin usque $2-4$ valvata, valvulis 3 stratis, stratum internum tenerum. Sporæ $43 \mu$, brunneæ, papillatæ. Elateres 275 ‥ Andræcia in planta graciliore, bracteis sæpe sparsis, denticulatis. Hab. Europa, Britannia, Hibernia, Germania, Gallia, Italia (Alpes Valsesiæ).

\section{G. Blyttii (Möreh) St.}

Syn. : Jungermannia Blyttii Mörch. Fl. Dan. X, 34. t. 2004.

Diplomitrium Blyttii Corda in Sturm. Fl. germ. II, p. 126.

Diplolæna Blyttii Nees. Hep. Eur. III, p. 339.

Blyttia Morkii Nees. Syn. Hep. p. 474.

Morkia Blyttii G. Ann. sc. nat. 1864, p. 83.

Dilæna Blyttii Dum. Hep. Eur. 1874, p. 138.

Pallavicinia Blyttii Lindb. Musci. scand. 1879, p. 10.

Major, viridis, subglaucescens, compacte cæspitans. Frons ad $25 \mathrm{~mm}$. longa, ex angusta basi ad $150 \mathrm{~mm}$. lata, simplex vel furcata (sub flore semper furcatim innovata). Costa crassa, ventre carinata valde producta, radicellis rufo-brunneis arcte repens. Alæ e basi crassa adscendente erectæ vel explanatæ, integerrimæ optime crispatæ, limbo unistrato angusto (vix 10 cellulas lato). Cellulæ alarum corticales $37 \mu$, subquadratæ, internæ multo majores, perlucentes et frondem reticulantes. Amph. parva, purpurea, lanceolata vel subulata, in apice plantæ valde numerosa, facile decidua. Bracteæ femineæ basi annulatim connatæ, perianthio breviores, profunde lobatæ, lobis inæqualibus spathulatis vel ligulatis vel emarginato-bilobis. Perianthia optime campanulata, magna, inflata, parum plicata et vix lamellata, ore late aperto profunde lobato, lobis late triangulatis acuminatis hic illic grosse dentatis. Calyptra crassa. Capsula ovalis, 3-4 valvata, valvulis bi-tristratis, stratum internum tenerum. Sporæ brunneæ, $33 \mu$, papillatæ. Elateres $220 \mu$. Androcia linearia, bracteis sparsis magnis erectis varie lobulatis plicatis et tortis, costam obvelantibus. Antheridia magna, subsessilia.

Hab. Germania, reg. subalpina (Alpen, Sudeten); Scandinavia. 


\section{MAKINOA Miyake. 1899.}

Plantæ frondosæ, magnæ vel maximæ, subteneræ, olivaceæ, ætate rufo-brunneæ, longe lateque expansæ, depresso-cæspitantes. Frons furcatim ramosa, ad $10 \mathrm{~cm}$. longa, $20 \mathrm{~mm}$. lata, plana, marginibus valde crispatis integerrimis vel repandis. Cellulæ internæ corticalibus majores. Costa angusta, postice parum producta, radicellis rufo-brunneis repens, medio ad 12 cellulas crassa, sensim in alas crassas excurrens, apice cellulis clavatis muciferis obtecta. Alæ pluristratæ, ad costam crassæ, versus marginem sensim attenuatæ, limbo marginali unistrato angusto. Inflorescentia dioica. Pistilla magna (ad $1 \mathrm{~mm}$. longa) numerosa, in fundo alveoli antici frondis aggregata, squama parva dentata a tergo tecta, Calyptra magna, longe exserta, rufo-brunnea, crassa, oblique erecta, cylindrica, subclavata, squamæ dorsali parce coalita, pistillis sterilibus ubique obsita. Pedunculus capsulæ ad $5 \mathrm{~cm}$. Iongus, crassus, hyalinus; capsula oblongo-cylindrica, $5 \mathrm{~mm}$. longa, usque ad basin bivalvata, valvulis bistratis; cellulæ externæ oblongo-hexagonæ, validissimæ, parietibus brunneis ubique maxime æqualiterque incrassatis; cellulæ internæ angustiores, longissimæ, parietibus minus validis semiannulatim incrassatis. Elateres axi capsulæ paralleli, stricti, utriculo valido, usque ad $960 \mu$ longi, apicibus longe attenuatis sine fibra spirali, terijo medio solum bispiro, spiris validissimis uno latere trigone ampliatis ibidemque confluentibus. Sporæ parvæ, sphæricæ, ad $27 \mu$, pallide flavo-virides, cuticula papillulis aspera. Andræcia in fundo alveoli antici costæ, squama humillima semilunari a tergo circumvallata; antheridia toro bene definito, crasso, a tergo ad apicem descendente inserta, alveolis magnis, ad retem connatis immersa, brevissime pedicellata, subsphærica; spermatozoidea gigantea apice longe biciliata.

MI. crispata (St.) Miyake Hedw. 1899, p. 201.

Syn. : Pellia crispata St. Bull. Herb. Boissier V, p. 103.

Hab. : Japonia (Faurie, Makino).

Diese eigenartige Gattung steht hinsichtlich der vegetativen Organe dem Genus Pellia zwar nahe, die Form der Kapsel bringt sie aber zu denjenigen Gattungen, die Schiffner bereits als Leptotheceær zusammengefasst 
hat; die nächstfolgenden Gattungen haben alle sphärische Kapseln und lassen sich ungezwungen in 2 Gruppen theilen :

1. Solche mit Elaterenträgern: Blasia (und wahrscheinlich auch Cavicularia), Pellia und Androcryphia.

2. Solche ohne Elaterenträger und deren Kapselschalen in Stücke zerfallen: Treubia, Petalophyllum und Fossombronia.

Die Stellung der Blüthen von Treubia und Fossombronia ist auch eine ausgesprochene Hinneigung zu den blättertragenden Lebermoosen, wo man bei Gattungen mit wenig geneigter Blattinsertion (wie Lophocolea) die Antheren in Taschen findet, welche am Rande des Stengels auf dessen dorsaler Seite stehen und den Schuppen von Treubia ganz analog sind; es sind Schutzorgane für die Blüthen.

In diesem Sinne gruppirt, folgen hier die oben erwähnten Gattungen, welche vielfach Uebergänge zu den foliosen Lebermoosen zeigen, ihrer dorsalen $q$ Blüthenstellung wegen aber den natürlichen Abschluss der thallosen (anacrogynen) Formen bilden.

\section{CA VICULARIA St. 1897.}

Plantæ frondosæ spectabiles, radicellis longis hyalinis arcte repentes, terricolæ, intense virides denseque depresso-cæspitantes. Frons furcatim ramosa, ad $\breve{~} \mathrm{~cm}$. longa, furcis ligulatis ad $5 \mathrm{~mm}$. latis (interdum multo angustioribus in locis minus humidis). Costa angusta, postice leniter convexa, antice plana, medio ad 17 cellulas crassa, sensim in alas attenuata, utriculis calciiferis longitudinaliter percursa. Alæ pluristratæ, limbo marginali unistrato angustissimo, rarius latiore, interdum nullo; cellulæ internæ frondis corticalibus multo majores; margo frondis vel planus vel undulatus vel crispatus. Auricula utroque latere costæ seriata, ut in Blasia subglobosa, poro parvo instructa, primo mucifera, deinde algis infesta et valde ampliata. Amphigastria parva, ad latus costæ biseriata, medio suo posteriore affixa, oblonga acuminata apice acuta vel emarginato-bidentula, margine dentato. Inflorescentia dioica. Flores fem. in frondis facie antica. Pistilla plura aggregata, nuda, involucro squamæformi et lunatim exciso a dorso tecta; alia pistilla sterilia solitaria sparsim in frondis superficie et in ipso dorso involucri. Capsula ignola. Androcia in planta graciliore et minore. Antheridia alveolis magnis costæ immersa, 
magna, sphærica, pedicello brevissimo, nusquam exserta, poro alveolari parvo. Plantæ femineæ steriles semper propaguliferæ, versus apicem frondis involucrum ut supra descriptum gerentes. Propagula majuscula, in fundo involucri dense aggregata, discoidea, plano-convexa, subsessilia (pedicello unicellulari) cellulis parvis clavatis muciferis circumdata, sæpe pedicello affixa germinantia. Unica species:

Cavicularia densa St. 1897, Bull. herb. Boiss., p. 87.

Hab. Japonia (Faurie, Ishikawa, Miyake).

Schiffner erwähnt noch eine zweite Art Brutknospen (in den Hüllen), die ich aber an meinen zahlreichen Aufsammlungen nirgends zu finden vermochte.

\section{BLASIA Micheli 1729.}

Plantæ frondosæ, mediocres, radicellis hyalinis arcte repentes, terrestres, intense virides, dense cæspitantes. Frons repetito-furcata, angusta, late costata. Costa postice valde convexa, antice canaliculata, abrupte in alas attenuata. Alæ in medio basali pluristratæ, inciso-lobatæ, lobis unistratis rotundatis integerrimis, folia fingentibus, in apice frondis imbricatis, incubis, sæpe crispatis; cellulæ frondis corticales parvæ, internæ multo majores, in costa parvæ elongatæ. In facie postica frondis, ubi costa in alas transit, adsunt cavitates parvæ, auricula dictæ, subglobosa, basi lata tamen inserta, vertice clausa et poro minuto perforata, primo mucore repleta, subinde semper algis infesta et valde ampliata; dua auricula utroque lobulo tributa, alterum margini supero lobuli, alterum infero approximatum. Amphigastria magna, ad latus costæ biseriata, centro suo tantum accreta, ovata grosseque dentata. Inflorescentia dioica. Flores feminei in facie antica frondis nudi, foliis floralibus nullis, post fecundationem involucro fusiformi crasso circumvallati, haud innovati; involucri apex prominulus, constrictus, mamillatus, cellulis incrassatis lignosus. Pistilla plura, aggregata, unum fecundatum involucratum, reliqua sterilia decidua. Calyptra inclusa, libera cellulis bistratis crassa. Capsula ellipsoidea, basi externa vallatim ampliata, subapophysata, in pedicello longiusculo, basi bulbo anguste conico inserto, ceterum usque ad basin quadrivalvis; valvulæ 3 -4 stratæ; cellulæ externæ longæ, 
brunneæ, parietibus radialibus incrassatæ; internæ tenerrimæ, late cubicæ, intimæ sæpe destructæ. Elateres remanentes in fundo capsulæ pauci, ampliores et grosse bispiri; elateres decidui ad $27 \mu$, bispiri, flavescentes. Sporæ ad $42 \mu$, primo tetragone, deinde inflatæ subsphæricæ, asperæ.

Plantæ masculæ rarissimæ angustiores; Antheridia antica, sparsa, alveolo parvo monandro imersa, ovalia, pedicello perbrevi inserta. Plantæ steriles sæpissime propapuliferæ, versus apicem frondis utriculum lageniforme gerentes; propagula discoidea, brevissime pedicellata, e cellulis utriculi internis papilliformibus orta.

\section{Blasia pusilla Mich. Nova pl. gen. p. 14 .}

Unica species per totam regionem sylvaticam Europæ, Asiæ et Americæ sept. distributa.

Leitgeb und Gœbel fassen die Lappen der Frons als Blätter auf, während ich den Standpunkt vertreten habe, dass schon in der Anlage derselben ein grosser Unterschied gegenüber den unter- und oberschlächtigen Blättern der Lebermoose obwaltet; wir haben schon bei der Gattung Symphyogyna gesehen, dass die Lappen der Frons aus Zähnen des Blattrandes entstanden sind und dass sie lediglich zum Schutze des Vegetationspunktes dienen; dasselbe ist der Fall bei Blasia, wo die jungen Thalluslappen gedrängt und flach übereinander geschoben das junge Gewebe besser schützen als die ungetheilte Frons es vermöchte. Dass die Blätter der Lebermoose aus solchen Formen entstanden sein mögen und dass wir hier die ersten Stadien dieser Umwandlung vor uns haben, ist eine nahe liegende Vermuthung; in der Gattung Schiffneria werden wir sehen, dass diese Pflanze bereits eine weitere Stufe der Differenzirung erreicht und schräg inserirte Blätter producirt hat.

Wo hier die Grenze zu ziehen ist und was wir bereits als Blätter auf dieser Stufenleiter ansprechen wollen, kann Jeder für sich entscheiden. Hier genügt es, die Thatsachen festzustellen.

Die Brutknospen erzeugenden Hüllen sind wahrscheinlich immer als degenerirte weibliche Involucra aufzufassen; es sind in ihnen auch Pistille bemerkt worden und dasselbe meldet Schiffner auch von der vorstehenden, sehr nahe verwandten Cavicularia. 


\section{PELLIA Raddi. 1820.}

Plantæ frondosæ, spectabiles, subcarnosæ, fragiles, virides vel olivaceæ, interdum purpurascentes vel rufo-brunneæ, arcte repentes, terricolæ, ripariæ vel paludicolæ, longe lateque expansæ et depressocæspitantes. Frons plana, margine undulata vel crispata, monopodialiter ramosa, sæpe ex apice innovando-prolifera, sub flore geminatim innovata, apice cellulis clavatis muciferis obtecta, intus transverse incrassata; incrassatio trabeculata, validissima, hyalina, in costa sæpe densissima, cellulas subepidermales longe percurrens, in alis multifurcata, interdum minus distincta. Costa angusta, postice parum prominens, sensim in alas crassas excurrens ideoque minus distincta. Alæ integerrimæ vel repandæ, pluristratæ, limbo marginali unistrato plus minus lato. Cellulæ internæ corticalibus majores. Inflorescentia monoica vel dioica. Flores utriusque sexus antici. Pistilla aggregata, post fecundationem involucrata. Involucra squamæformia vel plus minus calyciformia, foveolam amplam tegentia. Calyptra plus minus crassa, libera vel involucro connata, pistilla sterilia usque ad apicem suum gerens, inclusa vel longe exserta. Capsula longe pedicellata, sphærica, usque ad basin quadrivalvis, valvulis luteolis, pluristratis. Elateres remanentes fundo caspulæ inserti, comati, longi; elateres decidui multo breviores. Sporæ magnæ, ellipsoideæ, virides, pluricellulares, cuticula minute aspera. Andrœcia totam costam dense tegentia. Antheridia alveolis inflatis tempore maturitatis ruptis immersa.

Die Verdickungsleisten, welche sich nur in den fleischigen Theilen des Thallus finden und dieselben quer durchlaufen, liegen meist an den oberen Wänden der subepidermalen Zellen, in einer Ebene; sie gehen anschliessend von Zelle zu Zelle und verzweigen sich in den Flügeln, soweit sie mehrschichtig sind, oft mit kurzen Unterbrechungen; es kommen aber auch ringförmige Verdickungen vor, $d$. h. an vertikalen Querschnitten sieht man die Verdickung an der oberen und unteren Zellwand und an ihren beiden Stirnseiten einen geschlossenen Ring bilden, der, von Zelle zu Zelle sich wiederholend und anschliessend eine vertikale Kette von Ringen darstellt, die von Oben gesehen natürlich als eine einzelne Verdickungsleiste erscheint. Je nach der mehr oder weniger kräftigen Entwicklung der Pflanzen ist die Ausbildung dieser Verdickungen eine sehr variable bei allen Arten; am auffallendsten sind sie 
bei Pellia Neesiana zu finden, wo sie, animalen Rippen vergleichbar, das fleischige Gewebe durchziehen und ihm als ein mechanisches Element zur Stütze dienen.

Die Sporen aller Arten variiren ausserordentlich in der Grösse, je nachdem die Zelltheilung in denselben vorgeschritten ist, so dass eine Angabe der Durchmesser, weil zwecklos ganz unterbleiben musste, und für die Bestimmung der Pflanzen keinen Anhalt bietet.

Wir kennen 3 Arten, welche im nördlichen Gebiet von Europa, Asien und Amerika weit verbreitet sind, zu den gewöhnlichsten Bürgern jeder Localflora gehören, so dass spezielle Standorte anzuführen nicht nöthig ist.

Es ist nur im Allgemeinen zu bemerken, dass in Europa Lappland der nördlichste, Calabrien der südlichste bekannte Standort ist; in Asien gehen die Arten bis in die südlichsten Inseln Japans herab und sind auch aus dem Himalaya bekannt; in Sibirien und im nördlichen Japan sind sie gemein, in Amerika aus Vancouvers als nördlichsten Standort bekannt; leider sind die Bestimmungen'nicht immer zuverlässig, da Pellia Neesiana Limp. bisher häufig zu Pellia epiphylla gezogen oder eine sorgfältige Untersuchung der überall häufigen Pflanzen überhaupt unterlassen worden ist. Ich verweise in dieser Hinsicht auf Jacks Arbeiten, besonders auf seine Publikation Flora 1895, Band 81, Heft 1, mit Tafel, wo auch eine Richtigstellung der ausgegebenen Exsiccaten gegeben ist.

\section{Pellia epiphylla (L.) Lindb. Hep. in Hib. 1874, p. ๑334.}

Syn. : Jungermannia epiphylla L. Spec. pl. 1602.

Monoica, solum siliceum diligens. Frons ex angusta basi late oblonga vel obcordata, ad $15 \mathrm{~mm}$. lata, sæpe ex apice prolifera, plana, integerrima et parum undulata, Costa ad $\mathbf{1 6}$ cellulas crassa. Involucrum basi saccatum medio supero liberum, squamæforme, apice truncatum, 3-4 lobatum; lobuli cellulis papuloso-prominulis crenati. Calyptra arcuata, longe exserla, roseo picta, usque ad basin fere unistrata. Pedicellus capsulæ ad $10 \mathrm{~cm}$. longus; valvularum cellulæ externæ nodulose incrassatæ (a facie visæ), internæ semiannulatim incrassatæ. Elateres remanentes, comati, erecti, basi connati superne torti et divergentes, grosse tubulosi, quadrispiri, spiris validissimis. Elateres decidui minores et angustiores, valde torti, bispiri, spiris minus validis. Androcia in ipso ramo femineo hypogyna vel in ramis propriis.

2. Pellia Neesiana (G.) Limpr. in Cohn. Krypt. Fl. 1876, I, p. 329. Syn. : P. epiphylla var. Neesiana G. Hedw. 1867, p. 69. 
Dioica, minus robusta, angustior, sæpe rufo-brunnea, planta mascula sæpe purpurascens. Costa minus valida, ad 12 cellulas crassa. Involucra depressa vel adscendentia, compresso-cylindrica, ঙævia, apice truncata, hic illic cellulis prominulis subdenticulata, pariete dorsali (in planta sterili) sæpe fissa vel omnino aperta. Calyptra normaliter inclusa, crassa (basi 5 strata) apice bistrata. Capsula ut in præcedente.

Reliquis vix minus communis, forsan adhuc solum commutata.

3. Pellia calycina (Tayl.) Nees. Hep. Eur. 1838, III, p. 386.

Syn. : Jungermannia calycina Tayl, in Mackay. Fl. Hib. II, p. อั.े.

Pellia endiviæfolia Lindb. Hep. in Hib. 1874, p. 534.

Pellia fuciformis Nees. Hep. Eur. 1838, III, p. 388.

Dioica, minus robusta sæpe subtenuis, pro more fusco-purpurea, angusta, ramis numerosis instructa, alis crispatis. Involucra, suberecta, tubulosa, lævia, ore angustato lobato, lobulis paucispinosis. Calyptra inclusa, bistrata, basi sua involucro coalita. Capsula minor, pluristrata; cellulæ externæ magnæ cubicæ, nodulosæ incrassatæ, internæ tristratæ, humillimæ, haud incrassatæ. Elateres remanentes longissimi, tenuissimi, liberi sed comati, bispiri. Elateres decidui multoties breviores et sat validiores trispiri. Planta mascula valde angustata, multiramosa.

In rupibus calcariis vel in solo aquis calcariis saturato.

Die griechische Pflanze Pellia fuciformis Nees ist eine untergetauchte Wasserform obiger Art, wie jene bei Hochwasser nicht selten vorkommt; die ovalen Organe sind anhängende Diatomeen (Cocconeïs Pediculus Ktz.).

\section{ANDROCRYPHIA Nees.}

Plantæ foliosæ, spectabiles, virides, sæpe purpurascentes flaccidæ, arcte repentes, terricolæ vel paludicolæ. Caulis monopodialiter pauciramosus, costæformis, antice planus, vel leniter canaliculatus, postice valde productus, medio 12 cellulas crassus, cellulis internis majoribus, radicellis hyalinis repens. Folia subrotunda, parum imbricata, oblique a caule patula, pluristrata, limbo unistrato ad 20 cellulas tantum lato, postice breviter inserta, antice attenuatim in caule decurrentia, celerum margini antico caulis alatim adnata, minime succuba et fere omnino horizontalia, planoexplanata, flaccida; cellulæ foliorum ad $50 \mu$, basi duplo longiores, omnes 
exincrassatæ. Amphigastria caulina nulla. Inflorescentia monoica. Flores utriusque sexus in facie antica caulis. Pistilla aggregata, nuda, post fecundationem perianthio circumdata. Folia floralia quatuor, utroque latere 2, basi magis crassa, ceterum caulinis simillima, interdum parum crispata. Amphig. florale magnum, ex angusta basi linguæforme, foliis suis duplo brevius. Perianthium terminale, postice innovatum, subhorizontale, a latere compressum; inferne crassum, subteres, superne tenuior, ore unistrato bilabiato, truncato-rotundato, labiis repandis. Calyptra magna, libera, ipsa basi crassa pistillis sterilibus cincta, superne tenuis pistillis usque ad apicem fere ornatis. Pedunculus capsulæ ad $3 \mathrm{~cm}$. longus, cauli profunde insertus, bulbo conico sæpe usque ad tertium folium descendente. Capsula parva, sphærica, usque ad basin quadrivalvis, valvulis bistratis; cellulæ externæ hyalinæ cubicæ, parietibus radialibus incrassatæ, internæ laxe semiannulatim vel spiraliter incrassatæ. Sporæ virides, subsphæricæ, ad 650 in diam. pluricellulares, cuticula aspera. Elateres remanentes longi, crassi, quadri- et plurispiri, spiris validis laxe tortis. Elateres decidui minores, valde irregulares $(110$ ad $260 \mu)$ pro more trispiri, spiris capillaceis. Andrœcia flori fem. approximata, sæpe totam costam occupantia, irregulariter aggregata. Antheridia immersa, magna, brevissime pedicellata, in alveolis valde inflatis, tempore fecunditatis ruptis.

Species unica adhuc cognita :

A. confluens (Tayl.) Nees. Syn. Hep. p. 471.

Syn. : Androcryphia perphyrorhiza Nees. l. c. p. 470.

Noteroclada confluens Tayl. J. of Bot. 1844, p. 478.

Noteroclada leucorhiza Spruce. Edinb. Bot, Soc. 1885, p. 530.

Hab. Brasilia (G.-A. Lindberg; Gardiner, Diedrichsen, Puiggari, Glaziou, Wainio, Schwacke, Ule); Bolivia (Mandon); N. Granada (Lindig); Peruvia (Spruce); Mexico (Liebman); Argentinia (Lorentz); Chile (Dusén); Patagonia (Dusén); Fretum magellanicum (Savatier); Fuegia (Dusén).

Androcryphia perphyrorhiza wurde zuerst von Nees in Martius, Flora brasiliensis I, p. 343, als Jungermannia porph. beschrieben; in der Syn. Hep. ist dieses Exemplar, welches in Nees. Herbar heute noch liegt, als "planta masculina * bezeichnet; die Pllanze ist aber eine sterile weibliche und zeigt, dass hier ein arger Irrthum vorliegt; von den 2 minimalen Stengelchen, die nicht entfernt wie eine Androcryphia aussehen und die nach dem Etikett aus einem Rasen von Aneura pinguis herausgezogen wurden, trägt einer wenige vereinzelt stehende Pistille, der andere ist 
ganz steril ; an einer Stelle hat dieser aber eine seitliche Quetschung erfahren, so dass man einen Theil der Oberseite und ein Stück der Unterseite zugleich vor sich hat; die Wurzeln sind hier in Folge der Quetschung abgerissen; ihr basaler erweiterter Insertionstheil, der auch roth gefärbt ist wie die übrigen Rhizoiden, ist an der betreffenden Stelle allein erhalten; das abgerissene Wurzelstück hinterliess eine Oeffnung, durch welche man in das Lumen des Rhizoidenrestes hineinsehen kann; das Ganze sieht einigermassen einer eingesetzten Anthere ähnlich, gehört aber natürlich der ventralen Seite des Stengels an, was man nicht bemerkt hat; die übrigen noch erhaltenen rothen Rhizoiden beweisen es; dieser unglückliche Irrthum isı der Anfang einer ganzen Kette von weiteren Irrthümern geworden; denn die ächte Pflanze, welche Montagne erhielt und die in einer vorzüglichen Handzeichnung von Montagne im Herbarium Nees erhalten ist, stellte nun Nees zu seiner Jungermannia porphyrorhiza, obgleich sie keine rothen Wurzeln hat; Spruce hat später, weil er das Original von Nees nicht kannte, auch dieser Wurzeln wegen eine Noteroclada leucorhiza geschaffen, die aber auch nicht verschieden von Montágnes Pflanze ist, während Taylor aus gleichem Grund seine Noteroclada confluens als abweichende Art publizirte. Es giebt aber nur eine Art, sie sind alle gleich, diese verschiedenen Pflanzen und nur eine ist abweichend, das Original, welches lediglich eine etiolirte Form einer Fossombronia repräsentirt.

Die Gattungsdiagnose ist natürlich nach Montagnes Pflanze, der ächten, gemacht, weil die 2 Stückchen mit rothen Wurzeln nichts dazu hergeben konnten - als die rothe Farbe; so ist die Beschreibung sonst völlig zutreffend und der Name Androcryphia beizubehalten; der Speciesname porphyrorhiza dagegen, der von der Pflanze etwas hervorhebt, das sie überhaupt nicht besitzt, kann nicht bestehen bleiben. Die Gattung Noteroclada ist ohne Gattungsdiagnose publizirt und es ist als ältester zutreffender Name für die Pflanze daher Androcryphia confluens zu setzen, wie ihn die Syn. Hep. p. 471 bereits enthält.

Die Pflanze ist bisher stets in die Nähe von Fossambronia gestellt worden, natürlich in Folge der vermeintlichen rothen Wurzein und wegen des beblätterten Stengels, der, wie bei Fossambronia, den Uebergang der Thallosen zu den foliosen Formen darstellt; die Pflanze steht aber der Gattung Pellia viel näher und zwar so nahe, dass man sie ganz zu diesem Genus ziehen müsste, wenn nicht die normalen unterschlächtigen Blätter vorhanden wären. Schon der Habitus gut ausgebildeter Pflanzen ist ganz der einer Pellia; die eingesenkten Antheridien entfernen sie auch von 
Fossombronia und gleichen denen von Pellia; vor allem aber sind Perianth und Kapsel der letzteren Gattung ganz analog.

Das Perianth liegt horizontal und in der Ebene des kriechenden Sprosses, wenig ansteigend und entspringt wie bei Pellia der Oberseite des Stengels, resp. der Mittelrippe, als eine rein dorsale Bildung, an der die Blätter keinen Antheil haben; die Kapsel zerfällt nicht in unregelmässige Stücke wie bei Fossambronia und Petalophyllum, sondern spaltet sich in 4 gleich grosse Schalenstücke; im Grunde stehen Elaterenträger, wie bei Pellia und die Sporen sind denen dieser Gattung auch analog, gross, mehrzellig und chlorophyllhaltig, eine vorkeimartige Zelltheilung darstellend, es ist eine Pellia calycina mit Blättern versehen, die uns am besten, weil am lückenlosesten, den Uebergang einer Thallosen in eine foliose Form vor Augen führt. Fossombronia und Petalophyllum stehen gegenseitig in ähnlicher naher Verwandtschaft; mit unserem Genus aber haben sie wenig gemein.

\section{PETALOPHYLLUM G.}

in Lehm. Pug. VIII, p. 29.

Plantæ frondosæ, parvæ, teneræ, in arenosis humidis gregarie crescentes. Frons e basi exalata ad costam reducta subcircularis, apice profunde biloba, simpliciter vel furcatim continuata, ramis intercalaribus e latere costæ ortis rarissimis; innovationes ad costam reductæ, antice concavæ ad latera foliolis brevibus succubis liberis obsitæ. Costa crassa, postice valde producta, radicellis numerosis villosa. Alæ e basi adscendente curvatim explanatæ, ad basin frondis cordatim ampliatæ, teneræ, ad costam solum pluristratæ, anticæ lamellatæ; lamellæ simplices vel anostomosantes, plus minus regulariter versus marginem percurrentes, distincte et quasi radiatim divergentes, e facie antica costæ ortæ, medio suo latiores, versus marginem frondis attenuatæ, ipso margine in lobos liberos succube imbricatos excurrentes, ceterum appressæ i. e. margine suo libero versus apicem plantæ spectantes. Inflorescentia dioica. Flores feminei in costæ facie antica numerosi, pistillis aggregatis sorisque sæpe repetitis. Perianthia magna, ex angusta basi infundibulata vel campanulata, paucis bracteis adnatis anguste alata, ore parum angustato plus minus dentata. Calyptra libera, valida, perianthio parum minor, basi 
paucis pistillis sterilibus cincta. Capsula in pedicello longiusculo sphærica, majuscula, irregulariter rumpens, bistrata; cellulæ parietum externæ magnæ, hyalinæ validissimæ. Sporæ magnæ, reticulatim lamellatæ, lamellis altis asperis profunde foveolatæ. Elateres decidui, breves, bi- vel trispiri, spiris laxe tortis. Antheridia in facie antica frondis aggregata, bracteis monandrís, reticulatim connatis circumdata, ceterum sphærica in pedicello brevissimo.

Duæ species tantum cognitæ :

1. Petalophyllum Ralfsii (Wilson) G. Syn. Hep. p. 472.

Syn. : Jungermannia Ralfsii Wilson Engl. Bot. Suppl, tab. 2874.

Fossombronia corbuloeformis Trabut. Atlas Fl. Alg. 1886, p. 7.

Petalophyllum lamellatum Lindb. in Meddel. Soc. F. Fl, fenn. I, p. 91 .

Frons innovatione duplici, interdum simplici continuata, lamellis simplicibus in planta $\sigma$ anostomosantibus, planis percursa. Perianthia breviter inflato-cylindrica, ore repando, pauci-spinoso. Sporæ $76 \mu$. Elateres ad $200 \mu$, bispiri, spiris laxe tortis.

Hab. Britannia. Cornwall (Ralfs, Curnow); Hibernia (Wilson); Alger. (Trabut).

2. Petalophyllum Preissii G. Syn. Hep. p. 482.

Frons pro more furcatim innovata, lamellis ad costam anostomosantibus, crispatis. Perianthia campanulata, ore varie profundeque lacerato. Elateres trispiri, tenuiores quam in precedente. Sporas haud vidi.

Hab. Australia. Swan River (Drummond.); adhuc haud reperta.

\section{TREUBIA Gœbel.}

Plantæ frondosæ, magnæ vel maximæ, flaccidæ, olivaceæ, radicellis longis arcte repentes, terricolæ, longe lateque expansæ. Frons plana, monopodialiter ramosa, ramis irregulariter dispositis, ramis intercalaribus e latere costæ ortis rarissimis. Costa lata, basi angusta et subteres, superne plano-biconvexa, sensim in alas attenuata, utroque latere convexo-prominula; cellulæ internæ corticalibus multo minores; cellulæ centrales costæ longiores, angustæ, fasciculatim aggregatæ, antice bracteifera; bracteæ biseriatæ, parvæ, margine supero loborum approximatæ, MÉMOIREs DE L' HERBIER BoIsSIER, no $16,2 \%$ juin 1900. 
transverse insertæ, lamellatim connatæ; lamellæ humiles, erectæ et longitudinaliter (zigzag) a basi ad basin bractearum decurrentes. Alæ pluristratæ versus marginem attenuatæ, tenuiores, limbo unistrato sat lato, pseudofoliosæ i. e. usque ad costam inciso-lobatæ, lobis inferioribus sæpe remotiusculis sinubus rolundatis discretis, superne contiguis vel parum imbricatis, late ligulatis, margine supero (versus apicem caulis spectante) ab ipsa basi curvato, succubo. Flores utriusque sexus sparsi, bractearum fundo inserti. Pistilla numerosa, aggregata, paraphyllis circumdata, paraphylla numerosa, erecta, lanceolata vel spathulata, simplicia vel ramosa vel dentata, apice margineque cellulas parvas muciferas gerentia. Calyptra crassa, ad $12 \mathrm{~mm}$. longa, clavata, pistillis sterilibus et paraphyllis obtecta maxime mucosa, apice tantum nuda, papulosa, mamillam magnam crassam, conicam gerens. Capsula $2 \mathrm{~mm}$. in diam., in pedicello ad $\check{5} \mathrm{~cm}$. longo sphærica, usque ad basin 4 valvis, valvulis pluristratis, frustatim dissolutis, cellulæ internæ semiannulatim incrassatæ, externæ teneræ (parce destructæ). Sporæ parvæ, papillis hispidulæ. Elateres longissimi, longe attenuati, bispiri, spiris validis, ligulatis. Antheridia valde numerosa, aggregata, erecto divergentia quasi radiatim effusa, pedicellis longiusculis squamam superantia, ovoidea, paraphyllis nullis. Propagula in crista vel in fundo bractearum dense aggregata, pluricellularia, pedicello brevissimo.

Die Flügel des Thallus sind bis an den Rand der flachen biconvexen Rippe eingeschnitten; unterhalb des Einschnittes ist sie nur wenige Zelllagen stark; in dem tiefsten Punkte der Bucht entspringt der obere Rand des älteren Blattes, wie der untere des jüngeren; der erstere hat aber einen bogig hervortretenden Rand, welcher, da er anders nicht ausweichen kann, sich unter den nächstjüngeren Lobulus schiebt, wodurch eine scheinbar unterschlächtige Deckung entsteht; die Lappen des Thallus liegen aber sonst völlig in einer Ebene. Bei Treubia bracteata ist die Deckung eine noch weitergehende, weil hier der obere Rand jedes Lobuli weiter hervorgebogen ist und sich, von der Ansatzstelle ohrartig erweitert, frei unter die Costa schiebt. An verticalen Längs- und Querschnitten durch diese Region findet man niemals, dass der eine Rand auf der Oberseite der Rippe endet, der andere auf der Unterseite; es ist also eine wirkliche unterschlächtige Deckung nicht vorhanden. Selbstverständlich steht die Gattung den Blätter tragenden Lebermoosen nahe; wenn man aber den allmähligen Uebergang rein thalloser Formen (wie Symphyogyna und Cavicularia oder Metzgeria) in solche mit fiedrigen Thalluslappen und unter diesen wieder Uebergänge (wie Treubia sie zeigt) zu Schiffneria 
bis zu Fossombronia und Androcryphia präcisiren will, so geht es nicht an, dass man alle Thalluslappen summarisch mit * Blätter * bezeichnet und durch den Namen Unterschiede verwischt, die man hervorzuheben bemüht ist.

- 1. Treubia insignis Gœbel. Ann. Jard. Buit. IX, p. 1.

Planta maxima, ad $16 \mathrm{~cm}$. longa, $15 \mathrm{~mm}$. lata. Bracteæ dorsales parvæ, duplo latiores quam longæ, concavæ, suberectæ; margo superior loborum frondis arcuatus. Sporæ rufo-brunneæ, $22 \mu$. papillatæ. Elateres ad $1100 \mu$.

Hab. Java (Gœbel, Karsten, Stahl, Schiffner); Tahiti (Nadeaud).

2. Treubia bracteata St. n. sp.

Planta maxima, præcedenti simmillima. Bracteæ dorsales majores, subquadratæ, appressæ, lamellis decurrentibus nullis vel rudimentariis; margo superior loborum arcuatus, ad insertionem auriculatim ampliatus, succubus. Sterilis.

Hab. Samoa (Reinecke).

Ob es eine dritte Art (New Zealand, Sinclair, Cheeseman), (Patagonia accidentalis ad flumen Aysen, Dusén) giebt, ist zweifelhaft, da die Pflanzen steril sind und vegetativ geringe Unterschiede zeigen.

\section{FOSSOMBRONIA Raddi.,1820.}

Jung. Etr. in Act. Moden. 18, p. 40.

Plantæ foliosæ, pusillæ vel mediocres, interdum majusculæ, terricolæ sæpe paludicolæ, sæpius pallide virides, interdum fusco-virentes vel rufescentes, radiculis pro more sanguineis, interdum roseis vel pallidis arcte repentes, semper fere dense cæspitantes, rarius gregariæ.

Caulis fragilis, e simplice basi furcatus, sub flore simpliciter vel geminatim innovatus, ramis posticis nullis, ceterum crassus, postice valde productus, rotundatus vel carinatim angustatus, apice semper erectus, antice leniter canaliculatus, interdum apice recte in solum descendens tuberiferus.

Folia magna, oblique inserta, succuba, in caulis pagina ventrali semper brevissime inserta, antice plus minus longe - interdum usque ad medium 
caulis - decurrentia, medio basis semper pluristrata, ceterum tenera, ex angusta basi obcuneata, superne ampliata, sæpe latissima, margine angulata vel lobata, sæpissime crispata et incurva, rarius integerrima.

Folia floralia perianthio approximata semper majora, a reliquis sæpe diversa, magis et profundius incisa et dentata. Cellulæ foliorum semper exincrassatæ, magnæ, basi sæpe maximæ, in montosis et alpinis sæpe maximæ teneræ, in plantis exsiccatis flaccidissimæ.

Amphigastria nulla. Pistilla et Antheridia in axilla antica foliorum regulariter seriata, in plantis paroicis pistilla caulis medio inserta, antheridia ex contrario foliorum basi magis approximata.

Perianthia post fecundationem tantum evoluta, basi sæpe pistillis vicinis obsita, ibidemque breviter stipitata, ex angusta basi pyriformia vel turbinata vel campanulata, sæpe longitudinaliter plicata, superne tenera unistrata, basi semper crassa, bracteis filiformibus vel spathulatis jugata; bracteæ foliis breviores, longe accretæ, apice liberæ rarius a basi solutæ; perianthia in facie acroscopa sæpe profunde fissa; ore semper hiante recurvo, pro more lobato et crispato varieque armato.

Calyptra magna, pyriformis, basi crassa, perianthio multo brevior, interdum paucis pistillis sterilibus basi circumdata. Pedicellus capsulæ magno bulbo insertus, crassus, brevis. Capsula globosa, quadrivalvis, valvulis irregulariter rumpentibus, bistratis, stratum externum cellulis æqualiter incrassatis formatum, cellulæ internæ semiannulatim incrassatæ.

Sporæ majusculæ, plus minus brunneæ, tetraëdræ, exosporio in facie convexa varie armato, lamellato, vel papillato vel spinifero. Elateres breves, normaliter bispiri, spiris laxe tortis, validis, in paucis annuliformes.

Antheridia brevissime - in paucis longe - pedicellata, sæpe bracteata, bracteis vel lanceolatis vel cucullatis, antheridia a tergo tegentibus.

Die Gattung Fossombronia hat, mehr wie irgend eine der vorhergehenden, den Habitus der foliosen Formen; wenn sie dennoch zu den Thallosen gestellt wird, so wissen wir aus Leitgebs "Untersuchungen über die Lebermoose ", dass die Scheitelzelle auch hier erhalten bleibt und durch die Bildung des Perianths nicht aufgebracht wird; eine Zeit lang stellen diese Pflanzen zwar das Wachsthum ein, die 오 Blüthe erscheint terminal; sobald aber der Verbrauch der angesammelten Baustoffe zur Ausbildung der Reproduktions-0rgane sistirt ist, beginnt die Scheitelzelle wieder ihre Thätigkeit und die ausgebildete $q$ Blüthe sammt Perianth erscheinen nun dorsal. Die floralen Innovationen der foliosen 
(oder besser acrogynen) Lebermoose unterscheiden sich also wesentlich von denen unserer Gattung.

Die Stellung derselben am Schlusse der thallosen Formen, als vollendetes Mittelglied zwischen diesen und den acrogynen ist also eine natürliche; in der That hat unsere Gattung eine Anzahl Eigenschaften, welche sehr an die folioser Formen erinnern; so ist der Stengel bei vielen Arten fast stielrund, nur an der dorsalen Seite abgeflacht; er ist ein nothwendiges Attribut schräg gestellter Blätter; diese selbst sind vielen foliosen Formen entsprechend unterschlächtig inserirt, doch ist ihre Basis stets aus mehreren Lagen parenchymatischer Zellen aufgebaut, eine Eigenschaft, welche den Foliosen normaliter fehlt und an die Thallosen erinnert, deren seitlich verdünnte Costa allmählig in die Flügel übergeht. Die Stellung der Antheridien (wenigstens bei allen nicht parœcischen Formen) ist axillär und zeigt also eine nahe Verwandtschaft mit den foliosen Formen, die bekanntlich an gleicher Stelle der dorsalen Stengelseite die Antheridien in der Axel des Blattes entwickeln.

Alle Arten unserer Gattung sind in ihren Organen aus dünnwandigen Zellen aufgebaut und ihre älteren Sprosstheile gehen daher sehr bald zu Grunde, so dass nur selten Sprosssysteme erhalten sind; aus diesem Grunde ist auch die Bestimmung des Blüthenstandes eine wenig zuverlässige, da einst verbundene Glieder gelöst erscheinen.

Die in fast allen bisherigen Arbeiten stark vernachlässigte Angabe der Blattform hat zu dem Mythus Anlass gegeben, man könne dieselbe überhaupt nicht nutzbringend verwerthen; es unterliegt aber keinem Zweifel, dass die Blätter jeder Art eine konstante Form und einen Zellbau von messbar verschiedener Grösse besitzen; wenn es auch Arten giebt, die hierin wenig von einander abweichen, so giebt es doch viele, deren Blätter sehr charakteristische Formen zeigen.

Dagegen ist die Form des Perianths eine sehr einförmige, meist die eines Kreisels; wenige haben glockenförmige oder birnförmige Perianthien; sie sind theils allseitig geschlossen, theils (und zwar an demselben Stengel) an der acroskopen Seite bis zur Basis gespalten; hier findet sich gewöhnlich eine grosse freie Lacinie, welche mehrfach als Amphigastrium florale beschrieben worden ist; sie gehört aber den floralen Bracteen an, die allseitig das Perianth umgeben, stets auf eine mehr oder weniger lange Strecke mit ihm verwachsen sind und da, wo dasselbe gespalten ist, aus eben diesem Grunde nicht mit ihm verwachsen konnten, sondern als freie Lacinie den Spalt verdecken; von einem Amphigastrium kann also nicht die Rede sein, da dieses stets ventralen Ursprungs ist. 
Die beste Handhabe zur Unterscheidung der Arten bieten die Sporen, wie Lindberg zuerst gezeigt hat, ein Verdienst, das nur desshalb als ein grösseres erschien, weil man vorher deren Untersuchung in unglaublicher Weise vernachlässigt hatte.

Die Bekleidung der Sporen ist eine sehr verschiedene; sie zeigen (als erste Gruppe) entweder Lamellen, welche die convexe Seite des Tretraëders (nur diese ist stets in Betracht gezogen) radial überziehen und mehr oder weniger gabelig verlaufen; sie sind meist wenig zahlreich, seitlich zusammengedrückt und haben eine scharfe Oberkante, so dass sie da, wo die Lamelle den Rand der convexen Seite verlässt und scharf auf die Unterseite überbiegt, als dornige Fortsätze am Rande der Spore erscheinen; typisch für diese Gruppe ist $F$. pusilla Lindb.

Eine zweite Gruppe zeigt das Exospor durch netzig verbundene Lamellen in regelmässige sechseckige Felder getheilt; hier unterscheide ich 3 Unterabtheilungen, die den grössten Theil der Arten enthalten :

a) Sind die Lamellen zahlreich und alle gleich hoch, so erscheint der Rand der Spore wie von einem schmalen häutigen Flügel gesäumt; dieser Flügel ist in Wirklichkeit nicht vorhanden, sondern er entsteht aus dem Aufblick von Oben auf die convexe Fläche, an deren Peripherie die aufrechten coulissenartig hintereinander liegenden Lamellen als ununterbrochener Flügel erscheinen ( $F$. angulata Dickson).

b) Sind dagegen die Felder weniger zahlreich und weniger hoch, so erscheinen die überbiegenden radialen Wände des Lamellennetzes am Rande als kurze zahnförmige Fortsätze (F. Dumortieri).

c) Vielfach tragen die Lamellen an der Stelle, an welcher 3 zusammenstossen, eine aufrechtstehende Papille, so dass die Peripherie der Spore dicht papillös oder stachlig bekleidet erscheint, das Netz aber nur im Centrum des Bildes sichtbar ist (F. Husnoti).

Eine dritte Gruppe enthält diejenigen Arten, deren Exospor keine netzartige Lamellenbildung erkennen lässt; dasselbe ist dicht mit mehr oder weniger langen Papillen bekleidet und erscheint warzig oder lang stachlig, oft in dichtester Bedeckung (F. verrucosa Lindb., F. hispidissima St.). Nur bei einer Art dieser letzten Gruppe nimmt das Exospor eine ganz abweichende Bekleidung an; das Lamellennetz fehlt auch hier, aber es sind andere Lamellen vorhanden, welche rechtwinklig von der Oberfläche ausstrahlen, ziemlich entfernt stehen, seitlich zusammengedrückt und an der Spitze breit gestutzt sind (F. cæspitiformis De Not).

Die Untersuchung der Sporen geschieht am besten in Milchsäure, welche sie durchfälliger für das Licht macht und die Bildungen auf dem 
Exospor deutlicher erkennen lässt; ist die zugesetzte Flüssigkeit zu gering, so erhält die Spore durch die Ansaugung des Deckglases einen starken Druck, dergestalt, dass die Lamellen und Papillen nach allen Seiten verbogen und zerdrückt werden und ein ganz verzerrtes und undeutliches Bild entsteht; ein solches diente als Original zu der Zeichnung von F. Husnoti in der Revue bryol. 1890, Nr. 1.

Die Grösse des Sporen variirt innerhalb derselben Kapsel, doch ist es leicht, unter der grossen Anzahl die mittlere Grösse zu ermitteln. Die Länge der Elateren ist dagegen in einer Kapsel so verschieden, dass sie kein verlässliches Moment für die Unterscheidung der Arten abgeben können.

Dagegen lege ich Gewicht auf den Querschnitt des Stengels, welcher in vielen Fällen eine ausgeprägte constante Form zeigt, bald flach mit wenig convexer Wurzelseite, bald daselbst deutlich kielig verschmälert erscheint; bei anderen Arten ist er ventral stark abgerundet vortretend und seine Seiten vertical ansteigend, so dass er auf dem Querschnitt wie ein Sack zwischen den Blättern hängend erscheint.

Die rothe Wurzelfarbe ist, wie schon in der Gattungsdiagnose bemerkt, nicht allen Arten eigen.

\section{Fossombronia.}

\section{A. Sporæ furcatim lamellatæ.}

a. lamellis laxe dispositis.

1. Fossombronia pusilla (L.) Dum.

2. Fossombronia perpusilla (Col.) St.

3. Fossombronia crassifolia Spruce.

b. lamellis confertis.

4. Fossombronia cristata Lindb.

5. Fossombronia texana Lindb.

c. lamellis vermicularibus interruptis.

6. Fossombronia Stephanii Schffn. n. sp.

7. Fossombronia japonica Schffn.

B. Sporæ regulariter reticulatæ.

d. Sporce ambitu angulatim alater.

8. Fossombronia angulosa (Dicks.) Raddi.

9. Fossombronia brasiliensis St. n. sp.

10. Fossombronia lophoclada Spruce.

11. Fossombronia grandis St. n, sp.

12. Fossombronia reticulata St. 
e. lamellis margine dentatim prominulis.

13. Fossombronia lamellata St.

14. Fossombronia Dumortieri (H. et G.) Lindb.

15. Fossombronia cristula Aust.

16. Fossombronia incurva Lindb.

17. Fossombronia Zeyheri St. n. sp.

f. Spora ex angulis lamellarum papillata.

18. Fossombronia Husnoti Corb.

19. Fossombronia intestinalis Tayl.

20. Fossombronia longiseta Aust.

21. Fossombronia Naumannii Schffn.

C. Sporæ papillis asperæ vel hispidæ, lamellis reticulatis nullis.

g. lamellis plano-compressis, truncatis.

22. Fossombronia cæspitiformis De Not.

h. papillis longis hispida.

23. Fossombronia hispidissima St. n. sp.

24. Fossombronia spinifolia St. n. sp.

25. Fossombronia crispa Nees.

26. Fossombronia hamato-hirta St.

27. Fossombronia Mittenii Tindall.

i. papillis brevibus obtusıs.

28. Fossombronia papillata St.

29. Fossombronia australis Mitten.

30. Fossombronia gigantea St. n. sp.

31. Fossombronia Wrightii Aust.

32. Fossombronia verrucosa Lindb.

33. Fossombronia Macounii Aust.

34. Fossombronia leucoxantha L. L.

D. Incertæ sedis.

3ə. Fossombronia peruviana $\mathrm{H}$. et $\mathrm{G}$.

36. Fossombrania ptychophylla Spruce.

37. Fossombronia integerrima St. n. sp.

38. Fossombronia dentata St. n. sp.

39. Fossombronia carinata $\mathrm{G}$.

40. Fossombronia salina Lindb.

\section{A. Sporæ furcatim lamellatæ.}

\section{a. lamellis laxe dispositis.}

1. F. pusilla (L.) Dum. Rec. d'observ. p. 11.

Syn. : Jungermannia pusilla L. Spec. Pl. 1603. 
Monoica, minor, pallide-virens, pro more gregaria, maxime fotens. Caulis ad $10 \mathrm{~mm}$. longus, furcatus, postice parum productus leniterque convexus, subtriplo latior quam crassus. Folia conferta, basi triplo angustiora quam apice, plus minus crispata, late reniformia, 4-こ̆ angulata, angulis interdum apiculatis. Cellulæ $35 \times 40 \mu$, basales $450 \times 74 \mu$. Folia suprema profunde 5 loba, lobis arcte incurvis acuminatis acutis. Perianthia turbinata, ore amplo crispato paucilobato, lobis acutis recurvis. Sporæ ad $40 \mu$, furcatim lamellatæ, lamellis compressis, altis, in ambitu sporarum itaque longe prominentibus et quasi in spinam acuminatam abeuntibus; spinæ sub 24.

Hab. Sat rara in Britannia, Germania, Baden (Jack); Italia, Napoli (Cleve); Gallia, Paris (Bescherelle); Vancouver Island (Macoun); California (Howe).

2. F. perpusilla (Col.) St.

Syn. : Noteroclada perpusilla Colenso. N. Zeal. Inst.

Monoica, minor, pallide virens, cæspitosa. Caulis ad $7 \mathrm{~mm}$. longus, purpureus, postice valde convexus, subteres. Folia confertissima, erectoincurva, e basi obcuneata valde ampliata, 3-4 lobata, lobis carinatim conduplicatis arcte incurvis. Cellulæ apicales $37 \times 55 \mu$ medianæ $5 \check{5} \times 92 \mu$, basales $55 \times 130 \mu$. Perianthia longe stipitata, pyriformia, ore minus amplo recurvo, breviter lobulato meximeque crispato, sparsim dentato. Sporæ $3 \check{\mu} \mu$, rufo-brunneæ, laxe lamellatæ, lamellis furcatim ramosis, e lata basi compressis, altissimis, in ambitu sporarum itaque Ionge prominentibus et quasi in spinam validam acuminatam abeuntibus, spinæ sub 24, foveolæ sub $\mathbf{1 4}$ in facie convexa.

Hab. New Zealand (Colenso).

Quoad sporas $F$. pusillæ valde similis.

3. F. crassifolia Spruce. Edinb. Bot. Soc. 1885ั, p. 527.

Syn. : F. tenuifolia Spruce 1. c. p. 528.

Monoica, major, viridis, gregaria. Caulis ad $15 \mathrm{~mm}$. longus, parum ramosus, sub flore geminatim innovatus, crassus (2plo latior quam crassus) postice carinatim angustatus, antice itaque utroque latere attenuatus, radicellis ad aciem posticam reductis. Folia magna, tenerrima, conferta, longitudinaliter plicata, parum adscendentia, plano-disticha, obcuneata, marginibus lateralibus strictis, apice rotundata quadriloba, lobis late triangulatis acutis, hic illic dentatis. Cellulæ apice 5ั5 $\mu$, medio $55 \times 84 \mu$, basi $74 \times 148 \mu$. Perianthia foliis vix longiora, e basi bre - 
viter stipitata turbinata, uno latere profunde fissa, ore grosse plus minus profunde incisa, sublobulata, irregulariter grosse spinosa. Sporæ magnæ, $47 \mu$, rufo-brunneæ, laxe lamellatæ, lamellis furcatim ramosis, nusquam reticulatis, sæpe parallelis, basi validis superne compresso attenuatis; sporæ in ambitu itaque grosse spinosæ, spinis sub 20.

Hab. Andes quitenses in Monte Altar et Baños ad Montem Tunguragua (Spruce).

Die beiden Pflanzen sind völlig identisch und weichen nur in den vegetativen Organen ein wenig ab, doch nicht mehr, wie es der Standort im Thale und auf der Höhe mit sich bringt; die entscheidenden Merkmale, die Sporen, den kieligen Stengel und die 4 lappigen Blätter haben beide; auch die Blattzellen weichen in der Grösse nicht $a b$ und der Blüthenstand ist bei beiden monøecisch.

\section{b. lamellis confertis.}

4. F. crispata Lindb. Soc, pro F.et Fl. fenn.1873et Manip. II, p. 388. Syn. : F. Wondraczecki (Corda) Dum. Rec. d'obs. 183อ, p. 11.

Monoica, parva, viridis, gregarie crescens. Caulis ad $4 \mathrm{~mm}$. longus, furcatus, postice valde convexus, in sectione semi-circularis, antice planus. Folia plus minus conferta, pro more contigua, parum crispata, inferne sæpe plana, late ligulata, apice sinu lunato vel rectangulo biloba, lobis acutis vel varie angulatis. Cellulæ foliorum apice $37 \times 47 \mu$, medio $37 \times 74 \mu$, basi $47 \times 92 \mu$. Perianthia stipitata, optime campanulata, ore hiante, margine recurvo breviter lobulato, integerrimo vel paucidentato. Sporæ ad $40 \mu$ brunneolæ, dense reticulatim lamellatæ, lamellis in circumferentia sporæ dentatim prominulis, subparallelis et sub angulo acuto sat regulariter anastomosantibus, ceterum flexuosis; foveolæ itaque plus minus distincte anguste hexagonæ.

Hab. Europa. Germania haud rara. Gallia (Mars, Hy, Corbière); Anglia (Lyell); Suecia (Hartmann); Fennia (Nylander, Lindberg); America septentr. (Werner teste Underwood); Himalaya (Gamble).

Der Name $F$. Wondraczecki ist zu kassiren, da er ein nomen nudum geblieben ist; erst nach Lindbergs grundlegender Arbeit hat Dumortier (Hep. Europæ 1874, p. 174) durch Beschreibung der Sporen diesen Namen zu retten versucht, wie er denn auch Lindbergs Arbeit citirt.

5. F. texana Lindb. Acta Soc. Fl. F. fenn. 1875, p. 533.

Syn. : F. cubana Aust. Bot. Bull. 1876, p. 36 . 
Dioica, major, viridis, gregaria. Caulis ad $15 \mathrm{~mm}$. longus, angustus, subteres, rigidus et durus, ventre valde productus. Folia conferta, magna, ex angusta basi late reniformia, margine 4-כ̆ lobata, lobis late triangulatis, acutis vel apiculatis, sinubus obtusis plicatis. Cellulæ apicales $37 \times 37 \mu$, medianæ $40 \times 60 \mu$, basales 50 $092 \mu$. Perianthia foliis æquilonga, turbinata, vix stipitata, uno latere profunde fissa, ore varie lobatim inciso, lobis repandis obtusis, recurvo-erispatis. Sporæ ad 50 $\mu$, furcatim lamellatæ, lamellis humilibus, undulatis, in ambitu sporarum parum prominentibus.

Hab. Cuba (Wright).

Da nach Austin diese Pflanze auch in Texas vorkommen soll (ein Exemplar von diesem Standort ist nicht erhalten), so belasse ich zunächst den Speciesnamen, der natürlich zu ändern wäre, wenn sie daselbst thatsächlich nicht vorkommt. Die von mir untersuchten Sporen waren fast reif in der ungeöffneten Kapsel; der Befund stimmt aber mit Underwoods Beschreibung (Bol. Gaz. 1896, p. 71) gut überein.

\section{c. lamellis interruptis vermicularibus.}

\section{F. Stephanii Schffn. n. sp.}

Dioica, magna, pallide virens, dense cæspitosa. Caulis ad $10 \mathrm{~mm}$. longus, pauciramosus, sub flore simplieiter innovatus, angustus, postice valde productus, parum latior quam crassus, radicellis pallidis repens. Folia majuscula, conferta, oblique adscendentia, oblique ligulata, apice parum angustata rotundataque, integerrima, margine postico stricto, antico decurrente. Cellulæ apicales $47 \times 47 \mu$, medianæ $37 \times 74 \mu$, basales $37 \times 92 \mu$. Perianthia parva, haud stipitata, tenerrima, turbinata, ore parum lobủlato, integerrimo crispato. Sporæ magnæ 5ั0 $\mu$, vermiculariter lamellatæ, lamellis humilibus, irregulariter et frequenter anostomosantibus, retem irregularem sæpe interruptam formantibus, regulariter papillatis, papillis numerosis, longiusculis gracilibus hispidis.

Hab. Insula Bourbon (de l'Isle).

Die Sporen dieser Pflanze haben Lamellen, welche ein vollkommenes Netz bilden würden, wenn nicht überall Theile dieses Netzes fehlten; es enden eine Menge Lamellen blind; ganz ähnliches zeigen die Sporen mancher Ricciaarten.

7. F. japonica Schffn. Oest. Bot. Zeitschr. 1899, p. 389.

Autoica, parva, laxe cæspitosa lateque expansa. Caulis ad $3 \mathrm{~mm}$. longus, 
simplex vel furcatus, radicellis purpureis repens. Folia conferta, parum latiora quam Ionga, leniter lobulata, undulata, integerrima, margine antico late incurvo. Perianthia brevissima, late campanulata, uno latere fissa, ore hiante leniter lobulata, undulata. Sporæ ad $60 \mu$ flavo-brunneolæ, irregulariter lamellatim reticulatæ, lamellis hic illic interruptis. Elateres breves, $60-150 \mu$, vermiculares, annulatim incrassatæ, annulis hic illic fibra simpliçi interruptis. Anther idia aggregata, longe pedicellata.

Hab. Japonia, Tokyo, in horto botanico (Miyake).

\section{B. Sporæ regulariter reticulatæ.}

\section{d. Sporæ ambitu angulatæ.}

8. F. angulosa (Dickson) Raddi Jung. etrusca, p. 17.

Syn. : Jungermannia angulosa Dickson Crypt. brit. I, p. 7.

? Gymnomitrium erythrorhizum Bisch in Seuber et Hochst.

Flor. azor.

Dioica, viridis, dense cæspitosa sæpe late expansa. Caulis ad $15 \mathrm{~mm}$. longus, sub flore geminatim innovatus, angustus, postice valde productus. Folia conferta, magna, ex angusta basi spathulata, apice irregulariter 4-ว̆ lobata, lobis brevibus parvis acutis. Cellulæ $37 \mu$, medio 5 อ̆ $\times 148 \mu$, basales $5 \ddot{5} \times 20 \Xi \mu$. Perianthia turbinata, late stipitata, ore irregulariter inciso-lobulata vel subspinosa. Bracteæ breves lanceolatæ fere omnino accretæ. Sporæ $37 \mu$, regulariter reticulatim lamellatæ, foveolis sub 7 in facie convexa, lamellis altis, compressis, sporæ itaque in ambitu quasi angulatim alatæ.

Hab. Italia (Raddi, De Notaris, Levier, Nyman, Ảreangeli, Cleve); Britannia Insula Jersey (Mackenzie); Cornwall (Curnow); Hibernia (Moore, Taylor, Carrington, Lindberg); Amer. sept.,Florida, Alabama (Underwood); Texas (Thurow); Mobile (Sullivant); Cuba (Wright); Gallia (Corbière); Portugal (Moller).

Ob die Cuba-Pfianze hierher gehört, kann ich nicht sagen; es kommt $F$. brasiliensis auch in den Antillen vor und diese ist der $F$. angulosa ausserordentlich ähnlich.

\section{F. brasiliensis St. n. sp.}

Dioica, mediocris, viridis, laxe cæspitans. Caulis ad $4 \mathrm{~mm}$. longus, angustus, postice valde productus et carinatim angustatus. Folia contigua, 
plano disticha, spathulata vel subligulata, integerrima apice truncato-rotundata. Cellulæ $46 \mu$, medianæ $47 \times 92 \mu$, basales $54 \times 130 \mu$. Perianthia turbinata uno latere profunde fissa, ore profunde inciso-trilobata, lobis irregularibus, truncalis, repandis vel paucidentatis, crispalis. Sporæ $37 \mu$, regulariter reticulatim lamellatæ, foveolis ad 16 in facie convexa, lamellis humilibus, in ambitu sporarum angulatim prominulis. Elateres semper 3 vel 4 spiri.

Hab. Brasilia (Puiggari, Ule); Cuba (Wright); Insula Dominica (Elliolt).

\section{F. lophoclada Spruce. Edinb. B. Soc. 18850 , p. วั29.}

Dioica, mediocris, pallide-virens, in latas plagas expansa. Caulis ad $15 \mathrm{~mm}$. longus, simplex, sub flore geminatim innovatus, valde productus, duplo latior quam crassus, postice plano-convexus, lateribus abrupte adscendentibus rotundatis. Folia conferta, subhorizontaliter patula, inferiora late ligulata, inæqualiter biloba vel retusa, superiora majora, multoties latiora quam longa, antice decurrentia, margine postico quam anticus triplo longiora, apice obtuse inciso-triloba. Cellulæ $37 \times 37 \mu$, medianæ $47 \times 84 \mu$, basales $74 \times 110 \mu$. Perianthia foliis parum longiora, vix stipitata, campanulata, ore profunde quinquelobato, lobis repandis, crispatis. Bracteæ valde numerosæ, maximæ, perianthio æquilongæ, ligulatæ vel lanceolatæ superne longe liberæ. Sporæ $29 \mu$, rufobrunneæ, regulariter reticulatim lamellatæ, foveolis sub 15 in facie convexa, lamellis humilibus, in ambitu sporarum itaque angulatim prominulis.

Hab. Andes quitenses, in monte Campana (Spruce).

\section{F. grandis St. n. sp.}

Dioica, magna, fusco-viridis, dense cæspitosa. Caulis ad $20 \mathrm{~mm}$. longus, simplex, ex apice tantum innovatus, validus, plus duplo latior quam crassus, postice leniter convexus, lateribus abrupte adscendentibus, antice parum concavus. Folia magna, tenerrima, crispata, ipsa basi pluristrata, basi duplo angustiora quam apice, lateribus strictis brevibus, ambitu itaque late reniformia, apice late rotundata, sinuato quinqueloba, lobis brevibus apiculatis vel in spinam abeuntibus, sinubus radialiter plicatis. Cellulæ foliorum apicales $37 \times 47 \mu$, medianæ 5 วั $\times 140 \mu$, basales $5 \check{5} \times 18 \check{~} \mu$. Perianthia pro planta parva, longe et anguste stipitata, e basi angustissima late turbinata, ore profunde $3-4$ lobo, maxime hiante, lobis repandis parum tortis vel recurvis. Sporæ parvæ, $34 \mu$, laxe reticulatim lamellatæ, Iamellis humilibus, margine lamellatim et interrupte limbatæ. Foveolæ ad $8 \mu$ in diametro.

- Hab. Africa in monte Kilimandscharo (Volkens). 
12. F. reticulata St. Hedwigia 1894, p. 9.

Dioica, magna, valde robusta, pallide-flavo-virens, ætate rufescens, cæspitosa. Caulis ad $4 \mathrm{~cm}$ longus, $\mathbf{1}^{1 / 2} \mathrm{~mm}$ latus, repetito-furcatus, sub flore simpliciter innovatus, vix duplo latior quam crassus, postice parum convexus, lateribus abrupte adscendentibus. Folia maxime crispata, reniformia, antice longe et anguste decurrentia, caulis itaque alis confertis crispatis quasi lamellatus. Cellulæ $47 \times 74 \mu$ basales $50 \times 136 \mu$. Perianthia magna ad $6 \mathrm{~mm}$ longa, turbinata, ore repando vix crispato. Sporæ parvæ, $24 \mu$ minute reticulatim lamellatæ, foveolis in facie convexa sub 40 , lamellis humilibus, repandis vel minute cristatim denticulatis, sporæ itaque ob lamellas numerosas in ambitu quasi breviter inciso-alatæ.

Hab. New Zealand (Kirk).

e. lamellis humilibus margine dentatim prominulis.

13. F. lamellata St. Hedwigia 1894, p. 9.

Syn. : Fossombronia tuberifera Göbel Organogr. II, p. 264.

Dioica, parva, viridis, dense cæspitosa. Caulis ad $10 \mathrm{~mm}$. longus, repetito furcatus, postice valde productus, apice defoliato in terram descendens, tuberiferus. Folia suberecta, subquadrata vel apice ampliata, margine angulata crispata. Perianthia magna, substipitata, campanulata, ore amplo remote pauci-spinoso, valde crispato. Sporæ brunneæ $43 \mu$, reticulatim lamellatæ, foveolis sub 20 in facie convexa, lamellis ad retem laxam confluentibus, altissimis et compressis, in ambitu sporarum longe angusteque prominentibus; sporæ itaque lamellis truncatis patulis quasi stellatim bracteatæ apparent.

Hab. Buenos-Ayres (Hauthal), Venezuela, Tovar (Gobel).

Gabel hat diese Pflanze unter dem Namen F. tuberifera Göbel (in seiner Organographie II, p. 264) abgebildet; vorher erwähnte sie bereits Ruge (Flora 1893, Heft 4), woselbst auch eine Abbildung der Sprossspitze gegeben ist; meine Publikation ist viel älter und man hat den Namen, den ich gegeben hatle, leider unbeachtet gelassen; die Knollenbildung habe ich nicht untersuchen können.

14. F. Dumortieri (Hüb. et Genth.) Lindb. Manip. II, p. 417.

Syn. : Codonia Dumortieri Hüb. et G. Hep. Exsicc. No 80, 1837. Fossombronia foveolata Lindb. Manip. II, p. 382.

Ifonoica, parva, viridis, cæspitosa vel gregaria, paludicola maxime foetens. Caulis ad $4 \mathrm{~mm}$ longus parum ramosus, sub apice simpliciter in- 
novatus, postice valde productus, subcarinatus. Folia parva vix imbricata, oblique obcuneata, $3-4$ angulata. Cellula foliorum apicales $29 \times 47 \mu$, medianæ $29 \times 5 ๊ ๊ \mu$, basales $37 \times 74 \mu$ ubique unistratæ. Perianthia parva, turbinata vix plicata, ore hiante repando, lobulato, hic illic magna spina armato, margine sæpe recurvo; bracteæ parvæ, lineares superne liberæ. Sporce $40 \mu$, regulariter reticulatim lamellatæ, lamellis tenuibus salt altis, in circumferentia sporæ itaque quasi spinoso-prominulis.

Hab. Europa, nusquam rara in regione silvatica. America septentrionalis.

Da die Pflanze (unter dem Namen Codonia Dumortieri) in einer käuflichen Sammlung ausgegeben worden ist, so gilt sie natürlich als rite publizirt und Lindberg hat mit Recht seinen 1874 gegebenen Namen ( $F$. foveolata) kassirt. Die amerikanischen Botaniker weichen hierin leider $a b$.

15. F. cristula Aust. Acad. Philad. 1866, p. 228.

Monoica, pusilla, tenerrima, pallide virens, gregaria. Caulis ad $5 \mathrm{~mm}$. longus, postice valde productus, subteres, tenuis subsimplex sub flore simpliciter innovatus. Folia contigua adscendentia, late ligulata, basi vix angustiora, superne repanda, integerrima. Folia apicalia majora, crispata, profundius 4-5 lobulata, Iobulis rotundato prominulis sinubus late recurvis. Cellulæ $29 \times 37 \mu$, medio $37 \times 6 \breve{~} \mu$, basi $55 \times 110 \mu$. Perianthia substipitata, optime turbinata, tenerrima, uno latere profunde fissa, ore maxime hiante profunde quinquelobato, lobis rotundatis, crispatis sinubus recurvis. Sporæ $37 \mu$, lamellatim-reticulatæ, foveolis numerosis, lamellis altis, margine dentatim prominulis. Elateres breves, stricti, acuminati, annulatim incrassati, annulis remotiusculis, centro linea fusca percursis.

Hab. Amer. sept. New Jersey (Austin).

Die Verdickungen der Elateren machen den Eindruck, als liefe das eine der sonst spiraligen Verdickungsbänder central und gradlienig durch den Elaterenschlauch, während sich die sonst spiraligen Windungen des anderen Verdickungsbandes in isolirte Ringe aufgelöst haben. Hinsichtlich der Sporen steht unsere Pflanze der F. Dumortieri ausserordentlich nahe.

16. F. incurva Lindb. Manip. II, p. 381.

Dioica, minor, viridis sparsim inter muscos crescens. Caulis ad $5 \mathrm{~mm}$. longus, simplex, postice valde productus, antice canaliculatus vel subplanus. Folia conferta, irregulariter bi- vel triloba, sinubus acutis vel obtusis, lobis integerrimis vel dentatis incurvis. Cellulæ foliorum $37 \times 37 \mu$, basales $37 \times 92 \mu$. Perianthia ex angusta basi ovali-pyriformia, superne 
plicata, ore dilatato irregulariter serrato, hic illic subinciso, lacinulis acutis incurvis. Sporæ $20 \mu$, fusco-brunneæ vel nigro-violaceæ, plus minus regulariter lamellatim-reticulatæ, lamellis humilibus, in margine sporarum dentatim prominulis.

Hab. Fennia (Lindberg); Germania, Neu Ruppin (Warnstorf).

Dass diese Pfianze ein Subgenus (Lindberg), oder gar ein neues Genus (Schiffner in Engler und Prantl) bilden soll, vermag ich nicht einzusehen. Es giebt unter den Arten unserer Gattung alle Uebergänge vom breiten, flachen, thallusartigen Stengel bis zur drehrunden Form; auch die Form des Perianths ist in der Gattung sehr verschieden und variirt von der birnförmigen bis zur breit schüsselförmigen Gestalt; die eigentlich generischen Merkmale, nämlich die Stellung der Pistille und der Bau der Kapsel mit ihren tafelförmig zerfallenden 4 Klappen sind ganz die unserer Gattung. Der Vergleich dieser Pflanze mit Jungermannia incisa aber steht wirklich unter dem Niveau einer wissenschaftlichen Erörterung.

\section{F. Zeyheri St, n. sp.}

Dioica, major, pallide-virens, dense cæspitosa. Caulis repelito-ramosus, sub flore geminatim innovatus, ad $15 \mathrm{~mm}$. longus, crassus (fere triplo latior quam crassus) postice leniter convexus, lateribus oblique adscendentibus. Folia conferta, oblique erecta, obcuneato-rotunda, symmetrica et antice haud decurrentia, apice brevissime lobulata, lobulis acutis vel obtusis, sinubus recurvis crispatis. Cellulæ apice $47 \mu$. medio 50 อ̃ $\times 84 \mu$, basi $74 \times 110 \mu$. Perianthia foliis æquilonga, late campanulata vix stipitata, uno latere profunde fissa, ore grosse irregulariterque lacerata, laciniis truncatis grosse pauci-spinosis. Sporæ $37 \mu$, fusco-purpureæ, regulariter reticulatim lamellatæ, foveolis magnis sub 12 in facie convexa, lamellis humilibus, sporæ itaque ambitu remote breviterque papillato. Elateres bispiri, spiris validissimis.

Hab. Africa australis, Table Mountain (Zeyher).

\section{f. Sporæ ex angulis lamellarum papillatæ.}

18. F. Husnoti Corbière Rev. bryol. 1890, p. 3.

Monoica, minor, viridis, laxe cæspitans vel gregarie crescens. Caulis ad $10 \mathrm{~mm}$ longus, angustus, postice valde productus, stoloniferus, stolonibus crassis hyalinis subteretibus subterraneis. Folia parva, dense imbricata, e basi angusta obcuneata, reniformia, apice rotundata vel truncata, integerrima, parum crispata. Cellulæ foliorum apicales $36 \times 36 \mu$, medianæ 
$36 \times 72 \mu$, basales $54 \times 90 \mu$. Perianthia sessilia, ex angusta basi valde ampliata, fere scutellata, sæpe una latere profunde fissa, ore latissimo crispato, quinquelobo, lobulis angulatis vel acutis. Spor $\mathscr{X}$ ad $47 \mu$, distincte reticulatim lamellatæ, lamellarum angulis alte papillatis, papillis recte patulis strictis, anguste rectangulatis truncatis, margine sporarum itaque maxime hirto.

Hab. Gallia, Cherbourg (Corbière); Alger, Blida (Gay, Paris); Italia, Firenze (Levier).

In Gottsche und Rabenhorst Hep. Exsicc., Nr. 439, wächst diese Art mit F. verrucosa Lindb. gemischt und zwar in allen Exemplaren, die ich von diesem Werke untersuchen konnte. Diese Species ist wahrscheinlich verbreitet und nur bisher mit $F$. cæspitiformis verwechselt worden. Hinsichtlich der Sporen steht sie der $F$. intestinalis Taylor sehr nahe; sie sind bei beiden fast gleich.

19. $\boldsymbol{F}$. intestinalis Tayl. in Syn. Hep., p. 469.

Dioica, mediocris, viridis, sæpe purpurascens, dense depresso-cæspitosa. Caulis ad $\mathbf{2} \mathrm{cm}$ longus, furcatus, postice valde convexus, duplo latior quam crassus. Folia dense imbricata, triplo fere latiora quam longa, trilobala lobis brevibus rotundatis incurvis. Cellulæ foliorum $35 \mu$, basales $35 \times 120 \mu$. Perianthia turbinata, late breviterque stipitata, ore lobulato, lobulis brevibus recurvis et tortis. Sporæ ad $47 \mu$, distincte lamellatim reticulatæ, ex angulis lamellarum papillatæ, papillis angustis longiusculis, compresso-planis, truncatis, sporæ itaque ambitu maxime hirto.

Hab. Australia, Swan River (Drummond, Miss Sewell); Sydney (Whitelegge); Tasmania (Weymouth); New Zealand (Colenso).

Die Pflanze, welche Spruce (Hep. And. et Amaz. 1885, p. 529) beschreibt, und welche von den Aucklands-Inseln stammt, ist von ihm irrthümlich als Original betrachtet worden; daher seine von Mitten abweichende Meinung über diese Art; das Original stammt vom Swan River und die Auckland-Pflanze ist jedenfalls nur irrthümlich zu dieser Art gestellt worden; es ist wahrscheinlich meine $F$. gigantea.

Die Sporen von $F$. intestinalis sind fast genau die der vorstehenden F. Husnoti Corbière.

20. F. longiseta Austin. Acad. Philad. 1869, p. 228.

Dioica, mediocris, viridis, gregarie crescens. Caulis ad $150 \mathrm{~mm}$. longus, furcatus, postice valde productus, radicellis roseis repens. Folia parva, imbricata, breviter ligulata, plano-disticha vel leniter adscendentia, inteMÉMOIRES DE L'HERBIER BOISsIER, no 16, 2 J juin 1900. 
gerrima vel paucilobulata, vix unquam dentata, basi pluristrata. Cellulæx foliorum apicales $28 \times 37 \mu$, medianæ $28 \times 60 \mu$, basales $60 \times 150 \mu$. Perianthia magna, campanulata, interdum uno latere profunde fissa. Sporæ flavo-brunneæ ad $47 \mu$, distincte reticulatim lamellatæ, ex angulis lamellarum papillatæ, ambitu itaque muricatæ.

Hab. Am. sept., San Francisco (Bolander).

Die Abbildungen Howe's (Torrey Bot. Cl. 1899, tab. 99) zeigen so grosse Unterschiede in der Skulptur der Sporen, dass sicher verschiedene Arten darunter enthalten sind, wie das Howe auch p. 82 selbst vermuthet. Ich habe aus dem Herb. Gottsche die Pflanze von Ukiah leg. Bolander beschrieben, weil ich diese als das Original betrachte und der gleiche Sammler auch von Austin (Hep. Bor. Amer. 1873, p. 30) genannt wird; es ist kaum zweifelhaft, dass Bolander seine Aufsammlungen zugleich an Austin und Gottsche geschickt hat; im Uebrigen stimmt Austins Angabe "sporis valde muricatis») vollkommen mit dem Befund an den Bolander'schen Exemplaren überein, auch der diöcische Blüthenstand, auf den ich aber wenig bei dieser Gattung gebe, da die älteren Theile bei allen Arten so schnell absterben, dass die $Z$ weige, die einst verbunden waren, isolirt werden und nun der diöcische Blüthenstand sehr leicht für den monöcischen in die Erscheinung tritt.

21. F. Naumannii Schffn. Exp. Gazelle IV, p. 39.

Dioica, magna, dense cæspitosa, inferne brunnea superne pallide viridis.

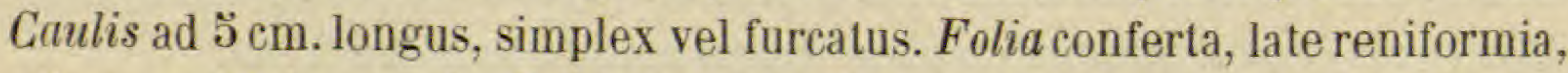
plicata subcrispata, $4-5$ lobata, lobis brevibus repando-prominulis apiculatis. Cellulæ $45 \times \times 63 \mu$, basales $37 \times 130 \mu$. Perianthia magna, plicata, turbinata, ore irregulariter dentato. Sporæ ad $40 \mu$, in facie convexa regulariter reticulatim lamellosa, foveolis parvis numerosis, lamellis ex angulo papillatis, papillis brevibus, truncatis, in ambitu sporarum valde numerosis, contiguis. Antheridia longissime stipitata, basi bractea lanceolata obtecta.

Hab. Kerguelen-Insulæ (Naumann, Exped. Gazelle).

\section{G. Sporæ papillis hispidæ, foveolis hexagonis nullis.}

g. lamellis patulis, plano-compressis, truncatis.

22. F. cæspitiformis DeNot. in G. et R. Hep. Exsicc. № 123.

Syn. : $F$. angulosa var. cæspitiformis Raddi. Mem. Mod. 18, p. 41. 
Monoica vel dioica, minor, viridis, dense cæspitosa, fœtens. Caulis ad $1 \check{\mathrm{b}} \mathrm{mm}$ longus, subteres, plus minus ramosus, sub flore simpliciter innovatus. Folia conferta, e basi obcuneata valde dilatata, margine optime crispata, integerrima. Cellulæ apicales $37 \times 5 ๊$ ă $\mu$, medianæ $47 \times 92 \mu$, basales $47 \times 130 \mu$. Perianthia breviter stipitata, campanulata, ore recurvo crispato subintegerrimo, uno latere sæpe ad basin usque fissa. Bracteæ magnæ, spathulatæ superne longe liberæ. Sporæ $46 \mu$, brunneæ, lacinulis plano-compressis rectangularibus recteque patulis bispidissimæ.

Hab. Italia (DeNotaris, Cleve, Evans, Levier); Græcia (Heldreich); Portugal, Coimbra (Moller); Algeria (Paris, Bovi, Trabut); Gallia (Cleve, Corbière); Anglia (Stabler); Madeira (Fritze); Tenerifa (Krause); Abyssinia (Schimper).

\section{h. papillis longis hispidæ.}

\section{F. hispidissima St. n, sp.}

Dioica, minor, viridis, gregaria. Caulis ad $4 \mathrm{~mm}$. longus, simplex, postice maxime productus, angustato-rotundatus (subcarinatus) minus latus quam crassus, in sectione quasi saccatus. Folia parva, obcuneata, vix magis lata quam longa, basi valde angustata lateribus strictis, apice repanda hic illic incurvo-crispata. Cellulæ foliorum apice $37 \times 55$ $37 \times 92 \mu$. Perianthia vix stipitata, ex angusta basi pyriformia, fere duplo longiora quam lata, sub ore contracta, subinde abrupte dilatata ore recurvo sinuato subcrispato. Sporæ fusco brunneæ, $3 \check{\mu} \mu$, papillis Iongiusculis creberrimis hispidissimæ.

Hab. Amer. sept., San Francisco (Bolander).

\section{F. spinifolia St. n. sp.}

Monoica, gracilis, fusco-viridis, gregaria. Caulis ad $12 \mathrm{~mm}$. longus, repetito-furcatus, tenuis, postice valde productus subteres. Folia parum imbricata, leniter adscendentia, ex angusta basi late obovata vel rotundata, varie grosseque spinosa, spinis $3-5$ majoribus sublobuliformibus acuminatis, acutis; reliquis multo minoribus. Cellulæ $36 \times 36 \mu$, basales parum longiores. Perianthia turbinata, foliis vix longiora, plurilobata, lobis irregulariter grosse spinosis, haud crispatis. Sporæ fusco-brunneæ ad $46 \mu$, papillis longis acutis et confertissimis hispidissimæ.

Hab. Africa australis, Gnadenthal (Breutel).

25. F. crispa Nees. Syn. Hep., p. 469.

Dioica, major, fusco-viridis, dense cæspitosa lateque expansa. Caulis ad 
$2 \mathrm{~cm}$. longus, parum ramosus, rigidus, angustus, postice valde productus. Folia parum imbricata, breviter ligulata, basi vix angustata, distiche patula, apice truncato-rotundata, crispata. Cellulæ $37 \times 5 \check{5} \mu$, basales $55 \times 74 \mu$. Perianthia breviter pedicellata, campanulata, ore hiante recurvo, integerrimo, parum crispato. Sporæ $4 \breve{3} \mu$, fusco-brunneæ, papillis longiusculis confertis hispidissimæ. Andrœcia totam caulem tegentia, antheridia seriata, bracteata, bracteis magnis, ovalibus, margine erosis, cucullatis.

Hab. Africa austrails, Table mountain (Ecklon, Mac 0wan) Gnadenthal (Breutel).

\section{F. hamato-hirta St. Hedwigia 1894, p. 8.}

Monoica, parva, viridis, in rupibus dense cæspitans. Caulis brevis, ad $10 \mathrm{~mm}$. longus, simplex, antice planus, postice valde productus, magis crassus quam latus, radicellis pallidis repens. Folia conferta, imbricata, tenerrima, ex angusta basi oblique lateque ligulata, apice plus minus profunde emarginato-biloba, lobis rotundatis, margine anteriore angulatim ampliata vel in dentem producta. Cellulæ foliorum apicales $37 \times 37 \mu$, medianæ $37 \times 74 \mu$, basales $37 \times 110 \mu$. Perianthia stipitata, superne abrupte dilatata, turbinata, ore lobato, lobis recurvis maxime crispatis. Sporæ $3 \check{a} \mu$, dense breviterque setulosæ, setulis hamatim incurvis.

Hab. Ascension Island (Gordon).

\section{F. Mittenii Tindall. J. of Bot. 1898, p. 4.4.}

Monoica? parva, flavo-virens. Caulis ad こ̆ mm. longus, simplex. Folia imbricata, crispata, hic illic angulata, magis lata quam longa. Perianthia pro planta magna, ore crenulato. Sporæ $47 \mu$, flavo-brunneæ, dense papillatæ, papillis acuminatis (110 in facie convexa). Elateres mediocres, bispiri.

Hab. Anglia, Braunton (Mitten).

Die Pflanze habe ich nicht gesehen und gebe die Diagnosa der Frau Tindall in Uebersetzung. Der Blüthenstand wird leider nicht erwähnt; auch der Querschnitt des Stengels und die Grösse der Blattzellen sind nicht angegeben, wohl aber wird die Pflanze wegen der Cuticula der Sporen mit $F$. papillata St. verglichen, welche grössere abgestumpfte Papillen besitzt; da die Sporenpapillen als " finely pointed ", also scharf zugespitzt (acuminatæ) beschrieben werden, so ist die Abbildung leider wenig der Diagnose entsprechend. 


\section{i. papillis brevibus obtusis.}

28. F. papillata St. Hedwigia 1889, p. 157.

Monoica, mediocris, pallide flavo-virens, dense cæspitosa. Caulis brevis ad $15 \mathrm{~mm}$. longus, simplex sub flore geminatim innovatus, crassus (vix duplo latior quam crassus) postice parum convexus, lateribus abrupte adscendentibus rotundatis. Folia conferta, erecta, obcuneato-reniformia crispata, hic illic angulata, ceterum integerrima. Cellulæ $3 \check{5} \times 3 \check{3} \mu$, basales $35 \check{\times} \times 120 \mu$. Perianthia magna, turbinata, uno latere profunde fissa, ore profunde plicato, varie torto et crispato, profunde lobulato, lobis obtusis. Bracteæ magnæ anguste spathulatæ, sæpe subliberæ. Sporæ $45 \mu$, badiæ, dense grosseque papillatæ, papillis conicis truncatis.

Hab. Australia, Queensland (Wild, Bailey).

\section{F. australis Mitt. Linn. Soc. 1877.}

Dioica, magna, apice viridis, inferne rufescens. Caulis ad $4 \mathrm{~cm}$. longus, parum longeque ramosus, ramis parum divergentibus, postice maxime productus. Folia conferta, maxima, ad $6 \mathrm{~mm}$. lata, antice longissime attenuatim decurrentia, margine plus minus grosse quadrispinosa, spinis minoribus interjectis. Cellulæ apicales $47 \times 5 \check{ }$ Perianthia campanulata, ore breviter 6 lobata, lobis remote dentatis. Sporæ $32 \mu$, papillis brevibus truncatis dense obtectæ.

Hab. Kerguelen (Eaton); New Zealand (Colenso).

Die Sporen, welche Mitten beschreibt, sind Sporenmutterzellen, zu 4 vereinigt; ob sie der Pflanze überhaupt angehören, ist fraglich; sie waren noch ganz jung, das Chlorophyll im Centrum zusammengeballt, so dass das Ganze mit einem hyalinen Saume eingefasst erscheint; die reifen Sporen sind danach zweifellos oben richtig beschrieben, obwohl nur wenige der Kapsel noch anhafteten.

\section{F. gigantea St. n. sp.}

Dioica, magna, robusta, flavo-virens, ætate rufescens vel brunneola, cæspitosa. Caulis ad $4 \mathrm{~cm}$. longus, furcatus, duplo latior quam crassus, postice valde convexus, medio $\mathbf{1 8}$ cellulas crassus. Folia conferta, reniformia basi pluristrata, validissima, breviter quadriloba, 3 lobi in margine apicali, quartus in margine anteriore, omnes late triangulati, obtusi vel

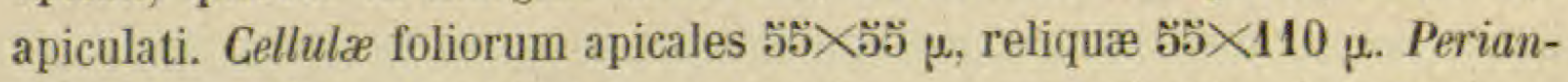
thia vix stipitata, turbinata, ore amplo recurvo crispato, integerrimo. 
Sporæ $46 \mu$, rufo-brunneæ, papillis humilibus densissime muricatæ. Elateres ad $190 \mu$ bispiri, spiris validis. Antheridia maxima, longe stipitata, dense seriata.

Hab. New Zealand (Knight, Kirk).

Siehe die Anmerkung zu F. intestinalis Taylor.

\section{F. Wrightii Aust. Bot. Bull. 1876, p. 36.}

Dioica, major, pallide virens, dense cæspitans. Caulis ad $10 \mathrm{~mm}$. longus, repelito-furcatus, sub flore simpliciter innovatus, angustus, ventre valde productus, vix duplo latior quam crassus, postice plano-convexus, lateribus abrupte adscendentibus rotundatis. Folia conferta, tenerrima, plano-disticha, basi duplo angustiora quam apice, valde asymmetrica, ad marginem ventralem rotundatim ampliata, ad anticum multo breviora ibidemque in acumen magnum producta, ceterum integerrima vel paucis dentibus armata, plicatulis numerosis marginalibus crispa. Cellulæ apice $37 \mu$, medio $450 \times 92 \mu$, basi $5 ّ \times 110 \mu$. Perianthia foliis minora, uno latere profunde fissa, turbinata, ore breviter paucilobulata, lobulis varie recurvis maxime crispatis. Sporæ fusco-purpureæ, $46 \mu$, papillis brevissimis rotundatis dense asperæ.

Hab. Cuba (Wright).

32. F. verrucosa Lindb. Manip. II, p, 386 .

Monoica, flavo-virens, major, dense cæspitosa. Caulis brevis, parum ramosus, postice valde productus, vix duplo latior quam crassus, in sectione late ovalis. Folia conferta, adscendentia, obcuneata superne valde ampliata, multiplicata subintegerrimæ. Cellulæ $37 \times 37 \mu$, basales multo majores ad $50 \times 130 \mu$. Perianthia campanulata, uno latere profunde fissa ore ampliato subintegerrimo multiplicato. Sporæ $38 \mu$, brunneæ, papillis validis humilibus obtusis dense verrucosæ. Elateres crassissimi, spiris 3-4 validissimis.

Hab. Algeria, Blida (Paris); Gallia, Cherbourg (Corbière).

Siehe die Anmerkung zu F. Husnoti Corb.

33. F. Macouni Aust. Bot. Bull. 1876, I, p. 36.

Hab. Canada, Portage La Lochs (Macoun).

Die Pflanze existirt in keiner Sammlung. Austin nennt die Sporen -parviusculæ subopacæ, densissime minutissime papillosæ., Vielleicht ist sie hieran doch wieder zuerkennen. 
34. F. leucoxantha L, et L. Syn. Hep. p. 469.

Dioica, major, subhyalina, dense cæspitosa longe lateque expansa. Caulis ad $15 \mathrm{~mm}$. longus, apice defoliato recte in terram descendens (tuberiferus?) maxime crassus posticeque valde productus, subteres. Folia magna, sæpe in pagina ventrali purpureo-maculata, subrotunda, confertissima, erecto-conniventia, valde concava, marginibus angulatis incurvis, Cellulæ $37 \times 56 \mu$, basales $56 \times 92 \mu$. Perianthia (ipse haud vidi) " campanulata, inciso-dentata."

Hab. Africa australis, Cape of good hope (Ecklon); Transvaal (Rehmann); Natal (Wilms).

Hierher gehört jedenfalls Foss. tumida Mitten, der nach der ganz misslungenen Beschreibung in der Synopsis Hep. seine Pflanze natürlich nicht identificiren konnte; er nennt die Sporen obscuræ papillosæ.

Fertile Exemplare habe ich leider nicht gesehen; die aufgeblasenen, fast farblosen Blätter lassen die Pfianze, welche in Südafrika weit verbreitet ist, sogleich erkennen; ob die Pflanze in diese Sektion der Gattung Fossombronia gehört, ist nach der mageren Besehreibung Mittens ganz zweifelhaft.

\section{Incertæ sedis.}

\section{F. peruviana Hpe et G. Linnæa $185 ั$ p. อัวั้.}

Sterilis, magna, valida, rufescens, dense cæspitosa. Caulis ad $3 \mathrm{~cm}$. longus, radicellis roseis brevibus repens, repetito-furcatus, duplo latior quam crassus, postice carinatim angustatus. Folia magna, late reniformia, e basi adscendente distiche explanata, radialiter plicata, superne angulata, angulis obtusis vel nullis. Cellulæ apicales $45 \times 45 \%$, basales $45 \times 74 \mu$.

Hab. Peruvia, Cordillera de Tuno, in rivulis (Lechler).

Siehe F. ptychophylla Spruce.

36. F. ptychophylla Spruce. Edinb. Bot. Soc. $188 \Xi$, p. 529.

Caulis ad $3 \mathrm{~cm}$. longus, simplex, carnosus, radicellis purpureis repens. Folia magna, albida, tenera, late imbricata, assurgenti-secunda, valde oblata, 2-3plo latiora quam longa, subrhomboidea, a basi radialiter pluriplicata, margine inæqualiter lobata et sinuata. Cellulæ magnæ, parum elongatæ.

Hab. Andes quitenses, in palude alpina montis Altar, $3700 \mathrm{~m}$. (Spruce).

Diese Pflanze habe ich nicht zu erhalten vermocht; wahrscheinlich 393 
gehört sie zu F. peruviana Hpe. et G. Spruce hatte von dieser Publikation (Linnæ 185̋̃) keine Kenntnis; beide Pflanzen sind nur steril bekannt; ihre Diagnosen decken sich aber fast vollständig.

\section{F. integerrima St. n. sp.}

Dioica, magna et robusta, pallide virens, dense cæspitosa. Caulis ad $25 \mathrm{~mm}$. longus, repetito-furcatus, crassus et validissimus, duplo latior quam crassus, postice subplanus, lateribus oblique adscendentibus. Folia magna ( $4 \mathrm{~mm}$. lata, $2 \mathrm{~mm}$. longa) late reniformia, subintegerrima, vix crispata, basi $3-4$ cellulas crassa. Cellulæ foliorum apicales $50592 \mu$, medianæ $74 \times 130 \mu$, basales $92 \times 150 \mu$. Antheridia magna, longe stipitata, bracteis parvis foliiformibus a tergo tecta.

Hab. New Zealand (Colenso).

\section{F. dentata St. n. sp.}

Sterilis, major, fusco-viridis, gregaria. Caulis ad $6 \mathrm{~mm}$. longus parum ramosus, pallide-virens, postice purpureus, latissimus, quadruplo latior quam crassus, ubique æquicrassus ( 16 cellulas), postice plano-convexus, lateribus abrupte adscendentibus, antice leniter concavus. Folia magna, imbricata, ex angusta basi late obcuneata, apice rotundata, lateribus strictis, margine præcipue apicali grosse regulariterque dentato-spinosa, spinis sub 20. Cellul $x$ foliorum apicales $40 \times 50 \mu$, versus basin sensim longiores, basales $50 \times \mathbf{1 5 0} \mu$, pluristratæ. Reliqua desunt.

Tasmania (Weymouth).

Die Pflanze ist durch die vegetativen Organe so hervorragend ausgezeichnet, dass ich nicht unterlassen wollte, sie hier mitaufzuführen, obwohl sie nur steril bekannt ist.

39. F. carinata G. Syn. Hep., p. 469.

Sterilis. Der Autor sagt von dieser Pflanze : folia erecta, arete imbricata, concava, sinuoso-undulata, dorso plerumque bicarinata, integra. Planta junior antheras et pistilla monstrabat; radiculæ albidæ sunt.

Hab. Mexico (Liebman).

40. F. salina Lindb. Acta Soc. F. Fl. fenn. 1875. p. ฮ333.

Die Pflanze ist vom Autor nicht beschrieben; Austin sammelte sie in sterilem Zustande und gab sie unter Nr. 119 aus, unter dem Namen F. angulosa. 
Haplomitrium. FRANZ STEPHANI. SPECIES hEPATICARUM.

Es ist nicht zu erwarten, dass beide vorstehende Pflanzen je zu identificiren sein werden.

\section{HAPLOMITRIUM Nees.}

Hep. Eur. III, p. 111.

Plantæ foliosæ, minores, carnosulæ, virides, terricolæ, e caudice ramoso subterraneo arhizo erectæ laxe cæspitantes vel muscis consociatæ. Caulis simplex vel ex axilla foliorum ramosus, sub flore innovatus, a dorso compressus, in sectione itaque late ellipticus, superne incrassatus et subteres, cellulis magnis (centralibus angustioribus et magis elongatis) formatus, ceterum crassus et pallidus, nusquam rhiziferus.

Folia inferiora oblique inserta, regulariter alternantia, concava, integerrima, postice breviter adnata, antice caulem latius incurrentia, imbricata, incuba; superiora multo majora, ex angusta basi conduplicatim concava, transverse inserta, asymmetrica, margine postico substricto, antico rotundato, vix longiora quam lata, apice normaliter triloba, lobo mediano longiore acute vel obtuso. Cellulæ foliorum magnæ, crassæ, basi pluristratæ, apice $27 \mu$, medianæ $36 \times 55$ crassatæ. Amphigastria regulariter cum foliis alternantia, magna, planoappressa, transverse inserta, foliis parum minora, similiter triloba.

Inflorescentia monoica vel dioica. Pistilla in axillis foliorum solitaria, nuda. Folia floralia (sub flore fecundato) bijuga, externa maxima conduplicatim concava, vaginatim opposita, erecta, apice acuta, margine irregulariter angulata vel sublobata, magno amphigastrio libero consociata; intima ad 2 vel 4, multo breviora et minora, anguste ligulata, integerrima, amphigastrio æquimagno anguste elliptico aucta.

Perianthium nullum. Calyptra libera, maxima, anguste cylindrica, crassa, basi paucis pistillis sterilibus cincta. Pedicellus capsulæ ad $8 \mathrm{~mm}$. longus, compressus, magno bulbo obconico insertus. Capsula oblongocylindrica, vix $2 \mathrm{~mm}$. longa, acuta, rima 1 (vel 2) dehiscens; valvulæ connectivo subapicali interno cohærentes, unistratæ, cellulis fibra annulari longitudinaliter inserto incrassatis. Elateres (omnes decidui) ad $240 \mu$. longi, tenuissimi, bispiri, spiris capillaceis. Sporæ parvæ, $27 \mu$, flavovirentes, minute papillatæ.

Antheridia in caule irregulariter distributa, ad 2 vel 3 aggregata vel 395 
seriata, bractea propria magna anguste ligulata a tergo tecta, ceteruin magna, tempore maturitatis aurantiaca, ovalia, pedicello crasso anguste obconico 4-6 cellulas longo.

Species unica :

H. Hookeri (Smith) Nees. Hep. Eur. III, p. 111.

Syn. : Jungermannia Hookeri Smith Engl. Bot. I, t. 2 อัวั5.

Scalius Hookeri Gray Nat. Arrang. 1821, № 24.

Die Pflanze ist zuweilen monœcisch, vielleicht immer, es gelang mir aber nicht, es immer nachzuweisen. Die Pistille stehen in den Axeln der Seitenblätter und da diese. Blätter sich nach der Befruchtung mächtig entwickeln und gedrängt stehen, so werden deren Pistille von dem sich bildenden Torus gemeinsam in die Höhe gehoben und in der fertilen Blüthe findet man daher deren stets mehrere, während sie unten am Stamme einzeln in der Blattachsel stehen, wie bei Fossombronia.

Wenn man ein gut entwickeltes Stämmchen dieser Pflanze mit Milchsäure behandelt, so dass es seine völlige Turgescenz und die natürliche Stellung seiner Organe erlangt hat, so findet man, dass sie zwei Reihen alternirender Blätter besitzt, wie jedes andere beblätterte Lebermoos; sie unterscheiden sich in der Form wenig von den ventral stehenden grossen Amphigastrien, welche aber dem Stengel flach aufliegend und transversal angeheftet sind, während jene schief inserirt sind, so zwar, dass ihre dorsale Basis höher am Stengel liegt als ihre ventrale und da diese nur wenig auf die Bauchseite übergreift, jene aber breiter auf der dorsalen angeheftet ist, so liegen die Blätter, dachig gelagert, viel mehr auf der dorsalen Seite und sind deutlich oberschlächtig. In der Axel dieser Amphigastrien habe ich niemals Reproduktionsorgane gefunden; wohl aber findet man beim Entblättern der dorsalen Seite zwischen den normal alternirende Blättern zerstreut, stets aber dem Stengelrande genähert, schmal zungenförmige Blätter, die Bracteen der Antheridien. Nach dem Bilde von Gottsche (Nova Acta XX, tab. XVI) kommen die Antheridien auch in reihenförmiger Anordnung vor und zwar steht das ältere Antheridium der Blattachsel am nächsten, die jüngeren reihen sich in acroscoper Richtung an; vielleicht ist das die normale Ausbildung; sie wäre dann der von Fossombronia analog; ich selbst habe sie nicht beobachtet. Diese männlichen Bracteen, die auch Fossombronia hat, wenn auch manchmal sehr klein, haben dazu beigetragen, dass man die regelmässig alternirende Stellung der Blätter und Amphigastrien an Haplomitrium bisher nicht erkannt hat. 
Da die Pistille am Rande des Stengels auf der dorsalen Seite im Schutze der Blattachsel stehen, so findet man, ganz wie bei Fossombronia, dasjenige Blatt, welches das befruchtete Pistill enthielt, sehr viel näher an der Haube als das opponirte Blatt; durch die enorme Entwicklung des Stengelgewebes nach der Befruchtung steht die Haube wohl in der Mediane des Stengels, das ursprüngliche Stengelblatt reicht aber dorsal viel weiter hinüber nach der Haube, so wie es vor der Befruchtung einst das Pistill umfasste.

Der radiärc Bau der Pflanze ist also unterwärts nicht erkennbar und sie ist daselbst zweifellos deutlich dorsiventral; anders verhalten sich die Schopfblätter der Blüthe, die quer inserirt sind, aus schmales Basis kielig hohl zusammengefaltet; die 2 obersten bilden vor dem Austritt der Kapsel eine lockere Scheide für die Haube; die innersten Hüllblätter sind viel kleiner, meist zu 3 oder 4, bandförmig und ventral von einem mächtigen Amphigastrium geschützt.

Viel deutlicher als an unserer Pflanze sieht man diese Verhältnisse an den exotischen Arten, die, bisher zu Haplomitrium gestellt, zu Calobryum gehören, da sie ein terminales, scheibenförmiges Andrœcium besitzen, die aber so eng mit Haplomitrium verwandt sind, dass ein Hinweis auf deren Bau wohl zulässig erscheint und zwar um so mehr, als man Calobryum auch einen radiären Bau zugeschrieben hat.

Die nahe Verwandtschaft mit Fossombronia berührte schon Lindberg (Manipulus Musc. II, p. 378). Auch er betont die Stellung der Pistille und Antheridien "in facie anteriore caulis" und hat also dasselbe gesehen wie ich. Leitgeb bemerkt in seinen Untersuchungen über die Lebermoose (unter Fossombronia), dass der Modus der Zellwandbildung Haplomitrium zu Fossombronia und Androcryphia bringe.

Der Stengel der Pflanze ist ausserhalb der Region der Frucht nicht stielrund, sondern breiter als dick, was ja bei Fossombronia auch der Fall ist; der radiäre Bau der Pflanze tritt also hier (und auch bei Calobryum) nur in der Blüthe auf; wir besitzen aber eine ganze Anzahl beblätterter Lebermoose, wo der dorsiventrale Bau in der Blüthe bei deren aufrechter Stellung nicht mehr erkennbar ist, wie hier aber durch die ventrale dritte Blattreihe, die unter der Blüthe endet, deutlich in Erinnerung gebracht wird. - Vom morphologischen Standpunkte aus mussten diese Analogien hier erwähnt und darauf hingewiesen werden, dass die grosse Lücke, welche diese Pflanzen von den übrigen Lebermoosen angeblich trennt, thatsächlich nicht vorhanden ist. Die beiden Gattungen Haplomitrium und Calobyum stehen zweifellos Fossombronia am näch- 
sten und bilden das letzte Glied aus der Reihe der Uebergangsformen zu den foliosen Hepaticis.

\section{CALOBRYUM Nees. Syn. Hep. p. 507.}

Plantæ foliosæ, magnæ, carnosulæ, virides. corticolæ, e caudice ramoso arhizo erectæ laxeque cæspitantes. Caulis simplex, sub flore haud innovatus, a dorso compressus, in sectione transversa alte biconvexus vel ellipticus, superne incrassatus et subteres, cellulis magnis formatus, pallidus, nusquam rhiziferus. Folia caulina oblique adnata, regulariter alternantia subplana, patula, integerrima, postice breviter inserta, antice in caule decurrentia, incuba; cellulæ magnæ, crassæ, basi pluristratæ. Amphigastria caulina regulariter cum foliis alternantia, patula, foliis interdum multo minora, transverse inserta, integerrima. Inflorescentia dioica. Pistilla in caule terminalia, numerosa, cellulis clavatis muciferis mixta. Folia floralia 4, externa maxima, sæpe armata, interna multo minora; amphig externum maximum, internum parvum. Perianthia nulla. Calyptra sæpe longissima, crassa, cellulis convexo-prominulis papulosa, mucore inundata, basi pistillis sterilibus valde numerosis cincta, ætate cellulis vacuis compressis chartacea. Pedicellus capsulæ compressus, magno bulbo obconico insertus. Capsula anguste cylindrica, acuta, longitudinaliter dehiscens; valvulæ connectivo apicali interno cohærentes, unistratæ, cellulis annulo longitudinaliter inserto incrassatis. Elateres decidui, longi, bispiri, spiris ligulatis arcte tortis. Sporæ parvæ, papillis parvis asperæ, flavo-virentes. Androcia in caule terminalia. Antheridia disco magno crasso plano vel leniter convexo inserta; bracteis 3 , disco connatis superne usque ad ejus marginem liberis, plano patulis. Discus ob caulem excentrice insertum asymmetricus, parte majore nutante. Antheridia valde numerosa, dense aggregata, pedicello longiusculo obcuneato affixa, interdum foliolis parvis mixta.

1. C. Blumii. Nees, I. c. p. อั07.

Syn. : Scalia carnosula. Mitt. Linn. Soc. 1891.

Major, pallide-virens, laxe cæspitans vel muscis consociata. Caulis ad $3 \check{\mathrm{mm}}$. longus, pallidus, ubique æquicrassus, sub flore haud incrassatus, valde compressus, plus duplo latior quam crassus, in sectione ellipticus. 
Folia remotiuscula, basi angusta oblique inserta, nusquam decurrentia, optime obcuneata, apice rotundata vel leniter obtusa, patula, haud imbricata. Cellulæ apicales $37 \mu$, medianæ 50 วั $\times 92 \mu$, basales $64 \times 110 \mu$, ceterum maxime crassæ, apice ร̌ว̆ $\mu$, basi $76 \mu$ altæ, folia itaque optime carnosula, ipsa basi solum pluristrata. Amphigastria regulariter cum foliis alternantia, remota, patula, foliis caulinis multo minora. Folia floralia bijuga, externa maxima, integerrima vel angulata, e basi obconica late rotundata, amphigastrio florali simillimo; interna multo minora, irregularia, sæpe inciso lobata, amphigastrio simili aucta. Calyptra longissima, ad $17 \mathrm{~mm}$. longa, optime clavata. Capsula $5 \mathrm{~mm}$. longa, uno latere rima longitudinaliter dehiscens. Sporæ parvæ $17 \mu$. Elateres longissimi, ad $600 \mu$, longe attenuati. Androcia in disco convexo, bracteis magnis obcuneatis coalito.

Hab. Java (Blume, Karsten, Schiffner, Fleischer); N. Guinea (Loria).

Scalia carnosula Nitt. habe ich nicht zu erlangen vermocht, glaube aber, dass sie zu vorstehender Art zu stellen sein wird; sie ist fertil nicht gesammelt worden.

2. G. mnioides (Lindb.) St.

Syn. : Rhopalanthus mnioides Lindb. Manip. II, p. 391.

Scalia rotundifolia Mitt. Linn. Soc. 1891, p. 204.

Major, pallide viridis, laxe cæspitans vel muscis consociata. Caulis ad $15 \mathrm{~mm}$. longus, pallidus, in planta sterili ubique æquicrassus, in planta fertili superne incrassatus, in sectione semper a dorso compressus, dein late ellipticus. Folia plantæ sterilis approximata, æquimagna, alternantia, optime disticha, suborbicularia, oblique inserta et distincte incuba, parum convexa, oblique patula, haud imbricata, in planta feminea sub flore majora et magis conferta ibidemque transverse inserta, semiamplexicaulia, subrecte patula, sub flore conduplicatim concava, omnia integerrima. Cellulæ folii apicales $37 \mu$, medianæ $37 \times 75 \mu$, basales $54 \times 150 \mu$, parietibus teneribus. Amph. magna, folis simillima, minora, cum illis regulariter alternantia transverse inserta oblique a caule patula. Folia floralia bijuga, externa maxima, oblonga, margine angulata, apice obtusa vel subacuta, intima externis æquilonga, multo tamen angustiora, lanceolata vel longe elliptica, calyptra breviora. Amph. florale intimum similiter angulatum vel remote subdenticulatum. Sporogonium magno bulbo obconico insertum. Calyptra $8 \mathrm{~mm}$. longa, maxime crassa, cellulis alte prominulis papulosa et maxime mucosa. Capsula (teste Mitten) $3 \mathrm{~mm}$. 
longa, in pedunculo $3 \mathrm{~cm}$. longo. Andrœecia in disco crasso subplano terminali. Antheridia ad 30, magna, foliolis mixta, tempore maturitatis pallide-cinnamomea, ovalia brevissime stipitata (teste Lindberg).

Hab. Japonia (Challenger Exped.); Tosa (Makino, Miyake), haud rara in parte subtropica insularum.

3. G. andinum (Spruce) St.

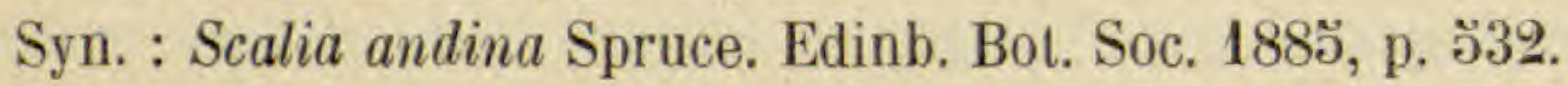

Viridis, major vel maxima, in cortice putrescente laxe cæspitans. Caulis ad $\check{5} \mathrm{~cm}$. longus, simplex vel pauciramosus, pallide-virens, ubique æquicrassus, sub flore parum incrassatus, a dorso compressus, in sectione ilaque late ellipticus. Folia remotiuscula nusquam nisi sub flore imbricata, in planta sterili obcuneato-ligulata vel oblongo-elliptica, oblique inserta, distincte incuba, postice breviter inserta, antice usque ad medium caulis adnata, subplana, oblique patula, integerrima. Celluloe foliorum apicales $47 \mu$, medianæ $54 \times 92 \mu$, basales $92 \times 150 \mu$, parietibus teneribus. Amph. in planta sterili anguste ligulata, transverse inserta, regulariter seriata, caule vix latiora, quam folia tamen breviora semper obtusa et integerrima. Folia floralia bijuga, externa maxima, obcuneato-rotundata, transverse inserta, integerrima hic illic angulata, intima duplo angustiora, oblonga, angulatim grosse dentata; amphigastrium intimum foliis suis simillimum. Calyptra ad $12 \mathrm{~mm}$. longa, anguste cylindrica, crassa, subhyalina; pedunculus capsulæ $20 \mathrm{~mm}$. longus. Capsula oblongo-cylindrico, $5 \mathrm{~mm}$. longa. Elateres ad $740 \mu$ longi, longe attenuati. Sporæ $22 \mu$.

Hab Andes peruviani (Spruce); Guadeloupe (l'Herminier); Dominica (Elliot). 


\section{INDEX}

Aitonia eximia Schffn. 78.

Fischeriana St. 83.

fissisquama St. 75 .

italica Lindb. 84.

lanigera Spruce 8 ă.

rupestris Forst. 80.

subplana Spruce 86.

Wrightii Und. 80.

Androcryphia Nees 367.

confluens (Tayl.) Nees 368.

porphyrorhiza Nees 368.

Aneura Dum. 203.

aberrans St. 210.

æquitexta St. 2 อั0.

alata St. 240.

albomarginata St. 267.

alcicornis (Tayl.) 264.

algoides (Tayl.) St. 223.

alterniloba Tayl. 270.

amazonica Spruce 244.

amboinensis St. 219.

andina Spruce 220 .

_ androgyna (Schffn.) St. 216.

attenuata St. 26 ö.

anstralis (Lehm.) 274.

autoica St. 232.

Baldwini St. 2 3ี3.

barbiflora St. 262.

bipinnata (Sw.) 274.

bipinnatifida Col. 2506.

bogotensis (G.) 213.

hrasiliensis (Angstr.) 274.

MÉMOIRES DE L'HERBIKR BOISSIER.
Aneura Breutelii St. 269.

cæspitans St. 216.

calcarea St. 266.

calva Schffn. 217.

canalieulata Nees 269.

cataractarum Spruce 252.

cervicornis Spruce 223.

ciliolata Spruce 239.

cochleata (H. et T.) St. 270.

Colensoi St. 248.

comosa St. 254.

compacta St. 260 .

conimitra St. 259.

coronopus DeNot, 271.

corralensis St. 252.

crassa (Schwägr.) 274.

crassiretis (Schffn.) St. 230.

crenulata St. 231.

crenulata Schffn. 245.

crispa Schffn. 225.

decrescens St. 227.

dentata St. 271.

diablotina Spruce 226.

dicrana St. 224.

digitiloba Spruce 258.

dilatata Spruce 254.

diminuta (Schfin.) St. 266.

distans Spruce 220.

elata St. 234.

emarginata St. 213.

epibrya Col. 270.

erecta St. 268. 
Aneura eriocaula (Hook.) 212. erosa St. 233.

- fastigiata (L. et L.) 242 . Fendleri St. 232. flaccidissima (Sehffn.) St. 243. floribunda St. 259.

fucoides (Sw.) St. 221. fuegiensis (Mass.) St. 210. fuscescens St. 227. Goebelii Schffn. 218. gogolensis St. 230.

Glaziovii Spruce 234. gracilis St. 262.

Græffei St. 214. granulata St. 272. grossidens St. 221. hamatiflora St. 25 ว.

_ heteroclada (Schffn.) St. 239. humilis (G.) St. 226.

- hymenophylloides (Sehffn.) St. 224.

hymenophytoides Spruce 228. Jackii (Schffn.) St. 217. inconspicua St. $25 \mathrm{~L}$. incurvata Lindb. 268. intermedia St. 233.

Karstenii St. 267.

Kowaldiana St. 2วัวั. laticostata Spruce 217. latifrondoides (Schffn.) St. 260. latifrons (Lindb.) St. 268. latissima Spruce 272. Lepervanchei St. 25 . . lepidomitra Spruce 23כ̃. leptophylla Spruce 233. Levieri (Schffn.) St. 261. limbata St. 241. lobata (Schffn.) St. 271. longiflora St. 256 . longispica St. 241. Loriana St. 243. macrostachya Spruce 231. major Lindb. 208.

Makinoana St. 244. marginata Col. 259. maxima (Schffn.) St. 270. metzgeriæformis St. 263.
Aneura micropinna St. 253. minima (C. et P.) St. 229. multifida (L.) Dum. 237. multifidoides (Schffn.) St. 215 . Nadeaudii St. 260.

Negeri St. 257.

nitida Col. 250 .

nobilis St. 229.

nudiflora St. 242.

oppositiflora St. 263.

pallida Spruce 237.

pallidevirens St. 272.

palmata (Hedw.) Dum. 263.

papillata (G.) St. 222.

papulosa St. 231.

parvula (Schffn.) St. 264.

pauciramea St. 253.

pectinata (Aust.) 255 .

pectinata Spruce 213.

perpusilla Col. 2 อั1.

pinguis (L.) Dum. 272.

pinnatifida Dum, 2 อั8.

planifrons Spruce 240.

platyclada (Schffn.) St. 249.

plumæformis Spruce 218.

plumosa (Mitt.) St. 218.

Poeppigii (L. et L.) St. 228.

polymorpha Col. $25 \% 6$.

portoricensis St. 249.

prehensilis (Tayl.) Mitt. 211.

ramosissima St. 229.

Regnellii (Angstr.) St. 214.

reticulata St. 242.

Ridleyi (Schffn.) St. 219.

saccatiflora St. 215 .

samoana St. 230.

Savatieri St. 211. scabra (Schffn.) St. 246.

Schwaneckei St. 273.

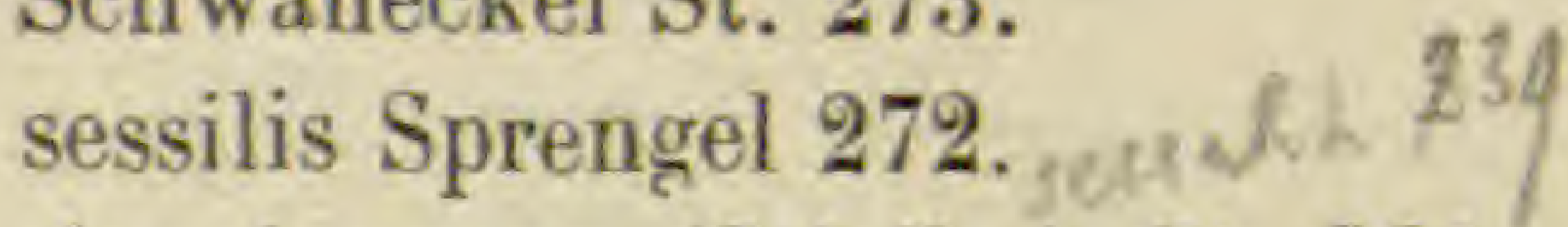

singalangana (Schffn.) St. 261.

singapurensis (Schffn.) St. 249.

spectabilis St. 206.

Spegazziniana (Mass.) 257. spinulifera (Mass.) St. 248.

Sprucei St. 213. squarrosa St. 222. 
Aneura Stephanii Besch. 245. stipatiflora St. 258.

_-stolonifera St. 247.

-striolata St. 247. subexalata (Schifn.) St. 261. subsimplex St. 264. sumatrana (Schffn.) St. 266. tahitensis St. 238. tamarisci St. 253. tamariscina St. 212. tasmanica St. 247. tenax St. 263. tenuicostata (Schffn.) St. 245 . tenuicula Spruce 231.

- tenuis St. 238. tjibodensis (Schffn.) St. 238. trichomanoides Spruce 235. tripinnata Spruce 234. umbrosa Schffn. 225. virgata G. 223.

- viridissima (Schffn.) St. 273. vitiensis St. 246. Wallisii St. 236.

Wettsteinii (Schffn.) St, 243. Zollingeri St. 220.

Anthrocephalus italicus Sassi 84 . nepalensis L. et B. 81 .

Blasia Mich. 363. pusilla Mich. 364 .

Blyttia byssophora Nees 317. cladorrhizans Tayl. 307. crispata Nees 316. Lyellii Nees 317. Lyellii var. hibernica Syn. 359. Mørkii Nees 360.

Phyllanthus Nees 307. pisicolor Tayl. 320. procumbens Tayl. 319. radiculosa Sande 320 . spinosa G. 314.

xiphoides Syn, 314 .

Boschia Weddellii Mont. 60.

Calobryum Nees 398. andinum (Spruce) St. 400. Blumii Nees 398. mnioides (Lindb.) St. 399. Calycularia Mitt. 3อั.
Calycularia birmensis St. 3909 .

— Blyttii (Mörch) St. 360. crispula Mitt. 357.

— hibernica (Hook.) St. 35ั9. laxa Lindb. 338. radiculosa St. 3 อั8.

Cavicularia St. 362 . densa St. 363.

Clevea Lindb. 66. andina Spruce 68.

- hyalina (Somm.) Lindb. 67. limbata (Aust.) Solms 70. pedicellata (Griff.) Lindb. 71. pulcherrima St. 69. robusta St. 69. Rousseliana (Mont.) Leitg. 68. suecica Lindb. 67.

Codonia Dumortieri Hüb, et G. 384 .

Conocephalum Necker 140.

- conicum (L.) Necker 141. supradecompositum (Lindb.) St. 141.

Corsinia Raddi 5ั7. marchantioides Raddi 57.

Cronisia Berk, 58. paradoxa (Wils, et Hook.) Berk. 59.

Cryptocarpus Curtisii Aust. 44.

Cryptomitrium Aust, 147. tenerum (Hook.) Aust. 148.

Cyathodium Kze. 62.

- aureonitens (Griff.) Schffn, 63. cavernarum Kze, 63.

_ fotidissimum Schffn. 64.

Dilæna Blyttii Dum. 360. hibernica Dum. 359. Lyellii Dum. 317.

Diplolæna Blyttii Nees 360 .

— cladorrhizans Tayl. 307. crispata Mont. 316. pisicolor Tayl. 320. procumbens Tayl. 319. tenuinervis Tayl. 315. xiphoides Tayl. 314. Diplomitrium Blyttii Corda 360.

Dumortiera B. Bl. Nees 148. — denudata Mitt. 15ั4. 
Dumortiera hirsuta (Sw.) R. Bl. Nees 1 อั.

- irrigua (Wils.) Nees 150.

nepalensis (Tayl.) Nees $\mathbf{1 5 0 .}$ Spathysii Nees 68. trichocephala (Hook.) Nees 150. velutina Schffn. Iอั1.

Duriæa helicophylla Bory et Mont. 202. Notarisii Bory et Mont. 202.

Duvalia brevipedunculata Mont. 148. Gayi Mont. 148.

intermedia Aust. 98̃. longiseta St. 95 . pilosa Lindb. 91.

rupestris Nees 94 . tenera G. 148.

Exormotheca Mitt. 144. fimbriata (Nees) Solms 145̆.

Holstii St. 14 . pustulosa Mitt. 144. Welwitschii St. 146.

Fegatella australis Tayl, 82.

- conica Raddi 141. limbata Tayl. 76 .

Fimbriaria Nees 97. abyssinica G. 122. africana Mont. 108. alpina St. 137. angolensis St. 113. angusta St. 104. atrispora St. $\mathbf{1 0 6 .}$ Austini Und. 129. australis Tayl. 130. Bachmanni St. 118 . Blumeana Nees 102. Bolanderi Aust. 126. Boryana Mont. 117. californica Hpe. 121. canelensis Spruce $\mathbf{1 1 3 .}$ cancasica St. 132. chilensis Mont. 136. commutata St. 128. conocephala St. 131. cubensis Lehm. 12 . dissoluta St. 115. Drummondii Tayl. 111. echinella G. 122.
Fimbriaria elegans Sprengel 125. elegans var. cubensis Syn. 125. fragrans (Schleich.) Nees 137. gigantea St. 106. gracilis Col. 139. incrassata St. 100. innovans (Aust.) Evans 114. khasiana (Griff.) Mitt. 118. Kiaerii Kaalaas $\mathbf{1 4 0 .}$ lateralis Howe 127. leptophylla Mont. 100.

Lindenbergiana Corda 135. Lindmanii St. 107. linearis St. 128. longebarbata St. 112 . Macounii St. 112. macropoda Spruce 134. maculata St. 104. Mandoni St. 133. marginata Nees 117. mollis Tayl. 133 . Muelleri G. 129. multiflora St. 124. muscicola St. 110. nana $\mathrm{Ldbg.} 67$. nepalensis Taylor 108. nudata Howe 138. pallidevirens Col. 139. Palmeri Aust. 139. parvipora St. 116. persica St. 114. pilosa (Wahl.) Tayl. 120. Preussii (Schffn.) St. 13ə. Pringlei Und. 109. Raddii Corda 102. saccata (Wahl.) 139. sanguinea L. et L. 124. setisquama St. 133 . Stahlii St. 127. subplana St. 132. tasmaniea St. 132. tenella Pears. $\mathbf{1 1 2 .}$ tenella (L.) Nees 133. tenera Mitt. 114.

— venosa L. et L. 101, 103. vesiculosa Aust. 121. violacea Aust. 119. 
Fimbriaria violacea Pears. 128.

viridis L. et L. 103.

Volkensii St. 107.

vulcanica (Schffn.) St. 114.

Wallichiana L. et L. 105 .

Whiteleggeana St. 131.

Wilmsii St. 116.

Wrightii Und. 110.

Zollingeri St. 103.

Fossombronia Raddi 373.

angulosa (Dicks.) Raddi 382.

angulosa var. cæspitiformis Raddi 388 .

australis Mitt. 391.

brasiliensis St. 382 .

cæspitiformis DeNot. 388.

carinata G. 394 .

corbulæformis Trabut 371.

crassifolia Spruce 379 .

crispa Nees 389.

crispata Lindb. 380.

cristula Aust. 385.

cubana Aust. 380.

dentata St. 394.

Dumortieri (Hueb. et G.) Lindb. 384.

foveolata Lindb. 384 .

gigantea St. 391.

grandis St. 383.

hamatohirta St. 390.

hispidissima St. 389.

Husnoti Corb. 386.

japonica Schffn. 381 .

incurva Lindb. 385̃.

integerrima St. 394.

intestinalis Tayl. 387 .

lamellata St. 384 .

leucoxantha L. et L. 393.

longiseta Aust. 387.

lophoclada Spruce 383.

Macouni Aust. 392.

Mittenii Tindall 390.

Naumanni Sehffn. 388.

papillata St. 391.

perpusilla (Col.) St. 379.

peruviana Hpe. et F. 393 .

ptychophylla Spruce 393.
Fossombronia pusilla (L.) Dum, 378.

reticulata St. 384.

salina Lindb. 394.

spinifolia St. 389.

Stephanii Schffn. 381.

tenuifolia Spruce 379.

texana Lindb. 380.

tuberifera Gœbel 384 .

verrucosa Lindb. 392.

Wondraczecki (Corda) Dum. 380.

Wrightii Aust. 392.

Zeyheri St. 386.

Funicularia Trevisan $ّ 9$. Weddellii (Mont.) Trev. 60.

Grimaldia Raddi 89 .

angustifolia (Neck.) Lindb. 89.

_-barbifrons Bisch. 92.

californica St. 91.

capensis St. 90.

carnica Mass. 91.

chilensis Mont. 90̃.

debilis Bisch. 65 .

dichotoma Raddi 89.

_ragrans (Balb.) Corda 92.

graminosa (Griff.) Schffn. 93.

inodora Wallr. 92.

peruviana Mont. 192.

pilosa (Horn.) Lindb. 91.

sessilis Sull. 92.

Gymnomitrium erythrorhizum Bisch. 382.

Haplomitrium Nees 395.

-Hookeri (Sm.) Nees 396.

Hymenophytum Dum. 305.

flabellatum (Hook.) 308.

leptopodum (Tayl.) 309.

malaccense St. 307.

Phyllanthus (Hook.) 307.

Hypenantron vulcanicum Schffn. 114.

Jungermannia alcicornis Tayl. 264.

angulosa Dicks. 382.

bipinnata Sw. 274.

Blyttii Møerch 360.

brasiliensis Nees 337.

byssophora L. et L. 317 .

calycina Tayl. 367.

canaliculata Nees 269. 
Jungermannia circinata Mont. 338. crassa Schwägr. 274. dichotoma Sw. 291. difformis Nees 326 . epiphylla L. 366. eriocaula Hook. 212.

— fastigiata L. et L. 242. flabellata Hook. 308. fucoides Nees 220.

- fucoides Sw. 221. furcata L. 289. hibernica Hook. 3599. Hookeri Sm. 396. Hymenophyllum Hook. 345. linearis Sw. 291.

_- Lyellii Hook. 317. multifida L. 237. palmata Hedw. 263.

_ Phyllanthus Hook. 307. pinguis L. 272. podophylla Thunb. 348 . Poppigii L. et L. 228. pusilla L. 378. Ralfsii Wils. 371 . rhizobola Schwägr. 347 . sinuata (Sw.) 344 .

Lunularia Mich. 142. cruciata (L.) Dum. 143. vulgaris Mich. 143.

Makinoa Miyake 361. — crispata (St.) Miyake 361. Marchantia L. $15 \%$. acaulis St. 195. amboinensis Mont. 166. angusta St. 189. assamica Griff. 168. Berteroana L. et L. 163 . Bescherellei St. 178. brasiliensis L. et L. 175. calcarata St. 183. caracensis St. 188. cartilaginea L. et L. 190. cataractarum Schffn. 195. cephaloscypha St. 163.

chenopoda L. 190. commutata Ldbg. 15๊. conica L. 141.
Marchantia crenata Aust. 178. cruciata L. 143. cuneiloba St. 171. Dillenii Lindb. 190.

-diptera Mont. 183. disjuncta Sull. 186. domingensis L. et L. 171 . Elliottii St. 172.

_ emarginata Nees 187. Fargesiana St. 183. foliacea Mitt. 167. fragrans Balb. 92. fragrans Schleich. 137. furciloba St. 189. fusca St. 174. geminata Nees 180. globosa Brid. 172. grossibarba St. 168.

- hemisphærica L. 88. hexaptera Rehdt. 190.

- hirsuta Sw. 150. hyalina Somm. 67. inflexa M. et N. 171. innovans Aust. 114. Kærnbachii St, 188. Kirkii St. 163.

_ lamellosa Hpe. et G. 164. Lecordiana St. 187. linearis L. et L. 171, 187. macropora Mitt. 181. macropora Jack et St. 182. Miqueliana Lehm. 176. multiloba St. 167. nepalensis L. et L. 184. nitida L. et L. 184. Notarisii Lehm. 193. oregonensis St. 193. paleacea Bertol. 174. pallida St. 194. palmata Nees 187. papillata Raddi 169. Pappeana Lehm. 178. parviloba St. 177. peruviana (Mont.) Nees 192. pileata Mitt. 191. pilosa Wahl. 120. pilcsa Horn 91. 
Marchantia planiloba St. 166. planipora St. 170. plicata N. et M. 1603.

- polymorpha L. 164. pusilla N. et M. 195 . quinqueloba Nees 1930. rubribarba St. 172. samoana St. 191. Schadenbergii St. 186. sciaphila Schffn. 181. simlana St. 173. squamosa L. et L. 169. subandina Spruce 173. subgeminata St. 192. subintegra Mitt. 178. tabularis Nees 1603. tenella L, 133. tenera Hook. 148. tholophora Bisch. 18 .̈.

— tosana St. 18 o.

_ Treubii Schffn. 181. trichocephala Hook. 150. umbellata St. 175. umbonata Wallr. 137. vaginata St. 194. viridula L. et L. 177. vitiensis St. 182. Wallisii Jack et St. 182. Wilmsii St. 170.

Metzgeria Raddi 275. acuminata St. 282. adscendens St. 298. albinea Spruce 296. algoides Tayl. 223. angusta St. 292. atrichoneura Spruce 298. aurantiaca St. 286. australis St. 295. bracteata Spruce 302. camerunensis St. 293. chilensis St. 285. clavæflora Spruce 301. comata St. 287. conjugata Lindb. 299. consanguinea Schffn. 293. convoluta St. 288. corralensis St. 281.
Metzgeria crassicostata St. $28 \%$. crenata St. 300. decipiens Schffı. 295. decrescens St. 280. dichotoma (Sw.) 291. Dusenii St. 290. effusa St. 291. Elliotii St. 284. eriocaula Syn. 212. filicina Mitt. 283. flavovirens Col. 289. frontipilis Lindb. 280. fruticola Spruce 301.

- fucoides Mont. 221. furcata (L.) 289. fuscescens Mitt. 293. glaberrima St. 287.

hamata Lindb. 297. hamata var. procera Lindb. 294.

hamatiformis Schffn. 294. Jackii St. 289. imberbis Jack et St. $280 ̈$. inflata St. 284.

Lechleri St. 290. leptomitra Spruce 300. leptoneura Spruce 297. Liebmaniana L. et G. 282 .

— Lindbergii Schaffn. 286. linearis (Sw.) 291. longiseta St. 282. longitexta St. 288. madagassa St. 292. magellanica Schfïn. 298. museicola St. 303. myriopoda Lindb. 304 . nitida Mitt. 295. nudifrons St. 303. papulosa St. 294. patagonica St. 288. Perrotana St. 286. planiusculaSpruce 289. Poppigii Ldbg. 228. polytricha Spruce 30:3. prehensilis Tayl. 211. procera Mitt. 294.

pubescens Raddi 279. quadrifaria St. 304 . 
Metzgeria recurva St. 297.

Renauldii St. 293.

rigida Lindb. 283.

rufula Spruce 292.

saccata Mitt. 290.

Sandei Schffn. 299.

scobina Mitt. 298.

sinuata Loitl. 287.

tahitensis St. 286.

terricola St. 281.

thomeensis St. 296.

Uleana St. 302.

Wallisiana St. 299.

Warnstorffii St. 297.

Mittenia decipiens G. 32 è. erythropus G. 322. spinosa G. 314.

Zollingeri G. 323 .

Mœrkia Blyttii G. 360.

- hibernica G. 359 .

Monoclea Hook. 350 .

Forsteri Hook. 33̈2.

Gottschei Lindb. 3อั2.

Monosolenium tenerum Griff. 63.

Myriorrhynchus fimbriatus Lindb, 145.

Neesiella Schifn. 93.

chilensis (Mont.) St. 95.

longiseta St. 95.

- rupestris (Nees) Schffn. 94.

Noteroclada confluens Tayl. 368 .

leucorhiza Spruce 368. perpusilla Col. 379 .

Octoskepos khasianus Griff. 118.

Oxymitra pyramidala Hueb. 56 .

Pallavicinius Gray 309.

ambiguus (Mitt.) St. 312.

attenuatus St. 316.

Baldwini Evans 341.

Blyttii Lindb. 360.

byssophorus (L. et L.) St. 317.

connivens (Col.) St. 324.

crassifrons St. 32 o.

erispatus (Mont.) St. 316.

cylindricus (Aust.) Evans 319.

decipiens (Mitt.) St. 32\%̈.

difformis (Nees) St, 326.

erimonus St. 321.
Pallavicinius erythropus (G.) St. 322. himalayensis Schffn. 317.

Husnoti St. 318.

—_indicus Schffn, 316. innovans St. 313. latifrons St. 322.

_ Levieri Schffn. 315 . longispinus St. 313.

—_ Lyellii (Hook.) Gray 317. piliferus St. 314.

pisicolor (Tayl.) St. 320. procumbens (Tayl.) St. 319.

— radiculosus (Sande) Schffn. 320. spinosus (G.) St. 314.

Stephanii Jack. 324. subciliatus Aust. 313 : subflabellatus Besch. 326. tenuinervis (Tayl.) St. 315. Wallisii Jack et St. 323. xiphoides (Tayl.) St. 314. Zollingeri (G.) Schffn. 323.

Pellia Raddi 36õ.

__ calycina (Tayl.) Nees 367 . crispata St. 361 . endiviæfolia Lindb. 367.

- epiphylla (L.) Lindb. 366.

_ epiphylla var. Neesiana G. 366. fuciformis Nees 367.

— Neesiana (G.) Limp. 366.

Peltolepis Lindb. 71.

— grandis Lindb. 72. sibirica Lindb. 72.

Petalophyllum G. 370. lamellatum Lindb. 371.

Preissii G. 371.

Ralfsii (Wils.) G. 371.

Plagiochasma L. et L. 72 .

Aitonia Nees 80. algericum St. 77 .

appendiculatum L. et L. 79 . australe (Tayl.) Nees 82.

Beccarianum St. 78. brasiliense St. 83. chlorocarpum Mont. 81. corulescens Nad. 82. Colsmannianum L. et G. 81 . cordatum L, et L. 77. 
Plagiochasma crenulatum G. 77. dschallanum St. 75. elongatum L. et G. 82 . erythrospermum Sull. 67. eximium (Schffn.) St. 78. extensum St. 85 .

Fischeri St. 83.

fissisquamum St. 7 . japonicum St. 74. intermedium L. et G. 79 . italicum (Sassi) DeNot. 84. lanigerum (Spruce) St. 85. limbatum (Tayl.) Nees 76 . megacarpum Griff. 86 . mexicanum L. et G. 84 . microcephalum St. 78. nepalense (L. et Bisch.) St. 81. paradoxum Griff. 86. pedicellatum Griff. 71 . peruvianum N. et M. 83 . pingue (Falc.) St. 86. polyearpum Griff. 86 . pterospermum Mass. 86. rupestre (Forst.) St. 80 . Rousselianum Mont. 68. Schimperi St. 8 כ. subplanum (Spruce) St. 86. tenue St. 76. validum Bisch. 81 . Wrightii Sull. 80 .

Platycoaspis tenera Lindb. 148.

Podomitrium Phyllanthus Mitt. 307.

Preissia Corda 1544.

— commutata (Ldbg.) Nees 155. mexicana St. 15 รั.

_- quadrata (Scop.) Nees 72, 155.

Pseudoneura bogotensis G. 213. brasiliensis Angstr. 274. eriocaula G. 212.

_ucoides G. 221. fuegiensis Schffn. 210. humilis G. 226. papillata G. 222. Peppigii G. 228. prehensilis G, 211. Regnellii Angstr. 214.

Reboulia Raddi 87 .
Reboulia graminosa Griff. 93:

— hemisphærica (L.) Raddi 88.

_ javanica Nees 88 .

_ longipes Sande 88.

ـ microcephala (Tayl.) Nees 88. Sullivanti Lehm, 88.

Rhacotheca azorica Bisch. 108.

Rhopalanthus mnioides Lindb. 399.

—_ Riccardia androgyna Schffn. 216. crassiretis Schffn. 230. decipiens Schffn. 224.

- diminuta Schffn. 266. elongata Schffn. 216. flaccidissima Schffn. 243. fuegiensis Mass. 210. fuscovirens Lindb. 272.

— heteroclada Schffn. 239.

— hymenophylloides Schffn. 224. Jackii Schfĩn. 217. incurva Lindb. 268. latifrondoides Schffn. 260. latifrons Lindb. 268. Levieri Schffn. 261.

— Iobata Schffn. 271. major Lindb. 258. maxima Sehffn. 270. minima C. et P. 229. multifidoides Schffn. 215. parvula Schffn. 264. platyclada Schfin. 249. Ridleyi Schffn. 219. rigida Schffn. 220.

- scabra Schffn. 2'6.

— serrulata Schffn. 239. singalangana Schffn, 261. singapurensis Schfin. 249. Spegazziniana Mass. 2 2.7. spinulifera Mass. 248.

_ subelaxata Schffn. 261. sumatrana Schfin. 266. tenuicostata Schffn. 24 כ̆. tjibodensis Schffn. 238.

— viridissima Schffn. 273.

- Wettsteinii Schfirn. 243.

Riccia Mich. 2.

abnormis St. 39. acuminata Tayl. 28. 
Riccia aggregata Und. 34.

albida Sull. 48.

albomarginata Bisch. 21.

amazonica Spruce 37.

amboinensis Schffn. 14.

angolensis St. 1 .

antarctica St. 32.

arvensis Aust. 31.

arvensis var. hirta Aust. 9.

asprella C. et P. 8.

atromarginata Levier 12. $\varepsilon$

Austini St. 28.

australis St. 29.

bahiensis St. 50 .

Balansæ St. 45.

Beckeriana St. 49 .

Beyrichiana Hpe. 10.

bicarinata Lindb. 13.2

bifurca Hoffm. 30.

Billardieri M. et N. 18.

Bischoffii Hüben 7. $\varepsilon$

Brandegei Und. 40.

Breidleri Jur. 10.

Breutelii Hpe. 17.

bulbifera St. 24.

bullosa Link 52, 146.

bullosa var. vesiculosa $\mathrm{C}$. et $\mathrm{P}$. 51.

burnettensis St. 4 5ี.

californica Aust. 7.

canaliculata Hoffm. 41.

cancellata Tayl. 41.

canescens St. 12.

cartilaginosa St. 25.

Catalinæ Und. 4 อ̆.

centrifuga Arnell 41.

chilensis St. 33.

ciliata Hoffm. 11. \&

ciliata Raddi 11.

eiliifera Link 7.

cochleata H. et T, อั3, 270.

commutata Jack 31 . \&

concava Bisch. 17, วั3.

congoana St. 20.

corcovadensis St. 29.

crassa St. $\check{1} 1$.

crassifrons Spruce 39.
Riccia crinita Tayl. 9.

crispatula Mitt. 20.

crystallina L. 43, 44, 50 .

Curtisii James 44 .

Delavayi St. 42.

deserticola St. 48.

discolor L. et L. 19.

Donnellii Aust. 39 .

Dufourii Nees 32.

Elliottii St. 16.

epicarpa Wallr. 27.

fimbriata Nees 53, 445.

flavispora St. 16.

fluitans L. 41 .

Frostii Aust. 42.

Fruchartii St. 22.

glauca L. 20.

glaucescens Carr. 30.

Gougetiana Monl 8.

grandis Nees 17.

grandisquama St. 17.

Hasskarliana St. 49.

Henriquesii Levier 13. E

hirta Und. 9.

hortorum Bory 15.

Huebeneriana Ldbg. 49.

japonica St. 6 .

inflexa Tayl. 21.

insularis Levier 27. \&

Junghuhniana N. et Ldbg. 30 .

lamellosa Austin 28.

lamellosa Raddi 32 .

lanceolata St. 34.

lanigera Spruce 36.

lata Tayl. 23

laxisquamata St. 46.

Lesquereuxii Aust. 16.

ligula St. 7.

limbata Bisch. 18.

Lindenbergii Sauter 27.

Lindmanii St. 12 .

linearis Schffn. 46 .

lusitanica Levier 9.

macrocarpa Levier et Jack 35 . ?

macropora St. 37.

macrospora St. 20.

mamillata St. 34 . 
INDEX.

Riccia marginata Lindb. 30. marginata C. et P. 24. Mauryana St. 19. membranacea G. et L. 36 .

Michelii Raddi 11. ह microspora St. 43. minima Ldbg. 13. minima Raddi 26. minima L. 26, 27. minutissima St. 30 . C Mœnkemeyeri St. 47. Montagnei St. $4 \mathbf{4}$. multifida St. 40. multilamellata St. 48 . muscicola St. 38. natans L. 53, รั4. nigrella DC. 26 . $\varepsilon$ nigrella Pears. 27. nigrescens Mont. ฮั3. nodosa Bouch. 41. novohannoverana Schffn. 46. numeensis St. 3 ö. ochrospora M. et N. 37. Oerstediana L. et Hpe. 44. palmata Ldbg. 11. papillispora St. 26. papillosa Moris 13. E papulosa St. 52. paradoxa DeNot. 11. paradoxa Wils, et Hook. 53, 59. paraguayensis Spruce 37. Pearsoni St. 27. $\varepsilon$ pedemontana St. 8. perennis St. 47. plana Tayl. 43. planobiconvexa St. 14. porosa Tayl. 29. pseudopapillosa Levier 14. $\mathcal{E}$ punctata Tayl. 34. purpurascens L. et L. 38. pyramidata Raddi 56 . Raddiana Jack et Levier 28. Rautanènii St. อั3. reticulata Sw. 53. Ridleyi Gepp 19. rubrispora St. 24. runssorensis St. 22.
Riccia Schweinfurthii St, 31 . setosa Müll. 13. sorocarpa Bisch. 27. spinosissima St. 11. Spruceana St. 37. spuria Dicks. 53, 64 . squamata Nees 33 . stenophylla Spruce $\mathbf{4 1}$. subalpina Limp. 11. snbinermis Lindb. 6 . subsimilis St. 42. subtilis St. 39.

Sullivantii Aust. 49. tenuilimbata St. 23. tenuis Aust. 36.

Trabutiana St. 32.

Treubiana St. I5. tuberosa Tayl. 53. tumida Ldbg. 11. velutina Wils. วั3, รั. . vesicata Tayl. 41. vesiculosa C. et $P$. วั0. victoriensis St. 4 है. Warnstorffii Limp. 10. ह Watsoni Aust. 42. Weinionis St. 18. Welwitschii St. 36 . Wichuræ St. 22.

Ricciocarpus Corda כั4. natans (L.) Corda 5̆4. velutinus (Wils.) St. 5ั5ั.

Riella Mont. 199.

Battandieri Trabut 201. Clausonis Let. 202. Cossoniana Trabut 202. gallica Balansa 201. helicophylla Mont. 202. Notarisii Mont. 202. Parisii G. 202. Reuteri Mont. 201. \&

Rupinia Corda 56. pyramidata Corda 56 .

Sandea supradecomposita Lindb. 141.

Sarcomitrium australe Lehm, 274. plumosum Mitt. 218. prehensile Mitt. 211.

Sauteria Nees 64 . 
Sauteria alpina Nees 6 5.

Berteroana Mont. 6.5.

crassipes Aust. 66.

limbata Aust. 70.

Rousseliana G. 68.

Sealius Hookeri Gray 396.

Scalia andina Spruce 400.

carnosula Mitt. 398.

rotundifolia Mitt. 399.

Sphærocarpus Mich. 196.

Berteroi Mont. 198.

californicus Aust. 198.

cristatus Howe 198.

Donnellii Aust. 197.

Jamesii Aust. 198.

Michelii Bell. 197.

terrestris (Mich.) Sm. 197.

texanus Aust. 197.

Spinella magellanica Schffn. 248.

Steetzia ambigua Mitt. 312.

Baldwini Aust. 341.

cylindrica Aust. 319.

decipiens Mitt. 325.

Symphyogyna M. et N. 327.

atronervia Tayl. 332.

Baldwini (Aust.) 341.

bogotensis (G.) St. 346.

brasiliensis Nees 337.

brevicaulis Col. 342 .

Brogniartii Mont. 343.

canaliculata St. 336.

circinata M. et N. 338.

connivens Col. 324 .

convoluta Tayl. 340.

crassicosta St. 331.

crassifrons Sull. 349 .

difformis M. et N. 326.

digitisquama St. 33..

exincrassata St. 342.

flabellata Mont. 308.

flavovirens Col. 345.

Gobelii St. 338.

Gottscheana M. et N. 341 .

grandibracteata St. 330.

Harveyana Tayl. 348.

Hochstetteri M. et N. 343.
Symphyogyna Hymenophyllum (Hook.)

M. et N. 345.

Hymenophyllum var. bogotensis G. 346 .

interrupta C. et P. 336.

irregularis St. 333.

Lehmanniana M. et N. 332.

leptopoda Tayl. 309.

leptothelia Tayl. 331.

marginata St. 33 '.

oblonga (Schwein.) Syn. 317.

obovata Tayl. 349 .

Phyllanthus Tayl. 307.

picta St. 33 .

podophylla (Thunb.) M. et $\mathrm{N}$. 348.

pulchra Tayl. 349.

rhizobola Mitt. 349.

rhizobola (Schwägr.) Nees 347.

rhodina Tayl. 332.

rubescens St. 333.

- Schweinitzii M. et N. 347.

semi-involucrata Aust. 339.

sinuata (Sw.) M. et N. 344 .

spinosa L. et G. 348.

stipitata St. 346.

subearnosa Lehm. 343.

subsimplex Mitt. 337.

tenuicostata St. 339.

trivittata Spruce 334 .

undulata Col. 340 .

vitiensis Jack etSt. 342. - vafida

Volkensii St. 339.

Synhymenium aureonitens Griff 63 .

Targiona L. 60.

bifurca Mont. 61.

capensis Hueb. 61.

convoluta L. et G. 61 .

elongata Bisch. 61.

hypophylla L. 61 .

mexicana L. et L. 61 .

Michelii Corda 61.

Tesselina pyramidata Dum. כ̋6.

Thallocarpus Curtiisi Lindb. 4'4.

Treubia Gopel 371.

bracteata St. 373 .

insignis Goeb. 373. 
INDEX.

Umbraculum flabellatum G. 308. leptopodum G. 309. Mülleri G. 308.

Wiesnerella Schffn. 153.

— Wiesnerella denudata (Mitt.) St. 1504. javanica Schffn. 154 . Zoopsis lobulata Col. 251.

\section{E R R A T A}

Pag. 32, Zeile 12 von oben Underwood statt Austin.

1) 44, Zeile 16 von oben James statt Jameson.

» ๖3. In der Aufzählung am Schluss ist binzuzufügen : Riccia lutescens Schwein. ist eine Marchantiacee.

» 63. Als Syn. zu No 2 ist hinzuzufügen : Cyathodium africanum Mitt. Linn. Soc. 1886 , vol. 22.

65. Zu S. Berteroana Mont. ist hinzuzufügen : in d'Orbigny Voy. Am. p. כั6.

65. Zu Grimaldia debilis Bisch. ist hinzuzufügen: Syn. Hep. p. כ๊eั2.

88, Zeile 14 von unten lies Pug $X$ statt Pag. $X$.

91, No 3 muss lauten: G. californica G. ms, in Underwood, Bot. Gazette. (Die Publication ist mir unbekannt.)

92. Zu Grimaldia fragrans (Balbis) Corda füge hinzu : in Nees Hep. Eur. IV, p. 223. 258, Zeile 2 von oben lies Riccardia major statt Aneura major. 